\title{
Institucionalidad social en \\ América Latina y el Caribe
}

\section{RODRIGO MARTÍNEZ}

Editor
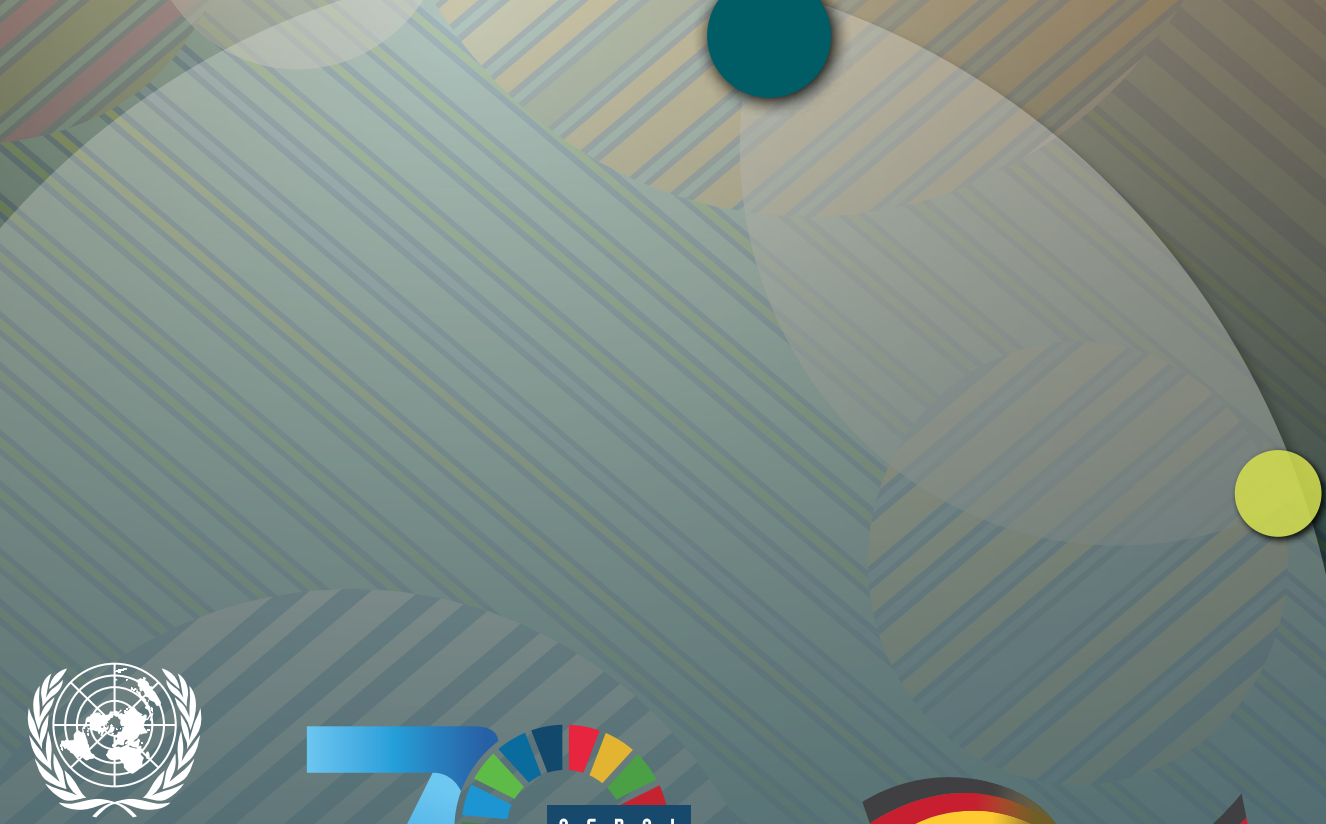

NACIONES UNIDAS

CEP

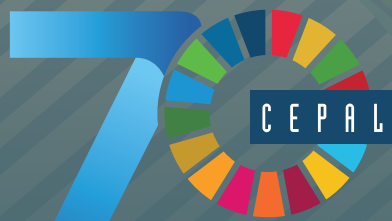

POR UN DESARROLLO SOSTENIBLE CON IGUALDAD
0
0
0
0
0
0
0
0
0 


\section{Gracias por su interés en esta}

\section{publicación de la CEPAL}

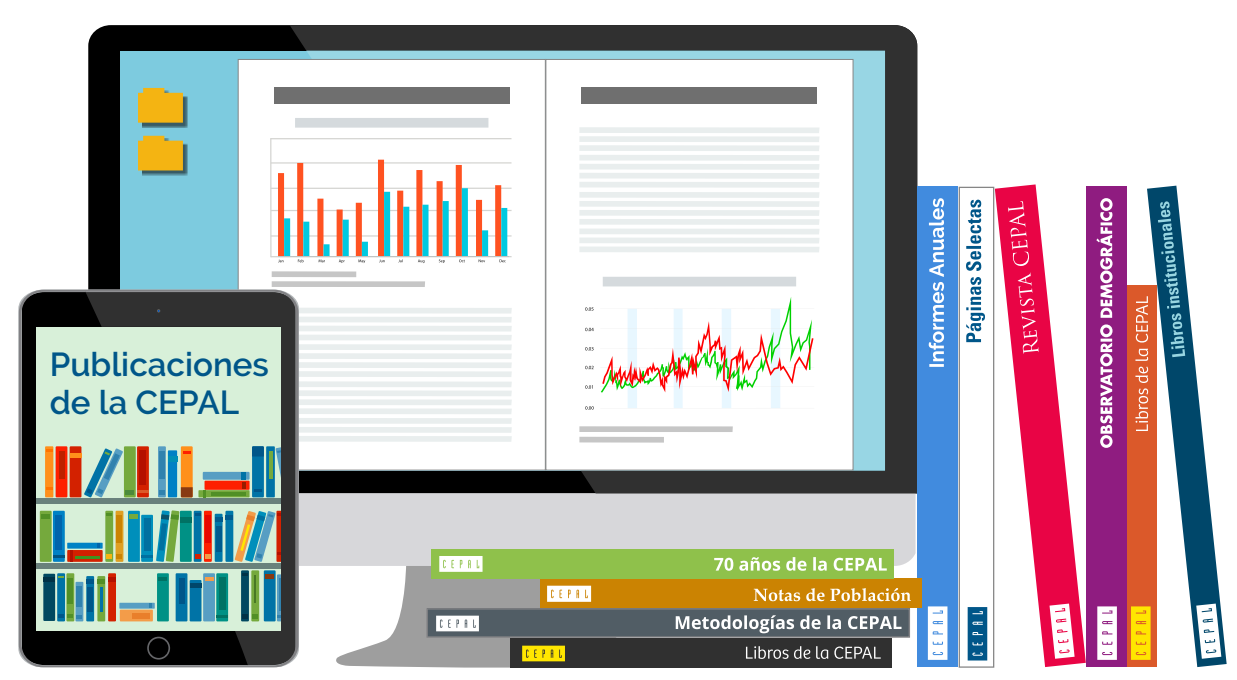

Si desea recibir información oportuna sobre nuestros productos editoriales y actividades, le invitamos a registrarse. Podrá definir sus áreas de interés y acceder a nuestros productos en otros formatos.

\section{Deseo registrarme}
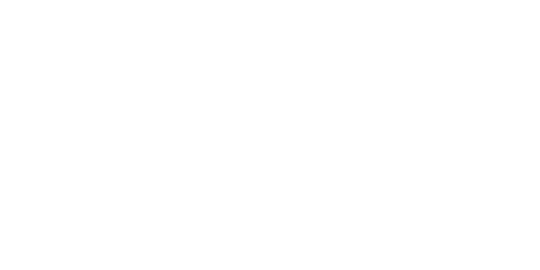

www.cepal.org/es/publications

facebook.com/publicacionesdelacepal

D.w.cepal.org/apps 


\title{
Institucionalidad social en América Latina y el Caribe
}

Rodrigo Martínez

\author{
Editor
}
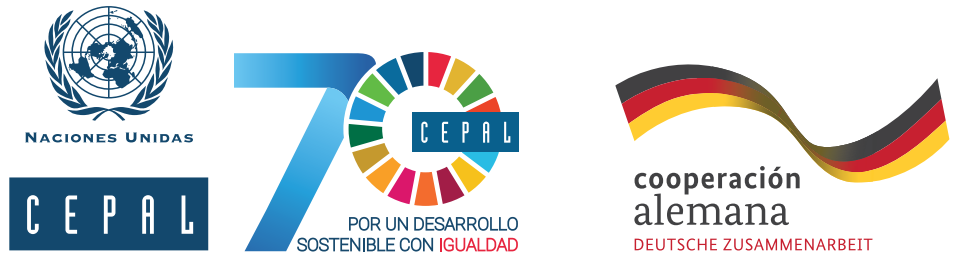


\section{Libros de la CEPAL}

\section{6}

\section{Alicia Bárcena}

Secretaria Ejecutiva

Mario Cimoli

Secretario Ejecutivo Adjunto

Raúl García-Buchaca

Secretario Ejecutivo Adjunto

para Administración y Análisis de Programas

\section{Laís Abramo}

Directora de la División de Desarrollo Social

\section{Ricardo Pérez}

Director de la División de Publicaciones y Servicios Web

Este documento ha sido preparado por Rodrigo Martínez, Oficial Superior de Asuntos Sociales de la División de Desarrollo Social de la Comisión Económica para América Latina y el Caribe (CEPAL), en el marco de los proyectos "Protección social, enfoque de derechos y desigualdad en América Latina" del programa Cambio Estructural para un Desarrollo Sostenible e Inclusivo en América Latina y el Caribe, y "Fortalecimiento de la institucionalidad para una protección social universal y sostenible" del programa Apoyo a la Implementación de la Agenda 2030 para el Desarrollo Sostenible en América Latina y el Caribe, ejecutados por la CEPAL en conjunto con la Agencia Alemana de Cooperación Internacional (GIZ) y financiado por el Ministerio Federal de Cooperación Económica y Desarrollo (BMZ) de Alemania.

Los capítulos fueron elaborados por Carlos Maldonado, Rodrigo Martínez, Marta Rangel, María Nieves Rico, Claudia Robles, Daniela Trucco, Heidi Ullman, Andras Uthoff y Mario Velásquez.

Se agradecen especialmente los valiosos comentarios de Laís Abramo y Martín Hopenhayn a todos los capítulos del libro.

Las opiniones expresadas en este documento son de exclusiva responsabilidad de los autores y pueden no coincidir con las de la Organización.

Diseño de portada: María Luisa Avaria U.

Publicación de las Naciones Unidas

ISBN: 978-92-1-121956-2 (versión impresa)

ISBN: 978-92-1-058593-4 (versión pdf)

ISBN: 978-92-1-358060-8 (versión ePub)

Número de venta: S.17.II.G.15

LC/PUB.2017/14-P/Rev.1

Distribución: $\mathrm{G}$

Copyright (C) Naciones Unidas, 2019

Todos los derechos reservados

Impreso en Naciones Unidas, Santiago

S.19-00424

Esta publicación debe citarse como: Rodrigo Martínez (ed.), Institucionalidad social en América Latina y el Caribe, Libros de la CEPAL, N 146 (LC/PUB.2017/14-P/Rev.1), Santiago, Comisión Económica para América Latina y el Caribe (CEPAL), 2019.

La autorización para reproducir total o parcialmente esta obra debe solicitarse a la Comisión Económica para América Latina y el Caribe (CEPAL), División de Publicaciones y Servicios Web, publicaciones.cepal@un.org. Los Estados Miembros de las Naciones Unidas y sus instituciones gubernamentales pueden reproducir esta obra sin autorización previa. Solo se les solicita que mencionen la fuente e informen a la CEPAL de tal reproducción. 


\section{Índice}

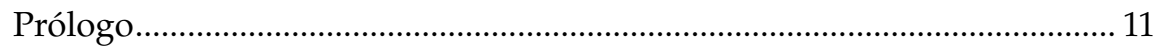

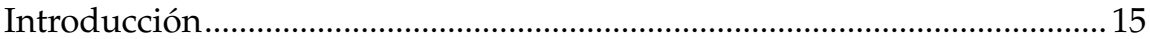

Parte 1

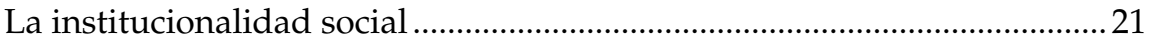

Capítulo I

Institucionalidad y desarrollo social

Rodrigo Martínez, Carlos Maldonado Valera........................................................ 23

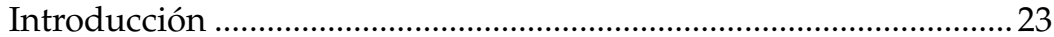

A. Institucionalidad social: conceptos básicos .................................25

B. Alcances temático y geográfico de la institucionalidad ............ 31

C. Dimensiones de la institucionalidad social ..................................34

1. La dimensión jurídico-normativa..............................................34

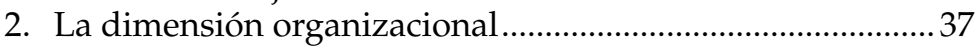

3. La dimensión técnico-operativa .............................................. 43

4. La dimensión de financiamiento .............................................. 46

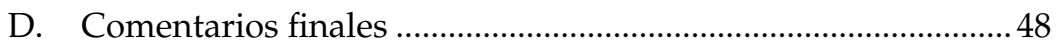

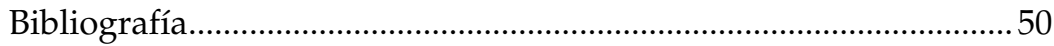

Capítulo II

La institucionalidad del desarrollo y la protección social

en América Latina y el Caribe: panorama y desafíos

Rodrigo Martínez, Carlos Maldonado Valera.........................................................53

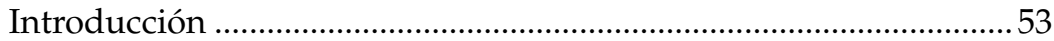


A. Marcos jurídico-normativos internacionales, regionales y nacionales

1. El marco internacional ...........................................................54

2. Marcos normativos nacionales relacionados

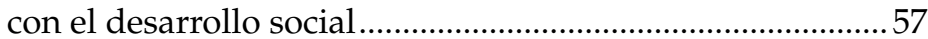

B. Características organizacionales y autoridad social......................60

1. Mandatos y foros regionales dedicados al desarrollo social en América Latina y el Caribe.

2. Las agendas sociales de algunos foros intergubernamentales

3. Modalidades de autoridad social...

4. Los ministerios y secretarías de desarrollo e inclusión social

5. La adscripción institucional de los programas de transferencias monetarias y de las pensiones no contributivas

6. Los desafíos de coordinación y articulación entre los actores de la protección social.

C. Herramientas de gestión y dimensión técnico-operativa............81

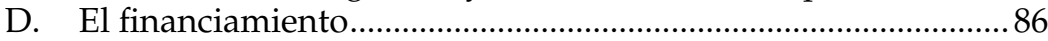

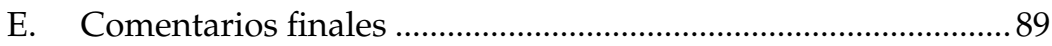

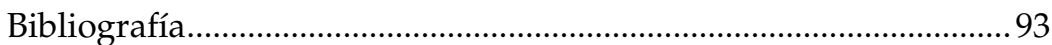

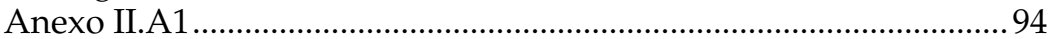

Parte 2

Componentes de la protección social y su institucionalidad 103

Capítulo III

Regulación del mercado de trabajo y protección social:

desafíos institucionales

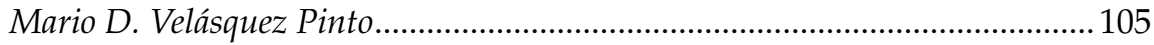

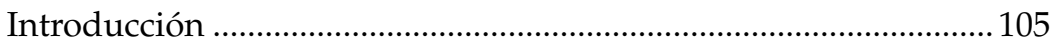

A. Regulaciones laborales y flexibilidad laboral

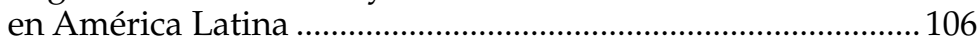

B. Regulaciones laborales y protección social.................................. 110

1. Riesgos y regulaciones laborales ........................................... 112

C. Regulaciones laborales ................................................................ 117

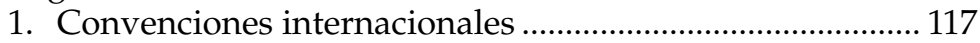

2. Garantías constitucionales...................................................123

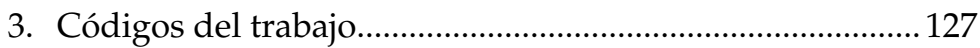

D. Dimensión organizacional para el cumplimiento de la regulación

1. La administración del trabajo .............................................141

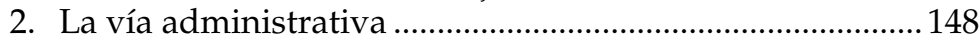

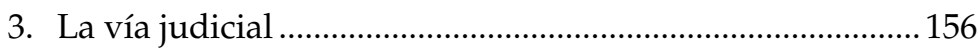




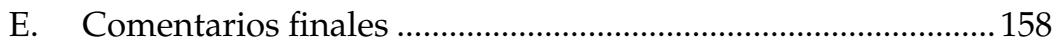

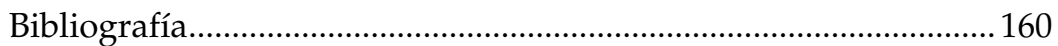

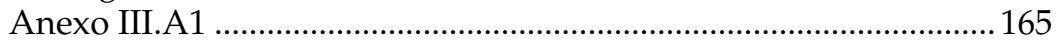

Capítulo IV

Aspectos institucionales de los sistemas de pensiones

en América Latina

Andras Uthoff

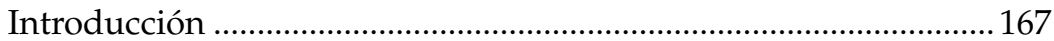

A. Sistema de pensiones y seguridad social .................................... 169

1. Opciones de diseño de un sistema de pensiones.................171

2. Tipología de sistemas de pensiones ........................................174

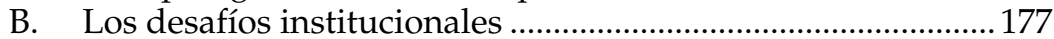

1. Elementos para resolver el conflicto entre eficiencia

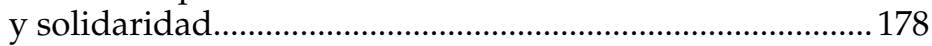

2. Elementos para la sostenibilidad asociada al proceso de envejecimiento .................................................................... 188

3. Algunas experiencias de reforma frente

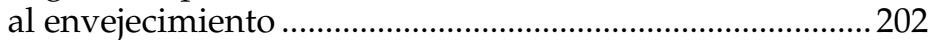

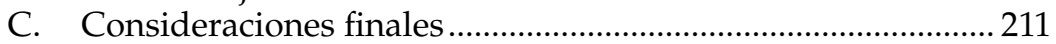

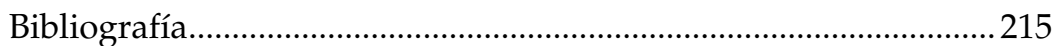

Capítulo V

El cuidado, pilar de la protección social: derechos, políticas e institucionalidad en América Latina

María Nieves Rico, Claudia Robles

Introducción

A. El cuidado como bien público: elementos para el diseño de sus políticas

B. Políticas integradas de cuidado como pilar de la protección social: desafíos para su institucionalidad

1. La naciente institucionalidad de las políticas de cuidado en América Latina: oportunidades y desafíos de articulación con los sistemas de protección social

2. Un marco normativo común y diferenciado: ¿se instala el derecho al cuidado?

C. Políticas y programas de cuidado: diversidad programática y baja carga fiscal

D. ¿De programas a sistemas integrados de cuidado?

Crear y fortalecer la institucionalidad

E. ¿Se avanza en la transversalización? ..........................................244

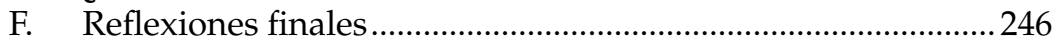

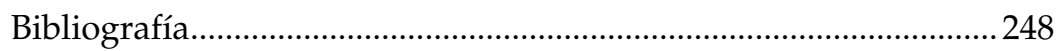




\section{Parte 3}

Políticas para poblaciones determinadas y su institucionalidad

Capítulo VI

Ciclo de vida y políticas sociales: las instituciones de juventud en la región

Daniela Trucco 255

Introducción

A. Los marcos jurídicos nacionales (y supranacionales) en materia de políticas de juventud

B. Dimensión organizacional: la gobernanza de las políticas de juventud

1. Instituciones coordinadoras y autoridad .............................261

2. Canales de participación ciudadana .......................................266

C. Planes o políticas sectoriales y acceso a recursos .....................268

D. Dimensión fiscal y financiamiento de las políticas

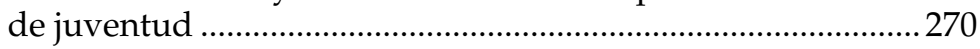

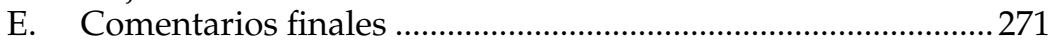

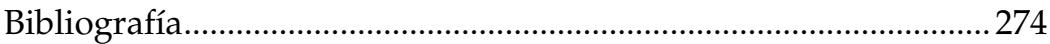

\section{Capítulo VII}

Discapacidad y políticas públicas: avances y desafíos institucionales en América Latina

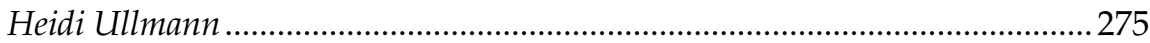

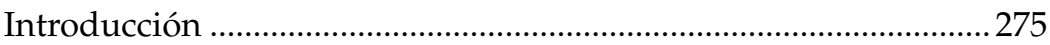

A. La dimensión jurídico-normativa ..............................................276

B. La dimensión organizacional .....................................................281

1. Las instituciones nacionales y sus características ...............282

2. Participación ciudadana en las instancias

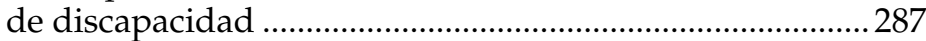

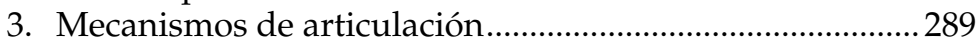

C. La dimensión técnico-operativa .....................................................293

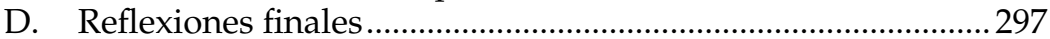

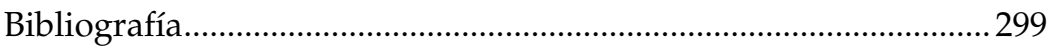

Capítulo VIII

Afrodescendientes latinoamericanos: institucionalidad

y políticas públicas

Marta Rangel.

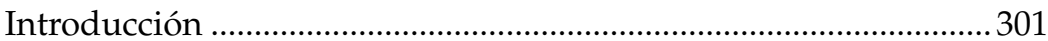

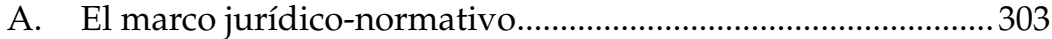

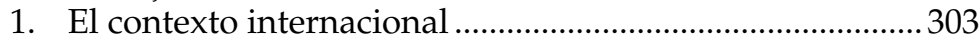

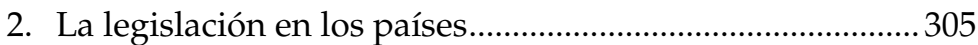

B. La dimensión organizacional: rasgos y características .............308

C. La dimensión técnico operativa: herramientas de gestión.....319 
D. Dimensión de financiamiento ....................................................320

E. Políticas destacadas para las personas

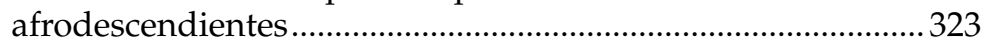

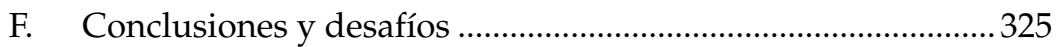

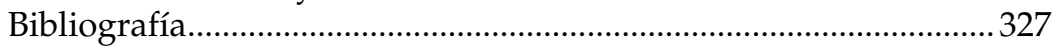

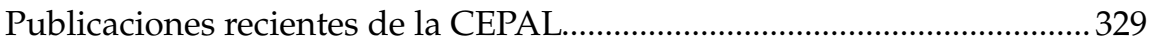

\section{Cuadros}

II.1 América Latina y el Caribe (33 países): existencia de normativa constitucional y específica en temas sociales sectoriales y referentes a segmentos determinados de población

II.2 América Latina y el Caribe: foros intergubernamentales sobre desarrollo social, según el tipo de instancia a la que están vinculados, 2015 .

II.3 América Latina y el Caribe: principales ejes temáticos de algunos foros intergubernamentales dedicados al desarrollo social

II.4 América Latina y el Caribe (22 países): tipo de autoridad que coordina el gabinete social o la principal entidad colegiada intersectorial del área social

II.5 América Latina y el Caribe (21 países): instancias responsables de los principales programas de transferencias monetarias y de pensiones no contributivas

II.6 América Latina y el Caribe (22 países): síntesis de algunas herramientas de gestión, planificación, evaluación y transparencia de los programas sociales, 2015.

II.7 América Latina (18 países): gasto social en tres grupos de países con distintos resultados en materia de protección y promoción social (promedio simple de cada grupo), alrededor del período 2015

II.8 América Latina y el Caribe (14 países): presupuesto del Ministerio de Desarrollo Social o instancia equivalente como proporción del gasto primario presupuestado, alrededor de 2015

II.A1.1 América Latina y el Caribe (26 países): instancias de gobierno dedicadas al desarrollo social, 2015

II.A1.2 América Latina y el Caribe (21 países): composición de las instancias colegiadas de coordinación intersectorial de políticas sociales, 2015 .

III.1 América Latina (14 países): tasa y composición del empleo informal no agrícola según categorías ocupacionales, 2013.

III.2 Matriz de análisis de la regulación del mercado laboral según riesgos en el ciclo de vida 
III.3 Convenios de la OIT en países de América Latina relacionados con etapas de ciclo de vida

III.4 América Latina (19 países): convenios de la OIT ratificados y en vigor, 2015

III.5 América Latina (19 países): protección constitucional ante riesgos relacionados con el trabajo según etapas del ciclo de vida, 2015.

III.6 América Latina (19 países): códigos del trabajo vigentes y año de creación, 2015.

III.7 América Latina (19 países): regulaciones laborales de los códigos del trabajo asociadas a protección social, según etapas del ciclo de vida

III.8 América Latina (19 países): instituciones de regulación laboral y protección social, 2015.

III.9 Brasil y Chile: dimensiones de la inspección del trabajo

III.10 América Latina (14 países): fortaleza de la inspección laboral, indicadores seleccionados

III.11 América Latina (18 países): cobertura frente a riesgos en el ciclo de vida, indicadores seleccionados

III.A1.1 Prestaciones previstas en el Convenio de la OIT núm. 102 $\mathrm{y}$ en convenios posteriores

IV.1 Opciones para el diseño de un sistema de pensiones .....................176

IV.2 América Latina y el Caribe (10 países): indicadores de cobertura en esquemas de contribuciones definidas por afiliados

IV.3 América Latina y el Caribe (8 países): indicadores de cobertura en esquemas de contribuciones definidas por cotizantes.

IV.4 Iniciativas encaminadas a conciliar la equivalencia de los contratos y solidaridad.

IV.5 Brasil, Chile y Uruguay: perfiles de los sistemas de pensiones

IV.6 América Latina y el Caribe (19 países): diferente transición de la fecundidad y mortalidad

IV.7 América Latina y el Caribe (19 países): costo de simulación de pensión universal como porcentaje del PIB nacional

IV.8 Iniciativas encaminadas a resguardar el sistema de riesgos vinculados con el envejecimiento poblacional

IV.9 América Latina y el Caribe: principales cambios paramétricos en los programas públicos de reparto, 2009-2015

V.1 América Latina y el Caribe (12 países): leyes de cuidado aprobadas entre 2015 y 2017

VI.1 América Latina (18 países): marco jurídico nacional en el área de juventud 
VI.2 América Latina y el Caribe (26 países): articulación y rectoría de las instancias de gobierno dedicadas a las personas jóvenes

VI.3 América Latina (18 países): canales de participación de las instituciones dedicadas a las personas jóvenes

VII.1 América Latina (19 países): año de ratificación o adhesión a la Convención Interamericana para la Eliminación de Todas las Formas de Discriminación contra las Personas con Discapacidad (1999) y la Convención sobre los Derechos de las Personas con Discapacidad (2006), al 1 de abril de 2017

VII.2 América Latina (19 países): principal norma que explicita derechos de las personas con discapacidad.

VII.3 América Latina (19 países): principales instituciones dedicadas a las personas con discapacidad

VII.4 América Latina (12 países): ejemplos de mecanismos de participación ciudadana en las instancias principales de discapacidad.

VII.5 América Latina (10 países): ejemplos de mecanismos y modalidades de articulación interinstitucional o intersectorial de las instancias principales de discapacidad.

VII.6 América Latina (11 países): ejemplos de mecanismos de articulación territorial en las instancias principales de discapacidad.

VII.7 América Latina (14 países): planes o estrategias nacionales para la promoción de los derechos de las personas con discapacidad.

VIII.1 América Latina: mecanismos de promoción de la igualdad racial

VIII.2 América Latina: recursos financieros disponibles para los mecanismos gubernamentales de promoción de la igualdad racial, 2016

\section{Gráficos}

II.1 América Latina y el Caribe (33 países): firma y ratificación o adhesión de pactos, convenciones y convenios relacionados con los derechos económicos, sociales y culturales

II.2 América Latina y el Caribe (22 países): año de creación de los ministerios u otras instancias dedicadas al desarrollo social

II.3 América Latina y el Caribe (25 países): principales instancias de gobierno formalmente encargadas de coordinar la atención a diversos segmentos de la población 
III.1 América Latina (14 países): empleo informal no agrícola, 2009 y 2011-2015

IV.1 América Latina (18 países): indicadores de envejecimiento, 1950-2100

VI.1 América Latina (14 países): ejes principales de política o plan sectorial de juventud

VII.1 América Latina (19 países): derechos consagrados en la ley principal de discapacidad

\section{Recuadros}

I.1 Componentes deseables de la institucionalidad social, según diversos estudios especializados ..............................................2. 27

IV.1 Principios fundamentales en seguridad social....................................169

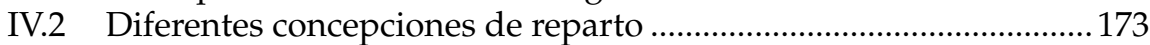

IV.3 Chile: financiamiento de la transición hacia el modelo de capitalización individual (extracto de la reciente Comisión Asesora Presidencial de Chile)

IV.4 El caso chileno: capitalización en cuentas de ahorro individuales

VII.1 La evolución de los enfoques de la discapacidad

\section{Diagramas}

I.1 Componentes de la dimensión organizacional a nivel del Gobierno central

I.2 Tipos y alcance de las autoridades sociales

II.1 Algunos segmentos de población objetivo en los marcos normativos de las políticas sociales

III.1 Estructura organizativa clásica de un ministerio de trabajo ............142

V.1 Componentes de una política integrada de cuidado 


\section{Prólogo}

Como ha señalado la Comisión Económica para América Latina y el Caribe (CEPAL) en sucesivas versiones del Panorama Social de América Latina, en las últimas décadas la región ha logrado importantes avances en materia social. Ejemplos de ello son la disminución de la pobreza y de la desigualdad en la distribución del ingreso, y la mejora en los indicadores de acceso y resultados en áreas como salud, educación, vivienda, saneamiento y participación laboral de las mujeres.

Sin embargo, la evolución positiva de algunos indicadores se ha frenado en la presente década, de la mano de una marcada disminución de las tasas de crecimiento económico. A su vez, la desigualdad en materia de derechos, medios y oportunidades continúa siendo una característica de nuestra región, en la que se replica una matriz de desigualdad social fundada en una cultura del privilegio y la heterogeneidad estructural de sus procesos productivos.

Esto ocurre en momentos en que el mundo se encuentra en un punto de inflexión. Por un lado, las distintas transformaciones a las que se enfrenta, asociadas a la volatilidad del crecimiento económico, el cambio climático, la revolución tecnológica, la migración y la transición demográfica, son una realidad que impone nuevos desafíos y una mayor resiliencia tanto a las personas afectadas como a las instituciones a cargo de diseñar e implementar mejores políticas públicas.

Por otro lado, los compromisos asumidos en la Agenda 2030 para el Desarrollo Sostenible, aprobada por los países en 2015, y sus 17 Objetivos de Desarrollo Sostenible marcan también un antes y un después. Se refleja en la Agenda una nueva forma de hacer frente a los desafíos del desarrollo, integrando los pilares económico, social y medioambiental de 
manera articulada y sinérgica, y destacando el principio de que nadie se quede atrás.

En continuidad con los Objetivos de Desarrollo del Milenio, los compromisos de la Agenda 2030 para el Desarrollo Sostenible son un hito del progresivo desarrollo institucional de las políticas públicas a nivel global, y han permitido asignar una importancia creciente a la lucha contra la pobreza y a la disminución de las desigualdades en materia de salud, educación, trabajo, vivienda, y por razón de género, raza o etnia. Se suman, a su vez, a los distintos acuerdos y pactos internacionales que han orientado las políticas públicas en los siglos XX y XXI, como la Declaración Universal de Derechos Humanos, los convenios de la Organización Internacional del Trabajo (OIT), el Pacto Internacional de Derechos Económicos, Sociales y Culturales (PIDESC), la Convención Americana sobre Derechos Humanos y el Protocolo Adicional a la Convención Americana sobre Derechos Humanos en Materia de Derechos Económicos, Sociales y Culturales (Protocolo de San Salvador), la Convención sobre la Eliminación de Todas las Formas de Discriminación contra la Mujer, la Declaración y Plataforma de Acción de Beijing, la Convención sobre los Derechos del Niño y la Declaración y Programa de Acción de Durban, entre tantos otros.

Estos acuerdos y compromisos se han traducido en distintos ajustes legales y organizacionales en la región. Entre estos ajustes organizacionales destacan nuevos ministerios, secretarías, consejos ministeriales, institutos y otras instancias de alcance nacional y subnacional, junto con instancias de nivel regional y subregional como conferencias, foros y pactos de integración e intercambio. En las últimas décadas, esto se refleja de manera clara en el caso de las políticas sociales y las orientadas al desarrollo y la protección social de poblaciones determinadas.

En este contexto de cambios y nuevos compromisos, continuar con los avances alcanzados en materia social en América Latina y el Caribe, evitar retrocesos y alcanzar los objetivos de la Agenda 2030 para el Desarrollo Sostenible, asegurándose de que nadie se quede atrás, supone que las políticas públicas asuman nuevos y mayores esfuerzos en materia de cobertura y calidad. Para ello, como se subraya en el documento presentado por la CEPAL en su período de sesiones más reciente, Horizontes 2030: la igualdad en el centro del desarrollo sostenible, es imprescindible consolidar la institucionalidad existente. Es fundamental que, tanto a nivel regional como nacional, los países cuenten con una institucionalidad a la altura de los desafíos presentes y futuros, que haga viables y sostenibles los logros y que garantice el ejercicio de los derechos de manera universal.

En este libro se revisan elementos de la institucionalidad de las políticas sociales en la región. Centrando la mirada en las políticas de protección social, seexaminan los principales conceptos de institucionalidad 
y autoridad social y se proponen cuatro dimensiones analíticas complementarias para su estudio: i) jurídico-normativa, ii) organizacional, iii) técnico-operativa y iv) de financiamiento. Sobre la base de estas dimensiones, se analizan los avances alcanzados y se discuten asignaturas pendientes a nivel regional y nacional.

Los trabajos aquí presentados fueron realizados en el marco de los programas de cooperación Cambio Estructural para el Desarrollo Sostenible e Inclusivo en América Latina y el Caribe (2014-2016) y Apoyo a la Implementación de la Agenda 2030 para el Desarrollo Sostenible en América Latina y el Caribe (2016-2018), ejecutados por la CEPAL en conjunto con la Agencia Alemana de Cooperación Internacional (GIZ), con financiamiento del Ministerio Federal de Cooperación Económica y Desarrollo (BMZ) de Alemania. Con ello, ambas instituciones buscan contribuir al mejoramiento de las políticas sociales, tanto desde el punto de vista de su análisis como de su diseño e implementación, y así avanzar hacia la consecución de los Objetivos de Desarrollo Sostenible a partir de un enfoque basado en derechos.

\section{Alicia Bárcena}

Secretaria Ejecutiva

Comisión Económica para

América Latina y el Caribe (CEPAL) 



\section{Introducción}

En las últimas décadas, la región de América Latina y el Caribe ha logrado avances importantes en materia social. Algunos ejemplos son las mejoras relacionadas con la reducción de la pobreza, la distribución del ingreso, el nivel educativo o los indicadores de salud y protección social. Sin embargo, la desaceleración económica y la volatilidad del crecimiento económico que hoy enfrenta la región, junto con los nuevos escenarios generados por el cambio climático, la revolución tecnológica, la transición demográfica y las dinámicas de la migración imponen nuevos desafíos a las políticas públicas.

En este contexto, para continuar con dichos avances, evitar retrocesos y alcanzar los objetivos de la Agenda 2030 para el Desarrollo Sostenible sin que nadie se quede atrás, las políticas públicas deben hacer nuevos y mayores esfuerzos en materia de cobertura y calidad, y para ello es fundamental contar con una institucionalidad a la altura de los desafíos, con certeza jurídica, capacidad de gestión y recursos suficientes.

La Comisión Económica para América Latina y el Caribe (CEPAL) ha hecho de la institucionalidad objeto central de estudio y ocupación, consciente de la relevancia de esta para alcanzar los objetivos de la función pública. Así, en el último documento del período de sesiones de la Comisión se subrayó la necesidad imprescindible de consolidar la institucionalidad existente, a fin de implementar con posibilidades de éxito la Agenda 2030 para el Desarrollo Sostenible. A su vez, la calidad de las políticas sociales y el estudio de su institucionalidad han ocupado un lugar importante en el trabajo de larga data de la División de Desarrollo Social de la CEPAL y en los intercambios sostenidos por las autoridades 
nacionales reunidas en la Primera Conferencia Regional sobre Desarrollo Social, realizada en Lima en noviembre de 2015.

En este libro se presenta una compilación de trabajos recientes sobre la institucionalidad de las políticas sociales en América Latina y el Caribe, realizados en el marco de los dos últimos programas de cooperación entre la CEPAL y la Cooperación Alemana ${ }^{1}$. Se examina la institucionalidad social a partir del análisis de las instancias gubernamentales que tienen como mandato central el diseño y la implementación de las estrategias de desarrollo social y superación de la pobreza de los países. Entre esas instancias figuran ministerios, secretarías y gabinetes coordinadores. Se incluyen también en este análisis las instancias y acuerdos internacionales que facilitan u orientan la institucionalización de las políticas sociales.

Más allá de las políticas de desarrollo social como marco general, se pone énfasis en la protección social y sus componentes. Se describe su evolución en las últimas décadas y se discuten los desafíos institucionales que supone garantizar el ejercicio de derechos universales y atender problemáticas y necesidades específicas de diversos segmentos de la población, así como cumplir los compromisos establecidos por los países en materia de desarrollo social.

Los avances registrados en la región en los últimos años en materia de indicadores sociales han ido acompañados de importantes desafíos en cuanto al diseño y la implementación de políticas, así como la conformación de sus bases institucionales. Cada país ha seguido su propia trayectoria, pero también hay elementos comunes que reflejan el estado actual de la institucionalidad encargada de la política social en los países de la región.

Un primer elemento que es preciso considerar a la hora de analizar el alcance y orientar la discusión sobre política social se refiere a los conceptos de desarrollo, inclusión y protección social. El concepto de desarrollo social incluye la idea de avanzar en todos los ámbitos y funciones de la política social, como la salud, la educación, la protección social, el trabajo, la vivienda, la seguridad alimentaria y nutricional, entre otros. Por su parte, el concepto de inclusión social se centra en hacer posible que el conjunto de la población reciba los beneficios del desarrollo, mediante la reducción de las brechas y el fomento de la participación en la vida social, económica y política. La protección social es un ámbito de la política pública cuya función es lograr un nivel de bienestar económico y social que, como mínimo, permita a la población salir de la pobreza y la

\footnotetext{
Programas de cooperación entre la CEPAL y el Ministerio Federal de Cooperación Económica y Desarrollo de Alemania (BMZ)/Agencia Alemana de Cooperación Internacional (GIZ): Cambio Estructural para el Desarrollo Sostenible e Inclusivo en América Latina y el Caribe (2014-2016) y Apoyo a la Implementación de la Agenda 2030 para el Desarrollo Sostenible en América Latina y el Caribe (2016-2018).
} 
proteja de los riesgos de caer en ella. También tiene el propósito de facilitar el acceso a servicios sociales y de promoción que permitan a las personas adquirir capacidades, ejercer sus derechos y desarrollarse a lo largo del ciclo de vida. Para esto, cuenta con los componentes contributivo y no contributivo, la regulación del mercado laboral y los sistemas de cuidado (Cecchini y Martínez, 2011).

Un segundo elemento relevante es el alcance geográfico del análisis. La institucionalidad social tiene un referente específico dentro de los países en términos de las leyes y la estructura organizacional encargada de las políticas. Esta no solo abarca el nivel central, sino que incluye también los niveles subnacionales y locales, ámbitos donde la implementación y el seguimiento de resultados de la política tienen lugar de forma más directa. También alcanza el ámbito internacional, a través de las instancias mundiales, regionales y subregionales que definen objetivos y metas, junto a los fundamentos éticos y legales para todos los Gobiernos. Esos mismos criterios se aplican a los organismos creados por el sistema internacional para llevar a cabo su seguimiento, compartir experiencias y buscar acuerdos de implementación, como los foros en que se busca promover el desarrollo social de la región: la Comisión Económica para América Latina y el Caribe (CEPAL), la Organización de los Estados Americanos (OEA), la Comunidad de Estados Latinoamericanos y Caribeños (CELAC), la Unión de Naciones Suramericanas (UNASUR), el Sistema de la Integración Centroamericana (SICA) o la Comunidad Andina (CAN), entre otros.

Un tercer elemento corresponde a las definiciones de autoridad e institucionalidad sociales, así como las dimensiones analíticas a considerar para su estudio. Las definiciones y el alcance de estos conceptos reflejan distintas interpretaciones y prioridades analíticas que, de no aclararse, pueden conducir a diferentes interpretaciones de una misma realidad. Por ello, el punto de partida para los trabajos que se presentan en este libro es una discusión conceptual y una propuesta de marco analítico, en el que se destacan cuatro dimensiones sobre cuya base se intenta avanzar en el estudio de la institucionalidad social: el sustrato jurídico-normativo sobre el que se asienta la política, el modelo organizacional con el que se implementa (incluida la autoridad social y los esquemas de coordinación), las herramientas de gestión desarrolladas para dar cuenta de los objetivos y la disponibilidad, fuente y sostenibilidad del financiamiento de las políticas.

El diseño de la institucionalidad de la política social enfrenta un desafío permanente en materia de diseño y operación, en relación con su modelo organizacional y el alcance de la autoridad social. Por un lado, esto se debe a la necesidad de dar cuenta de las funciones sociales de gobierno (protección social, salud, educación, vivienda, recreación, entre otras) con el objeto de alcanzar objetivos en ámbitos definidos de la política pública. 
Por otro, responde a la necesidad de atender a segmentos poblacionales determinados según su caracterización de género, raza y etnia, ciclo de vida o discapacidad, entre otros factores, a fin de satisfacer sus necesidades particulares y reducir brechas, procurando así garantizar derechos a todos en la diversidad. De esta manera, junto con los tradicionales ministerios sectoriales, en los últimos tiempos se han desarrollado en algunos países nuevas reparticiones que centran su atención en dichas poblaciones y que comparten su labor entre la coordinación de actores y la implementación de programas propios.

Sobre la base de los elementos indicados se desarrolla el trabajo descrito en el presente libro, que se estructura en ocho capítulos agrupados en tres partes. La primera parte incluye una mirada al conjunto de la institucionalidad social en América Latina y el Caribe, con un primer capítulo en que se revisan algunos conceptos básicos para el análisis de la institucionalidad a la luz de los planteamientos elaborados en la región en las últimas décadas. A su vez, se presenta una propuesta analítica para abordar la institucionalidad social, partiendo de una reflexión sobre sus alcances temático y geográfico y continuando con una discusión conceptual en torno a las cuatro dimensiones mencionadas anteriormente, que destacan por su relevancia para el estudio, diseño e implementación de las políticas sociales, y que permiten orientar los trabajos incluidos en los siguientes capítulos del libro. Sobre la base de esta discusión conceptual, en el segundo capítulo se presenta un panorama de la institucionalidad social en la región, desde las últimas décadas del siglo XX hasta la actualidad, con énfasis en los avances y desafíos que entraña desde el punto de vista del desarrollo de una política de protección social de calidad.

La segunda parte la componen tres capítulos, en los que se analizan los avances y desafíos institucionales asociados a tres componentes de la protección social en América Latina. Se comienza en el tercer capítulo con una discusión sobre el trabajo decente y los requisitos institucionales de la regulación del mercado laboral, y se continúa con un panorama de los avances alcanzados en esta materia. Luego, en el cuarto capítulo, se presenta un análisis de los sistemas de pensiones vigentes en la región y los desafíos institucionales que afrontan las entidades encargadas de la seguridad social, a la luz de los principios fundamentales de esta y el futuro del envejecimiento poblacional. Por último, en el quinto capítulo se examinan las políticas de cuidado y su desarrollo institucional en la región, tomando en consideración su relevancia como componente de la protección social y el importante papel que desempeñan en este ámbito las mujeres y el trabajo no remunerado. 
En la tercera parte se centra el análisis de la institucionalidad asociada a políticas sociales para poblaciones determinadas y se destacan sus requisitos particulares y los avances que se han dado en la región en esta materia. Así, en el sexto capítulo se analiza el caso de la juventud como objeto de políticas particulares a lo largo del ciclo de vida. En el séptimo se analizan las instituciones a cargo de las políticas públicas orientadas a las personas con discapacidad, sus logros y desafíos. Por último, en el octavo capítulo se discute la institucionalidad de las políticas orientadas a la población afrodescendiente, el camino recorrido en las últimas décadas y los pasos que parece necesario dar en este ámbito.

Sin tener por objetivo agotar el análisis, se espera que el lector obtenga un panorama de los modelos, avances y desafíos que tiene la institucionalidad de las políticas sociales en los países de la región. Cabe esperar también que esta información sea un estímulo para continuar con el estudio y desarrollo institucional, a fin de avanzar progresivamente en la implementación de políticas sociales de calidad (efectivas, eficientes, sostenibles y transparentes). Esos avances deberían contribuir a reducir la huella social del desarrollo, garantizar derechos y alcanzar las metas contenidas en los objetivos de la Agenda 2030 para el Desarrollo Sostenible. 

Parte 1

La institucionalidad social 



\title{
Capítulo I \\ Institucionalidad y desarrollo social
}

\author{
Rodrigo Martínez ${ }^{1}$ \\ Carlos Maldonado Valera ${ }^{2}$
}

\section{Introducción}

La institucionalidad de las políticas sociales ha sido desde hace mucho tiempo objeto de estudio en la Comisión Económica para América Latina y el Caribe (CEPAL), y ha formado parte de las publicaciones recientes más importantes de la División de Desarrollo Social (CEPAL, 2015 y 2016b). En el documento de posición del trigésimo sexto período de sesiones de la Comisión en 2016 se subraya la necesidad imprescindible de consolidar la institucionalidad existente a fin de implementar la Agenda 2030 para el Desarrollo Sostenible y se destaca la persistencia de "una dinámica por sectores que fracciona el ámbito social y, más aún, lo separa del ámbito económico, así como una estructura jerárquica que subordina la institucionalidad social a las autoridades económicas" (CEPAL, 2016a, pág. 164).

Oficial Superior de Asuntos Sociales de la División de Desarrollo Social de la Comisión Económica para América Latina y el Caribe (CEPAL).

2 Oficial de Asuntos Sociales de la División de Desarrollo Social de la Comisión Económica para América Latina y el caribe, (CEPAL). 
En el presente capítulo se expone una propuesta de marco de análisis de la institucionalidad de las políticas sociales, a partir de la cual a lo largo del libro se describen elementos del panorama de la institucionalidad social vigente en los países, de acuerdo con la información oficial disponible.

El foco principal del análisis lo componen las instancias gubernamentales que tienen como mandato central el diseño y la implementación de las estrategias de desarrollo social, protección social y superación de la pobreza de los países. Entre estas instancias se incluyen ministerios, secretarías y gabinetes coordinadores.

En primer lugar, cabe diferenciar entre los conceptos de desarrollo, inclusión y protección social. Mientras el desarrollo social se centra en la idea de avanzar en todos los ámbitos y funciones que componen la política social, la inclusión social tiene el objetivo de hacer que toda la población sea parte del proceso de desarrollo y reciba sus beneficios. La protección social se refiere a un ámbito de la política pública cuya función es lograr un nivel de bienestar económico y social que, como mínimo, permita a la población salir de la pobreza, la proteja de los riesgos de caer en ella y facilite el acceso a servicios sociales y de promoción que permitan a las personas adquirir capacidades, ejercer sus derechos y desarrollarse a lo largo del ciclo de vida (Cecchini y Martínez, 2011).

Para el análisis de la institucionalidad es también fundamental tener en cuenta el alcance geográfico, considerando tanto el ámbito nacional, con sus distintos niveles administrativos (central, subnacional —estados, departamentos, provincias o regiones-y local), como el ámbito internacional, a nivel mundial, regional y subregional.

No obstante, avanzar en este objetivo requiere reflexionar previamente sobre las definiciones de autoridad e institucionalidad sociales, así como las dimensiones analíticas que se deben considerar para su estudio. Estos elementos son el punto de partida del trabajo aquí presentado.

El capítulo se estructura en cuatro partes. En la primera se discuten conceptos básicos sobre institucionalidad y autoridad, así como sus funciones y responsabilidades. En la segunda se examina brevemente el alcance temático, poblacional y geográfico de este tema. En la tercera se aborda la propuesta analítica que fundamenta el estudio, haciendo hincapié en el peso de cuatro dimensiones complementarias para el análisis de la institucionalidad social. En la cuarta y última se presentan algunas conclusiones y observaciones sobre el tema. 


\section{A. Institucionalidad social: conceptos básicos}

La discusión en torno a la institucionalidad de las políticas sociales tiene antecedentes importantes en la región. En diversos estudios se ha planteado la importancia de que las políticas y programas sociales estén sujetos a reglas y normas explícitas, transparentes y reconocidas por los actores, con el propósito de maximizar su contribución al logro de objetivos y el cumplimiento efectivo de derechos $\mathrm{y}$, en la medida de lo posible, minimizar su uso con criterios particulares, políticos o sencillamente ineficientes. También se ponen de relieve las características deseables de dicha institucionalidad, en su mayoría centradas en la operación y gestión de los programas (Franco y Székely, 2010; Székely, 2015), así como la manera en que la planificación, presupuestación, ejecución, evaluación y demás fases del ciclo de las políticas se orientan a resultados concretos (Kaufmann, Sanginés y García Moreno, 2015). En algunos abordajes se subraya la deseabilidad de continuidad de las políticas (Machinea y Cruces, 2010), de programas concretos (Irarrázaval, 2006) e incluso de los actores vinculados a dichas políticas (Braun y Vélez, 2004). Esta idea de continuidad no implica inmovilidad ni inmutabilidad. Más bien supone que la modificación de las políticas ha de seguir un patrón de cambio estructurado, sujeto a ciertas normas y procedimientos establecidos (no arbitrarios).

Una visión de la institucionalidad social que vaya más allá de la gestión también debe ocuparse de que las políticas y programas sean capaces de responder a nuevas expectativas y demandas, y avanzar respecto de la garantía de derechos. Es decir, que las políticas sociales puedan cambiar, no de forma arbitraria y desordenada, sino con base en procedimientos e instancias identificables y predecibles, que les impriman continuidad y capacidad de respuesta ante nuevos desafíos y demandas sociales (Stein y otros, 2008).

La política social presenta similitudes con otros sectores en cuanto a los desafíos estructurales que supone el contraste, a veces patente, entre la institucionalidad formal y las prácticas sociales y de gobierno. Esa distancia entre el de jure y el de facto constituye un rasgo recurrente en los países de la región. Ello no cancela, sino que refuerza, la importancia de consolidar marcos normativos e institucionales ambiciosos, aun cuando su plena vigencia se construya paulatinamente (Gargarella, 2013a y 2013b).

De acuerdo con Repetto (2004), la institucionalidad social se refiere al conjunto de reglas de juego formales e informales (incluidas las rutinas y costumbres organizacionales) que se ponen en funcionamiento para procesar y priorizar los problemas sociales y, a la vez, enmarcar 
el contenido y la dinámica administrativa y política de las políticas sociales. Así, la institucionalidad social representa un entramado de incentivos que estructura los límites y oportunidades de negociación y acción para los actores de la política social, pero no por fijar un marco estable se eliminan las posibilidades de transformación más o menos amplias de dicha institucionalidad. Ahora bien, el énfasis en las reglas y prácticas informales es difícil de evidenciar sin acercamientos cualitativos y casuísticos, por lo que es conveniente un abordaje centrado en los marcos institucionales formales como anclaje para un análisis comparativo.

Algunos autores (Irarrázaval, 2006; Machinea y Cruces, 2010) incorporan la consideración sobre el territorio en el momento de desarrollar los atributos de la institucionalidad social. Esto aparece asociado a los procesos de descentralización y a la consideración de las particularidades que trae aparejada la territorialidad para la política social. De ahí la importancia de incorporar esta dimensión mediante la aplicación de mecanismos específicos que representen los intereses de los actores subnacionales en el marco de la institucionalidad analizada, junto con el establecimiento de instancias de coordinación entre niveles de gobierno, dentro de las políticas sectoriales.

Además, cabe considerar la capacidad de rectoría, regulación e interacción con el mercado. Este atributo se relaciona con: a) la protección del acceso; b) la definición de normas de calidad y contenidos de los servicios; c) la mejora de la eficiencia de la gestión privada; d) la garantía de condiciones de competencia y organización del mercado que eviten prácticas perjudiciales; e) la producción y difusión igualitaria de información veraz y oportuna, y f) el establecimiento de instancias que permitan arbitrar conflictos entre proveedores y la población usuaria (Machinea y Cruces, 2010). Los actores privados pueden considerarse parte de la sociedad civil en un sentido amplio, junto con otros actores no gubernamentales (organizaciones sociales, instituciones académicas, entre otros), en la medida en que incidan en el ciclo de las políticas sociales, aunque su regulación descanse en última instancia en el Estado. Esta es una condición necesaria para asegurar la garantía de derechos y, en general, de la normativa, sobre todo en países donde esté más avanzada la privatización o tercerización de campos específicos de la política social (salud, seguridad social, educación, entre otros).

En el recuadro I.1 se resumen algunos de los elementos deseables de la institucionalidad social recogidos por diversos estudios. 


\section{Recuadro I.1 \\ Componentes deseables de la institucionalidad social, según diversos estudios especializados}

Existen varias propuestas sobre los componentes que sería conveniente incluir en una institucionalidad social adecuada. En la mayoría se reconocen los siguientes atributos:

- La existencia de una estrategia a largo plazo coherente y sostenida, que no cambie su esencia frente a cambios de gobierno, crisis políticas o situaciones coyunturales. Esto no implica que la política social sea rígida e invariable frente a la situación socioeconómica. Lo que significa es que debe responder de forma adecuada ante los shocks económicos, pero no cambia arbitrariamente frente a modificaciones de los equilibrios políticos.

- La consideración de los enfoques de derechos y de género como ejes orientadores normativos y prácticos del diseño e implementación de las políticas y programas sociales. Lo anterior supone, por un lado, que estos enfoques incorporan como objetivo último el goce efectivo de derechos $\mathrm{y}$, por el otro, la búsqueda sistemática de la igualdad de género.

- La existencia de reglas claras y conocidas por todos los actores como atributo para definir cómo operan los programas, a qué población van dirigidos, qué tipo de apoyo ofrecen, cuáles son los criterios para la inscripción y selección de destinatarios, y cuáles son sus corresponsabilidades. Además, en las reglas de operación es donde pueden establecerse los mecanismos para facilitar y sistematizar la participación de los ciudadanos. Las reglas de operación (y los lineamientos en general) sirven, entre otras cosas, para que los empleados públicos tengan claridad de cómo deben ejecutarse los programas sociales y para homogeneizar su actuación. Ello permite asegurar el uso eficaz, eficiente, oportuno, transparente y equitativo de los recursos públicos. Además, las reglas claras facilitan la coordinación horizontal y vertical, en la medida en que se atribuyen responsabilidades, obligaciones y recursos concretos a cada dependencia o nivel de gobierno.

- La existencia de espacios de coordinación entre distintos actores gubernamentales encargados de ejecutar la política social. Se trata de actores de distintos niveles de gobierno (central, provincial o regional, municipal o de alcaldía) o sectores. Por ello resulta indispensable establecer ámbitos en que se pueda, por ejemplo, compartir información, articular esfuerzos y asignar recursos de manera eficaz y eficiente.

- El desarrollo de capacidades técnicas permanentes en los organismos encargados de las distintas etapas de la política social. Para llevar a cabo una política social eficaz, resulta fundamental contar con cuadros profesionales capacitados para ejercer las distintas funciones. 
Recuadro I.1 (conclusión)

- La existencia de mecanismos de recolección y análisis de información confiable que permitan evaluar el avance de la estrategia y mejorar los programas. Toda estrategia social debe velar por el uso eficiente de los recursos escasos para atender los problemas sociales más importantes. Con ese fin, es fundamental disponer de información adecuada para la toma de decisiones, con ámbitos institucionales dedicados a la evaluación y el seguimiento de las acciones sociales y su impacto. En concreto, los atributos institucionales relacionados con la transparencia y la rendición de cuentas se traducen en la disponibilidad de la información de los programas sociales por diferentes medios (entre ellos, los electrónicos). Algunas de las informaciones que convendría hacer públicas son: los padrones de destinatarios, el presupuesto asignado para la operación del programa, los reportes de ejercicio del gasto y la disponibilidad de las evaluaciones de los programas.

- La incorporación de mecanismos de control y fiscalización que posibiliten la rendición de cuentas y permitan sancionar a los funcionarios que no se ajusten a la normativa vigente. Para ello es importante que los programas sociales tengan indicadores con los que se pueda medir su grado de avance o desempeño. Además, el desempeño y los resultados de los programas sociales deberían evaluarse de forma periódica a fin de exponer y comprender las dinámicas políticas específicas de cada uno y determinar si se utilizan con fines electorales. Por último, los programas sociales deberían contemplar mecanismos que posibiliten la presentación de quejas y denuncias cuando se presenten anomalías o cuando sean utilizados con fines políticos. Dichos mecanismos y su modo de utilización deberían difundirse tanto entre el personal de la organización como entre la población destinataria. Tales controles pueden estar a cargo de otra entidad pública interna o externa (mecanismos intraestatales) o de actores de la sociedad civil (mecanismos sociales).

- La participación de actores sociales que consoliden la continuidad de los programas. Existen diversos actores sociales que, al tener horizontes de planeamiento más largos que los actores gubernamentales, pueden fortalecer algunos programas sociales. De esta forma se evita su eliminación ante cambios políticos coyunturales y se eleva la capacidad del programa por medio de demandas y colaboración específica.

\footnotetext{
Fuente: John Ackerman, Organismos autónomos y democracia: el caso de México, Ciudad de México, Siglo XXI, 2007; Rolando Franco y Miguel Székely, "Institucionalidad social en América Latina", Documentos de Proyectos (LC/W.312), Santiago, Comisión Económica para América Latina y el Caribe (CEPAL), 2010; Miguel Székely, "Cambios en la institucionalidad de la política de protección social en América Latina y el Caribe: avances y nuevos desafíos", Nota Técnica, N 810, Washington, D.C., Banco Interamericano de Desarrollo, 2015; Simone Cecchini y Rodrigo Martínez, "Protección social inclusiva en América Latina. Una mirada integral, un enfoque de derechos", Libros de la CEPAL, N 111 (LC/G.2488-P), Santiago, Comisión Económica para América Latina y el Caribe (CEPAL), 2011; Fabián Repetto y Fernanda Potenza, "Documento final de consultoría. Institucionalidad social y autoridad social en América Latina y el Caribe. Abordaje conceptual, avances y desafíos de la institucionalidad de la políticas social y de la protección social", inédito, 2015; Eduardo Bohórquez, "Hacia una nueva arquitectura de la información pública y política social en el Distrito Federal", Ensayos para la Transparencia en el Distrito Federal, N 9, Ciudad de México, Instituto de Acceso a la Información Pública del Distrito Federal, 2009; José Luis Machinea y Guillermo Cruces, "Instituciones de la política social: objetivos, principios y atributos", Institucionalidad social en América Latina, R. Franco y M. Székely (coords.), Documentos de Proyectos (LC/W.312), Santiago, Comisión Económica para América Latina y el Caribe (CEPAL), 2010; Magdalena Sepúlveda, "De la retórica a la práctica: el enfoque de derechos en la protección social en América Latina", Serie Políticas Sociales, № 189 (LC/L.3788), Santiago, Comisión Económica para América Latina y el Caribe (CEPAL), 2014.
} 
Cuanto más desarrollada sea la institucionalidad social, mayor probabilidad habrá de alcanzar políticas sociales de calidad (efectivas, eficientes, sostenibles y transparentes), sean sectoriales, de promoción o de protección ${ }^{3}$.

Considerando lo hasta aquí mencionado, por institucionalidad social se entiende el conjunto de reglas, recursos y estructuras organizacionales sobre y con los cuales se gestiona la política social, desde el diagnóstico y la priorización de objetivos hasta la implementación y la evaluación de sus resultados.

Por su parte, la autoridad social es la instancia del Estado a cargo de ejercer la función de gobierno de la política social. Es aquella que, legitimada por las partes y con respaldo político, detenta el poder de dirigir y coordinar la institucionalidad social, y de ejercer la rectoría. Así, como complemento de lo planteado por Acuña y Repetto (2007), entre las responsabilidades asociadas a su función de gobierno se incluyen:

- definir y priorizar los objetivos y metas que guiarán la política, sobre la base de una mirada integral respecto de las problemáticas conexas;

- fijar estándares, normas y regulaciones sobre los que se diseña e implementa la política;

- diseñar planes, estrategias y metodologías de intervención;

- definir modelos de gestión y asignar responsabilidades y funciones a las áreas y actores involucrados en la atención de la temática;

- distribuir los recursos necesarios para el cumplimiento de las actividades ligadas al cumplimiento de responsabilidades y funciones asignadas;

- coordinar y reglamentar las acciones de los actores gubernamentales y no gubernamentales, de la sociedad civil y del sector privado que participan en las distintas etapas de implementación de las políticas y programas sociales;

- monitorear el avance de las actividades, el cumplimiento de la metodología de intervención y el alcance de las metas operativas en cantidad, tiempo, forma y costos;

- $\quad$ sistematizar la información pertinente y evaluar los resultados de la implementación de la política, y

- redefinir la política (sus alcances, objetivos, metas y metodología de intervención) en función de las conclusiones de la evaluación. 
Estas responsabilidades no necesariamente recaen en una sola entidad, sino que puede existir una autoridad colegiada o repartida entre varias dependencias. Así, pueden definirse como "autoridad social" instancias de coordinación intersectorial como, por ejemplo, un gabinete social o un consejo económico y social.

Existe, además, la posibilidad de indicar autoridades sectoriales y autoridades sociales temáticas (por ejemplo, un consejo nacional de la infancia) que funcionan como comisiones intersectoriales especializadas para atender alguna problemática social o las necesidades de algún segmento o grupo de la población, y las propias autoridades sectoriales cuando algún ministerio posee capacidades de gobierno y de coordinación de un ámbito de la política social.

De esta forma, cabe preguntarse cuáles son las instancias que detentan formalmente el poder legítimo de la función de gobierno en los distintos ámbitos o sectores de la política social y sus distintos componentes, y si poseen la capacidad formal y real de desempeñar dicha función en la práctica.

Los problemas sociales son por lo general multifactoriales en sus causas, y multidimensionales en sus expresiones. Por tanto, requieren abordajes integrales en los que la función de coordinación adquiere una relevancia central para la gestión de la autoridad social y de las autoridades sociales temáticas ${ }^{4}$. Esta función remite a la relación entre actores, a los que se requiere hacer converger con facultades y recursos diversos para atender problemas complejos, y actuar de manera articulada en la ejecución de tareas y responsabilidades en el marco de una dirección estratégica común.

Según el nivel de profundidad, se hace distinción entre la coordinación intersectorial de alta intensidad y la de baja intensidad (Cunill-Grau, Repetto y Bronzo, 2015; Repetto y Potenza, 2015a). La primera se da cuando los diferentes sectores intervienen conjuntamente en las diferentes fases del ciclo de una política o programa. Es decir, cuando participan en el diseño, la ejecución y la evaluación, intercambiando información e incluso recursos financieros, para enfrentar un problema que han definido en forma conjunta. En la segunda, la acción pública

A fin de asegurar su integralidad, un sistema de protección social debe considerar dos ejes en el diseño de su oferta programática: el horizontal (los distintos sectores de acción de la política social, como desarrollo social, trabajo, salud, educación u otros) y el vertical (según los niveles administrativos mediante los cuales se ejecuta la política y sus programas, incluidos los actores del sector privado, la sociedad civil y los propios destinatarios). A su vez, para que esta oferta sea realmente integral, y refleje la heterogeneidad existente en la población objetivo, se deben tener en cuenta otros dos ejes: longitudinal (que contemple las características de las distintas etapas del ciclo de vida) y transversal (que identifique las especificidades de género, raza y etnia, formalidad laboral y área de residencia, entre otras) (Cecchini y Martínez, 2011). 
representa la sumatoria de las acciones sectoriales, con un plan de acción básico coordinado por alguna instancia central. Sin embargo, en este caso las actividades de planificación, elaboración de presupuesto y evaluación continúan siendo abordadas en forma independiente por los sectores, y la coordinación se centra sobre todo en los asuntos operacionales.

Más allá de modelos organizacionales específicos, en el análisis de la institucionalidad importa evaluar el grado de coordinación intersectorial y el alcance y la cobertura sectorial. Por ejemplo, la intersectorialidad puede orientarse desde un objetivo transversal, como la incorporación de la perspectiva de género o el enfoque de derechos en todas las políticas. También puede utilizarse para enfrentar algún desafío específico, como la erradicación de la pobreza extrema o el establecimiento de sistemas integrados de protección social. Así, la intersectorialidad puede abarcar un conjunto de organizaciones especializadas, o el conjunto de actores relacionados con las políticas sociales, o incluso organismos de la totalidad de las políticas públicas (OPS/OMS, 2015).

Con base en las consideraciones y referencias analizadas, a continuación se presentan algunas dimensiones analíticas a fin de profundizar en el estudio de la institucionalidad social en la región, tanto a nivel de toda la política social, como específicamente de los sistemas de protección social.

\section{B. Alcances temático y geográfico de la institucionalidad}

En las últimas décadas, en América Latina y el Caribe se han ido configurando distintos procesos de desarrollo de una institucionalidad orientada a mejorar la calidad de las políticas sociales en general y los sistemas de protección social en particular. Así, un primer elemento a discutir es a qué políticas sociales refiere la institucionalidad social.

Los primeros trabajos sobre institucionalidad y autoridad en las políticas sociales surgieron en la década de 1990, junto al desarrollo de los fondos de inversión social. Estos fondos, difundidos por toda la región, centraron su accionar en la lucha contra la pobreza y sus efectos, mediante la ampliación de la cobertura de servicios de salud, de la educación y de los servicios de agua y saneamiento, principalmente con expansión de infraestructura. Esto no significa que las políticas sociales surgieran en dicho período, pues los ministerios sectoriales tienen una larga historia de desarrollo en la región. Sin embargo, el surgimiento de estas nuevas instancias concitó el interés por analizar la institucionalidad social y sus alcances.

Así, al hablar de institucionalidad social cabe hacer referencia a dos niveles distintos de alcance o cobertura temática: 
i) Extendido. Hay abordajes que incluyen al conjunto de las políticas asociadas a las funciones sociales de gobierno y las instancias públicas y privadas que participan en su implementación. Es decir:

- las políticas sectoriales, que tienen por objetivo mejorar la calidad de vida y garantizar derechos, mediante la provisión de bienes y servicios de salud, educación y vivienda, entre otros;

- las políticas de promoción social, que buscan el desarrollo de capacidades mediante el fortalecimiento del capital humano y el mejoramiento de las condiciones del entorno (como la intermediación laboral o la capacitación), a fin de mejorar la productividad y la capacidad autónoma de generar ingresos;

- la protección social, orientada a garantizar el acceso a niveles básicos y universales de bienestar y el ejercicio de los derechos económicos, sociales y culturales. Siguiendo a Cecchini y Martínez (2011, págs. 126 a 129), las funciones de la protección social son:a) garantizar un ingreso que permita sostener niveles de calidad de vida considerados básicos para el desarrollo de las personas, lo que implica que cada país defina ese nivel de vida sobre la base de sus condiciones y posibilidades; $b$ ) identificar la demanda insatisfecha y garantizar el acceso a servicios sociales (salud, educación y vivienda, entre otros) y de promoción, derivando a la población hacia las instituciones encargadas de su prestación, y c) fomentar el trabajo decente mediante la promoción de mejores políticas laborales con el fin de contribuir a la superación del riesgo asociado al mundo laboral, velando por que las personas en edad de trabajar se incorporen al mercado laboral formal.

ii) Restringido. Otros análisis solo centran la mirada en las políticas relacionadas con la lucha contra la pobreza y la protección social no contributiva, así como en las instancias de gobierno que tienen autoridad sobre estos temas. En esta segunda mirada, la imagen organizacional de la institucionalidad social se refiere comúnmente a los ministerios o secretarías de desarrollo social y a las instancias de coordinación interinstitucional dedicadas a dichos fines.

Un segundo elemento que es fundamental considerar, particularmente en el caso de las políticas sociales, es su cobertura poblacional y el grado en que abarcan al conjunto de la población o se restringen a ciertos segmentos o grupos específicos o prioritarios. Así, se identifican dos tipos de cobertura poblacional: 
i) Universal. Se refiere al caso en que la institucionalidad contempla al conjunto de la población de un país, sin hacer distinciones.

ii) Focalizada. Es el caso de los desarrollos institucionales que tienen por mandato garantizar derechos y atender las necesidades de ciertos segmentos poblacionales cuyas características hacen necesaria una especialización de la acción pública. Corresponden a esta categoría las políticas que buscan mejorar el bienestar y garantizar el goce de derechos de los niños, las orientadas al desarrollo de áreas o pueblos indígenas, o bien las centradas en la promoción de la inclusión y los derechos de las personas con discapacidad, entre muchas otras.

A diferencia del alcance temático, que se refiere a objetivos específicos relacionados con funciones sociales particulares, en la distinción basada en la cobertura poblacional se pone el acento en las características de la población objetivo de la política. En general, cuando se aborda la institucionalidad de las políticas focalizadas, se incluyen en ellas todas las funciones sociales atingentes a la población de que se trate, considerando justamente sus brechas y necesidades particulares. Esta distinción, que puede parecer simple en términos analíticos, tiene una importancia mayor al organizar la institucionalidad. Esto es particularmente válido en lo referente a la autoridad a cargo de las políticas en cada país, y a los requisitos de articulación entre los organismos a cargo de temas y los centrados en poblaciones.

Un tercer elemento relativo a los desarrollos institucionales observados en la región se refiere a sus diferencias en materia de alcance geográfico y, por tanto, al mayor o menor nivel de cobertura y autonomía de su autoridad. Dicho alcance puede ser nacional y subnacional, o bien supranacional e internacional.

i) Nacional. En general, la primera imagen que se tiene cuando se habla de institucionalidad y autoridad, se circunscribe al ámbito nacional. Esto se refiere en primer lugar al nivel central, pero también abarca la escala subnacional (estados, provincias, departamentos) y local, como principales escenarios de la implementación de las políticas sociales.

ii) Supranacional o internacional. A través de diversos organismos internacionales y de integración, los Estados han avanzado en el desarrollo de la institucionalidad social a nivel mundial, regional y subregional. Los acuerdos y compromisos establecidos en dichas instancias, y las políticas de cooperación que de ellos se derivan, conforman también una instancia de desarrollo de la institucionalidad social con efectos sinérgicos importantes para las políticas públicas nacionales, así como para la generación de tendencias compartidas e incluso de agendas comunes en torno al desarrollo social. 
Visto lo anterior, cuando se hace referencia a la institucionalidad social y sus avances, es importante considerar y especificar la cobertura y alcances temático, poblacional y geográfico. Estos factores sirven de marco a las diferentes instancias gubernamentales e internacionales involucradas, a su capacidad de coordinación y articulación (sectorial $\mathrm{u}$ horizontal a nivel del Gobierno central y vertical o territorial entre distintos niveles de gobierno), a su coherencia con respecto al reconocimiento formal y la garantía efectiva de derechos (en especial los derechos económicos, sociales y culturales), a la participación de distintos actores y la rendición de cuentas ante participantes, ciudadanía y sociedad civil, así como a los recursos financieros y de gestión movilizados.

\section{Dimensiones de la institucionalidad social}

Además de los alcances a los que puede hacer referencia el análisis de la institucionalidad social, cabe preguntarse sobre los elementos o dimensiones en que se ha de centrar su estudio y cómo interactúan para configurar modelos característicos, en particular a escala nacional, pero también respecto de la escala supranacional.

Con ese fin, y como un intento de abarcar de la manera más amplia posible las características y la diversidad de los modelos, el presente capítulo se centra en cuatro dimensiones: jurídico-normativa, organizacional, técnico-operativa y fiscal.

\section{La dimensión jurídico-normativa}

A medida que la democracia se ha ido consolidando en la región y el enfoque de derechos ha ido ganado terreno en el ámbito social, una dimensión de gran relevancia de la institucionalidad social es la jurídico-normativa. Esto se refiere al sustrato legal sobre el que se diseñan e implementan las políticas y que rige la participación de los diversos actores.

Esta dimensión se compone del conjunto de marcos constitucionales, leyes y reglamentos de cada país. A ellos se suman los tratados y acuerdos internacionales firmados o ratificados, que tienen validez legal interna o sirven como referencia para los compromisos asumidos por los Estados a nivel nacional e internacional en el área social.

La identificación y el conocimiento de este conjunto de elementos jurídico-normativos permiten tener una primera referencia acerca de los compromisos que el país asume en materia de política social, tanto a nivel de la comunidad internacional como ante sus propios ciudadanos. También permiten definir con claridad el respaldo jurídico de las acciones 
gubernamentales en esta área y su jerarquía. Esta última depende de si se trata de un mandato originado en compromisos internacionales, planteado en la Constitución nacional, dispuesto en leyes orgánicas o simples, o establecido en normativas de menor rango, como los decretos o las disposiciones administrativas.

En resumen, según su cobertura geográfica, esta dimensión se compone de:

- Normativa internacional: El compromiso que ha asumido cada país a nivel internacional se plasma en la adhesión, firma o ratificación de tratados o convenios. En particular, es relevante conocer la situación del país con respecto al Pacto Internacional de Derechos Económicos Sociales y Culturales (PIDESC) y a otros tratados o convenciones que puedan estar vinculados a un área específica de la política social o referidos a determinada población objetivo (como la Convención sobre los Derechos del Niño o la Convención sobre los Derechos de la Persona con Discapacidad) $)^{5}$. Por último, deben considerarse acuerdos y compromisos regionales o subregionales, que puedan constituir marcos más ambiciosos y exhaustivos. Por ejemplo, en el ámbito interamericano, hay varias convenciones y tratados de gran relevancia social en la defensa de los derechos humanos en general (la Convención Americana sobre Derechos Humanos en Materia de Derechos Económicos, Sociales y Culturales y el Protocolo de San Salvador), así como en temáticas y colectivos específicos (la Convención Interamericana para Prevenir, Sancionar y Erradicar la Violencia contra la Mujer).

La relevancia de sumar esta dimensión internacional al análisis de la institucionalidad social reside en que, muchas veces, de ella se deriva el mandato para la creación o reformulación de instituciones y su correspondiente expresión en organismos que encarnan las funciones sociales del gobierno. También pueden constituir un incentivo para la movilización y generación de nuevas demandas sociales por parte de actores de la sociedad civil, así como propuestas de política por parte de los propios actores políticos y gubernamentales.

Destacan, entre otros instrumentos, las convenciones internacionales sobre los derechos del niño, el Convenio sobre la Seguridad Social (Norma Mínima), 1952 (Núm. 102) de la Organización Internacional del Trabajo (OIT), la Convención sobre la Eliminación de Todas las Formas de Discriminación contra la Mujer y la Convención sobre los Derechos de las Personas con Discapacidad. 
- Normativa nacional: En relación con la normativa nacional en materia social, en primer lugar, es necesario conocer en qué grado la Constitución integra y ofrece garantías acerca del cumplimiento de los derechos económicos, sociales y culturales. La existencia de este amparo legal contribuye a las aspiraciones de continuidad en el tiempo de aquellos objetivos estratégicos.

También puede suceder que la garantía acerca de esos derechos esté planteada en marcos normativos de menor envergadura, por ejemplo, leyes orgánicas, generales o sectoriales, códigos y reglamentos. En este caso, es relevante tanto la consideración acerca de los derechos sociales en general (educación, trabajo, salud, vivienda, entre otros), como la referida a aspectos específicos del desarrollo o la protección social (contributiva, no contributiva y acciones en materia de cuidado), o a poblaciones determinadas (infancia, mujeres, indígenas, entre otras).

A su vez, se puede encontrar respaldo jurídico en los decretos administrativos que rigen la política social de un gobierno, o en instrumentos más coyunturales que plasman la visión que se tiene en determinado período con respecto al desarrollo (ya sea en términos generales o específicamente del desarrollo social) y las estrategias planteadas en consecuencia. Tales definiciones se encuentran contenidas en instrumentos de gestión, como los planes nacionales de desarrollo o los planes estratégicos de cada área social o que se orientan a ciertos segmentos de población.

Por último, sumado a los compromisos, derechos y garantías que se estipulan en las distintas leyes y normas, cabe destacar los respaldos legales que definen, orientan o sirven de marco a las demás dimensiones de la institucionalidad. Se trata, por ejemplo, de las disposiciones legales que definen los mandatos, las autoridades a cargo y los demás actores involucrados en el diseño e implementación de las políticas sociales, así como la normativa por la que se rigen los procedimientos y herramientas de gestión, y las leyes que estructuran los presupuestos destinados a la implementación de las políticas.

Desde el punto de vista del enfoque de derechos, cabe señalar que la formalización de compromisos con la garantía de derechos sociales suele considerarse un rasgo necesario, aunque no suficiente, de la institucionalidad social. Esa garantía concreta depende también de la disponibilidad de recursos y la voluntad política de concretarlos paulatinamente y de establecer las políticas, mecanismos y programas para hacerlos efectivos (Sepúlveda, 2014). 


\section{La dimensión organizacional}

Esta dimensión se relaciona con la estructura formal y los modelos de toma de decisiones y de comunicación y coordinación existentes entre los diversos actores que participan en la implementación de las políticas. En el plano supranacional, ello incluye los organismos internacionales, regionales y subregionales. En el plano nacional involucra los niveles central, subnacional y local, así como las organizaciones de la sociedad civil, el sector privado y la propia población destinataria, cada uno con su papel respectivo.

Derivada del marco jurídico-normativo y de la organización general de cada Estado, la dimensión organizacional se refiere a los organismos que detentan la autoridad y, por tanto, tienen a su cargo las funciones de coordinación y de gobierno en materia social. También se refiere a la estructura gubernamental que caracteriza a los distintos organismos y el alcance que tienen sus mandatos. En suma, refleja la distribución de funciones en materia social, lo que puede abarcar el conjunto de la política social o un área en particular.

En articulación con el sustrato legal, y como reflejo del nivel de desarrollo de la institucionalidad, el nivel jerárquico de cada organismo ha de estar amparado en una disposición constitucional o en una ley orgánica o simple, un decreto presidencial o una resolución ministerial. Cuanto mayor sea el rango de la norma que le da origen, mayores serán las expectativas con respecto a su sostenibilidad a lo largo del tiempo y a su reconocimiento por parte de los actores involucrados en su puesta en marcha y funcionamiento. Además, el sustrato legal en que se basa la estructura, se designa la autoridad social, se define su mandato y se distribuye el poder, es clave para la legitimidad de los procesos y la toma de decisiones.

Por supuesto, el hecho de que desde el punto de vista normativo esté planteada una clara asignación de responsabilidades y modelos de coordinación no es suficiente para que esto ocurra en la práctica. Sin embargo, es una condición necesaria. Si hay confusión legal o indefinición sobre estas cuestiones, será difícil lograr una articulación y complementariedad entre los actores involucrados. Este tipo de consideraciones tiene particular relevancia cuando se trata de áreas de la política social que incumben a los gobiernos subnacionales (políticas descentralizadas) o bien de alta participación de organizaciones sociales y actores privados (políticas con impronta de tercerización, de privatización o participativas).

Como se ha indicado, además de considerar el conjunto de la política social, en la dimensión organizacional también se consideran los 
aspectos vinculados con la creación de organismos que tienen mandatos específicos (lucha contra la pobreza, promoción de políticas de protección social o mecanismos promotores del desarrollo social). Esta información permite hacer una aproximación a la estructura y las funciones que tiene la política social en un determinado país (véase el diagrama I.1). En este sentido, cabe preguntarse: ¿qué estatus jurídico tienen las distintas instancias y qué rango posee la norma que los crea? ¿cuáles son las áreas del Gobierno central que se encargan de la política social? ¿qué rango tienen esas áreas (ministerios, secretarías, oficinas presidenciales)? ¿a través de qué mecanismos institucionales se relacionan entre ellas? ¿cuál es el área que ejerce las funciones de gobierno y de coordinación (en su caso) sobre el conjunto de la política social? ¿cuáles son las áreas que ejercen las funciones de gobierno y coordinación sobre componentes específicos de la política social que tienen carácter intersectorial? ¿qué actores gubernamentales y no gubernamentales integran las distintas instancias en cada nivel organizacional?

\section{Diagrama I.1 \\ Componentes de la dimensión organizacional a nivel del Gobierno central}

Niveles de coordinación y estructura gubernamental
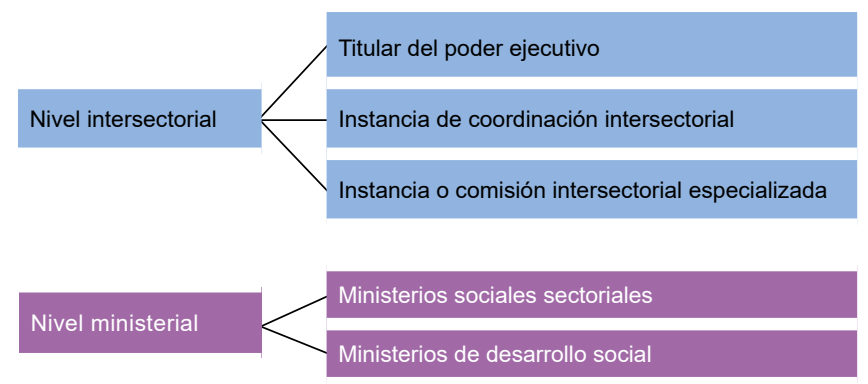

Nivel sub-ministerial _ Instancias dependientes de un ministerio

Fuente: Elaboración propia, sobre la base de F. Repetto y F. Potenza, "Institucionalidad social y autoridad social en América Latina y el Caribe: abordaje conceptual, avances y desafíos de la institucionalidad de la política social y de la protección social”, 2015, inédito.

En base a lo señalado hasta aquí, entre los elementos que cabe considerar para caracterizar la dimensión organizacional de la institucionalidad a nivel nacional se incluyen:

- La autoridad: Como se ha indicado, un elemento central del análisis de la dimensión organizacional consiste en determinar qué organismos cumplen las funciones de autoridad social y si dicha autoridad se concentra en una instancia única o es 
compartida. Por ejemplo, podría compartirse entre instancias colegiadas, como un gabinete social bajo la autoridad de la Presidencia de la República, o entre consejos de coordinación intersectorial, especializados en una temática social (como la lucha contra la pobreza) o en un grupo de población (como la infancia). También pueden presentarse casos en que determinada autoridad sectorial tenga el mandato general de coordinar a los demás ministerios en el área social (véase el diagrama I.2).

Diagrama I.2

Tipos y alcance de las autoridades sociales

Organismos con funciones de
coordinación y gobierno $\quad$ Alcance de los mandatos y políticas
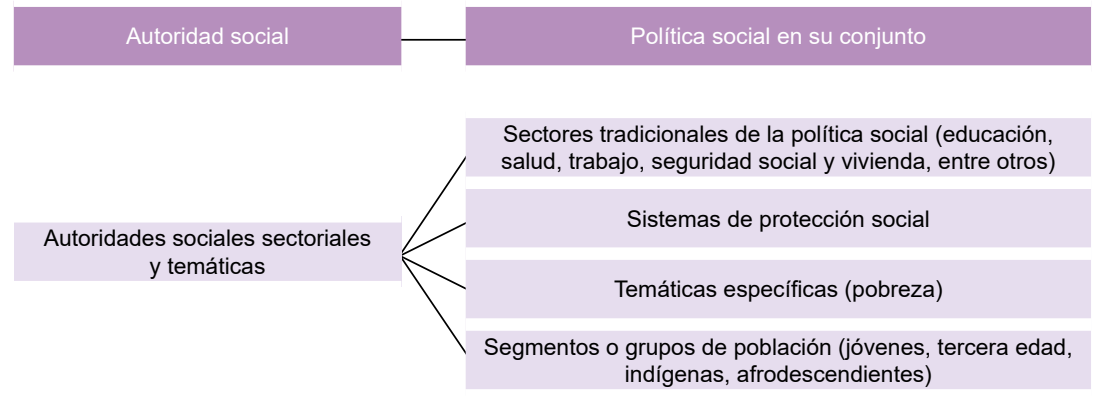

Fuente: Elaboración propia, sobre la base de F. Repetto y F. Potenza, "Institucionalidad social y autoridad social en América Latina y el Caribe: abordaje conceptual, avances y desafíos de la institucionalidad de la política social y de la protección social", 2015, inédito.

La base legal a partir de la que se definen los roles y responsabilidades es un indicador clave del grado de institucionalización alcanzado en la definición de la autoridad. La fecha de creación de la autoridad social es también relevante, pues refleja su estabilidad temporal. La antigüedad permite conocer si se trata de organismos de muy reciente creación, o que aún no han pasado la prueba de trascender al gobierno que los ha conformado o, de lo contrario, si son organismos de larga data, con historia y trayectoria acumulada.

Cuanto más alto sea el nivel que ocupan estas autoridades sociales en la estructura gubernamental, mayor será su potencial de influencia sobre la toma de decisiones y el desarrollo de las políticas.

- La estructura gubernamental: En segundo lugar, cabe determinar cuáles son los organismos y actores que forman parte de la gestión 
de la política social (presidencia o vicepresidencia y sus delegados, ministerios, secretarías, institutos, oficinas y programas, entre otros) o que intervienen en ella, cómo se conforma la delegación de autoridad entre los distintos niveles de gobierno (central, subnacional o local) y cuál es el rol de los organismos externos, las organizaciones comunitarias y no gubernamentales y la población general.

En los casos en que existe una autoridad social colegiada, su estructura refleja el nivel de compromiso y autonomía sectorial en la toma de decisiones (por ejemplo, cuando participan directamente la presidencia o vicepresidencia), el grado de coordinación con las demás funciones de gobierno (por ejemplo, cuando participan los ministerios económicos) y el papel que se asigna a actores externos al gobierno (representantes de instituciones académicas, organizaciones de la sociedad civil $\mathrm{u}$ otros).

Caracterizar la estructura también permite determinar el nivel de concentración o dispersión de la autoridad y, por tanto, el grado en que se presentan espacios de autonomía en la gestión. Es decir, si esta se desarrolla de manera centralizada, desconcentrada o descentralizada, si hay externalización de ciertas funciones o servicios y si se promueve la participación de la sociedad civil.

Complementan esta información el tipo de funciones asignadas a cada actor de la estructura, en especial a la autoridad social relacionada con la planificación estratégica y la priorización (lineamientos y orientaciones de las políticas, intervención en el proceso presupuestario, y ejercicio del monitoreo y la evaluación), rectoría, coordinación y regulación de otros actores no gubernamentales y solución de conflictos entre los actores institucionales del sector.

El área de incumbencia y el tipo de funciones asignadas presentan cierta particularidad si se centra la mirada en el nivel de las "autoridades sectoriales". En este caso, es conveniente conocer su estructura interna, con las reparticiones que la conforman, los temas específicos y las poblaciones en que se enfoca cada una de ellas. Esta descripción ha de incluir también los procesos de cambio organizacional, en curso y precedentes, sus fundamentos, objetivos y vinculación con los objetivos de política.

Cuanto más participativa y descentralizada sea la estructura, mayores serán las demandas en términos de coordinación interinstitucional. Esta necesidad de coordinación incluye tanto la articulación vertical (entre niveles de gobierno) como horizontal (entre sectores). 
Una manera de organizar la información referente a la forma en que se estructura la institucionalidad social es considerar tres niveles:

i) El nivel interministerial, que permite identificar qué instancias ejercen la labor de coordinación a nivel central y detentan la autoridad en el ámbito social (Presidencia, instancia interministerial o ministerial, entre otras). También permite conocer cuáles son las instancias de coordinación entre ministerios y otras reparticiones del poder ejecutivo, que definen el direccionamiento y las prioridades de la política pública en lo referente al desarrollo social (por ejemplo, gabinetes sociales, consejos económicos y sociales, e instancias de coordinación propias de la Presidencia o la oficina del primer ministro). Además de la coordinación a nivelinterministerial, estenivel puedeinvolucrar mecanismos de coordinación territorial entre el Gobierno central y otros niveles de gobierno. Por último, puede incluir instancias de coordinación intersectorial especializadas temáticamente o centradas en la atención de grupos de población específicos (por ejemplo, consejos nacionales de la infancia).

ii) El nivel propiamente ministerial, que ayuda a analizar la configuración de los distintos ministerios sociales (o instancias equivalentes del Poder Ejecutivo) que están a cargo de las funciones sociales o de rectoría. Es preciso considerar sus mandatos (funciones asignadas) y su estatus jurídico para aprehender la importancia relativa del desarrollo social dentro de la estructura gubernamental central, así como su grado de autonomía y especialización en comparación con otras áreas sectoriales del gobierno. En especial, la existencia de un ministerio de desarrollo social es relevante, no solo para constatar el nivel de importancia asignado al tema, sino también para conocer cuáles son sus funciones, de qué áreas de política y grupos de población se ocupa y con qué recursos y capacidades cuenta para ello.

iii) Por último, la estructura subministerial considera las instancias que ejecutan y gestionan acciones y programas sociales específicos, según ámbitos de política (por ejemplo, cuidados, discapacidad) o grupos específicos de población objetivo (por ejemplo, institutos de juventud o para los adultos mayores). También se incluyen diversos mecanismos de gestión y coordinación operativa de los programas sociales, que pueden ser intraministeriales y territoriales (en especial, la relación entre niveles de gobierno), con sus 
respectivas particularidades en lo relativo a las facultades y autonomía de los niveles subnacionales (dependiente de las características de la división político-administrativa de cada país).

El grado y tipo de responsabilidad que asume cada uno de los actores de la estructura organizacional también es un elemento que caracteriza a esta dimensión de la institucionalidad. Al respecto, Székely (2010 y 2015) plantea que los sistemas jurídicos de los países de América Latina establecen por lo menos tres tipos de códigos de conducta que rigen el comportamiento de un empleado público. En cada uno se incluye la previsión de las causas de responsabilidad y las sanciones correspondientes. El primero se refiere a la responsabilidad política, prevista para sancionar a los funcionarios públicos de mayor nivel (presidente, vicepresidentes, ministros, legisladores, autoridades locales). El segundo hace referencia a las responsabilidades administrativa en las que se puede incurrir por faltar a las obligaciones del servicio público. El tercero alude a la responsabilidad penal que resulta de la comisión de un delito.

- Los modelos de comunicación: La forma en que se toman y comunican las decisiones entre los actores tiene características propias en cada país, asociadas a la estructura de su institucionalidad y la legalidad vigente.

La formalización de las comunicaciones y el establecimiento de protocolos para su difusión (interna y externa) son elementos que repercuten favorablemente en la claridad de los procesos decisorios y del rol de los actores en ellos. Esto contribuye a la previsibilidad de las comunicaciones y a mitigar riesgos en la implementación, con lo cual se profundiza la institucionalidad. El contrapunto es que este tipo de instrumentos puedan exacerbar los aspectos más negativos de la burocracia, en lo que se refiere a limitar la eficiencia y la flexibilidad para atender situaciones cambiantes.

Estas características ofrecen una primera panorámica acerca de las limitaciones y oportunidades que pueden encontrar esos organismos al ejercer las funciones de coordinación y de gobierno. Un corolario de lo anterior es que, a mayor especialización sin capacidad de coordinación de la institucionalidad, mayor riesgo de dispersión, duplicación y fragmentación de la acción pública. Como se ha dicho, se puede suponer que cuanto más formalizada y explícita sea la estructura a cargo de la gestión, más asentada y sostenible será la institucionalidad.

Como se apunta más adelante, la coherencia entre mandatos, estructura gubernamental, instrumentos de gestión y montos o recursos 
gestionados es un determinante importante de los resultados de las políticas y programas en el área social.

\section{La dimensión técnico-operativa}

La tercera dimensión analítica de la institucionalidad social es la técnicooperativa. En ella se incluyen los instrumentos y herramientas necesarios para implementar la política de manera eficaz (que cumpla con las metas de ejecución y cobertura), eficiente (en el uso de los recursos), efectiva (en alcanzar los objetivos de la política), transparente y participativa. En la mayoría de los estudios previos en materia de institucionalidad social se presta mayor atención a esta dimensión, en detrimento de las dimensiones normativa (central desde el punto de vista de un enfoque de derechos), organizacional y de financiamiento. Ello puede entenderse como resultado del mayor interés que se concedió durante la década de 1990 a la incorporación de criterios de eficiencia y efectividad en los organismos a cargo de los programas de lucha contra la pobreza.

Esta dimensión supone considerar los procedimientos, recursos físicos y capacidades técnicas disponibles respecto de la implementación de las políticas públicas en su conjunto, o bien exclusivamente las sociales. Para su análisis, se destacan tres grandes categorías: i) los instrumentos y procesos de planificación estratégica; ii) los sistemas de información para el diagnóstico, monitoreo y evaluación, y iii) las herramientas relacionadas con la transparencia y la rendición de cuentas.

i) Planificación y programación: Se refiere a la disponibilidad, de parte de la autoridad social y los distintos actores de la estructura, de herramientas de priorización e implementación que permitan alcanzar sus objetivos institucionales de manera efectiva y eficiente. Esto puede venir determinado desde la misma ley que define sus funciones (Ley de Ministerios) o especificado en sus reglamentos y planes institucionales (planes nacionales de desarrollo o planes estratégicos de menor rango). En síntesis, se trata de detectar la existencia y el funcionamiento de procedimientos formales de implementación de una planificación estratégica y de planes operativos que orienten la gestión con base en resultados, además de la disponibilidad de herramientas, con metas, mapas de procesos, plazos y presupuestos claros, así como con los recursos técnicos adecuados para su implementación (capacidad física y de profesionales y técnicos suficientes en términos de cantidad y calidad).

No se trata solamente de que existan procedimientos formales, sino también de conocer de qué tipo de planificación se 
trata. En particular, es importante saber si la planificación está orientada a la obtención de resultados y si se cuenta con instrumentos asociados a la gestión de la calidad. Por ejemplo, la planificación por procesos, el vínculo programaciónpresupuesto, la pertinencia de la estructura organizacional y los procedimientos formales de monitoreo, auditoría y control.

Los instrumentos descritos permiten limitar el margen de acción discrecional de los gestores, sobre todo en lo referente a la manera en que funcionan los programas y en que se asignan o distribuyen los bienes o servicios que ofertan. Si bien la definición de estas cuestiones puede promoverse (e incluso exigirse) desde el ámbito de la autoridad social o la autoridad social temática, su desarrollo y aplicación efectiva corresponden a cada uno de los sectores. Cabe destacar por su relevancia la existencia de reglas de operación de los programas y servicios, con definición clara de criterios y procedimientos para el reparto de los recursos ofrecidos, así como de un marco legal que reglamente y sancione las conductas inapropiadas.

ii) Sistemas de información, monitoreo y evaluación: Supone la disponibilidad de procedimientos propios para la recolección y análisis de datos sobre la realidad social, así como de padrones o registros de participantes y de seguimiento de la ejecución física y presupuestaria. Es decir, sistemas que permitan disponer de información útil para la toma de decisiones en las distintas etapas de la gestión (diagnóstico, formulación, monitoreo y evaluación de procesos y de impactos). Al respecto no solo es necesario determinar si existen sistemas y cuáles son sus características, sino también qué grado de integración presentan.

Junto con el análisis de integralidad entre los procesos relacionados con cada etapa de la gestión, resulta especialmente importante saber si dichos sistemas se circunscriben a la gestión de programas o proyectos específicos o alcanzan al conjunto de una política. En el caso de la autoridad social y la autoridad social temática, reviste particular importancia conocer en qué medida han podido promover el desarrollo de evaluaciones de políticas (consideradas integralmente) y no solo de programas o intervenciones en forma aislada.

De particular relevancia es la integralidad de la función de evaluación, pues su aporte final difiere según la etapa del ciclo de vida del proyecto en que se utilice. Si se aplica ex ante, durante la formulación, proporciona los criterios de decisión para aceptar una propuesta de política específica $u$ ordenar las alternativas 
consideradas en función de las relaciones existentes entre sus costos e impacto (o beneficio). Si se aplica ex post, durante la operación o tras su conclusión, permite determinar el grado de alcance de los objetivos (operacionales y de resultado), así como el costo en que se ha incurrido. También permite reorientar la operación, mediante la adecuación del diseño realizado o la adaptación a las condiciones cambiantes del contexto. Además, posibilita aprender de la experiencia. Así, la evaluación y el monitoreo sirven de marco de referencia para formular un programa o proyecto y para medir la eficacia, la eficiencia, los efectos y los impactos de dicha iniciativa, así como las relaciones existentes entre la gestión y los resultados. Por consiguiente, es de central importancia que se considere la evaluación ex ante y ex post (Martínez, 2015; Cohen y Martínez, 2004).

El ejercicio de la función de evaluación supone diferentes instancias, entre las que cabe destacar la identificación clara de los indicadores sobre cuya base se evaluarán los programas (sobre todo en lo que se refiere al resultado o el impacto), la existencia de mecanismos que permitan la obtención y el análisis regular de información, la implementación de procesos de monitoreo, la realización de evaluaciones periódicas y el análisis articulado de ambos procesos.

Desde una perspectiva macro, también es necesario conocer en qué medida las evaluaciones se realizan en forma integral o constituyen un ejercicio aislado de determinados organismos. En este contexto, la autoridad social o la autoridad social temática pueden desempeñar un papel central, al priorizar las evaluaciones que deben realizarse (de forma convenida con las máximas autoridades del país y los actores involucrados en cada caso) y definir su alcance. La oferta de asistencia técnica específica a este respecto puede provenir tanto de las propias autoridades antes mencionadas como de organismos especializados de la institucionalidad de cada país (como es el caso del Consejo Nacional de Evaluación de la Política de Desarrollo Social (CONEVAL) en México).

iii) Mecanismos de rendición de cuentas y transparencia: Estos se centran en la relación entre la gestión interna de la política, el uso de recursos y la asignación presupuestaria, lo que al final trae a escena a nuevos actores (como el Poder Legislativo, que aprueba y fiscaliza la asignación de recursos) y vincula la gestión de la autoridad social (y demás organismos propios de este ámbito) con la autoridad económica. 
Estos procedimientos también incluyen los mecanismos de transparencia y supervisión ciudadana, que permiten que las autoridades informen sobre sus acciones. Para desarrollar estos procesos es central contar con instancias establecidas de difusión de resultados a la ciudadanía y fortalecer el uso de las tecnologías de la información y las comunicaciones.

Cabe mencionar al respecto la distinción entre rendición de cuentas vertical (o social) y horizontal (o intraestatal). En el primer caso, los actores gubernamentales deben responder a los cuestionamientos y demandas de diversos actores sociales (la opinión pública, la sociedad civil, los destinatarios de los programas, entre otros), y la transparencia y la contraloría social desempeñan un papel central. Por su parte, los mecanismos de rendición de cuentas horizontales son aquellos en que una entidad gubernamental tiene el mandato legal y formal de vigilar las acciones de otra entidad pública, en el marco de una "institucionalización legal de la desconfianza" (Mainwaring y Welna, 2003; O'Donnell, 2003).

Si bien este último aspecto se puede relacionar con el papel que desempeñan los sistemas de información, monitoreo y evaluación de las políticas y programas sociales, la responsabilidad recae en los mecanismos más generales de auditoría y supervisión de las políticas públicas en los distintos niveles de gobierno. Así, es indispensable avanzar en ambas dimensiones para que las políticas y programas sociales estén sujetos en la menor medida posible a un uso político o clientelar y generen una legitimidad social extensa, basada en una implementación sujeta a normas y procedimientos verificables, con apego a derecho, y abierta al escrutinio público.

\section{La dimensión de financiamiento}

La cuarta dimensión propuesta, se refiere al financiamiento. Su estudio aporta dos elementos significativos al análisis de la institucionalidad social. Por un lado, la consideración acerca de la magnitud de los recursos destinados a financiar las políticas sociales permite estimar la prioridad que tienen tales problemáticas para un determinado país, desde la perspectiva de los encargados de adoptar decisiones en materia de políticas públicas. Por otro lado, esta magnitud también señala el margen de maniobra de los funcionarios públicos. Las dotaciones presupuestarias escasas o insuficientes para hacer frente a una problemática social compleja y amplia representan un límite infranqueable para la política social, que va más allá de las posibilidades de la gestión propiamente dicha. 
Entre los aspectos que destacan como indicadores relevantes para conocer de esta dimensión se incluyen:

- Fuente de financiamiento: El primer elemento a considerar en esta dimensión es el origen de los recursos. Mientras estos sean mayormente dependientes de los ingresos propios del país y estén definidos por una ley específica o tengan una partida protegida en el presupuesto nacional, mayor será la seguridad y estabilidad financiera y la institucionalidad de las políticas financiadas con ellos. En cambio, cuando dependen de préstamos, donaciones del exterior o aportes voluntarios privados, mayor es la vulnerabilidad del financiamiento y menor es el grado de institucionalidad de las políticas.

La normativa que respalda dichas fuentes de financiamiento también facilita o limita la autonomía o discrecionalidad que tienen los organismos para hacer uso de los recursos que se les asignan.

- Suficiencia de recursos: Es complejo precisar si el presupuesto asignado a una determinada área social resulta o no suficiente para hacer frente a los problemas que deben resolverse. Sin embargo, se puede hacer una caracterización al respecto a partir de su monto per cápita y su tasa de crecimiento, como parte del gasto total o del producto interno bruto (PIB) o, incluso, desde el punto de vista de su evolución histórica. Estos indicadores permiten analizar tanto la disponibilidad de recursos para financiar la política social como su estabilidad a lo largo del tiempo.

Desde el punto de vista de la institucionalidad social, y teniendo en cuenta la información disponible, se deben considerar dos indicadores importantes: i) el monto relativo del gasto social desde una perspectiva funcional, y ii) la cantidad y proporción de recursos fiscales manejados por instancias gubernamentales clave, como los ministerios de desarrollo social.

- Capacidad de ejecución: Con independencia de la magnitud de los recursos, es importante determinar también la capacidad de ejecución de los organismos a cargo de la política social, y la diferencia entre los recursos asignados y aquellos efectivamente ejecutados. Las posibles razones de una ejecución deficiente se vinculan generalmente con elementos de la dimensión técnico-operativa, particularmente el perfil del equipo a cargo de la política o programa, y con el contexto - político, social, económico y medioambiental- en el que se desarrolla la política. La incorporación de información respecto de estos temas permite obtener una imagen panorámica sobre lo que sucede en las áreas 
sociales en contraste con otros sectores de las políticas públicas. También posibilita una comparación y un análisis internos (por ejemplo, sobre la capacidad de ejecución de los organismos encargados de la protección social contributiva, frente al mismo atributo de los que gestionan la protección social no contributiva).

Por último, cabe mencionar que un análisis más pormenorizado acerca del financiamiento también permite profundizar en el vínculo entre la autoridad social y la autoridad económica. De lo anterior se derivan algunas cuestiones de singular interés. Por ejemplo, la manera en que se toman las decisiones acerca de la magnitud de recursos asignados a un determinado sector, política o programa; la verdadera participación que tiene en esas decisiones la autoridad social; el tipo de alianzas que se gestan entre las áreas sociales para hacer contrapeso a decisiones basadas fundamentalmente en argumentos fiscales, y el tipo de relaciones y negociaciones que establece la autoridad económica con las áreas sociales (bilaterales o conjuntas).

En esta perspectiva de análisis se combinan elementos propios de la institucionalidad formal (lo que las normas definen en cuanto al proceso de asignación presupuestaria) e informal (la práctica, las costumbres, la memoria organizacional sobre estos procesos). El carácter cualitativo de esta información puede exceder la capacidad de revisión sistemática, pero es fundamental su consideración en el desarrollo de estudios puntuales.

\section{Comentarios finales}

Como se ha detallado en el presente capítulo, en las aproximaciones de las últimas décadas sobre el tema de la institucionalidad social en la región se ha hecho énfasis en una o dos dimensiones, ya sea la legal, la organizacional o la de gestión. En este caso se ha hecho un intento por profundizar en dichas dimensiones y abrir el análisis hacia otros ámbitos. Se parte del entendimiento de que, para avanzar en políticas sociales de calidad (que sean efectivas, eficientes, sostenibles y transparentes), se requiere trabajar en las distintas dimensiones de manera complementaria. Ello no es posible sin un abordaje integral. Esto no significa que con los elementos aquí tratados se complete todo el análisis. Al contrario, con ello se intenta promover nuevos desarrollos que permitan hacer cada vez más exhaustivo su estudio.

Un primer elemento que conviene destacar es el alcance temático que se tiene en mente al hablar de institucionalidad social. Según el marco de referencia que se utilice, esta puede incluir todas las funciones sociales o restringirse a las que más se orientan a la erradicación de la pobreza y la protección social no contributiva. La especificación de este marco es clave al intentar avanzar en este tipo de análisis. 
Un segundo elemento que se resalta es el alcance geográfico. El verdadero concepto de institucionalidad no se restringe al ámbito nacional y menos aun al Gobierno central, como habitualmente se hace. Es cierto que este último es muy relevante, pero los compromisos internacionales, y las instancias de deliberación y acuerdo entre países definen metas, enfoques y estándares. Al mismo tiempo, la cooperación entre las instituciones nacionales de distintos países genera aprendizajes mutuos y sinergias relevantes. Se da un caso similar con el ámbito subnacional y la participación de los distintos actores públicos y privados. La forma en que estos se articulan y su capacidad de gestión son determinantes centrales de la política pública.

Un tercer elemento es la especificidad de la política social. Este aspecto suele estar organizado a la vez sectorialmente y por segmentos de población determinados, con lo que se generan múltiples espacios de intersección y mandatos compartidos. Ello pone de relieve, como en ningún otro ámbito de política, que la coordinación interinstitucional es un elemento estructural determinante en la organización y los logros de dicha política. Al mismo tiempo, tensiona el sentido y la legitimidad que confieren los distintos actores a la autoridad social de cada país.

En pocas palabras, a partir de la propuesta analítica que se ha expuesto en este capítulo se puede deducir que las dimensiones normativa y organizacional permiten definir las características de la autoridad social de un país. Es decir, permiten establecer la entidad o entidades de la estructura del Estado que tienen la facultad y el mandato formal de ejercer la función de gobierno en materia de desarrollo social, determinar el sustrato legal en que se sostiene dicha autoridad y analizar las diversas instancias que participan en la gestión de las políticas, sus esquemas de coordinación y su articulación operativa. Ellas constituyen los cimientos y la estructura con que se ha de gestionar la política.

Un desarrollo institucional efectivo supone definir normativas, autoridad, modelo de organización, mandatos y esquemas de coordinación y comunicación. No obstante, estas definiciones no suelen ser parte del diseño de soluciones para optimizar impactos y eficiencias, sino del marco general sobre cuya base se diseña. Conocer las oportunidades y limitaciones en estos ámbitos es central cuando se busca acometer el desafío de un desarrollo social inclusivo, basado en derechos.

Las dimensiones técnico-operativa y de financiamiento, en tanto, aportan el análisis de los distintos tipos de recursos con que la organización puede dar cuenta de sus mandatos y normas. La infraestructura operativa y el modelo de financiamiento definen los límites de capacidad de gestión de dichas políticas. Si no se dispone de los procedimientos adecuados, la información necesaria, personas capacitadas y recursos financieros estables, entre otras cosas, no es posible elaborar políticas de calidad. 
Sobre la base del análisis de estos elementos y la coherencia entre ellos, en el siguiente capítulo se analiza la institucionalidad que existe en la región en el ámbito de las políticas de desarrollo social. Este análisis se realiza a partir de las instancias gubernamentales encargadas del diseño y la implementación de las estrategias de desarrollo e inclusión social y la superación de la pobreza. Como se verá, la institucionalidad de las políticas sociales es heterogénea entre los distintos países. No obstante, todos muestran avances en las últimas tres décadas, ya sea en las bases jurídico-normativas de las políticas, los modelos organizacionales y de autoridad social, las herramientas técnicas y de gestión o los montos de recursos y esquemas de financiamiento. Se observa una ampliación de los mandatos y de los mecanismos de coordinación. Cada vez con mayor frecuencia, estos no se limitan a la superación de la pobreza, sino que abarcan la construcción de sistemas de protección social más integrados y la garantía de derechos. Sin embargo, quedan aún importantes desafíos, y también existen grandes oportunidades, en lo que respecta al avance hacia una política social de calidad.

\section{Bibliografía}

Ackerman, J. (2007), Organismos autónomos y democracia: el caso de México, Ciudad de México, Siglo XXI.

Acuña, C. H. y F. Repetto (2007), “Un aporte metodológico para comprender (y mejorar) la lógica político-institucional del combate a la pobreza en América Latina", Documento de Trabajo, N 44, Buenos Aires, Universidad de San Andrés.

Bohórquez, E. (2009), "Hacia una nueva arquitectura de la información pública y política social en el Distrito Federal", Ensayos para la Transparencia en el Distrito Federal, $N^{\circ}$ 9, Ciudad de México, Instituto de Acceso a la Información Pública del Distrito Federal.

Braun, M. y C. E. Vélez (2004), "Retos institucionales para la equidad y sustentabilidad del desarrollo social en América Latina", Washington D.C., Banco Interamericano de Desarrollo (BID).

Cecchini, S. y R. Martínez (2011), "Protección social inclusiva en América Latina: una mirada integral, un enfoque de derechos", Libros de la CEPAL, $\mathrm{N}^{\circ} 111$ (LC/G.2488-P), Santiago, Comisión Económica para América Latina y el Caribe (CEPAL).

CEPAL (Comisión Económica para América Latina y el Caribe) (2016a), Horizontes 2030: la igualdad en el centro del desarrollo sostenible (LC/G.2660/Rev.1), Santiago. (2016b), Panorama Social de América Latina 2015. Documento informativo, Santiago. (2015), "Desarrollo social inclusivo. Una nueva generación de políticas para superar la pobreza y reducir la desigualdad en América Latina y el Caribe" (LC/L.4056(CDS.1/3)), Santiago.

Cohen, E. y R. Martínez (2004), “Manual. Formulación, evaluación y monitoreo de proyecto sociales", Santiago, Comisión Económica para América Latina y el Caribe (CEPAL). 
Cunill-Grau, N., F. Repetto y C. Bronzo (2015), “Coordinación pro integralidad de las instituciones de protección social", Instrumentos de protección social: caminos latinoamericanos hacia la universalización, S. Cecchini y otros (eds.), Libros de la CEPAL, Nº 136 (LC/G.2644-P), Santiago, Comisión Económica para América Latina y el Caribe (CEPAL).

Franco, R. y M. Székely (2010), "Institucionalidad social en América Latina", Documentos de Proyectos (LC/W.312), Santiago, Comisión Económica para América Latina y el Caribe (CEPAL).

Gargarella, R. (2013a), “Dramas, conflictos y promesas del nuevo constitucionalismo latinoamericano", Anacronismo e Irrupción. Revista de Ciencia y Filosofía Política, vol. $3, \mathrm{~N}^{\circ} 4$.

(2013b), Latin American Constitutionalism, 1810-2010: The Engine Room of the Constitution, Nueva York, Oxford University Press.

Irarrázabal, I. (2006), "Institucionalidad de la política social en Chile. Propuestas para los nuevos desafíos", La nueva realidad de la pobreza en Chile, Santiago, Fundación Libertad y Desarrollo.

Kaufmann, J., M. Sanginés y M. García Moreno (2015), Construyendo gobiernos efectivos: logros y retos de la gestión pública para resultados en América Latina y el Caribe, Washington, D.C., Banco Interamericano de Desarrollo (BID).

Machinea, J. L. y G. Cruces (2010), "Instituciones de la política social: objetivos, principios y atributos", Institucionalidad social en América Latina, R. Franco y M.Székely (coords.), Documentos de Proyectos (LC/W.312), Santiago, Comisión Económica para América Latina y el Caribe (CEPAL).

Mainwaring, S. y C. Welna (2003), "Introduction", Democratic Accountability in Latin America, Oxford University Press.

Martínez, R. (2015), "Monitoreo y evaluación de políticas de protección social", Instrumentos de protección social. Caminos latinoamericanos hacia la universalización, Simone Cecchini y otros (eds.), Libros de la CEPAL, N 136 (LC/G.2644-P), Santiago, Comisión Económica para América Latina y el Caribe (CEPAL).

O'Donnell, G. (2003), "Horizontal accountability: the legal institutionalization of mistrust", Democratic Accountability in Latin America, vol. 1, Scott Mainwaring y Christopher Welna, Oxford University Press.

OPS/OMS (Organización Panamericana de la Salud/Organización Mundial de la Salud) (2015), Intersectorialidad y equidad en salud en América Latina: una aproximación analítica, Washington, D.C.

Repetto, F. (2004), "Capacidad estatal-requisito necesario para una mejor política social en América Latina", Documentos de Trabajo del INDES, I-52, Washington, D.C., Banco Interamericano de Desarrollo (BID).

Repetto, F. y F. Potenza (2015a), “Documento final de consultoría. Institucionalidad social y autoridad social en América Latina y el Caribe. Abordaje conceptual, avances y desafíos de la institucionalidad de la política social y de la protección social".

(2015b), "Institucionalidad social y autoridad social en América Latina y el Caribe: abordaje conceptual, avances y desafíos de la institucionalidad de las políticas social y de la protección social", inédito.

Sepúlveda, M. (2014), "De la retórica a la práctica: el enfoque de derechos en la protección social en América Latina", Serie Políticas Sociales, N 189 (LC/L.3788), Santiago, Comisión Económica para América Latina y el Caribe (CEPAL). 
Stein, E. y otros (eds.) (2008), Policymaking in Latin America: How Politics Shapes Policies, Washington, D.C., Banco Interamericano de Desarrollo (BID).

Székely, M. (2015), "Cambios en la institucionalidad de la política de protección social en América Latina y el Caribe: avances y nuevos desafíos", Nota Técnica, $\mathrm{N}^{\circ}$ 810, Washington, D.C., Banco Interamericano de Desarrollo (BID).

(2010), "Midiendo el nivel de institucionalidad de las políticas sociales en América Latina", Institucionalidad social en América Latina, R. Franco y M. Székely (eds.), Documentos de Proyectos (LC/W.312), Santiago, Comisión Económica para América Latina y el Caribe (CEPAL). 
Capítulo II

\title{
La institucionalidad del desarrollo y la protección social en América Latina y el Caribe: panorama y desafíos
}

\author{
Rodrigo Martínez ${ }^{1}$ \\ Carlos Maldonado Valera ${ }^{2}$
}

\section{Introducción ${ }^{3}$}

A la luz de las dimensiones indicadas en el primer capítulo, en este se describen los principales rasgos, logros y desafíos que presentan los países para avanzar en la conformación de una institucionalidad que se traduzca en una política social de calidad (efectiva, eficiente, sostenible y trasparente) con miras a la consecución del desarrollo e inclusión social y la superación de la pobreza en los países de América Latina y el Caribe. A ese respecto, en la primera parte se establece un panorama de los marcos jurídiconormativos que caracterizan a la región. En especial, se ofrece una mirada a nivel internacional y nacional, con el fin de construir un escenario más

Oficial Superior de Asuntos Sociales de la División de Desarrollo Social de la Comisión Económica para América Latina y el Caribe (CEPAL).

2 Oficial de Asuntos Sociales de la División de Desarrollo Social de la Comisión Económica para América Latina y el Caribe (CEPAL).

3 Los autores agradecen a Guillermo Sunkel, Oficial de Asuntos Sociales, Gabriel Kattan, Matías Salces y Fabiana Pierre, Consultores de la División de Desarrollo Social de la CEPAL, por su colaboración en la recolección, sistematización y análisis de la información sobre institucionalidad social en América Latina y el Caribe. 
allá de los marcos nacionales y describir las diferencias y semejanzas entre los países, así como las particularidades de la región desde el punto de vista de los compromisos asumidos por los Estados en virtud de diversos instrumentos jurídicos internacionales de gran relevancia para el desarrollo social y el avance en la garantía de derechos. En segundo lugar, se estudia la dimensión organizacional de la institucionalidad. Se abordan, por un lado, los rasgos principales de los foros dedicados al desarrollo social a nivel regional y, por el otro, las características organizacionales y las principales autoridades en materia social a nivel nacional, los mandatos y rasgos de los ministerios de inclusión y desarrollo social, así como las instancias gubernamentales a cargo de algunos segmentos clave de población, la adscripción institucional de los programas de transferencias condicionadas y las pensiones sociales. Este doble abordaje permite poner de relieve cómo se ha construido una agenda social a nivel de la región, con algunas temáticas recurrentes, de la mano de un diálogo en diversos foros entre los ámbitos nacional y regional. También permite señalar algunas dificultades comunes en materia de coordinación. En tercer lugar, se presenta un panorama de los principales instrumentos de política pública y gestión que caracterizan a la región en materia social, con miras a mostrar los avances de las últimas décadas, así como los desafíos pendientes. En cuarto lugar, se aborda la dimensión del financiamiento de la institucionalidad, con énfasis en el gasto social total, desglosado según sus funciones principales y el presupuesto de los ministerios de inclusión y desarrollo social de la región como porcentaje del gasto público, con el fin de tener una idea del peso presupuestal de tales instancias. La última sección reúne algunos comentarios y reflexiones sobre el conjunto de lo detallado.

\section{A. Marcos jurídico-normativos internacionales, regionales y nacionales}

El sustrato jurídico de la política social de cada país tiene distintos referentes y componentes. En un primer nivel están los mandatos y objetivos propuestos en los instrumentos de cooperación e integración y en distintos foros internacionales, que suponen un compromiso para los Estados. A ellos se suman los derechos establecidos en la constitución y en los distintos instrumentos legales y reglamentos existentes en cada país.

\section{El marco internacional}

Entre los instrumentos internacionales que dan marco a las políticas sociales a nivel mundial y regional, destaca la Declaración Universal de Derechos Humanos de 1948, a la que siguen los convenios de la Organización Internacional del Trabajo (OIT), en particular el Convenio sobre Igualdad de Remuneración, 1951 (Núm. 100), el Convenio sobre la 
Seguridad Social (Norma Mínima), 1952 (Núm. 102), el Convenio sobre la Discriminación (Empleo y Ocupación), 1958 (Núm. 111) y el Convenio sobre Pueblos Indígenas y Tribales, 1989 (Núm. 169); el Pacto Internacional de Derechos Económicos, Sociales y Culturales (PIDESC), de 1966, así como la Convención Americana sobre Derechos Humanos y el Protocolo Adicional a la Convención Americana sobre Derechos Humanos en Materia de Derechos Económicos, Sociales y Culturales (Protocolo de San Salvador), ambos suscritos en el marco de la Organización de los Estados Americanos (OEA), en 1969 y 1988, respectivamente. Asimismo, entre los instrumentos internacionales que han servido de referente para las legislaciones nacionales se incluyen la Declaración y Plataforma de Acción de Beijing (1995), en materia de igualdad de género, suscrita por 31 países de la región, o la Declaración y el Programa de Acción de Durban (2001), relativos a la lucha contra el racismo, la discriminación racial, la xenofobia y las formas conexas de intolerancia en el plano nacional, regional e internacional, firmados por 28 países ${ }^{4}$. Además, el Programa de Acción de la Conferencia Internacional sobre la Población y el Desarrollo, aprobado en 1994, en la Conferencia Internacional sobre la Población y el Desarrollo de El Cairo, con la presencia de 31 países de la región, ha sido de gran valor para orientar las políticas sociales y favorecer la adopción de un enfoque de derechos.

Aunque algunos de estos instrumentos parezcan algo remotos en el tiempo, han tenido un efecto fundamental en la política social del presente siglo. Con el impulso que en su momento les imprimieron la Declaración de Copenhague sobre Desarrollo Social, de 1995, y la Declaración del Milenio, de 2000, y sus Objetivos de Desarrollo del Milenio (ODM), han permitido asignar una importancia creciente a la lucha contra la pobreza y a la disminución de las desigualdades en materia de salud, educación, trabajo, vivienda y por razones de género y raza o etnia. Estos esfuerzos adquieren hoy un renovado impulso con la Agenda 2030 para el Desarrollo Sostenible, que impone nuevos compromisos y desafíos a los países y a la institucionalidad de las políticas sociales a nivel nacional y regional.

Como se muestra en el gráfico II.1, de los 33 países de América Latina y el Caribe, 29 se han adherido (explícita o implícitamente) al Pacto Internacional de Derechos Económicos, Sociales y Culturales (PIDESC). Sin embargo, solo en 14 de ellos este instrumento ha sido firmado y ratificado por el poder legislativo. En tanto, al Protocolo de San Salvador sobre derechos económicos, sociales y culturales solo se han adherido 16 países. Por su parte, las convenciones internacionales específicas con

Aprobados, respectivamente, en la Cuarta Conferencia Mundial sobre la Mujer, celebrada en Beijing en 1995, y en la Conferencia Mundial contra el Racismo, la Discriminación Racial, la Xenofobia y las Formas Conexas de Intolerancia, celebrada en Durban (Sudáfrica) en 2001. Véase [en línea] http://www.un.org/womenwatch/daw/beijing/pdf/Beijing\%20full\%20report\%20S. pdf y http://www.un.org/es/events/pastevents/cmcr/aconf189_12.pdf. 
mayor adhesión por parte de los países de la región son la Convención sobre los Derechos del Niño y la Convención sobre la Eliminación de Todas las Formas de Discriminación contra la Mujer, que cuentan con la ratificación o adhesión de 33 países. Además, 32 países han ratificado o se han adherido a la Convención Internacional sobre la Eliminación de Todas las Formas de Discriminación Racial. Destaca también la reciente Convención sobre los Derechos de las Personas con Discapacidad, de 2006, que cuenta con la ratificación o adhesión de 30 países 5 .

\section{Gráfico Il.1}

\section{América Latina y el Caribe (33 países): firma y ratificación o adhesión de pactos, convenciones y convenios relacionados con los derechos económicos, sociales y culturales}

(En número de países)

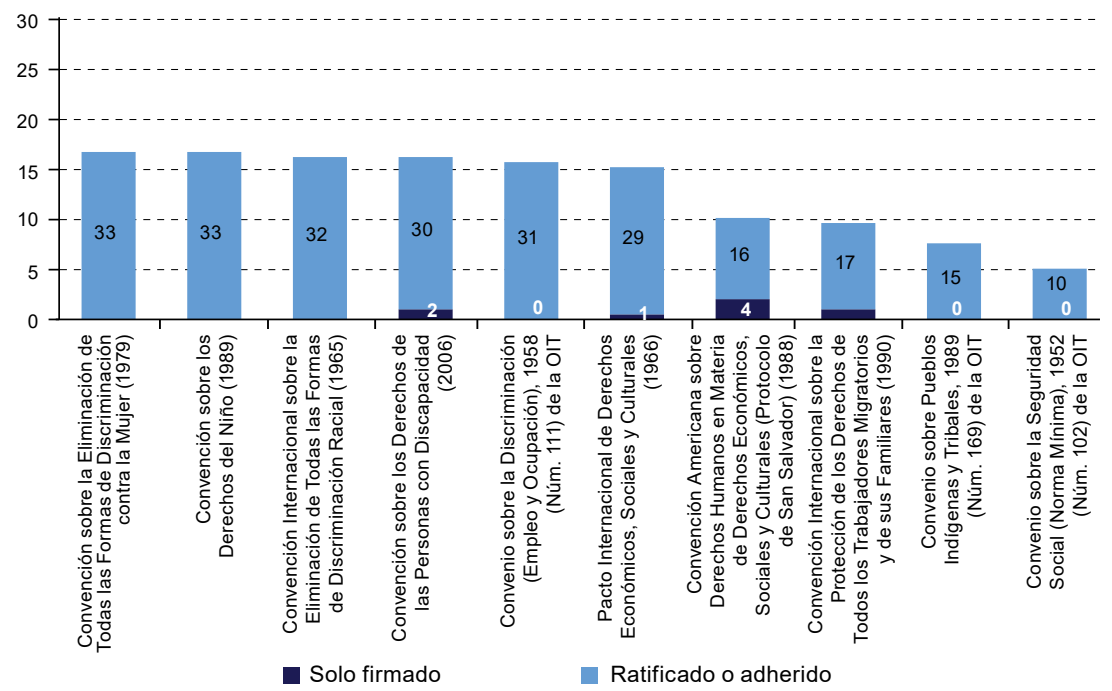

Fuente: Comisión Económica para América Latina y el Caribe (CEPAL), sobre la base de información oficial de los respectivos países.

En el ámbito laboral, el Convenio sobre la Discriminación (Empleo y Ocupación), 1958 (Núm. 111) de la OIT ha sido ratificado por la gran mayoría de los países de la región. Este es considerado el primer instrumento internacional relativo a la discriminación y protege a todos los trabajadores ante la discriminación por raza, color, sexo, religión, opinión política, ascendencia nacional, origen social y otros criterios que pueda definir cada Estado. Además, al ratificarlo, los países asumen el compromiso de desarrollar políticas de promoción de la igualdad de oportunidades y de trato en esas áreas.

La ratificación o adhesión suponen una aceptación del carácter jurídicamente vinculante de estos instrumentos, mientras que la firma representa solo una aceptación de principio, a la que sigue la ratificación como acto final. 
Otros convenios de la OIT relacionados con la protección social han alcanzado un menor nivel de ratificación en la región; entre ellos destaca el Convenio sobre la Seguridad Social (Norma Mínima), 1952 (Núm. 102), ratificado por solo 10 países, así como el Convenio sobre la Protección de la Maternidad (Revisado), 1952 (Núm. 103) y el Convenio sobre la Protección de la Maternidad, 2000 (Núm. 183), ambos ratificados por apenas 9 países. Con respecto a segmentos específicos de la población, 15 países de un total de 33 han ratificado el Convenio sobre Pueblos Indígenas y Tribales, 1989 (Núm. 169), con el que se busca, entre otras disposiciones, superar las prácticas discriminatorias que afectan a estos pueblos, sobre la base de los principios fundamentales de consulta y participación. A su vez, el Convenio sobre las Trabajadoras y los Trabajadores Domésticos, 2011 (Núm. 189) ha tenido una expresiva adhesión en la región, donde cuenta con 12 de las 22 ratificaciones realizadas en todo el mundo. No obstante, 21 países de la región aún no lo han ratificado.

A la luz de lo indicado, se puede decir que los países de la región muestran un alto nivel de adhesión a los convenios internacionales que hacen referencia a los derechos humanos, situación que supone un escenario propicio para el desarrollo de políticas sociales basadas en este enfoque. Sin embargo, ello no es suficiente para asegurar la adopción de tales medidas y menos sus resultados. A continuación se describen los avances jurídicos que se han hecho al respecto a nivel de los países.

\section{Marcos normativos nacionales relacionados con el desarrollo social}

En las últimas décadas, los marcos normativos nacionales han tenido un importante desarrollo en la región. La normativa en materia social estuvo marcada por una dinámica sectorial, en la que desempeñaron un papel protagónico las funciones sociales relacionadas con los sectores tradicionales de la política social, como educación, salud, seguridad social y trabajo. No obstante, a partir de los años 1990 y paralelamente al desarrollo de nuevos marcos internacionales, los marcos normativos nacionales evolucionaron. De esta forma se visibilizaron y afinaron nuevas temáticas, como el desarrollo social y los derechos y el bienestar de determinados segmentos de la población.

Desde el punto de vista conceptual, pueden distinguirse los segmentos de población que corresponden a etapas particulares del ciclo de vida, en especial la infancia y adolescencia, la juventud y las personas mayores. Incluso es factible desagregar más cada etapa con el fin de discernir necesidades específicas en el diseño de políticas y programas. Por ejemplo, esto se puede aplicar en el caso de la primera infancia e incluso en los primeros 1.000 días de vida, como etapas cruciales para el desarrollo de las personas. También pueden distinguirse diversos colectivos transversales, entre los que sobresalen las mujeres como grupo de población mayoritario, pero históricamente discriminado, así como 
las personas con discapacidad, las personas afrodescendientes y los pueblos indígenas, cuya condición de subordinación, marginación y discriminación ha ido incorporándose como parte de la agenda social en la mayoría de los países (véase el diagrama II.1). Otros colectivos transversales, como las personas migrantes, comparativamente han tenido menor visibilidad al menos a nivel normativo, pese a que representan un serio y creciente desafío para las políticas públicas y la garantía efectiva de los derechos humanos en la región.

\section{Diagrama II.1 \\ Algunos segmentos de población objetivo en los marcos normativos de las políticas sociales}

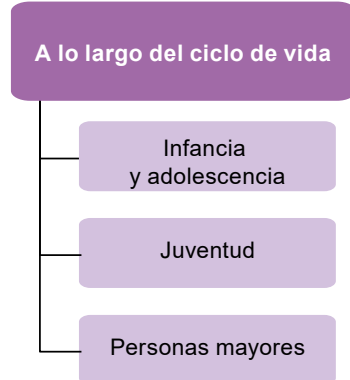

Con relación a las normativas nacionales y considerando las distintas funciones del área social, se constata que, entre los 33 países de la región, se identificaron 22 textos constitucionales que mencionan explícitamente los derechos a la educación. En 20 casos se menciona el derecho al trabajo y la seguridad social, y en 19 casos, el derecho a la salud, ámbitos en los que a su vez la gran mayoría cuenta con legislación específica. El derecho a la vivienda aparece con menor frecuencia, a saber, en 15 textos constitucionales. A su vez, 32 países disponen de una normativa específica en materia de trabajo y seguridad social y 24 tienen legislación respecto al derecho a la vivienda. Por su parte, de los 33 casos analizados, el concepto de desarrollo social aparece mencionado en una sola constitución, y únicamente 9 países tienen legislación específica sobre esa temática. Lo anterior refleja la evolución histórica de la institucionalidad social en la región, caracterizada por una creciente especialización temática y funcional. A su vez, esto es reflejo de una diversificación de las capacidades estatales, de los recursos técnicos y fiscales y de la agenda y las prioridades de la política social.

En cuanto a la mención de los derechos de segmentos determinados de la población, cabe destacar el caso de los niños, niñas y adolescentes, a 
quienes se hace referencia explícitamente en las constituciones de 17 países, seguidos por las personas de edad (16 países), las personas con discapacidad (15 países), y las personas afrodescendientes e indígenas (12 países). Con menor frecuencia sobresalen las menciones a nivel constitucional de los derechos de las mujeres (10 países) y de las personas jóvenes (7 países). Por su parte, con respecto a la legislación nacional, 29 países tienen marcos normativos específicos sobre los derechos de los niños, niñas y adolescentes, 23 sobre las personas con discapacidad, 20 sobre las personas jóvenes y las mujeres, y 19 sobre las personas de edad (véase el cuadro II.1).

\section{Cuadro II.1}

\section{América Latina y el Caribe (33 países): existencia de normativa constitucional y específica en temas sociales sectoriales y referentes a segmentos determinados de población ${ }^{\mathrm{a}}$} (En número de países)

\begin{tabular}{|c|c|c|c|c|}
\hline \multirow[b]{2}{*}{ Eje } & \multirow[b]{2}{*}{ Categoría } & \multicolumn{2}{|c|}{ Normativa constitucional } & \multirow[b]{2}{*}{$\begin{array}{l}\text { Normativa } \\
\text { específica }\end{array}$} \\
\hline & & $\begin{array}{c}\text { (Total con } \\
\text { menciones indirectas } \\
\text { no incluidas) }\end{array}$ & $\begin{array}{c}\text { (Total con } \\
\text { menciones } \\
\text { indirectas incluidas) }\end{array}$ & \\
\hline \multirow{5}{*}{$\begin{array}{l}\text { Temas } \\
\text { sectoriales }\end{array}$} & Educación & 22 & 23 & 27 \\
\hline & $\begin{array}{l}\text { Protección del trabajo } \\
\text { y seguridad social }\end{array}$ & 20 & 23 & 32 \\
\hline & Salud & 19 & 21 & 28 \\
\hline & Vivienda & 15 & 16 & 24 \\
\hline & Desarrollo social & 1 & 8 & 9 \\
\hline \multirow{6}{*}{$\begin{array}{l}\text { Grupos o } \\
\text { segmentos } \\
\text { de la } \\
\text { población }\end{array}$} & Niños, niñas y adolescentes & 17 & 18 & 29 \\
\hline & Jóvenes & 7 & 11 & 20 \\
\hline & Personas de edad & 16 & 16 & 19 \\
\hline & Mujeres & 10 & 14 & 20 \\
\hline & Personas con discapacidad & 15 & 17 & 23 \\
\hline & $\begin{array}{l}\text { Personas afrodescendientes } \\
\text { e indígenas }\end{array}$ & 12 & 13 & 14 \\
\hline
\end{tabular}

Fuente: Comisión Económica para América Latina y el Caribe (CEPAL), sobre la base del análisis de los textos constitucionales y una revisión de las principales legislaciones nacionales en materia social.

a Se hace referencia a los textos constitucionales en que explícitamente se evocan los derechos en cada temática o de cada segmento. Por ejemplo, con excepción de Chile y Costa Rica, las constituciones se refieren al menos en alguna dimensión a las personas con discapacidad, casi siempre en materia de no discriminación laboral y de pensiones por invalidez, pero solo en 15 casos se hace referencia explícita o se detallan los derechos y la protección de dicho segmento. En el caso de las normas legales nacionales, se examinó la existencia de leyes relativas a diversas temáticas sociales sectoriales (educación, salud, vivienda y desarrollo, asistencia y protección social), así como a grupos poblacionales específicos a lo largo del ciclo de vida (infancia, juventud y personas de edad) y transversales (género, pueblos indígenas y personas con discapacidad).

Es importante destacar que, si entre los criterios de observación se incluyeran las menciones indirectas en las constituciones de los 33 países de la región, aumentaría el número de constituciones que incluyen en sus contenidos la protección de los principales derechos sociales y de grupos específicos de la población. Por ejemplo, cuando se hace referencia a la garantía de derechos o la no discriminación por motivos relacionados con el sexo, la raza, la etnia o la edad de las personas, entre otras distinciones. 
Una manera de analizar los contenidos temáticos de los marcos normativos nacionales en materia social consiste en estudiar en qué casos existe una legislación general dedicada a las más importantes temáticas sectoriales del desarrollo social, así como a algunos de los principales segmentos de población que priorizan las políticas sociales. Para ello se adoptó como criterio la identificación de las principales normativas que contemplan temáticas sectoriales relacionadas con la garantía de los principales derechos sociales. Dentro de los 33 casos observados, entre las temáticas sectoriales con leyes generales, leyes orgánicas o códigos, la mayor cantidad de casos corresponde a la protección del trabajo y la seguridad social, con 32 normativas identificadas. Le sigue la salud, con 28, la educación, con 27, y la vivienda, con 24 . Solo 9 países cuentan con legislación referida al desarrollo social. Con respecto a grupos o segmentos determinados de la población, a nivel regional, los niños, niñas y adolescentes son objeto de normativas en 29 países, seguidos por las personas con discapacidad en 23 casos, las personas jóvenes en 20, las mujeres en 20, las personas de edad en $19 \mathrm{y}$, por último, las personas afrodescendientes e indígenas en 14 casos.

Desde la perspectiva del grado de cumplimiento de derechos conforme a la clasificación del Alto Comisionado de las Naciones Unidas para los Derechos Humanos, América Latina y el Caribe alcanza un alto nivel en cuanto a indicadores estructurales relacionados con la promulgación de legislación y la ratificación de instrumentos internacionales. Sin embargo, su nivel de cumplimiento disminuye de manera significativa en lo referente a la implementación efectiva (el proceso que traduce los compromisos formales de los Estados en el diseño e implementación de políticas) y a la obtención de logros y resultados concretos que dan sustento al cumplimiento de dichos instrumentos nacionales e internacionales. Así, más allá de los avances en la dimensión jurídico-normativa, persiste el desafío de avanzar hacia una institucionalidad de calidad (efectiva, eficiente, sostenible y transparente), particularmente en relación con las demás dimensiones con que se analiza la institucionalidad social.

\section{B. Características organizacionales y autoridad social}

En esta sección se presentan dos elementos importantes desde el punto de vista organizacional. Por una parte, están los foros regionales dedicados al desarrollo social que han asumido un protagonismo creciente en la región y han contribuido a generar una agenda regional en este ámbito. Por otra, se abordan los principales rasgos de la estructura organizacional de la política social de los países de América Latina en la actualidad

La información está actualizada hasta junio de 2017. Véase [en línea] dds.cepal.org/bdips. 


\section{Mandatos y foros regionales dedicados al desarrollo social en América Latina y el Caribe}

Un componente relevante de la institucionalidad social son los foros intergubernamentales en que los gobiernos de América Latina y el Caribe han ido construyendo una agenda social con especificidades y compromisos propios. Su relevancia institucional está relacionada con el marco jurídico-normativo, pues son espacios de deliberación que generan objetivos y definen mandatos. Se articulan particularmente con las características organizativas, pues expresan los espacios y modalidades que utilizan los países para generar acuerdos y facilitar la articulación regional de políticas.

Así, los foros son la expresión organizacional de los mandatos internacionales del área social y permiten coordinar esfuerzos entre los países para mejorar la política social y sus instituciones. Posibilitan el intercambio de experiencias, la búsqueda de consensos en torno a posiciones comunes, la promoción de relaciones de cooperación y avances en la construcción de una agenda social regional. También pueden tener otros objetivos, como dar seguimiento a mandatos o generar información, analizar propuestas para establecer prioridades de política social y definir planes de acción. Debido a todo lo anterior, los foros tienen una enorme riqueza y relevancia para las políticas que se implementan a nivel regional y nacional.

Como contrapartida, la existencia de múltiples instancias que buscan fines iguales, o similares, conlleva riesgos. Entre ellos se cuentan la duplicación de tareas y esfuerzos, la fragmentación y potencial dispersión de compromisos y la competencia entre los distintos foros por convertirse en la voz autorizada sobre la cuestión social, lo que puede dificultar la construcción de una agenda regional compartida y coherente.

Con el objetivo de contribuir al análisis de este importante proceso, en esta sección se hace un intento de clasificación y ordenamiento de los diversos foros intergubernamentales explícitamente orientados al avance de la agenda social en la región. Se consideran dos aspectos: su evolución, con una distinción de los principales tipos existentes, y sus contenidos, con una precisión de los ámbitos en que se han establecido compromisos y metas.

Un primer elemento a destacar en el período reciente en América Latina y el Caribe es la multiplicidad de instancias de carácter intergubernamental (conferencias, reuniones, foros y consejos) que están explícitamente orientadas al avance de la agenda social. Sin considerar 
aquellos especializados en términos sectoriales ${ }^{8}$, en la región existen 15 foros intergubernamentales relacionados con el desarrollo y la inclusión social, de los cuales solo uno fue creado antes de $2000^{9}$.

La cantidad de foros vigentes evidencia, por un lado, la necesidad y el interés por profundizar la colaboración entre los países en el área social y coordinar esfuerzos para mejorar la política social y sus instituciones; compartir objetivos, logros y dificultades en el desarrollo de la política social, y compartir aproximaciones analíticas y metodológicas para avanzar en la medición y comprensión de los principales problemas sociales. Por otro lado, da cuenta de la creciente importancia que ha adquirido lo social en la agenda de desarrollo de los países en las últimas décadas. A su vez, estas instancias complementan (o podrían complementar) los acuerdos internacionales sobre desarrollo, contribuyendo a la adaptación regional de objetivos y metas de la agenda mundial, o bien dando seguimiento a su cumplimiento. También pueden constituir una plataforma para enfatizar desafíos propios de la región en materia social, como es la elevada desigualdad que la caracteriza.

Un primer intento de clasificación permite distinguir dos tipos de foros en términos de su vinculación, es decir, de la instancia en que

\footnotetext{
Se trata de instancias intergubernamentales vinculadas a las políticas sociales sectoriales, como las de salud, educación, trabajo y vivienda u otras. En el ámbito de la salud, cabría considerar la Conferencia Sanitaria Panamericana del Comité Regional de la OMS para las Américas y el Organismo Andino de Salud, que tiene a cargo la implementación del Convenio Hipólito Unanue. En el ámbito de la educación, se pueden mencionar la Conferencia Iberoamericana de Educación de la Organización de Estados Iberoamericanos para la Educación, la Ciencia y la Cultura (OEI), que se celebra en el marco de las Cumbres Iberoamericanas (véase [en línea] http://www. oei.es/cumbres.htm), y el Proyecto Regional de Educación para América Latina y el Caribe (PRELAC) de la Organización de las Naciones Unidas para la Educación, la Ciencia y la Cultura (UNESCO) y la Organización del Convenio Andrés Bello de Integración Educativa, Científica, Tecnológica y Cultural (CAB). En el área del trabajo, cabe destacar la Reunión Regional Americana de la Organización Internacional del Trabajo (OIT), de carácter tripartito (compuesta por representaciones de Gobiernos, organizaciones de empleadores y trabajadores de las Américas), y la Conferencia Interamericana de Ministros de Trabajo, en el ámbito de la Organización de los Estados Americanos (OEA). Entre las instancias regionales o iberoamericanas de seguridad social, cabe mencionar la Organización Iberoamericana de Seguridad Social (OISS) y la Conferencia Iberoamericana de Ministros y Máximos Responsables de Seguridad Social. Es preciso destacar que la OISS, en el marco de la Cumbre Iberoamericana, tiene a cargo la implementación del Convenio Multilateral de Seguridad Social, que se plantea como el "primer instrumento internacional a nivel iberoamericano que protege los derechos de millones de trabajadores migrantes, sus familias y trabajadores de multinacionales en el ámbito de prestaciones económicas, mediante la coordinación de legislaciones nacionales en materia de pensiones, como garantía de la seguridad económica en la vejez, la incapacidad o muerte, protegidos bajo los esquemas de la Seguridad Social de los diferentes Estados Iberoamericanos" (véase [en línea] http://www.oiss.org/Que-es,5335.html). Tampoco se consideran en el análisis las conferencias intergubernamentales que están orientadas al mejoramiento de las condiciones sociales de determinados segmentos poblacionales, dado que, aun cuando los temas que tratan evidentemente son parte del desarrollo social, están orientadas a la construcción de una agenda más específica en torno a los derechos de las mujeres, la juventud, la infancia o las poblaciones indígenas y afrodescendientes.

9 El Consejo para el Desarrollo Humano y Social, de la Comunidad del Caribe (CARICOM), creado en 1973.
} 
fueron creados y desde la cual operan (véase el cuadro II.2). Así, se observa que 12 de ellos están insertos en instancias intergubernamentales de integración, ya sean regionales o subregionales. La condición que hace posible la incorporación de lo social en este tipo de estructuras es un cambio de la agenda de integración regional que, junto a los asuntos vinculados al comercio, va dando cabida a nuevos temas (Dabène, 2012). Por otra parte, hay tres foros intergubernamentales en el ámbito del desarrollo social vinculados a organismos de las Naciones Unidas: el Foro de Ministros de Desarrollo Social, de la Organización de las Naciones Unidas para la Educación, la Ciencia y la Cultura (UNESCO); el Foro Ministerial para el Desarrollo en América Latina y el Caribe, del Programa de las Naciones Unidas para el Desarrollo (PNUD), y la Conferencia Regional sobre Desarrollo Social de América Latina y el Caribe, órgano subsidiario de la CEPAL ${ }^{10}$.

Independientemente de la instancia a la que se encuentren vinculados, los foros se distinguen por la orientación con que han sido creados y los objetivos a los que responden. Desde esta perspectiva, se distinguen tres tipos de foros: aquellos que se constituyen como espacios de debate, aquellos en que se formulan análisis y propuestas, y los que se dedican principalmente a realizar el seguimiento de los mandatos y compromisos regionales ${ }^{11}$. De los 15 foros indicados, cuatro son principalmente espacios de debate, es decir, instancias que permiten intercambiar experiencias, buscar consensos para adoptar posiciones comunes, promover la cooperación y avanzar en la construcción de una agenda social regional. Los foros creados con este objetivo son el Foro Ministerial para el Desarrollo Social en América Latina y el Caribe del PNUD, la Conferencia Iberoamericana de Ministros y Máximos Responsables de la Seguridad Social de la Secretaría General Iberoamericana (SEGIB), la Reunión de Ministros y Altas Autoridades de Desarrollo Social del Mercado Común del Sur (MERCOSUR) y el Consejo de Ministros para el Desarrollo Social y Humano de la Organización de Estados del Caribe Oriental (OECO).

10 Esta Conferencia fue creada en virtud de la resolución 682(XXXV), aprobada en el trigésimo quinto período de sesiones de la CEPAL celebrado en mayo de 2014. La primera reunión de la Conferencia Regional sobre Desarrollo Social de América Latina y el Caribe tuvo lugar en Lima en noviembre de 2015 y fue organizada de manera conjunta por la CEPAL y el PNUD. A su vez, en noviembre de 2016, en Santo Domingo, se llevó a cabo la primera Reunión de la Mesa Directiva de la Conferencia Regional sobre Desarrollo Social de América Latina y el Caribe. Otros órganos subsidiarios de la CEPAL que desempeñan un importante papel en el desarrollo y seguimiento de agendas muy relevantes para el desarrollo social son la Conferencia Regional sobre la Mujer de América Latina y el Caribe y la Conferencia Regional sobre Población y Desarrollo de América Latina y el Caribe.

11 Se han clasificado los foros de acuerdo con la función principal que desempeñan, según lo establecido en su misión. Ello no significa que un foro de un determinado tipo no desempeñe otras funciones. 


\section{Cuadro II.2}

América Latina y el Caribe: foros intergubernamentales sobre desarrollo social, según el tipo de instancia a la que están vinculados, 2015

\section{A. Organismos de las Naciones Unidas}

\begin{tabular}{llcll}
\hline Institución & Foro & $\begin{array}{l}\text { Año de } \\
\text { creación }\end{array}$ & $\begin{array}{l}\text { Periodicidad } \\
\text { de los } \\
\text { encuentros }\end{array}$ & Tipo de foro \\
\hline $\begin{array}{l}\text { Comisión Económica para } \\
\begin{array}{l}\text { América Latina y el Caribe } \\
\text { (CEPAL) }\end{array}\end{array}$ & $\begin{array}{l}\text { Conferencia Regional } \\
\text { sobre Desarrollo Social } \\
\text { de América Latina y } \\
\text { el Caribe }\end{array}$ & 2015 & Bienal & $\begin{array}{l}\text { Instancia de } \\
\text { análisis y } \\
\text { propuestas }\end{array}$ \\
\hline $\begin{array}{l}\text { Programa de las Naciones } \\
\text { Unidas para el Desarrollo } \\
\text { (PNUD) }\end{array}$ & $\begin{array}{l}\text { Foro Ministerial para el } \\
\text { Desarrollo en América } \\
\text { Latina y el Caribe }\end{array}$ & 2007 & Anual & $\begin{array}{l}\text { Instancia de } \\
\text { debate }\end{array}$ \\
\hline $\begin{array}{l}\text { Organización de las } \\
\text { Naciones Unidas para la }\end{array}$ & $\begin{array}{l}\text { Foro de Ministros de } \\
\text { Desarrollo Social } \\
\text { y lacación, la Ciencia }\end{array}$ & 2001 & $\begin{array}{l}\text { Dos veces al } \\
\text { año (pero ha } \\
\text { sido irregular) }\end{array}$ & $\begin{array}{l}\text { Instancia de } \\
\text { análisis y } \\
\text { propuestas }\end{array}$ \\
\hline
\end{tabular}

B. Foros intergubernamentales regionales

\begin{tabular}{|c|c|c|c|c|}
\hline Institución & Foro & $\begin{array}{l}\text { Fecha de } \\
\text { creación }\end{array}$ & $\begin{array}{l}\text { Periodicidad } \\
\text { de los } \\
\text { encuentros }\end{array}$ & Tipo de foro \\
\hline $\begin{array}{l}\text { Comunidad de Estados } \\
\text { Latinoamericanos y } \\
\text { Caribeños (CELAC) }\end{array}$ & $\begin{array}{l}\text { Reunión de Ministras, } \\
\text { Ministros y Autoridades } \\
\text { de Desarrollo Social } \\
\text { y Erradicación del } \\
\text { Hambre y la Pobreza }\end{array}$ & 2013 & $\begin{array}{l}\text { Cada dos años } \\
\text { (última reunión } \\
\text { fue en 2015) }\end{array}$ & $\begin{array}{l}\text { Instancia de } \\
\text { análisis y } \\
\text { propuestas }\end{array}$ \\
\hline \multirow[t]{2}{*}{$\begin{array}{l}\text { Organización de los Estados } \\
\text { Americanos (OEA) }\end{array}$} & $\begin{array}{l}\text { Comisión } \\
\text { Interamericana de } \\
\text { Desarrollo Social } \\
\text { (CIDES) }\end{array}$ & 2010 & $\begin{array}{l}\text { Cuando } \\
\text { se estima } \\
\text { necesario (sin } \\
\text { periodicidad } \\
\text { fija) }\end{array}$ & $\begin{array}{l}\text { Instancia de } \\
\text { seguimiento } \\
\text { de mandatos }\end{array}$ \\
\hline & $\begin{array}{l}\text { Reunión de Ministros } \\
\text { y Altas Autoridades de } \\
\text { Desarrollo Social }\end{array}$ & 2008 & Bienal & $\begin{array}{l}\text { Instancia de } \\
\text { seguimiento } \\
\text { de mandatos }\end{array}$ \\
\hline $\begin{array}{l}\text { Asociación Latinoamericana } \\
\text { de Integración (ALADI) }\end{array}$ & $\begin{array}{l}\text { Reunión de Ministros } \\
\text { del Área Social de los } \\
\text { Países Miembros de } \\
\text { ALADI }\end{array}$ & 2009 & $\begin{array}{l}\text { Cuando } \\
\text { se estima } \\
\text { necesario (sin } \\
\text { periodicidad } \\
\text { fija) }\end{array}$ & $\begin{array}{l}\text { Instancia de } \\
\text { análisis y } \\
\text { propuestas }\end{array}$ \\
\hline $\begin{array}{l}\text { Secretaría General } \\
\text { Iberoamericana (SEGIB) }\end{array}$ & $\begin{array}{l}\text { Conferencia } \\
\text { Iberoamericana de } \\
\text { Ministros y Máximos } \\
\text { Responsables de la } \\
\text { Seguridad Social }\end{array}$ & 2000 & $\begin{array}{l}\text { Bienal a partir } \\
\text { de } 2015\end{array}$ & $\begin{array}{l}\text { Instancia de } \\
\text { debate }\end{array}$ \\
\hline
\end{tabular}


Cuadro II.2 (conclusión)

C. Foros intergubernamentales subregionales

\begin{tabular}{|c|c|c|c|c|}
\hline Institución & Foro & $\begin{array}{l}\text { Año de } \\
\text { creación }\end{array}$ & $\begin{array}{l}\text { Periodicidad de } \\
\text { los encuentros }\end{array}$ & Tipo de foro \\
\hline $\begin{array}{l}\text { Organización de Estados } \\
\text { del Caribe Oriental (OECO) }\end{array}$ & $\begin{array}{l}\text { Consejo de Ministros } \\
\text { para el Desarrollo } \\
\text { Social y Humano }\end{array}$ & 2014 & Anual & $\begin{array}{l}\text { Instancia } \\
\text { de debate }\end{array}$ \\
\hline $\begin{array}{l}\text { Mercado Común del Sur } \\
\text { (MERCOSUR) }\end{array}$ & $\begin{array}{l}\text { Reunión de Ministros } \\
\text { y Altas Autoridades de } \\
\text { Desarrollo Social del } \\
\text { MERCOSUR }\end{array}$ & 2011 & Dos veces al año & $\begin{array}{l}\text { Instancia } \\
\text { de debate }\end{array}$ \\
\hline $\begin{array}{l}\text { Unión de Naciones } \\
\text { Suramericanas } \\
\text { (UNASUR) }\end{array}$ & $\begin{array}{l}\text { Consejo Suramericano } \\
\text { de Desarrollo Social }\end{array}$ & 2009 & Anual & $\begin{array}{l}\text { Instancia de } \\
\text { análisis y } \\
\text { propuestas }\end{array}$ \\
\hline $\begin{array}{l}\text { Secretaría de la } \\
\text { Integración Social } \\
\text { Centroamericana (SISCA), } \\
\text { subsistema social del } \\
\text { Sistema de la Integración } \\
\text { Centroamericana (SICA) }\end{array}$ & $\begin{array}{l}\text { Consejo de Ministros } \\
\text { del Área Social }\end{array}$ & 2008 & Anual & $\begin{array}{l}\text { Instancia de } \\
\text { seguimiento } \\
\text { de mandatos }\end{array}$ \\
\hline $\begin{array}{l}\text { Alianza Bolivariana para } \\
\text { los Pueblos de Nuestra } \\
\text { América (ALBA) }\end{array}$ & $\begin{array}{l}\text { Reunión del Consejo } \\
\text { Ministerial del Área } \\
\text { Social }\end{array}$ & 2004 & $\begin{array}{l}\text { Cuando se estima } \\
\text { necesario (sin } \\
\text { periodicidad fija) }\end{array}$ & $\begin{array}{l}\text { Instancia de } \\
\text { seguimiento } \\
\text { de mandatos }\end{array}$ \\
\hline Comunidad Andina (CAN) & $\begin{array}{l}\text { Consejo Andino } \\
\text { de Ministros de } \\
\text { Desarrollo Social }\end{array}$ & 2004 & Anual & $\begin{array}{l}\text { Instancia de } \\
\text { análisis y } \\
\text { propuestas }\end{array}$ \\
\hline $\begin{array}{l}\text { Comunidad del Caribe } \\
\text { (CARICOM) }\end{array}$ & $\begin{array}{l}\text { Consejo para el } \\
\text { Desarrollo Humano } \\
\text { y Social }\end{array}$ & 1973 & $\begin{array}{l}\text { Cuando se estima } \\
\text { necesario ( } \sin \\
\text { periodicidad fija) }\end{array}$ & $\begin{array}{l}\text { Instancia de } \\
\text { análisis y } \\
\text { propuestas }\end{array}$ \\
\hline
\end{tabular}

Fuente: Comisión Económica para América Latina y el Caribe (CEPAL), sobre la base de información oficial de los respectivos organismos.

Por su parte, hay siete foros que tienen como objetivo principal generar información, análisis y propuestas y establecer prioridades de política social. Como es evidente, también son espacios de intercambio de experiencias que fomentan el debate entre los responsables públicos de la toma de decisiones y promueven relaciones de cooperación. Además, algunos de ellos realizan también el seguimiento de mandatos. Entre estos foros se incluyen el Foro de Ministros de Desarrollo Social de la UNESCO, la Reunión de Ministros del Área Social de los Países Miembros de la Asociación Latinoamericana de Integración (ALADI), la Reunión de Ministras, Ministros y Autoridades de Desarrollo Social y Erradicación del Hambre y la Pobreza de la CELAC, el Consejo Suramericano de Desarrollo Social de la UNASUR, el Consejo Andino de Ministros de Desarrollo Social de la CAN, el Consejo para el Desarrollo Humano y Social de la Comunidad del Caribe (CARICOM) y la Conferencia Regional sobre Desarrollo Social de América Latina y el Caribe de la CEPAL. Entre otros aspectos, esta última busca promover la mejora de las políticas nacionales de desarrollo social, proveer insumos técnicos a petición de los países, examinar la pobreza multidimensional y avanzar en la medición de la pobreza, la desigualdad y las brechas estructurales. 
Por último, los cuatro foros que tienen la función de dar seguimiento a mandatos específicos son la Reunión de Ministros y Altas Autoridades de Desarrollo Social de la OEA, que tiene como secretaría técnica al Departamento de Desarrollo Económico y Social (DDES) de dicha Organización; la Comisión Interamericana de Desarrollo Social (CIDES) de la OEA, cuya secretaría técnica también es el Departamento de Desarrollo Económico y Social (DDES); el subsistema social del Sistema de la Integración Centroamericana (SICA), que cuenta con un Consejo de Ministros del Área Social y una Secretaría de la Integración Social Centroamericana (SISCA), y la Reunión del Consejo Ministerial del Área Social de la Alianza Bolivariana para los Pueblos de Nuestra América (ALBA), que se propone instrumentar y hacer seguimiento de los programas sociales en beneficio de los pueblos de los países de la región.

En ciertas áreas especializadas existen experiencias que representan un ejemplo de desarrollo institucional a nivel regional, como es el caso de algunos organismos subregionales orientados a la ejecución y operacionalización de convenios en temáticas sociales de sectores específicos. Entre estos cabe mencionar el Organismo Andino de Salud, encargado de la implementación del Convenio Hipólito Unanue, y la Organización del Convenio Andrés Bello de Integración Educativa, Científica, Tecnológica y Cultural (CAB) (véase el cuadro II.2).

\section{Las agendas sociales de algunos foros intergubernamentales}

En el caso de los foros intergubernamentales de desarrollo social mencionados, es interesante analizar el foco de sus agendas, si existe convergencia y complementariedad entre ellas y a qué ámbitos corresponden los compromisos establecidos. Para abordar estas interrogantes, se presenta un breve panorama de los contenidos de las agendas de siete de esos foros ${ }^{12}$. Como se observa en el cuadro II.2, cinco de ellos tienen como orientación principal la generación de información, análisis y propuestas y dos se enfocan en el seguimiento de mandatos.

En términos generales, existe bastante convergencia y complementariedad entre las agendas de estos foros, principalmente orientados a la superación de la pobreza y de las desigualdades sociales desde un enfoque de derechos. También predomina la concepción de la pobreza como un fenómeno multidimensional, que requiere ser abordado a través de políticas sociales integrales. Además, en la medida en que varios

12 Se consideran únicamente aquellos foros donde existe algún tipo de documentación, plan de acción, mandatos u otros, que permita determinar los ejes temáticos de las agendas y precisar en qué ámbitos se han establecido compromisos y metas. No se consideran los foros constituidos como espacios de debate. 
de estos foros están vinculados a instancias de integración, en sus agendas está presente — de forma más o menos explícita— la concepción de que los procesos de integración regional pueden contribuir a una mayor igualdad e inclusión social.

Además de la superación de la pobreza y las desigualdades, otros temas recurrentes en los foros son la seguridad alimentaria y nutricional, la importancia de desarrollar la institucionalidad de las políticas sociales y la necesidad de desarrollar políticas sociales integrales (véase el cuadro II.3). Así, desde el punto de vista temático, estos elementos constituyen lo que puede denominarse el "núcleo duro" de las agendas de los foros de desarrollo social.

A su vez, existe una diversidad temática, ya que cada foro tiene su especificidad. Así, en los respectivos planes de acción se identifican ámbitos que solo están presentes en la agenda de una o dos iniciativas. Entre los foros que están vinculados a organismos de integración regional, la ALADI resalta la dimensión social del proceso de integración y plantea como ejes temáticos específicos la integración productiva y la facilitación del comercio como apoyo a la inclusión social. La CELAC y la SISCA tienen entre sus principales ejes temáticos la provisión universal de servicios sociales (educación y salud), en tanto que la UNASUR plantea como temas específicos la participación social y la economía social, con inclusión productiva y generación de oportunidades.

La Comisión Interamericana de Desarrollo Social (CIDES), de la OEA, pone en la agenda dos temas que son clave en la lucha por la erradicación de la pobreza y las desigualdades: la protección social y la generación de empleo para poblaciones vulnerables ${ }^{13}$.

Por último, en los mandatos de la Conferencia Regional sobre Desarrollo Social de América Latina y el Caribe hay un énfasis en la producción de información, el análisis y la asistencia técnica. En particular en 2015 se solicitó a la CEPAL que organizara y mantuviera actualizadas las bases de datos en tres temas clave: i) inversión social, ii) programas de protección social no contributiva, y iii) juventud e inclusión social. En términos de investigación, se le insta a que profundice en el análisis de las múltiples dimensiones de la desigualdad, la pobreza y la vulnerabilidad, con particular atención a las mujeres, las poblaciones indígenas y afrodescendientes, el ciclo de vida y el territorio. También se alienta a la CEPAL a ahondar en el análisis integrado de las políticas económicas, productivas y sociales y de protección del empleo y promoción del trabajo decente, enfatizando la importancia del intercambio de experiencias entre los países y fomentando la cooperación Sur-Sur. En términos de asistencia técnica, se le solicita que apoye a los países en el fortalecimiento de sus sistemas de evaluación de políticas públicas y la promoción del intercambio de experiencias.

13 Véase [en línea] http://www.oas.org/es/sedi/ddse/paginas/cpo_cides.asp. 


\section{Cuadro II.3}

\section{América Latina y el Caribe: principales ejes temáticos de algunos foros intergubernamentales dedicados al desarrollo social}

\section{Foros intergubernamentales $y$ año del documento en que se establecen los ejes}

Conferencia Regional sobre Desarrollo Social de América Latina y el Caribe, de la Comisión Económica para América Latina y el Caribe (CEPAL) (2015)
Principales ejes temáticos

1. Apoyar a los países en el fortalecimiento de sus sistemas de evaluación de políticas públicas

2. Promover intercambios de experiencias entre los países y profundizar el análisis integrado de las políticas económicas y sociales

3. Profundizar el análisis de las múltiples dimensiones de la desigualdad, la pobreza y la vulnerabilidad

4. Organizar, mantener y actualizar bases de datos sobre inversión social, programas de protección social no contributiva y juventud e inclusión social
Consejo Suramericano de Desarrollo Social, de la Unión de Naciones Suramericanas (UNASUR) (2015)

1. Desarrollo con inclusión

2. Seguridad alimentaria y lucha contra la malnutrición

3. Economía social, solidaria o comunal con inclusión productiva y generación de oportunidades

4. Participación social

5. Cooperación regional en políticas sociales

Reunión de Ministras, Ministros y Autoridades de Desarrollo Social y 1. Fortalecer la seguridad alimentaria

2. Universalización de la salud Erradicación del Hambre y la Pobreza, de la 3 . Universalización de la educación Comunidad de Estados Latinoamericanos y Caribeños (CELAC) (2013)

Consejo Andino de Ministros de Desarrollo Social, de la Comunidad Andina (CAN) (2011)

4. Programa de alfabetización

1. Superación de la pobreza y las desigualdades

2. Titularidad y garantía de derechos

3. Identidad y sentido de pertenencia

4. Superación de las asimetrías territoriales

5. Garantía de la inversión social

6. Prevención de los impactos sociales del cambio climático y los desastres naturales

Comisión Interamericana de Desarrollo Social (CIDES), de la Organización de los Estados Americanos (OEA) (2010)

1. Protección e inclusión social

2. Generación de empleo para poblaciones vulnerables

3. Reducción de la pobreza

4. Seguridad alimentaria y nutricional

Reunión de Ministros del Área Social de los Países Miembros de la Asociación Latinoamericana de Integración (ALADI) (2009)

1. Cooperación como herramienta de apoyo a la inclusión social

2. Integración productiva como instrumento de la inclusión social

3. Profundización y facilitación del comercio en apoyo a la inclusión social

Consejo de Ministros del Área Social, de la Secretaría de la Integración Social Centroamericana (SISCA) (2008)
1. Fortalecimiento de la institucionalidad social de Centroamérica

2. Provisión efectiva de servicios sociales básicos

3. Bienestar social y desarrollo humano

Fuente: Comisión Económica para América Latina y el Caribe (CEPAL), sobre la base de Asociación Latinoamericana de Integración (ALADI), "Plan de acción priorizado para el desarrollo de la dimensión social del proceso de integración" (ALADI/CR/Resolución 360), 16 de diciembre de 2009; Comunidad de Estados Latinoamericanos y Caribeños (CELAC), "Plan de Acción de Políticas Públicas en materia social de la CELAC", 2013; Unión de Naciones Suramericanas (UNASUR), "Plan de Acción 2015-2017"; Comunidad Andina (CAN), "Objetivos Andinos de Desarrollo Social (OANDES)", Lima, 2011; Secretaría de la Integración Social Centroamericana (SISCA), "Agenda estratégica social del sistema de integración centroamericano", 2008; Organización de los Estados Americanos (OEA) [en línea] http://www.oas.org/es/sedi/ddse/ paginas/cpo_cides.asp\#_HIk1; CEPAL, "Resolución 1(I)", Conferencia Regional sobre Desarrollo Social de América Latina y el Caribe", Lima, 2015. 
Los temas comunes y específicos de las agendas de los foros intergubernamentales de desarrollo social son una contribución relevante para la formulación de una agenda regional de desarrollo social que debe nutrirse de los intereses e inquietudes de los países en cada escenario regional o subregional particular. También es central la consideración de las prioridades temáticas de dichos foros y el diálogo que estos parecen tener con el pilar social de la Agenda 2030 para el Desarrollo Sostenible.

\section{Modalidades de autoridad social}

En la región se presentan distintas modalidades de autoridad social, según el lugar que ocupan en la estructura general del Estado, el origen de su delegación y su conformación ${ }^{14}$.

- Designación desde la Presidencia o Vicepresidencia: instancia técnica especializada a nivel central del ejecutivo, cuya autoridad está formalizada normalmente por un decreto del poder ejecutivo.

- Entorno familiar del ejecutivo: la instancia recae típicamente en la figura de la primera dama, con el rol de coordinar programas de asistencia social.

- Organismos nacionales de planificación: su ubicación jerarquizada y sus funciones permiten potencialmente coordinar las relaciones intersectoriales, pero pueden carecer del requerido nivel de especialización técnica en materia social.

- Ministerio de Desarrollo o Inclusión Social: ministerio o secretaría especializada en la lucha contra la pobreza y la protección social no contributiva. Comúnmente tiene responsabilidades de coordinación, aun cuando la superposición de funciones, la disparidad de recursos y la historia hacen difícil su consolidación como autoridad coordinadora de toda la política social.

14 Las modalidades descritas son tipos ideales, que no necesariamente se presentan de manera pura en cada país, y no son excluyentes entre sí. Por ejemplo, en un mismo país puede coexistir una modalidad centrada en la Presidencia de la República o un ministerio de desarrollo social con capacidad de coordinación y, a la vez, un gabinete social. Es más, la proliferación de mandatos que impliquen duplicaciones o la creación sucesiva de nuevas instancias pueden traducirse en la coexistencia de varias modalidades. 
- Ministerio coordinador: organismo designado para mediar y coordinar el conjunto de instancias relevantes del área social, ya sean del Gobierno central o de otros niveles de gobierno. El caso más conocido es el del Ecuador, que entre 2008 y 2017 contó con esta modalidad para toda la estructura de gobierno ${ }^{15}$.

- Entidades colegiadas intersectoriales: gabinetes sociales o consejos económicos y sociales, compuestos normalmente por los ministros del área social y las direcciones de servicios especializados, encabezados por el Presidente, un Vicepresidente o un ministro designado como coordinador, con una secretaría técnica colegiada o radicada en el área de planificación.

Cabe destacar que, entre los 33 países de la región sobre los que se dispone de información oficial, las entidades colegiadas están presentes en 22 casos. Así, más que un modelo único o alternativo a los demás, representan una instancia complementaria, en que la autoridad sobre la política social se distribuye entre las distintas reparticiones del Estado (véase el cuadro II.4). En su gran mayoría, estos consejos o gabinetes están coordinados por el Presidente o Vicepresidente. Los Ministerios de Desarrollo Social (o equivalentes) solo cumplen esa función en siete casos. Esto refleja la existencia de una disociación entre la autoridad formal y la autoridad real de los ministerios que tienen la misión de coordinar la política social ${ }^{16}$. Al mismo tiempo, más que adoptar un modelo específico, es necesario que la instancia con ese liderazgo posea los mandatos, recursos y capacidad de coordinación interinstitucional en materia social.

En los últimos años han surgido también entidades colegiadas que se dedican a temáticas específicas (pobreza, protección social, desnutrición y seguridad alimentaria y nutricional, cuidado, discriminación, género y otras) o a determinados segmentos de población. Estas últimas pueden ser transversales (como los mecanismos nacionales para el adelanto de las mujeres y la promoción de la igualdad racial, o las instancias de promoción de los derechos de las personas con discapacidad, entre otras), o bien centrarse en promover los derechos y el bienestar de segmentos de la población en una etapa concreta de la vida (como la infancia, la juventud o la vejez).

5 Este modelo se modificó con la llegada del Gobierno del Presidente Lenin Moreno, el 24 de mayo de 2017, que eliminó los ministerios coordinadores en el Ecuador.

16 En el cuadro II.A1.2 del anexo II.A1 se presenta en detalle la composición de las instancias colegiadas de coordinación intersectorial del área social de cada país. 
Cuadro II. 4

América Latina y el Caribe (22 países): tipo de autoridad que coordina el gabinete social o la principal entidad colegiada intersectorial del área social

\begin{tabular}{|c|c|c|c|c|c|}
\hline País & $\begin{array}{c}\text { Presidencia, } \\
\text { Vicepresidencia } \\
\text { o delegado } \\
\text { presidencial }\end{array}$ & $\begin{array}{l}\text { Ministerio de } \\
\text { Desarrollo } \\
\text { o Inclusión } \\
\text { Social }\end{array}$ & $\begin{array}{c}\text { Entorno } \\
\text { familiar o } \\
\text { conyugal } \\
\text { del ejecutivo }\end{array}$ & $\begin{array}{l}\text { Ministerio } \\
\text { de otra } \\
\text { cartera }\end{array}$ & $\begin{array}{c}\text { Ministerio } \\
\text { coordinador } \\
\text { de asuntos } \\
\text { sociales }\end{array}$ \\
\hline Antigua y Barbuda & $x$ & & & & \\
\hline Argentina & & $x$ & & & \\
\hline Belice & $x$ & & & & \\
\hline $\begin{array}{l}\text { Bolivia (Estado } \\
\text { Plurinacional de) }\end{array}$ & $x$ & & & & \\
\hline Brasil & & $x$ & & & \\
\hline Chile & & $x$ & & & \\
\hline Colombia & & & & $x$ & \\
\hline Costa Rica & $x$ & & & & \\
\hline Ecuador ${ }^{a}$ & & & & & $x$ \\
\hline El Salvador ${ }^{b}$ & & & & $x$ & \\
\hline Guatemala & $x$ & & & & \\
\hline Haitic & & & $x$ & & \\
\hline Honduras & $x$ & & & & \\
\hline México & & $x$ & & & \\
\hline Nicaraguad $^{d}$ & & & $x$ & & \\
\hline Panamá & & $x$ & & & \\
\hline Paraguay & $x$ & & & & \\
\hline Perú & $x$ & & & & \\
\hline República Dominicana & $x$ & & & & \\
\hline Trinidad y Tabago & & $x$ & & & \\
\hline Uruguay & & $x$ & & & \\
\hline $\begin{array}{l}\text { Venezuela (República } \\
\text { Bolivariana de) }\end{array}$ & $x$ & & & & \\
\hline Total & 10 & 7 & 2 & 2 & 1 \\
\hline
\end{tabular}

Fuente: Comisión Económica para América Latina y el Caribe (CEPAL), sobre la base de información oficial de los países.

a En el Ecuador, a partir de la asunción del Gobierno del Presidente Lenin Moreno, en mayo de 2017, se inició una reforma importante en relación con los ministerios coordinadores. El Ministerio Coordinador de Desarrollo Social, que presidía el Consejo Sectorial de Desarrollo Social hasta aquel momento (según se establece en el Decreto núm. 117-A de febrero de 2007), se transformó en la Secretaria Técnica del Plan Toda una Vida, adscrita a la presidencia y con rango ministerial. Por otra parte, el Decreto núm. 34 de junio de 2017 estableció nuevos Consejos Sectoriales, coordinados por un consejero, ministro - autoridad designada por el Presidente. La Secretaría Técnica del Plan Toda una Vida coordina el Consejo Sectorial de Desarrollo Social.

b En El Salvador, el Gabinete de Gestión Social e Inclusión, por decisión presidencial, es coordinado por el Ministerio de Salud.

c En Haití, en 2012, se creó la Comisión Nacional de Lucha contra el Hambre y la Malnutrición, liderada por la Primera Dama de la República. En 2017 esta instancia aparece como inactiva, pero no se dispone de información oficial que establezca su disolución formal o la creación de nuevas instancias.

d En Nicaragua, el Ejecutivo nombra a la persona a cargo de la entidad coordinadora de la instancia intersectorial (Consejo de Comunicación y Ciudadanía de la Presidencia del Poder Ciudadano). 


\section{Los ministerios y secretarías de desarrollo e inclusión social}

A nivel nacional, las instancias con rango ministerial en las áreas de educación, salud y trabajo tienen una larga trayectoria en los países de la región. En cambio, como se muestra en el gráfico II.2, los ministerios (o secretarías) de desarrollo e inclusión social apenas surgen a finales de siglo XX y, sobre todo, durante el siglo XXI.

\section{Gráfico II.2}

América Latina y el Caribe (22 países): año de creación de los ministerios $\mathrm{u}$ otras instancias dedicadas al desarrollo social ${ }^{\mathrm{a}}$

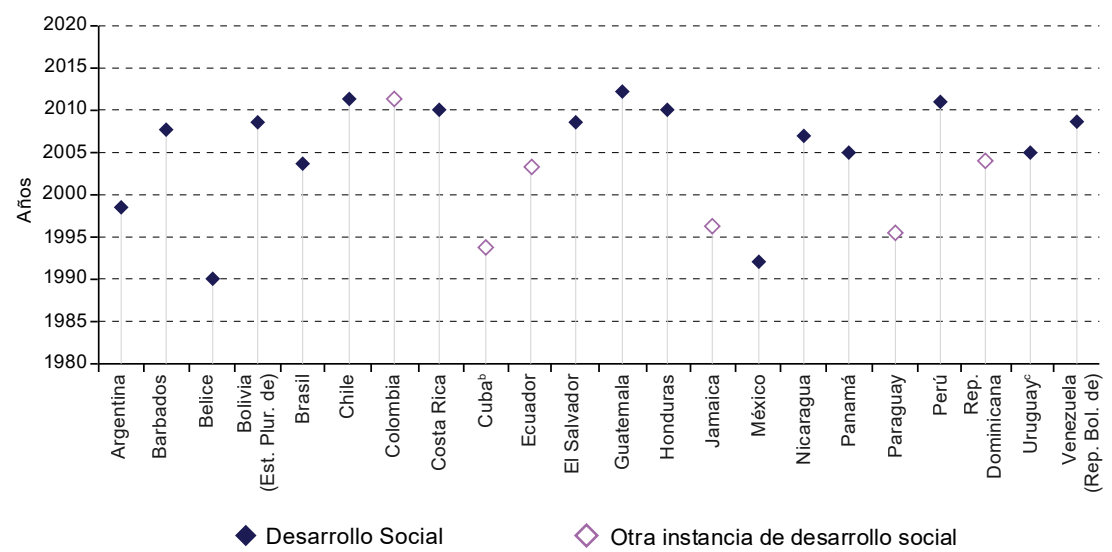

Fuente: Comisión Económica para América Latina y el Caribe (CEPAL), sobre la base de información oficial de los países.

a No están incluidos en el gráfico los países de los que no se tiene la fecha de creación del Ministerio de Desarrollo Social (Antigua y Barbuda, Bahamas, Dominica, Granada, Guyana, Haití, Saint Kitts y Nevis, San Vicente y las Granadinas, Santa Lucía, Suriname y Trinidad y Tabago).

b El Ministerio de Trabajo y Seguridad Social de Cuba se creó en 1994, a través del Decreto Ley núm. 147 para la reorganización de los organismos de la Administración Central del Estado. En 2001 se creó el Instituto Nacional de Seguridad Social, que hace más compleja la labor del Ministerio, y, a través del Acuerdo núm. 7335 del Consejo de Ministros de 19 de diciembre de 2012, se le otorgó la misión de proponer, dirigir y controlar la política del Estado y el Gobierno en materia de trabajo, protección, seguridad e higiene del trabajo, seguridad social y prevención, asistencia y trabajo social.

c El Ministerio de Vivienda y Promoción Social del Uruguay se disolvió en 1977.

Varios de estos ministerios surgieron a partir de los fondos de inversión social (FIS), creados durante la década de 1990 como entidades autónomas y transitorias dedicadas al desarrollo de programas y proyectos de lucha contra la pobreza y de inversión en infraestructura de servicios sociales, sobre todo de salud, educación y agua y saneamiento. Justamente en dicho período la discusión sobre autoridad e institucionalidad social pasó a formar parte del debate, centrado, en particular, en el posicionamiento de lo social frente a la autoridad económica y en el 
fomento de la efectividad y eficiencia de los programas sociales a través de las dimensiones de organización y de instrumentos de evaluación, monitoreo y registro de participantes (Franco y Székely, 2010).

En la actualidad, los ministerios especializados en las políticas de desarrollo e inclusión social se han difundido de manera significativa y la mayoría de los países disponen de esta instancia o de una repartición específica adscrita a la Presidencia o Vicepresidencia, con atención especial al diseño, la implementación y la coordinación de dichas políticas. No obstante, cabe destacar que no todos cuentan con una ley que los ampare, sino que algunos se sustentan en un decreto administrativo de la Presidencia.

Así, se aprecia en la región un panorama institucional heterogéneo en cuanto a la estructura organizacional y la autoridad social. Además de ser diversas en cuanto al nivel que ocupan en la estructura del Estado y a su estatus jurídico, en algunos casos estas entidades han sido designadas formalmente para coordinar las políticas de desarrollo e inclusión social. En otros casos, comparten la autoridad con otras reparticiones o instancias.

A su vez, algunas de las entidades que detentan la autoridad en lo social tienen objetivos semejantes, pero también presentan sus especificidades en los distintos países. Así, el análisis de la misión y los mandatos de las entidades nacionales dedicadas al desarrollo social y el panorama de las instancias que dependen de ellas ayudan a tener una idea de los desafíos relativos a la coordinación intersectorial de las políticas de protección social no contributiva. En su gran mayoría, estos desafíos se centran en políticas relacionadas con la pobreza, la protección y la inclusión social y, en menor medida, en la provisión de diversas modalidades de cuidado.

Por otra parte, todas estas entidades conviven con un número creciente de instancias dedicadas al bienestar y la garantía de los derechos de segmentos determinados de la población, como los niños y adolescentes, las personas mayores, las personas con discapacidad, los pueblos indígenas y las poblaciones afrodescendientes, entre otros. En este diverso panorama, es posible caracterizar algunas modalidades institucionales asociadas a sus mandatos.

La primera modalidad corresponde a los casos en que el mandato de estos ministerios de desarrollo social establece que se hagan cargo de las necesidades de los segmentos de población antes mencionados. De los 25 países de la región sobre los que se dispone de información, en 15 de ellos los ministerios del área de desarrollo social tienen bajo su dirección las instancias dedicadas a las personas de edad, 5 se ocupan de los 
institutos de juventud, 8 atienden a las instituciones con el mandato de velar por el bienestar y derechos de la población infantil y adolescente, 7 tienen que ver con temas relacionados con la mujer y otros 9 atienden a las personas con discapacidad (véase el gráfico II.3). En los casos de Chile y el Uruguay, el Ministerio de Desarrollo Social concentra el mandato y la gestión de varios de estos segmentos.

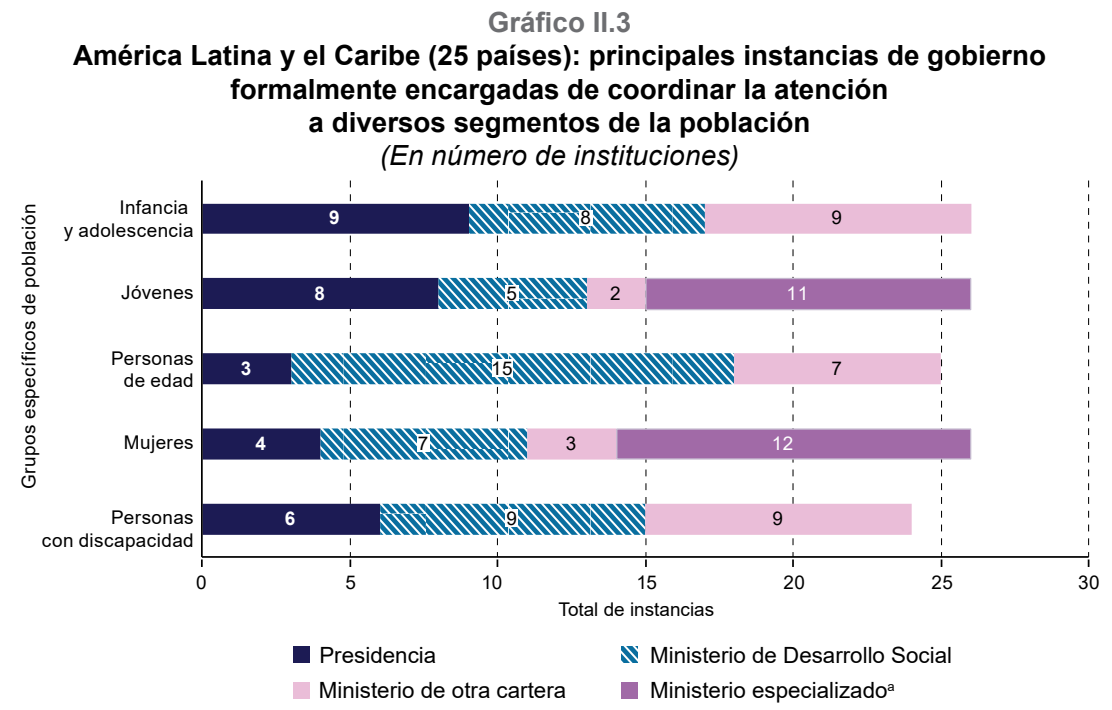

Fuente: Comisión Económica para América Latina y el Caribe, sobre la base de datos oficiales de los ministerios y secretarías dedicadas al desarrollo social.

a Se refiere a casos en que existen ministerios explícitamente dedicados a un segmento de población, pero que además pueden tener otros mandatos simultáneos con respecto a otros grupos de población o problemáticas sociales.

Una segunda modalidad, que suele ser complementaria a la anterior, consiste en la existencia de comisiones intersectoriales compuestas por diversos ministerios y otras entidades, y la mayoría de las veces coordinadas por la Presidencia o Vicepresidencia. Un ejemplo son las instancias encargadas del bienestar y los derechos de la población infantil (consejos de la infancia), modalidad que se observa en 9 de los 25 países. El principal desafío es que dichas instancias intersectoriales tengan la autoridad para coordinar una multiplicidad de ministerios y otras entidades gubernamentales (e incluso no gubernamentales). Dado que poseen mandatos extensos (en general, la promoción o garantía de un conjunto amplio de derechos), resulta fundamental su capacidad de movilización de recursos y de coordinación de las entidades de gobierno involucradas en la implementación de acciones de protección social. 
La tercera alternativa que conlleva desafíos propios de coordinación es la existencia de ministerios específicos centrados en segmentos de población (ver Parte 3). Tal es el caso, con frecuencia, de los mecanismos nacionales creados para promover el adelanto de las mujeres, que suelen consistir en un ministerio que atiende las necesidades y derechos de las mujeres o bien en una persona titular del mecanismo que tiene rango ministerial ${ }^{17}$. En este caso, el desafío radica en la capacidad de coordinación de estas entidades con los demás ministerios, en especial con los que tienen por objetivo promover el desarrollo social. Ello se refiere tanto a la implementación de políticas y programas de protección social como a garantizar la coordinación con otras instancias del Gobierno central, con el fin de asegurar que las necesidades de cada segmento sean tomadas en cuenta por el conjunto de la acción pública gubernamental.

El desafío que comparten estas modalidades en materia de implementación de políticas de protección social consiste en velar por que sus funciones básicas (proteger y asegurar el ingreso, identificar la demanda insatisfecha y garantizar el acceso a servicios sociales y a políticas de promoción, así como fomentar el trabajo decente como vía de acceso a la protección y al bienestar social) se cumplan para cada segmento de la población, ya sea mediante acciones generales o específicas (véase el gráfico II.3).

El entrecruzamiento de objetivos sectoriales con la atención a grupos o segmentos poblacionales genera un desafío que caracteriza a los ministerios de desarrollo e inclusión social y los diferencia de las demás reparticiones del Estado. Las lógicas propias de la implementación de políticas con segmentación poblacional son complementarias pero no necesariamente sinérgicas con la especialización temática y sectorial.

Además, no se suele recurrir a modelos organizacionales con una lógica matricial y "adhocrática" para cumplir de manera efectiva y eficiente los distintos objetivos. Más bien se tiende a reproducir las estructuras de los ministerios de línea (tradicionales) y generar instancias con fines específicos (por tema o población), en que la atomización y competencia se convierten en un riesgo mayor y la coordinación o articulación, en un desafío creciente.

En suma, existe una gran variedad de modelos y alternativas de autoridades sociales en cada segmento de población priorizado

17 Véase al respecto Observatorio de Igualdad de Género de América Latina y el Caribe, "Ficha técnica: nivel jerárquico de los Mecanismos para el Adelanto de la Mujer (MAM)" [en línea] http://www.cepal.org/oig/html/niveljerarquico2.html. 
o singularizado a nivel institucional (comisiones intersectoriales, instancias dependientes de la presidencia o vicepresidencia, ministerios, viceministerios e institutos, entre otros). En la tercera parte del libro se abordan los casos específicos de la institucionalidad orientada a la población afrodescendiente, las personas jóvenes y las personas con discapacidad.

\section{La adscripción institucional de los programas de transferencias monetarias y de las pensiones no contributivas}

Otro ejemplo de los desafíos institucionales de la protección social no contributiva es la adscripción institucional de los programas de transferencias condicionadas y de las pensiones sociales. Como se ha indicado, la relevancia de estas iniciativas reside menos en su peso fiscal relativo y más en su cobertura y orientación hacia los estratos de menores ingresos.

En el cuadro II.5 puede apreciarse que, de 21 países de la región que implementan al menos un programa de transferencias monetarias a nivel nacional, en 10 casos este se encuentra adscrito al Ministerio de Desarrollo Social o a la entidad ministerial equivalente; en 6, a la Presidencia, y en 5, a alguna otra cartera ministerial. En el caso de los 19 países en que existe algún programa nacional de pensiones no contributivas, en 8 de ellos este está adscrito al Ministerio de Desarrollo Social o la entidad ministerial equivalente; en 2, a la Presidencia, y en 9, a alguna otra cartera ministerial. En suma, aunque se observa la aparición de entidades ministeriales abocadas al desarrollo social como protagonistas de la protección social no contributiva y con mandatos formales en ese ámbito, la rectoría de los principales programas, al menos los de mayor alcance, no siempre está bajo su responsabilidad. En buena medida esto se relaciona con los modelos de autoridad social de cada país, el papel que se otorga a las entidades ministeriales dedicadas al desarrollo social, y la existencia y adscripción institucional de las prestaciones no contributivas en los sistemas de pensiones. Esto pone de relieve la necesidad de avanzar en materia de coherencia y articulación entre los modelos de autoridad, en los mandatos y las estructuras ministeriales y programáticas existentes, así como entre estos y los múltiples actores que participan en sistemas de protección social más complejos que en el pasado, como se plantea en los siguientes apartados. 


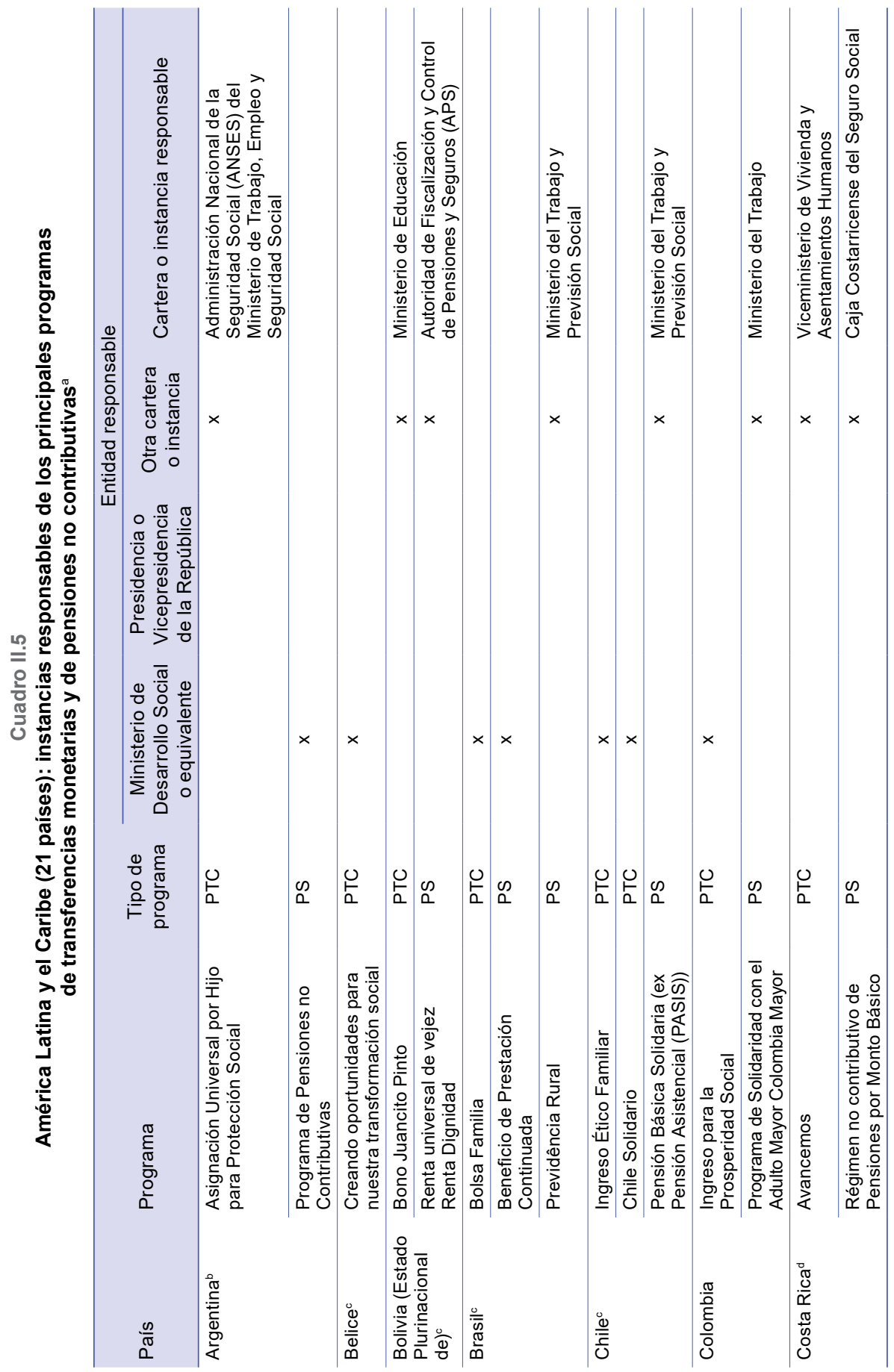




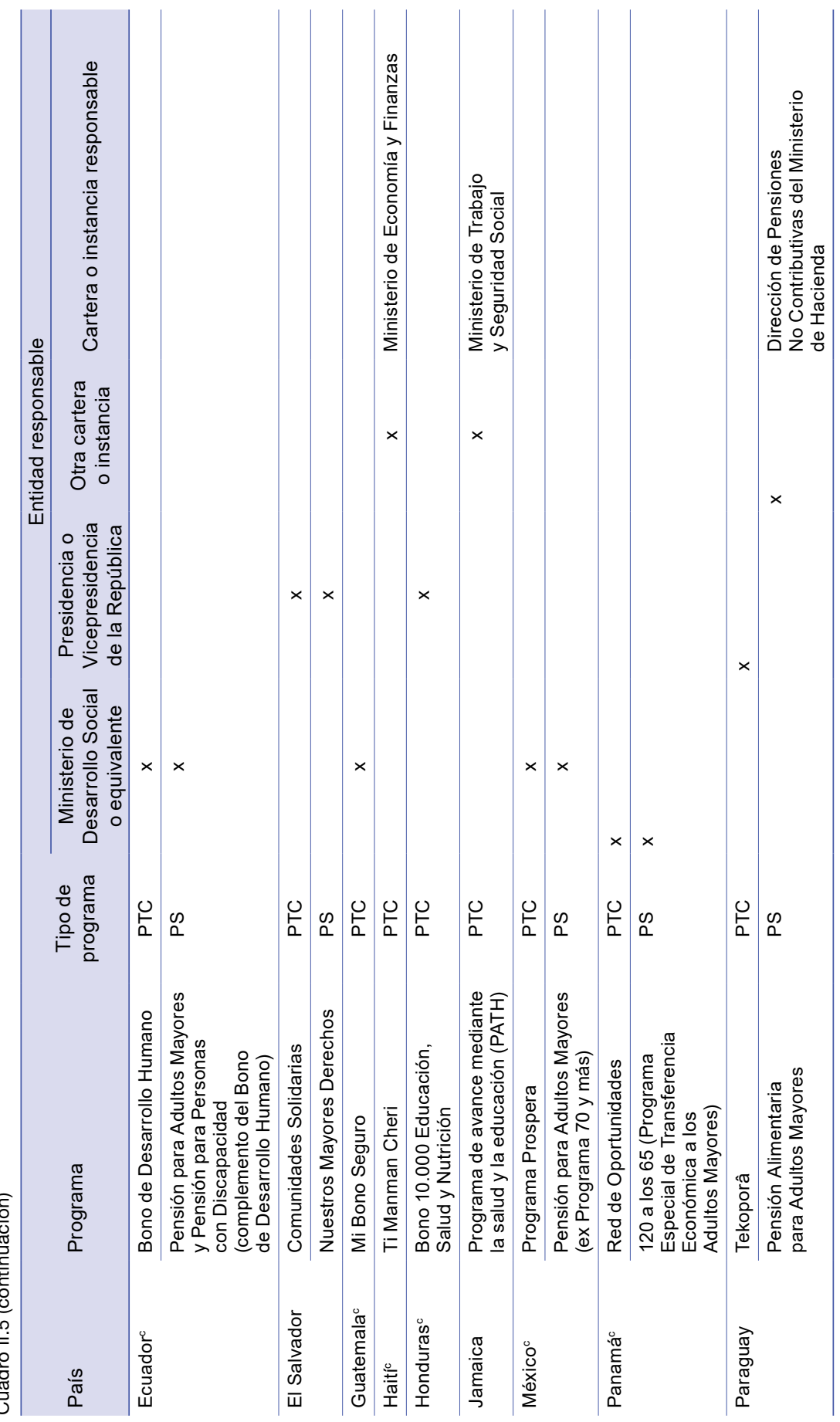




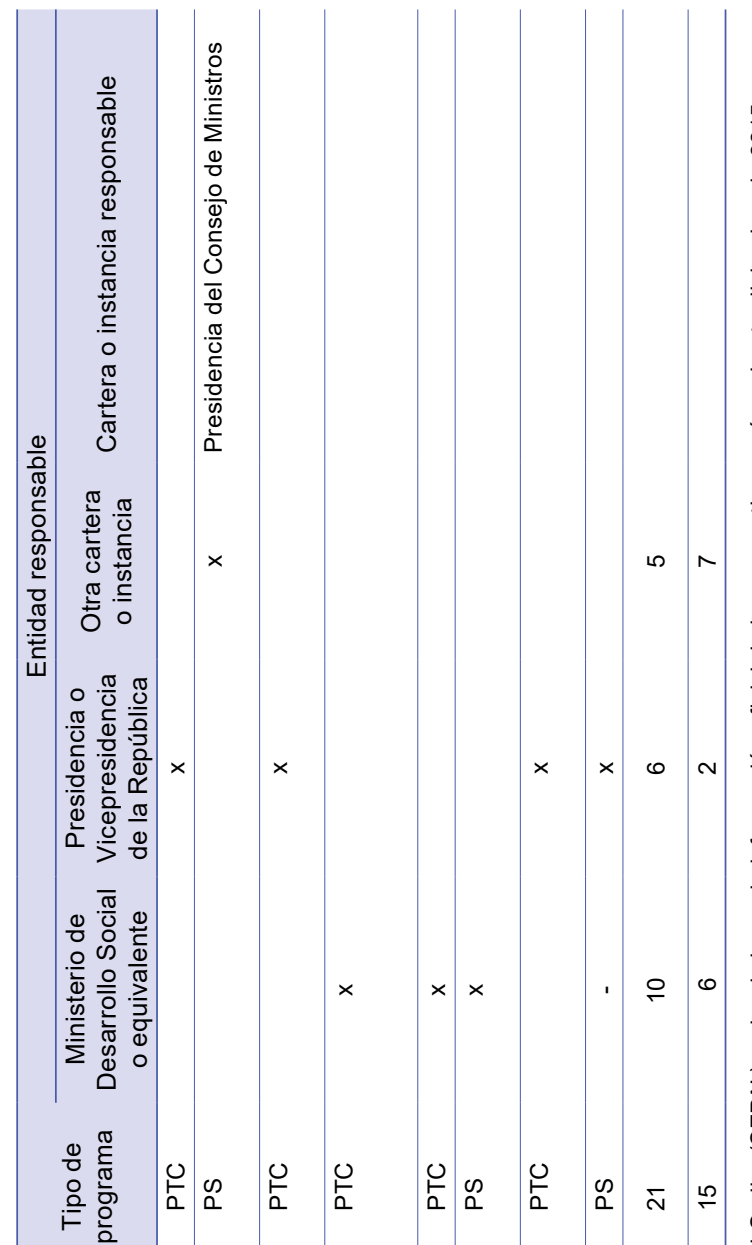

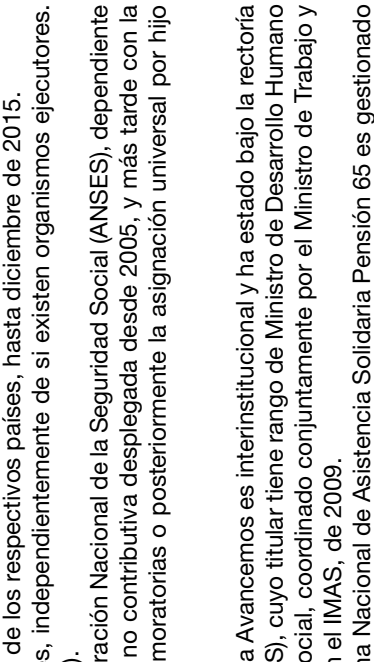

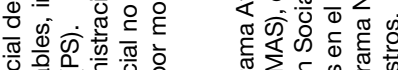
는

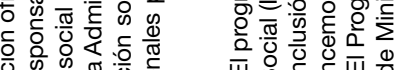

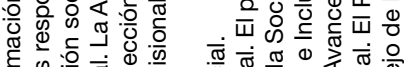

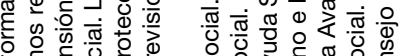

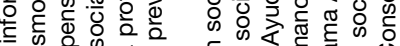
ه

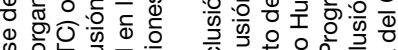

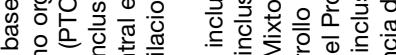
娄 就 $\overline{0}$ क

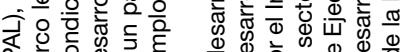

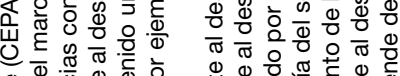

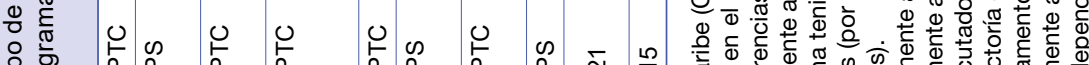

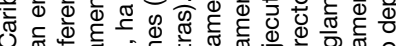

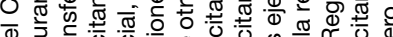

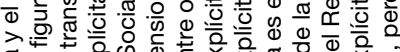

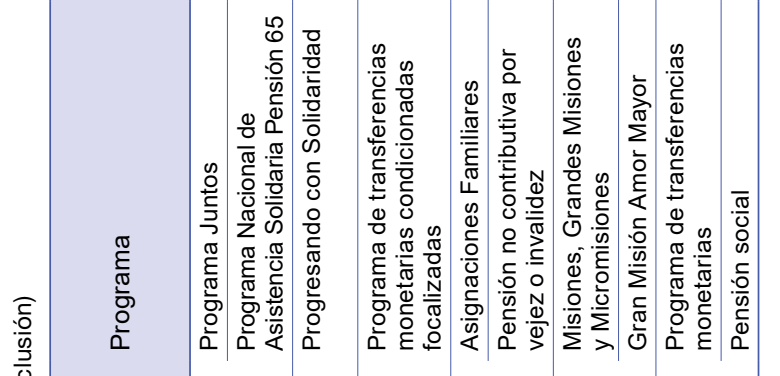
『

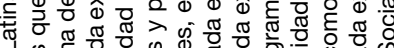

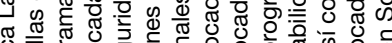

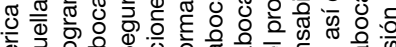
这

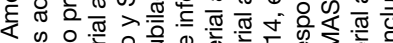
ช

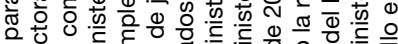

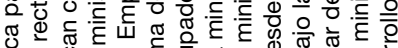

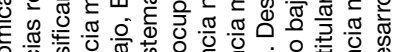

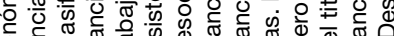

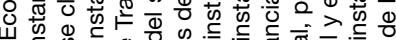

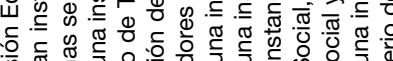

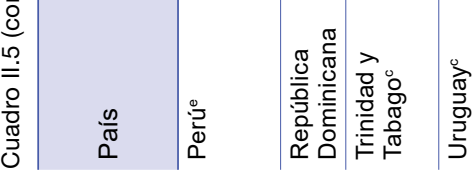
कू है

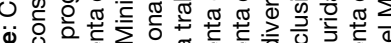

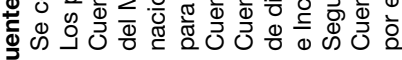




\section{Los desafíos de coordinación y articulación entre los actores de la protección social}

La necesidad de una mayor articulación de la política social en general, y de los sistemas de protección social en particular, ocurre en varios niveles y dimensiones. Como se ha planteado en estudios previos, el nivel de coordinación intersectorial representa una solución de continuidad que va desde la comunicación y la coordinación entre diversos actores institucionales hasta un trabajo consolidado o integral. En esa labor, ante una misma problemática, los actores llevan a cabo el conjunto de fases del ciclo de sus políticas y programas de manera intersectorial, sobre la base de procedimientos y prácticas comunes e incluso compartiendo recursos, responsabilidades y acciones, así como el monitoreo y la evaluación conjunta (OPS/OMS, 2015). Construir altos niveles de coordinación intersectorial supone costos políticos, financieros, organizacionales y de tiempo, por lo que dicha colaboración se justifica en caso de enfrentar problemáticas de gran complejidad y envergadura (Cunill-Grau, Repetto y Bronzo, 2015; Repetto y Potenza, 2015). A continuación se esbozan algunas dimensiones y desafíos de la coordinación institucional de los sistemas de protección social.

\section{a) Coordinación entre los distintos sectores de la política social}

Las inercias sectoriales se contraponen con frecuencia al diseño de políticas y programas sociales orientados a abordar y producir impactos en varias dimensiones del bienestar. La experiencia de los programas de transferencias monetarias constituyó en su momento una innovación, al conjugar acciones coordinadas e intersectoriales en materia asistencial, educativa, nutricional y sanitaria. Actualmente, la mayoría de estos programas están desarrollando mayores capacidades de vinculación y coordinación con otras acciones sectoriales relacionadas con el empleo y el desarrollo productivo. Su fin común es incidir en un mejor aprovechamiento de los años de educación logrados en el marco de los propios programas mediante una inserción laboral menos precaria y que contribuya a una salida de la pobreza. No obstante, queda aún por implantarse en la mayoría de los países la lógica del trabajo intersectorial, que incluye la planificación conjunta, el establecimiento de objetivos comunes y la racionalidad integradora en cuanto al presupuesto y los sistemas de evaluación y desempeño, entre otros elementos.

\section{b) Coordinación entre componentes contributivos y no contributivos de la protección social}

La existencia de sistemas de protección social con elevados niveles de cobertura, equidad y sostenibilidad fiscal se vincula fuertemente con la posibilidad de que, a largo plazo, el acceso a ese sistema esté menos 
segmentado y los componentes contributivos y no contributivos respondan a una misma lógica de inclusión social y a una vocación de universalidad, con un análisis conjunto del riesgo y coherencia entre los incentivos y el financiamiento. En el período reciente el pilar no contributivo se ha expandido de forma autónoma en la región para hacer frente a los vacíos de cobertura de la seguridad social tradicional. No obstante, un desafío pendiente consiste en expandir esta última a sectores que hasta ahora han tenido poca cobertura, así como construir vasos comunicantes entre las políticas y programas no contributivos, la seguridad social y el mercado de trabajo formal. Aunque no hay pruebas concluyentes de los incentivos adversos de la migración de los programas no contributivos hacia mecanismos contributivos y formales, una tarea pendiente es la construcción de alternativas y mecanismos institucionales que establezcan vínculos entre ambos.

c) Coordinación entre entidades sociales con mandatos generales y autoridades sociales temáticas centradas en problemáticas sociales o segmentos de población (transversales o por etapas de la vida)

La aparición de autoridades sociales temáticas es una consecuencia del enriquecimiento y la creciente complejidad de la agenda social de la región. Dichas entidades se han centrado en abordar de forma intersectorial ciertos temas o problemáticas sociales como la discriminación, la desigualdad, la pobreza o el cuidado, así como la promoción de los derechos y la atención de las necesidades de segmentos de población determinados (las mujeres, las personas con discapacidad, las poblaciones afrodescendientes o los pueblos indígenas) y aquellos relativos a las diferentes etapas de la vida (infancia, juventud y vejez). Un desafío institucional clave es lograr que el trabajo de dichas entidades, sobre la base de sus mandatos más o menos extensos, se traduzca en mayores niveles de transversalización y de coordinación intersectorial, y no en una fragmentación de la arquitectura institucional reflejada en políticas y programas dispersos y más motivados por la competencia que por la colaboración. En el caso específico de los sistemas de protección social, la misión de estas entidades resulta de relevancia para transversalizar o articular la atención de los distintos componentes y singularizar necesidades y carencias particulares. La experiencia de los sistemas de cuidado (que se describe en el capítulo V) ilustra estos desafíos.

\section{Herramientas de gestión y dimensión técnico-operativa}

Un factor clave para contar con una institucionalidad que posibilite una política social de calidad es disponer de infraestructura y equipamiento, instrumentos, protocolos y procedimientos, así como recursos físicos 
y humanos que permitan implementar adecuadamente los planes gubernamentales a fin de alcanzar las metas de política.

Al revisar los antecedentes disponibles de los 33 países de la región, se concluye que en la actualidad solo 21 países tienen un plan o estrategia de desarrollo social explícito. Aun cuando su mera existencia representa un rasgo positivo, en muchos casos estos planes se circunscriben a los ciclos de gobierno y no son la expresión de políticas de Estado. Ello refleja una debilidad institucional, pues se pone en riesgo la sostenibilidad temporal que muchas políticas requieren para alcanzar objetivos sociales de largo plazo. En las áreas de salud y educación, la implementación de estos planes es de larga data, pero en el caso de las estrategias de lucha contra la pobreza y de desarrollo e inclusión social, la tradición es más corta. En los fondos de inversión social (FIS) de la década de 1990 se implantaron de modo incipiente algunos sistemas de evaluación y monitoreo, con procesos de evaluación ex ante. Esto se expandió al presente siglo, acompañado de los programas de transferencias condicionadas (PTC), lo que ha sumado importantes innovaciones en cuanto a capacidad técnica y administrativa, junto a una ampliación de las evaluaciones de impacto. Así, en la mayoría de los países de América Latina y el Caribe se han ido construyendo herramientas de gestión relacionadas con la administración de información de gestión y la articulación de los programas sociales, como padrones de registro de participantes, total o parcialmente integrados, y sistemas de monitoreo y evaluación de los programas de desarrollo social.

Entre los elementos que caracterizan a los modelos de evaluación vigentes en la región se destaca que estos han tenido una mayor tendencia hacia la evaluación ex post, lo que genera una importante difusión de los diseños experimentales y cuasi experimentales de estimación de impactos. Entre las limitaciones más recurrentes se encuentra su desconexión con la evaluación de procesos y los indicadores del monitoreo, lo que condiciona la capacidad de atribución de sus resultados a los propios programas. Tampoco se ha desarrollado suficientemente el análisis de costo-efectividad, en que se vinculan los resultados con los costos incurridos. A esto se suma que los modelos se mantienen en una lógica de programa y no de política, lo que limita la capacidad de tomar decisiones sobre el conjunto de la gestión pública existente en un ámbito determinado, por ejemplo, del conjunto de componentes de la protección social o de las estrategias de lucha contra la pobreza y la desigualdad (Martínez, 2015).

En cuanto a la rendición de cuentas, resulta esencial la existencia de normas y procedimientos formales dentro del Estado para controlar 
y verificar el funcionamiento de las políticas y programas sociales. En esos procesos son clave los sistemas de monitoreo y evaluación, así como los registros de participantes y las reglas de operación, junto con los mecanismos (generales y sectoriales) de contraloría y auditoría de la acción pública. Esto se complementa con los instrumentos de rendición de cuentas propios de las entidades que implementan las políticas y programas de desarrollo social y el rol que ejercen diversos actores no estatales, incluidos los participantes de los programas, la sociedad civil y sus organizaciones y los medios de comunicación, entre otros.

Junto a la rendición de cuentas, los mecanismos de participación tienen un rol relevante para mejorar el diseño e institucionalizar y potenciar el impacto y la sostenibilidad de las políticas. Estos abarcan una serie de modalidades, desde los ejercicios de presupuesto participativo y los foros de consulta sectoriales o temáticos hasta los mecanismos de participación de los destinatarios en la gestión de los programas. Destacan, tanto por su extensión y magnitud como por sus resultados, las Conferencias Nacionales de Asistencia Social en el Brasil, en las que se desarrolla un extenso proceso de diálogo y consulta que se inicia en el ámbito municipal y llega hasta el nacional, e involucra la elección de delegados en cada una de esas etapas y la participación de diversos órganos gubernamentales coordinados por el Ministerio de Desarrollo Social y Agrario, junto con las organizaciones de la sociedad civil y los usuarios de los programas. Las Conferencias Nacionales de Asistencia Social han tenido resultados tan importantes como la creación del sistema nacional de asistencia social.

Como puede observarse en el cuadro II.6, si se toma como aproximación la existencia de sistemas de información, evaluación y transparencia, actualmente la mayoría de las entidades ministeriales dedicadas al desarrollo social cuentan con este tipo de herramientas. Del conjunto de 22 países sobre los que se dispone de información, 19 tienen registros de destinatarios de los programas sociales, aunque en pocos casos se trata de sistemas integrados y actualizados periódicamente. Con respecto a los sistemas de información social, en 9 casos existe un sistema de tipo sectorial (es decir, propio de la entidad ministerial abocada al desarrollo social) y en 5 casos dichos sistemas comprenden el conjunto de las políticas sociales del Gobierno central. También se observa la existencia de al menos 15 países que cuentan con instancias dedicadas a la evaluación de los programas gubernamentales, incluidos los programas sociales, y 9 con sistemas de evaluación sectoriales. Finalmente, en materia de transparencia, se identificaron 16 sistemas de acceso a la información pública, que dependen del Gobierno o bien son específicos de las entidades ministeriales dedicadas al desarrollo social. 


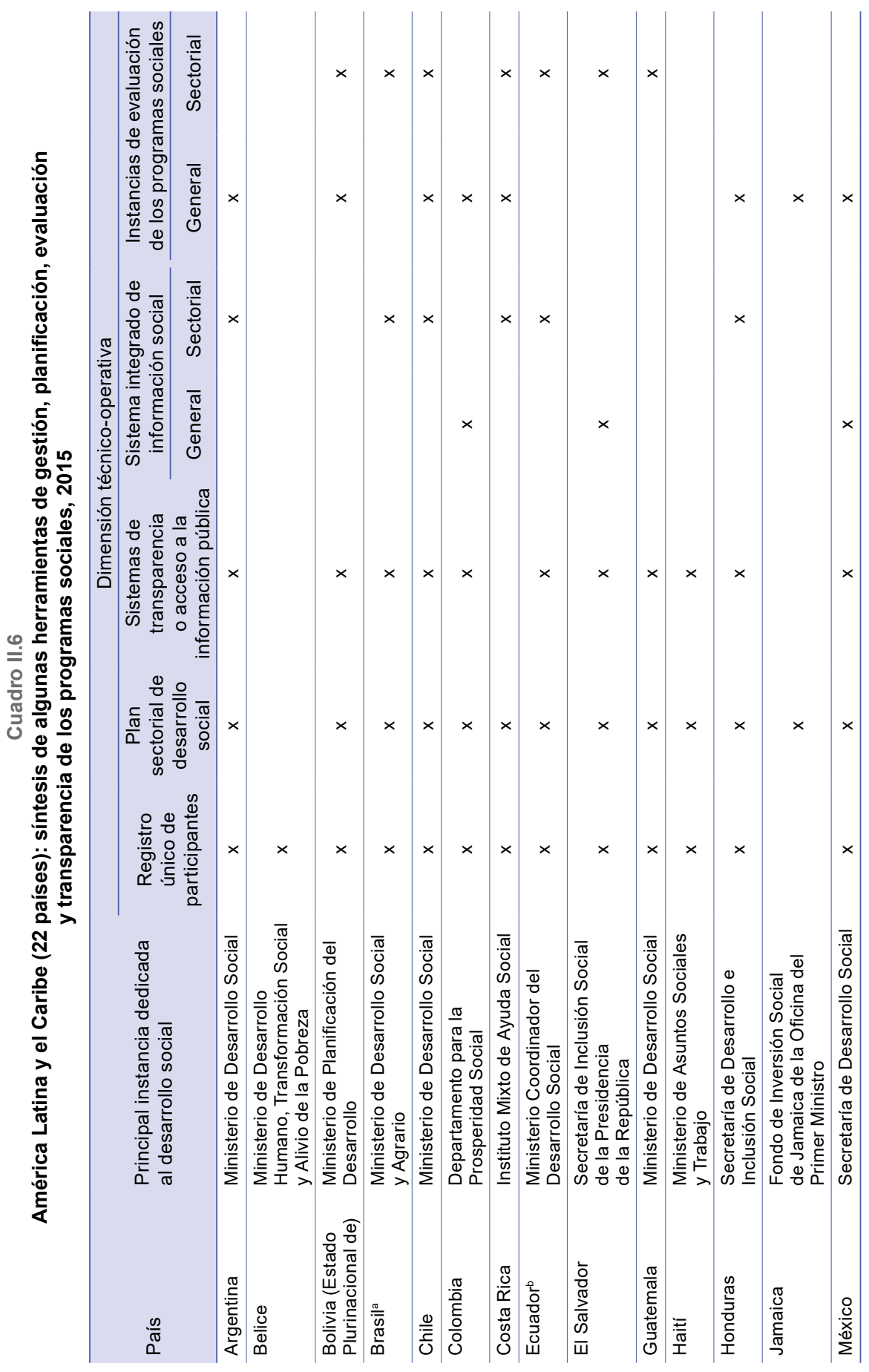




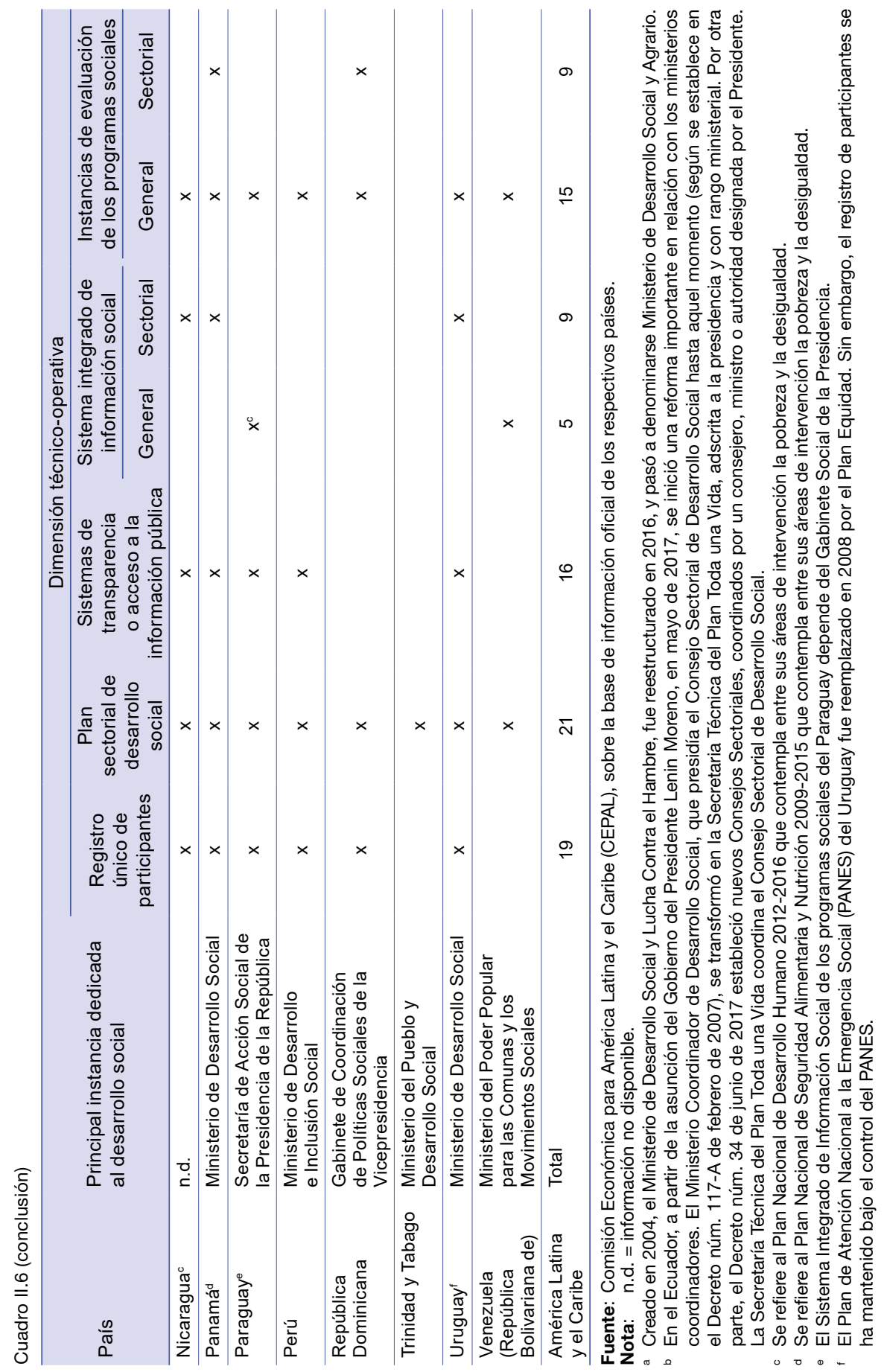




\section{El financiamiento}

La proporción de recursos públicos destinados a cada función de gobierno es un indicador básico de su prioridad política y económica. A la vez, su volatilidad ante los ciclos económicos demuestra cuán dependiente del contexto es dicha asignación. Así, el aumento de los recursos destinados a las políticas sociales en relación con el producto interno bruto (PIB) y su relativa estabilidad son factores fundamentales para la sostenibilidad y el fortalecimiento institucional de dichas políticas.

El crecimiento sostenido que los recursos destinados a lo social han tenido en la región refleja una progresiva institucionalización de la política social en términos de su financiamiento, en particular en lo que se refiere a la lucha contra la pobreza y a la protección social. Si bien la tasa de crecimiento de esos recursos varía, se ha mantenido positiva y ha sido un soporte central para hacer frente a la crisis internacional de fines de la década de 2000. Sin embargo, las necesidades regionales son aún de gran magnitud y persisten importantes desafíos en cuanto a la disponibilidad de recursos. Todavía se está lejos de llegar a los niveles de gasto (absoluto y relativo) existentes en los países de la Organización de Cooperación y Desarrollo Económicos (OCDE) (que en promedio bordean el $27 \%$ del PIB).

La comparación de los recursos disponibles y su participación en el PIB entre diferentes países muestra que la institucionalidad no es homogénea en este aspecto y tampoco en lo que se refiere a la cobertura de servicios existente en los distintos ámbitos de política. En general, los países con mayores necesidades tienen una menor cobertura de servicios y menos recursos per cápita y les asignan una menor prioridad fiscal (véase el cuadro II.7).

En los párrafos anteriores se ha comentado sobre el aporte de los programas de transferencias condicionadas a la institucionalidad social, en relación con la coordinación y con las herramientas de gestión. Un elemento que contrasta con su cobertura, que bordea el $21 \%$ de la población en la región, es que los recursos de esos programas solo representaban, alrededor de 2013, un 0,39\% del PIB como promedio regional (en los distintos países alcanzaban niveles de entre el 0,01\% y el 1,13\% del PIB). Al mismo tiempo, los montos per cápita fluctuaban entre los 0,51 y 41,19 dólares mensuales (CEPAL, 2015). Esto puede ser un buen indicio de eficiencia, pero también expresa el nivel de prioridad que estos programas tienen en los países. 


\section{Cuadro II.7 \\ América Latina (18 países): gasto social en tres grupos de países con distintos resultados en materia de protección y promoción social (promedio simple de cada grupo), alrededor del período 2015}

(En dólares de 2010 y porcentajes del PIB)

\begin{tabular}{|c|c|c|c|c|c|c|}
\hline \multirow{3}{*}{ Indicador } & \multicolumn{2}{|c|}{ Grupo 1} & \multicolumn{2}{|c|}{ Grupo 2} & \multirow{2}{*}{\multicolumn{2}{|c|}{$\begin{array}{c}\text { Grupo } 3 \\
\text { Bolivia (Estado } \\
\text { Plurinacional de), } \\
\text { Ecuador, El Salvador } \\
\text { Guatemala, Honduras } \\
\text { Nicaragua, Paraguay } \\
\text { Perú y República } \\
\text { Dominicana }\end{array}$}} \\
\hline & \multicolumn{2}{|c|}{$\begin{array}{l}\text { Argentina, Brasil, } \\
\text { Chile, Costa Rica, } \\
\text { Panamá y Uruguay }\end{array}$} & \multicolumn{2}{|c|}{$\begin{array}{c}\text { Colombia, México y } \\
\text { Venezuela (República } \\
\text { Bolivariana de) }\end{array}$} & & \\
\hline & $\begin{array}{l}\text { Sector } \\
\text { público }\end{array}$ & $\begin{array}{l}\text { Gobierno } \\
\text { central }^{\mathrm{b}}\end{array}$ & $\begin{array}{l}\text { Sector } \\
\text { público }^{\mathrm{a}}\end{array}$ & $\begin{array}{l}\text { Gobierno } \\
\text { central }^{\mathrm{b}}\end{array}$ & $\begin{array}{l}\text { Sector } \\
\text { público }\end{array}$ & $\begin{array}{l}\text { Gobierno } \\
\text { central }^{\mathrm{b}}\end{array}$ \\
\hline $\begin{array}{l}\text { Gasto público social } \\
\text { per cápita } \\
\text { (en dólares de 2010) }\end{array}$ & 2101,0 & 1445,0 & 1131,0 & 832,0 & 407,0 & 318,0 \\
\hline $\begin{array}{l}\text { Gasto público en } \\
\text { protección social } \\
\text { per cápita } \\
\text { (en dólares de 2010) }\end{array}$ & 863,0 & 699,0 & 413,0 & 267,0 & 99,0 & 73,0 \\
\hline $\begin{array}{l}\text { Gasto público social } \\
\text { (en porcentajes del PIB) }\end{array}$ & 19,9 & 13,0 & 15,0 & 10,9 & 11,5 & 9,1 \\
\hline $\begin{array}{l}\text { Gasto público en } \\
\text { protección social } \\
\text { (en porcentajes del PIB) }\end{array}$ & 8,1 & 6,3 & 5,5 & 3,5 & 2,8 & 2,0 \\
\hline $\begin{array}{l}\text { Gasto público } \\
\text { en educación } \\
\text { (en porcentajes del PIB) }\end{array}$ & 5,3 & 3,7 & 4,7 & 4,5 & 4,5 & 4,0 \\
\hline $\begin{array}{l}\text { Gasto público } \\
\text { en salud } \\
\text { (en porcentajes del PIB) }\end{array}$ & 4,7 & 2,1 & 3,1 & 1,7 & 2,7 & 2,2 \\
\hline $\begin{array}{l}\text { Gasto público en } \\
\text { vivienda y servicios } \\
\text { comunitarios } \\
\text { (en porcentajes del PIB) }\end{array}$ & 1,4 & 0,6 & 1,0 & 1,0 & 0,9 & 0,7 \\
\hline $\begin{array}{l}\text { Gasto público en } \\
\text { actividades recreativas, } \\
\text { cultura y religión } \\
\text { (en porcentajes del PIB) }\end{array}$ & 0,2 & 0,1 & 0,4 & 0,2 & 0,3 & 0,1 \\
\hline $\begin{array}{l}\text { Gasto público en } \\
\text { protección del } \\
\text { medio ambiente } \\
\text { (en porcentajes del PIB) }\end{array}$ & 0,2 & 0,1 & 0,2 & 0,1 & 0,4 & 0,1 \\
\hline
\end{tabular}

Fuente: Comisión Económica para América Latina y el Caribe (CEPAL), sobre la base de S. Cecchini y R. Martínez, Protección social inclusiva en América Latina. Una mirada integral, un enfoque de derechos, Libros de la CEPAL, N 111 (LC/G.2488-P), Santiago, Comisión Económica para América Latina y el Caribe (CEPAL), 2011.

En el caso del sector público Panamá y Bolivia (Estado Plurinacional de) presentan información de 2014 y la República Bolivariana de Venezuela, de 2009. En los casos de Chile, el Ecuador, Guatemala, Honduras, Nicaragua, Panamá, el Paraguay, la República Dominicana, el Uruguay y Venezuela (República Bolivariana de), los datos corresponden al Gobierno central. Bolivia (Estado Plurinacional de), el Brasil y Colombia corresponden a gobierno en general. De la Argentina, El Salvador y México, corresponden a sector público no financiero. De Costa Rica y el Perú, corresponden a sector público.

b En el caso del Gobierno central, Panamá presenta información de 2014 y la República Bolivariana de Venezuela, de 2009. 
Un indicador sobre la prioridad que asignan los países de la región a las políticas de desarrollo e inclusión social es el presupuesto anual de los Ministerios de Desarrollo Social o la entidad equivalente en relación con el presupuesto público total, aspecto en el que se observa igualmente una alta heterogeneidad, pero con una distribución distinta a la observada en el cuadro II.7. Dicho porcentaje va desde el 1,0\% en Nicaragua y el Uruguay, o el 1,1\% en el Paraguay, hasta el 5,2\% en el Perú y el 6,0\% en la Argentina (véase el cuadro II.8). De acuerdo con esas cifras, el peso presupuestario de esas entidades estaría en un nivel de bajo a moderado, lo que contrasta con la relevancia de sus tareas ${ }^{18}$. Si bien tales montos no reflejan la movilización de recursos de otras instancias ministeriales que actúan en coordinación, sí brindan una idea de su peso relativo dentro del Gobierno central.

\section{Cuadro II. 8}

América Latina y el Caribe (14 países): presupuesto del Ministerio de Desarrollo Social o instancia equivalente como proporción del gasto primario presupuestado, alrededor de $2015^{\mathrm{a}}$

(En porcentajes)

\begin{tabular}{llc}
\hline País & Ministerio de Desarrollo Social o equivalente & Porcentaje \\
\hline Argentina & Ministerio de Desarrollo Social & 6,0 \\
\hline Brasilb $^{b}$ & Ministerio de Desarrollo Social y Lucha contra el Hambre & 3,9 \\
\hline Chile & Ministerio de Desarrollo Social & 1,7 \\
\hline Colombia & Departamento para la Prosperidad Social & 2,4 \\
\hline Costa Rica & $\begin{array}{l}\text { Ministerio de Desarrollo Humano e Inclusión Social, } \\
\text { Instituto Mixto de Ayuda Social (IMAS) }\end{array}$ & 3,3 \\
\hline Ecuador & Ministerio de Inclusión Económica y Social & 3,4 \\
\hline Guatemala & Ministerio de Desarrollo Social & 3,2 \\
\hline Haití & Ministerio de Asuntos Sociales y Trabajo & 3,1 \\
\hline México & Secretaría de Desarrollo Social & 3,2 \\
\hline Nicaragua & Ministerio de la Familia, Adolescencia y Niñez & 1,0 \\
\hline Panamá & Ministerio de Desarrollo Social & 2,7 \\
\hline Paraguay & Secretaría de Acción Social & 1,1 \\
\hline Perú & Ministerio de Desarrollo e Inclusión Social & 5,2 \\
\hline Uruguay & Ministerio de Desarrollo Social & 1,0 \\
\hline $\begin{array}{l}\text { América Latina y el Caribe } \\
\text { (promedio simple) }\end{array}$ & & 2,8 \\
\hline
\end{tabular}

Fuente: Comisión Económica para América Latina y el Caribe (CEPAL), sobre la base de las leyes de presupuesto de los países.

a Los valores corresponden a montos presupuestados, no necesariamente ejecutados.

b El Ministerio de Desarrollo Social y Lucha Contra el Hambre, cambió de nombre en 2016, cuando pasó a denominarse Ministerio de Desarrollo Social y Agrario.

18 Los valores indicados corresponden a una clasificación administrativa y no funcional del gasto social. 
Otro elemento que se debe considerar en esta dimensión es la calidad de los procesos de recolección y difusión de información. Aun cuando se ha avanzado en la incorporación de los enfoques, categorías y procedimientos del análisis funcional del gasto, persiste una heterogeneidad en cuanto a la cobertura institucional y la clasificación de las funciones sociales, así como en lo que respecta a la consideración de los aportes privados, ya sea por cofinanciamiento de atenciones (gasto de bolsillo) o por aporte de fundaciones y organizaciones no gubernamentales (ONG) u otras entidades. Por otro lado, el enfoque analítico todavía es fundamentalmente contable y de control de presupuesto, y se ha avanzado poco hacia la apreciación del gasto como parte integral de la gestión de la política pública y la toma de decisiones ${ }^{19}$.

\section{E. Comentarios finales}

Como se ha indicado en el presente libro, el análisis de las dimensiones jurídico-normativa, organizacional, técnico-operativa y de inversión y financiamiento, es fundamental para el estudio de la institucionalidad social. Al respecto, es importante observar las realidades nacionales, pero también el panorama internacional y regional. En efecto, en años recientes, la agenda sobre desarrollo social en América Latina y el Caribe ha tenido múltiples avances positivos en cuanto a la institucionalidad en todos esos ámbitos, de la mano de distintos procesos de integración, diálogo e intercambio entre los países. Se registra bastante convergencia y complementariedad en los contenidos de las agendas de esa multiplicidad de foros, en especial en una perspectiva orientada a la superación de la pobreza y las desigualdades sociales desde un enfoque de derechos. Además, predomina la concepción de la pobreza como un fenómeno multidimensional que requiere ser abordado a través de políticas sociales integrales. Esto es fundamental, pues implica compartir elementos conceptuales para definir una agenda social coherente a nivel de la región. Por otro lado, en la agenda de esos foros está presente (de forma más o menos explícita) la concepción de que los procesos de integración regional pueden contribuir a una mayor igualdad e inclusión social.

19 Para mejorar estos sistemas de medición deben articularse las propuestas metodológicas del Manual de estadísticas de finanzas públicas del Fondo Monetario Internacional (FMI) con el Sistema de Cuentas Nacionales, en la línea de las cuentas satélite, e incluir la información de costos e inversión como parte integral del sistema de análisis de la gestión social, articulada con la información social, con miras a potenciar la racionalidad en la toma de decisiones hacia la maximización de los impactos y la eficiencia en el uso de los recursos (Martínez y Collinao, 2010; Martínez, 2015). 
Dichas temáticas son compatibles con las orientaciones principales que ha tomado la Agenda 2030 para el Desarrollo Sostenible, lo que ayudará a coordinar el monitoreo de las nuevas prioridades a nivel regional. Por otro lado, también hay temas específicos que destacan en la agenda de algunas instancias, lo que amplía su diversidad.

Con respecto a la institucionalidad social a nivel de cada país, la coordinación y articulación intersectorial persiste como un ámbito que requiere mayor desarrollo para promover una gestión sistémica e integrada de las políticas sociales en la región. Esta necesidad responde a las características de multidimensionalidad de los fenómenos sociales y la especialización temática de los sectores (por ejemplo, en ministerios de salud, educación, desarrollo social, trabajo y vivienda). También tiene que ver con especificidades de los diversos segmentos poblacionales atendidos, relacionadas con el ciclo de vida o con características y determinantes de género, raza, etnia o condición de discapacidad.

Otro desafío organizacional es la articulación vertical entre distintos niveles de gobierno (central, subnacional y local), así como la consolidación y ampliación de los mecanismos de consulta y participación. Avanzar en estos elementos es fundamental para el diseño e implementación de políticas realmente integrales y participativas.

En materia de gestión, los países de la región han mostrado avances importantes en cuanto a modelos e instrumentos. Ello se refleja en la expansión de reglamentos de programación y sistemas de registro de participantes, así como en la incorporación de procesos de diseño y evaluación ex ante, monitoreo y evaluación de impacto de programas. Esto representa un avance auspicioso en lo que se refiere a la efectividad, eficiencia, transparencia y sostenibilidad de las políticas sociales. Sin embargo, subsisten desafíos importantes, como la evaluación a nivel del conjunto de la política (no solo de programas), la expansión de los conocimientos y técnicas entre quienes gestionan la política y el desarrollo de un mayor número de mecanismos de rendición de cuentas, más claros y con participación de distintos actores, entre otros.

Además, se requiere avanzar en cuanto a la garantía de recursos suficientes y estables para enfrentar los desafíos de la política social, en particular la referente a la protección social de la población en situación de pobreza e indigencia. En ese proceso, la identificación de alternativas vinculadas con reglas fiscales que favorezcan la política social y la asociación de esta con iniciativas de "reforma fiscal verde" se perfilan como posibles caminos de acción. 
Una mirada a la institucionalidad de la protección social no contributiva muestra un panorama diverso, pero con desafíos comunes. En general, se observa la necesidad de coherencia y articulación entre los modelos de institucionalidad y las estructuras ministeriales y programáticas existentes, así como de estas con los múltiples actores que participan en sistemas de protección social hoy más complejos que en el pasado. Por ejemplo, la rectoría de los programas de transferencias monetarias y de las pensiones sociales no siempre radica en las entidades que tienen el mandato formal de combatir la pobreza o promover la protección social, lo que implica necesariamente una mayor coordinación. Otro desafío es balancear el objetivo de promover la protección social para todas las personas, con la atención y visibilización de necesidades particulares de distintos segmentos de población, en lo que confluyen diversas entidades gubernamentales. Así, un desafío central en materia institucional es la coordinación intersectorial entre las diversas áreas de la política de protección social, entre los componentes contributivos y no contributivos y los sistemas de cuidado, y entre entidades con mandatos generales y las que tienen mandatos específicos.

En síntesis, los países de la región han hecho avances significativos en materia de institucionalidad social, lo que augura mejoras sustantivas en la calidad, efectividad, eficiencia, transparencia y sostenibilidad. En esa área no existe un modelo único deseable, sino desafíos importantes que deben acometerse, entre los que se cuentan:

- Consolidar una base jurídico-normativa que dé sostenibilidad a la política social como política de Estado y posibilite avanzar hacia objetivos más estructurales y de largo plazo que sobrepasen el alcance de los períodos de gobierno.

- Fortalecer la capacidad de coordinación y articulación de las políticas de superación de la pobreza con las políticas de protección social entendidas de forma integral, con otras áreas de la política social (educación, salud, trabajo, vivienda) y con el ámbito económico, de infraestructura y de desarrollo productivo. Esta necesidad se origina en la multidimensionalidad de los fenómenos de la pobreza, la desigualdad y el desarrollo social. También responde a la especialización temática de los sectores, a lo que se suma la necesidad de atender características poblacionales particulares, según etapas del ciclo de vida, sexo, raza, etnia y discapacidad. 
- Mejorar la capacidad de articulación y cooperación entre los niveles de gobierno central, regional y local, con énfasis en aquellos particularmente débiles y emplazados en las zonas más pobres, y desarrollar instancias de participación de las poblaciones destinatarias de la política y de sus organizaciones, así como de actores privados relevantes. La heterogeneidad en cuanto a capacidad técnica y recursos (físicos, humanos y financieros) de los niveles subnacionales también es un reto relevante a acometer, debido a que esos aspectos tienden a ser más débiles en las zonas que se encuentran más distantes del Gobierno central y presentan mayores niveles de pobreza.

- Profundizar la capacidad de la gestión pública en materia social, mediante la formalización de procedimientos que abarquen desde la definición de planes hasta la evaluación de sus resultados, así como la disponibilidad de información confiable y oportuna para guiar la toma de decisiones con el fin de maximizar los impactos y la eficiencia.

- Disponer de recursos suficientes para atender las necesidades de una política social de calidad, transformando la idea de gasto corriente en la de inversión social, y mejorando su registro y divulgación, tanto en lo referente al financiamiento como a la ejecución.

Por último, deben promoverse espacios de acuerdo y pactos sociales y políticos amplios orientados hacia la concreción de objetivos superiores, como los establecidos en la Agenda 2030 para el Desarrollo Sostenible (CEPAL, 2015). Estos acuerdos son un sustrato clave para institucionalizar y legitimar en el transcurso del tiempo las nuevas políticas de protección social. Junto al acuerdo social y político, se requiere avanzar en cuanto al logro de un pacto fiscal que asegure recursos suficientes y estables para concretar los objetivos de erradicación de la pobreza, garantía de derechos y disminución sustantiva de la desigualdad social en América Latina y el Caribe. 


\section{Bibliografía}

Cecchini, S. y R. Martínez (2011), Protección social inclusiva en América Latina: una mirada integral, un enfoque de derechos, Libros de la CEPAL, N 111 (LC/G.2488-P), Santiago, Comisión Económica para América Latina y el Caribe (CEPAL).

CEPAL (Comisión Económica para América Latina y el Caribe) (2015), Desarrollo social inclusivo: una nueva generación de politicas para superar la pobreza y reducir la desigualdad en América Latina y el Caribe (LC/L.4056(CDS.1/3)), Santiago.

Cunill-Grau, N., F. Repetto y C. Bronzo (2015), "Coordinación pro integralidad de las instituciones de protección social", Instrumentos de protección social: caminos latinoamericanos hacia la universalización, Simone Cecchini y otros (eds.), Libros de la CEPAL, N 136 (LC/G.2644-P), Santiago, Comisión Económica para América Latina y el Caribe (CEPAL).

Dabène, O. (2012), “Explaining Latin America's fourth wave of regionalism: regional integration of a third kind", documento presentado en el Congreso Internacional de la Asociación de Estudios Latinoamericanos (LASA), San Francisco, mayo.

FMI (Fondo Monetario Internacional) (2014), Manual de estadísticas de finanzas públicas 2014, Washington, D.C.

Franco, R. y M. Székely (2010), "Institucionalidad social en América Latina", Documentos de Proyectos (LC/W.312), Santiago, Comisión Económica para América Latina y el Caribe (CEPAL).

Martínez, R. (2015), "Monitoreo y evaluación de políticas de protección social", Instrumentos de protección social: caminos latinoamericanos hacia la universalización, S. Cecchini y otros (eds.), Libros de la CEPAL, N 136 (LC/G.2644-P), Santiago, Comisión Económica para América Latina y el Caribe (CEPAL).

Martínez, R. y M. P. Collinao (2010), “Gasto social: modelo de medición y de análisis para América Latina y el Caribe", Manuales, N 65 (LC/L.3171-P), Santiago, Comisión Económica para América Latina y el Caribe (CEPAL).

OPS/OMS (Organización Panamericana de la Salud/Organización Mundial de la Salud) (2015), Intersectorialidad y equidad en salud en América Latina: una aproximación analítica, Washington, D.C.

Repetto, F. y F. Potenza (2015), “Documento final de consultoría. Institucionalidad social y autoridad social en América Latina y el Caribe: abordaje conceptual, avances y desafíos de la institucionalidad de la políticas social y de la protección social", inédito. 


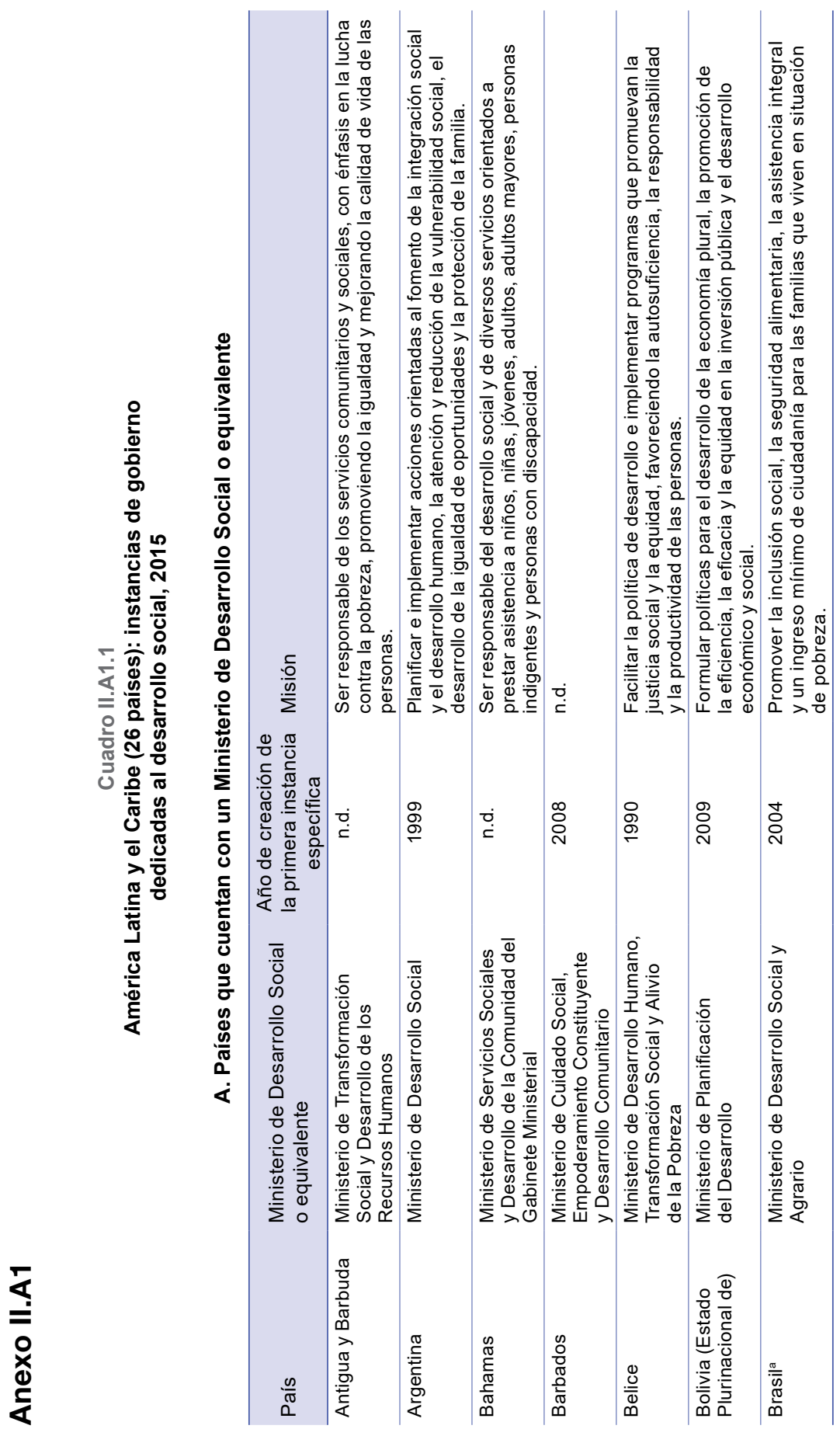




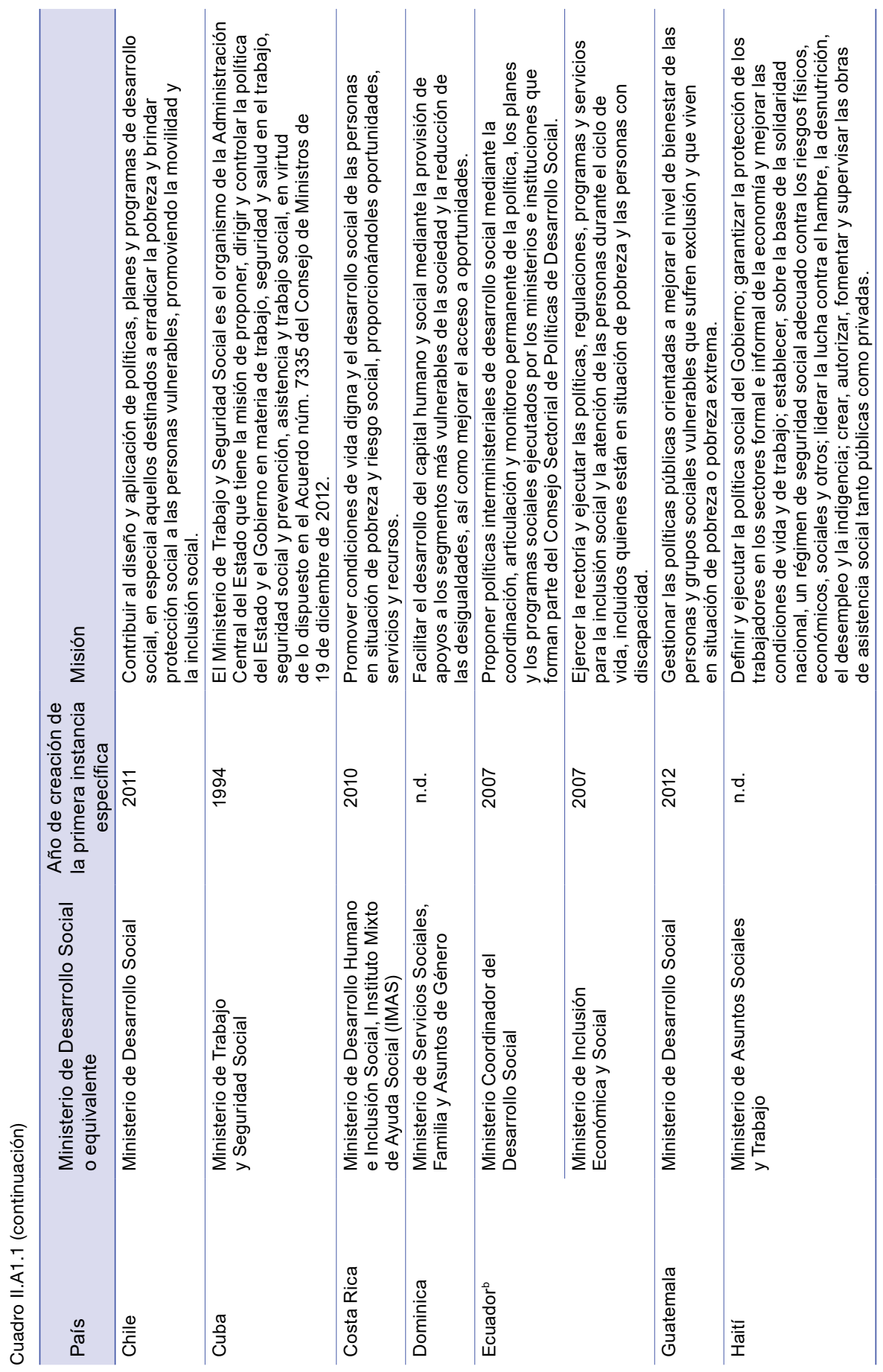




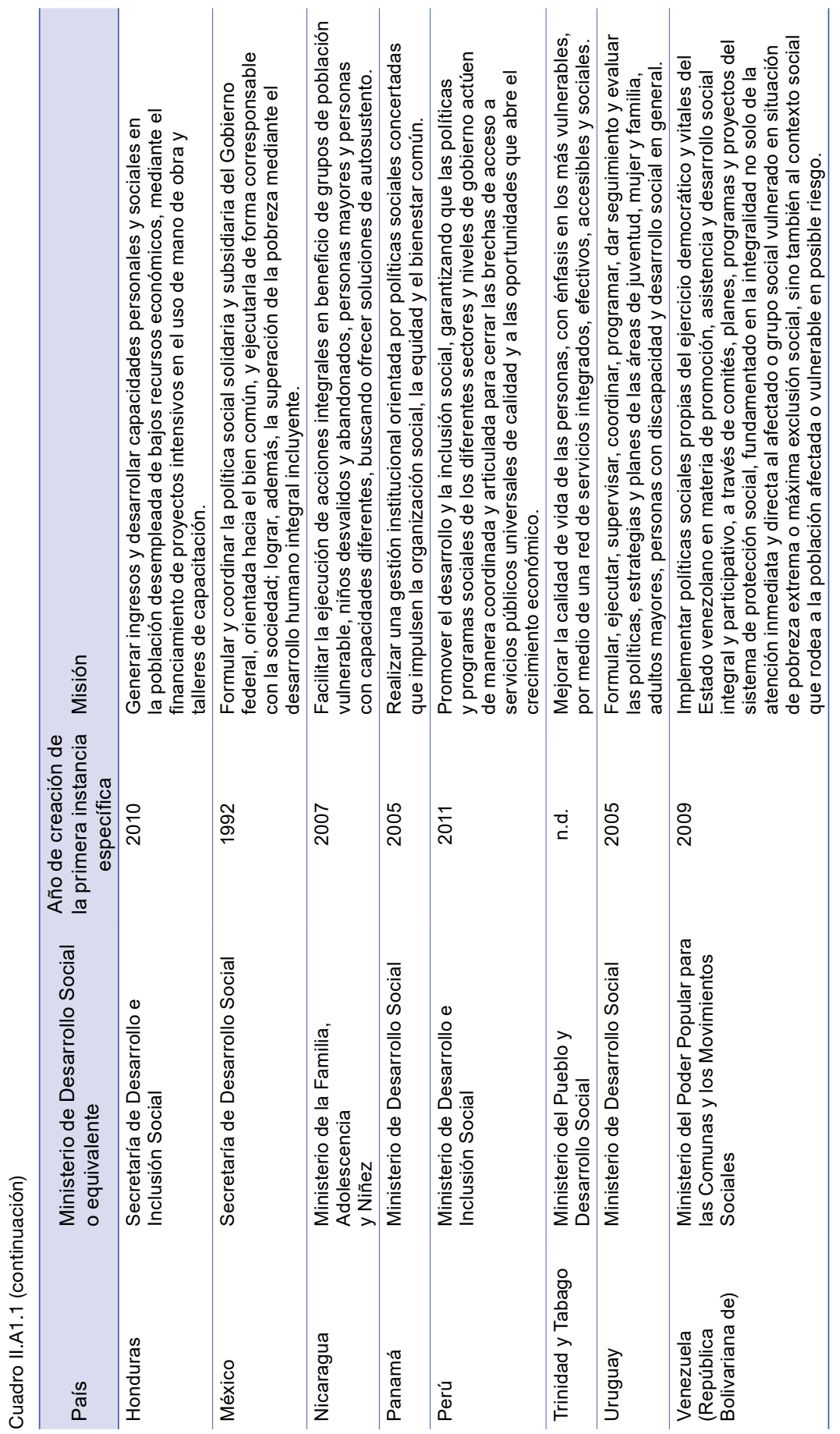




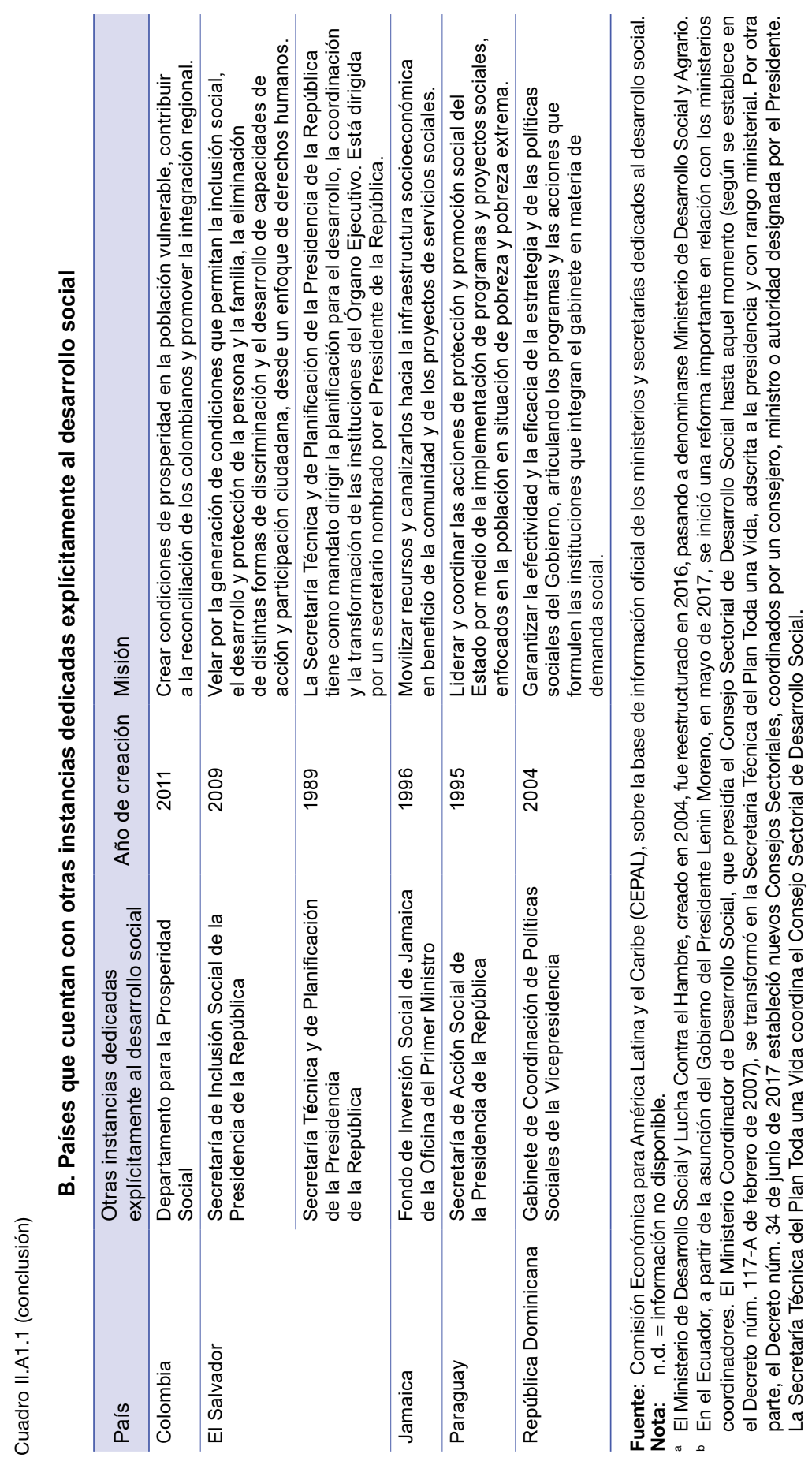




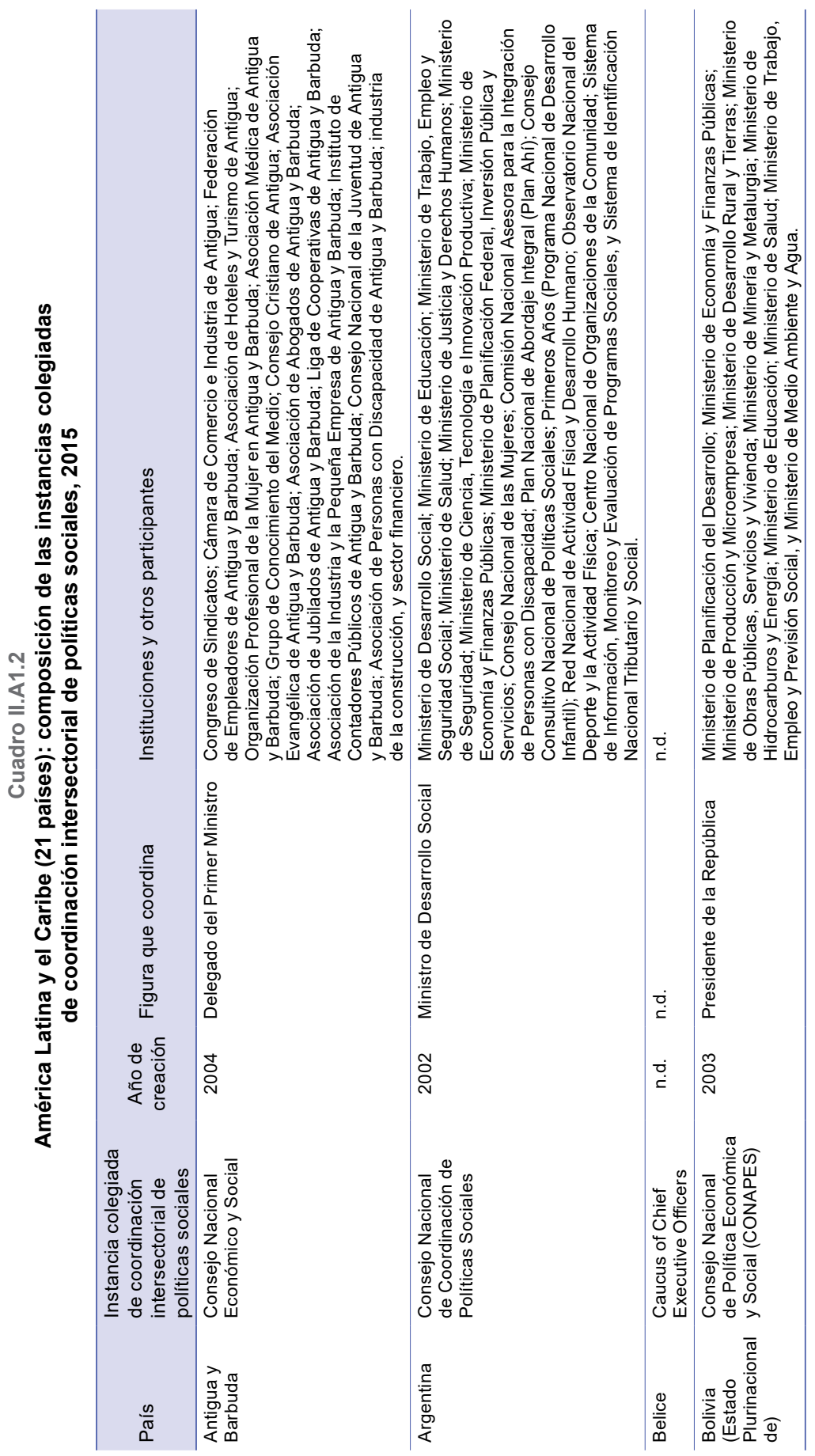




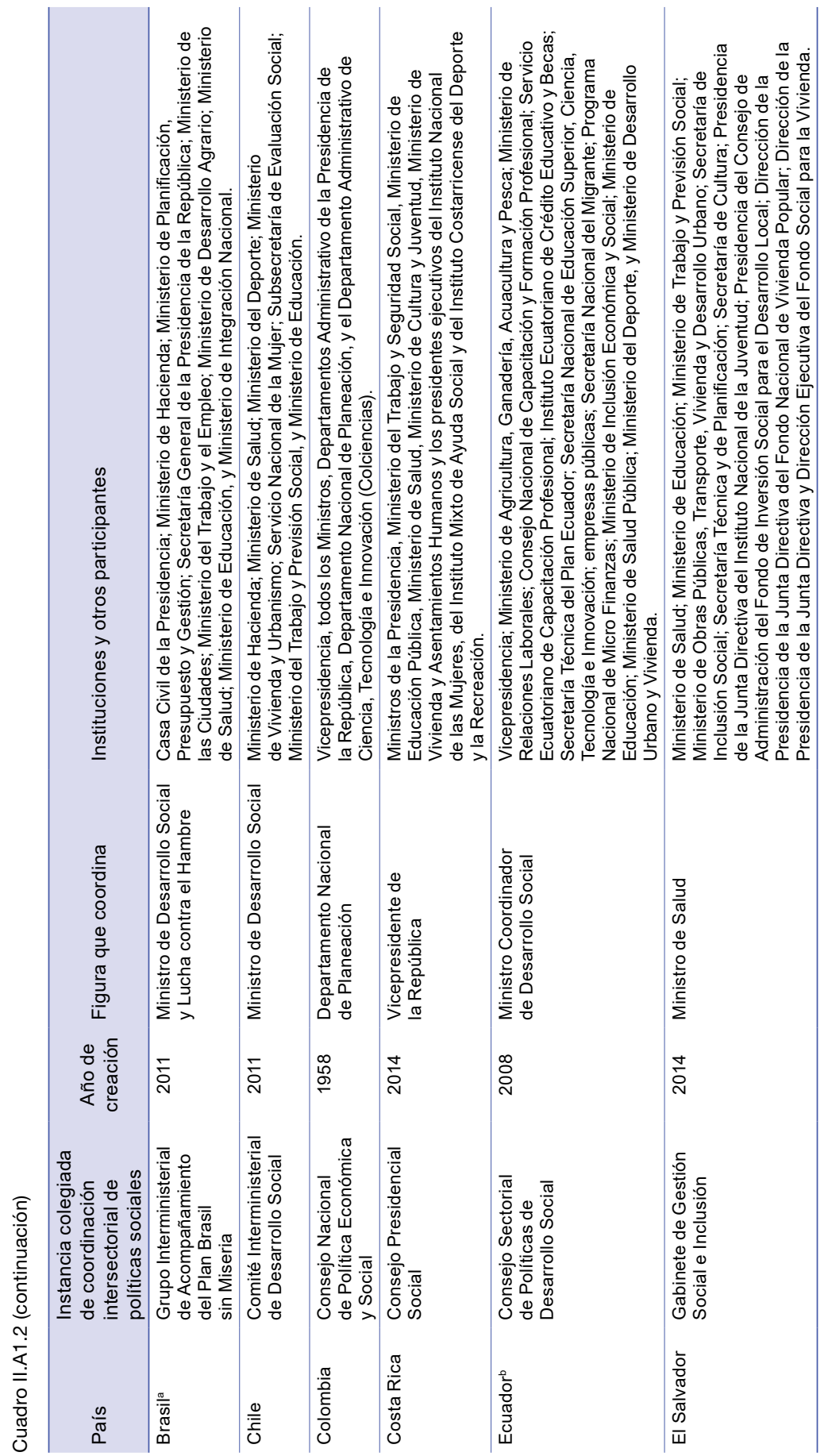




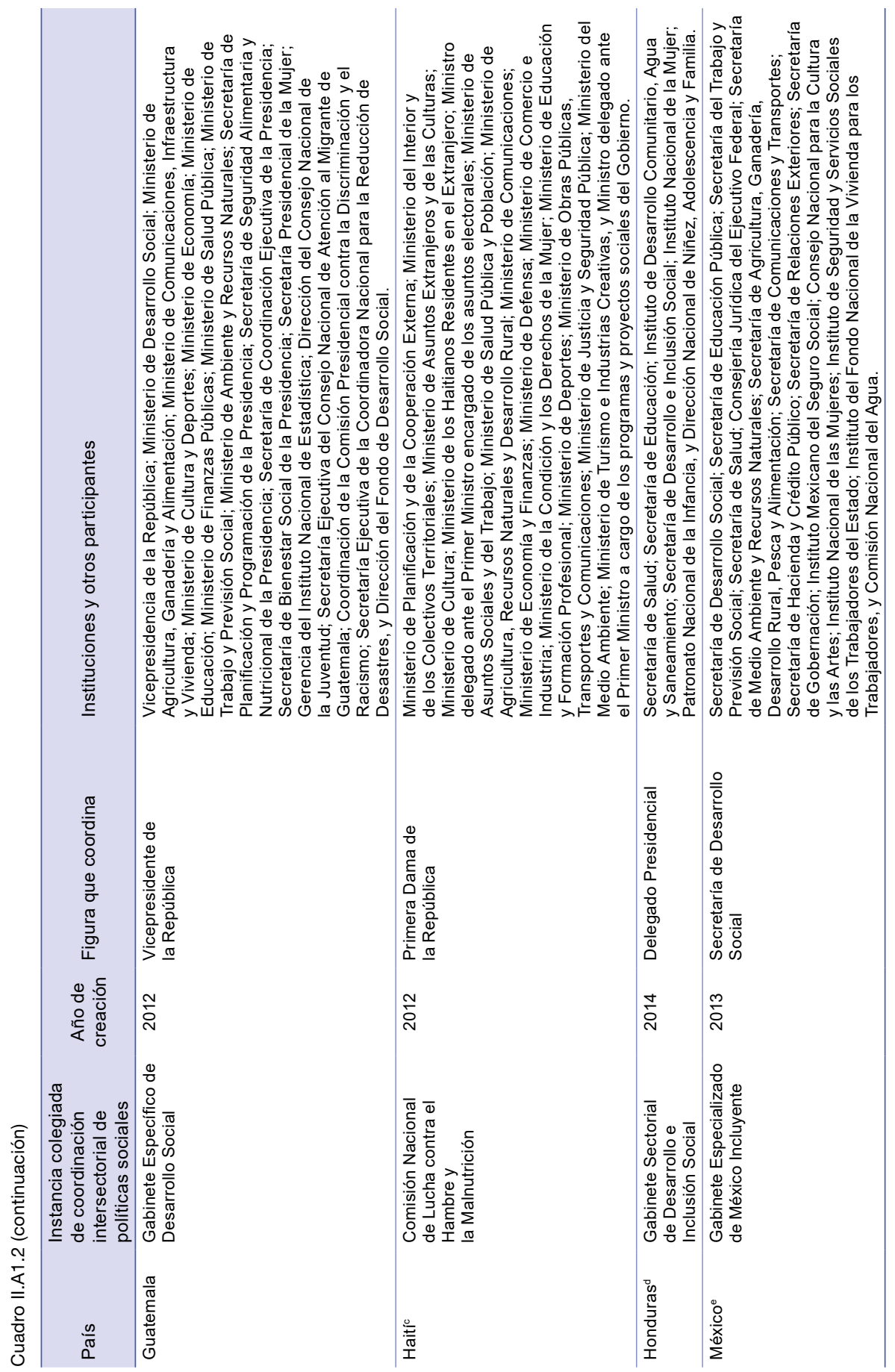




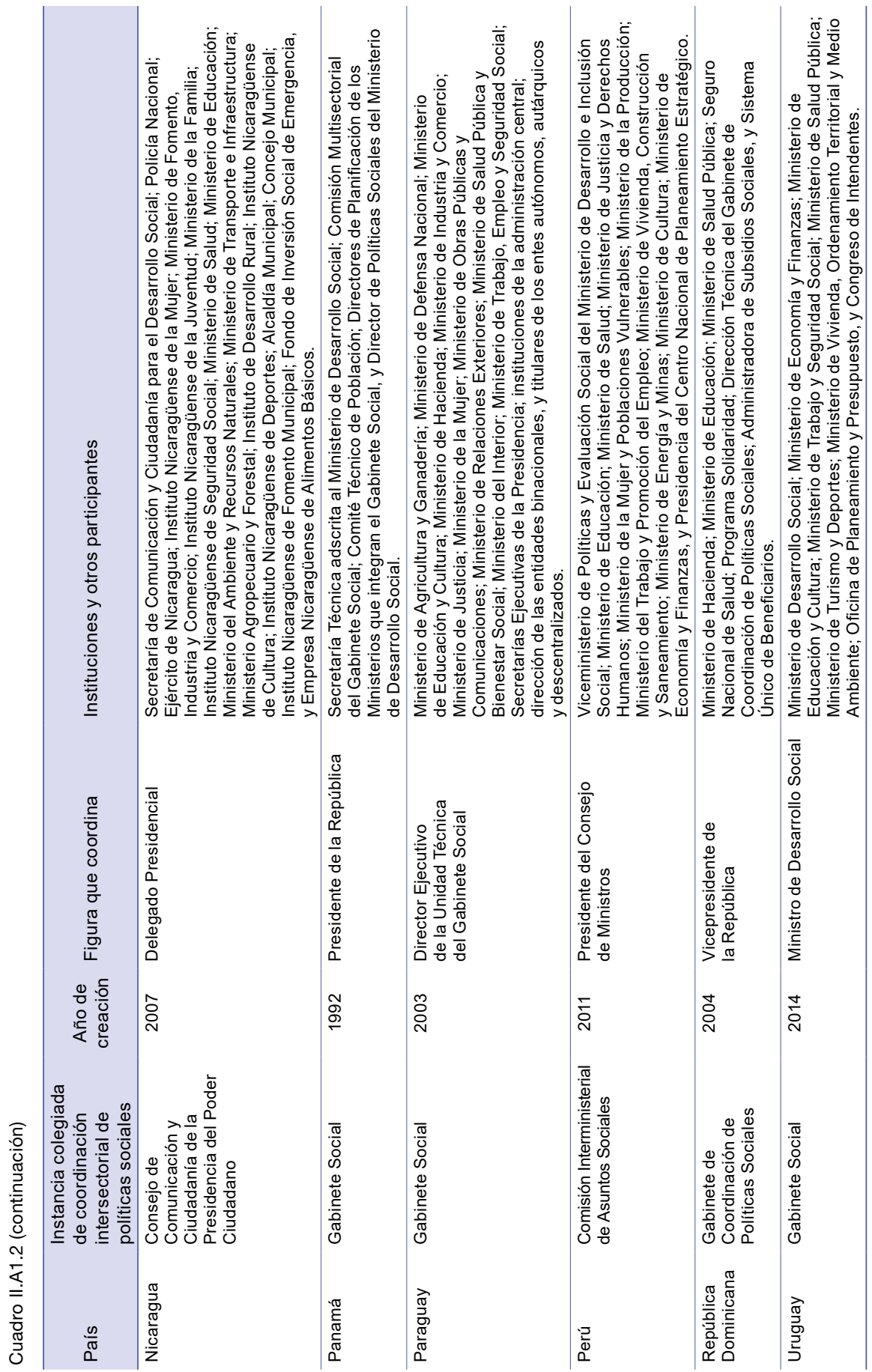




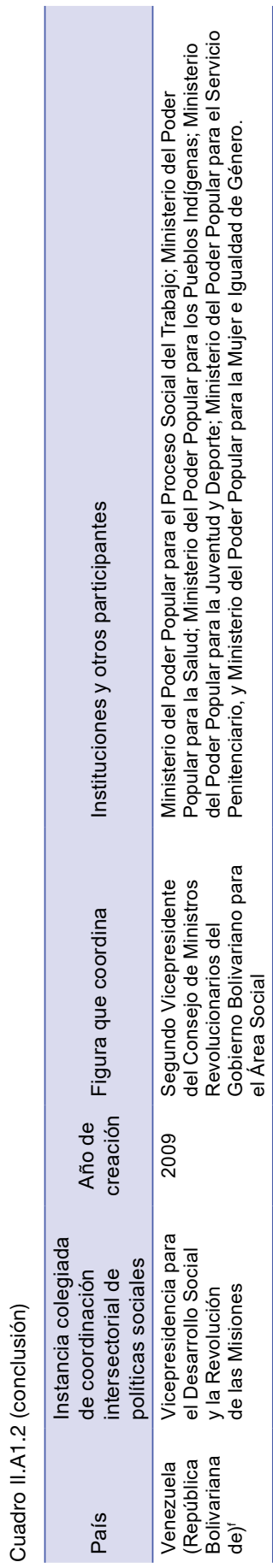

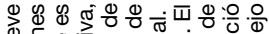

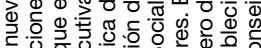
휴.

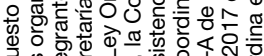
을뜨 至

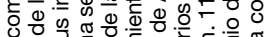
तथ क

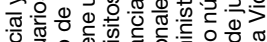

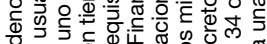

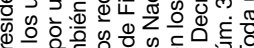

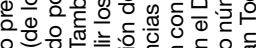

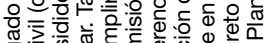
ठ্তু

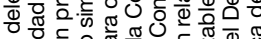

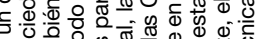
万人

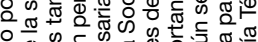
응

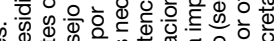

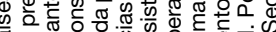
ळึं

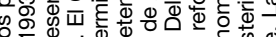

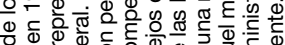

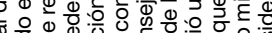
인

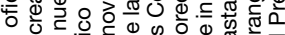

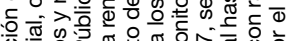

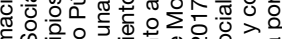

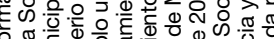

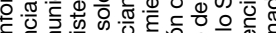

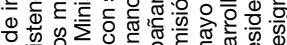

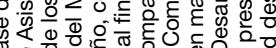
ฮ

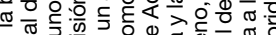

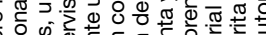

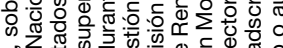
乙

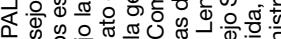
嵓

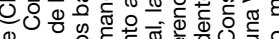

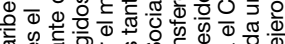
ర ब. ๙

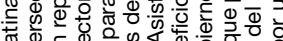

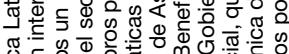
ฮ్

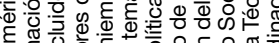
远产.

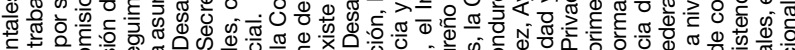

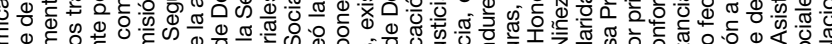

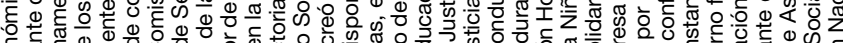

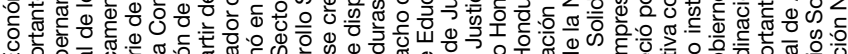

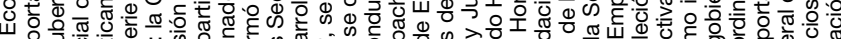

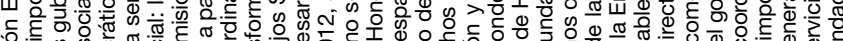

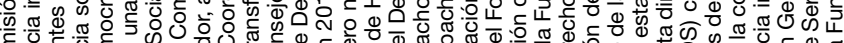

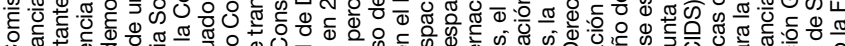

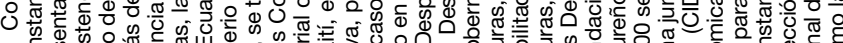

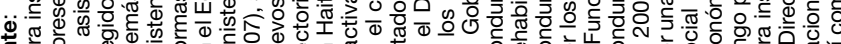

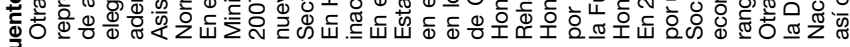


Parte 2

Componentes de la protección social y su institucionalidad 



\section{Capítulo III \\ Regulación del mercado de trabajo y protección social: desafíos institucionales}

Mario D. Velásquez Pinto ${ }^{1}$

\section{Introducción ${ }^{2}$}

En este capítulo se hace un análisis de la institucionalidad de las regulaciones laborales como un componente de la protección social. Es decir, del conjunto de normas y acciones destinado a proteger el trabajo decente y facilitar la protección social de los trabajadores y sus dependientes.

Se comienza por la discusión sobre el papel de las regulaciones laborales y las propuestas y medidas destinadas a otorgar flexibilidad a los mercados de trabajo en la región (mediante la desregulación de los años ochenta y noventa), así como sus efectos negativos en la calidad del empleo y el aumento de la desprotección y la pobreza. A partir de ello, se ha revalorizado el papel de las regulaciones laborales como componentes de la protección social, en conjunto con la elaboración de políticas activas destinadas a perfeccionar el funcionamiento de los mercados de trabajo y fortalecer la inserción laboral productiva.

Consultor de la División de Desarrollo Social de la Comisión Económica para América Latina y el Caribe (CEPAL).

2 Este capítulo se basa en el documento "Regulación del mercado de trabajo y protección social en países de América Latina", elaborado por Mario Velásquez, con la colaboración de Fabiana Pierre y Matías Salces, Asistentes de Investigación de la División de Desarrollo Social de la CEPAL (véase Velásquez, 2016). 
En la segunda sección se examina el alcance de la relación entre las regulaciones laborales como componentes de la protección social. En la tercera se presenta una propuesta de análisis basada en el rol de las normas laborales para proteger a los trabajadores ante un conjunto de riesgos que surgen durante el ciclo de vida, tanto en la etapa previa a la vida activa como en la de participación en la fuerza de trabajo y en la vejez. Respecto de cada etapa y cada riesgo identificado, se indican regulaciones laborales específicas.

En la cuarta sección se intenta verificar la existencia de las normas y sus contenidos a nivel de cada país. Para ello se recurre sobre todo a tres fuentes principales: la ratificación de los convenios internacionales de la Organización Internacional del Trabajo (OIT), las garantías nacionales fundamentales expresadas en las respectivas constituciones y los códigos del trabajo.

En la quinta parte del capítulo se examina el diseño institucional dispuesto para velar por el cumplimiento de las normas. Se consideran el diseño y las funciones básicas de los ministerios de trabajo, así como las características de las vías judicial y administrativa. En este último caso, se presenta además una descripción de los sistemas, sus funciones y su fortaleza institucional, a partir de un conjunto de indicadores. Se culmina con el análisis de indicadores de resultados, que informan acerca del grado de protección existente frente a los riesgos antes descritos.

El apartado final contiene reflexiones sobre los logros alcanzados y los desafíos que se presentan en los países de América Latina para avanzar hacia una institucionalidad fortalecida que contribuya a la sostenibilidad y la eficacia de la regulación del mercado laboral, como componente central para universalizar el trabajo decente y la protección social en la región.

\section{A. Regulaciones laborales y flexibilidad laboral en América Latina ${ }^{3}$}

Las regulaciones del mercado de trabajo, y su efectivo cumplimiento, son factores decisivos para que las relaciones laborales se desarrollen en condiciones de libertad, igualdad, seguridad y dignidad humana. Estos son los atributos en que se basa la OIT para definir el trabajo decente y sirven de referencia para el establecimiento de estándares internacionales en la materia.

\footnotetext{
En este estudio solo se hace referencia al trabajo remunerado y sus regulaciones. Se excluye del análisis el trabajo no remunerado, es decir, la producción de bienes y servicios realizada por los miembros del hogar para la que no se dispone de valoración de mercado, pero que contribuye al bienestar familiar y social. Algunas de estas actividades se relacionan con las propias necesidades de la familia, como el cuidado de niños y adultos, la cocina, la jardinería y el mantenimiento del hogar, o la atención a otras personas, por ejemplo, amigos que estén de visita o parientes que vivan fuera del hogar.
} 
En las últimas décadas, se ha cuestionado en la región el papel y la efectividad de tales regulaciones. Esto sucedió sobre todo en los años noventa, debido a la creencia de que los procesos de liberalización de las economías para facilitar el comercio de bienes y servicios y los flujos financieros internacionales requerían mayor flexibilidad salarial $\mathrm{y}$ movilidad laboral (Banco Mundial, 1995).

Con el fin de facilitar la reestructuración y el ajuste a medida que los países se abrían a una mayor competencia e integración en la economía mundial, se consideró necesario modificar las regulaciones en los ámbitos de las relaciones laborales individuales y colectivas, así como en el de las contribuciones sociales y demás gravámenes aplicados sobre los salarios. Se presuponía que estos producían efectos negativos al favorecer a quienes tenían buenos trabajos, en detrimento de los desempleados y los trabajadores de la economía informal. La flexibilidad del mercado de trabajo se entendía como un factor clave para el éxito de las reformas que anticipaban el crecimiento de la región ${ }^{4}$.

Vega Ruiz (2005) determinó que 11 de 17 países latinoamericanos analizados habían implantado reformas laborales favorables a la flexibilidad entre 1990 y 2005. Las reformas más profundas se habían realizado en la Argentina y el Perú, seguidos de otros cuatro países (Brasil, Colombia, Ecuador y Panamá), donde fueron importantes, aunque menos amplias. En otros cinco países (Chile ${ }^{5}$, Guatemala, Nicaragua, República Dominicana y Venezuela (República Bolivariana de)) las reformas fueron de menor magnitud.

Ello se vio complementado con cambios en las políticas de protección social de base contributiva. Una de las áreas privilegiadas de intervención, bajo este enfoque, fue la de pensiones (véase el capítulo IV). En efecto, el Banco Mundial alentó su privatización y la conformación de un sistema multipilar, en que se debía considerar un componente constituido por planes de ahorro, de carácter obligatorio, financiados íntegramente por los cotizantes y gestionados por empresas privadas (Banco Mundial, 1994). Se esperaba que este tipo de sistema alentara el crecimiento económico, el desarrollo de los mercados de capitales y de la inversión y, con ello, el empleo productivo, base indispensable a su vez para el desarrollo de los sistemas contributivos de seguridad social.

En cuanto a los resultados obtenidos, Fraile (2009) sostiene que tales políticas sociolaborales casi nunca produjeron los frutos previstos. La flexibilización laboral, la descentralización de la negociación colectiva,

$4 \quad$ Véanse Lora y Pagés (1997); Edwards y Lustig (1997); Heckman y Pagés (2000 y 2004); Kuczynski y Williamson (2003); Singh y otros (2005), citados por Fraile (2009).

5 En Chile, los cambios se realizaron con anterioridad al período del estudio citado, sobre todo mediante el Plan Laboral de 1979. Desde 1990, los Gobiernos democráticos han ido cambiando parcialmente sus disposiciones. 
la privatización de las pensiones y el peso creciente del mercado en la provisión de bienestar social causaron, a menudo, un aumento de la informalidad y de las desigualdades y una reducción de la protección social, sin estimular el empleo.

El comportamiento del mercado de trabajo no mejoró de manera significativa tras las reformas, por lo que no se cumplió la expectativa de que la liberalización incrementaría la demanda de mano de obra (Berg, Ernst y Auer, 2006). En cambio, la inestabilidad laboral aumentó en la región durante los años noventa, pues la antigüedad media en los puestos de trabajo disminuyó hasta situarse en 7,6 años a finales del decenio, mientras que en los países de la Organización de Cooperación y Desarrollo Económicos (OCDE) ascendía a 10,5 años (Tokman, 2007).

No obstante, la flexibilidad salarial también era elevada en América Latina entre 1980 y 2000. En el conjunto de la región, la participación de los salarios en el producto interno bruto (PIB) descendió en 13 puntos porcentuales entre 1990 y 2005 (IIEL, 2008).

El desempleo abierto fluctuó, aunque con tendencia ascendente, sobre todo después de las crisis económicas periódicas que se registraron en la segunda mitad de la década de 1990. El problema principal radicó en la baja calidad de los puestos de trabajo creados. Entre 1990 y 2003, seis de cada diez personas ocupadas trabajaban en la economía informal y solo cinco de cada diez nuevos asalariados cotizaban a la seguridad social (OIT, 2004). Ello puso en evidencia que las medidas de flexibilidad laboral no parecían haber resultado eficaces para reducir la informalidad.

$\mathrm{Al}$ considerar las tendencias registradas en los mercados de trabajo, no resultó extraño que la privatización de los sistemas de pensiones no lograse ampliar la cobertura de seguridad social como se anticipaba. Dicha cobertura, medida como porcentaje de cotizantes activos respecto de la fuerza de trabajo, se había reducido para el año 2002 en los 12 países latinoamericanos que habían comenzado a renovar sus sistemas de pensiones en el decenio de 1980 (Mesa-Lago, 2004). Esta experiencia mostró, además, que la precariedad y la inestabilidad del empleo ponen en peligro la capacidad de los trabajadores de acumular cotizaciones suficientes para tener derecho a una pensión mínima al llegar a la jubilación (véase el capítulo IV).

Al final de los años considerados, se pudieron constatar los escasos avances en la reducción de la pobreza y en la desigualdad de los ingresos. La pobreza en América Latina se redujo de un 48,3\% en 1990 a un $44 \%$ en 2002, pero se mantuvo por encima del $40,5 \%$ de 1980 . En términos absolutos, respecto de 1980, la población bajo la línea de la pobreza había aumentado en 120 millones de habitantes (CEPAL, 2009). A su vez, la desigualdad de ingresos se profundizó en los años noventa, cuando se situó muy por encima del promedio internacional. 
La experiencia descrita pone de manifiesto la importancia de las regulaciones laborales como componente fundamental de la protección social. En efecto, la desregulación de las normas laborales como vía para aumentar la flexibilidad de los mercados de trabajo contribuyó a la precarización de los empleos. Ello afectó el potencial de incremento de la productividad asociada a ocupaciones estables y en condiciones de trabajo decente, y contribuyó a que se redujeran los niveles de protección social de los trabajadores y de sus dependientes.

La flexibilidad laboral incluye dos dimensiones: i) la del mercado de trabajo, y ii) la del trabajo como factor productivo (Amadeo y Camargo, 1993). La primera puede entenderse como la capacidad de la economía o del mercado de trabajo de retomar una posición óptima de equilibrio después de un choque exógeno o frente a cambios en sus condiciones. Por tanto, alude a la facilidad para ajustar las dotaciones de personal de las empresas o para que los trabajadores se trasladen de un segmento a otro del mercado (flexibilidad externa). También alude a la adaptación de la organización del trabajo (flexibilidad interna), que incluye la capacidad de realizar diversas tareas, el ajuste de las remuneraciones y la redistribución de los tiempos de trabajo, entre otros factores. La segunda, en cambio, se refiere a la adaptabilidad del propio trabajador, y depende del grado de adaptación de su capital humano y de su potencial de crecimiento de productividad.

Entre los tipos de flexibilidad señalados existen interdependencias que es necesario considerar. Por ejemplo, en economías que presentan alta flexibilidad de los salarios y del empleo, tienden a predominar contratos de trabajo por tiempos limitados, el desempleo es más frecuente y los salarios suelen variar ampliamente a lo largo del ciclo, todo lo cual afecta la estabilidad laboral y la calidad del trabajo. En cambio, los contratos de trabajo prolongados contribuyen al aumento de la productividad, ya sea mediante incentivos de promoción y buenas condiciones de trabajo, o de carácter pecuniario, vinculados al desempeño, así como oportunidades de entrenamiento.

En definitiva, de lo anterior se derivan dos conclusiones principales. La primera es que es posible deducir que existe un nivel óptimo de flexibilidades deseables, ciertamente menor que el máximo de flexibilidad posible. La experiencia comentada es elocuente al respecto. En segundo término, aquel nivel óptimo de flexibilidades requiere un marco de regulaciones laborales que, de manera simultánea, contribuyan a un funcionamiento eficiente de los mercados de trabajo y de la promoción del trabajo decente. A fin de lograr dicho equilibrio se requieren regulaciones laborales adecuadas que garanticen la protección de los derechos económicos y sociales de los trabajadores para enfrentar los cambios. Con ello se aseguraría el acceso a la protección social ante los riesgos propios que el trabajador enfrenta tanto en su vida activa como con posterioridad a ella, lo que también beneficiaría a sus dependientes en las etapas previas a su inserción en los mercados de trabajo. 


\section{B. Regulaciones laborales y protección social}

La protección social tiene por objeto garantizar un ingreso que permita mantener niveles mínimos de calidad de vida, acceder a servicios sociales y de promoción, y universalizar el trabajo decente. De acuerdo con Cecchini y Martínez (2011), para el logro de tales objetivos se deben considerar tres componentes principales: i) la protección social no contributiva (asistencia social); ii) la protección social contributiva (seguridad social), y iii) la regulación de los mercados laborales. Esta última se entiende como el conjunto de normativas y estándares orientados a fomentar y proteger el trabajo decente.

La inclusión de las regulaciones de los mercados de trabajo como componente de la protección social permite incorporar la protección de los derechos individuales y colectivos de los trabajadores como un elemento crítico en la reducción y mitigación de los riesgos asociados con el déficit de trabajo decente (Barrientos y Hulme, 2008). Ese déficit caracteriza a la región, y las políticas de protección social contributiva y no contributiva buscan resolverlo.

Sin embargo, es necesario tener en cuenta que las regulaciones del mercado laboral en América Latina cubren solo a un segmento de la población en edad de trabajar, ya que la incidencia de la informalidad en el empleo es significativa y abarca a algo menos de la mitad de los trabajadores no agrícolas, como se ilustra en el gráfico III.1 ${ }^{6}$. Esto constituye una barrera estructural en términos de la aplicación efectiva de las normas laborales en la región y del alcance de la protección que de ellas se deriva.

El informe (OIT, 2014) se refiere al empleo informal no agrícola. El empleo informal en la agricultura presenta particularidades que es necesario analizar con detalle. $\mathrm{Al}$ respecto, en $\mathrm{La}$ medición de la informalidad: Manual estadístico sobre el sector informal y el empleo informal, de 2013, la OIT sostiene: “La mayoría de los países excluyen las actividades agrícolas y afines del ámbito de las estadísticas del sector informal pero algunos países las incluyen. La resolución de la $15^{\text {a }} \mathrm{CIET}$ reconoció que, desde un punto de vista conceptual, esas actividades deberían incluirse en el ámbito del sector informal si las realizan empresas de hogares y si cumplen con los criterios de la definición del sector informal. Por razones prácticas vinculadas con la recolección de datos, sin embargo, la resolución de la $15^{\text {a }}$ CIET (OIT, 1993a, párrafos 16 y 20) aceptó la opción de excluir las actividades agrícolas y afines del ámbito de las encuestas del sector informal y realizar una medición por separado. El razonamiento fue que la mayoría de los países en desarrollo tienen un gran sector agrícola, principalmente compuesto de pequeñas empresas de hogares no registradas, y que la inclusión de dichas empresas en las encuestas del sector informal conduciría a una considerable expansión de las operaciones y al aumento de los costos de las encuestas. Además, muchas oficinas nacionales de estadísticas ya tienen establecido un sistema de encuestas agrícolas cuya cobertura incluye (o puede extenderse para incluir) empresas de hogares no constituidas en sociedad, dedicadas a las actividades agrícolas y afines". Por otra parte, hay que considerar que, si bien no todas las actividades rurales son agrícolas, la mayoría de estas últimas son rurales. 
Gráfico III.1

América Latina (14 países): empleo informal no agrícola, 2009 y 2011-2015 (En porcentajes)

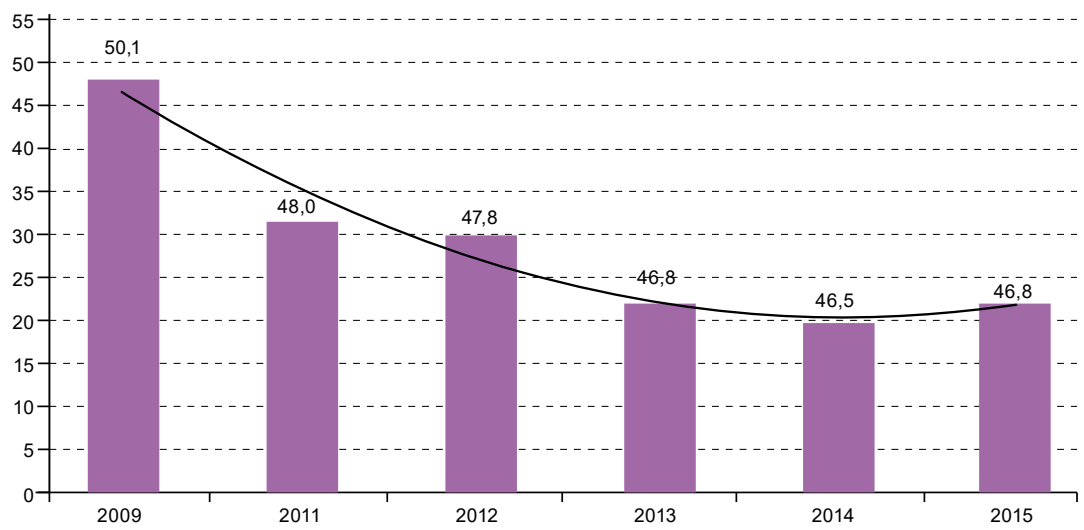

Fuente: Organización Internacional del Trabajo (OIT), Panorama Laboral 2016. América Latina y el Caribe, Lima, Oficina Regional para América Latina y el Caribe, 2016.

Según la OIT (2016), la proporción de empleo informal (respecto del empleo total no agrícola) disminuyó en el período 2009-2014, al pasar de un $50,1 \%$ a un $46,5 \%$, debido a un escenario económico favorable y a la aplicación de un conjunto de políticas específicas en los países de la región. No obstante lo anterior, se observa una reversión de la tendencia en 2015, año en que repunta hasta alcanzar un $46,8 \%$. Este porcentaje fue similar al registrado en 2013, con lo que al menos unos 133 millones de trabajadores se encontraban en la informalidad en 2015. Si se tiene en cuenta que la tendencia a la desaceleración de las economías de la región ha persistido (y en algunos casos se han registrado caídas), es muy probable que la tasa de empleo informal se haya incrementado nuevamente en 2016.

Respecto de las características de los trabajadores informales, según la OIT (2013), un 30,5\% del empleo informal en 2013 correspondía a empleadores y trabajadores por cuenta propia, así como asalariados de unidades de producción informales no registradas, con escasa dotación de capital y pequeña escala de operaciones (lo que les dificulta alcanzar un adecuado nivel de productividad y volúmenes de producción suficientes). En tanto, había un 11,4\% de empleados que trabajaban en el sector formal, lo que se debía sobre todo al incumplimiento del marco normativo, el desconocimiento de la ley, la incapacidad económica o la debilidad institucional. Un tercer grupo estaba compuesto por trabajadores con empleo informal en el sector de los hogares (en su mayoría, del servicio doméstico), y representaba un 4,9\% del empleo total no agrícola en dicho año. 
Al desagregar esas estadísticas por categoría ocupacional, como se indica en el cuadro III.1, las mayores tasas de informalidad se presentan entre los trabajadores por cuenta propia $(82,3 \%)$, seguidos por los trabajadores domésticos $(77,5 \%)$ y los asalariados de microempresas con menos de diez trabajadores $(58,6 \%)$, la que supera en más de cuatro veces la registrada en empresas con más de diez trabajadores. Entre estas tres categorías se concentra el 79\% del total de trabajadores informales de los países de la región analizados.

Cuadro III.1

América Latina (14 países): tasa y composición del empleo informal no agrícola según categorías ocupacionales, 2013 (En porcentajes)

\begin{tabular}{lcc}
\hline Categoría ocupacional & $\begin{array}{c}\text { Tasa de empleo informal } \\
\text { en cada categoria }\end{array}$ & $\begin{array}{c}\text { Composición del } \\
\text { empleo informal }\end{array}$ \\
\hline Total & 46,8 & 100 \\
\hline Asalariados (incluye empleadores) & 33,7 & 52,7 \\
\hline Del sector público & 15,9 & 4,3 \\
\hline De empresas privadas & 32,9 & 38,1 \\
\hline De uno a diez trabajadores & 58,6 & 27,8 \\
\hline Más de diez trabajadores & 14,4 & 9,4 \\
\hline De hogares & 77,5 & 10,3 \\
\hline Trabajadores por cuenta propia & 82,3 & 40,9 \\
\hline Trabajadores familiares auxiliares & 100 & 5,3 \\
\hline Otros & 96,7 & 1,1 \\
\hline
\end{tabular}

Fuente: Organización Internacional del Trabajo (OIT), La medición de la informalidad: Manual estadístico sobre el sector informal y el empleo informal, Ginebra, 2013.

Al ampliar las oportunidades de trabajo decente, se aumenta el potencial de reducir y mitigar los riesgos y demandas de la protección social durante la vida activa de los trabajadores, en su etapa activa y en su retiro, así como de proteger a sus dependientes.

\section{Riesgos y regulaciones laborales}

Considerando el papel señalado de las regulaciones laborales como componente de la protección social, a continuación se presenta un enfoque destinado a su análisis. En primer término, se plantea que el vínculo entre las normas y la protección es el trabajador dependiente. Esto se debe a que las regulaciones mencionadas se aplican a partir de la existencia de una relación laboral y permiten generar protecciones frente a determinados riesgos que: a) el propio trabajador enfrenta; $b$ ) enfrentan sus dependientes en las etapas anteriores a la incorporación a la vida laboral, y c) le habilitarán al trabajador el acceso a la protección una vez que abandone la vida activa. 
El análisis planteado reconoce en el trabajador y en la existencia de la relación de trabajo, la vía por la que las regulaciones se tornan en componentes de protección frente a determinados riesgos que requieren una cobertura adecuada. Esto se debe a sus efectos potenciales en el desarrollo del trabajo decente, respecto de tres poblaciones relacionadas que se definen al incorporar la dimensión del ciclo de vida: i) los propios trabajadores; ii) sus dependientes, y iii) quienes se retiran de la fuerza de trabajo ${ }^{7}$.

\section{a) Etapa previa a la vida activa}

Hay dos riesgos principales: la desprotección del recién nacido y del niño en sus etapas primarias de formación, y las inserciones laborales precarias bajo las modalidades de trabajo infantil o las formas no reguladas de trabajo de los adolescentes.

Respecto de la primera situación mencionada, el objetivo de la protección es asegurar condiciones de bienestar del que está por nacer, del recién nacido y del niño durante todo su proceso de crecimiento y desarrollo. En este caso, las regulaciones laborales más relevantes seleccionadas son las que establecen el descanso prenatal y posnatal, las licencias para alimentación y el cuidado de los hijos por enfermedad, y el derecho a disponer de salas cuna $u$ otras alternativas que se adopten con un propósito similar.

En cuanto a la prevención de la inserción laboral precaria, tanto en la infancia como en la adolescencia, las normas laborales atingentes son, principalmente, aquellas que prohíben el trabajo infantil y las que regulan el trabajo de los adolescentes mediante la exigencia de condiciones de trabajo adecuadas y la atención a casos especiales.

\section{b) Durante la vida laboral activa}

Se identifican tres áreas principales de riesgos: i) la ausencia de contratos de trabajo como condición mínima para el resguardo de derechos básicos de los trabajadores en la relación laboral; ii) los impedimentos para el ejercicio del derecho a la sindicación y la negociación colectiva, y iii) la ausencia de cobertura frente a riesgos de accidentes del trabajo y enfermedades profesionales, así como ante la eventualidad del desempleo.

Las principales regulaciones laborales relevantes ante los riesgos señalados son la obligatoriedad de formalizar el contrato de trabajo individual con el objetivo de reconocer las obligaciones básicas de dicha relación en

Cabe tener presente que la protección social en las etapas del ciclo de vida señaladas no es exclusiva de las normas e instituciones laborales. Por ejemplo, la cobertura de riesgos relacionados con la salud no se circunscribe al ámbito de los accidentes del trabajo ni las enfermedades profesionales, como sucede con otras enfermedades comunes o crónicas e incapacitantes que también pueden impedir la actividad laboral en forma temporal o permanente. En tal caso, la unidad de análisis radica en los sistemas de salud y la cobertura que brindan. 
materia de horarios y jornadas de trabajo y descanso, horas extraordinarias, vacaciones pagadas, monto y periodicidad del pago de remuneraciones. También se busca definir las causales por las que se puede rescindir el contrato y las consecuencias que puedan derivarse para las partes.

Entre las materias básicas reguladas en un contrato de trabajo, cabe destacar la vigencia de un salario mínimo. Este se determina según las características de cada país y tiene por finalidad garantizar el derecho de todo trabajador a un nivel de consumo básico y de condiciones de vida, con independencia del trabajo que desempeñe y de la calificación que requiera para ello. Además, adquiere especial importancia inhibir todo tipo de discriminación laboral, ya sea por condición de género, raza o condición social, o de otra especie. Dicha discriminación suele expresarse con mayor frecuencia en diferenciales de salarios que no se explican por las funciones realizadas ni por los niveles de calificación o experiencia laboral de quienes las realizan.

En el área de los derechos colectivos, las regulaciones laborales apuntan a garantizar el derecho de todo trabajador a organizarse con el objetivo de velar por el cumplimiento de sus derechos expresados en los contratos de trabajo y en las normas laborales y sobre condiciones de trabajo. También se intenta facilitar formas de denunciar su incumplimiento y permitir que los sindicatos representen a sus afiliados ante el empleador, a fin de resolver las contingencias propias de la vida de las empresas y mejorarlas teniendo en cuenta su aporte al proceso productivo.

Una función esencial de un sindicato es la de negociar colectivamente con los empleadores, con el fin de establecer (en un contrato colectivo) condiciones de trabajo y empleo acordes con la de las empresas o el sector de actividad en que operan, tales como: i) evolución real de las remuneraciones en el tiempo; ii) beneficios asociados al cumplimiento de metas; iii) inversiones en capacitación para el trabajo; iv) mecanismos de promoción interna, y v) prevención y vigilancia de las condiciones de trabajo.

Un tercer ámbito de interés para el análisis en esta etapa se refiere al cumplimiento de la responsabilidad de la empresa de garantizar una cobertura de protección ante el riesgo de accidentes del trabajo y enfermedades profesionales y de desempleo. En el primer caso, se entiende que se trata del derecho del trabajador a operar en un lugar seguro y, al mismo tiempo, el deber del empleador de establecer medidas de prevención o de compensación (monetaria o de servicios) si el evento se ha producido. Esto es independiente de la modalidad utilizada, que puede ser de cargo directo o basarse en la contratación de un seguro para estos efectos.

En cuanto al riesgo de desempleo de un trabajador, en los casos en que no exista incumplimiento del contrato de trabajo por el empleado, suele establecerse para el empleador la obligación de compensar al trabajador por los despidos sin causa justa, sobre bases que están normalmente 
definidas y reguladas en los respectivos códigos del trabajo. No obstante lo anterior, algunos países tienen seguros de desempleo, que garantizan ingresos a los trabajadores en el período de cesantía y les sirven de apoyo para encontrar un nuevo puesto de trabajo. En tales circunstancias, se establecen obligaciones por las que se exige que el empleador haga contribuciones para asegurar la protección ante dicho evento.

\section{c) En la vejez}

Uno de los principales riesgos es el de ausencia o insuficiencia de cobertura de los sistemas de seguridad social (sobre todo de pensiones y de salud) para proteger los ingresos y las condiciones generales de bienestar.

Desde el punto de vista de las regulaciones laborales y su relación con la protección frente a los riesgos señalados, dicha protección se obtiene por lo general sobre la base de los aportes efectuados a sistemas contributivos durante la vida activa. Lo anterior está directamente relacionado con una trayectoria laboral desempeñada en condiciones de trabajo decente. En caso contrario, la protección requerida descansará en las condiciones de acceso y suficiencia de los beneficios de los sistemas no contributivos.

Con independencia del tipo de sistema que proporcione la protección requerida, la cobertura y suficiencia de los beneficios siempre estará condicionada a su sostenibilidad financiera. En todo caso, es necesario tener en cuenta que las dimensiones de cobertura, suficiencia y sostenibilidad deben conciliarse. Si se subordinan las primeras a la sostenibilidad, se incrementa el riesgo de no cubrir a toda la población que lo requiere o de que las prestaciones no sean suficientes para aliviar la pobreza en la vejez.

En el cuadro III.2 se ilustra la matriz de análisis desarrollada a partir de las consideraciones presentadas. Según las etapas del ciclo de vida, se identifican los principales riesgos y las regulaciones laborales seleccionadas para enfrentarlos. Sin embargo, la existencia de una norma no es condición suficiente para garantizar la protección requerida si no se dispone de la capacidad de promover y fiscalizar su cumplimiento, así como sancionar su eventual incumplimiento.

A partir de las dimensiones jurídico-normativa y organizacional descritas en el capítulo I, a continuación se analiza la situación que se presenta en los países de la región en cuanto a la institucionalidad de la regulación laboral como componente de la protección social y su capacidad de dar cuenta de sus objetivos. Este análisis se centra en los ámbitos de la promoción del cumplimiento de las normas laborales, la fiscalización de las condiciones de trabajo y la aplicación de sanciones ante el incumplimiento. Se trata de tres áreas complementarias que potencian el cumplimiento de las normas laborales. 


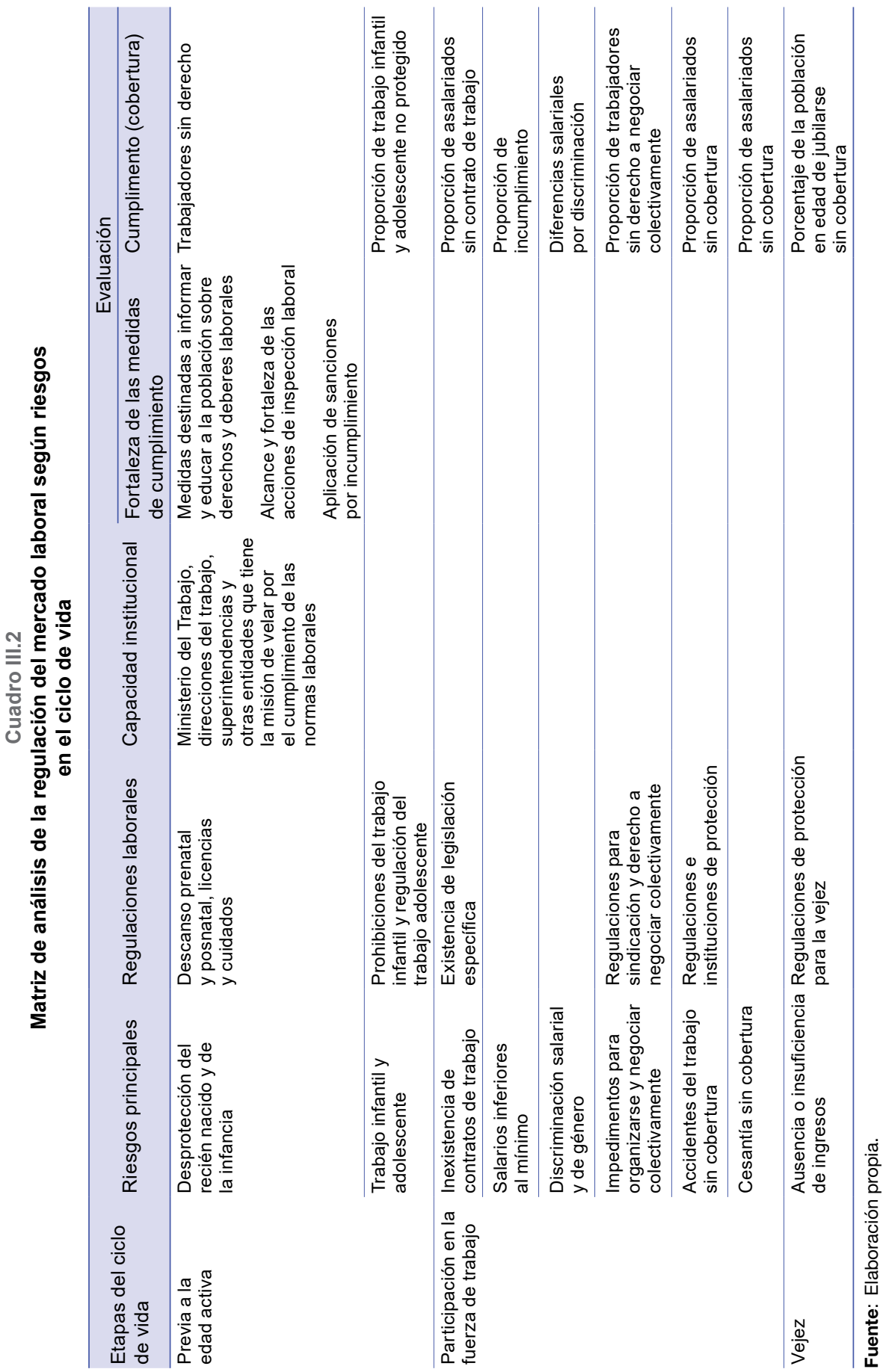




\section{Regulaciones laborales}

A la luz de lo señalado en la sección anterior, se perfilan dos preguntas fundamentales a responder para dar cuenta de la dimensión jurídiconormativa de la institucionalidad en el caso de la regulación del mercado laboral, como parte del sistema de protección social. Dichas preguntas son: i) ¿existen normas o regulaciones destinadas a proteger a los trabajadores ante el conjunto de riesgos señalados?, y ii) ¿cuáles son sus contenidos? Para responderlas, se examinan a continuación las distintas fuentes jurídicas, según su jerarquía, desde la adhesión a convenios internacionales y su ratificación, así como los contenidos presentes a nivel constitucional, hasta los códigos del trabajo, leyes especiales y decretos específicos.

\section{Convenciones internacionales}

En el plano internacional, la regulación aplicable al trabajo y las relaciones laborales presenta un nivel de desarrollo institucional que sobresale respecto a otros ámbitos de la política social, tanto en su amplitud como en su profundidad, historia y participación de actores (gobiernos, empleadores y trabajadores). La OIT promueve entre sus 178 Estados miembros la necesidad de mantener ciertos estándares laborales de tratamiento mínimo, basados en convenios internacionales, recomendaciones y resoluciones, con el objetivo de mejorar las condiciones de vida y de trabajo ${ }^{8}$.

\section{a) Convenios de la OIT y protección ante riesgos en el ciclo de vida}

Entre los convenios que se relacionan directamente con los objetivos de la regulación del mercado de trabajo como componente de la protección social se encuentran los llamados fundamentales y otros denominados técnicos. El Consejo de Administración de la OIT ha establecido que hay

En el marco de la OIT, un convenio es una norma internacional (aprobada en una conferencia internacional del trabajo) y su eficacia en cada país está condicionada a su ratificación por la autoridad competente del Estado. Si un país decide ratificar un convenio, en general este entra en vigor allí un año después de la fecha de la ratificación. Los países que ratifican convenios se obligan a implementarlos en su legislación y prácticas nacionales. El control de la aplicación de los convenios de la OIT se realiza tanto mediante memorias anuales que cada Estado miembro ha de rendir sobre su cumplimiento del convenio, como mediante el control directo, que consiste en un sistema de denuncias ante el Consejo de Administración o los órganos de control, planteadas por los Estados miembros (quejas) o por las representaciones sindicales de trabajadores o empresarios ("reclamaciones"). Para garantizar la aplicación de los convenios, la OIT cuenta con un procedimiento de supervisión muy desarrollado. Las recomendaciones de la OIT son propuestas sin carácter vinculante, dirigidas a los Estados miembros, que solo los obligan a informar al Director de la OIT sobre el estado de la respectiva legislación interna y el grado de observancia de lo recomendado. Las resoluciones, por su parte, expresan la opinión o criterio de la OIT sobre determinadas materias y, en consecuencia, carecen de obligatoriedad y suelen ser anticipaciones de futuras recomendaciones y convenios, formuladas mediante exhortación o invitación, bien a los Estados miembros, al Consejo de Administración, al Director General o a la propia OIT. 
ocho convenios fundamentales 9 . Abarcan desde la libertad de asociación y la libertad sindical hasta el reconocimiento efectivo del derecho de negociación colectiva, la eliminación de todas las formas de trabajo forzoso u obligatorio, la abolición efectiva del trabajo infantil y la eliminación de la discriminación en el empleo y ocupación. Al respecto, la OIT lanzó en 1995 una campaña para lograr la ratificación universal de dichos convenios. En la actualidad se registran más de 1.200 ratificaciones, lo que representa un $86 \%$ del número posible de ratificaciones a nivel mundial.

Si se consideran las etapas del ciclo de vida, los riesgos de la etapa de la niñez y la adolescencia se abordan en diversos convenios de la OIT: el Convenio sobre el Trabajo Nocturno de los Menores (Industria), 1919 (Núm. 6); el Convenio sobre la Protección de la Maternidad, 2000 (Núm. 183); el Convenio sobre la Abolición del Trabajo Forzoso, 1957 (Núm. 105); el Convenio sobre la Edad Mínima de Admisión al Empleo, 1973 (Núm. 138) y el Convenio sobre la Prohibición de las Peores Formas de Trabajo Infantil, 1999 (núm. 182) (véase el cuadro III.3).

\section{Cuadro III.3}

\section{Convenios de la OIT en países de América Latina relacionados con etapas de ciclo de vida}

\begin{tabular}{|c|c|c|c|}
\hline Convenios & Año & Contenidos fundamentales & Etapa \\
\hline $\begin{array}{l}\text { C006. Convenio } \\
\text { relativo al Trabajo } \\
\text { Nocturno de los } \\
\text { Menores en la } \\
\text { Industria }\end{array}$ & 1919 & $\begin{array}{l}\text { Queda prohibido emplear durante la noche a } \\
\text { personas menores de } 18 \text { años en empresas } \\
\text { industriales, públicas o privadas, o en } \\
\text { sus dependencias. }\end{array}$ & $\begin{array}{l}\text { Niñez y } \\
\text { adolescencia }\end{array}$ \\
\hline $\begin{array}{l}\text { C087. Convenio sobre } \\
\text { la Libertad Sindical } \\
\text { y la Protección } \\
\text { del Derecho } \\
\text { de Sindicación }\end{array}$ & 1948 & $\begin{array}{l}\text { Los trabajadores y los empleadores, sin ninguna } \\
\text { distinción y sin autorización previa, tienen el } \\
\text { derecho de constituir las organizaciones que } \\
\text { estimen convenientes, así como el de afiliarse } \\
\text { a estas organizaciones, con la sola condición } \\
\text { de observar los estatutos pertinentes. }\end{array}$ & $\begin{array}{l}\text { Edad de } \\
\text { trabajar }\end{array}$ \\
\hline $\begin{array}{l}\text { C098. Convenio } \\
\text { sobre el Derecho } \\
\text { de Sindicación y de } \\
\text { Negociación Colectiva }\end{array}$ & 1949 & $\begin{array}{l}\text { Los trabajadores deberán gozar de adecuada } \\
\text { protección contra todo acto de discriminación } \\
\text { tendiente a menoscabar la libertad sindical en } \\
\text { relación con su empleo. }\end{array}$ & $\begin{array}{l}\text { Edad de } \\
\text { trabajar }\end{array}$ \\
\hline $\begin{array}{l}\text { C100. Convenio } \\
\text { sobre Igualdad de } \\
\text { Remuneración }\end{array}$ & 1951 & $\begin{array}{l}\text { Garantizar la aplicación a todos los trabajadores } \\
\text { del principio de igualdad de remuneración entre } \\
\text { la mano de obra masculina y la mano de obra } \\
\text { femenina por un trabajo de igual valor. }\end{array}$ & $\begin{array}{l}\text { Edad de } \\
\text { trabajar }\end{array}$ \\
\hline
\end{tabular}

9 Se trata de los siguientes convenios: el Convenio sobre la Libertad Sindical y la Protección del Derecho de Sindicación, 1948 (Núm. 87); el Convenio sobre el Derecho de Sindicación y de Negociación Colectiva, 1949 (Núm. 98); el Convenio sobre el Trabajo Forzoso, 1930 (Núm. 29); el Convenio sobre la Abolición del Trabajo Forzoso, 1957 (núm. 105); el Convenio sobre la Edad Mínima de Admisión al Empleo, 1973 (Núm. 138); el Convenio Sobre la Prohibición de las Peores Formas de Trabajo Infantil, 1999 (Núm. 182); el Convenio sobre la Igualdad de Remuneración, 1951 (Núm. 100), y el Convenio relativo a la Discriminación en materia de Empleo y Ocupación, 1958 (Núm. 111). 
Cuadro III.3 (conclusión)

\begin{tabular}{|c|c|c|c|}
\hline Convenios & Año & Contenidos fundamentales & Etapa \\
\hline $\begin{array}{l}\text { C102. Convenio } \\
\text { relativo a la Norma } \\
\text { Mínima de la } \\
\text { Seguridad Social }\end{array}$ & 1952 & $\begin{array}{l}\text { Garantizar la concesión de prestaciones de } \\
\text { asistencia médica, monetarias por enfermedad, } \\
\text { desempleo, vejez, accidente de trabajo y } \\
\text { enfermedad profesional, prestaciones familiares, } \\
\text { de maternidad, de invalidez y de sobrevivencia. }\end{array}$ & $\begin{array}{l}\text { Edad de } \\
\text { trabajar } \\
\text { y vejez }\end{array}$ \\
\hline $\begin{array}{l}\text { C105. Convenio } \\
\text { sobre la Abolición del } \\
\text { Trabajo Forzoso }\end{array}$ & 1957 & $\begin{array}{l}\text { Suprimir y no hacer uso de ninguna forma de } \\
\text { trabajo forzoso u obligatorio. }\end{array}$ & $\begin{array}{l}\text { Niñez y } \\
\text { adolescencia } \\
\text { y edad } \\
\text { de trabajar }\end{array}$ \\
\hline $\begin{array}{l}\text { C111. Convenio } \\
\text { relativo a la } \\
\text { Discriminación en } \\
\text { materia de Empleo } \\
\text { y Ocupación }\end{array}$ & 1958 & $\begin{array}{l}\text { Llevar a cabo una política nacional que promueva, } \\
\text { por métodos adecuados a las condiciones y a la } \\
\text { práctica nacionales, la igualdad de oportunidades } \\
\text { y de trato en materia de empleo y ocupación, con } \\
\text { objeto de eliminar cualquier discriminación. }\end{array}$ & $\begin{array}{l}\text { Edad de } \\
\text { trabajar }\end{array}$ \\
\hline $\begin{array}{l}\text { C131. Convenio } \\
\text { relativo a la Fijación de } \\
\text { Salarios Mínimos }\end{array}$ & 1970 & $\begin{array}{l}\text { Establecer un sistema de salarios mínimos que } \\
\text { se aplique a todos los grupos de asalariados } \\
\text { cuyas condiciones de empleo hagan apropiada la } \\
\text { aplicación del sistema. }\end{array}$ & $\begin{array}{l}\text { Edad de } \\
\text { trabajar }\end{array}$ \\
\hline $\begin{array}{l}\text { C138. Convenio sobre } \\
\text { la Edad Mínima de } \\
\text { Admisión al Empleo }\end{array}$ & 1973 & $\begin{array}{l}\text { Seguir una política nacional que asegure la } \\
\text { abolición efectiva del trabajo de los niños y eleve } \\
\text { progresivamente la edad mínima de admisión al } \\
\text { empleo o al trabajo, a un nivel que haga posible el } \\
\text { más completo desarrollo físico y mental de } \\
\text { los menores. }\end{array}$ & $\begin{array}{l}\text { Niñez y } \\
\text { adolescencia }\end{array}$ \\
\hline $\begin{array}{l}\text { C 155. Convenio sobre } \\
\text { Seguridad y Salud de } \\
\text { los Trabajadores }\end{array}$ & 1981 & $\begin{array}{l}\text { Prevé la adopción de una política nacional } \\
\text { coherente sobre seguridad y salud en el trabajo, } \\
\text { tomando en consideración las condiciones y las } \\
\text { prácticas nacionales. }\end{array}$ & $\begin{array}{l}\text { Edad de } \\
\text { trabajar }\end{array}$ \\
\hline $\begin{array}{l}\text { C158. Convenio sobre } \\
\text { la Terminación de la } \\
\text { Relación de Trabajo } \\
\text { por Iniciativa } \\
\text { del Empleador }\end{array}$ & 1982 & $\begin{array}{l}\text { Establece el principio de que no se pondrá término } \\
\text { a una relación de trabajo, salvo que exista para } \\
\text { ello una causa justificada, relacionada con la } \\
\text { capacidad o conducta del trabajador o basada en } \\
\text { las necesidades de funcionamiento de la empresa. }\end{array}$ & $\begin{array}{l}\text { Edad de } \\
\text { trabajar }\end{array}$ \\
\hline $\begin{array}{l}\text { C161. Convenio sobre } \\
\text { los Servicios de Salud } \\
\text { en el Trabajo }\end{array}$ & 1985 & $\begin{array}{l}\text { Prevé el establecimiento de servicios de salud en } \\
\text { el ámbito de la empresa. }\end{array}$ & $\begin{array}{l}\text { Edad de } \\
\text { trabajar }\end{array}$ \\
\hline $\begin{array}{l}\text { C182. Convenio sobre } \\
\text { la Prohibición de las } \\
\text { Peores Formas de } \\
\text { Trabajo Infantil }\end{array}$ & 1999 & $\begin{array}{l}\text { Adoptar medidas inmediatas y eficaces para } \\
\text { conseguir la prohibición y la eliminación de las } \\
\text { peores formas de trabajo infantil con carácter } \\
\text { de urgencia. }\end{array}$ & $\begin{array}{l}\text { Niñez y } \\
\text { adolescencia }\end{array}$ \\
\hline $\begin{array}{l}\text { C183. Convenio sobre } \\
\text { la Protección de } \\
\text { la Maternidad }\end{array}$ & 2000 & $\begin{array}{l}\text { Establece } 14 \text { semanas de prestaciones de } \\
\text { maternidad para las mujeres. }\end{array}$ & $\begin{array}{l}\text { Niñez y } \\
\text { adolescencia }\end{array}$ \\
\hline $\begin{array}{l}\text { C187. Convenio sobre } \\
\text { el Marco Promocional } \\
\text { para la Seguridad y } \\
\text { Salud en el Trabajo }\end{array}$ & 2006 & $\begin{array}{l}\text { Promover una cultura de prevención en materia de } \\
\text { seguridad y salud con vistas al logro progresivo de } \\
\text { un medio de trabajo seguro y saludable. }\end{array}$ & $\begin{array}{l}\text { Edad de } \\
\text { trabajar }\end{array}$ \\
\hline $\begin{array}{l}\text { C189. Convenio sobre } \\
\text { el Trabajo Decente } \\
\text { para las Trabajadoras } \\
\text { y los Trabajadores } \\
\text { Domésticos }\end{array}$ & 2011 & $\begin{array}{l}\text { Asegurar la promoción y la protección efectivas } \\
\text { de los derechos humanos de todos los } \\
\text { trabajadores domésticos. }\end{array}$ & $\begin{array}{l}\text { Edad de } \\
\text { Trabajar }\end{array}$ \\
\hline
\end{tabular}

Fuente: Elaboración propia, sobre la base de Organización Internacional del Trabajo (OIT), "Ratificaciones por convenio", NORMLEX Information System on International Labour Standards, 2015 [en línea] http://www.ilo.org/dyn/normlex/es/f?p=1000:12001:0::NO::.: 
Entre los convenios cuya aplicación protege las condiciones de trabajo en la edad de trabajar, cabe mencionar el Convenio sobre la Terminación de la Relación de Trabajo por Iniciativa del Empleador, 1982 (Núm. 158); el Convenio sobre la Indemnización por Accidentes del Trabajo, 1925 (Núm. 17); el Convenio sobre las Enfermedades Profesionales (Revisado), 1934 (Núm. 42); el Convenio sobre la Libertad Sindical y la Protección del Derecho de Sindicación, 1948 (Núm. 87); el Convenio sobre el Derecho de Sindicación y de Negociación Colectiva, 1949 (Núm. 98); el Convenio sobre Igualdad de Remuneración, 1951 (Núm. 100); el Convenio relativo a la Discriminación en materia de Empleo y Ocupación, 1958 (Núm. 111); el Convenio relativo a la Fijación de Salarios Mínimos, 1970 (Núm. 131), y el Convenio relativo a la Norma Mínima de la Seguridad Social (Norma Mínima), 1952 (Núm. 102), que también aborda riesgos en la vejez.

Entre los convenios que se aplican para proteger a los trabajadores vinculados por una relación de trabajo cabe mencionar la Recomendación sobre la Relación de Trabajo, 2006 (Núm. 198). En ella se dispone que los Estados miembros deberían formular y aplicar una política nacional que incluya medidas tendientes a ofrecer orientaciones sobre la manera de determinar la existencia de una relación de trabajo y sobre la distinción entre trabajadores asalariados e independientes, así como medidas tendientes a luchar contra las relaciones de trabajo encubiertas (OIT, 2015d).

En dicho ámbito también se inscribe el Convenio relativo al Trabajo Nocturno de los Menores en la Industria, 1919 (Núm. 1) de la OIT, aprobado en 1919, con el fin de limitar las horas de trabajo y disponer períodos adecuados de descanso para los trabajadores. Es de destacar que han transcurrido casi 100 años desde su aprobación, lo que es prueba de una larga historia de desarrollo institucional en este tema. Actualmente, las normas de la OIT amplían y especifican este marco regulatorio en varios aspectos relacionados con la promoción del trabajo decente (OIT, 2015e). Entre las preocupaciones de la OIT cabe mencionar las de garantizar el acceso a salarios adecuados y regulares, el pago regular de los salarios, la fijación de los niveles de salario mínimo y el pago de los salarios adeudados en caso de insolvencia del empleador (OIT, 2015e).

En el área de las relaciones colectivas, hay dos convenios fundamentales que regulan la protección del ejercicio de los derechos de sindicación y de negociación colectiva (el Convenio sobre la Libertad Sindical y la Protección del Derecho de Sindicación, 1948 (Núm. 87) y el Convenio sobre el Derecho de Sindicación y de Negociación Colectiva, 1949 (Núm. 98)). Dicha protección se entiende como un requisito necesario para la solidez de la negociación colectiva y del diálogo social (OIT, 2015k).

Además, se han seleccionado convenios internacionales que regulan la protección del acceso a la seguridad social de los trabajadores, sobre todo en el ámbito de la seguridad y salud en el trabajo: el Convenio 
sobre Seguridad y Salud de los Trabajadores, 1981 (Núm. 155), y el Protocolo de 2002 relativo al Convenio sobre Seguridad y Salud de los Trabajadores, 1981; el Convenio sobre los Servicios de Salud en el Trabajo, 1985 (Núm. 161), y el Convenio sobre el Marco Promocional para la Seguridad y Salud en el Trabajo, 2006 (Núm. 187).

Finalmente, por su importancia para la etapa de la vejez, es necesario considerar el Convenio relativo a la Norma Mínima de la Seguridad Social, 1952 (Núm. 102), que establece la norma mínima para el nivel de las prestaciones de la seguridad social y las condiciones para poder acceder a ellas. Comprende las nueve ramas principales de la seguridad social, a saber, asistencia médica, enfermedad, desempleo, vejez, accidentes del trabajo y enfermedades profesionales, familia, maternidad, invalidez y prestaciones de sobrevivientes.

Para aplicar dicho Convenio se ofrece a los Estados la posibilidad de ratificarlo al aceptar en un inicio al menos tres de las nueve ramas, y luego acatar las obligaciones derivadas de las restantes, con lo que se permite alcanzar progresivamente todos los objetivos establecidos en el Convenio. El nivel de prestaciones mínimas puede determinarse en relación con el nivel salarial del país de que se trate (véase el cuadro III.A1.1 del anexo). También pueden preverse excepciones temporales para los países cuya economía y servicios médicos estén insuficientemente desarrollados. Ello les permitiría restringir el ámbito de aplicación del Convenio y la cobertura de las prestaciones otorgadas.

Estrechamente vinculada con el Convenio núm. 102 está la Recomendación sobre los Pisos de Protección Social, 2012 (Núm. 202), que proporciona orientaciones para establecer y mantener pisos de seguridad social. También encauza la puesta en marcha de pisos de protección social en el marco de estrategias de extensión de la seguridad social, a niveles más elevados para el mayor número de personas posibles, según las orientaciones de las normas de la OIT en esta materia.

\section{b) Ratificaciones y puesta en vigor}

En el cuadro III.4 se enumeran los convenios que han ratificado y puesto en vigor los países de América Latina y que, por lo tanto, forman parte de las legislaciones nacionales. Como es posible advertir, en el caso de los convenios fundamentales, su aplicación se verifica en prácticamente todos los países analizados. Los que registran un menor número de ratificaciones son el Convenio sobre la Terminación de la Relación de Trabajo por Iniciativa del Empleador, 1982 (Núm. 158) (solo lo ha ratificado la República Bolivariana de Venezuela). De modo similar, el Convenio sobre la Protección de la Maternidad, 2000 (Núm. 183), solo ha sido ratificado por Cuba, aunque hay que considerar que instrumentos anteriores, como el Convenio sobre la Protección de la Maternidad (Revisado), 1952 (Núm. 103), aún están en vigor en el Brasil, Bolivia (Estado Plurinacional de), Chile, el Ecuador y el Uruguay (OIT, 2015b). 


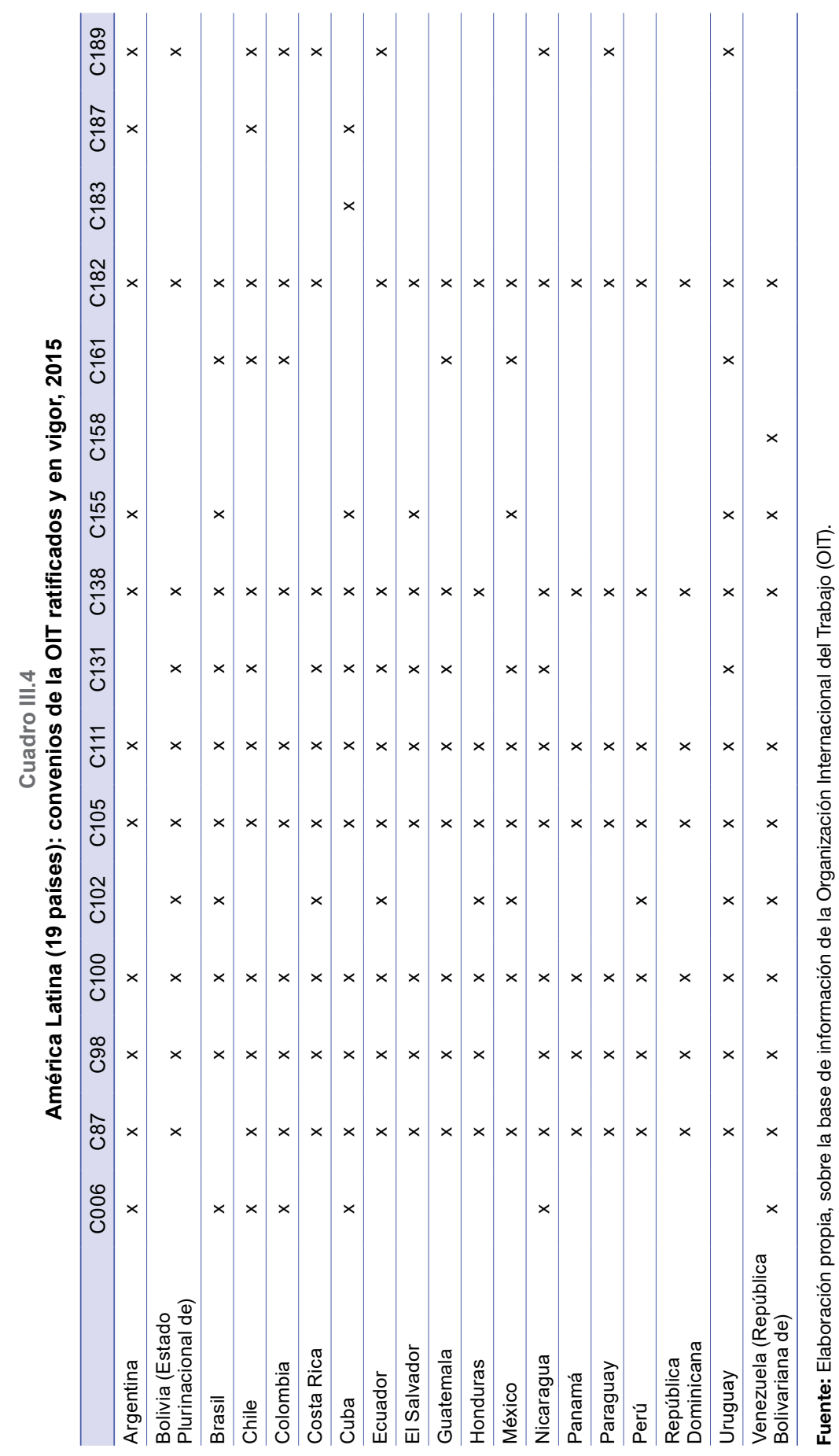


Si se consideran los convenios de más reciente aprobación, como el Convenio sobre el Marco Promocional para la Seguridad y Salud en el Trabajo, 2006 (Núm. 187), se observa un menor grado de ratificaciones entre los países, aunque hay que señalar que el Convenio sobre la Indemnización por Accidentes del Trabajo, 1925 (Núm. 17) ha sido ratificado por la Argentina, Bolivia (Estado Plurinacional de), Colombia, México, Nicaragua y Panamá, y que el Convenio sobre las Enfermedades Profesionales (Revisado), 1934 (Núm. 42) ha sido ratificado por la Argentina, Bolivia (Estado Plurinacional de), el Brasil, Cuba, Honduras, México y Panamá. En cambio, el Convenio sobre el Trabajo Decente para las Trabajadoras y los Trabajadores Domésticos, 2011 (Núm. 189), ha experimentado un proceso de ratificación relativamente más rápido. En cuanto al Convenio núm. 102 sobre seguridad social (norma mínima), algo menos de la mitad de los países considerados lo han ratificado y puesto en ejecución.

Finalmente, se observa que, de los 16 convenios seleccionados, el mayor número de ratificaciones corresponde a Chile y el Uruguay. También se puede apreciar que la mayoría de los países han ratificado entre 9 y 11 convenios; que Honduras, el Paraguay y el Perú han ratificado la mitad, y que la República Dominicana solo ha ratificado 7.

\section{Garantías constitucionales}

Se puede encontrar una segunda fuente jurídica de normas laborales en las respectivas constituciones nacionales. Como se desprende del cuadro III.5, en todos los países considerados existen artículos en que se hace mención explícita del trabajo remunerado. En la mayoría de los casos, este derecho queda comprendido en el concepto de libertad de trabajo (Chile y Costa Rica), o de función social (El Salvador). Se establece la obligación de procurar el pleno empleo, y que este ha de ser protegido y organizado bajo principios de justicia social.

En cuanto a las materias específicas, si bien no se mencionan todas las de interés para el presente análisis, suelen incluirse la protección de la maternidad, el descanso remunerado y la lactancia, la prohibición del trabajo forzado e infantil y, en algunos casos, la regulación del trabajo de menores. Sin embargo, a pesar de que algunos países incluyen en sus respectivas constituciones la protección de la maternidad, muchos no han ratificado ni puesto en vigor el Convenio núm. 183 o algunos de los anteriores sobre la misma materia. 


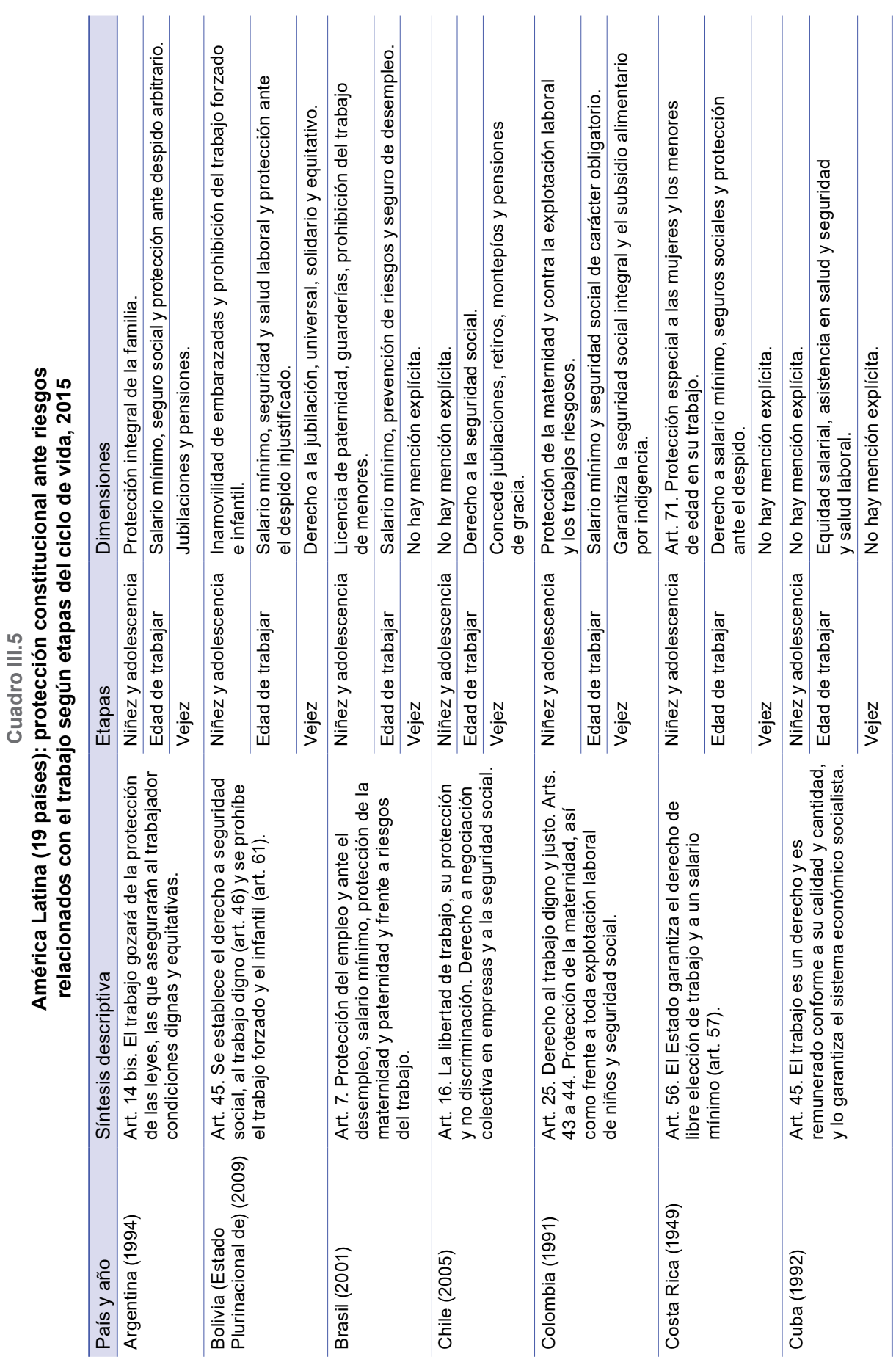




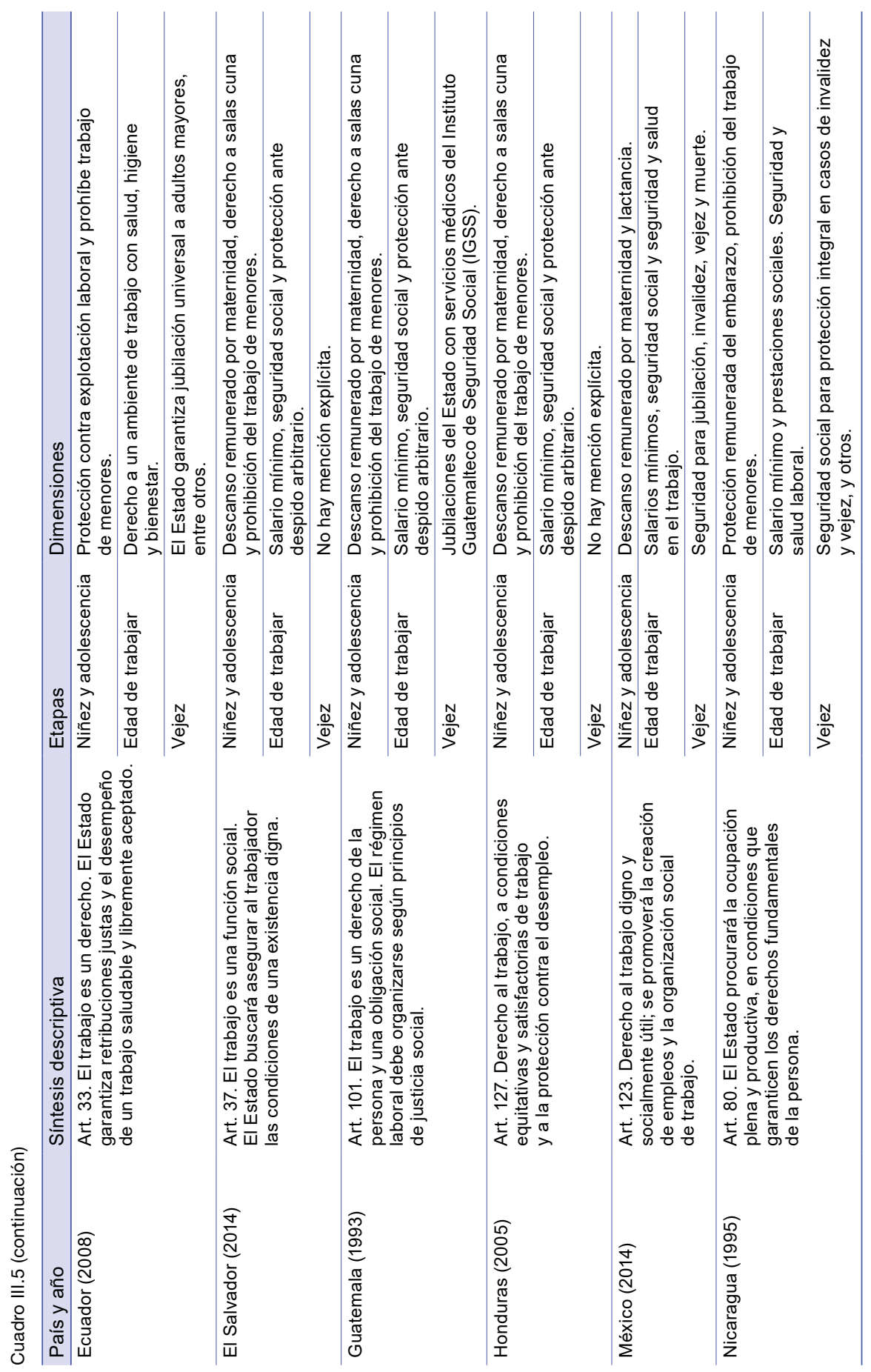




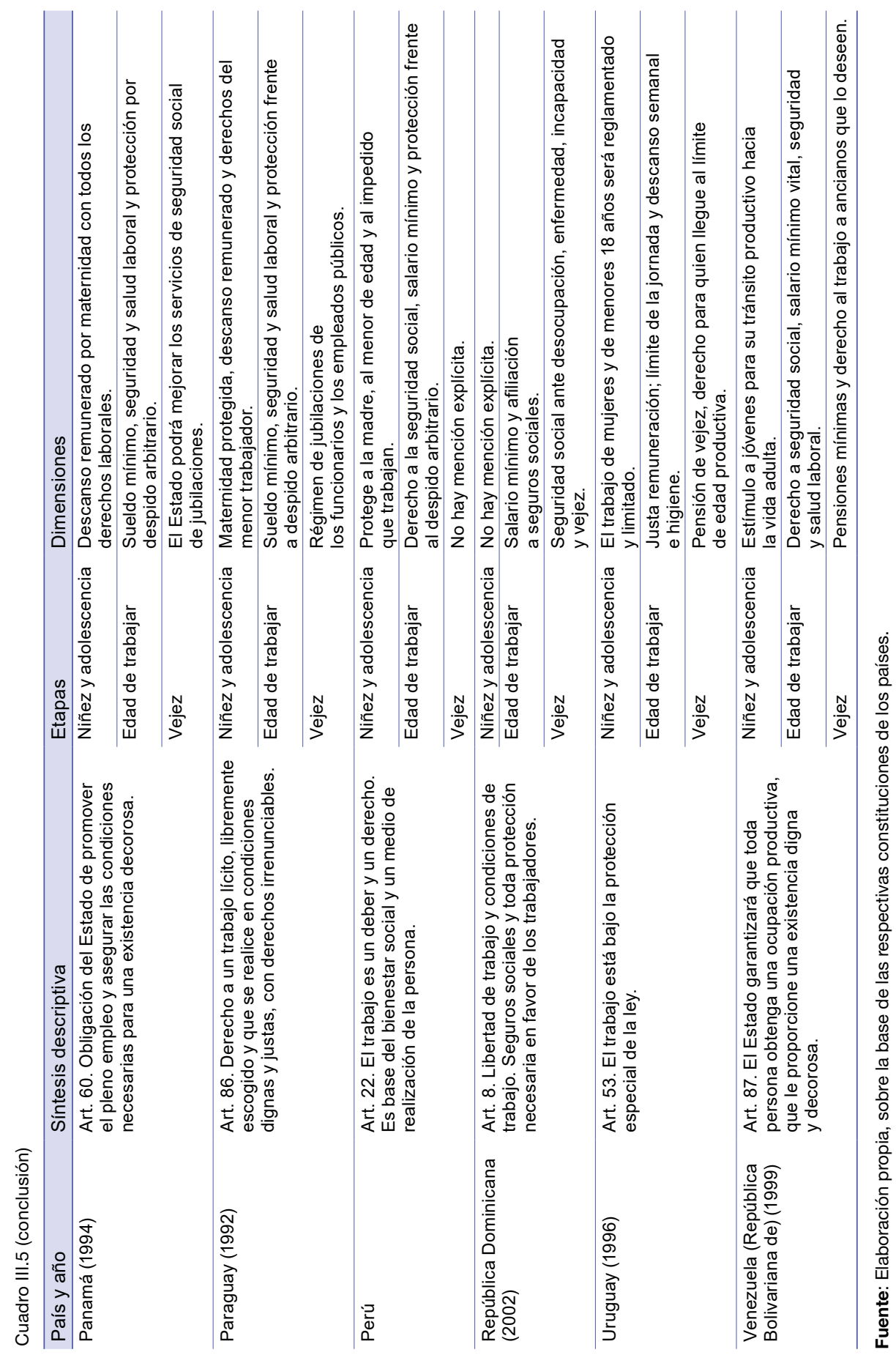


Respecto de la protección en la edad de trabajar, es frecuente la garantía de un salario mínimo para los trabajadores y jornadas de trabajo reguladas, así como el derecho a ser amparado por los mecanismos de la seguridad social ante diversas contingencias en la vida activa. La protección ante el despido injustificado, la equidad salarial y el derecho a un ambiente de trabajo en condiciones de salud y seguridad también son temas recurrentes de las garantías ofrecidas en los distintos países de la región. Sin embargo, hay siete países que no han ratificado el Convenio relativo a la Fijación de Salarios Mínimos, 1970 (Núm. 131), y ninguno ha ratificado los tres convenios seleccionados sobre seguridad y salud en el trabajo. Esta es una esfera que presenta menor coherencia con las garantías declaradas al nivel constitucional. Esta particularidad también se presenta, aunque con menor intensidad, en materia de protección en la vejez y en cuanto al grado de ratificación del Convenio núm. 102 de norma mínima en seguridad social.

\section{Códigos del trabajo}

El siguiente nivel de fuente jurídica de las normas laborales lo proporciona el Código del Trabajo, un conjunto de normas sistematizadas que regulan las relaciones entre los empleadores y los trabajadores. Se trata de marcos regulatorios especialmente concebidos para asegurar un conjunto de derechos y obligaciones que emanan de la relación laboral.

En el cuadro III.6 se presenta información sistematizada sobre la existencia de regulaciones laborales en los países de América Latina, y se proporciona información acerca de las versiones más recientes. Los códigos del trabajo suelen contener normas que regulan el contrato individual en aspectos específicos del trabajo de menores, las jornadas, las remuneraciones y su protección, y los permisos y feriados, así como los contratos especiales para grupos de trabajadores. Hay capítulos en que se desarrollan normas sobre la protección de la maternidad y la vida familiar, y sobre la discriminación laboral y la protección ante riesgos de accidentes y enfermedades laborales, entre otras. Finalmente, suelen incluir normas referentes a la constitución de las organizaciones sindicales y su funcionamiento, así como regulaciones respecto de los procesos de negociación colectiva y la inclusión en los sistemas de seguridad social. 


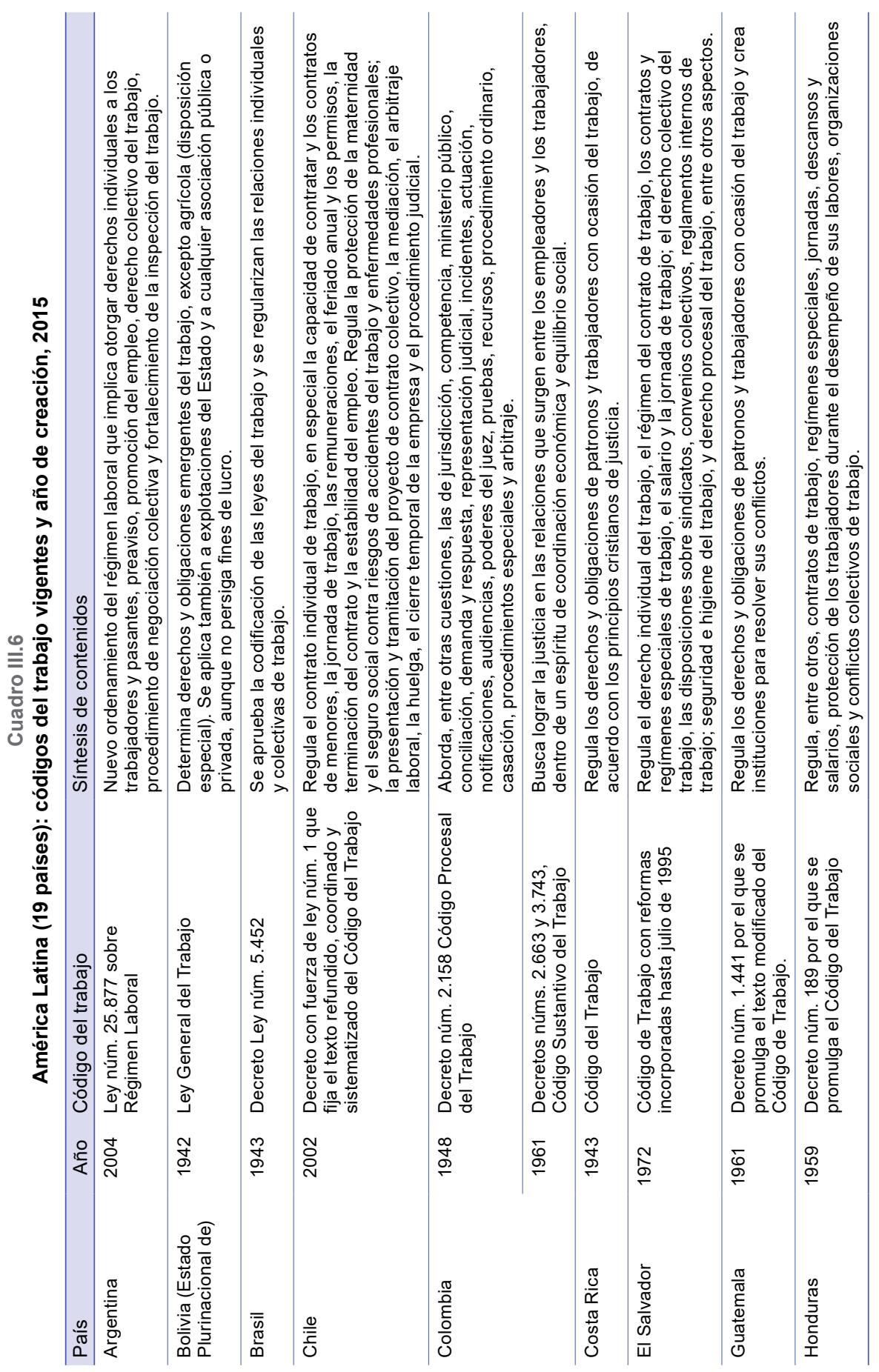




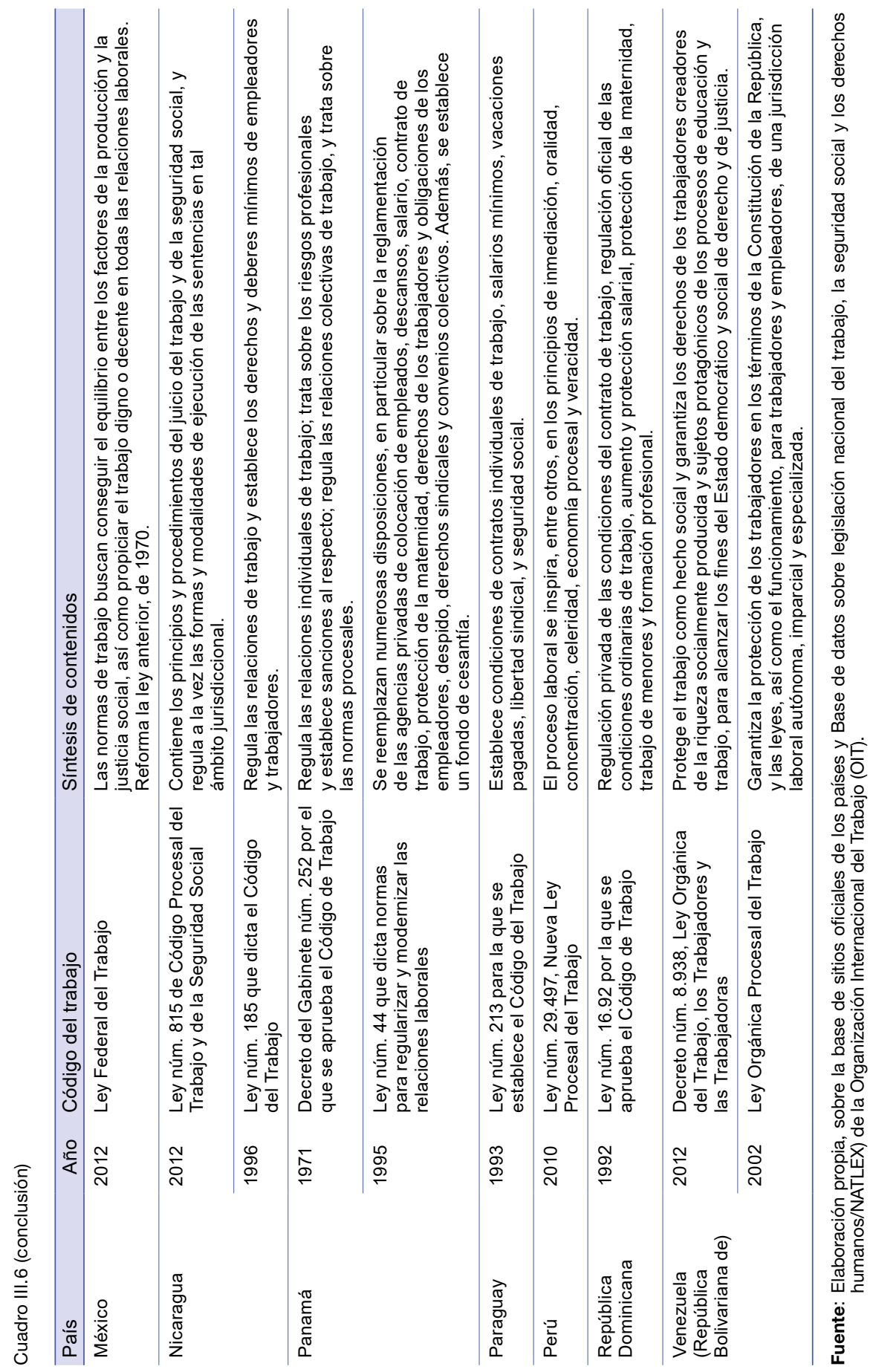


Es necesario tener en cuenta que, si bien la matriz de regulaciones laborales de los países de la región fue alterada en los años ochenta y noventa con el objetivo de imprimir flexibilidad a los mercados de trabajo, como se indicó con anterioridad, desde entonces dicha tendencia se ha revertido parcialmente. Como lo señala Bensusán (2013), la flexibilización de las regulaciones no resolvió los problemas del mercado de trabajo, sino que los agravó, pues amplió la brecha entre los trabajadores y dio origen a nuevas desigualdades ${ }^{10}$. Como reacción, algunos países de la región han revitalizado la intervención estatal, fortalecido los sindicatos e impulsado la implementación de políticas públicas orientadas a generar empleos de calidad y proporcionar mayor protección social.

Weller (2009) afirma que, en la década de 2000, en general no hubo reformas flexibilizadoras profundas y que ello coincidió con una actitud de mayor cautela frente a las propuestas de desregulación radical (Freeman, 2005) que se asumió en el debate internacional. Aclara que las medidas de esta naturaleza se concentraron en la micro y pequeña empresa, o en sectores específicos, como el de la agroexportación en el Perú.

En cambio, advierte que en las reformas más recientes se ha puesto énfasis en la revisión de las relaciones laborales colectivas con miras a ajustarlas a las normas de la OIT, reforzar la negociación colectiva y, en algunos casos, extenderla a nuevos grupos de trabajadores. Por su parte, las aplicadas en el ámbito de las relaciones laborales individuales han tenido un sello protector. Además, los Gobiernos han adoptado medidas correctivas a fin de reducir la precariedad de los puestos de trabajo y subsanar las deficiencias existentes en la protección social. Por ejemplo, se ha aumentado el salario mínimo (Argentina, Brasil, Chile y Uruguay), restringido los contratos temporales (Argentina y Bolivia (Estado Plurinacional de)) y reglamentado la subcontratación (Chile, Colombia, Perú y Uruguay).

Al considerar la etapa de protección del recién nacido y los riesgos de inserción precaria temprana en el mercado de trabajo, conviene destacar las regulaciones de protección de la maternidad, por las que se asegura el descanso obligatorio y remunerado. Este es el caso de la prohibición expresa de restringir contratos de trabajo por matrimonio o embarazo en el Brasil, el Ecuador y El Salvador. En Panamá, en cambio, se establecen condicionantes, ya que se ha dispuesto que la mujer que se encuentre en estado de gravidez solo puede ser despedida por causa justificada y previa

10 Véanse además Tokman (2007 y 2011) y Fitoussi y Rosanvallon (1997). 
autorización judicial. Por otra parte, se presenta una multiplicidad de regulaciones sobre el derecho al descanso prenatal y posnatal, por ejemplo, en Chile (con 6 y 12 semanas respectivamente), la República Dominicana (6 y 6 semanas) y Venezuela (República Bolivariana de) (6 y 20 semanas), entre otros.

Del mismo modo, se adoptan disposiciones que obligan al empleador a establecer centros de cuidado, lactancia y alimentación en las empresas, bajo diversas modalidades de salas cuna, guarderías o centros de atención preescolar. Este objetivo se logra en el Brasil, por ejemplo, con instituciones de carácter público. Por su parte, en Colombia operan centros de atención integral para la primera infancia dirigidos a preescolares menores de 7 años, y que están al servicio de familias de empleados públicos y privados. Mientras tanto, en México se ha establecido el Instituto Mexicano del Seguro Social (IMSS). Hay otras modalidades que operan a nivel de las empresas, que deben disponer el acceso a este tipo de instalaciones, según el número de trabajadoras: más de 20 en Chile, Honduras y Venezuela (República Bolivariana de); más de 30 en Costa Rica y Guatemala, y más de 50 en Colombia.

También suelen existir disposiciones que prohíben el trabajo infantil o de menores y regulan el trabajo de adolescentes, aunque el límite de edad varía según el país de que se trate. Así, por ejemplo, en Chile se prohíbe el trabajo de menores de 18 años en faenas peligrosas y se establecen multas por la contratación de menores sin los resguardos legales requeridos. Su incumplimiento es sancionado con multas al empleador. Se aplican disposiciones similares en el Ecuador y Nicaragua, o por el trabajo de menores de 18 años en Honduras, menores de 15 años en el Paraguay y menores de 14 en Guatemala. El trabajo de los adolescentes también es regulado en el Estado Plurinacional de Bolivia mediante contratos de aprendices. En el Brasil se prohíbe el trabajo de menores de 14 años. Con otros límites de edad y exigencias de un representante legal, existen restricciones similares en El Salvador, México y el Paraguay.

Para la etapa de la vida laboral, existe un amplio abanico de regulaciones destinadas a garantizar condiciones de trabajo adecuadas para enfrentar los riesgos de precariedad y desprotección. Por un lado, hay normas que aseguran el derecho a percibir un salario mínimo establecido según las modalidades especiales de cada país. Por otro, en todos los casos, hay normas que regulan el acceso y reconocen la obligación de proteger al trabajador ante accidentes del trabajo y enfermedades profesionales. Esta responsabilidad recae siempre en el empleador, y no se circunscribe 
a garantizar una indemnización en caso de accidente o enfermedad profesional (la que puede implementarse mediante la contratación de un seguro). Se hace hincapié en que los empleadores dispongan las condiciones de seguridad adecuadas para prevenir dichas situaciones. Por ejemplo, en la Argentina se aplica la suspensión de faenas ante riesgo grave o inminente. En la mayoría de los casos se establecen multas por incumplimiento de las normas.

También recae en el empleador la obligación de inscribir al empleado en los sistemas de seguridad social. De modo similar, en todos los países existen regulaciones que protegen al trabajador ante el despido arbitrario. Se trata de garantizar un pago en compensación por el incumplimiento del contrato por parte del empleador, o cuando no exista causa justificada para el despido.

Además, en los respectivos códigos del trabajo se encuentran incluidas las materias destinadas a asegurar el derecho a la protección de los sistemas de seguridad social. En el caso de la vejez, se trata de proveer la correspondiente protección después de la vida activa, en condiciones diversas según el país de que se trate.

Junto con la obligación de inscribir a los trabajadores en los seguros sociales, se debe informar sobre los aportes efectuados, como se hace en la Argentina. Por otra parte, con frecuencia se considera causa justa para poner término al contrato de trabajo si el trabajador se hace beneficiario de una pensión o jubilación, como sucede en Colombia, Costa Rica, Guatemala, Honduras y El Salvador. En muchos casos, se establece una compensación monetaria, ya sea como un monto equivalente a desahucio en la República Dominicana, a un salario adicional en Nicaragua o a los aportes realizados al Fondo de la Vivienda para los Trabajadores en México.

También se advierten situaciones especiales, como el retiro forzoso de los mayores de 65 años en el Estado Plurinacional de Bolivia, salvo acuerdos de permanencia que no superen los 3 años. Otra situación especial se da en El Salvador, donde tienen derecho a ser jubilados por sus empleadores los trabajadores que hayan prestado servicios durante 25 años en forma continua o discontinua.

En el cuadro III.7 se presenta una lista detallada del contenido de las regulaciones laborales, según etapas del ciclo de vida y riesgos principales de desprotección. 


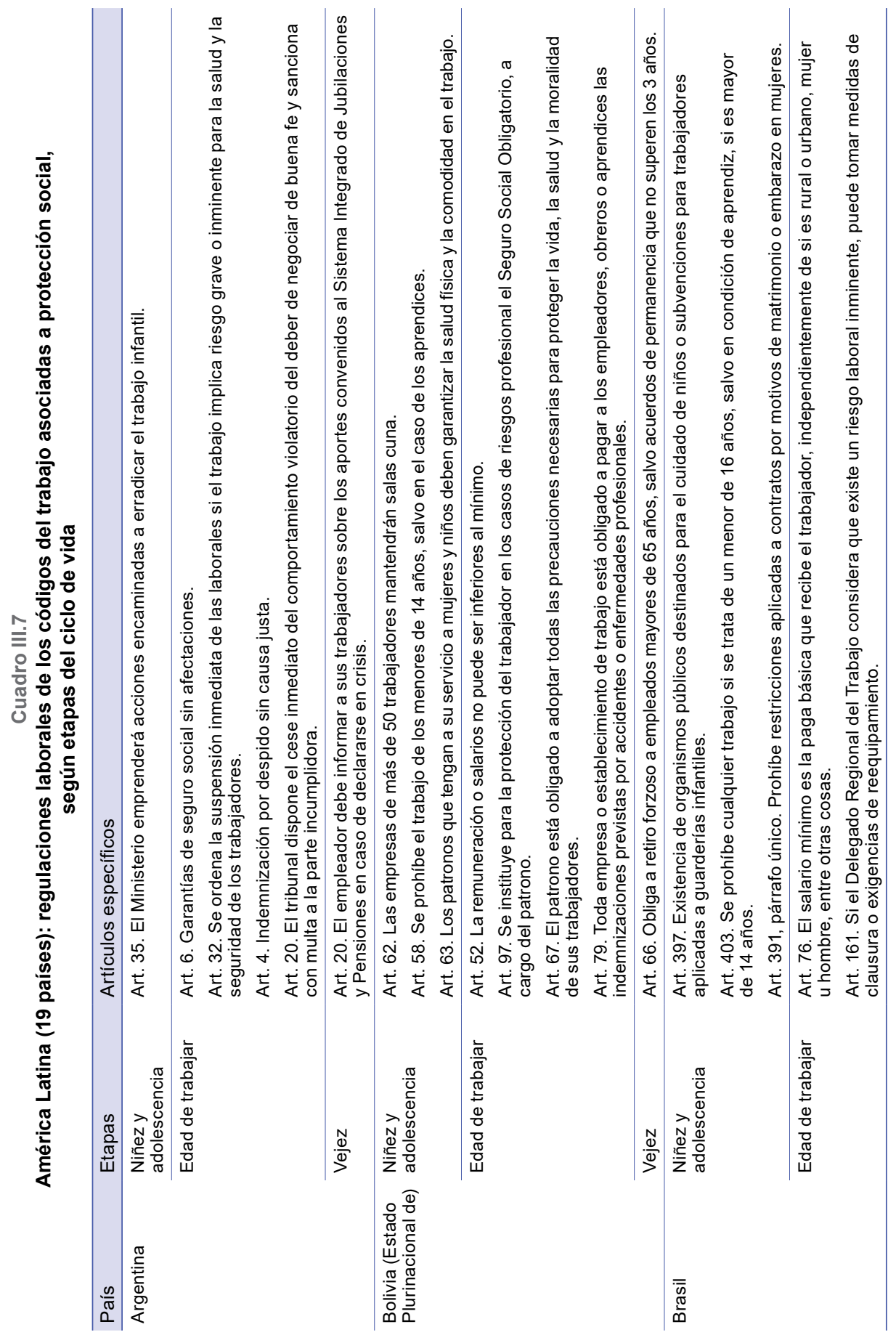




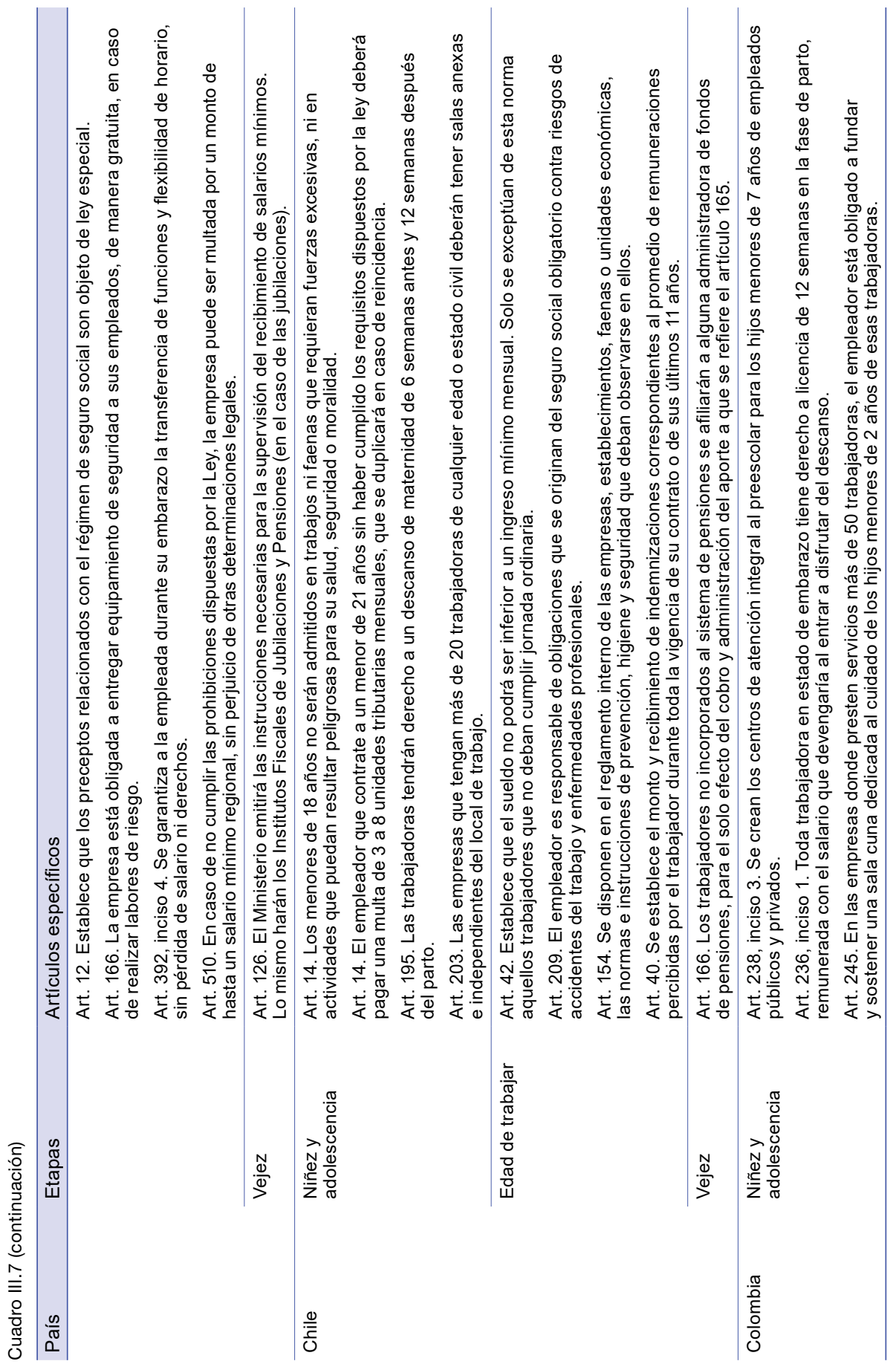




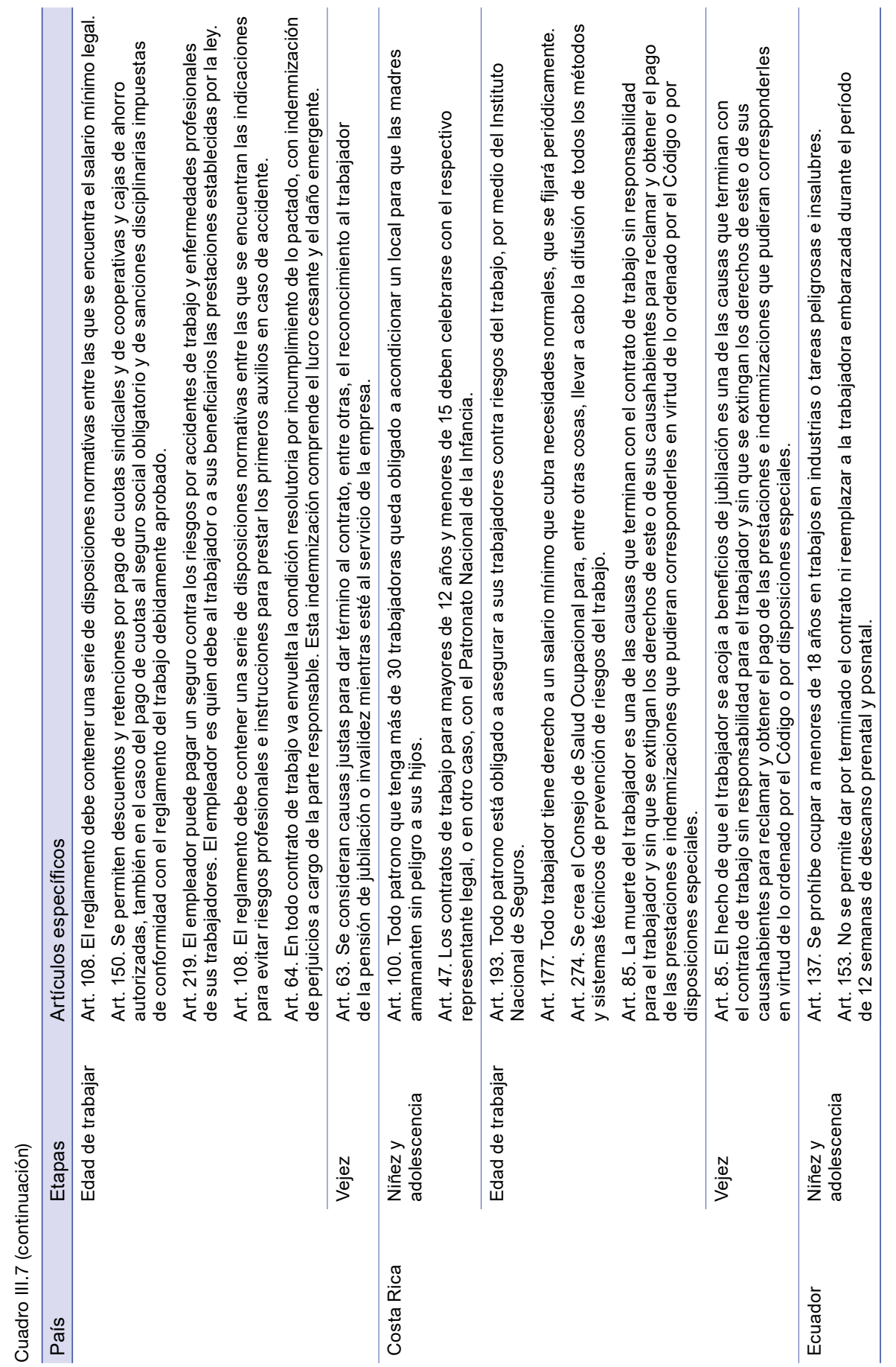




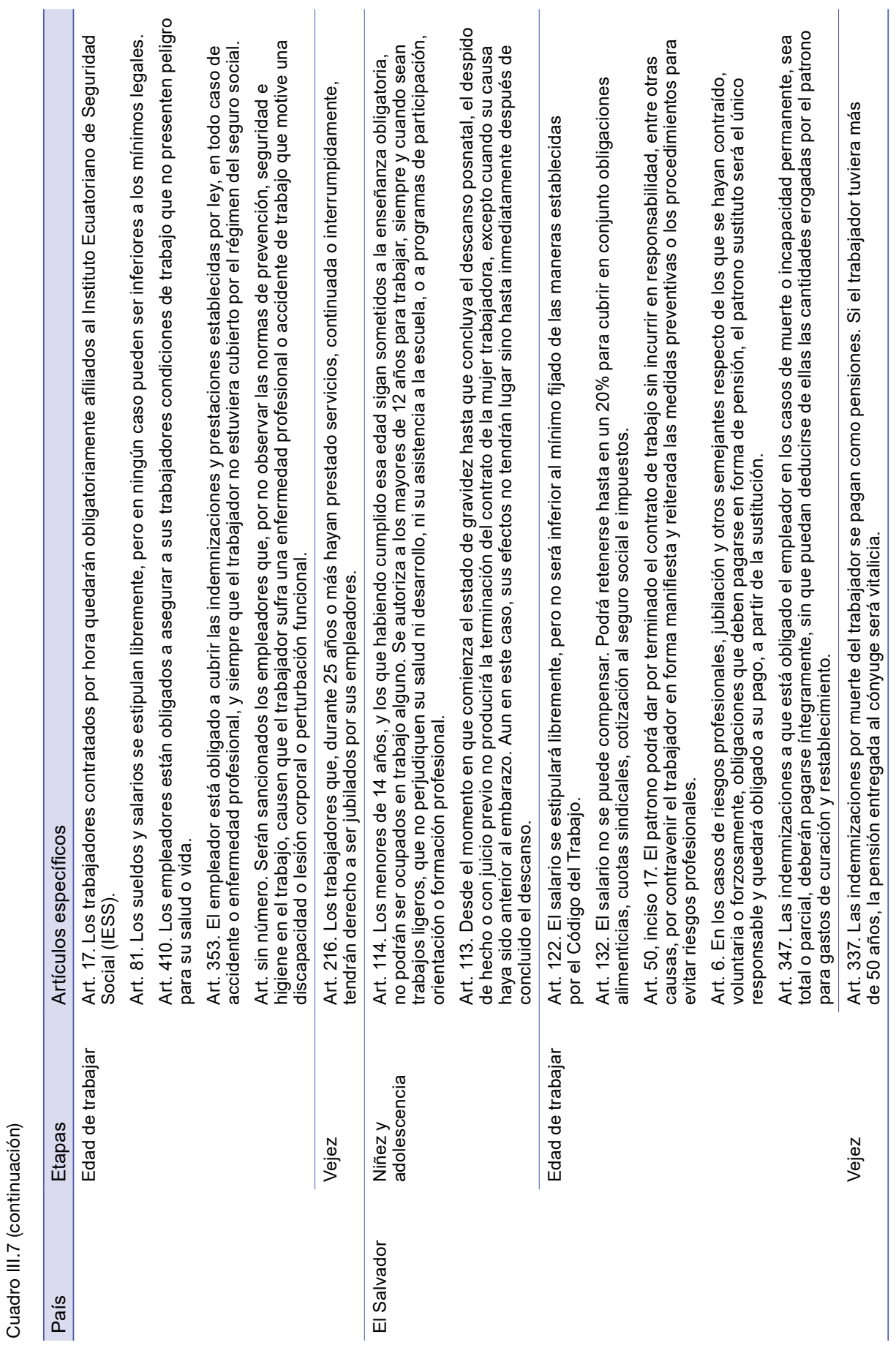




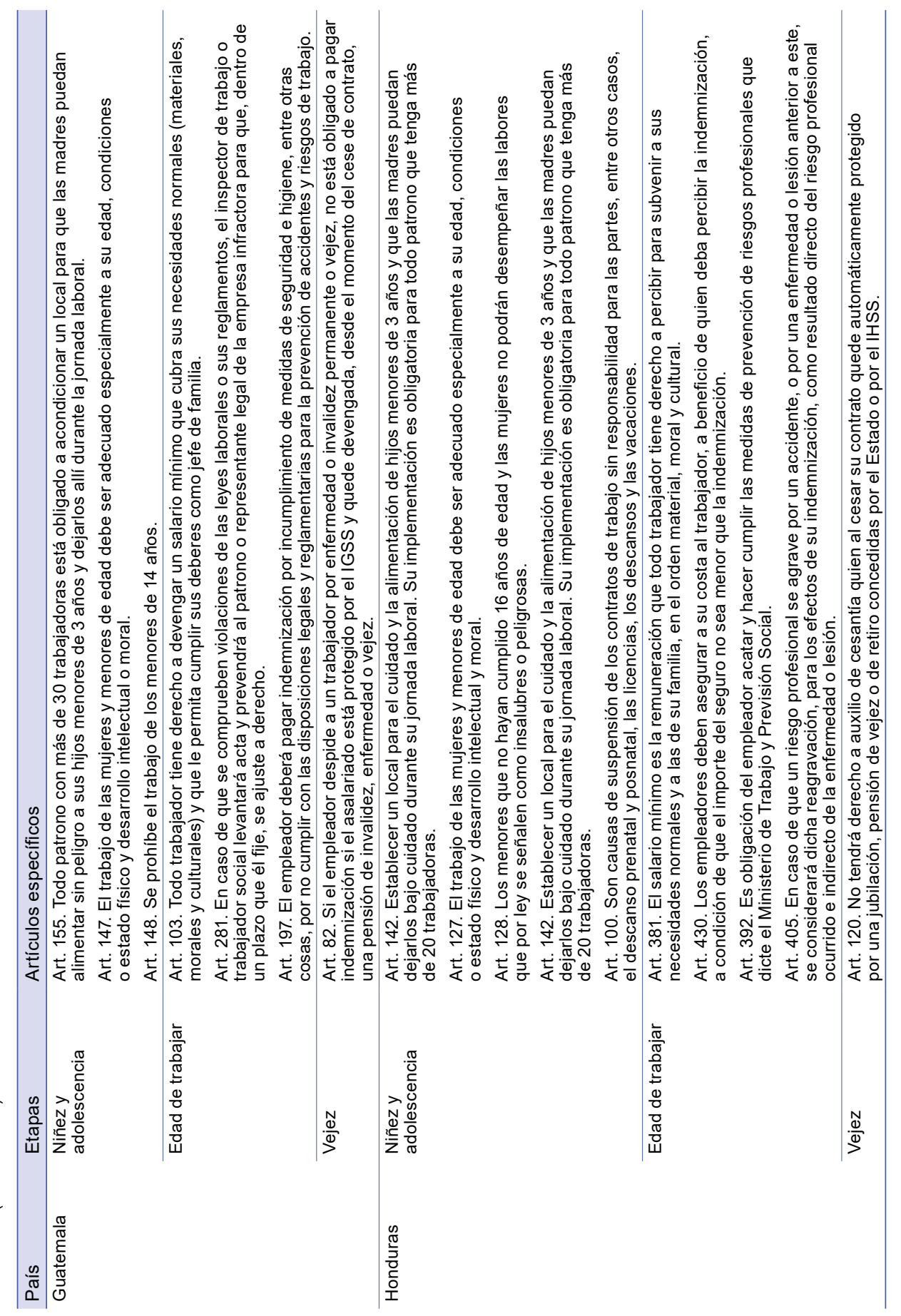




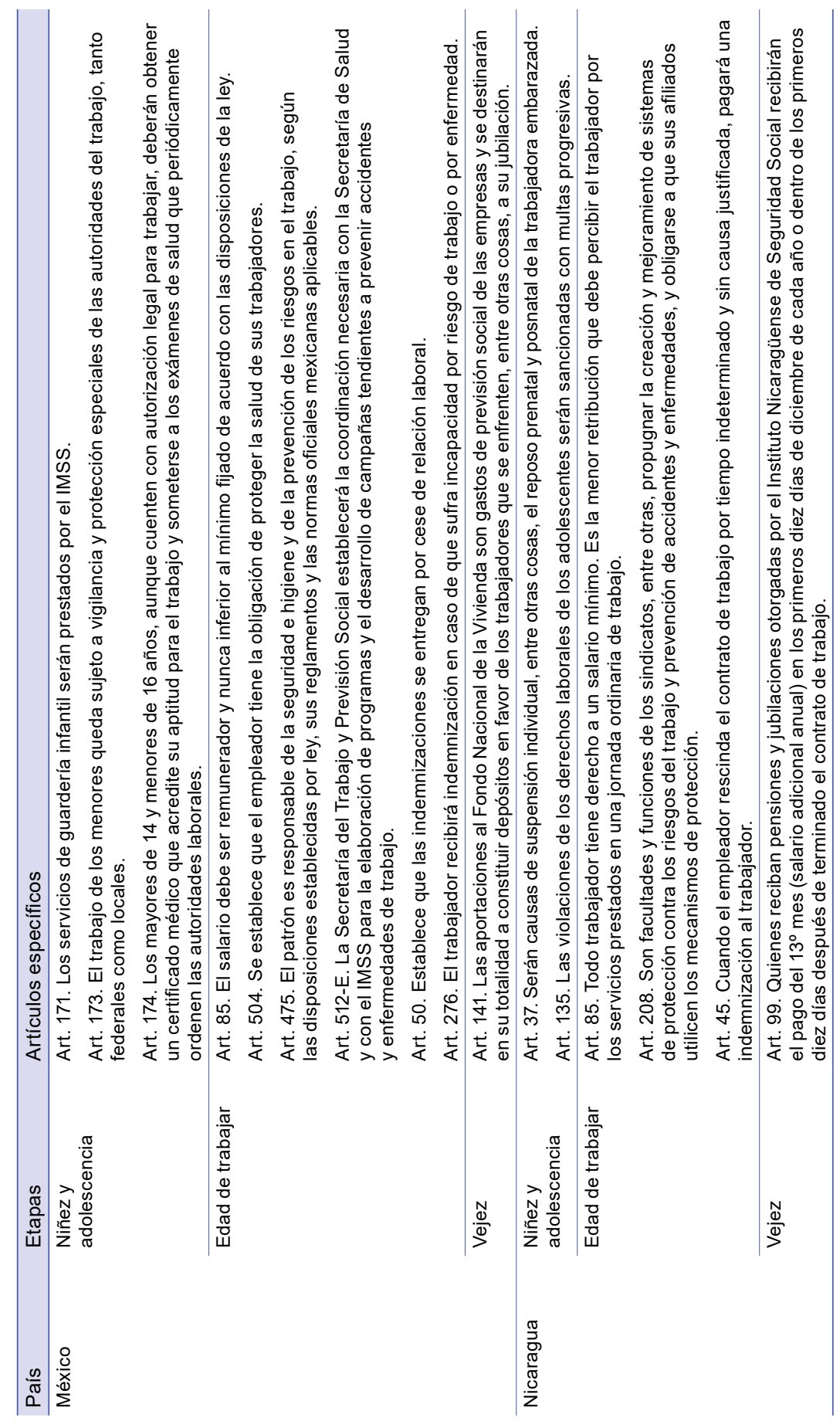




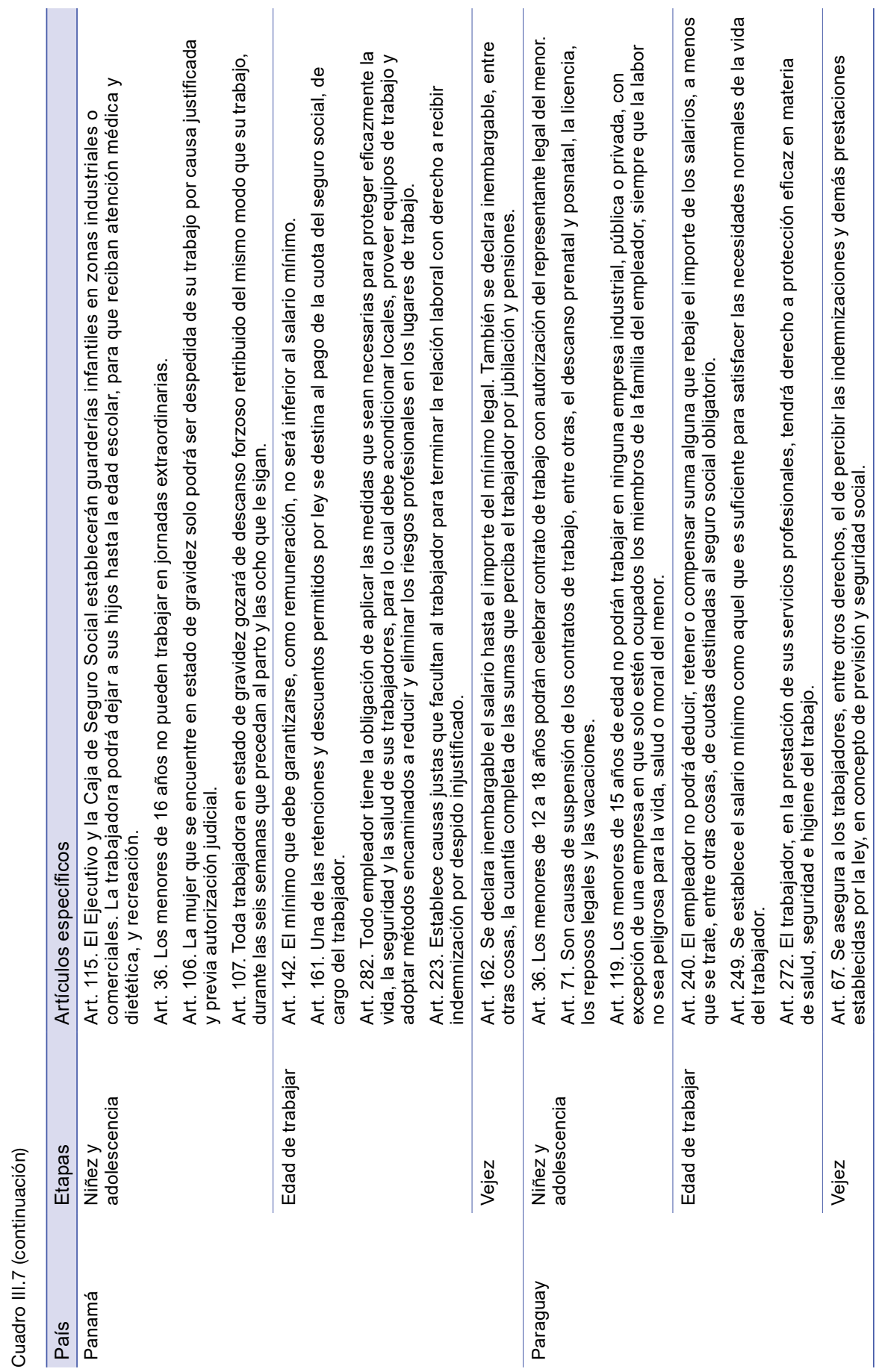




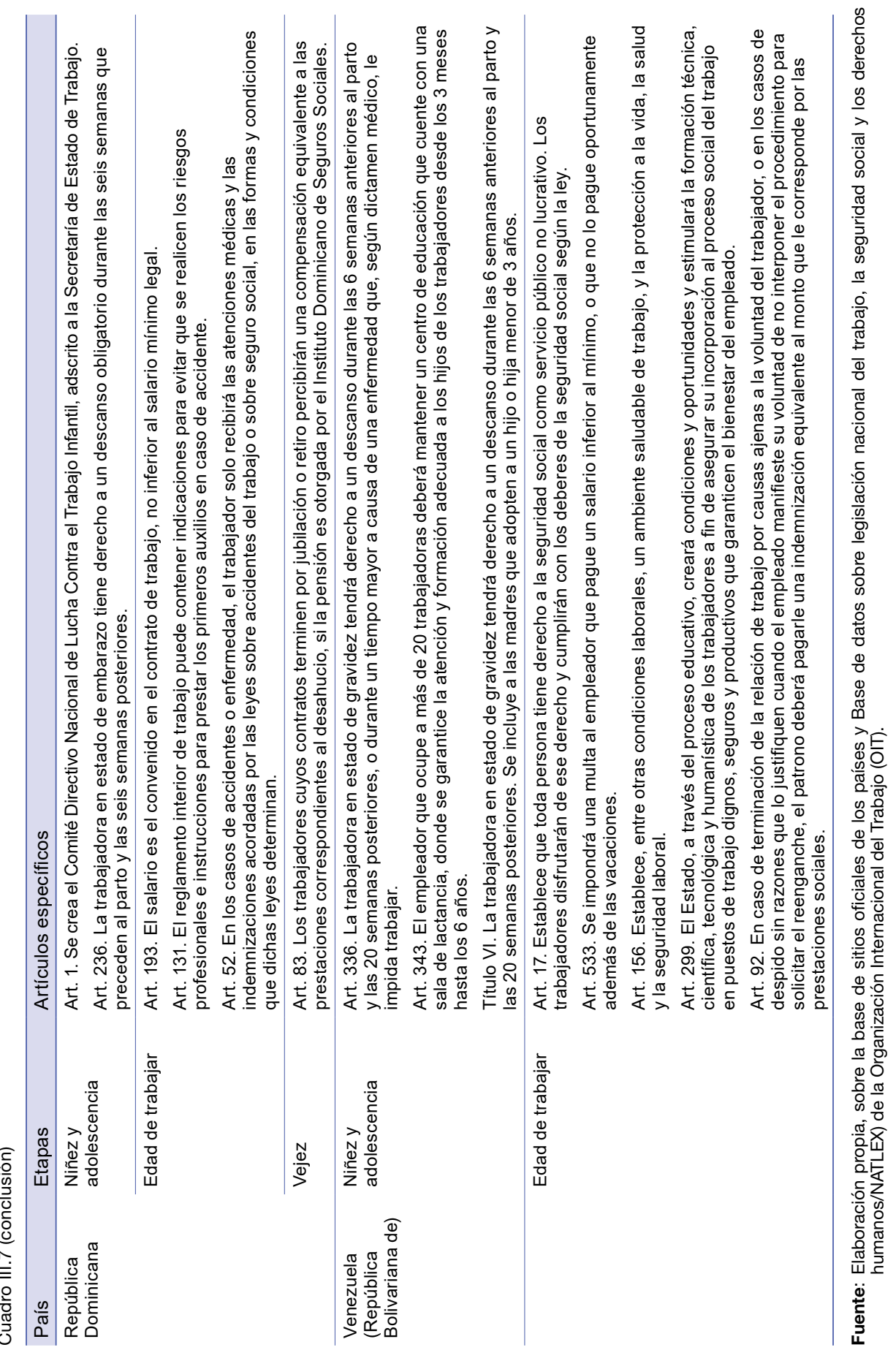




\section{Dimensión organizacional para el cumplimiento de la regulación}

Como se indica en el capítulo I, no es suficiente la existencia de regulaciones para asegurar los efectos deseados en la protección social durante el ciclo de vida. La fortaleza institucional de la autoridad rectora de las políticas, y de los distintos actores que componen la organización a cargo de implementarlas, es determinante para asegurar el cumplimiento de la matriz normativa ${ }^{11}$.

En este apartado se describen las principales instancias de gobierno responsables de la generación, aplicación y fiscalización del cumplimiento del conjunto de normas y regulaciones del trabajo analizadas.

\section{La administración del trabajo}

La administración del trabajo como ámbito de gobernanza se remonta a la segunda mitad del siglo XIX'12. El objetivo era regular los mercados laborales mediante una intervención sistemática y continua del gobierno, a fin de mejorar las condiciones de trabajo y preservar el equilibrio entre los intereses de los empleadores y de los trabajadores. La principal motivación de los gobiernos era mantener la paz social y evitar conflictos sociales importantes. Gradualmente, se fueron creando instituciones, desde las primeras inspecciones del trabajo y oficinas de empleo, hasta los ministerios de trabajo.

La OIT señala tres modelos principales de estructura y organización de un ministerio de trabajo que no se excluyen entre sí y que en un mismo país a menudo se combinan: i) gestión directa (la mayor parte de las actividades son competencia del propio ministerio y de sus departamentos); ii) gestión indirecta (la gestión se realiza a través de departamentos descentralizados), y iii) gestión delegada (el recurso a órganos independientes existentes o nuevos, de los que se ocupa el ministerio). Cualquiera que sea el modelo elegido o su combinación, por lo general, un ministerio de trabajo consta de unidades que pueden agruparse en tres categorías principales: i) departamentos técnicos; ii) servicios de apoyo a la gestión, y iii) servicios administrativos generales, como se ilustra en el diagrama III.1.

11 La capacidad o fortaleza institucional puede concebirse como la habilidad de los ministerios para desempeñar sus funciones en la administración del trabajo, y movilizar y adaptar sus recursos con miras a elaborar políticas. En esta se identifican los componentes administrativos en el nivel micro de los recursos humanos, en cuanto a su suficiencia y pertinencia para el desarrollo de las tareas institucionales, y en el nivel meso, que alude al diseño organizacional y la consistencia respecto a los objetivos organizacionales. Se agrega el componente político, que se relaciona con la habilidad para impulsar los objetivos de la organización, considerando el entorno de relaciones con los actores políticos, el Estado y otros individuos o grupos que operan en el área de los asuntos públicos. Véase una discusión sobre este concepto en Velásquez (2011).

12 Basado en OIT (2011). 
Diagrama III.1

Estructura organizativa clásica de un ministerio de trabajo

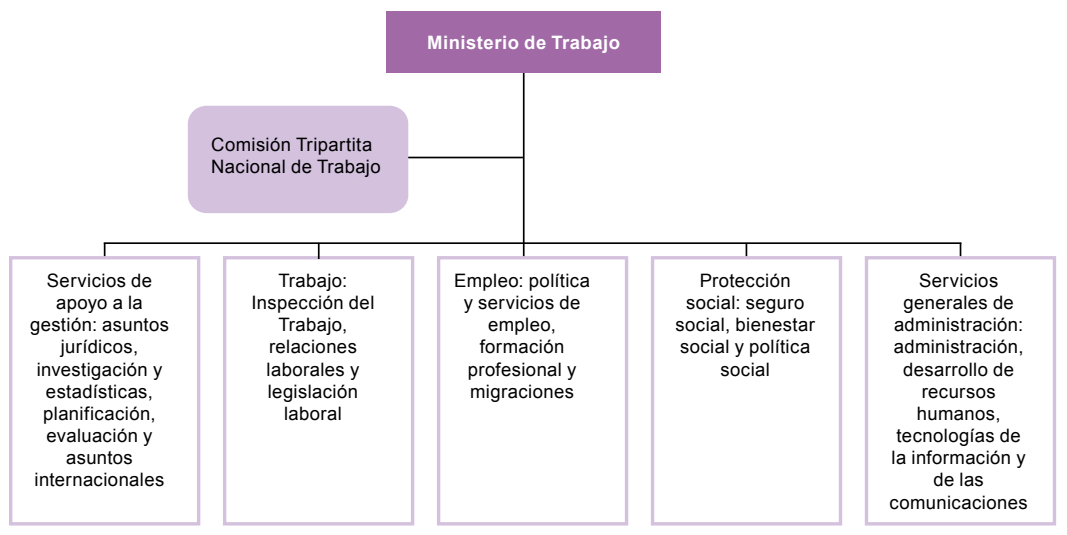

Fuente: Organización Internacional del Trabajo (OIT), "Administración del trabajo e inspección del trabajo", Conferencia Internacional del Trabajo, 100冈 reunión, 2011 [en línea] http://www.ilo.org/ wcmsp5/groups/public/---ed_norm/---relconf/documents/meetingdocument/wcms_153936.pdf.

Los servicios de apoyo a la administración se ocupan de gestionar los recursos humanos, materiales y financieros. Por su parte, los de apoyo a la gestión son de vital importancia para un funcionamiento adecuado y suelen comprender las áreas de planificación, programación, evaluación, asesoramiento jurídico, redacción de textos jurídicos, relaciones internacionales, investigación y estadísticas. Estos cumplen una función clave en la formulación de las políticas, planes y programas del ministerio y requieren de personal bien instruido y con experiencia, cuyos conocimientos superen la esfera laboral.

En la mayoría de los ministerios, las unidades técnicas se encargan de áreas temáticas, como las de relaciones laborales, legislación, empleo, seguridad social, inspección del trabajo y condiciones de trabajo. Se ocupan de supervisar la administración y aplicación de las políticas y la legislación en materia laboral, redactar nuevas políticas y textos de leyes, y prestar asesoramiento e informar sobre su aplicación. También suelen ocuparse del análisis estadístico de datos y de elaborar informes descriptivos del terreno; crear y mantener bases de datos nacionales; preparar informes anuales, y celebrar consultas directas con las organizaciones de empleadores y de trabajadores. Una función específica de un ministerio de trabajo es la de apoyar el diálogo social interprofesional o intersectorial, promover la negociación colectiva y mediar entre las partes en caso de conflicto laboral. De ordinario, el ministerio tiene un departamento específico a cargo de las relaciones laborales, que presta asistencia en la negociación colectiva y la mediación, entre otros ámbitos. 
A lo largo del tiempo, la función de los ministerios de trabajo pasó de su orientación original de protección, aplicación y sanción, a una que suponía un mayor protagonismo en el desarrollo económico de los países; sobre todo en los ámbitos de la política de empleo y la protección social. Así, dentro de las funciones tradicionales de protección mediante la regulación de las condiciones de trabajo, en la que destaca la inspección laboral, en los últimos decenios ha adquirido mayor importancia el componente de empleo (formular políticas de empleo y políticas pasivas o activas del mercado de trabajo) y seguridad social.

La configuración de los sistemas de administración del trabajo y sus instituciones varía en función de las características de cada país, aunque también se observan algunas similitudes. Si bien la autoridad en los sistemas nacionales de administración del trabajo suele ser el Ministerio de Trabajo, algunas políticas conexas son a menudo una responsabilidad exclusiva o compartida con otras carteras, como los ministerios de asuntos sociales o desarrollo social, economía, finanzas, educación, salud, interior o juventud.

También es frecuente que la prestación de servicios sea delegada en órganos paraestatales. Por ejemplo, puede dividirse entre organismos especializados en colocación, formación profesional, seguridad y salud en el trabajo, mediación y arbitraje, o administración de los diversos regímenes de protección social, ya sea en materia de previsión o de desempleo. Ahora bien, dichos órganos presentan grados distintos de autonomía en cuanto a la gestión, el financiamiento y la prestación de servicios. Al respecto, y aunque se deleguen funciones en estas entidades, es fundamental que el ministerio continúe desempeñando su función de rectoría y formulación de políticas y que ello no implique el debilitamiento de sus funciones técnicas, debido a la emigración de personal calificado que suele verificarse en estos casos.

De acuerdo con la información disponible, la responsabilidad principal respecto de la generación, aplicación y fiscalización de las normativas laborales entre los países latinoamericanos recae en los ministerios o secretarías de trabajo (véase el cuadro III.8). Estos, a su vez se organizan en áreas de especialización funcional de trabajo y seguridad social. En relación con esas ramas se disponen, en un segundo nivel, un viceministerio (Colombia, Ecuador, Guatemala, Panamá, Paraguay y Perú), direcciones generales (Bolivia (Estado Plurinacional de), El Salvador, Honduras y Uruguay) o secretarías (Argentina, Brasil, Chile y México). De estas direcciones dependen a su vez, direcciones generales, subdirecciones o subsecretarías, respectivamente, que muestran un mayor grado de especialización según las áreas funcionales a que corresponden. 


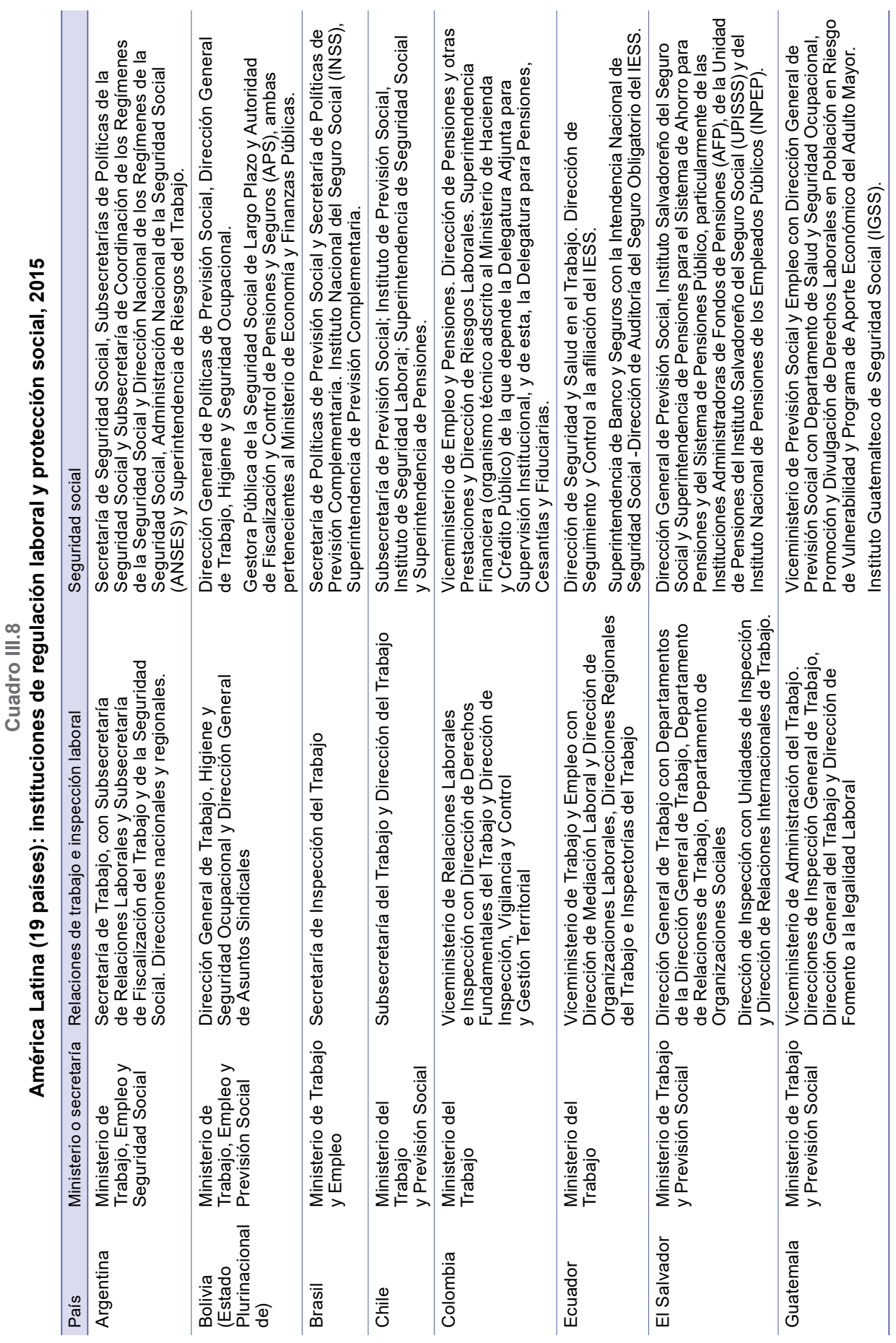




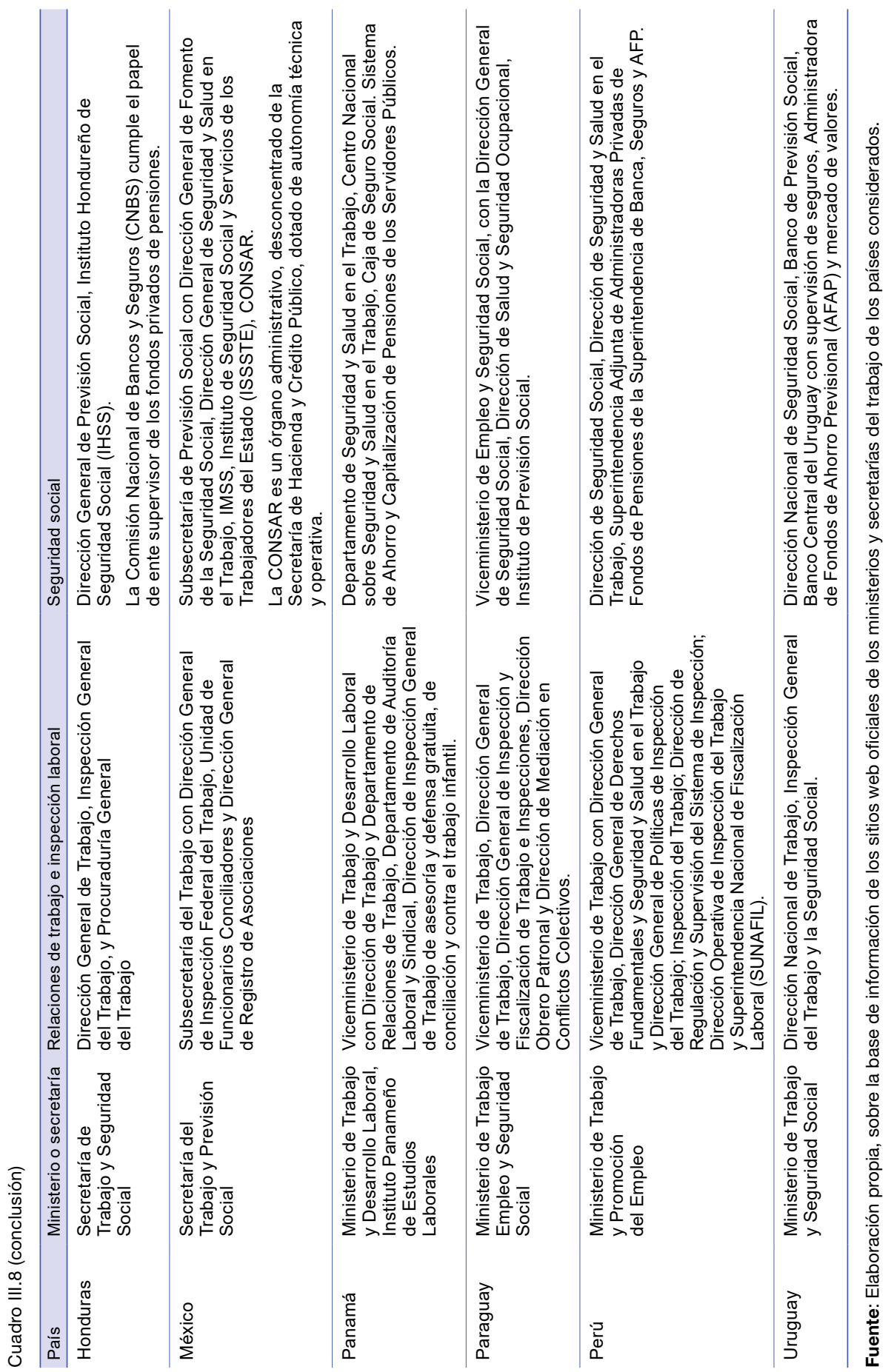


En el área de trabajo, las subdivisiones en el nivel señalado consideran normalmente direcciones de trabajo orientadas a la fiscalización del cumplimiento de las normas laborales. A su vez, pueden contar con unidades dependientes especializadas en las inspectorías del trabajo (con sus reparticiones al nivel territorial), en relaciones laborales (organizaciones sociales) y en materias de mediación en conflictos laborales.

Con diseños institucionales variados, en los países de la región se desempeña la mayoría de estas funciones. Las diferencias principales se advierten en que, en algunos casos, en el área de trabajo se incluyen los asuntos relacionados con las condiciones de seguridad y salud laboral (Argentina, Bolivia (Estado Plurinacional de), Perú y Uruguay), lo que muestra la decisión de coordinar bajo una única dirección las acciones en materia de trabajo y seguridad laboral. En otros casos, existen unidades especializadas que desarrollan funciones de promoción y procuraduría para el cumplimiento normativo, como sucede en Guatemala (Dirección de Fomento a la Legalidad Laboral), Honduras (Procuraduría General del Trabajo) y Panamá (Asesoría y Defensa Gratuita), lo que ilustra la idea de desplegar una variedad de acciones para promover el cumplimiento de las normas más allá de la vía de la fiscalización y sanción por incumplimiento. En todo caso, la mención de las experiencias señaladas no implica que estas acciones no tengan lugar en los demás países, sino que suelen estar incorporadas en las modalidades de inspección laboral existentes.

Cabe destacar el caso de la Superintendencia Nacional de Fiscalización Laboral (SUNAFIL), creada en el Perú en 2014, como una experiencia con que se busca proporcionar un servicio especializado en la supervisión del cumplimiento de las normas, que depende directamente del viceministerio encargado y requiere una estrecha coordinación con la Dirección de Regulación y Supervisión del Sistema de Inspección. El seguimiento y la evaluación a mediano plazo de este nuevo diseño institucional son de especial interés desde el punto de vista del análisis de la efectividad del cumplimiento de normas y sus efectos en la protección social.

Por otra parte, en el área de la seguridad social, los ministerios suelen disponer de una estructura similar a la señalada en el ámbito del trabajo, en particular, en materia de diseño y generación de normas y políticas. Cabe mencionar las direcciones de seguridad de salud laboral y las direcciones de previsión social como parte de los organismos de línea de muchos de los ministerios o secretarías de trabajo. Sin embargo, como se indicó con anterioridad, en esta área, y sobre todo en la de pensiones, 
es donde se verifica la existencia de superintendencias y entidades especializadas y autónomas de los ministerios del trabajo, que tienen la misión exclusiva de supervisar la administración de los diversos sistemas que operan en ella.

Tal vez el caso que mejor ilustra este diseño organizacional es el de Chile, donde se dispone de dos superintendencias: i) la Superintendencia de Pensiones, que tiene por finalidad proteger el patrimonio de los cotizantes de las administradoras de fondos de pensiones, supervisar la operación del Pilar Solidario de pensiones y el funcionamiento del Seguro de Cesantía, y ii) la Superintendencia de Seguridad Social, que fiscaliza el desempeño de las entidades que operan el seguro de accidentes del trabajo y enfermedades profesionales, entre otras. En ambos casos se mantiene la dependencia del Ministerio del Trabajo y Previsión Social, y de la Subsecretaría de Previsión Social en materia de diseño y generación de la normativa por la que se rigen los distintos sistemas supervisados.

Una situación como la descrita se presenta en la mayoría de los países respecto de los que se ha levantado información en el área de pensiones (véase el cuadro III.8). En efecto, la regularidad que se muestra radica en si existe una superintendencia (comisión o banco) creada para vigilar la administración de los fondos de pensiones, y que no depende del Ministerio de Trabajo.

Estos son los casos de la Gestora Pública de la Seguridad Social de Largo Plazo y la Autoridad de Fiscalización de Pensiones y Seguros (APS), ambas pertenecientes al Ministerio de Economía y Finanzas Públicas en el Estado Plurinacional de Bolivia; la Superintendencia Financiera (adscrita al Ministerio de Hacienda y Crédito Público), de la que depende la Delegatura para Pensiones en Colombia; la Superintendencia de Banco y Seguros con la Intendencia Nacional de Seguridad Social-Dirección de Auditoría del Seguro Obligatorio del IESS en el Ecuador; la Superintendencia de Pensiones para el Sistema de Ahorro para Pensiones y del Sistema de Pensiones Público en El Salvador; la Comisión Nacional de Bancos y Seguros (CNBS) en Honduras; la Comisión Nacional del Sistema de Ahorro para el Retiro (CONSAR), dependiente de la Secretaría de Hacienda y Crédito Público en México; la Superintendencia Adjunta de Administradoras Privadas de Fondos de Pensiones de la Superintendencia de Banca, Seguros y AFP en el Perú, y el Banco Central del Uruguay, con la supervisión de seguros, las Administradoras de Fondos de Ahorro Previsional (AFAP) y el mercado de valores. 
Por lo general, las situaciones mencionadas han sido justificadas por sus diseñadores en función de las debilidades institucionales que caracterizan el funcionamiento de los ministerios de trabajo $y$, en particular, la administración financiera de los fondos de ahorro para pensiones. En todo caso, esta es un área potencial de tensiones interinstitucionales, pues la rectoría del sistema, y su diseño y normativa, siguen siendo un ámbito propio de los ministerios de trabajo y previsión social, y dichos ministerios deben fortalecer su capacidad en la materia.

\section{La vía administrativa}

La policía de trabajo o inspección del trabajo es la entidad del Estado destinada a verificar el cumplimiento de las normas laborales y de seguridad social, y a sancionar las infracciones. La naturaleza de su actuación es la de fiscalización del comportamiento del empleador. Este puede derivar en delitos de naturaleza penal sobre sus trabajadores ${ }^{13}$. En este sentido, la inspección es la médula de efectividad de las normas laborales existentes (Vega, 2009).

\section{a) Factores clave y caracterización de los sistemas}

A continuación se examinan algunos factores que permiten caracterizar los sistemas de inspección laboral e identificar condiciones clave para su funcionamiento ${ }^{14}$. Estos sistemas pueden ser generales o especializados, según si existe o no distribución de responsabilidades de materias entre los diferentes servicios de inspección. A los sistemas generales les incumbe, por ejemplo, el control de las condiciones de trabajo y de empleo, así como de las cuestiones relativas al entorno de trabajo y las relaciones laborales. En algunos casos, también les incumben la formación profesional, la migración y la seguridad social. Por su parte, los sistemas especializados se orientan a contenidos determinados y suelen ser supervisados por una o más unidades centrales. Entre ambas categorías, existen sistemas basados en equipos interdisciplinarios, en que un solo inspector posee las competencias profesionales necesarias para brindar un servicio multifuncional en cada servicio local de inspección del trabajo.

En numerosos países los servicios de inspección tienen competencia en la solución de conflictos, la participación en la negociación de convenios colectivos a iniciativa de las partes, la recopilación y valoración de datos

13 Cuando la inspección del trabajo detecta incumplimientos que derivan en faltas de tipo penal, estas suelen estar vinculadas a la trata de personas y al trabajo infantil, como ha sucedido en la Argentina y el Brasil.

14 Basado en Loyo y Velásquez (2015) y OIT (2011). 
socioeconómicos e informes técnicos para las autoridades laborales, y otras funciones de registro y de carácter administrativo. Algunos incluyen la vigilancia e implementación de los derechos colectivos o se les asignan atribuciones en materia de despidos, como es el caso de Chile, Colombia y Venezuela (República Bolivariana de), mientras que otros excluyen o restringen esta posibilidad (Bensusán, 2009). El abanico de funciones atribuidas es muy variado y responde a culturas y tradiciones nacionales diferentes.

De lo anterior se desprende que la inspección del trabajo es una institución de naturaleza mixta. Por una parte, fiscaliza la aplicación de la ley, mientras que, por otra, presta servicios de información, formación y consulta. La inspección es un órgano público calificado, que une la realidad laboral con la administración de trabajo. En algunos países llega a convertirse en órgano de consulta institucionalizada para planificar la política social y la legislación.

La inspección previene, informa y actúa sin tener que recurrir siempre a la represión o la sanción. Evita conflictos en su origen y soluciona problemas laborales de hecho, sin que medie una sentencia judicial. Además, al tener la posibilidad de sancionar según su propia apreciación, su acción tiene el potencial de ser doblemente efectiva.

Sumada a la función de control general sobre las disposiciones legales estrictamente relativas a las condiciones de trabajo y a la protección de los trabajadores, la labor de la inspección también tiende a evitar riesgos laborales, lo que constituye su dimensión preventiva. Si su función esencial es hacer cumplir las normas y proporcionar asesoría técnica e información al respecto, el papel preventivo también es parte de ese cometido. En la mayor parte de los países los inspectores articulan de facto los enfoques preventivo y represivo, ya que su actuación no tiende tanto a buscar la infracción para sancionarla, sino más bien a lograr el respeto y la aplicación de la norma.

Las funciones de control y de asesoramiento son complementarias, ya que con ellas se busca la aplicación objetiva de las disposiciones legales. Esto no implica que la de asesoramiento sustituya a la de control. Las acciones de advertencia o recomendación son fundamentales y, en muchos países, se plasman como un estado intermedio entre el asesoramiento y la sanción, lo que las convierte en una pieza clave del proceso administrativo.

Con el fin de lograr una actuación eficaz del inspector, este debe tener la facultad de ingresar libremente en los centros de trabajo y todo otro lugar donde razonablemente se presuponga que se realice alguna 
actividad laboral. También debe poder llevar a cabo las pruebas, los exámenes y las investigaciones que considere pertinentes y, en especial, interrogar a las partes interesadas, solo o ante testigos, sobre la aplicación de las disposiciones legales. Además, deben ser funcionarios públicos profesionales e independientes, cuya contratación se realice en función de aptitudes comprobadas y cuyo empleo sea estable.

En la actualidad, la inspección del trabajo aparece como sustento de la administración del trabajo, uno de los pilares del tripartismo. En su doble faceta de representación del Estado y actuación directa en las relaciones laborales, es la institución más indicada para apoyar el desarrollo, a pequeña y mediana escala, de las múltiples dimensiones del diálogo social y las relaciones laborales. El tripartismo en la inspección no solo crea un sentido de apropiación del proceso, sino que brinda a las partes una forma de intervención directa y la comprensión de las formas de trabajar para conseguir los fines (Erikson, 2005).

La educación de los actores sociales sobre las disposiciones legales y su aplicación, así como la prevención de los riesgos para garantizar la salud o la vida de las personas, potencian la eficacia de la inspección, con la participación de todos los asociados en la relación de trabajo. En esta dimensión, los consejos consultivos tripartitos del trabajo ofrecen un espacio privilegiado para comunicar información a las organizaciones de empleadores y de trabajadores.

A modo de ejemplo, en el cuadro III.9 se presenta una caracterización de los sistemas de inspección del trabajo del Brasil y Chile (que se ubican entre los de mayor grado relativo de desarrollo en la región), sobre la base de los principios orientadores de la OIT. No obstante los casos concretos del Brasil y Chile, el panorama general en la región sobre la materia se caracteriza por marcadas debilidades institucionales, en sus distintas dimensiones. Entre ellas cabe mencionar las limitaciones que impiden que los ministerios dispongan efectivamente de facultades legales para ejercer la rectoría y potenciar la labor de los inspectores, así como contar con la capacidad operativa y de recursos humanos que exige el eficaz desempeño de esta función. También se observa la necesidad de desarrollar modalidades de coordinación con otras entidades especializadas sectoriales en labores de fiscalización y en la promoción de la participación de los actores laborales en el diseño, seguimiento y evaluación de tales acciones, con el objetivo de ampliar la gama de materias observadas y la necesidad de cubrir diversos sectores productivos y áreas geográficas (Loyo y Velásquez, 2015). 


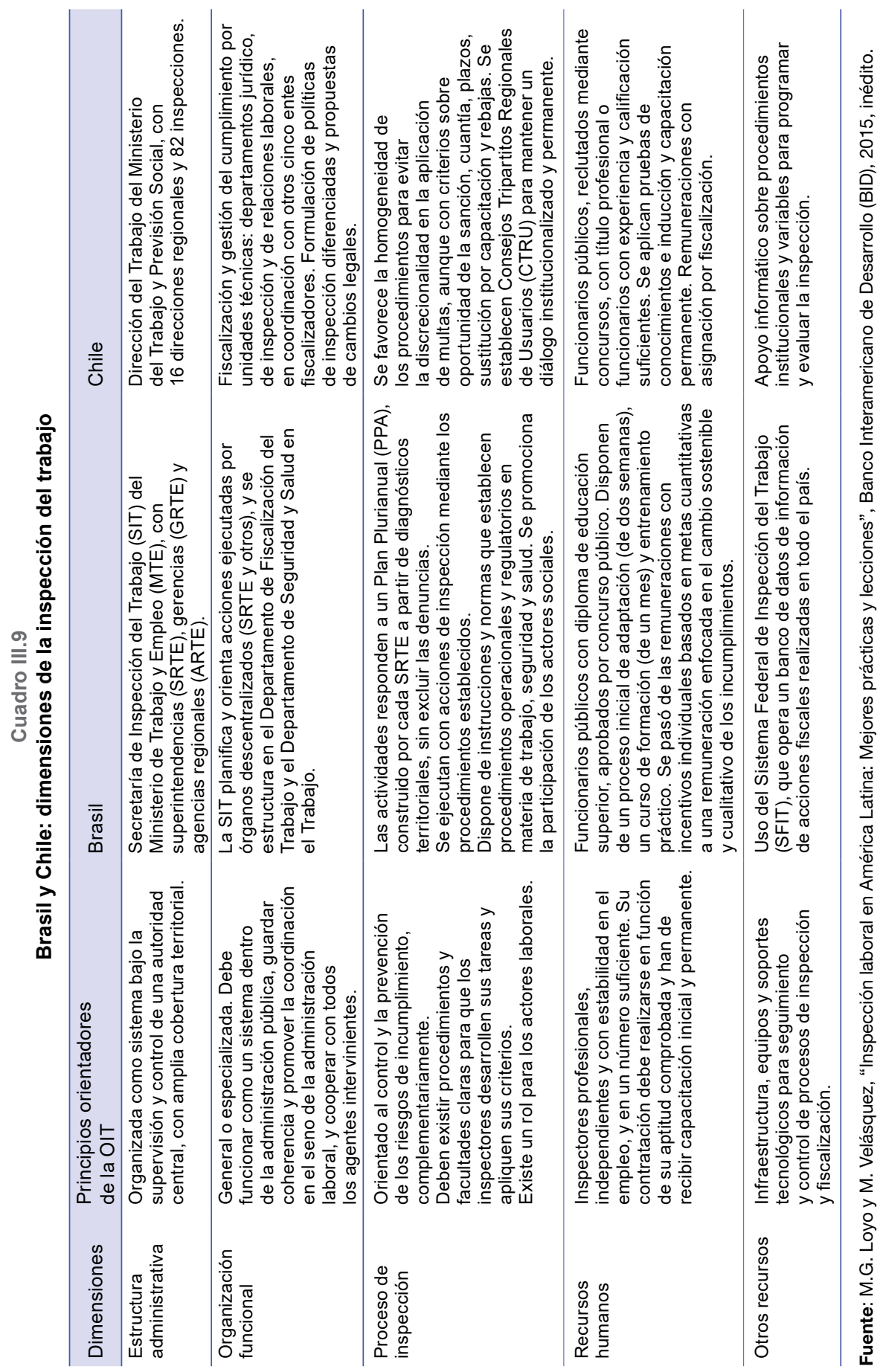




\section{b) Fortaleza institucional}

Junto con los aspectos de diseño, estructura organizacional y funciones complementarias ya observados, es clave para el análisis tener una visión sobre la fortaleza institucional (capacidad de gestión) de los servicios de inspección laboral.

En el cuadro III.10 se presenta un conjunto de indicadores seleccionados. A modo de referencia, en la primera columna se indica el número absoluto de inspectores del trabajo por país. En la segunda se muestra la proporción que representa la dotación de inspectores respecto del total de empleados del sector público, como medida indirecta de la importancia que cada Estado otorga al desarrollo de estas funciones. Chile, Colombia, Panamá y el Uruguay se ubican en los primeros lugares respecto del promedio simple calculado, aunque se trata de proporciones poco significativas respecto del parámetro de comparación. Las más bajas se registran en México, el Paraguay y Venezuela (República Bolivariana de). Luego se muestra la relación entre el número de inspectores del trabajo y el total de asalariados del sector privado. Esto da una idea de la cobertura potencial media, si se considera que el estándar de la OIT es de un inspector por cada 40.000 trabajadores (0,0025\%) en países de menor desarrollo relativo. La mayoría de los países superan dicho estándar (sobre todo Chile, Panamá y el Uruguay), mientras que México, el Paraguay y Venezuela (República Bolivariana de) no lo superan.

Cuadro III.10

\section{América Latina (14 países): fortaleza de la inspección laboral, indicadores seleccionados}

\begin{tabular}{|c|c|c|c|c|c|}
\hline Países & $\begin{array}{c}\text { Total de } \\
\text { inspectores } \\
\text { (en número } \\
\text { de personas) }\end{array}$ & $\begin{array}{l}\text { Inspectores/ } \\
\text { empleados } \\
\text { públicos } \\
\text { (en porcentajes) }\end{array}$ & $\begin{array}{l}\text { Inspectores/ } \\
\text { asalariados } \\
\text { privados } \\
\text { (en porcentajes) }\end{array}$ & $\begin{array}{l}\text { Visitas por } \\
\text { inspector } \\
\text { (promedio } \\
\text { anual) }\end{array}$ & $\begin{array}{l}\text { Empleadores } \\
\text { inspeccionados } \\
\text { (en porcentajes) }\end{array}$ \\
\hline Argentina & 402 & 0,02 & 0,004 & 338,8 & 31 \\
\hline Brasil & 2775 & 0,02 & 0,005 & 99,8 & 12 \\
\hline Chile & 1282 & 0,15 & 0,027 & 84,9 & 32 \\
\hline Colombia & 462 & 0,05 & 0,005 & 26,8 & 1 \\
\hline Costa Rica & 96 & 0,03 & 0,008 & 132,6 & 17 \\
\hline Ecuador & 169 & 0,03 & 0,005 & 141,4 & 12 \\
\hline México & 376 & 0,01 & 0,001 & 131,6 & 2 \\
\hline Nicaragua & 95 & & & 141,5 & 10 \\
\hline Panamá & 217 & 0,09 & 0,025 & 369,8 & 70 \\
\hline Paraguay & 22 & 0,01 & 0,002 & 17,5 & 0 \\
\hline Perú & 386 & 0,03 & 0,007 & 161 & 0 \\
\hline $\begin{array}{l}\text { República } \\
\text { Dominicana }\end{array}$ & 147 & 0,03 & 0,009 & 376,2 & 36 \\
\hline Uruguay & 125 & 0,05 & 0,013 & 166 & 26 \\
\hline $\begin{array}{l}\text { Venezuela } \\
\text { (República } \\
\text { Bolivariana de) }\end{array}$ & 125 & 0,00 & 0,003 & 112,4 & 4 \\
\hline Promedio simple & 477,1 & 0,04 & 0,005 & 164,3 & 18 \\
\hline
\end{tabular}

Fuente: Elaboración propia, sobre la base de Organización Internacional del Trabajo (OIT), Base de datos ILOSTAT. 
Adicionalmente, como medida de la intensidad de la acción que desarrollan los inspectores, se registra el número medio anual de visitas a los centros de trabajo de cada país. Este promedio es mayor en los casos de la Argentina, Panamá y la República Dominicana, y más bajo en Colombia y el Paraguay.

En cuanto a la cobertura de la población inspeccionada en un año, mediante la relación porcentual entre el número de visitas anuales realizadas respecto del total de empleadores, la región muestra un promedio del 18,1\% entre 14 países considerados. Ello implica que, en un quinquenio, teóricamente todas las empresas habrán sido objeto de una inspección. Por encima del promedio señalado, se ubican la Argentina, Chile, Panamá, la República Dominicana y el Uruguay, mientras que las bajas coberturas corresponden a Colombia, México, el Paraguay y el Perú.

En definitiva, desde el punto de vista de la fortaleza de los servicios de inspección laboral se muestra una relación directa entre la dotación de inspectores y la población potencial protegida. Esto sucede en el caso de Chile y Panamá, y el grupo constituido por México, el Paraguay y Venezuela (República Bolivariana de), en que no se logra superar las restricciones propias de una reducida planta de inspectores con una mayor eficacia de las inspecciones, lo que finalmente deriva en una reducida proporción poblacional protegida. En cambio, destaca la capacidad mostrada por la Argentina y la República Dominicana, con alto porcentaje de inspecciones de empleadores, pese a no disponer de una dotación de funcionarios particularmente alta para el desarrollo de estas funciones.

\section{c) Principales resultados en cobertura ante riesgos}

De acuerdo con la matriz de análisis propuesta para el desarrollo de este estudio, a continuación se analizan los resultados obtenidos en diversos ámbitos de protección de los trabajadores, frente a los principales riesgos considerados en el ciclo de vida.

En el cuadro III.11 se expone un conjunto de indicadores que se han seleccionado para ilustrar el estado de la protección que se deriva, entre otros factores, de las regulaciones laborales analizadas. En la primera columna se presenta el indicador referido a la proporción del empleo informal respecto del total del empleo no agrícola, según se definió con anterioridad, y que en el caso de los países considerados alcanza un 52,6\% en promedio (simple). Esta información es especialmente relevante a efectos del presente análisis, pues la informalidad en el empleo representa una barrera estructural que excluye de la protección de las regulaciones laborales a más de la mitad de los trabajadores de la región. Según la información presentada, el empleo informal es más elevado en países de Centroamérica, y también en el Paraguay y el Perú. Las proporciones más bajas se encuentran en Costa Rica y el Uruguay, aunque en cada caso abarcan a algo más de un tercio de los trabajadores no agrícolas. 


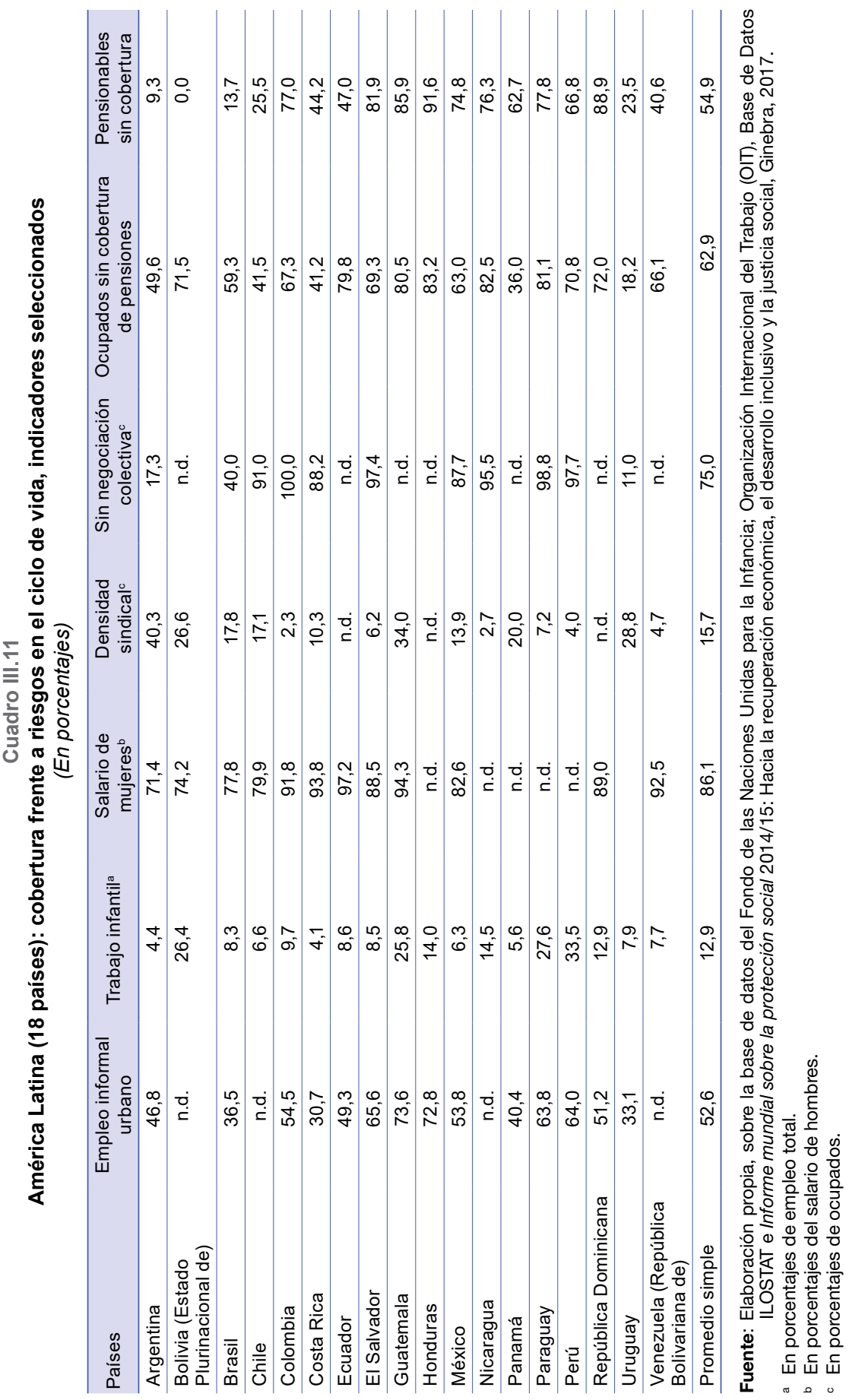


Al considerar las etapas del ciclo de vida, la fase previa de edad activa se refiere a la proporción de trabajo infantil, definida como el porcentaje de niños de entre 5 y 14 años de edad que se desempeñan en dicha condición ${ }^{15}$. El promedio de los países considerados alcanzó un $12,9 \%$. Ello pone de relieve que, pese a la decisión de los miembros la OIT de abolir este tipo de prácticas, aún persiste una desprotección de la infancia y adolescencia, sobre todo en Bolivia (Estado Plurinacional de), Guatemala, el Paraguay y el Perú.

Respecto de la etapa de la vida activa se pueden utilizar cuatro indicadores. Por una parte, la discriminación salarial en el empleo entre mujeres y hombres se ilustra mediante la relación porcentual entre la remuneración media de las mujeres respecto de los hombres, que asciende al $86,1 \%$ en el promedio de los países sobre los que se dispone de información. La brecha es significativa, y resulta especialmente elevada en la Argentina y Bolivia (Estado Plurinacional de). No obstante, se requiere afinar la construcción de dicho indicador con información desagregada que permita controlar el tipo de ocupación.

En materia de derechos colectivos, se dispone de información sobre la densidad sindical. Esto se refiere a la proporción de trabajadores que se encuentran afiliados a una organización sindical respecto del total de los ocupados y la proporción de los que no pueden participar en la negociación colectiva. Ambos indicadores están relacionados, pues una baja tasa de sindicalización suele estar asociada a una baja cobertura de la negociación colectiva. Sin embargo, dicha relación no es estrictamente proporcional, ya que depende del contenido específico de las normas sobre la materia. Por ejemplo, depende de si los beneficios obtenidos por los sindicalizados en las negociaciones colectivas pueden extenderse a los no sindicalizados y si las negociaciones superan el ámbito de la empresa.

Los resultados obtenidos indican que persiste entre los países una densidad sindical relativamente baja, del orden de un $15,7 \%$ en promedio. Es más baja aún en Colombia, El Salvador, Nicaragua, el Paraguay, el Perú y Venezuela (República Bolivariana de). Por su parte, una alta proporción de los trabajadores ocupados está excluida del derecho a negociar colectivamente (un $75 \%$ en promedio), siendo más bajas aún las

15 La información sobre trabajo infantil (UNICEF, 2015) se refiere a un trabajo realizado por un niño o niña que no alcance la edad mínima especificada para el tipo de ocupación de que se trate (según determine la legislación nacional, de acuerdo con las normas internacionales) y que, por consiguiente, impida la educación y el pleno desarrollo del niño. También se considera trabajo infantil toda labor que ponga en peligro el bienestar físico, mental o moral del niño, ya sea por su propia naturaleza o por las condiciones en que se realiza. Se denomina trabajo peligroso. Las formas incuestionablemente peores de trabajo infantil son las que se definen a nivel internacional como esclavitud, trata de personas, servidumbre por deudas y otras formas de trabajo forzoso, así como el reclutamiento forzoso de niños para utilizarlos en conflictos armados, prostitución, pornografía y otras actividades ilícitas. 
proporciones que se presentan en Chile, Colombia, El Salvador, México, el Paraguay y el Perú. En relación con los indicadores mencionados, también se deben perfeccionar considerando la población relevante en cada caso, es decir, la población sindicalizable o que esté en condiciones de negociar.

En lo que se refiere al riesgo de no contar con ingresos en la etapa de la vejez, se dispone de la proporción de ocupados que no están registrados en los sistemas de pensiones durante su vida activa y el porcentaje de quienes no poseen dicha cobertura, aunque cumplan el requisito de edad para pensionarse. En el caso de los ocupados, la cobertura alcanza a un $62,9 \%$ del total y es mayor aún en países de Centroamérica, donde supera el $80 \%$. Mientras tanto, en Panamá registra un $36 \%$ y la más baja se da en el Uruguay, con solo un 18,2\%. Esta amplia dispersión de resultados se debería analizar con mayor detalle, tanto en función de la importancia del empleo asalariado y del empleo informal, como de la tasa de reemplazo y el valor absoluto de las pensiones, entre otros factores.

Finalmente, la proporción de adultos en edad de pensionarse que no cuenta con cobertura de pensiones alcanza un $54,9 \%$ en promedio entre los distintos países. Este grado de desprotección se relaciona con la brecha ya señalada de la cobertura en la vida activa e implica que los sistemas no contributivos serán los que deben asegurar un ingreso para su subsistencia en la vejez.

\section{La vía judicial}

Según Ciudad (2014): "El arreglo directo en la empresa y los sistemas de solución de conflictos establecidos en los convenios colectivos constituyen el ideal. Pero en defecto de ellos la administración de justicia laboral es la llamada a hacer cumplir con la legalidad y el estado de derecho, así como otorgar protección a sus ciudadanos". Sin embargo, el mismo autor señala que la administración de justicia laboral en la mayoría de los países de América Latina necesita una profunda revisión, modernización y fortalecimiento. Añade: "sin desconocer los avances obtenidos, en el ámbito judicial laboral en diversos países, todavía tenemos instituciones débiles e ineficientes. No siempre se ha podido garantizar un ágil y célere respeto pleno de los derechos humanos vinculados al trabajo ni de los derechos laborales en general, ni proporcionar a los ciudadanos que trabajan los elementos esenciales de seguridad" (Ciudad, 2009).

Varios países han emprendido reformas en este sentido, por lo que el autor mencionado sugiere aprender de las buenas prácticas observadas en Chile, Colombia, Nicaragua y el Uruguay, entre otros ${ }^{16}$. Uno de los

16 En el caso de Chile en 2013, según la información disponible sobre un total de 282.247 causas ingresadas y terminadas en tribunales laborales del país, un 59,6\% fue objeto de avenimiento, conciliación o se acogió demanda monitoria. Véase INE (2014). 
aspectos que considera de especial importancia es el de fortalecer la conciliación judicial, aumentando las facultades del juez en esta materia y también la conciliación administrativa previa a cargo del Ministerio de Trabajo, a que las partes podrían someterse en forma voluntaria. Además, propone que el juez tenga amplias facultades de investigación, y pueda excepcionalmente ordenar la práctica de alguna prueba adicional. Para ello se debe respetar el derecho de defensa de las partes y evitar duplicaciones de audiencias. En Costa Rica, por ejemplo, se establece una sola audiencia de conciliación y juicio, salvo en casos cuya complejidad amerite dos audiencias.

Ciudad propone establecer la contestación a la demanda oral e innovar en el sistema de recursos o de impugnación, mediante el que se revisan las resoluciones judiciales, los procedimientos abreviados de menor cuantía, las modalidades especiales para la tutela de derechos fundamentales y los conflictos colectivos jurídicos ${ }^{17}$. Además, como el sistema de juicios orales es de una mayor calidad de justicia, pero a la vez es más exigente, dinámico y complejo, se requiere un nivel de preparación y destreza que solo pueden brindar abogados que no solo sean laboralistas, sino especialistas en litigación oral. De ahí surge la necesidad de fortalecer el sistema de defensa jurídica gratuita para los trabajadores y empleadores de escasos recursos, como se hace en Chile con el sistema de defensoría laboral, a cargo del Ministerio de Justicia ${ }^{18}$.

Frente a los diversos desafíos planteados, se torna necesario a su vez satisfacer las necesidades de capacitación de todos los operadores jurídicos, y contar con sistemas profesionalizados y eficientes para la gestión y organización de los despachos judiciales. Se los debe dotar de los recursos e infraestructura que requiere un sistema de juicios orales, a saber, más jueces, salas de audiencia, medios de grabación audiovisual, y un soporte administrativo y de gestión más sólido que en el caso del sistema escrito.

17 Costa Rica y Nicaragua han incorporado modalidades especiales respecto de la tutela de los derechos fundamentales del trabajo, de conformidad con la Declaración de la OIT relativa a los Principios y Derechos Fundamentales en el Trabajo (libertad sindical y negociación colectiva, igualdad y no discriminación, abolición del trabajo forzoso y eliminación del trabajo infantil). Se incluyen todas las formas de discriminación: por motivos de género, acoso moral, acoso sexual, entre otras.

18 La Reforma a la Justicia Laboral, de implementación gradual, se encuentra vigente en todo el territorio de Chile desde 2009, con 26 juzgados laborales, 84 jueces especializados y 136 defensores laborales, quienes ofrecen representación gratuita en procedimientos judiciales a los trabajadores que la necesiten. Con los criterios de focalización se pretende garantizar el acceso a la justicia laboral al mayor número de trabajadores que lo requieran y no lo puedan costear. En virtud de lo anterior, las Oficinas de Defensoría Laboral (ODL), garantizan una cobertura máxima del $97,52 \%$ a los asalariados pertenecientes a los tres primeros quintiles y de un $83,61 \%$ a todos los asalariados del país. Desde su implementación, las oficinas de defensa laboral han atendido 64.505 casos. De estos, 18.737 han requerido la presentación de demandas ante los tribunales, lo que corresponde a un 29\% de los casos atendidos. Véase Ministerio de Justicia (2011). 
Es importante incorporar en el análisis la dimensión de la eficacia de la justicia laboral. Sin embargo, su estudio en la región no se ha incluido en este capítulo, dada su amplitud y complejidad, así como la escasez y dispersión de fuentes de información que posibiliten el análisis comparado, las que normalmente se encuentran en el ámbito de los ministerios de justicia.

\section{E. Comentarios finales}

Del análisis aquí realizado sobre la institucionalidad de la regulación del mercado laboral en países de América Latina, es posible extraer un conjunto de reflexiones sobre los avances alcanzados y los desafíos con que tropieza su desarrollo.

En cuanto a la dimensión jurídico-normativa de los principales resultados sobre regulaciones laborales en función de los riesgos señalados en el ciclo de vida, se observa que, en general, es relativamente alto el grado de ratificación y puesta en vigor de los convenios internacionales, sobre todo los fundamentales. No ocurre lo mismo con los aplicables a la esfera de la seguridad y la salud en el trabajo, o los relacionados con el compromiso de ofrecer garantías mínimas en las ramas de la seguridad social. Por su parte, las garantías constitucionales, como marco fundamental, en general reconocen y consideran la protección de los derechos analizados. No obstante, se presentan situaciones en que un derecho está resguardado por la Constitución y, sin embargo, no se ha ratificado el convenio pertinente. Por último, en los códigos del trabajo se suelen abordar con normas específicas cada uno de los riesgos señalados, aunque el contenido de la norma varía de un país a otro.

En cuanto a la organización y la capacidad de los países para lograr un efectivo cumplimiento de las normas, su estudio enfrenta un grado mayor de complejidad. Por una parte, se considera que la vía tradicional para la resolución de los conflictos laborales, así como del incumplimiento de la legislación laboral, es la judicial, mediante la intervención de los tribunales especializados en materia de trabajo. Este es un ámbito en que se requiere levantar información que no siempre está disponible, salvo en algunos países donde se han implementado reformas de la justicia laboral, normalmente radicada en los ministerios de justicia u organizaciones del sector.

Avanzar en esta dimensión es de vital importancia, ya que la justicia laboral es un elemento clave para el cumplimiento de las normas, la resolución de controversias y el logro de una protección eficaz. Así pues, los contenidos y resultados de las reformas de la justicia laborales emprendidos en la región deberían considerarse e integrarse en el análisis. 
La vía administrativa como elemento destinado a velar por el cumplimiento de las normas laborales es parte constitutiva de los sistemas de administración del trabajo en distintos países que tienen organismos especializados, como las inspecciones del trabajo. Al mismo tiempo, la evidencia analizada muestra que se presentan importantes debilidades relacionadas con la dotación de inspectores para cubrir a la población relevante. También existen debilidades en materia de apoyo de infraestructura física y tecnológica, capacidad de llevar a cabo procesos de inspección que vinculen las acciones de prevención y sanción, facultades para el desarrollo de la función de inspección en todos los lugares de trabajo y existencia de recursos humanos calificados para su desempeño. En todo caso, para tener un panorama completo sobre la capacidad y fortaleza institucional de la vía administrativa se necesitaría más información cuantitativa, así como evaluaciones de impacto. Ello permitiría clasificar a los países en función del grado de fortaleza institucional y, sobre dicha base, analizar los resultados que finalmente se obtienen en materia de cumplimiento y protección.

Del análisis de los resultados en cuanto al grado de cumplimiento o cobertura de la población relevante en situación de riesgo o desprotección, es posible concluir que hay situaciones de menor incumplimiento relativo en materia de trabajo infantil y discriminación salarial. Sin embargo, la desprotección es mayor en cuanto a las características de los empleos (un $52,6 \%$ del empleo es informal), al ejercicio de los derechos colectivos (un $15,7 \%$ de los ocupados pertenecen a una organización sindical y un $75 \%$ no está cubierto por instrumentos derivados de negociaciones colectivas). Algo similar ocurre en relación con el riesgo de no contar con un ingreso en la vejez (un 62,9\% de los ocupados no está registrado en los sistemas de pensiones en la vida activa y un 54,9\% de la población mayor de 65 años no dispone de cobertura de pensiones). Esta situación es de particular relevancia en el caso de las mujeres, que presentan brechas significativas de ingresos y protección con relación a los hombres.

Cabe destacar que, a partir del análisis preliminar realizado y su contraste con los resultados disponibles, aún no es posible arribar a conclusiones definitivas que expliquen hasta qué punto la desprotección se debe al incumplimiento o inobservancia de las normas laborales. Sin embargo, es posible describir algunos elementos que deben considerarse en eventuales nuevas etapas de desarrollo de esta base conceptual y metodológica:

- Se requiere avanzar más en cuanto a la medición de la eficacia de la norma. Es decir, la existencia de una norma no es condición suficiente para asegurar su cumplimiento ni el logro del efecto deseado en términos de la protección buscada. Se requiere el estudio pormenorizado de cada regulación y sus distintas 
variaciones de un país a otro, y conocer los efectos de su implementación en la práctica (evasión, elusión u otros efectos no considerados). Ello es particularmente importante en el contexto de alta informalidad laboral existente en la región.

- La vigencia de una norma debe contrastarse con algún estándar relevante. Por ejemplo, aunque todos los asalariados del país recibieran una remuneración igual o superior al salario mínimo, sería necesario determinar si dicha garantía mínima les permitiría financiar una canasta básica para sí y sus dependientes.

- Para completar el análisis propuesto habría que tener en cuenta la dimensión de empleo considerada por los ministerios de trabajo, en cada caso, junto con las funciones de regulación de las relaciones laborales (área de trabajo) y de regulación y políticas en seguridad social (área de seguridad social), independientemente de que su efecto en la protección social debería ser indirecto. Del mismo modo, como se señaló con anterioridad, se han de incluir los efectos de las experiencias de reforma de la justicia laboral, cuando sea pertinente.

- Por último, se requiere contar con nuevas fuentes de información que permitan construir un mayor número de indicadores respecto de los distintos riesgos considerados fundamentales. Dada la existencia de una alta proporción de empleo informal, siempre se ha de considerar la distinción entre la población total y la población fiscalizada por los servicios de inspección laboral.

\section{Bibliografía}

Amadeo, E. y J. Camargo (1996), "Labor flexibility, productivity and adjustment", Las instituciones laborales frente a los cambios en América Latina: Contribuciones a un seminario (Santiago de Chile, mayo de 1993), J. Figueiredo (ed.), Ginebra, Instituto Internacional de Estudios Laborales, Organización Internacional del Trabajo.

Banco Mundial (1995), Informe sobre el Desarrollo Mundial 1995. El mundo del trabajo en una economía integrada, Oxford, Oxford University Press.

(1994), Averting the Old-Age Crisis. Policies to Protect the Old and Promote Growth, Nueva York, Oxford University Press.

Barrientos, A. y D. Hulme (eds.) (2008), Social Protection for the Poor and Poorest. Concepts, Policies and Politics, Basingstoke, Palgrave Macmillan.

Bensusán, G. (2013), "Reforma laboral, desarrollo incluyente e igualdad en México", serie Estudios y Perspectivas, Nº 143 (LC/L.3624), Ciudad de México, Sede Subregional de la CEPAL en México. (2009), "La inspección del trabajo en América Latina: Teorías, contextos y evidencias", Estudios Sociológicos, vol. 27, № 81, Ciudad de México, El Colegio de México. 
Berg, J., Ch. Ernst y P. Auer (2006), Meeting the Employment Challenge: Argentina, Brazil and Mexico in the Global Economy, Boulder, Colorado, Lynne Rienner.

Bertranou, F. y G. Pérez (2006), "Normas internacionales del trabajo, seguridad social y pensiones", OIT Notas, N², Santiago, Organización Internacional del Trabajo (OIT).

Cecchini, S. y R. Martínez (2011), Protección social inclusiva en América Latina. Una mirada integral, un enfoque de derechos, Libros de la CEPAL, N 111 (LC/G.2488-P), Santiago, Comisión Económica para América Latina y el Caribe (CEPAL).

CEPAL (Comisión Económica para América Latina y el Caribe) (2009), Panorama Social de América Latina 2008 (LC/G.2402-P), Santiago.

Chahad, J. (2009), "Flexibilidad y seguridad en el mercado de trabajo: en busca de alternativas para mejorar la protección social de los trabajadores brasileños", El nuevo escenario laboral latinoamericano. Regulación, protección y políticas activas en los mercados de trabajo, J. Weller (ed.), Buenos Aires, Siglo XXI.

Ciudad, A. (2014), "Avances en la modernización de la justicia laboral peruana y desafíos para el futuro inmediato", Revista de Derecho del Trabajo y Seguridad Social, año 1, No 1, Lima, Ciudad Universitaria de San Marcos [en línea] https: / / tallerdelaboral.files.wordpress.com/2015/01/revista-de-derecho-laboral-yseguridad-social.pdf. (2009), "Modernización de la justicia laboral en América Latina”, Managua [en línea] http:/ / www.poderjudicial.gob.ni/pjupload/laboral/pdf/dradolfo.pdf.

Dirección del Trabajo (2015), "Código del Trabajo", Santiago [en línea] http: / / www. dt.gob.cl/legislacion/1611/articles-95516_recurso_2.pdf.

Edwards, S. y N. Lustig (eds.) (1997), Labor Markets in Latin America: Combining Social Protection with Market Flexibility, Washington, D.C., Brookings Institute Press.

Erikson, B. (2005), "Intereses compartidos: los sindicatos y la inspección de trabajo", Revista de Educación Obrera, vol. 3-4, N 140-141, Ginebra, Organización Internacional del Trabajo (OIT).

Filgueira, F. y otros (2006), “Universalismo básico: Una alternativa posible y necesaria para mejorar las condiciones de vida", Universalismo básico: Una nueva política social para América Latina, C.G. Molina (dir.), Washington, D.C., Banco Interamericano de Desarrollo (BID).

Fitoussi, J.-P. y P. Rosanvallon (1997), La nueva era de las desigualdades, Buenos Aires, Editorial Manantial.

Fraile, L. (2009), “La experiencia neoliberal de América Latina. Políticas sociales y laborales desde el decenio de 1980", Revista Internacional del Trabajo, vol. 128, $\mathrm{N}^{\circ}$ 3, Ginebra, Organización Internacional del Trabajo (OIT).

Freeman, R. (2005), “Labour market institutions without blinders: the debate over flexibility and labour market performance", NBER Working Paper, $\mathrm{N}^{\mathrm{o}} 11286$, Cambridge, Massachusetts, National Bureau of Economic Research (NBER).

Goldin, A. (2009), "Flexibilidad laboral y seguridad del trabajador: Una perspectiva argentina", El nuevo escenario laboral latinoamericano. Regulación, protección y políticas activas en los mercados de trabajo, J. Weller (ed.), Buenos Aires, Siglo XXI.

Heckman, J. y C. Pagés (2004), Law and Employment: Lessons from Latin America and the Caribbean, Chicago, Chicago University Press.

(2000), "The cost of job security regulation: Evidence from Latin American labour markets", Working Paper, $\mathrm{N}^{\circ}$ 430, Washington, D.C., Banco Interamericano de Desarrollo. 
IIEL (Instituto Internacional de Estudios Laborales) (2008), Informe sobre el trabajo en el mundo 2008. Desigualdades de renta en la era de la finanza global, Ginebra, Organización Internacional del Trabajo (OIT).

INE (Instituto Nacional de Estadísticas) (2014), "Justicia", Informe anual 2013, Santiago [en línea] http://www.ine.cl/canales/menu/publicaciones/calendario_ de_publicaciones/pdf/completa_justicia_2013.pdf.

Kuczynski, P.P. y J. Williamson (eds.) (2003), After the Washington Consensus: Restarting Growth and Reform in Latin America, Washington, D.C., Institute for International Economics.

Lora, E. y C. Pagés (1997), "Legislación laboral en el proceso de reformas estructurales de América Latina y el Caribe", Documento de Trabajo, N 4065, Washington, D.C., Banco Interamericano de Desarrollo (BID).

Loyo, M.G. y M. Velásquez (2015), “Inspección laboral en América Latina: mejores prácticas y lecciones", Banco Interamericano de Desarrollo (BID), inédito.

Mesa-Lago, C. (2004), "Evaluación de un cuarto de siglo de reformas estructurales de pensiones en América Latina", Revista de la CEPAL, No 84 (LC/G.2258-P), Santiago, Comisión Económica para América Latina y el Caribe (CEPAL).

Ministerio de Justicia (2011), “Cuenta sectorial” [en línea] http://2010-2014.gob.cl/ media/2010/05/JUSTICIA.pdf.

Ministerio Secretaría General de la Presidencia (2005), “Chile. Constitución (1980). Fija el texto refundido, coordinado y sistematizado de la Constitución Política de la República de Chile" Santiago, 17 de septiembre [en línea] http:/ /www. leychile.cl/Navegar?idNorma=242302.

OIT (Organización Internacional del Trabajo) (2017), Informe Mundial sobre la Protección Social 2014/15: hacia la recuperación económica, el desarrollo inclusivo y la justicia social, Ginebra.

(2016), Panorama Laboral 2016. América Latina y el Caribe, Lima, Oficina Regional para América Latina y el Caribe.

(2015a), "Ratificaciones por convenio", NORMLEX Information System on International Labour Standards [en línea] http://www.ilo.org/dyn/ normlex/es/f?p=1000:12001:0::NO:::.

(2015b), "Protección de la maternidad", Normas del trabajo [en línea] http: / / www.ilo.org/global/standards/subjects-covered-by-internationallabour-standards/maternity-protection/lang--es/index.htm.

(2015c), "Trabajo infantil", Normas del trabajo [en línea] http:/ /www.ilo.org/ global/standards/subjects-covered-by-international-labour-standards/childlabour/lang--es/index.htm.

(2015d), "Promoción del empleo", Normas del trabajo [en línea] http:/ /www.ilo. org/global/standards/subjects-covered-by-international-labour-standards / employment-promotion/lang--es/index.htm.

(2015e), "Tiempodetrabajo",Normasdeltrabajo[enlínea]http:/ /www.ilo.org/ global/standards / subjects-covered-by-international-labour-standards / working-time/lang--es/index.htm.

(2015f), "Salarios", Normas del trabajo [en línea] http:/ / www.ilo.org/global/ standards / subjects-covered-by-international-labour-standards / wages / lang--es/index.htm.

(2015g), "C131 - Convenio sobre la Fijación de Salarios Mínimos, 1970 (Núm. 131)" [en línea] http://www.ilo.org/dyn/normlex/es/ f?p=1000:12100:0::NO::P12100_ILO_CODE:C131. 
(2015h), “Seguridadenelempleo",Normasdeltrabajo[enlínea]http:/ /www.ilo. org/global/standards/subjects-covered-by-international-labour-standards / employment-security/lang--es/index.htm.

(2015i), "Igualdad de oportunidades y de trato", Normas del trabajo [en línea] http:/ / www.ilo.org/global/standards/subjects-covered-by-internationallabour-standards/equality-of-opportunity-and-treatment/lang--es/index.htm. (2015j), "Otras categorías particulares de trabajadores", Normas del trabajo [en línea] http:/ / www.ilo.org/global/standards/subjects-covered-by-internationallabour-standards/specific-categories-of-workers/lang--es/index.htm.

(2015k), "Libertad sindical", Normas del trabajo [en línea] http://www.ilo. org/global/standards/subjects-covered-by-international-labour-standards / freedom-of-association/lang--es/index.htm.

(2015l), "Seguridad y salud en el trabajo", Normas del trabajo [en línea] http://www.ilo.org/global/standards/subjects-covered-by-internationallabour-standards/occupational-safety-and-health/lang--es/index.htm.

(2015m), "Databases and subjects", ILOSTAT Database [en línea] http:// www.ilo.org/ilostat/faces/help_home/data_by_subject?_adf.ctrl-state= 24er6ate8_252\&_afrLoop $=1235234311911441$.

(2015n), "ILOSTAT Database" [en línea] http://www.ilo.org/ilostat/faces/ oracle/webcenter/portalapp/pagehierarchy/Page131.jspx?_afrLoop= 673213457537053\&_adf.ctrl-state $=18 \times 51 \times 011 b \_86 \&$ clean $=$ true $\% 40 \% 3 F \_a f r L o o p$ \%3D673213457537053\%26clean\%3Dtrue\%26_adf.ctrl-state\%3Dxqgct6rx6_2993.

(2014), Panorama Laboral Temático 1. Transición a la formalidad en América Latina y el Caribe, Lima, Oficina Regional para América Latina y el Caribe.

(2013), La medición de la informalidad: manual estadístico sobre el sector informal y el empleo informal, Ginebra.

(2011), "Administración del trabajo e inspección del trabajo", Conferencia Internacional del Trabajo, 100ª reunión [en línea] http:/ / www.ilo.org/wcmsp5/ groups / public/---ed_norm/---relconf/documents / meetingdocument / wcms_153936.pdf.

(2004), Panorama Laboral 2004. América Latina y el Caribe, Lima, Oficina Regional para América Latina y el Caribe.

(1993), "Resolución sobre las estadísticas del empleo en el sector informal, adoptada por la decimoquinta Conferencia Internacional de Estadísticos del Trabajo (enero de 1993)" [en línea] http://www.ilo.org/public/spanish/ bureau/stat/download/res/infsec.pdf.

Singh, A. y otros (2005), "Stabilization and reform in Latin America: a macroeconomic perspective on the experience since the early 1990s", Occasional Paper, $\mathrm{N}^{\circ} 238$, Washington, D.C., Fondo Monetario Internacional (FMI).

Tokman, V. (2011), "Informalidad en América Latina: balance y perspectivas de políticas", Revista Internacional de Estadística y Geografía. Realidad, Datos y Espacio, vol. 2, $\mathrm{N}^{\circ}$ 3, Ciudad de México, Instituto Nacional de Estadística y Geografía (INEGI).

(2007), "Informalidad, inseguridad y cohesión social en América Latina", Revista Internacional del Trabajo, vol. 126, No 1-2, Ginebra, Organización Internacional del Trabajo (OIT).

(2004), Una voz en el camino. Empleo y equidad en América Latina: 40 años de búsqueda, Santiago, Fondo de Cultura Económica. 
UNICEF (Fondo de las Naciones Unidas para la Infancia) (2015), “Definiciones conceptuales para un sistema integral de protección a la infancia", Serie Los derechos de los niños, una orientación y un límite, $\mathrm{N}^{\mathrm{o}} 4$, Santiago.

Vega Ruiz, M.L. (2009), "La inspección de trabajo en Europa: retos y logros en algunos países seleccionados aún en tiempos de crisis", Documento de Trabajo, $\mathrm{N}^{\circ}$ 3, Ginebra, Organización Internacional del Trabajo (OIT). (2005), La reforma laboral en América Latina: 15 años después. Un análisis comparado, Lima, Oficina Regional de la OIT para América Latina y el Caribe [en línea] http://www.oit.org/wcmsp5/groups/public/---americas/---ro-lima/ ---ilo-buenos_aires/documents/publication/wcms_bai_pub_2.pdf.

Velásquez, M. (2016), "Regulación del mercado de trabajo y protección social en países de América Latina", serie Políticas Sociales, N²18 (LC/L.4244), Santiago, Comisión Económica para América Latina y el Caribe (CEPAL).

(2011), "Diagnóstico y análisis institucional de ministerios de trabajo en América Latina. Aplicación a los casos de Chile, Colombia, Paraguay y Perú", Notas Técnicas, N IDB-TN-349, Washington, D.C., Banco Interamericano de Desarrollo (BID).

(2009), "Flexibilidad, protección y políticas activas en Chile", El nuevo escenario laboral latinoamericano. Regulación, protección y políticas activas en los mercados de trabajo, J. Weller (ed.), Buenos Aires, Siglo XXI.

Weller, J. (2009), “Avances y retos para el perfeccionamiento de la institucionalidad laboral en América Latina", El nuevo escenario laboral latinoamericano. Regulación, protección y políticas activas en los mercados de trabajo, J. Weller (ed.), Buenos Aires, Siglo XXI. 


\section{Anexo III.A1}

\section{Cuadro III.A1.1}

\section{Prestaciones previstas en el Convenio de la OIT núm. 102 y en convenios posteriores ${ }^{a}$}

\begin{tabular}{|c|c|}
\hline Rama & Contenido \\
\hline \multirow[t]{2}{*}{ Asistencia médica } & $\begin{array}{l}\text { - Convenio núm. 102: dispone la asistencia preventiva y la asistencia } \\
\text { médica general, comprendidas las visitas a domicilio, la asistencia de } \\
\text { especialistas, el suministro de productos farmacéuticos esenciales que } \\
\text { se hayan recetado, y la asistencia prenatal, durante el parto y puerperal } \\
\text { prestada por un médico o por una comadrona diplomada, así como la } \\
\text { hospitalización cuando sea necesaria. }\end{array}$ \\
\hline & $\begin{array}{l}\text { - Convenio núm. 130: establece las mismas prestaciones que el Convenio } \\
\text { núm. 102, más la asistencia odontológica y la readaptación médica. }\end{array}$ \\
\hline \multirow[t]{2}{*}{$\begin{array}{l}\text { Prestaciones } \\
\text { de enfermedad }\end{array}$} & $\begin{array}{l}\text { - Convenio núm. 102: pagos periódicos que correspondan al menos al } \\
45 \% \text { del salario de referencia. }\end{array}$ \\
\hline & $\begin{array}{l}\text { - Convenio núm. 130: pagos periódicos por al menos el } 60 \% \text { del salario } \\
\text { de referencia. También el pago de los gastos de sepelio en caso de } \\
\text { fallecimiento del beneficiario. }\end{array}$ \\
\hline \multirow[t]{2}{*}{$\begin{array}{l}\text { Prestaciones } \\
\text { de desempleo }\end{array}$} & $\begin{array}{l}\text { - Convenio núm. 102: pagos periódicos que correspondan al menos al } \\
45 \% \text { del salario de referencia. }\end{array}$ \\
\hline & $\begin{array}{l}\text { - Convenio núm. 168: pagos periódicos por al menos el } 50 \% \text { del salario } \\
\text { de referencia. Más allá del período inicial, posibilidad de aplicar } \\
\text { reglas especiales de cálculo. El conjunto de prestaciones a las que el } \\
\text { desempleado puede tener derecho, debe garantizarle condiciones de } \\
\text { vida saludables y dignas, según las normas nacionales. }\end{array}$ \\
\hline \multirow[t]{2}{*}{$\begin{array}{l}\text { Prestaciones } \\
\text { de vejez }\end{array}$} & $\begin{array}{l}\text { - Convenio núm. 102: pagos periódicos que correspondan al menos al } \\
40 \% \text { del salario de referencia. Obligación de revisar las tasas de las } \\
\text { prestaciones pertinentes tras variaciones sensibles del nivel general de } \\
\text { ganancias o del costo de vida. }\end{array}$ \\
\hline & $\begin{array}{l}\text { - Convenio núm. 128: pagos periódicos que correspondan al menos al } \\
45 \% \text { del salario de referencia. Las mismas condiciones que el Convenio } \\
\text { núm. } 102 \text { en relación con la revisión de las tasas. }\end{array}$ \\
\hline \multirow[t]{2}{*}{$\begin{array}{l}\text { Prestaciones en } \\
\text { caso de accidente } \\
\text { del trabajo y } \\
\text { enfermedad } \\
\text { profesional }\end{array}$} & $\begin{array}{l}\text { - Convenio núm. 102: asistencia médica, pagos periódicos que } \\
\text { correspondan al menos al } 50 \% \text { del salario de referencia en casos de } \\
\text { incapacidad laboral o invalidez; prestaciones para las viudas o para los } \\
\text { hijos a cargo en caso de fallecimiento del sostén de la familia, con pagos } \\
\text { periódicos que correspondan al menos al } 40 \% \text { del salario de referencia. } \\
\text { Posibilidad de convertir los pagos periódicos en una suma global, en } \\
\text { determinadas condiciones. Excepto en el caso de la incapacidad para } \\
\text { trabajar, se establece la obligación de revisar las tasas de los pagos } \\
\text { periódicos siguiendo cambios sustanciales en el costo de vida. }\end{array}$ \\
\hline & $\begin{array}{l}\text { - Convenio núm. 121: igual que el convenio núm. 102, más algunos tipos } \\
\text { de asistencia en el lugar de trabajo. Pagos periódicos que correspondan } \\
\text { al menos al } 60 \% \text { del salario de referencia en casos de incapacidad } \\
\text { laboral o invalidez, prestaciones para las viudas, para el viudo inválido } \\
\text { y a cargo, y para los hijos a cargo, en caso de fallecimiento del sostén } \\
\text { de la familia, con pagos periódicos correspondientes al menos al } 50 \% \\
\text { del salario de referencia. Obligación de fijar un monto mínimo para } \\
\text { estos pagos, posibilidad de convertir los pagos en una suma global en } \\
\text { determinadas condiciones y prestaciones complementarias para las } \\
\text { personas discapacitadas cuyo estado requiere la asistencia constante } \\
\text { de una tercera persona. }\end{array}$ \\
\hline
\end{tabular}


Cuadro III.A1.1 (conclusión)

\begin{tabular}{|c|c|}
\hline Rama & Contenido \\
\hline $\begin{array}{l}\text { Prestaciones } \\
\text { familiares }\end{array}$ & $\begin{array}{l}\text { - Convenio núm. 102: pagos periódicos o suministro de alimentos, vestido, } \\
\text { vivienda, vacaciones o asistencia doméstica, o una combinación de los dos. }\end{array}$ \\
\hline \multirow[t]{2}{*}{$\begin{array}{l}\text { Prestaciones } \\
\text { de maternidad }\end{array}$} & $\begin{array}{l}\text { - Convenio núm. 102: asistencia médica que deberá comprender, por lo } \\
\text { menos, la asistencia prenatal, durante el parto y puerperal prestada por } \\
\text { un médico o por una comadrona diplomada, así como la hospitalización } \\
\text { cuando sea necesaria; pagos periódicos que correspondan al menos al } \\
45 \% \text { del salario de referencia. }\end{array}$ \\
\hline & $\begin{array}{l}\text { - Convenio núm. 183: prestaciones médicas que deberán comprender } \\
\text { la asistencia prenatal, durante el parto y puerperal, así como } \\
\text { la asistencia hospitalaria cuando sea necesaria; prestaciones } \\
\text { pecuniarias que garanticen a la mujer subvenir a su mantenimiento } \\
\text { y al de su hijo en buenas condiciones de salud y con un nivel de vida } \\
\text { conveniente. Al menos dos tercios de las ganancias anteriores, } \\
\text { o una cuantía comparable. }\end{array}$ \\
\hline \multirow[t]{2}{*}{$\begin{array}{l}\text { Prestaciones } \\
\text { de invalidez }\end{array}$} & $\begin{array}{l}\text { - Convenio núm. 102: pagos periódicos que correspondan al menos al } \\
40 \% \text { del salario de referencia; obligación de revisar los montos de las } \\
\text { prestaciones pertinentes, en caso de variaciones sensibles del nivel } \\
\text { general de ganancias o del costo de vida. }\end{array}$ \\
\hline & $\begin{array}{l}\text { - Convenio núm. 128: pagos periódicos que correspondan al menos al } \\
50 \% \text { del salario de referencia; obligación de revisar estos montos en } \\
\text { caso de variaciones sensibles del nivel general de ganancias o del costo } \\
\text { de vida. Obligación de prestación de servicios de rehabilitación } \\
\text { y adopción de medidas para favorecer la colocación de las personas } \\
\text { con discapacidad en un empleo idóneo. }\end{array}$ \\
\hline \multirow[t]{2}{*}{$\begin{array}{l}\text { Prestaciones de } \\
\text { sobrevivientes }\end{array}$} & $\begin{array}{l}\text { - Convenio núm. 102: pagos periódicos que correspondan al menos al } \\
40 \% \text { del salario de referencia; obligación de revisar estos montos en } \\
\text { caso de variaciones sensibles del nivel general de ganancias o del } \\
\text { costo de vida. }\end{array}$ \\
\hline & $\begin{array}{l}\text { - Convenio núm. 128: pagos periódicos que correspondan al menos al } \\
45 \% \text { del salario de referencia; obligación de revisar estos montos en } \\
\text { caso de variaciones sensibles del nivel general de ganancias o del } \\
\text { costo de vida. }\end{array}$ \\
\hline
\end{tabular}

Fuente: Elaboración propia sobre la base de Organización Internacional del Trabajo (OIT), "Ratificaciones por convenio", NORMLEX Information System on International Labour Standards [en línea] http://www.ilo.org/dyn/normlex/es/f?p=1000:12001:0::NO:::.

a Esta información no incluye las disposiciones sobre la duración y las condiciones para tener derecho a las prestaciones. Tampoco comprende las excepciones que se permiten en virtud de estos instrumentos ni los niveles más elevados de prestaciones en las recomendaciones pertinentes. 


\section{Capítulo IV \\ Aspectos institucionales de los sistemas de pensiones en América Latina}

Andras Uthoff ${ }^{1}$

\section{Introducción ${ }^{2}$}

El Secretario General de las Naciones Unidas, Ban Ki Moon, planteó que es una obligación hacerse cargo de los cambios demográficos, en particular del creciente número de adultos mayores en el mundo. Llamó a comprometerse a eliminar las barreras a la plena participación de los adultos mayores en la sociedad, a la vez que a proteger sus derechos y dignidad.

La pregunta acerca de cómo deben diseñarse e implementarse los sistemas de pensiones para sostener a largo plazo pensiones de calidad es una interrogante común a nivel mundial. Sin embargo, la respuesta depende del contexto en que se aplicará el sistema y los desarrollos institucionales que lo sostienen. Este capítulo se refiere a estos aspectos.

Consultor de la División de Desarrollo Social de la Comisión Económica para América Latina y el Caribe (CEPAL).

2 Este capítulo se basa en el documento "Aspectos institucionales de los sistemas de pensiones en América Latina", elaborado por Andras Uthoff, con la colaboración de Fabiana Pierre, Consultores de la División de Desarrollo Social de la CEPAL, véase Uthoff (2016). 
Los sistemas de pensiones son parte de la política de protección social $^{3}$ en su componente de seguridad social (también llamada seguro social o previsión social $)^{4}$. Su objetivo es suavizar el consumo a lo largo del ciclo de vida, asegurar ingresos en casos de invalidez y sobrevivencia, y aliviar la pobreza en la vejez. Estos sistemas deben adaptarse a diferentes contextos que, en lo esencial, difieren en aspectos relacionados con la demografía, las condiciones laborales de sus afiliados, el rol que se asigna al Estado para recaudar y administrar recursos, y el nivel de desarrollo económico e institucional alcanzado en el país donde se aplican. Para su diseño, los países deben optar entre distintas alternativas de: i) fuentes de financiamiento; ii) modalidad de gestión financiera; iii) forma de definir sus beneficios; iv) administración del sistema, y v) redistribución hacia los más necesitados. Requieren instituciones de provisión, regulación y supervisión de su funcionamiento en forma sostenible a lo largo del tiempo.

Conforme a lo planteado en el capítulo I, en relación con las cuatro dimensiones de la institucionalidad, en este capítulo se analizan los desarrollos institucionales necesarios para los sistemas de pensiones. Su examen tiene el objeto de asegurar que el desempeño de cada sistema concilie la lógica de su financiamiento con la de los principios de la seguridad social y que garantice que a lo largo de varias generaciones se puedan superar los riesgos (captura de los fondos, cambios demográficos, crisis económicas y financieras) frente a los cuales el funcionamiento del sistema es vulnerable.

La evidencia que se examina en este trabajo muestra que, en todos los avances, las dimensiones de la institucionalidad no son excluyentes y deben combinarse. Se concluye que se trata de un esfuerzo continuo para que, junto con el aseguramiento de la solvencia y sostenibilidad del sistema a lo largo del tiempo, se garantice un acceso universal a prestaciones dignas ${ }^{5}$ y asequibles ${ }^{6}$.

El trabajo se organiza en tres secciones además de esta introducción. En la primera se plantean los desafíos que enfrenta el diseño de un sistema de pensiones y las opciones existentes. En la segunda se destaca la

Concepto utilizado en las ciencias políticas y económicas con el que se designa una propuesta política o modelo general del Estado y de la organización social, según el cual el Estado provee servicios en cumplimiento de derechos sociales a la totalidad de los habitantes de un país.

4 Según la Organización Internacional del Trabajo (OIT), el seguro social o la previsión social es la protección que la sociedad proporciona a sus miembros, mediante una serie de medidas públicas, contra las privaciones económicas y sociales que, de no ser así, ocasionarían la desaparición o una fuerte reducción de los ingresos por causa de enfermedad, maternidad, accidente de trabajo, o enfermedad laboral, desempleo, invalidez, vejez y muerte. También contempla la protección en forma de asistencia médica y de ayuda a las familias con hijos.

5 Se refiere al derecho a acceder a un nivel de prestación que el sistema otorga a un ciudadano, y que la sociedad establece dado el cumplimiento de sus deberes ciudadanos y la condición de retirado, inválido o sobreviviente.

6 Con esto se hace alusión a que se pueda conseguir o alcanzar bajo la modalidad de operar del sistema. 
importancia de los desarrollos institucionales adoptados y su respuesta a los desafíos futuros. En la tercera se presentan comentarios finales a modo de conclusión.

\section{A. Sistema de pensiones y seguridad social}

Los sistemas públicos de pensiones son parte de la protección social contributiva o seguridad social de un país 7 . Se han diseñado para asegurar logros sociales relativos a las pensiones en casos de: i) discapacidad del trabajador; ii) sobrevivencia como dependiente de un trabajador que fallece y que era el proveedor del hogar; iii) trabajadores que alcanzan la edad que la sociedad ha definido como elegible para dejar de trabajar y optar por vivir de una pensión asociada a su historia laboral, y iv) personas que están en situación de vejez e invalidez y carecen de ingreso para su sustento (alivio de la pobreza).

Como parte de la seguridad social, los sistemas públicos de pensiones se sustentan en cimientos que conforman una organización, una institución, o un ideal en seis principios sin los cuales perdería identidad y razón de ser: universalidad, igualdad, solidaridad, integridad, unidad y sostenibilidad financiera (véase el recuadro IV.1).

Recuadro IV.1

Principios fundamentales en seguridad social

\section{Universalidad de la cobertura}

En sus dos vertientes, por una parte, la subjetiva, que todas las personas deben estar amparadas por la seguridad social, principio que se deriva de su naturaleza de derecho humano fundamental. Por otra, la objetiva, que la seguridad social debe cubrir todas las contingencias (riesgos) a que se expone una persona que vive en sociedad.

Este principio se relaciona con el tema actual de la seguridad social: la falta de cobertura frente a algunas contingencias sufridas por los ciudadanos.

\section{Igualdad, equidad o uniformidad en el trato}

Este principio, no exclusivo de la seguridad social, implica que todas las personas deben ser amparadas igualitariamente ante una misma contingencia. Analizando las desigualdades sociales y económicas, el tratamiento debe ser adecuado a efectos de que la prestación cubra en forma digna el riesgo en cuestión, independientemente de la referida desigualdad.

También puede definirse como igualdad de trato, ya que implica que todo ser humano como tal tiene el derecho a la seguridad social, y se prohíbe toda clase de discriminación en cuanto a raza, color, sexo, idioma, religión, opinión política o de cualquier otra índole, origen nacional o social, posición económica, nacimiento o cualquier otra condición.

Véanse las definiciones en notas anteriores. 
Recuadro IV.1 (conclusión)

\section{Solidaridad y redistribución del ingreso}

Este principio es esencial para poder distinguir entre un sistema de seguridad social y un seguro privado. Cada cual aporta al sistema de seguridad social según su capacidad contributiva y recibe prestaciones de acuerdo a sus necesidades. Esto constituye una herramienta indispensable a efectos de cumplir el objetivo esencial: la redistribución de la riqueza con justicia social.

La solidaridad puede referirse a la del sano con el enfermo, la del joven con el anciano (intergeneracional u horizontal), o también entre las personas de diferentes ingresos, de los que más tienen con los que menos tienen (intrageneracional o vertical). Incluso existe la solidaridad geográfica entre regiones de más recursos y otras más pobres.

\section{Integridad y suficiencia de las prestaciones}

La prestación que se otorgue debe cubrir en forma plena y oportuna la contingencia de que se trate: debe responder a las necesidades efectivas del sector al que van destinadas, con niveles de dignidad, oportunidad y eficacia.

\section{Unidad, responsabilidad del Estado, eficiencia y participación en la gestión}

La unidad, la responsabilidad del Estado y la eficiencia suponen un sistema en que toda institución estatal, paraestatal o privada, que actúe en el campo de la previsión social implementada por el Estado, lo haga bajo cierta unidad o coordinación con el fin de evitar duplicaciones e ineficiencias en la gestión.

La participación se refiere a que la sociedad se involucre en la administración y dirección de la seguridad social a través de sus organizaciones representativas y también de su financiamiento. El Convenio sobre la Seguridad Social (Norma Mínima), 1952 (Núm. 102) de la OIT se refiere a la participación de los representantes de los trabajadores y posiblemente de los empleadores. En sentido amplio, la participación (informativa, consultiva, asesora o directiva), implica que se haga sentir la opinión de todos los que de una forma u otra están alcanzados por la seguridad social.

\section{Sostenibilidad financiera}

El plan de seguridad social debe ser viable desde el punto de vista financiero de acuerdo con la capacidad económica del país. También debe implementarse por etapas, pero como parte de un plan general, e indicar las prioridades en su puesta en práctica, así como ir avanzando cuando existan los recursos.

Fuente: Elaboración propia, sobre la base de convenios y recomendaciones de la Organización Internacional del Trabajo (OIT).

Es interesante destacar que el marco normativo de los principios de la seguridad social incluye el financiamiento de sus beneficios en forma solvente y sostenible. Esto exige la conciliación de sus objetivos sociales con los requisitos económicos referidos a su financiamiento, en particular al diseño de tasas impositivas directas e indirectas que, en lo esencial:

- Cumplan su objetivo social de proveer beneficios dignos en casos de vejez, invalidez y sobrevivencia.

- Sean armónicos con la política macroeconómica, en tanto no ejerzan presión sobre la capacidad competitiva de la mano de obra; no aumenten la carga fiscal del país más allá de lo que 
autorizan los acuerdos de responsabilidad fiscal y no distorsionen la demanda de instrumentos financieros.

Se genera así un desafío de política pública. Dadas las enormes desigualdades y restricciones presupuestarias que subsisten en las economías latinoamericanas, el diseño de un sistema de pensiones debe basarse en un importante contrato social. Dicho contrato debe estar llamado a conciliar el principio de equivalencia (es decir, que sea actuarialmente solvente a lo largo del tiempo) con los principios de universalidad y solidaridad (que incluya subsidios cruzados que vayan desde quienes tienen capacidad de ahorro hacia quienes no la tienen), con el fin de lograr un acceso a beneficios dignos para todos. Esta tarea no es nueva. Se refleja en una tipología de acuerdos que, a lo largo de la historia, han sugerido diferentes diseños y responden a selecciones que las autoridades han hecho entre las opciones existentes para el diseño de un sistema de pensiones.

\section{Opciones de diseño de un sistema de pensiones}

Los sistemas diseñados para proveer beneficios de pensiones y hacer exigibles los derechos son resultado de opciones entre al menos los cinco aspectos relevantes que se enumeran a continuación y que involucran importantes desarrollos institucionales.

i) Participación del afiliado en el financiamiento: se refiere a si el ciudadano debe o no aportar al financiamiento para ser partícipe del sistema. Existen tres modalidades:

- Cuando es contributivo, el afiliado debe aportar regularmente al sistema.

- Cuando es no contributivo, el afiliado no debe contribuir directamente al sistema, sino que este se financia mediante otras fuentes.

- Una combinación de las dos anteriores.

ii) Gestión financiera de los recursos. Los recursos que acumula el sistema y con los que se pagan las pensiones pueden gestionarse de dos maneras opuestas:

- Reparto: un contrato entre generaciones en que los económicamente activos aportan sus cotizaciones al sistema para el pago de pensiones de quienes ya están retirados y para la acumulación de un fondo de reserva intertemporal. Equivale a un fondo colectivo que se acumula con una prima media general o escalonada y se asigna con una regla de beneficio definida de antemano.

- Capitalización individual: se establece una cuenta de ahorro para cada trabajador activo afiliado, en la que se depositan 
y capitalizan sus cotizaciones para su uso personal en el momento de pensionarse. La pensión se define luego según el monto acumulado (de capital e intereses) y otros parámetros $^{8}$. Esta alternativa es justa actuarialmente para el individuo, pero carece de solidaridad. Para conseguirla, requiere complementarse con otros mecanismos.

iii) Regla para otorgar beneficios. Los beneficios a los que da derecho el sistema deben establecerse de alguna manera. Hay dos alternativas extremas:

- El plan de beneficio definido establece una regla para determinar la prestación sobre la base de normas claras relacionadas con la historia laboral. Así, el beneficio se determina mediante una fórmula que incorpora el salario del trabajador, los años de servicio, la edad de jubilación y otros factores?

- En el plan de contribución definida, los aportes asociados a cada afiliado (por el empleado, el empleador o ambos) están predeterminados, pero el monto del beneficio se desconoce hasta que se calcula en el momento de la jubilación. En un acuerdo típico de contribución definida, las contribuciones se hacen a una cuenta que crece mediante su inversión en instrumentos financieros autorizados. Al jubilarse, el trabajador dispone de un fondo acumulado en una cuenta de su propiedad, que puede utilizar para comprar una pensión. Los fondos acumulados suelen ser portables, de forma que puedan trasladarse voluntariamente entre diferentes administradoras. En un plan de contribución definida, el costo se calcula con facilidad, pero el beneficio de un plan depende del saldo que tenga la cuenta cuando los contribuyentes quieran utilizar sus fondos. La inversión de la contribución seguirá los ciclos económicos (recesión o depresión, expansión, auge, declive o desaceleración), por lo que el beneficio no se puede conocer de antemano. En un régimen de cuentas de ahorro financiero individuales (como el de Chile), el propio afiliado es quien asume los riesgos. En un régimen de capitalización virtual (nocional), el patrocinador (el Estado) es quien asume estos riesgos (así es, por ejemplo, el modelo sueco).

La capitalización es plena, pero individual. Se utiliza como sistema de ahorro obligatorio para el retiro, pero no para cubrir contingencias. La persona debe disponer de un seguro complementario para invalidez y muerte y al final del período de ahorro, el monto ahorrado se utiliza para comprar una prestación vitalicia o temporal.

9 Estos factores pueden ser criterios de reajuste para actualizar la prestación con la inflación; integrar servicios de seguridad social o incentivos para una jubilación anticipada, o continuar con el trabajo. 
iv) Administración pública o privada.Sibien un sistema depensiones público es responsabilidad del Estado, su gestión puede estar a cargo de terceros, ya sean cajas gremiales, administradoras privadas $\mathrm{u}$ otras entidades. Hay dos alternativas extremas de administración de la gestión del sistema, pero siempre el responsable es el Estado.

- Administración estatal, cuando el mismo Estado o alguna institución de su dependencia gestiona la marcha del sistema.

- Administración privada, cuando un tercer agente privado administra el sistema, lo que requiere un alto grado de regulación y supervisión estatal.

v) Mecanismos de distribución. Cuando un trabajador llega a una situación de invalidez, muerte (con sobrevivencia de algún dependiente) o de vejez, es posible que aún no haya cumplido los requisitos para recibir pensiones, o que se encuentre en situación de pobreza. En estos casos existen dos opciones.

- Distributivo, cuando el sistema tiene un componente de subsidios cruzados o desde otras fuentes para el alivio de la pobreza en situaciones de invalidez, sobrevivencia y vejez.

- No distributivo, cuando el sistema no dispone de un componente de alivio de la pobreza y las personas deben recurrir a políticas asistenciales.

En el recuadro IV.2 se presenta un detalle con las diferentes concepciones de reparto que se consideran para los sistemas de pensiones.

\section{Recuadro IV.2}

\section{Diferentes concepciones de reparto}

Es usual referirse al concepto de reparto cuando se pagan pensiones con ingresos corrientes. No obstante, cuando se refiere al mecanismo de financiamiento, esos ingresos alimentan un fondo a partir del cual se pagan pensiones futuras. De ahí que convenga precisar si se trata de:

- Pensiones de reparto: Aquellas pagadas (habitualmente por el Estado) a partir de ingresos impositivos corrientes y no de un fondo acumulado.

- Esquemas de reparto de capitalización colectiva: Son regímenes de beneficios definidos en que las prestaciones se financian mediante un contrato intergeneracional. La generación activa aporta una prima que permitirá costear las prestaciones de la generación ya retirada y acumular un fondo de reserva para futuras contingencias. Se dice que el sistema opera mediante el endeudamiento entre generaciones, con el compromiso de que cada sucesiva generación de jóvenes aportará para la generación que se retira. El esquema opera con una reserva técnica a partir de la que puede determinarse la prima, con dos alternativas extremas: 
Recuadro IV.2 (conclusión)

- Prima media general: Cuando se fija desde el comienzo una tasa de aporte constante que permitirá garantizar indefinidamente su viabilidad financiera. La prima se calcula en un nivel necesario para que el valor actual de todos los ingresos futuros probables sea igual al valor actual de todos los gastos futuros probables. Durante un período inicial (varias décadas) los ingresos superan los gastos. El excedente se va a la reserva técnica. En el futuro, cuando el costo supera la prima (gastos mayores que ingresos por contribuciones), se utilizan los rendimientos y parte de la reserva para cubrir la diferencia.

- Prima media escalonada: Plantea períodos de equilibrio de 10 a 15 años, sobre cuya base se modifica la prima. Es un régimen de reparto donde se contemplan cambios en la prima conforme a evaluaciones actuariales que exijan ajustes a mayores gastos por concepto de nuevos casos, aumentos de años de cobertura, mayores esperanzas de vida, o reajustes no programados. Es un esquema intermedio entre reparto simple y prima media general, en que: a) se definen períodos de equilibrio durante los cuales la prima no varía; b) se garantiza el equilibrio financiero durante ese período para luego pasar a otro escalón; c) hay acumulación de fondos, pero en menor medida que en el sistema de prima media general, y d) los intereses de la reserva se utilizan para financiar gastos.

- Esquemas de reparto de capitalización colectiva simple: El régimen de reparto simple consiste en evaluar cada año el costo de las prestaciones y establecer el nivel de los ingresos necesarios para cubrirlas, siendo posible en la práctica que se constituya alguna reserva para contingencias.

- Esquemas de reparto de cuentas individuales y capitalización nocional: Es un régimen de contribución definida que se financia con cotizaciones de los activos y utiliza un acuerdo social para determinar la forma de capitalizar los aportes que se administran mediante el reparto. En estos esquemas: a) no se garantiza al individuo un nivel de beneficio o prestación; b) se lleva un registro de aportes para el retiro, pero no se invierten, sino que se capitalizan conforme a indicadores de desempeño de la economía (aumento de salarios reales, incrementos de productividad u otro); c) al final del período, el monto así capitalizado se utiliza para proveer una prestación vitalicia o temporal, y d) se debe disponer de un seguro complementario para invalidez y muerte. Esta alternativa es justa actuarialmente para el individuo y puede modificarse la fórmula de reajuste a fin de establecer mecanismos de solidaridad, de forma que se redistribuyan las ganancias de productividad entre todos.

Fuente: Elaboración propia.

\section{Tipología de sistemas de pensiones}

Es habitual hacer referencia a cuatro modelos de organización del financiamiento y determinación de beneficios, que se distinguen por su origen histórico. 
- El primer tipo es el seguro social o bismarckiano ${ }^{10}$. Es un sistema de contribuciones tripartitas (con aportes del trabajador, su empleador y el Estado), gestionado por un régimen de reparto, de beneficios definidos, administrado por el Estado. Al no haber un componente de alivio de la pobreza, este objetivo se cumple mediante políticas asistenciales. Este sistema ha predominado en América Latina, pero con una baja cobertura debido al alto grado de informalidad en el mercado de trabajo.

- $\quad$ El segundo tipo es el de seguridad social o beveridgiano ${ }^{11}$. Es un sistema no contributivo, financiado exclusivamente con rentas generales, administrado por el presupuesto público (transferencias), de beneficios definidos, gestionado por el Estado y con un componente de alivio de la pobreza. Este sistema se ha visto limitado en América Latina por las bajas bases y cargas tributarias para financiarlo.

- El tercero, denominado de capitalización en cuentas individuales, fue impulsado por las instituciones financieras internacionales en la década de 1990. Ante el inminente cambio demográfico, la escasez de ahorro financiero a largo plazo y los riesgos políticos y demográficos que vulneraban los sistemas de reparto, dichas instituciones sugirieron modificar la gestión financiera de los sistemas originales contributivos. Esto se hace bajo el régimen de capitalización en cuentas individuales de contribuciones definidas ${ }^{12}$. La administración es privada y está regulada y supervisada por el Estado, sin un componente de alivio de la pobreza. Su funcionamiento ha fallado debido a la dificultad de cubrir la informalidad y a la ausencia de subsidios cruzados para apoyar a quienes tienen baja capacidad de ahorro (bajo nivel de ingreso imponible y limitada densidad de cotizaciones). Además, se ha generado una serie de conflictos entre la regulación y la supervisión de las empresas de administración de fondos.

El cuarto tipo es el mixto o multipilar, que surge como respuesta a las enseñanzas extraídas de cada uno de los modelos anteriores. Con este objetivo, y para superar los problemas de exclusión (inequidad), ineficiencia e insolvencia, se sugieren combinaciones de las diferentes alternativas. Existen sistemas que articulan lo contributivo y lo no contributivo, combinan reparto con capitalización, entregan pensiones tanto de beneficios como de contribuciones definidas, integran la gestión financiera mediante la capitalización y el manejo del presupuesto estatal, buscan la mezcla

En honor a su gestor inicial, el canciller alemán Otto von Bismarck.

A propósito de Lord Beveridge, su gestor inicial en el Reino Unido.

12 Solo se define la cotización y el beneficio es el resultado de la capitalización final en cada cuenta individual. 
apropiada de administración estatal y privada (de forma que se fortalezcan los mecanismos de competencia, y rediseñan el componente de alivio de la pobreza mediante incentivos al trabajo y al ahorro.

En el cuadro IV.1 se muestran ejemplos de países que de alguna forma han asimilado alguna de las tipologías descritas ${ }^{13}$.

\section{Cuadro IV.1}

\section{Opciones para el diseño de un sistema de pensiones}

\begin{tabular}{|c|c|c|c|c|c|}
\hline Opciones & $\begin{array}{l}\text { Beveridge } \\
\text { Pensión } \\
\text { universal }\end{array}$ & $\begin{array}{l}\text { Bismarck } \\
\text { Reparto } \\
\text { público }\end{array}$ & $\begin{array}{l}\text { Capitalización } \\
\text { individual }\end{array}$ & $\begin{array}{l}\text { Mixto o } \\
\text { paralelo }\end{array}$ & $\begin{array}{l}\text { Capitalización } \\
\text { nocional }\end{array}$ \\
\hline \multicolumn{6}{|c|}{ Participación en financiamiento } \\
\hline Contributivo & & $x$ & $x$ & $x$ & $x$ \\
\hline No contributivo & $x$ & & & $x$ & \\
\hline \multicolumn{6}{|l|}{ Gestión financiera } \\
\hline Reparto & $\mathrm{x}$ & $\mathrm{x}$ & & $x$ & $x$ \\
\hline $\begin{array}{l}\text { Ahorro y } \\
\text { capitalización }\end{array}$ & & & $x$ & $x$ & \\
\hline \multicolumn{6}{|l|}{ Beneficios } \\
\hline $\begin{array}{l}\text { Beneficios } \\
\text { definidos }\end{array}$ & & $x$ & & $x$ & \\
\hline $\begin{array}{l}\text { Contribuciones } \\
\text { definidas }\end{array}$ & & & $x$ & $x$ & $x$ \\
\hline \multicolumn{6}{|l|}{ Administración } \\
\hline Estatal & $\mathrm{x}$ & $\mathrm{x}$ & & $\mathrm{x}$ & $\mathrm{x}$ \\
\hline $\begin{array}{l}\text { Privada, regulada } \\
\text { y supervisada }\end{array}$ & & & $x$ & $x$ & \\
\hline \multicolumn{6}{|l|}{ Rol redistributivo } \\
\hline $\begin{array}{l}\text { Garantía de un } \\
\text { mínimo }(\mathrm{GM})\end{array}$ & $x$ & $x$ & $x$ & $x$ & $x$ \\
\hline $\begin{array}{l}\text { GM más alivio de } \\
\text { la pobreza }\end{array}$ & & & $x$ & & $\mathrm{x}$ \\
\hline Ejemplos & $\begin{array}{l}\text { Nueva } \\
\text { Zelandia y } \\
\text { Brasil rural }\end{array}$ & $\begin{array}{l}\text { Ecuador, } \\
\text { Nicaragua, } \\
\text { Venezuela } \\
\text { (República } \\
\text { Bolivariana } \\
\text { de) y Brasil } \\
\text { (Régimen } \\
\text { Propio de } \\
\text { Previsión Social } \\
\text { (RPPS)) }\end{array}$ & $\begin{array}{l}\text { Bolivia (Estado } \\
\text { Plurinacional } \\
\text { de), Chile, EI } \\
\text { Salvador, México, } \\
\text { República } \\
\text { Dominicana y } \\
\text { Brasil (pensión } \\
\text { complementaria) }\end{array}$ & 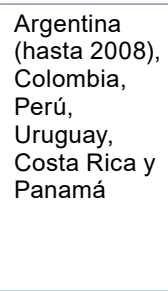 & $\begin{array}{l}\text { Suecia, Brasil } \\
\text { (Régimen } \\
\text { General de } \\
\text { Previsión } \\
\text { Social (RGPS), } \\
\text { adaptación) }\end{array}$ \\
\hline
\end{tabular}

\footnotetext{
Fuente: Elaboración propia.
}

a Programa de Asistencia al Trabajador Rural (PRORURAL)/Fondo de Asistencia al Trabajador Rural (FUNRURAL) que ofrece pensiones, aunque precarias, a los trabajadores rurales, pescadores y extractores de minerales (garimpeiros) que hayan cumplido 65 años. Sin embargo, la pensión es exclusiva para el jefe de hogar con un límite máximo de un salario mínimo.

b Régimen General de Previsión Social, bajo la lógica de la Regla de Cálculo Previsional, donde se relaciona el monto recaudado de las cotizaciones con la pensión.

13 Respecto de cada opción expuesta en forma binaria existen situaciones intermedias que pueden plantearse. 


\section{B. Los desafíos institucionales}

Como política de Estado que trasciende a los gobiernos, un sistema de pensiones debe sustentarse en valores constitucionales y permitir su adaptación a los permanentes conflictos que la realidad interpone al logro de sus objetivos. Por ende, la institucionalidad que se construya a partir de las opciones recién revisadas supone la implementación de un sistema que se base en los principios de la seguridad social. Dado que el acceso universal a beneficios dignos como forma de titularizar derechos sociales es la racionalidad que persigue la política de protección social, se plantea una pregunta fundamental: ¿cómo garantizar en forma permanente el acceso a pensiones dignas para personas de baja capacidad de ahorro en un sistema financieramente sostenible?

Desde trabajos anteriores, la CEPAL advirtió de la importancia de la solidaridad cuando señaló: "La situación actual obliga a replantearse la protección social en el marco de una solidaridad integral, en que se combinen mecanismos contributivos y no contributivos. Esto hace necesaria la concertación de un nuevo pacto social que tenga a los derechos sociales como horizonte normativo, y a las desigualdades y restricciones presupuestarias como limitaciones que es necesario reconocer y enfrentar. En otras palabras, se requiere conciliar los imperativos éticos que sirven de marco a un contrato centrado en derechos sociales con las restricciones financieras. Asimismo, es importante realzar la eficiencia en el uso de los recursos, a efectos de ampliar la cobertura y elevar la calidad de los servicios, en especial para los sectores de menores recursos" (CEPAL, 2006, pág. 12).

Al respecto surgen dos tipos de necesidades de desarrollo institucional. En primer lugar, cumplir los objetivos fundamentales del sistema para conciliar la eficiencia y la solidaridad y proteger al sistema de los riesgos que influyen sobre su lógica de funcionamiento y sus resultados. Luego, actuar sobre las cuatro dimensiones de la institucionalidad (véase el capítulo I): i) la jurídico-normativa, resaltando un marco legal que pueda respaldar toda la estructura de seguridad social (pilar contributivo y no contributivo); ii) la organizacional, orientada a contar con una autoridad en el tema de pensiones, capaz de articular y dialogar con todas las instancias de gobierno y los participantes en el sistema; iii) la técnico-operativa, considerando la transparencia, la participación civil y la rendición de cuentas como las principales herramientas de gestión que puedan mover la institucionalidad del sistema de pensiones a un ambiente más democrático e inclusivo, y iv) el financiamiento, para garantizar la solvencia y el equilibrio fiscal ante las presiones de los cambios demográficos, por el riesgo financiero de inversión y por los ciclos económicos. 


\section{Elementos para resolver el conflicto entre eficiencia y solidaridad}

La evaluación de un sistema de pensiones es tanto un tema normativo como de método. En el primer plano, los sistemas deben ser justos y promover la equidad, considerando sus dos dimensiones (vertical y horizontal). Desde la perspectiva de la equidad vertical, podría justificarse subsidiar a quienes experimenten problemas económicos y no estén en condiciones de cotizar. Sin embargo, en los sistemas contributivos es necesario incentivar la cotización, lo que debe hacerse manteniendo algún tipo de equivalencia entre lo aportado y lo recibido. Desde la perspectiva de la equidad horizontal, dos personas con similares historias laborales y previsionales deberían tener los mismos beneficios.

En el segundo plano, una vez decidido el marco normativo, los métodos buscan la eficiencia mediante el logro de las metas trazadas al menor costo para el afiliado. Ello implica un sistema que proteja al individuo de la mejor forma posible frente a riesgos que afectan la operación del sistema.

En relación con este desafío, los sistemas de pensiones como componentes de la política de protección social se encuentran en una inflexión histórica que exige un cambio de enfoque. Este implica reconocer que los mecanismos instituidos de solidaridad con fines de protección social, basados exclusivamente en el mercado del trabajo (modelos bismarckianos de seguros sociales), no han demostrado una capacidad incluyente. En efecto, la generación de trabajo decente (formal y estable) y de niveles contributivos no ha permitido alcanzar los niveles de financiamiento necesarios para garantizar la cobertura universal.

En los cuadros IV.2 y IV.3 se aprecian rasgos coincidentes en todas las experiencias reportadas por la Federación Internacional de Administradoras de Fondos de Pensiones (FIAP) en que se incentivó la cotización extremando el argumento de contribuciones definidas y el concepto de propiedad de la cotización. Por ejemplo, si bien se logra afiliar a un porcentaje significativo de la población económicamente activa (PEA), solo una fracción de esa población cotiza de manera regular ${ }^{14}$. En América Latina, la alta incidencia de la pobreza, el desempleo y el subempleo (asociado con la informalidad), así como la escasa presencia de políticas contracíclicas de protección social (en particular, seguros de desempleo), hacen que un alto porcentaje de la PEA pase largos períodos de su historia laboral subempleada o desempleada, sin posibilidad

14 Las cifras de afiliación deben compararse con cuidado. En algunos países, los sistemas de contribuciones definidas $(\mathrm{CD})$ no son obligatorios, excepto para personas de altos ingresos y empleo estables (por ejemplo, en el Uruguay y Costa Rica, que tienen sistemas mixtos). En otros, los afiliados optan entre el plan de contribuciones definidas (CD) y el de beneficios definidos (BD) (el Perú y Colombia, que tienen sistemas paralelos). 
de cotizar. Por ende, sus integrantes presentan historias previsionales con bajas densidades de cotizaciones que limitan su capacidad de autofinanciar su pensión. A ello se suma la incompatibilidad de roles entre quienes ejercen el trabajo en el hogar, en tareas de cuidado, y su papel potencial en el mercado de trabajo. Este factor suele tener un efecto discriminatorio contra el acceso de las mujeres a la protección social contributiva. Así, es de esperar que, a lo largo de su vida activa, muchos afiliados a los sistemas contributivos experimenten importantes lagunas previsionales que les impidan ahorrar lo suficiente como para autofinanciar su pensión.

\section{Cuadro IV.2}

América Latina y el Caribe (10 países): indicadores de cobertura en esquemas de contribuciones definidas por afiliados

(En afiliados como porcentaje de la PEA)

\begin{tabular}{lrrrrr}
\hline $\begin{array}{l}\text { Sistemas obligatorios } \\
\text { en América Latina }\end{array}$ & 2011 & 2012 & 2014 & 2015 & $\begin{array}{c}\text { Variación de } \\
\text { 2011 a 2015 }\end{array}$ \\
\hline Bolivia (Estado Plurinacional de) & 34,53 & 28,17 & 29,14 & 31,48 & 3,05 \\
\hline Chile & 110,20 & 113,09 & 114,29 & 115,35 & 5,15 \\
\hline Colombia & 43,59 & 46,57 & 52,44 & 54,34 & 10,75 \\
\hline Costa Rica & 94,57 & 97,78 & 112,81 & 118,34 & 23,77 \\
\hline El Salvador & 100,19 & 107,24 & 94,53 & 98,07 & $-2,12$ \\
\hline México & 85,75 & 87,30 & 89,28 & 88,80 & 3,05 \\
\hline Panamá & 24,40 & 24,20 & 15,41 & 15,91 & $-8,49$ \\
\hline Perú & 22,84 & 24,01 & 34,93 & 36,37 & 13,53 \\
\hline República Dominicana & 51,72 & 55,13 & 58,32 & 60,99 & 9,27 \\
\hline Uruguay & 64,54 & 68,53 & 73,84 & 76,50 & 11,96 \\
\hline Promedio simple de América Latina & $\mathbf{6 3 , 2 3}$ & $\mathbf{6 5 , 2 0}$ & $\mathbf{6 7 , 5 0}$ & $\mathbf{6 9 , 6 2}$ & $\mathbf{6 , 3 9}$ \\
\hline
\end{tabular}

Fuente: Federación Internacional de Administradoras de Pensiones (FIAP), Los sistemas de pensiones multipilares: invirtiendo en el futuro, Santiago, 2016.

Nota: Los valores superiores al $100 \%$ responden a que se registra doble afiliación y se incluye a quienes ya están percibiendo beneficios.

Sin desmedro de la necesidad de promover políticas que generen más y mejores empleos, no cabe esperar que a corto o mediano plazo el empleo sea suficiente como mecanismo de protección de la mayoría de la población frente a riesgos relacionados con la falta de ingresos, la salud y el envejecimiento. Ello hace que sea indispensable explorar una combinación de las tres vías mencionadas.

Como resultado, varios países realizaron reformas estructurales que cambiaron las formas de financiar el sistema, gestionar ese financiamiento y vincular los derechos y obligaciones de los afiliados ${ }^{15}$. Si bien se puso de

15 Durante la década de 1990 la mayor reforma se refería a cambiar el sistema de reparto por la introducción total o parcial de un sistema de capitalización individual (por ejemplo, se procedió de este modo en la Argentina, Bolivia (Estado Plurinacional de), Chile (en 1981), El Salvador, la República Dominicana y el Uruguay). En ese momento se constituyó el nuevo paradigma, que contó con el apoyo de las instituciones financieras internacionales al amparo de condicionalidades en los programas de renegociación de la deuda de esos países. 
manifiesto la importancia de las opciones revisadas en este documento, también se evidenció el gran desafío de los sistemas a la hora de conciliar la eficiencia con la equidad.

Cuadro IV.3

América Latina y el Caribe (8 países): indicadores de cobertura en esquemas de contribuciones definidas por cotizantes

(En afiliados como porcentaje de la PEA)

\begin{tabular}{lccccc}
\hline $\begin{array}{l}\text { Sistemas obligatorios } \\
\text { en América Latina }\end{array}$ & 2011 & 2012 & 2014 & 2015 & $\begin{array}{c}\text { Variación de } \\
\text { 2011 a 2015 }\end{array}$ \\
\hline Chile & 61,61 & 63,89 & 59,73 & 64,54 & 2,87 \\
\hline Colombia & 18,81 & 18,91 & 22,04 & 20,83 & 2,02 \\
\hline Costa Rica & 42,19 & 41,89 & 48,94 & 50,74 & 8,65 \\
\hline El Salvador & 27,38 & 28,44 & 23,62 & 24,26 & $-3,12$ \\
\hline México & 28,49 & 29,29 & 29,91 & 30,00 & 1,51 \\
\hline Perú & 9,90 & 11,37 & 15,37 & 15,79 & 5,89 \\
\hline República Dominicana & 24,49 & 25,50 & 27,95 & 29,45 & 4,96 \\
\hline Uruguay & 40,69 & 43,26 & 45,88 & 42,22 & 1,53 \\
\hline Promedio simple de América Latina & $\mathbf{3 1 , 7 0}$ & $\mathbf{3 2 , 8 2}$ & $\mathbf{3 4 , 1 8}$ & $\mathbf{3 4 , 7 4}$ & $\mathbf{3 , 0 4}$ \\
\hline
\end{tabular}

Fuente: Federación Internacional de Administradoras de Pensiones (FIAP), Los sistemas de pensiones multipilares: invirtiendo en el futuro, Santiago, 2016.

Los desarrollos institucionales necesarios para asegurar a todos el acceso a pensiones dignas, incluidas las personas de baja capacidad de ahorro, han seguido tres vías:

- la articulación del financiamiento contributivo y no contributivo;

- la organización de subsidios cruzados implícitos o explícitos desde personas o agentes económicos con alta capacidad de ahorro hacia los de baja capacidad de ahorro, $y$

- la definición de beneficios dignos en respuesta a los derechos que surgen por la condición de ciudadano o de haber contribuido financieramente al sistema.

\section{a) La articulación del financiamiento contributivo y no contributivo}

La protección social responde a dos lógicas, según el tipo de relación existente entre el esquema de financiamiento y los beneficios: la que relaciona el monto de la jubilación, correspondiente a cada participante del sistema, con los aportes (o cotizaciones) realizados durante la etapa activa, y la que recurre a los impuestos o subsidios cruzados.

En el primer caso, el individuo espera una clara relación entre lo que aporta a la seguridad social y los beneficios que recibe. Se habla 
entonces de un financiamiento contributivo y el acceso a un beneficio acorde con lo contribuido. El caso extremo es una cuenta de ahorro individual obligatorio.

En el segundo caso, se habla de un financiamiento no contributivo y el acceso a un beneficio que no guarda relación con la cotización. Ello permite avanzar hacia la equidad en el acceso a prestaciones. La expresión más tangible es la asistencia social. Los contribuyentes hacen sus aportes mediante los impuestos generales y los beneficios no guardan una relación directa con lo aportado. Esta modalidad funciona como un mecanismo de redistribución, es decir, mediante la canalización de transferencias de los que más tienen a los de menores ingresos.

La precisión de cuáles y cuántos derechos están garantizados y, por lo tanto, cuáles son los riesgos que la sociedad está dispuesta a asumir como responsabilidad colectiva, debe conducir a la definición explícita de los bienes de carácter público de los que el Estado se hace responsable de forma insustituible e indelegable. Dicha definición es independiente de si la provisión de esos bienes está a cargo de instituciones públicas o privadas.

En este marco, un pacto o contrato social en que se estipulen los estándares aceptables de protección social de todos los ciudadanos siempre se desplazará a lo largo de una línea cuyos extremos son la equidad individual (entendida como la relación directa entre aportes y contribuciones a nivel de cada individuo) y la equidad social (es decir, la optimización social de estas retribuciones a partir de la suma de aportes). El equilibrio ideal, que articula los financiamientos de tipo contributivo y no contributivo, es el que permite movilizar de manera eficiente un máximo posible de recursos para promover el acceso a niveles dignos de pensiones para todos.

\section{b) La organización de subsidios cruzados}

Existen dos grandes categorías de subsidios que permiten que las personas de bajas rentas y capacidad de ahorro accedan a una pensión digna durante la vejez. Se trata de los subsidios explícitos al beneficio que perciben y los subsidios cruzados implícitos. Ambos pueden operar simultáneamente o por separado.

Los subsidios explícitos son transferencias en efectivo a personas de escasa capacidad de ahorro. Durante la etapa contributiva, esto puede realizarse mediante cupones, exención de impuestos, créditos imponibles y aportes patronales. En la etapa pasiva, puede recurrirse a la transferencia de ingresos a los beneficiarios potenciales o efectivos del sistema que se encuentren en situación de pobreza. Los subsidios pueden ser organizados por el patrocinador del sistema (habitualmente, el Estado), de modo que 
se conozca su origen y financiamiento, y pueden centrarse en atender realidades particulares.

También es posible configurar el sistema de modo que genere implícitamente subsidios desde las personas de alta capacidad de ahorro hacia las de baja capacidad de ahorro. Ello suele requerir una cuidadosa regulación de la fórmula de beneficios definidos.

\section{c) Los beneficios dignos por derechos ciudadanos y contributivos ${ }^{16}$}

Un sistema de pensiones basado en la ciudadanía social requiere de una institucionalidad incluyente que garantice a todas las personas las mismas oportunidades de participar en sus beneficios, en sus deberes $\mathrm{y}$ en las decisiones que se toman respecto de cómo orientarlo. Es decir, mediante la acción deliberada del Estado, se demanda la exigibilidad de la titularidad de derechos a partir de un proceso de participación e inclusión y un freno a las desigualdades económicas.

Dado que el logro de la titularidad de derechos económicos, sociales y culturales requiere recursos, instituciones y capacidades públicas, su exigibilidad solo puede irse condicionando e incrementando a lo largo del tiempo, y varía de una sociedad a otra. Además, requiere un sistema que vaya perfeccionando instituciones, ampliando la provisión de recursos y activos, y que avance en el procesamiento de las demandas sociales. Se hace imprescindible definir permanentemente en qué se traducen los derechos sociales de las personas con discapacidad, adultos mayores o sobrevivientes. Es decir, debe conocerse el abanico de acceso a prestaciones, activos y beneficios al que todo destinatario potencial puede aspirar por su condición de ciudadano, y cuáles son los plazos que fija la sociedad para el logro de la plena titularidad.

Lo indicado implica la necesidad de avanzar en el ámbito de la política en sus distintos campos de intervención, como la política social, las estructuras impositivas, la orientación y magnitud del gasto público social, y sus efectos redistributivos y de expansión de oportunidades para una vida digna en la tercera edad. También es preciso avanzar en cuanto a la mitigación de los costos sociales mediante la aplicación de políticas contracíclicas ante la volatilidad económica, y la eficiencia en la gestión para optimizar los efectos que tienen los programas y las políticas de protección social e inclusión en la población que vive en la pobreza o es vulnerable a ella. Deben instituirse políticas orientadas a la protección de la familia y el cuidado de ancianos que ofrezcan, además, mayores posibilidades a las mujeres de incorporarse al mercado laboral.

16 Basado en CEPAL (2015, cap. I). 


\section{d) Algunas experiencias}

Diversas reformas en proceso intentan adaptar los diseños institucionales de los sistemas de pensiones al desafío de conciliar la sostenibilidad financiera con la solidaridad necesaria a fin de garantizar prestaciones dignas para todos. En el cuadro IV.4 se presenta una síntesis de algunas experiencias recientes de reforma. Se puede apreciar que, sobre la base de las tres vías mencionadas, esta preocupación es una realidad en la región.

\section{Cuadro IV.4}

Iniciativas encaminadas a conciliar la equivalencia de los contratos y solidaridad

\begin{tabular}{|c|c|c|c|}
\hline & $\begin{array}{l}\text { Vía de la articulación de } \\
\text { financiamiento contributivo } \\
\text { y no contributivo }\end{array}$ & $\begin{array}{l}\text { Vía de la organización de } \\
\text { subsidios cruzados }\end{array}$ & $\begin{array}{l}\text { Vía de los beneficios } \\
\text { dignos ciudadanos y } \\
\text { contributivos }\end{array}$ \\
\hline $\begin{array}{l}\text { Dimensión } \\
\text { jurídico- } \\
\text { normativa }\end{array}$ & $\begin{array}{l}\text { Naturaleza del beneficio: } \\
\text { - Contratos individuales } \\
\text { - Obligatorios (Bolivia } \\
\text { (Estado Plurinacional } \\
\text { de), Chile, El Salvador, } \\
\text { México y República } \\
\text { Dominicana) } \\
\text { - Voluntarios (Brasil) } \\
\text { - Opcionales (Colombia } \\
\text { y Perú) } \\
\text { - Contratos sociales (Brasil, } \\
\text { Colombia, Costa Rica, } \\
\text { Ecuador, Panamá y Perú) }\end{array}$ & $\begin{array}{l}\text { Rol del Estado: } \\
\text { - Activo (financia y provee) } \\
\text { - Derechos (Brasil, Costa } \\
\text { Rica y Uruguay) } \\
\text { - Asistencial (Chile) } \\
\text { - Subsidiario (Chile) }\end{array}$ & $\begin{array}{l}\text { - Alivio de la pobreza } \\
\text { (Brasil, Chile (1981), } \\
\text { Costa Rica, Estados } \\
\text { Unidos y Uruguay) } \\
\text { - Derecho a una } \\
\text { garantía de un piso } \\
\text { por antigüedad y } \\
\text { condición de pobreza } \\
\text { o desigualdad (Chile } \\
\text { (1981 y 2008), Costa } \\
\text { Rica y Estados Unidos) }\end{array}$ \\
\hline $\begin{array}{l}\text { Dimensión } \\
\text { organizacional }\end{array}$ & $\begin{array}{l}\text { - Ministerios del Sector } \\
\text { Público (Argentina, Brasil, } \\
\text { Ecuador, Honduras } \\
\text { y Nicaragua) } \\
\text { - Regulación y articulación } \\
\text { público-privada (Bolivia } \\
\text { (Estado Plurinacional de), } \\
\text { Chile, Colombia, Costa } \\
\text { Rica, El Salvador, México, } \\
\text { Panamá, Perú, República } \\
\text { Dominicana y Uruguay) } \\
\text { - Regulación con iniciativa } \\
\text { privada (Brasil } \\
\text { y Estados Unidos) }\end{array}$ & $\begin{array}{l}\text { Creciente articulación } \\
\text { de los Ministerios de } \\
\text { Desarrollo Social, de Salud } \\
\text { y de Trabajo y Previsión } \\
\text { Social (Argentina, Brasil, } \\
\text { Chile, Colombia, Costa } \\
\text { Rica, México y Uruguay) }\end{array}$ & $\begin{array}{l}\text { - Ofrecidas en red } \\
\text { asistencial (Brasil, } \\
\text { Chile (1981), Costa } \\
\text { Rica, Estados Unidos } \\
\text { y Uruguay) } \\
\text { - Ofrecida por el propio } \\
\text { sistema (Chile (2008), } \\
\text { Costa Rica y Estados } \\
\text { Unidos) }\end{array}$ \\
\hline $\begin{array}{l}\text { Dimensión } \\
\text { técnico- } \\
\text { operativa }\end{array}$ & $\begin{array}{l}\text { Análisis actuarial } \\
\text { permanente entre } \\
\text { derechos y: } \\
\text { - Cotizaciones (todos) } \\
\text { - Aportes patronales } \\
\text { (eliminados en algunos) } \\
\text { - Aportes fiscales } \\
\text { (diferentes) } \\
\text { - Reforma tributaria } \\
\text { (viabilidad) }\end{array}$ & $\begin{array}{l}\text { - Política asistencial } \\
\text { - Instrumento o criterio } \\
\text { de focalización } \\
\text { - Pilares estancos } \\
\text { o integrados }\end{array}$ & $\begin{array}{l}\text { - Topes, garantías y } \\
\text { cuotas establecidas } \\
\text { por ley (Brasil, Chile, } \\
\text { Costa Rica, Estados } \\
\text { Unidos y Uruguay) } \\
\text { - Niveles regulados con } \\
\text { incentivos a cotizar }\end{array}$ \\
\hline
\end{tabular}


Cuadro IV.4 (conclusión)

\begin{tabular}{|c|c|c|c|}
\hline & $\begin{array}{l}\text { Vía de la articulación de } \\
\text { financiamiento contributivo } \\
\text { y no contributivo }\end{array}$ & $\begin{array}{l}\text { Vía de la organización de } \\
\text { subsidios cruzados }\end{array}$ & $\begin{array}{l}\text { Vía de los beneficios } \\
\text { dignos ciudadanos y } \\
\text { contributivos }\end{array}$ \\
\hline $\begin{array}{l}\text { Dimensión de } \\
\text { financiamiento }\end{array}$ & $\begin{array}{l}\text { Ley de Responsabilidad } \\
\text { Fiscal } \\
\text { - Partidas para garantías } \\
\text { por pasivos contingentes } \\
\text { - Déficits previsionales } \\
\text { - Financiamiento de } \\
\text { desarrollos institucionales } \\
\text { de regulación } \\
\text { y articulación }\end{array}$ & $\begin{array}{l}\text { - A partir de impuestos } \\
\text { generales hacia la } \\
\text { población elegible según } \\
\text { criterio de focalización } \\
\text { (Chile, Costa Rica, Estados } \\
\text { Unidos y Uruguay) } \\
\text { - A partir de algún ítem } \\
\text { del Presupuesto de la } \\
\text { Nación (Brasil) } \\
\text { - De altos a bajos ingresos } \\
\text { o cotizaciones (Brasil y } \\
\text { Estados Unidos) } \\
\text { - Desde empresas agrícolas } \\
\text { hacia la población rural } \\
\text { en situación de pobreza } \\
\text { (Brasil) }\end{array}$ & $\begin{array}{l}\text { - Las leyes de } \\
\text { presupuesto cada vez } \\
\text { se guían más por leyes } \\
\text { de responsabilidad } \\
\text { fiscal (Chile, Costa } \\
\text { Rica, Estados Unidos } \\
\text { y Uruguay) } \\
\text { - Leyes estaduales de } \\
\text { presupuesto (Brasil) }\end{array}$ \\
\hline
\end{tabular}

Fuente: Elaboración propia.

Resulta interesante observar que las diferentes experiencias de diseño de los sistemas de pensiones con miras a alcanzar un concepto más amplio de seguridad social combinan estas vías mediante la construcción de pilares, niveles o regímenes que no siempre están bien articulados o integrados.

A modo de ilustración, se puede señalar que en el Brasil esto se hace a través de tres pilares ${ }^{17}$ :

i) El pilar 1 regula la cotización, define los beneficios y se basa en la afiliación obligatoria.

ii) El pilar 2 premia la capacidad de ahorro y está configurado por la denominada previsión complementaria de carácter individual o corporativo.

iii) El pilar 3 es de carácter subsidiado, en forma de asistencia social, y otorga pensiones no contributivas a personas ancianas que están por debajo de la línea de pobreza. Hay un subsidio especial destinado a costear la pensión para el alivio de la pobreza rural a partir de la recaudación tributaria por concepto de exportaciones agrícolas.

En el caso de Chile, la historia reciente permite definir dos etapas diferenciadas.

i) Antes de 2008, se hacía a través de tres pilares:

- El pilar 1, contributivo, obligatorio y de contribuciones definidas, pero con una pensión mínima garantizada sujeta a

17 La información aquí contenida no incluye los cambios iniciados en 2016. 
20 años de cotización y al autofinanciamiento de un beneficio por debajo de un piso.

- El pilar 2, voluntario y de contribuciones definidas para elevar la pensión autofinanciada.

- Una pensión asistencial (PASIS) no contributiva, sin vínculo con los pilares anteriores, sujeta a la holgura fiscal y asignada por cuotas.

ii) Después de la reforma de 2008 se integraron los subsidios al sistema mediante un nuevo pilar solidario:

- El pilar 1 continuó siendo obligatorio y de contribuciones definidas. Se eliminó la pensión mínima garantizada con 20 años de cotizaciones.

- El pilar 2 permaneció igual.

- Se incorporó un pilar solidario en reemplazo de la pensión mínima garantizada y la PASIS, con el fin de rediseñar el mecanismo de determinación de la garantía de una pensión mínima con subsidios inversamente proporcionales a la capacidad de ahorro (cobertura mínima garantizada). Se establece, por una parte, un ítem presupuestario de rentas generales para financiar solidaridad (Fondo de Solidaridad) y, por otra, derechos de pensiones para el $60 \%$ más pobre de la población, financiados con aportes de rentas generales (fondo solidario). Se dirige a personas sin ahorro (Pensión Básica Solidaria (PBS)) y con ahorro (Aporte Previsional Solidario (APS)).

En Costa Rica se diseñó un sistema integrado de pensiones, conformado por cuatro componentes:

i) El Régimen de Pensiones Básico, administrado por la Caja Costarricense de Seguro Social (CCSS). El monto de la pensión por vejez del Régimen de Invalidez, Vejez y Muerte de la CCSS es una cuantía básica del salario medio, calculada sobre las últimas 240 cotizaciones realizadas por el afiliado y actualizada por la inflación.

ii) El Fondo de Capitalización Laboral (FCL) es un ahorro constituido con el aporte patronal del $3 \%$ del salario del trabajador que reporta a la CCSS. Dichos aportes se acreditan en las cuentas individuales que son propiedad de los trabajadores que administran la Operadora de Pensiones Complementarias (OPC).

iii) El Régimen Voluntario de Pensiones Complementarias es un plan de pensiones adquirido que, en virtud de la Ley núm. 7523, puede ser trasladado a otra operadora, en cuyo caso 
se reconocerá únicamente la antigüedad, mientras que el resto de las condiciones se regirán por lo establecido en la Ley de Protección al Trabajador.

iv) Las pensiones no contributivas tienen dos componentes: el Régimen no Contributivo de Pensiones por Monto Básico (RNC) y la Pensión Mínima (PM) del Régimen de Invalidez, Vejez y Muerte.

En los Estados Unidos se ha promovido la solidaridad dentro del sistema por medio de las siguientes opciones:

- En el sistema contributivo de seguridad social se establecen subsidios cruzados implícitos mediante la fijación de un techo y una regla de beneficios proporcional al ingreso.

- Se ofrece una pensión asistencial para el alivio de la pobreza en la vejez.

- Se promueven mercados de ahorro privado previsional al margen del sistema mediante incentivos tributarios.

Por su parte, en el Uruguay se mantiene un sistema mixto con tres componentes. Para la aplicación de subsidios, en el marco de diferentes regímenes se determinan los siguientes niveles de ingresos individuales de percepción mensual, siempre que constituyan asignaciones computables.

- Primer nivel (régimen de jubilación por solidaridad intergeneracional). Este régimen comprende a todos los afiliados por sus asignaciones computables, o por tramos de estas, hasta 5.000 pesos uruguayos. Esto da origen a prestaciones que se financian mediante aportación patronal, personal y estatal.

- Segundo nivel (régimen de jubilación por ahorro individual obligatorio). Este régimen comprende el tramo de asignaciones computables superiores a 5.000 pesos uruguayos y hasta 15.000 pesos uruguayos, lo que da origen a prestaciones que se financian exclusivamente con aportación personal. Su administración está a cargo de instituciones públicas, incluido el Banco de Previsión Social o de personas u organizaciones privadas (artículo 92 de la Ley de Seguridad Social).

- Tercer nivel (ahorro voluntario). Por el tramo de asignaciones computables que excedan de 15.000 pesos uruguayos, el trabajador puede aportar o no a cualquiera de las entidades administradoras referidas en el inciso anterior.

A estos tres niveles, se suman las pensiones no contributivas para el alivio de la pobreza en la vejez (véase el cuadro IV.5). 


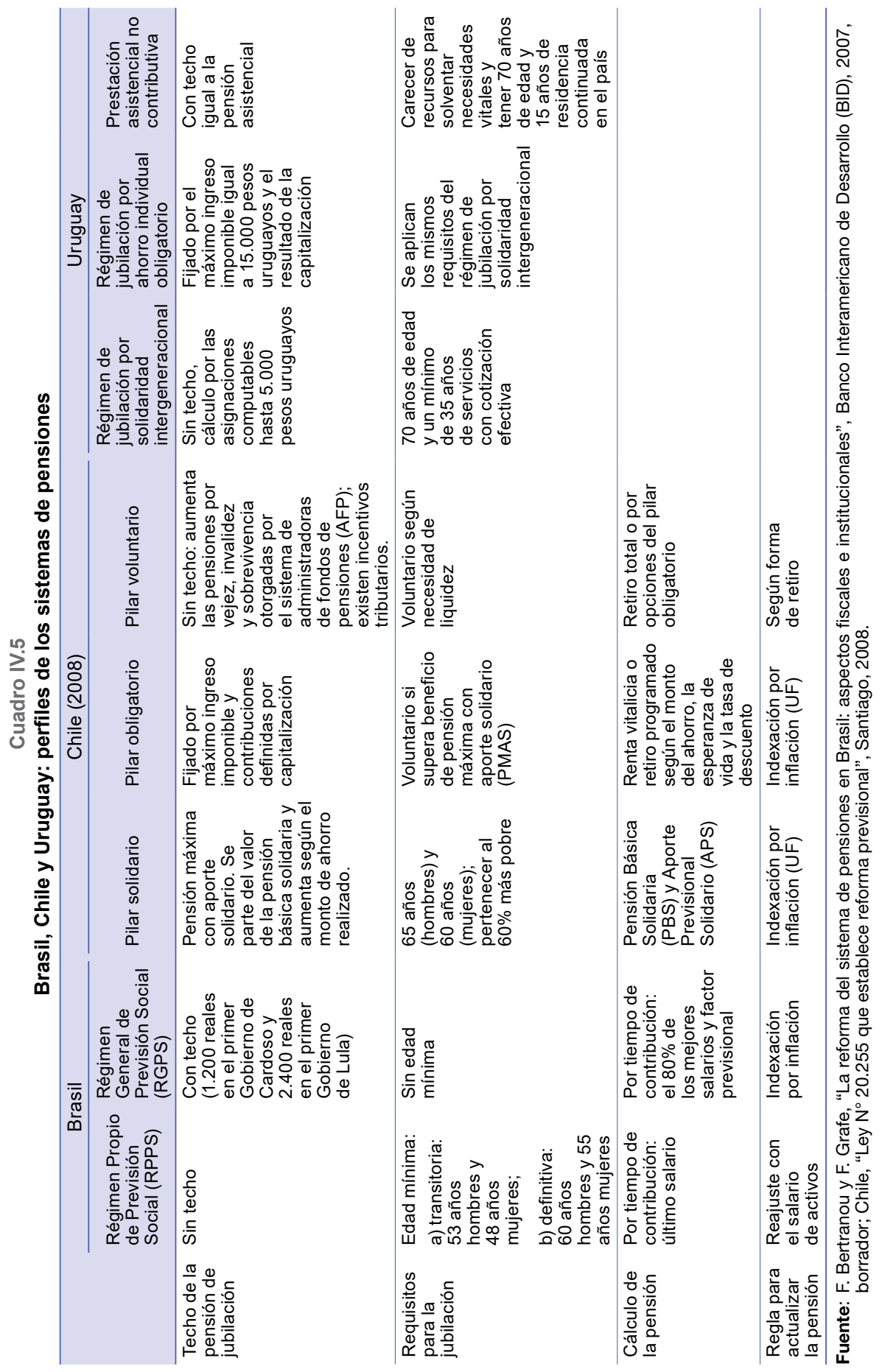




\section{Elementos para la sostenibilidad asociada al proceso de envejecimiento}

Los desarrollos institucionales de los sistemas de pensiones también pueden evaluarse por su capacidad de hacer frente a los riesgos que afectan su funcionamiento a lo largo de generaciones.

Este segundo desafío surge debido al inminente envejecimiento de la población en el transcurso del tiempo. Asociado a ello, los cambios en la estructura de edades de la población total y en la esperanza de vida como consecuencia de reducciones en la mortalidad, y también de acontecimientos políticos, sociales, económicos y financieros, afectan el contexto en el que opera el sistema de pensiones.

El proceso de envejecimiento es heterogéneo entre países y también en el interior de cada país, y sus principales causas son la transición de altos a bajos niveles de fecundidad y las permanentes reducciones de la mortalidad que prolongan la vida de los habitantes (véase el cuadro IV.6).

El perfil del envejecimiento se ilustra habitualmente con tres indicadores: i) el índice de envejecimiento, que mide la relación entre los adultos mayores (en este caso mayores de 60 años) y los jóvenes (menores de 15 años); ii) la edad mediana de la población, y iii) la relación de apoyo potencial que mide la relación entre las personas en edad de trabajar (entre 15 y 60 años) y los adultos mayores (véase el gráfico IV.11) ${ }^{18}$.

En 1950 en América Latina, por cada 100 jóvenes había 13,6 adultos mayores, cifra que aumentó a 42,8 en 2015 y llegará a 106 en 2040. La edad mediana era de 19,9 años en 1950, llegó a 28,9 años en 2015 y superará los 37 años en 2040. La relación de apoyo potencial indica que, en 1950, por cada adulto mayor había 9,7 personas en edad de trabajar. En 2015 esta cifra se había reducido a casi la mitad $(4,9)$ y solo será de 2,6 en 2040. Chile y el Brasil (junto con la Argentina, Cuba y el Uruguay) se ubican entre los países que presentan más rápido descenso de la fecundidad y fuertes manifestaciones de envejecimiento en América Latina.

Las implicancias del envejecimiento en el diseño y la sostenibilidad de los sistemas de pensiones son importantes. Si se debilita la base demográfica para sostener un sistema de reparto ${ }^{19}$, cae la relación

18 Las edades de corte habitualmente difieren entre países. En este documento se adoptan las que utilizan el Centro Latinoamericano y Caribeño de Demografía (CELADE)-División de Población de la CEPAL para proporcionar los datos y computar los indicadores de envejecimiento.

19 El reparto se entiende como la modalidad en que las cotizaciones de los hoy activos financian las pensiones de los hoy pasivos, con el entendimiento de que las generaciones siguientes harán lo mismo. Por ello, en la medida en que disminuye la relación de potenciales activos a pasivos, y a menos que existan reservas o se cambien parámetros como la tasa de cotización, la tasa de reemplazo o la edad de jubilación, se debilita el mecanismo para financiar pensiones (véase el recuadro IV.2). 
potencial ${ }^{20}$ de sostenibilidad. Esta ya se encuentra en valores inferiores a 4 en la Argentina, Cuba y el Uruguay. Llegará a ese nivel en cinco años más en Chile y en una década en el Brasil. También va en aumento la esperanza de vida al jubilarse, lo que afecta los beneficios de los sistemas basados en la administración de cuentas de ahorro individuales. La expectativa de vida más allá de los 60 años en los países latinoamericanos aumentará de 20,2 a 21,1 años en el caso de los hombres y de 23,4 a 24,4 años en el de las mujeres. En Chile, lo hará de 20,9 a 21,6 años para los hombres y de 25,0 a 25,9 años para las mujeres (CELADE, 2011).

\section{Cuadro IV.6 \\ América Latina y el Caribe (19 países): diferente transición de la fecundidad y mortalidad}

\begin{tabular}{|c|c|c|c|c|c|c|}
\hline \multirow[t]{2}{*}{ País } & \multicolumn{3}{|c|}{ Tasa global de fecundidad } & \multicolumn{3}{|c|}{$\begin{array}{l}\text { Esperanza de vida al nacer } \\
\text { (en años) }\end{array}$} \\
\hline & $1950-1955$ & $2010-2015$ & $2045-2050$ & $1950-1955$ & 2010-2015 & $2045-2050$ \\
\hline $\begin{array}{l}\text { Bolivia (Estado } \\
\text { Plurinacional de) }\end{array}$ & 6,8 & 3,1 & 1,8 & 40,4 & 67,0 & 76,5 \\
\hline Guatemala & 7,0 & 3,7 & 1,8 & 42,0 & 71,3 & 78,1 \\
\hline Honduras & 7,5 & 2,9 & 1,7 & 41,7 & 72,8 & 78,6 \\
\hline Nicaragua & 7,2 & 2,5 & 1,7 & 42,3 & 72,7 & 78,4 \\
\hline Paraguay & 6,5 & 2,7 & 1,7 & 62,7 & 72,3 & 77,3 \\
\hline Colombia & 6,8 & 2,4 & 1,9 & 50,6 & 73,8 & 79,0 \\
\hline Costa Rica & 6,7 & 1,7 & 1,7 & 57,3 & 79,1 & 82,0 \\
\hline Ecuador & 6,7 & 2,6 & 1,8 & 48,6 & 75,5 & 81,4 \\
\hline El Salvador & 6,3 & 2,1 & 1,8 & 45,1 & 72,3 & 78,1 \\
\hline México & 6,7 & 2,2 & 2,0 & 50,7 & 76,6 & 81,3 \\
\hline Panamá & 5,8 & 2,5 & 1,9 & 56,8 & 77,3 & 82,6 \\
\hline Perú & 6,9 & 2,4 & 1,8 & 43,9 & 74,0 & 79,1 \\
\hline República Dominicana & 7,6 & 2,5 & 1,9 & 46,0 & 72,7 & 77,8 \\
\hline $\begin{array}{l}\text { Venezuela (República } \\
\text { Bolivariana de) }\end{array}$ & 6,5 & 2,4 & 1,8 & 55,2 & 74,5 & 79,6 \\
\hline Brasil & 6,2 & 1,8 & 1,7 & 51,0 & 73,2 & 79,5 \\
\hline Chile & 5,0 & 1,8 & 1,6 & 54,8 & 79,0 & 82,1 \\
\hline Argentina & 3,1 & 2,2 & 1,8 & 67,2 & 76,0 & 80,7 \\
\hline Cuba & 4,2 & 1,5 & 1,6 & 59,4 & 79,2 & 82,1 \\
\hline Uruguay & 2,7 & 2,0 & 1,7 & 66,1 & 80,0 & 81,6 \\
\hline
\end{tabular}

Fuente: Centro Latinoamericano y Caribeño de Demografía (CELADE)-División de Población de la CEPAL, Estimaciones y proyecciones demográficas, Santiago, Comisión Económica para América Latina y el Caribe (CEPAL), 2011.

La tasa global de fecundidad (TGF) es el promedio de hijos e hijas que nacerían de una mujer perteneciente a una cohorte hipotética de mujeres que durante su vida fértil tuvieran hijos de acuerdo a las tasas de fecundidad por edad de un determinado período de estudio (normalmente de un año determinado) y no estuvieran expuestas a riesgos de mortalidad desde el nacimiento hasta el término del período fértil. La esperanza de vida es la media de la cantidad de años que vive una determinada población absoluta o total en cierto período.

20 Se califica de potencial por ser una razón puramente demográfica, en que no se considera lo que pasa efectivamente con respecto al trabajo y el ahorro previsional entre la población en edad de trabajar. 


\section{Gráfico IV.1 \\ América Latina (18 países): indicadores de envejecimiento, 1950-2100}

A. Relación de apoyo potencial (P15-59 años/P>60)

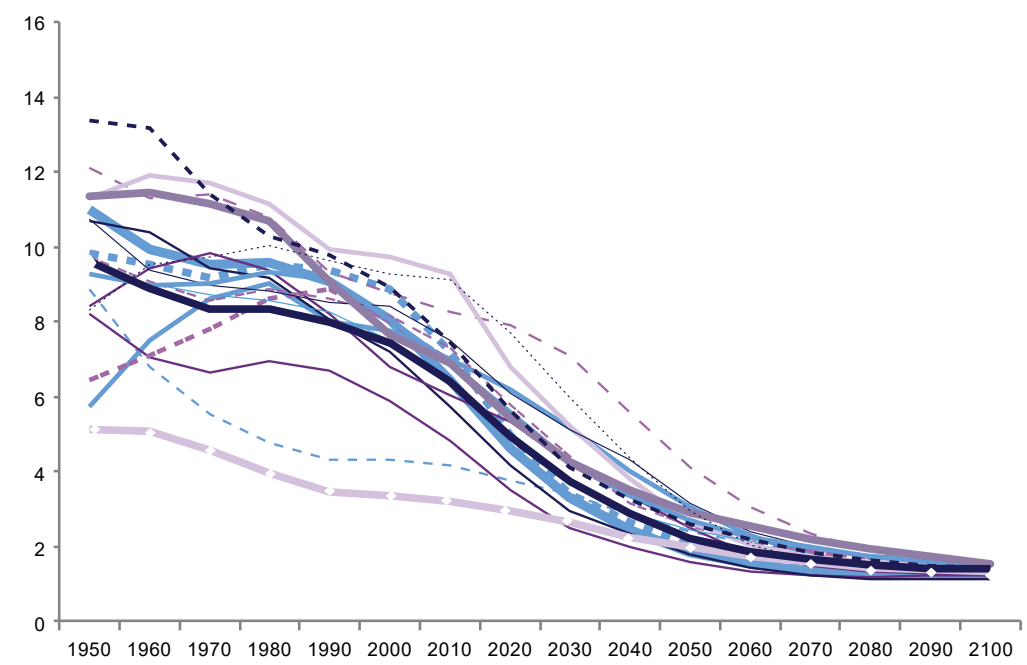

B. Índice de envejecimiento $(P>60 / P<15)^{*} 100$

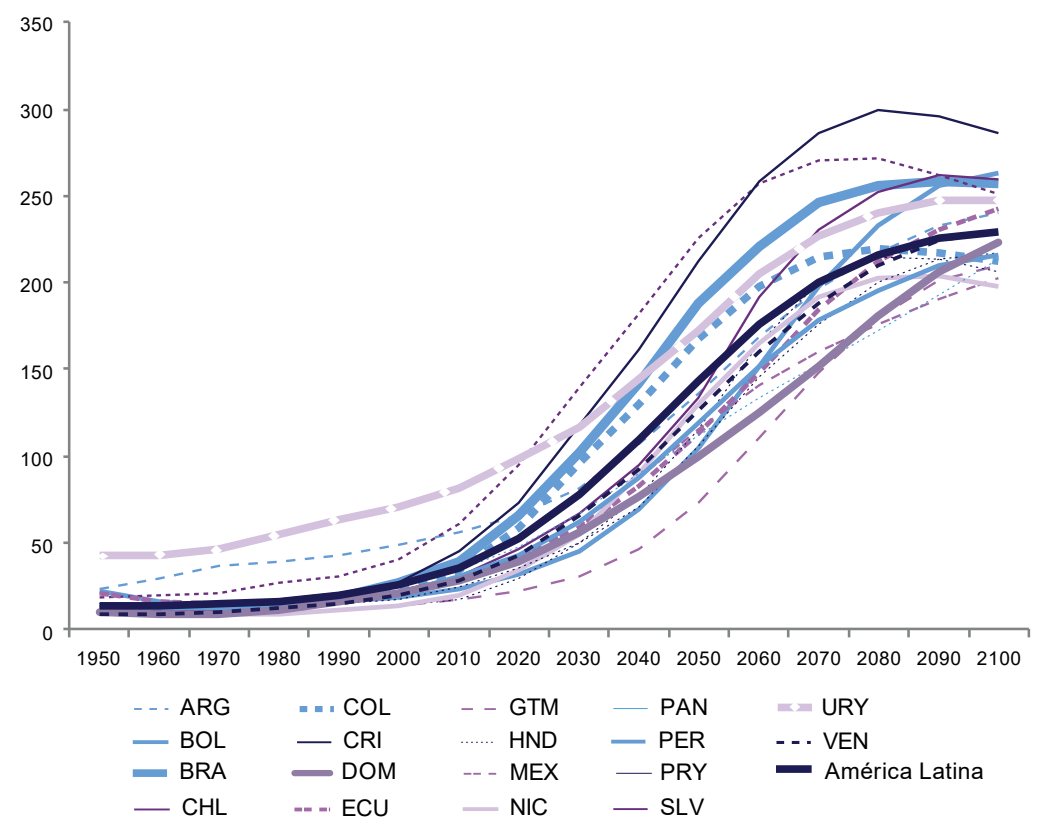


Gráfico IV.1 (conclusión)
C. Edad mediana

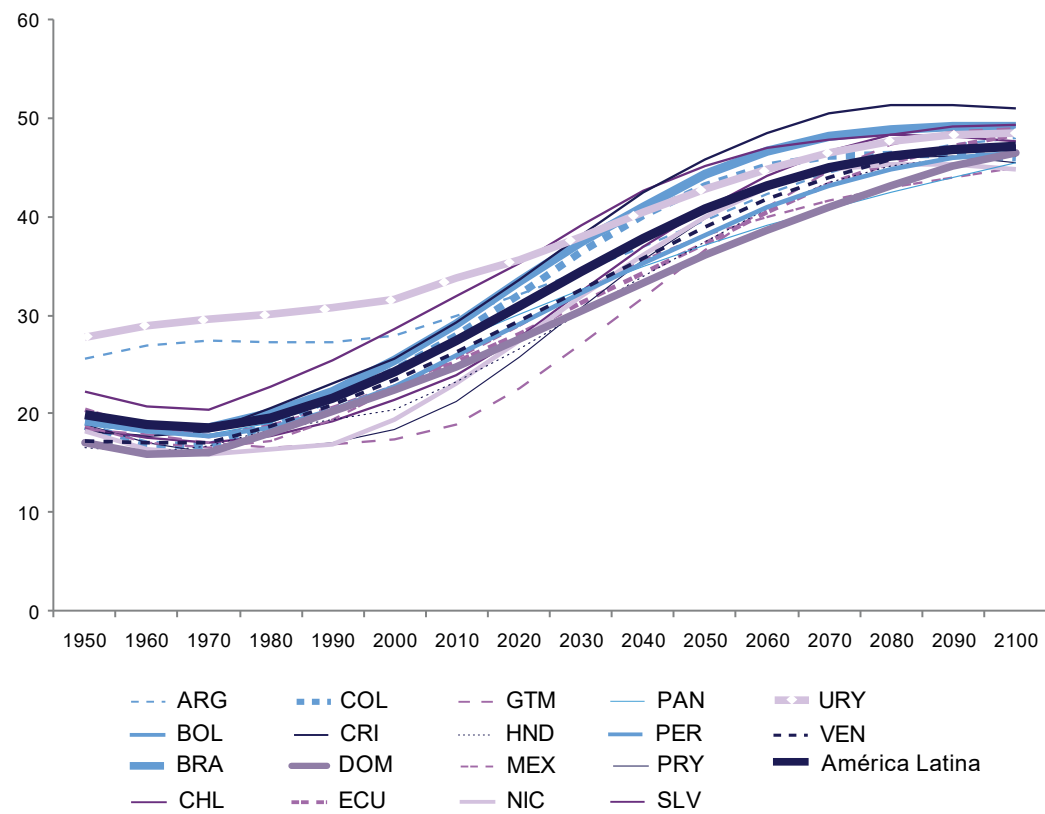

Fuente: Centro Latinoamericano y Caribeño de Demografía (CELADE)-División de Población de la CEPAL, Estimaciones y proyecciones de población, Santiago, Comisión Económica para América Latina y el Caribe (CEPAL), 2015.

Nota: Indice de envejecimiento = (población de 60 y más / población de 0 a 14 años) * 100. Relación de apoyo potencial $=$ (población de 15 a 59 años) / (población de 60 y más).

Lo que preocupa a las autoridades son los efectos financieros de estos cambios. Por ejemplo, en relación con la garantía de una pensión universal y supuestos razonables de crecimiento del producto interno bruto (PIB), es posible ilustrar que el costo de su financiamiento aumentaría si se mantiene la edad de jubilación. A modo de hipótesis, supóngase que para cada país se simula un valor de la pensión universal equivalente al $10 \%$ de su PIB per cápita ${ }^{21}$ para los mayores de 60 años. Este costo superaría el 1,4\% del PIB en los países más envejecidos en 2010 y, en los 30 años siguientes, excedería el 2,2\% del PIB. Bajo iguales condiciones, en ese mismo lapso de tiempo, en Chile el costo pasaría del 1,3\% al 2,7\% del PIB y en el Brasil, del $1,0 \%$ al 2,4\%. En el cuadro IV.7 se presenta el costo como porcentaje del PIB de cada país, de lo que significaría una transferencia a todos sus adultos mayores de 60, 75 u 80 años, equivalente al 10\% del PIB per cápita ${ }^{22}$.

21 En Chile, la Pensión Básica Solidaria (PBS) equivale aproximadamente a 120 dólares mensuales (valor muy por debajo del salario mínimo, que supera los 350 dólares) y su valor relativo corresponde al 10\% del PIB per cápita.

22 Los cálculos se han hecho tomando como referencia el valor de la PBS en Chile, pero en algunos países, como Colombia, no se pueden ofrecer pensiones por valores inferiores al salario mínimo. 
Cuadro IV.7

América Latina y el Caribe (19 países): costo de simulación de pensión universal como porcentaje del PIB nacional ${ }^{\mathrm{a}}$

\begin{tabular}{|c|c|c|c|c|c|c|c|c|c|}
\hline \multirow{2}{*}{ País } & \multicolumn{3}{|c|}{2010} & \multicolumn{3}{|c|}{2025} & \multicolumn{3}{|c|}{2040} \\
\hline & $P>60$ & $P<75$ & $\mathrm{P}>80$ & $P<60$ & $\mathrm{P}<75$ & $\mathrm{P}>80$ & $P>60$ & $P>75$ & $P<80$ \\
\hline $\begin{array}{l}\text { Bolivia (Estado } \\
\text { Plurinacional de) }\end{array}$ & 0,71 & 0,16 & 0,07 & 0,97 & 0,24 & 0,11 & 1,39 & 0,39 & 0,20 \\
\hline Guatemala & 0,65 & 0,18 & 0,09 & 0,74 & 0,22 & 0,12 & 1,03 & 0,30 & 0,17 \\
\hline Honduras & 0,62 & 0,18 & 0,09 & 0,87 & 0,23 & 0,13 & 1,35 & 0,39 & 0,22 \\
\hline Nicaragua & 0,62 & 0,18 & 0,10 & 0,97 & 0,24 & 0,14 & 1,52 & 0,46 & 0,26 \\
\hline Paraguay & 0,77 & 0,20 & 0,11 & 1,09 & 0,29 & 0,15 & 1,47 & 0,47 & 0,27 \\
\hline Colombia & 0,86 & 0,21 & 0,11 & 1,41 & 0,34 & 0,17 & 1,96 & 0,65 & 0,36 \\
\hline Costa Rica & 0,95 & 0,27 & 0,15 & 1,66 & 0,41 & 0,23 & 2,35 & 0,84 & 0,47 \\
\hline Ecuador & 0,86 & 0,25 & 0,13 & 1,27 & 0,34 & 0,19 & 1,81 & 0,60 & 0,34 \\
\hline El Salvador & 0,94 & 0,29 & 0,16 & 1,20 & 0,39 & 0,24 & 1,65 & 0,55 & 0,32 \\
\hline México & 0,88 & 0,24 & 0,13 & 1,30 & 0,36 & 0,20 & 1,96 & 0,60 & 0,35 \\
\hline Panamá & 0,97 & 0,27 & 0,15 & 1,41 & 0,41 & 0,24 & 2,01 & 0,69 & 0,41 \\
\hline Perú & 0,88 & 0,23 & 0,11 & 1,27 & 0,34 & 0,19 & 1,86 & 0,57 & 0,32 \\
\hline República Dominicana & 0,86 & 0,25 & 0,13 & 1,29 & 0,34 & 0,19 & 1,80 & 0,60 & 0,34 \\
\hline $\begin{array}{l}\text { Venezuela (República } \\
\text { Bolivariana de) }\end{array}$ & 0,86 & 0,21 & 0,11 & 1,34 & 0,34 & 0,17 & 1,85 & 0,61 & 0,34 \\
\hline Brasil & 1,02 & 0,27 & 0,15 & 1,66 & 0,44 & 0,24 & 2,40 & 0,84 & 0,48 \\
\hline Chile & 1,31 & 0,38 & 0,21 & 2,06 & 0,59 & 0,33 & 2,65 & 1,05 & 0,61 \\
\hline Argentina & 1,46 & 0,47 & 0,26 & 1,73 & 0,57 & 0,32 & 2,18 & 0,76 & 0,46 \\
\hline Cuba & 1,71 & 0,54 & 0,30 & 2,67 & 0,83 & 0,50 & 3,61 & 1,45 & 0,78 \\
\hline Uruguay & 1,85 & 0,67 & 0,39 & 2,13 & 0,76 & 0,46 & 2,53 & 0,99 & 0,61 \\
\hline
\end{tabular}

Fuente: Elaboración propia.

a Costo expresado (como porcentaje del PIB) de entregar una pensión universal anual (equivalente a un $10 \%$ del PIB per cápita) a todos los adultos mayores $(P>60, P>75$ y $P>80)$.

El financiamiento de un sistema no contributivo con una garantía universal pasa a ser un componente estable del presupuesto fiscal. Este es mayor a medida que crece la proporción de la población elegible y mientras más elevado sea el nivel del beneficio universal garantizado ${ }^{23}$. El peso de dichas transferencias en el presupuesto fiscal es directamente proporcional al porcentaje del total de la población que representan los beneficiarios ${ }^{24}$. En el caso de una pensión de vejez, esta proporción aumentará en la medida en que se incluya entre los beneficiarios a personas de menos edad y que la población envejezca. El valor del beneficio es una decisión administrativa sujeta a un debate político y a la restricción presupuestaria que habitualmente ocurre durante el debate de la Ley de Presupuestos del Sector Público. Todos estos elementos deben considerarse en un acuerdo social sobre este tipo de sistema. Por ende, es ineludible el debate técnico y político sobre estos parámetros (edad de jubilación y beneficio).

23 La generosidad de una garantía universal se mide como la relación entre el beneficio monetario y el PIB per cápita.

24 Por cierto, también lo es la generosidad de la transferencia expresada en porcentaje del PIB per cápita. 
Los encargados de la gestión financiera de los aportes que los afiliados realizan a los sistemas de pensiones contributivos deben velar por su sostenibilidad a largo plazo.

Para enfrentar el envejecimiento poblacional, las cuatro dimensiones que consideran los desarrollos institucionales pueden clasificarse en relación con la forma en que abordan los desafíos que este trae aparejado. A saber:

i) ajustes ante cambios en la estructura de edades y en la esperanza de vida a la edad de retiro;

ii) políticas para mejorar la capacidad de inclusión del mercado laboral;

iii) regulación del destino asignado a los fondos de pensiones (para transferirlos dentro de una misma generación o entre distintas generaciones), $\mathrm{y}$

iv) regulación prudencial para el resguardo de su rentabilidad en los mercados financieros.

\section{a) Ajuste ante cambios en la estructura de edades y en la esperanza de vida a la edad de retiro}

La capacidad de financiar pensiones para un grupo grande de beneficiarios dependerá del monto de la pensión, pero también del número de afiliados que aportan al sistema y el monto de sus cotizaciones. Frente a estos cambios, los sistemas que operan bajo este régimen de administración financiera (contratos solidarios entre generaciones) deben realizar cambios en sus parámetros. Esto implica un importante debate político acerca de si se debería elevar la edad de jubilación, aumentar la tasa con que aportan las generaciones activas, reducir la relación entre la pensión que reciben los beneficiarios y los salarios de los activos que aportan al sistema, o complementar el sistema con pensiones privadas de contribución definida ${ }^{25}$.

Por su parte, el mecanismo de capitalización debe hacer frente a los aumentos de la esperanza de vida más allá de la edad de retiro. Una manera de lograrlo sería convencer al afiliado de cotizar más (en forma similar al reparto, con mayor tasa de cotización o mayor tiempo de cotización). Otra manera consistiría en reducir los beneficios a partir de las modalidades en que el sistema vincula su ahorro con el monto y la continuidad de sus pagos (renta vitalicia o retiro programado).

Desde la perspectiva organizacional es importante definir un patrocinador del sistema que se responsabilice de sus resultados y funcionamiento. Dicho patrocinador debe velar por que, conforme a la ley, los beneficios ofrecidos a los afiliados estén financiados tanto en los regímenes basados en contratos de reparto como en los de capitalización. En los primeros, esto se debe a que la relación de apoyo potencial

25 El efecto de estos cambios demográficos puede atenuarse en la medida en que los sistemas de reparto hayan administrado en forma apropiada un fondo de reservas desde las etapas en que tenían una alta relación de apoyo potencial. 
cambia y compromete la capacidad del patrocinador de cumplir con los beneficios definidos. En los segundos, se debe a que los aumentos en la esperanza de vida a la edad de jubilación determinan los niveles de las pensiones para un mismo nivel de ahorro, lo que afecta al afiliado en forma individual ${ }^{26}$.

Cabe destacar que el mecanismo de reparto se basa en la solidaridad entre generaciones, mediante un contrato en que las generaciones activas financian las pensiones de las pasivas. El mecanismo de capitalización, en tanto, se basa en una buena regulación y supervisión de la gestión financiera que hagan los administradores (públicos o privados) de los fondos de pensiones, $\mathrm{y}$ en el establecimiento de criterios de equivalencia entre lo aportado y los beneficios.

El Estado tiene participación directa en la provisión de pensiones no contributivas y constituye el patrocinador de última instancia e impulsor de reformas con costos fiscales. Por esas razones, debe asumir un rol fundamental de tipo técnico-operativo en el monitoreo de los cambios demográficos y en el financiamiento de las implicaciones que estos lleguen a tener sobre el aporte no contributivo necesario para adaptar el sistema a dichos cambios.

En cuanto al financiamiento, se requiere que la gestión de los fondos de pensiones no ejerza futuras presiones sobre las cuentas fiscales para garantizar su sostenibilidad. Por ese motivo, su gestión exige modelos actuariales que aseguren que sus parámetros (tasa de cotización, edad de jubilación y tasa de reemplazo) se ajusten a la estructura y cambios demográficos y del mercado de trabajo, que afectan su relación efectiva de sostenibilidad (afiliados activos que cotizan o afiliados pasivos con derecho a beneficios). El costo para el fisco de las garantías explícitas del Estado por atender las necesidades de los adultos mayores en el marco del sistema se ve afectado por el envejecimiento. El carácter no contributivo de un sistema no anula los riesgos demográficos, ya que el envejecimiento conduce necesariamente a dos fenómenos. En primer lugar, cada año una mayor proporción de la población llega a la edad de retiro, con el consiguiente cambio de la estructura de edades e incremento de la proporción de adultos mayores sujetos a políticas de previsión y asistencia. En segundo lugar, las tasas de sobrevida de los adultos mayores aumentan, lo que impone la necesidad de realizar mayores transferencias en los presupuestos para una misma pensión (véase el cuadro IV.8).

\footnotetext{
Los sistemas de capitalización en cuentas individuales no escapan al efecto de los cambios demográficos. Por el contrario, los constantes avances en la esperanza de vida a la edad de jubilación hacen que el monto de ahorro acumulado para autofinanciar una pensión deba financiar un mayor número de años, por lo que el único efecto es que se disminuye la pensión. La diferencia en este caso es que, a fin de evitar menores pensiones, la decisión de postergar la edad de jubilación y ahorrar más depende del individuo y no de la política pública.
} 


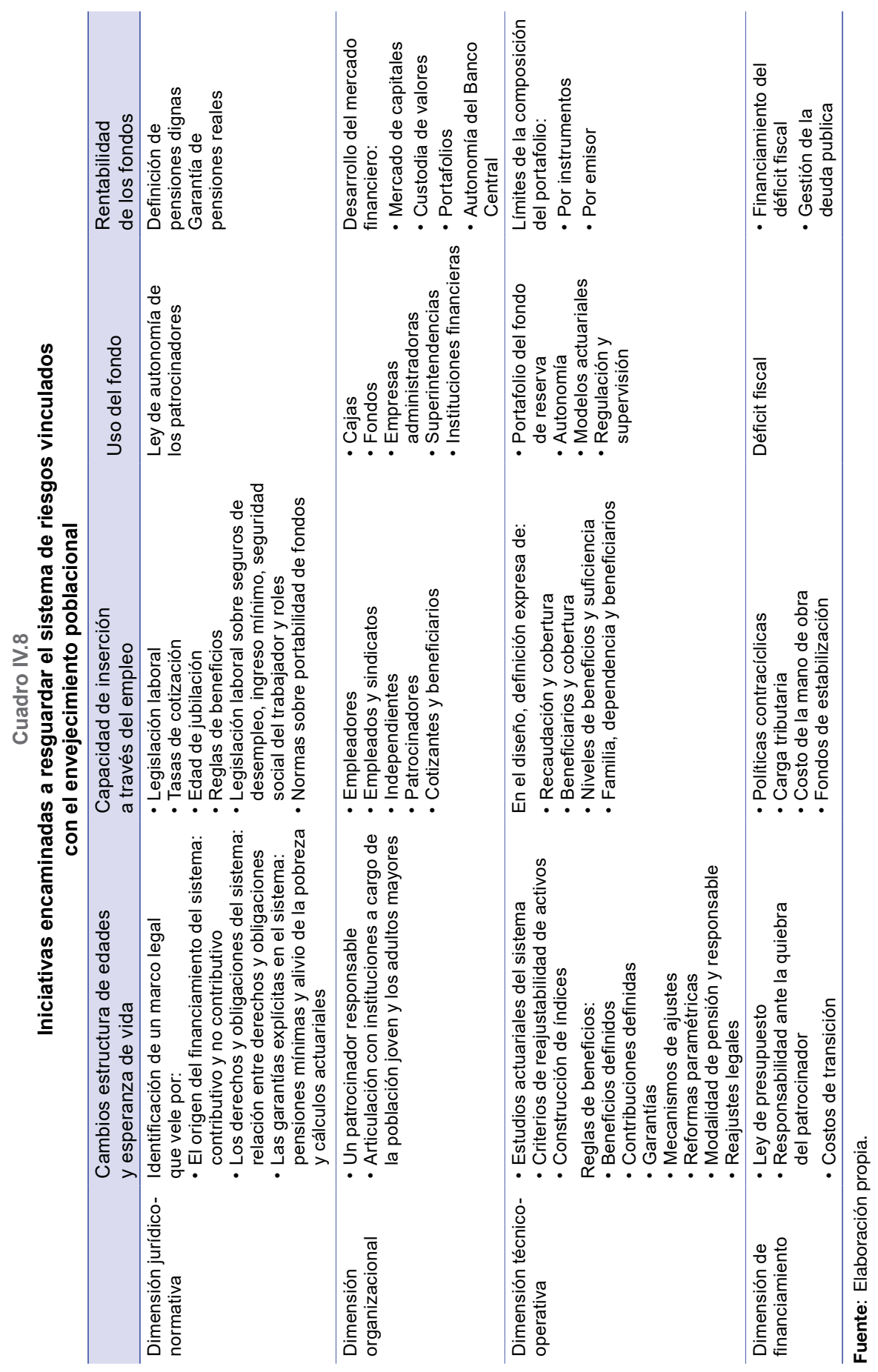




\section{b) Ajuste ante las variaciones de la calidad del trabajo en el mercado laboral}

Los riesgos del ciclo económico afectan a todo sistema contributivo, independientemente de su gestión financiera. A través de sus efectos sobre la calidad del empleo de las personas, dichos riesgos determinan la capacidad de los afiliados de cotizar de manera regular. En el caso de los sistemas no contributivos, los ciclos económicos pueden conducir a situaciones de restricción presupuestaria del gobierno que afectan su capacidad de mantener los niveles de cobertura y suficiencia de las garantías.

En el marco normativo, el hecho de definir un sistema como contributivo entraña la determinación de las exigencias impositivas para participar, las cuales se refieren a la tasa de cotización y la edad legal para jubilarse. También supone el establecimiento de reglas claras para vincular el cumplimiento de estas exigencias con la prestación que el sistema le ofrece, todo ello en el marco de otros beneficios de las leyes laborales. En los sistemas no contributivos, la ley de responsabilidad fiscal delimita la holgura con que se revisan la cobertura y la suficiencia de las garantías en la ley de presupuestos.

La densidad de cotizaciones en los sistemas contributivos, es decir la frecuencia con que un afiliado puede cotizar y aportar al sistema, adquiere una importancia fundamental. Esto depende de la forma en que los actores y sus representantes estén en condiciones de velar por la continuidad y calidad del empleo. El carácter heterogéneo del mercado laboral, definido por la segmentación entre trabajos formales e informales y la movilidad de los trabajadores entre estas categorías, incide en la capacidad del patrocinador de asegurar la continuidad de las cotizaciones. Por ese motivo, en el plano organizacional, el manejo de las relaciones laborales entre empleadores y trabajadores, así como el apoyo al emprendimiento y el derecho de los trabajadores, asumen una importancia vital, en tanto contribuyen a la formalización del empleo.

Durante las edades activas (entre 15 y 65 años), una persona podrá insertarse en un sistema contributivo si logra participar en la actividad económica, ocuparse y cotizar. Ello está asociado a sus posibilidades de tener un trabajo formal y depende de la capacidad de la economía de generar tales empleos. Por ende, los sistemas son sensibles a si el crecimiento económico de un país ha permitido que el mercado laboral se transforme o no en un instrumento de inclusión social para la mayor parte de la población. Esta es una debilidad del desarrollo latinoamericano que afecta tanto los sistemas de capitalización como los de reparto, donde la capacidad de contribuir al sistema determina la titularidad de los derechos de los afiliados. Por esta razón, la CEPAL ha recomendado sistemas que combinen financiamiento contributivo y no contributivo (Cecchini y Martínez, 2011). 
En el pilar no contributivo no existen problemas de densidad de cotizaciones, por lo que el mercado de trabajo y la incompatibilidad de roles se superan con el criterio de universalidad con que se asigne la pensión. Sin embargo, dado que el ítem previsional pasa a ser un componente del presupuesto, es fundamental su análisis en el debate sobre la ley de presupuesto de cada año, a menos que existan reglas de asignación de recursos intertemporales con fines previsionales y de responsabilidad fiscal.

Ante la inminente vulnerabilidad de la recaudación del sistema durante los ciclos económicos, existen desarrollos directos e indirectos en relación con:

- La existencia o no de políticas contracíclicas de naturaleza macroeconómica, ya sea de financiamiento o de seguros de desempleo.

- El monitoreo de la estructura y estrategia de las familias durante el ciclo, asegurando que:

- Los miembros activos mantengan la continuidad de sus cotizaciones.

- Los miembros pasivos conserven la continuidad de sus beneficios.

- La estructura de incentivos del sistema no se vea afectada por las repercusiones que pudiera tener el ciclo económico sobre otras decisiones en el hogar.

En particular, la batería de instrumentos de política debe ser coherente con la lógica de financiamiento del sistema, y asegurar la cobertura y la suficiencia de sus prestaciones.

En la dimensión fiscal existe una marcada interrelación entre la modalidad de financiamiento, el diseño del sistema y las políticas contracíclicas. Debe quedar claramente delimitado el reconocimiento de garantías explícitas, ya sea en modelos no contributivos o contributivos, a fin de suplir las deficiencias originadas por las diferentes densidades de cotizaciones. Por ende, es usual establecer condiciones de elegibilidad muy estrictas para acceder a las prestaciones. El diseño de la afiliación debe ser lo suficientemente flexible para promover la movilidad de los trabajadores entre alternativas ocupacionales, así como para asegurar que el nivel de la tasa de cotización guarde relación con los niveles de suficiencia de las prestaciones y la competitividad de la mano de obra en el contexto de la globalización. Estas consideraciones de naturaleza macroeconómica se refieren a la esencia del vínculo con la fiscalidad y, en los casos más extremos, se han traducido en la creación de fondos de estabilización para hacer frente a contingencias. 


\section{c) Regulación de destino y uso (propiedad) de los fondos de pensiones}

En lo que respecta al uso de los fondos de pensiones (de reservas o cuentas individuales) existe una preocupación por tratar de mantenerlos fuera del alcance de agentes que tienen intereses diferentes al del financiamiento de las pensiones de sus afiliados. Se habla del riesgo del uso político de un fondo cuando predomina un sistema de administración controlada por el gobierno. Históricamente, este riesgo se ha identificado con la gestión de los modelos públicos de reparto ${ }^{27}$. No obstante, el fondo también puede llegar a ser controlado por intereses de grupos económicos, riesgo que se acentúa en los modelos de capitalización.

La autoridad debe velar por que la administración de estos fondos no se vea afectada por conflictos de intereses con la gerencia de las firmas donde invierten, ni con los grupos que los administran. La creación de un fondo que sustituya los sistemas originales de reparto por los de capitalización individual también se ve afectada por la decisión política acerca de la forma de financiar el costo de la transición desde el sistema original de reparto. Se debe legislar para asegurar la autonomía entre el administrador y el patrocinador, así como la desvinculación entre el patrimonio del trabajador y el del administrador.

En la dimensión organizacional debe establecerse con claridad la estructura y naturaleza del gobierno corporativo que administra el fondo en representación del patrocinador. Existe un gran dilema, ya que, por un lado, es su representante y, por otro, debe guiarse por criterios estrictos en beneficio de los intereses previsionales de los afiliados y no del patrocinador. La naturaleza financiera y poco tangible de los resultados de la administración hace que sea muy difícil establecer la forma de generar esta autonomía. Desde el plano organizacional, hay conflictos de intereses cuando:

- La administración financiera se concentra en una industria, para lo cual debe institucionalizarse una superintendencia encargada de la regulación organizacional y prudencial de la industria.

- El único administrador de estos fondos es el Estado o alguna institución que dependa de este. En ese último caso, la administración del fondo de pensiones debería independizarse de la gestión del presupuesto fiscal. De lo contrario, existe el riesgo político de que la liquidez de los fondos de pensiones se aproveche con fines de endeudamiento público. Muchas veces esto se justifica por su rentabilidad social, pero no por su rentabilidad financiera, que es la que hace crecer los fondos de pensiones a

La experiencia de la reforma en la Argentina en 2010 demuestra que, en tanto el componente de capitalización de un sistema de pensiones no se consolide como pieza fundamental del sistema previsional y del funcionamiento del mercado de capitales, estará siempre sometido al riesgo político de la estatización de los fondos. 
largo plazo. No obstante, también existe el riesgo político de que los fondos se utilicen en alternativas menos rentables desde el punto de vista previsional, cuando grupos ajenos al gobierno controlan la administración de los fondos para sus intereses.

La implementación de un sistema de pensiones debe transparentar la relación de su financiamiento con el presupuesto fiscal y con las alternativas de inversión en el país. El propósito sería evitar que el Estado, en casos de déficit, actúe como prestamista de última instancia del sistema o que, en caso de superávit, desplace permanentemente a otros inversionistas del acceso al fondo. Esto se relaciona tanto con la dimensión operacional como con la fiscal de la institucionalidad.

Como lo demuestra la experiencia argentina, el mecanismo de capitalización en cuentas individuales y su administración por parte de empresas privadas reguladas por el Estado no es garantía de que este problema se evite. Tras la adopción de una serie de medidas que perseguían mejorar la cobertura y la libertad de opción entre ambos regímenes jubilatorios (facilidades de pago para trabajadores autónomos y enmiendas legislativas no estructurales que se presentaban como mejoras del sistema mixto preexistente), las presiones sobre el sistema terminaron en un cambio radical y estructural definitivo que eliminó la capitalización individual. Luego de 14 años de régimen mixto, se creó en su lugar el Sistema Integrado Previsional Argentino (SIPA). Se volvió al régimen de reparto y de administración pública, a través de la Administración Nacional de la Seguridad Social (ANSES), el organismo de gestión de seguridad social más importante (creado en diciembre de 2008 en virtud de la Ley núm. 26.425) ${ }^{28}$.

En la dimensión de la fiscalidad, se debe disponer de modelos actuariales que delimiten las garantías explícitas del Estado de las garantías que ofrece el sistema. Un aspecto relevante de la experiencia regional ha sido la forma en que los países que transitaron desde regímenes de reparto a otros de capitalización han administrado los costos de transición que afectan el déficit previsional y su presión sobre las finanzas públicas. En Chile se ajustaron las cuentas fiscales mediante reducciones en otros gastos bajo condiciones de dictadura (véase el recuadro IV.3), pero en el resto de los países no se han logrado ajustes similares. El efecto a largo plazo ha sido una mayor presión del fisco sobre los recursos de los fondos de pensiones para el pago de pensiones $\mathrm{u}$ otros gastos, con lo que se ha desplazado la inversión privada. Un caso extremo es el de El Salvador, donde los costos de la transición no se han financiado. Esto ha traído como consecuencia un incremento de la deuda pública con el sistema y el pago de pensiones muy bajas que requieren subsidios.

28 En este proceso se pone fin a la tendencia a la litigiosidad. Se crea el Fondo de Garantía de Sustentabilidad administrado por la ANSES, de acuerdo a reglas en materia de inversiones similares a las que poseían las Administradoras de Fondos de Jubilaciones y Pensiones, y también se crea un Comité Legislativo de Supervisión en 2008. 


\section{Recuadro IV.3}

\section{Chile: financiamiento de la transición hacia el modelo de capitalización individual (extracto de la reciente Comisión Asesora Presidencial de Chile)}

En materia de sostenibilidad fiscal, se separa el análisis de los costos derivados de la transición iniciada en 1981 y los costos adicionales de la reforma de 2008, particularmente del Sistema de Pensiones Solidarias. El gasto originado por la transición iniciada en 1981 (bonos de reconocimiento, déficit operacional y garantía estatal de pensión mínima) llegó a ser casi un $5 \%$ anual del PIB en 1984. Este gasto ha ido disminuyendo a medida que se ha pagado la mayor parte de los costos asociados al cambio de sistema. En valor presente, el costo de la transición se estimó en el equivalente a un $136 \%$ del PIB de 1981 y fue asumido por el Estado mediante una combinación de reformas tributarias, recortes de gastos y emisión de deuda. El gasto para cubrir el déficit operacional llegó a un 1,6\% del PIB en 2012 (Informe de Finanzas Públicas de 2014), y se espera que al 2025 los gastos de tipo transitorios disminuyan al $1 \%$ del PIB, según proyecciones de la DIPRES. El costo total de la transición de la reforma estructural se proyecta a un $2,7 \%$ del PIB en 2025 y no desaparecerá sino hasta 2050 , tomando 70 años para extinguirse, más que las proyecciones originales (Mesa-Lago y Bertranou, 2015).

La disciplina fiscal implícita en la transición realizada en Chile tiene dos connotaciones comparadas con otras experiencias internacionales de transición, entre un sistema mayoritariamente de reparto y otro de capitalización individual. Primero, el ahorro fiscal necesario para acomodar gastos que llegaron a representar cerca del $5 \%$ del PIB y que aún perdura, no tiene comparación en períodos democráticos de debate de la Ley de Presupuestos en Chile. Segundo, el ahorro fiscal anterior fue el que evitó que el Estado desplazara, mediante títulos de deuda, otras inversiones alternativas donde colocar los fondos de pensiones, lo que, a su vez, permitió desarrollar el mercado de capitales.

Es por ello que esta experiencia es única, responde a una situación especial y su financiamiento ha recaído en la generación que ha debido experimentar y en las que aún experimentarán los efectos del ajuste fiscal, además de autofinanciar su pensión.

Fuente: Comisión Asesora Presidencial sobre el Sistema de Pensiones, Informe final, Santiago, 2015, págs. 57 a 58.

\section{d) Regulación prudencial ante la vulnerabilidad financiera}

Los fondos de pensiones de capitalización o los fondos de reserva de los sistemas de reparto representan un ahorro financiero a largo plazo y deben disponer de un componente de liquidez para pagar las pensiones según lo requiera el sistema. Su manejo financiero es vulnerable a las fluctuaciones de los mercados financieros donde se invierten. Este riesgo de inversión debe someterse a estrictas normas de regulación y supervisión prudencial.

Los riesgos de inversión son más sensibles a los modelos que generan fondos de pensiones (individuales o públicos de reserva). Una 
situación particular enfrentan los países que sustituyen su sistema de reparto por el de capitalización y financian el costo de la transición con deuda pública ${ }^{29}$.

Para asegurar la expresión de sus beneficios en consumos reales considerados dignos, la valoración de estos fondos se reporta en términos reales, ya que debería permitir su crecimiento más allá de las tendencias inflacionarias, de modo que el ahorro aumente en términos reales. El manejo del riesgo inflacionario, cuando los valores no están indexados, y del riesgo cambiario, cuando el fondo se ha diversificado con un portafolio que incluye activos de mercados financieros extranjeros, son otros factores de vulnerabilidad.

Lo que se aprecia en la práctica son dos tendencias importantes. A corto plazo existe volatilidad en la rentabilidad de los portafolios. A largo plazo, la rentabilidad de los fondos es altamente sensible a la madurez del sistema. En las primeras etapas se logran mayores rentabilidades y cada cohorte sucesiva que participa del sistema ve disminuida la rentabilidad histórica de su fondo.

En materia normativa, el veloz crecimiento de los fondos de pensiones plantea el desafío de dotar al mercado de capitales de una sólida institucionalidad que permita canalizar esos recursos hacia la obtención de pensiones dignas mediante su uso socialmente rentable. Esto podría lograrse a través de una gama de instituciones e instrumentos financieros sujetos a regulación prudencial.

En materia organizacional, el desarrollo institucional es decisivo para una buena administración de fondos de pensiones. Se deben distinguir los fondos de pensiones, sus entidades administradoras y las superintendencias encargadas de la regulación y supervisión de estas últimas. Ello permite actualizar y perfeccionar las regulaciones y normas sobre distintos aspectos de un mercado de capitales en rápida expansión: sociedades anónimas abiertas, transacciones con valores, transparencia del mercado, clasificación del riesgo de los valores de oferta pública, progresiva ampliación de las alternativas de inversión de los fondos de pensiones y redefinición del rol de las superintendencias de valores y seguros, entre otras cosas.

En materia operacional, se deben establecer regulaciones que tengan en cuenta la concentración de los fondos de pensiones en acciones de sociedades anónimas que prestan servicios públicos y la escasez de instrumentos financieros. También es preciso velar por las nuevas necesidades de ordenamiento institucional ligadas a la inversión de fondos de pensiones en el exterior, el perfeccionamiento de la industria de seguros

29 Por ejemplo, en la experiencia de El Salvador, la imposibilidad de incorporar en el presupuesto de la nación un ítem para el pago del déficit previsional ocasionado por la transición supone un incremento paulatino de la deuda previsional del Estado con el sistema. 
de vida (que paga pensiones bajo la modalidad de planes de renta vitalicia), y la regulación de conglomerados financieros ante la expansión de los bancos hacia diversos segmentos de los mercados de crédito y capital. Por tratarse de ahorros obligatorios de los propios trabajadores, que serán su principal fuente de ingreso en sus edades pasivas, los fondos de pensiones y sus respectivas entidades administradoras deben estar sujetos a una férrea regulación y supervisión prudencial.

En caso de privatizar su administración, el patrimonio de la sociedad administradora debe estar completamente separado del patrimonio del fondo de pensiones. Cada sociedad debería administrar solo un fondo y asegurar una rentabilidad mínima al gestionar sus activos. Las normas que rigen la cartera de activos de los fondos señalan que todos los títulos y valores deben cumplir rigurosas normas de evaluación de riesgos y clasificarse en categorías de riesgo bajas. Esa cartera está sujeta a una amplia diversificación por instrumento financiero y por emisor. Se somete a una valoración continua a precios de mercado y a la custodia de los títulos y valores que la componen en el Banco Central.

En materia de fiscalidad, es preciso permitir que el ahorro previsional haga un aporte directo importante al ahorro nacional, aunque el efecto neto sobre este último sea difícil de establecer, en particular por haber sustitución o complementación de otras formas de ahorro. Por ello, la relación entre ahorro público y ahorro previsional ayuda a comprender su efecto neto positivo sobre el ahorro nacional. Esto indica que la relación de las finanzas públicas con el déficit previsional se torna fundamental para que la canalización de cotizaciones hacia el nuevo sistema de pensiones contribuya al ahorro nacional. Su efecto no debe circunscribirse al pago por el sector público de las pensiones, ya sea por concepto de garantías, por déficit operacional derivados de alguna transición o por la quiebra de algún actor del sistema.

\section{Algunas experiencias de reforma frente al envejecimiento}

En diferentes experiencias se ha intentado mejorar los sistemas en relación con la protección del afiliado ante los riesgos de vejez, invalidez y muerte, y ante las deficiencias del propio sistema. En la mayoría de los países se han mantenido los diseños de tipo bismarckiano y se han ajustado sus parámetros, mientras que en otros se han aplicado reformas estructurales.

A medida que se van implementando los sistemas de pensiones, independientemente de su naturaleza, es necesario reformarlos con el fin de actualizar sus parámetros y referencias y ajustar los cambios a las nuevas exigencias socioeconómicas. Puede observarse que el desequilibrio financiero de los sistemas de pensiones es una de las principales variables que justifica la necesidad de reformas, sean estas de tipo sustitutivo, mixto o paramétrico. 


\section{a) Reformas paramétricas}

En ausencia de reformas estructurales, los países realizan reformas paramétricas. En el cuadro IV.9 aparece un resumen de los principales cambios paramétricos que han tenido lugar en los programas públicos de reparto de los últimos años.

En el caso del Brasil, basado en la experiencia de Suecia, se optó por mantener la gestión financiera bajo el régimen de reparto, pero avanzar hacia la definición de beneficios a partir de una fórmula de cálculo previsional que se asemeja a un mecanismo de contribuciones definidas. Estos sistemas se conocen como modelos nocionales, en que el régimen de gestión financiera es de reparto, pero las pensiones se definen sobre la base de planes de contribuciones definidas. A su vez, estas se capitalizan a una tasa de descuento acordada por la sociedad, tomando en consideración diversos criterios acerca del funcionamiento de la economía.

En el Ecuador, se aprobó en 2015 la Ley de Justicia Laboral por la que se modifica el código laboral del país. Tres disposiciones de la Ley hacen referencia a las pensiones. En la primera, se extiende la cobertura del sistema público de reparto a las amas de casa no asalariadas. Las mujeres afiliadas cotizarán al sistema según su ingreso familiar, como un porcentaje del salario básico unificado (SBU), que actualmente es de 354 dólares al mes. Las afiliadas podrán optar por una pensión de vejez cuando hayan cumplido los 65 años y hayan acumulado al menos 240 cotizaciones (20 años de afiliación). Los requisitos para recibir una pensión por invalidez varían según la edad: las mujeres de 15 a 25 años de edad deberán tener un mínimo de 6 cotizaciones mensuales, mientras que las mayores de 46 años deberán contar con al menos 60 cotizaciones mensuales. En segundo término, se elimina el $40 \%$ que el Gobierno estaba obligado a contribuir al seguro de vejez, invalidez y sobrevivencia. En cambio, el Gobierno solo contribuirá cuando el Instituto Ecuatoriano de Seguridad Social (IESS) no disponga de los recursos necesarios para cumplir sus obligaciones de pago de los beneficios de la seguridad social. Esta medida en particular ha generado mucha polémica en el país, debido a que vulnera la sostenibilidad financiera del sistema público de reparto. Entre las propuestas para cubrir el faltante generado por la ausencia de contribución del Estado se encuentran el aumento de la edad de retiro, el incremento de las tasas de cotización de trabajadores y empleadores y la reducción del nivel de beneficios. Por último, la Ley contempla la modificación de la metodología de indexación de los beneficios. Desde 2010, los ajustes iban desde un $4,31 \%$ hasta un $16,6 \%$, dependiendo del nivel (los jubilados con menores ingresos recibían los mayores ajustes). En adelante, los beneficios se ajustarán solo en función de la tasa media de inflación del año anterior (Social Security Administration, 2015). 


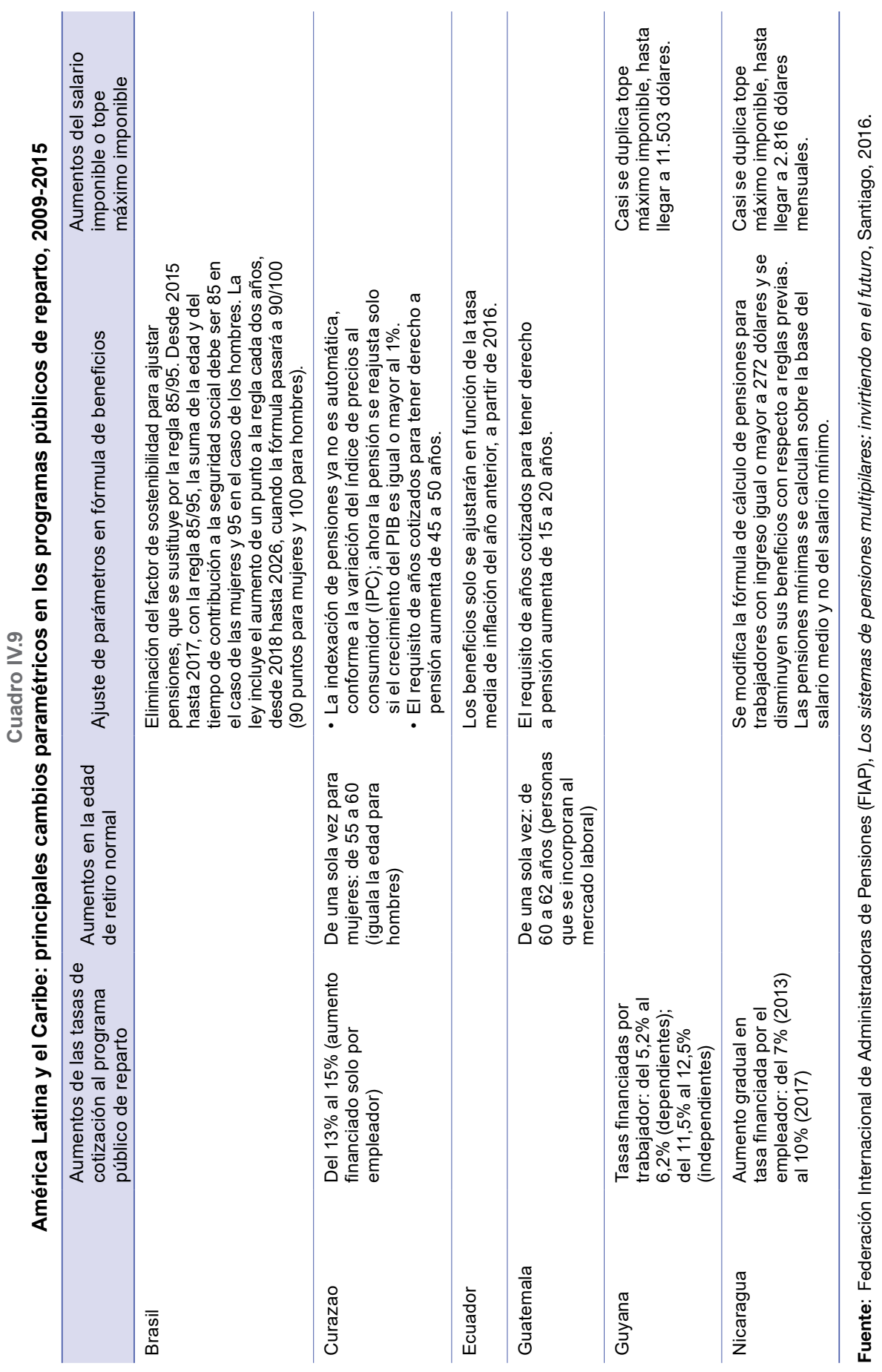


En Guatemala, a partir de 2011 entraron en vigor modificaciones en el sistema público de reparto. Entre ellas destacan un aumento de la edad mínima de jubilación para las personas que se incorporan al mercado laboral, de 60 a 62 años, y un aumento del número mínimo de años de contribución requeridos para obtener una pensión, de 15 a 20 años. De manera transitoria, se mantuvo la opción de jubilarse a los 60 años para todos los trabajadores que estuvieran cubiertos por el sistema en 2010. No obstante, en ese caso el número mínimo de años de contribuciones requerido para obtener una pensión se incrementó anualmente en un año, hasta alcanzar los 20 años en 2015 (Social Security Administration, 2011).

En Guyana, se realizó en 2013 una reforma paramétrica sobre la tasa de contribución destinada al sistema público de reparto financiada por los trabajadores. La tasa se incrementó en un punto porcentual, del 5,2\% al $6,2 \%$ del salario en el caso de los trabajadores dependientes, y del 11,5\% al 12,5\% del salario en el caso de los trabajadores independientes (la tasa de contribución financiada por los empleadores se mantuvo inalterada en un 7,8\%). Además, con el fin de proteger a los trabajadores de menores ingresos, el Gobierno subsidiará el incremento de la tasa de contribución de los trabajadores que tengan ingresos inferiores a los 50.000 dólares de Guyana (243 dólares) mensuales (Social Security Administration, 2013).

También en 2013, Nicaragua publicó el Decreto Ejecutivo núm. 39-2013, por el que se reforma la Ley del Instituto Nicaragüense de Seguridad Social (INSS), que establece el marco legal del sistema público de reparto del país. El plan incluye un aumento gradual de la tasa de contribución del empleador, de un 7\% en 2013 a un 10\% en 2017 ( 1 punto porcentual en 2014 y 2015, y 0,5 puntos porcentuales en 2016 y 2017). Aunque la tasa de contribución del trabajador permanecería en un $4 \%$ hacia 2015 , casi se duplicó el tope máximo imponible a las contribuciones mensuales, tanto de los trabajadores como de los empleadores, pues llegó a los 72.140 córdobas (aproximadamente 2.816 dólares). A partir de 2016, el INSS ajustará el tope máximo imponible en función del salario medio de todos los trabajadores afiliados al INSS. También se aplicó otra modificación a la fórmula de cálculo de los beneficios concedidos a cerca del $25 \%$ de los trabajadores afiliados al INSS (quienes ganan al mes más de 7.000 córdobas, aproximadamente 272 dólares).

Los cambios de la fórmula nicaragüense conducirán a beneficios inferiores a los que se obtenían bajo las reglas anteriores (los analistas estiman que ahora será necesario trabajar ocho años más para mantener el mismo nivel de beneficios). Por otra parte, las pensiones mínimas se calculan con base en el salario medio y no el salario mínimo (los estudios señalan que el salto del salario mínimo en un $135 \%$ en los últimos cinco años agudizó la presión sobre los recursos del INSS para los próximos 
años). El Gobierno espera que con todas esas medidas el INSS pueda proyectar su vida sostenible al menos hasta 2036. El Gobierno no propuso aumentar la edad de jubilación, actualmente de 60 años, ni las semanas de cotización (750). El Fondo Monetario Internacional (FMI) ha propuesto a Nicaragua aumentar de 60 a 65 años la edad de jubilación y duplicar de 750 a 1.500 las semanas de cotización (pasar de 14,4 a 28,84 años). También se ha llamado a disminuir la informalidad del mercado laboral, que alcanza el $70 \%$. Según cifras oficiales, se trata de un segmento que percibe bajos salarios, no tiene acceso a la seguridad social y permanece bajo el umbral de la pobreza (Social Security Administration, 2014).

\section{b) Las reformas estructurales}

En 1981, bajo el régimen militar y siguiendo opciones favorables al mercado, se reformó el sistema previsional chileno, de múltiples cajas que operaban sobre la base de regímenes de reparto a un sistema único de cuentas de ahorro individuales obligatorias. Además:

- Se mantuvo el régimen contributivo.

- Se sustituyó el esquema de reparto por la capitalización en cuentas individuales.

- Se sustituyó el régimen de beneficios definidos por otro de contribuciones definidas.

- La administración de los fondos pasó de cajas paraestatales a empresas privadas.

- Se fortaleció la regulación y supervisión por parte del Estado, sin un componente explícito de alivio de la pobreza.

- En 2008 se volvió a reformar para incluir un pilar explícito de alivio de la pobreza y mejorar la competencia y eficiencia entre las empresas privadas ${ }^{30}$.

- También en 2008 se aprueba una nueva ley por la que se modifican las garantías explicitas de una pensión mínima garantizada y la pensión asistencial. Estas fueron reemplazadas por un pilar solidario que garantiza beneficios al $60 \%$ de las familias más pobres, en forma de Pensión Básica Solidaria (PBS) si no han autofinanciado una pensión y de Aporte Previsional Solidario (APS) para complementar las pensiones autofinanciadas hasta un mínimo garantizado por ley.

A raíz de la experiencia chilena, con el apoyo de instituciones internacionales, durante los años noventa se iniciaron reformas estructurales similares en Bolivia (Estado Plurinacional de), El Salvador y México

30 Véase la Ley núm. 20.255 de Chile. 
(primero en el Instituto Mexicano del Seguro Social (IMSS) y luego en el Instituto de Seguridad y Servicios Sociales de los Trabajadores del Estado (ISSSTE)), y también en la República Dominicana. Por su parte, en Colombia y el Perú se mantuvieron en forma paralela el sistema bismarckiano original y los mecanismos de capitalización en cuentas individuales, dejando que el afiliado seleccionara en cuál participar. La Argentina y el Uruguay, y posteriormente Costa Rica y Panamá, optaron por un diseño mixto que consistió en complementar el sistema bismarckiano, a partir de cierto umbral, con cuentas de capitalización individual. En 2010, se suprimió en la Argentina el componente de capitalización y se volvió a un sistema exclusivo de reparto, beneficios definidos y administración pública ${ }^{31}$. En el recuadro IV.4 se exponen más detalles relativos al caso chileno.

\section{Recuadro IV.4}

\section{El caso chileno: capitalización en cuentas de ahorro individuales}

Los fundamentos del actual sistema chileno de pensiones fueron diseñados en 1981 bajo un régimen de facto, sin debate democrático y con opciones seleccionadas de antemano. Ello propició la implementación de un mercado competitivo de administración de cuentas de ahorro en el que primaron criterios economicistas antes que los de seguridad social. Tales criterios llevaron a su punto más álgido la contradicción entre el principio de equivalencia, que facilitaba la venta de contratos individuales de ahorro por parte de empresas especializadas, y el principio de solidaridad, que aseguraba un acceso universal y asequible a una vejez digna. También pusieron en tela de juicio la inmunidad de los afiliados a los riesgos inherentes de los sistemas de pensiones que administran ahorros a largo plazo.

Las opciones seleccionadas en aquel tiempo fueron extremas. Se adoptó un sistema de contribuciones definidas, con capitalización en cuentas individuales, administración privada y un rol distributivo del Estado. Se establecieron garantías mínimas, pero las condiciones de elegibilidad resultaron ser muy exigentes. Este rol se vio modificado radicalmente en la reforma de 2008, cuando se integró al sistema un pilar solidario que reemplazó la pensión mínima garantizada por una combinación de cuatro beneficios: i) la pensión básica solidaria de invalidez; ii) la pensión básica solidaria de vejez; iii) el aporte previsional solidario de invalidez, y iv) el aporte previsional solidario de vejez. Los dos primeros beneficios eran para personas sin historias contributivas y los dos segundos, para complementar las pensiones autofinanciadas hasta un mínimo. Ambos se entregan a beneficiarios pertenecientes al $60 \%$ de las familias más pobres del país.

Con la vuelta de la democracia en 1990, los sucesivos gobiernos revisaron los resultados del sistema de pensiones sobre la base de tres

31 Tomando en cuenta las proyecciones hacia el futuro, los estudios disponibles muestran que, en ausencia de reformas, los desequilibrios financieros irán aumentando. En México, antes de la reforma, se esperaba un déficit de la seguridad social superior al 3\% del PIB a partir de 2017. En Colombia, por su parte, se había estimado que llegaría a un 3,5\% del PIB en 2015, y en el Estado Plurinacional de Bolivia, al 5\% del PIB en 2002 (Schmidt-Hebbel, 1995, y Von Gersdorff, 1997). 
Recuadro IV.4 (continuación)

criterios: su costo para el fisco, su cobertura y su suficiencia. Además, se cuestionó la falta de competencia en el mercado de administradoras y se señalaron los conflictos de intereses que se generaban en torno a la administración de los fondos acumulados.

Como se detalla a continuación, a pesar de estas iniciativas de las finanzas públicas por imponer un sistema operado por el sector privado y el mercado, los resultados de cobertura y suficiencia no fueron buenos. Después de más de 25 años de operación, el Gobierno socializó las cifras tanto del costo de la transición como de cobertura y suficiencia del sistema. En el informe de la Comisión Marcel, instancia conformada por expertos de diversas tendencias y encargada de elaborar un diagnóstico y propuestas de reforma del sistema de pensiones, se plantea: "Después de servir gran parte de la deuda implícita asociada a la transición de un sistema a otro, la cual se estimó en valor presente igual a $136 \%$ del PIB, que ha significado cifras de déficit previsional superiores al $4 \%$ del PIB por varios años y que aún continuarán por varios años más (Arenas de Mesa, 2006) (...), el sistema solo permitía que un $45 \%$ de los afiliados autofinanciara sus pensiones, un $5 \%$ calificara para la garantía de la pensión mínima y un $50 \%$ quedaba desprotegido" (Consejo Asesor Presidencial para la Reforma Previsional de Chile, 2006, sobre la base de Berstein, Larraín y Pino, 2005).

Entre los principales elementos a considerar se destacan:

- Conflicto entre los principios de equivalencia y solidaridad: la lógica del sistema chileno, al ser actuarialmente justo desde la perspectiva individual, donde el valor presente de las prestaciones es igual al valor presente de las cotizaciones, impide toda forma de solidaridad entre afiliados. Por ende, quien por diversos motivos tenga una baja capacidad de ahorro a lo largo de su vida activa, termina condenado a una vejez en condiciones de pobreza.

- Riesgos asociados con el envejecimiento: los temas de la densidad de cotizaciones (la frecuencia con que un afiliado cotiza al sistema), el monto de la cotización (la tasa obligatoria del aporte), la rentabilidad neta que obtenía (la eficiencia del sistema) y la creciente expectativa de vida a la edad de retiro (cambios demográficos), pasaron a ser fundamentales en la determinación de los beneficios de los afiliados. Así, el sistema, que parecía inmune a los problemas de los sistemas de reparto, volvió a manifestarlos con igual fuerza. El sistema falló en su capacidad para evitar lagunas previsionales, al no considerar las diferentes condiciones laborales e incentivos de los afiliados. Tampoco se ha establecido un mecanismo de ajuste paramétrico que dé cuenta de las condiciones que permiten asegurar la calidad de las pensiones como consecuencia de la baja tasa de ahorro, la tendencia a la baja de las rentabilidades netas de sus fondos y los cambios demográficos. La lógica del sistema, no obstante, culpaba al afiliado por no tomar en forma individual y voluntaria la decisión de cotizar más durante un mayor período de tiempo y escoger mejores opciones de inversión ${ }^{2}$.

- Desarrollos institucionales. Es importante destacar la forma en que se ha tratado de integrar la participación ciudadana al debate sobre las reformas. Luego cabría discutir las diferentes dimensiones del 
desarrollo institucional, que se han puesto de relieve en la forma en que se está intentando conciliar la eficiencia con la solidaridad y proteger el sistema de los riesgos que lo afectan. Para compatibilizar el principio de equivalencia con la solidaridad y el alivio de la pobreza en la vejez se consideraron los siguientes elementos:

- La participación ciudadana, promovida por las Comisiones Marcel y Bravo. Tal vez este sea uno de los desarrollos institucionales más interesantes con relación a los sistemas de pensiones en Chile. Se refiere a la convocatoria de grupos de expertos para el examen de una reforma. Puede calificarse como organizacional, aunque luego, paradójicamente, condujo a la modificación del marco jurídico-normativo.

- Tanto en su primer Gobierno (2006-2010), como en el segundo (2014-2018), la Presidenta Michelle Bachelet convocó a grupos de expertos para que examinaran el sistema y sugirieran mejoras. Con diferentes variantes, estas comisiones tuvieron las siguientes características: eran independientes del Gobierno, estaban presididas por un profesional de la confianza de la Presidencia (que disponía de una Secretaría Ejecutiva, financiada por el Gobierno), y sus miembros fueron convocados por Decreto con un mandato claro. Además, estaban constituidas por equipos multipartidarios y multidisciplinarios de profesionales especializados que trabajaron ad honorem y realizaron consultas ciudadanas y con grupos de interés que solicitaban audiencias. Por último, emitieron un informe no vinculante que, una vez aprobado por la Presidencia, se sometió al análisis de técnicos gubernamentales con miras a elaborar un proyecto de ley que se presentara al Congreso.

- La dimensión jurídico-normativa de la reforma de 2008: acceso universal y pobreza. Frente a un gasto histórico por concepto del déficit previsional, originado en este caso por la transformación del sistema, y la cruda evidencia de bajas tasas de cobertura y suficiencia del nuevo sistema, la Comisión Marcel estimó oportuno sugerir la creación de un pilar solidario. Este se integraría al sistema existente y permitiría aliviar la pobreza en la vejez, pues subsidiaría por igual a quienes no participaban del sistema y a quienes no ahorraban lo suficiente. El principal cambio jurídico-normativo que trajo la reforma fue la Ley núm. 20.255, por la que se modificó el marco legal vigente y se introdujeron los importantes cambios mencionados. Este cambio legislativo le dio mayor trascendencia y permanencia a la reforma.

- Las dimensiones organizacional y técnico-operativa de la reforma de 2008: múltiples partes que deben actuar de forma coordinada. En el siguiente diagrama se representa el nuevo marco institucional con que se busca coordinar los diferentes organismos que intervienen en la lógica del nuevo Sistema de Pensiones Solidarias (SPS). En lo esencial, se fortalecen, reforman o generan nuevas instituciones e instrumentos de gestión con miras a implementar cuatro funciones fundamentales del nuevo sistema de pensiones solidario chileno: la estrategia previsional, la administración y operación del SPS, la regulación y supervisión del sistema, y la participación y educación ciudadana. 
Recuadro IV.4 (conclusión)

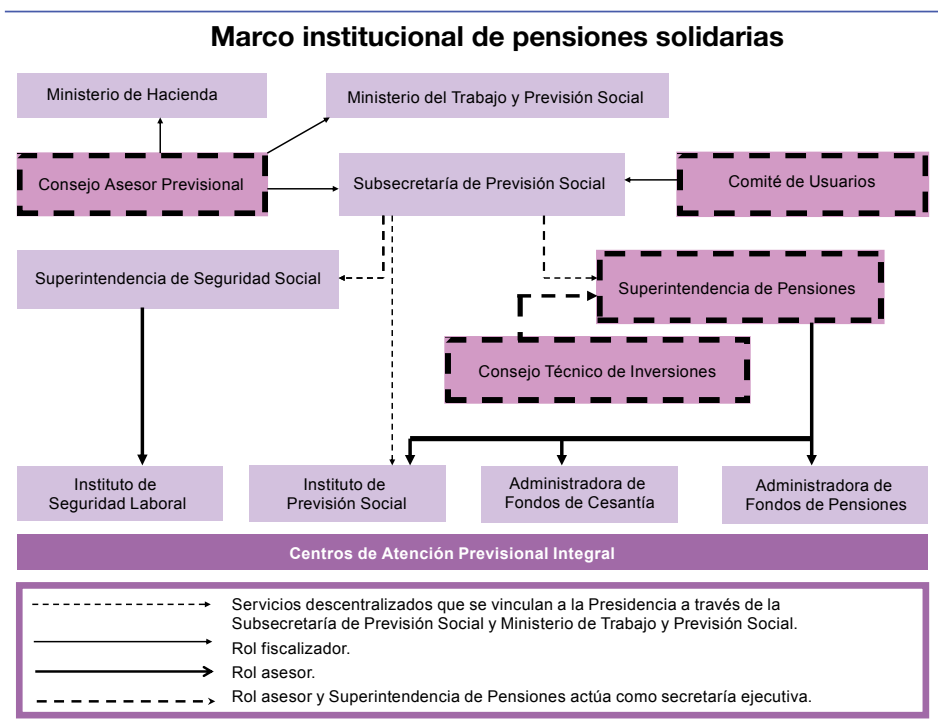

Por su parte, cabe puntualizar algunos aspectos sobre el envejecimiento y el financiamiento contributivo y no contributivo.

- Respecto a los cambios paramétricos para ajustarse a las demandas del envejecimiento, la particularidad del caso chileno radica en que, a fin de evitar que se reduzcan las pensiones, la decisión de retirarse más tarde y ahorrar más corresponde al individuo y no a la política pública. Se privilegia la propiedad del ahorro y la libertad de elección en mercados supuestamente competitivos.

- La gestión financiera de los aportes de los afiliados al sistema de pensiones en su parte contributiva debe realizarse protegiendo los derechos de los afiliados en torno al debido resguardo de sus ahorros para velar por su sostenibilidad a largo plazo. Esta sigue siendo sensible a cambios demográficos, a los ciclos y crisis de la economía, a las fluctuaciones del mercado financiero y al uso político de los fondos.

- Las dimensiones organizativa y operacional. Entre los elementos de organización y gestión más relevantes se incluyen: el Sistema de Consultas y Ofertas de Montos de Pensión (SCOMP), la Superintendencia de Pensiones (SUPEN), creada por la Ley núm. 20.255 de marzo de 2008 como sucesora y continuadora legal de la Superintendencia de Administradora de Fondos de Pensiones. La nueva superintendencia es un organismo contralor, técnico y altamente profesionalizado, cuyo objetivo es mantener una estrecha vigilancia y control del SPS (sistema que administra el Instituto de Previsión Social (IPS)), de las Administradoras de Fondos de Pensiones (AFP) y de la Administradora de Fondos de Cesantía (AFC) (entidad que recauda las cotizaciones, invierte los recursos y paga los beneficios del seguro de cesantía).

Fuente: Subsecretaria de Previsión Social, Informe anual 2009, Santiago, Consejo Consultivo Previsional, 2010 [en línea] http://www.previsionsocial.gob.cl/ccp/ documentos/informes/informe-ccp-2009.pdf.

a Durante la década pasada se optó por crear cinco alternativas de inversión para los cotizantes (multifondos). Las alternativas se diferencian entre sí según el nivel de riesgo y rentabilidad esperada, y según el portafolio de inversión de cada cotizante. De esta manera se le permite decidir la forma en que se distribuirán sus ahorros en cada fondo. 


\section{Consideraciones finales}

Los sistemas de pensiones tienen como propósito suavizar las variaciones en la capacidad de consumo a lo largo del ciclo de vida. En particular, han de proveer ingresos en casos de vejez, invalidez y sobrevivencia a la muerte del principal perceptor de rentas. Se trata de instrumentos de ahorro, pero también de aseguramiento y transferencias. Se guían por principios de la seguridad social que buscan que todas las personas accedan a los beneficios, independientemente de su capacidad de aportar primas o cotizaciones para el financiamiento del sistema.

En tal sentido, el sistema está sujeto a vulnerabilidades que pueden entorpecer el logro de la cobertura universal o de su sostenibilidad financiera. Sus diseños apuntan a contar con una institucionalidad capaz de crear las condiciones para mitigar esos riesgos y las vulnerabilidades que condicionan sus resultados. Tales desarrollos institucionales se insertan en las cuatro dimensiones descritas al inicio de este documento. De los casos abordados, se destacan los siguientes aspectos:

- En relación con la dimensión jurídico-normativa, se requiere contar con un marco normativo que establezca principios que permitan articular el sistema de pensiones en torno a tres pilares: contributivo, no contributivo y semicontributivo. La finalidad es satisfacer la titularidad de derechos en casos de vejez, invalidez y muerte, mediante un sistema que combine diferentes formas de vincular los derechos con las obligaciones.

- En cuanto a la dimensión organizacional, no sirven las soluciones extremas. Debe evitarse la selección de situaciones excluyentes de financiamiento, gestión financiera, vínculos entre aportes y beneficios, carácter público o privado de la administración y carácter universal o focalizado del asistencialismo. Es necesario dimensionar el rápido envejecimiento poblacional debido a la fuerza de las tendencias demográficas y la debilidad de la inclusión social a través del mercado laboral, ya que generan dilemas y cambios en el contexto en que operan los sistemas, a los que no responde ningún paradigma excluyente. Los desarrollos institucionales deben adaptarse a la naturaleza heterogénea y cambiante de estos contextos, dando pie a la articulación entre diferentes ministerios.

- Respecto a la dimensión operativa e instrumental, no existe un solo instrumento que permita lograr el objetivo de asegurar una vejez digna a todas las personas. Por el contrario, la ausencia de mercados de trabajo inclusivos se manifiesta en una baja densidad de cotizaciones a lo largo del ciclo de vida productiva 
de los afiliados activos. Esto, junto con la baja rentabilidad asociada tanto al crecimiento de la masa laboral como a los retornos de los activos financieros, genera la necesidad de nuevos instrumentos para hacer frente a permanentes desequilibrios entre obligaciones y derechos. En los países se debate sobre la incorporación de instrumentos que combinan criterios de eficiencia y de equidad para dar cuenta de estos factores. El desarrollo de mecanismos efectivos de gestión democrática, con alto grado de transparencia en las cuentas públicas, rendición de cuentas sobre el manejo de los recursos y la toma de decisiones, y participación de la sociedad civil en la elaboración de las propuestas de reforma, constituyen una parte fundamental de la implementación técnico-organizacional para lograr la eficacia y la equidad de los sistemas.

- Finalmente, en cuanto a la dimensión fiscal, la evidencia de un rápido envejecimiento de la población, con un mercado de trabajo débil en términos de inclusión social, indica que es necesario repensar los mecanismos instituidos de solidaridad con miras a la protección social. El mercado de trabajo no ha demostrado una capacidad incluyente en términos de generación de trabajo decente ni de niveles suficientes de contribución. Junto con la promoción de políticas que generen más y mejores empleos, no cabe esperar que a corto o mediano plazo el empleo sea suficiente como mecanismo de financiamiento para la protección de la mayor parte de la población frente a riesgos relacionados con el envejecimiento. Esta situación obliga a replantearse la protección social en el marco de una solidaridad integral en que se combinen mecanismos contributivos y no contributivos. Ello hace necesaria la concertación de un pacto fiscal y un nuevo pacto social que tengan los derechos sociales como horizonte normativo, y las desigualdades y restricciones presupuestarias como limitaciones que es necesario reconocer y enfrentar. En otras palabras, se requiere conciliar los imperativos éticos que sirven de marco a un contrato centrado en derechos sociales con las restricciones financieras de cada contexto. Además, a efectos de ampliar la cobertura y elevar la calidad de los servicios, en especial para los sectores de menores recursos, es importante aumentar la eficiencia en el uso de los recursos (CEPAL, 2006).

Como lo afirma la CEPAL (2015), en sociedades heterogéneas y desiguales como las latinoamericanas no hay modelos únicos deseables. En materia de pensiones, el sistema de capitalización individual de la 
experiencia chilena (incluido su pilar solidario) y el de otros países de la región enfrentan desafíos comunes. Estos guardan relación con el rápido envejecimiento debido a los cambios demográficos, las bajas densidades de cotizaciones provocadas por la precariedad y vulnerabilidad estructural del empleo, las políticas coyunturales para lidiar con las oscilaciones del ciclo macroeconómico y la necesidad de jerarquizar las prioridades ante la frágil sostenibilidad fiscal a largo plazo, entre otros factores.

Ante la pregunta de cómo garantizar un acceso asequible a una vejez digna a toda persona independientemente de su capacidad de ahorro, los países deberán continuar buscando combinaciones de las modalidades siguientes:

- La articulación responsable del financiamiento contributivo y no contributivo.

- La organización de subsidios cruzados implícitos o explícitos de personas o agentes económicos con alta capacidad de ahorro hacia personas de baja capacidad de ahorro.

- La definición de beneficios dignos en respuesta a los derechos que surgen por la condición de ciudadano o de haber contribuido financieramente al sistema.

- Los ajustes paramétricos implícitos o explícitos para conciliar la sostenibilidad financiera con la suficiencia de los beneficios y los cambios demográficos y del mercado de trabajo.

- Las políticas encaminadas a mejorar la capacidad de inclusión del mercado laboral.

- La delimitación de la propiedad y el destino de los fondos de pensiones si los hubiera.

- La regulación prudencial con miras al resguardo de la rentabilidad de dichos fondos en los mercados financieros.

Los sistemas de pensiones operan en contextos específicos que, en el caso de América Latina, se caracterizan por la heterogeneidad de las condiciones laborales de sus trabajadores y de la vulnerabilidad en que se desenvuelven sus familias. Los sistemas que basan exclusivamente su financiamiento en fuentes contributivas, y en la titularización de los derechos previsionales con esquemas de contribuciones definidas, reproducen en la tercera edad las implicaciones de las precariedades de las etapas formativas y productivas de los afiliados. Es diferente el caso de los sistemas que emplean una mayor cuota del financiamiento para implementar subsidios cruzados entre sus afiliados y beneficiarios. De esta forma se logra que todos accedan a un piso mínimo de dignidad en la vejez pero, al mismo tiempo, se debilita la sostenibilidad financiera del sistema. 
Los sistemas de seguridad social en materia previsional deben lidiar con las causas que reproducen en la vejez la desigualdad que muestran las sociedades de la región durante todas las etapas del ciclo de vida. Este capítulo se ha centrado en los desarrollos institucionales necesarios para conciliar la sostenibilidad financiera de un sistema de pensiones a lo largo de generaciones con la cuota de solidaridad necesaria para apoyar a quienes experimentaron condiciones precarias en las etapas previas del ciclo de vida y fueron excluidos de los beneficios del crecimiento. Del análisis de la experiencia de Chile se destacan las limitaciones que para esta tarea tienen los marcos normativos explícitos en su constitución y los valores culturales de los ciudadanos. El sistema chileno, basado exclusivamente en un pilar contributivo de capitalización en cuentas de ahorro individuales y una limitada red de subsidios en un pilar solidario, no ha podido dar cuenta de las fragilidades derivadas de la realidad de su mercado de trabajo y de la desigualdad. Es posible que en el futuro cercano se vean amplios debates y reformas en torno a los cuatro puntos señalados en el párrafo anterior. Ello permitirá ir superando la baja suficiencia de los beneficios con que el sistema ha ampliado su cobertura, donde el $79 \%$ de los beneficiarios obtiene pensiones por debajo del salario mínimo (350 dólares) y el $44 \%$, por debajo de la línea de pobreza (127,3 dólares).

A fin de avanzar en los principios de la seguridad social, en la región se deberían realizar cada vez mayores esfuerzos por: i) combinar fuentes de financiamiento; ii) gestionar ese financiamiento con mecanismos de reparto y de capitalización; iii) establecer pisos mínimos de beneficios definidos e incentivos que propicien mayores esfuerzos individuales de ahorro, y iv) desarrollar asociaciones público-privadas para la administración del sistema con el fin de conciliar la sostenibilidad y la solidaridad. En definitiva, se requiere una política de Estado con una institucionalidad que asegure una vejez digna para todos, mediante la articulación del componente de pensiones con otras medidas de protección social. 


\section{Bibliografía}

Arenas de Mesa, A. (2006) "Gasto público y pensiones: la experiencia chilena", presentación en el XVIII Seminario Regional de Política Fiscal [en línea] http:/ / www.cepal.org/ilpes/noticias/paginas/0/23680/Alberto\%20Arenas.ppt.pdf.

(1999) "Efectos fiscales del sistema de pensiones de Chile: proyección del déficit previsional 1999-2037", documento presentado en el Seminario "Responsabilidades Fiscales de los Sistemas de Pensiones", Santiago, Ministerio de Hacienda.

Arenas de Mesa, A. y M. Marcel (1999), "Fiscal Effects of Social Security Reform in Chile: The Case of the Minimum Pension", documento presentado en el segundo Foro Regional APEC sobre Fondos de Pensiones.

Banco Mundial (1994), Averting the Old-Age Crisis, Nueva York, Oxford University Press [en línea] http:/ /documentos.bancomundial.org/curated/es/1994/09/698030/ averting-old-age-crisis-policies-protect-old-promote-growth.

Barr, N. y P. Diamond (2008), Reforming Pensions: Principles and Policy Choices, Nueva York, Oxford University Press).

Berstein, S., G. Larraín y F. Pino (2005), “Datos y perspectivas de la cobertura en la reforma de pensiones de Chile", presentación en la Reunión de Comisiones Técnicas de la AIOS en Colombia.

Bertranou, F.M. (2013), "Restrictions, problems and dilemmas of social provision in Latin America: facing challenges from aging and income inequality", Well-being and Social Policy, vol. 1, N 1, Organización Internacional del Trabajo.

Bertranou, F. y F. Grafe (2007), "La reforma del sistema de pensiones en Brasil: aspectos fiscales e institucionales", Banco Interamericano de Desarrollo (BID), borrador [en línea] http://www.iadb.org/res/publications/pubfiles/pubCSI-145_esp.pdf.

Calvo, E., F. Bertranou y E. Bertranou (2010), “Are old-age pension system reforms moving away from individual retirement accounts in Latin America?", Journal of Social Policy, vol. 39, N², Cambridge University Press.

Cecchini, S. y R. Martínez (2011), "Protección social inclusiva en América Latina. Una mirada integral, un enfoque de derechos", Libros de la CEPAL, N 111 (LC/G.2488-P), Santiago, Comisión Económica para América Latina y el Caribe (CEPAL).

CELADE (Centro Latinoamericano y Caribeño de Demografía (CELADE)-División de Población de la CEPAL) (2015), Estimaciones y proyecciones demográficas, Santiago, Comisión Económica para América Latina y el Caribe.

CEPAL (Comisión Económica para América Latina y el Caribe) (2015), “Desarrollo social inclusivo. Una nueva generación de políticas para superar la pobreza y reducir la desigualdad en América Latina y el Caribe" (LC/L.4056(CDS.1/3)), Santiago. (2013), "Hitos discursivos sobre protección social en América Latina y mapeo de la cobertura de los sistemas de salud y pensiones: una sinopsis", Panorama Social de América Latina 2013 (LC/G.2580), Santiago.

(2012), Panorama Social de América Latina 2011 (LC/G.2514-P), Santiago de Chile. (2006), La protección social de cara al futuro: acceso, financiamiento y solidaridad (LC/G.2294(SES.31/3)), Santiago de Chile.

Chile (2008), "Ley $\mathrm{N}^{\circ} 20.255$ que establece reforma previsional", Santiago. (1980), “Decreto Ley N 3.500 que establece nuevo sistema de pensiones", Santiago.

Comisión Asesora Presidencial sobre el Sistema de Pensiones (2015), Informe final, Santiago[enlínea]http://www.comision-pensiones.cl/Documentos/GetInforme yhttps:/ / prensa.presidencia.cl/lfi-content/otras/informes-comisiones/Informe Pensiones.pdf. 
ConsejoAsesorPresidencial parala ReformaPrevisional(2006), Elderechoaunavidadigna enlavejez. Haciaun contratosocial conlaprevisiónen Chile[enlínea]https:/ /www.previ sionsocial.gob.clsps/download/estudios-previsionales/comisionpensiones / documentos-interes-general/informe-consejo-asesor-presidencial-reforma-delsistema-previsional-comision-marcel-2006.pdf.

Consejo Consultivo Previsional del Gobierno de Chile (2009-2014), Informe anual [en línea] http:/ / www.previsionsocial.gob.cl/ccp/informes.php.

DIPRES (Dirección de Presupuesto) (2007), “Fondo de Reserva de Pensiones. Informe trimestral a marzo 2007" [en línea] http://www.dipres.gob.cl/572/ articles-21683_doc_pdf.pdf.

FIAP (Federación Internacional de Administradores de Fondos de Pensiones) (2016), Los sistemas de pensiones multipilares: invirtiendo en el futuro, Santiago. (2011), Informe Semestral, $\mathrm{N}^{\circ}$ 31, Santiago, junio [en línea] http://www.fiapin ternacional.org/wp-content/uploads/2016/01/informe_semestral_n_31-1.pdf.

Filgueira, F. y otros (2006), “Universalismo básico: una alternativa posible y necesaria para mejorar las condiciones de vida", Universalismo básico: una nueva política social para América Latina, C.G. Molina (ed.), Ciudad de México, Banco Interamericano de Desarrollo (BID)/Editorial Planeta [en línea] http://www.iadb.org/wmsfiles/ products/publications/documents/2220408.pdf.

Fultz, E. (2012), "The retrenchment of second-tier pensions in Hungary and Poland: a precautionary tale", International Social Security Review, vol. 65, Nº 3 .

Hohnerlein, E.M. (2013), "Pension re-reform in Argentina", Zeitschrift für ausländisches und internationales Arbeits- und Sozialrecht (ZIAS), N³/2012.

Maldonado, C. y A. Palma (2014), “El caso de la reforma previsional chilena 2005-2008", serie Políticas Sociales, N 183 (LC/L.3665), Santiago, Comisión para América Latina y el Caribe (CEPAL).

Mesa-Lago, C. (2004), "Las reformas de pensiones en América Latina y su impacto en los principios de la seguridad social", serie Financiamiento del desarrollo, N 144 (LC/L.2090-P), Santiago, Comisión Económica para América Latina y el Caribe (CEPAL).

Ministerio de Previsión Social (2010), "Análisis de Seguridad Social, 2009".

OCDE (Organización de Cooperación y Desarrollo Económicos), “OECD Pensions Outlook 2012" [en línea] http://www.oecd.org/finance/private-pensions/ 50560110.pdf.

Peña,M.(2012), “Instrumentotécnicodefocalizacióndelsistemadepensionessolidarias” [en línea] http://www.previsionsocial.gob.cl/cu/wp-content/archivo/201201-09-Acta-Ord-32-Adjunto-Instrumento-Tecnico-Focalizacion-SPS-MPena.pdf.

PNUD (Programa de las Naciones Unidas para el Desarrollo) (2011), Informe sobre desarrollo humano 2011. Sostenibilidad y equidad: un mejor futuro para todos, Nueva York.

Rivera, E. (2014), “La reforma previsional de 2008 en Chile. Un análisis desde la política pública", Pactos sociales para una protección social más inclusiva. Experiencias, obstáculos y posibilidades en América Latina y Europa, M. Hopenhayn y otros (eds.) serie Seminarios y conferencias, $N^{\circ} 76$ (LC/L.3820), Santiago, Comisión para América Latina y el Caribe (CEPAL).

Rofman, R. y M.L. Oliveri (2011), "La cobertura de los sistemas previsionales en América Latina: conceptos e indicadores", serie de Documentos de Trabajo sobre Políticas Sociales, $N^{\circ}$ 7, Banco Mundial [en línea] http:/ / siteresources.worldbank. org/INTARGENTINAINSPANISH/Resources/CoberturaPrevisionalLAC.pdf. 
Schmidt-Hebbel, K. (1995), "La reforma pensional colombiana: efectos fiscales y macroeconómicos", Bogotá, Asociación Colombiana de Administradoras de Fondos de Pensiones y de Cesantía (Asofondos).

Social Security Administration (2015), "International Update", mayo [en línea] https://www.ssa.gov/policy/docs/progdesc/intl_update/2015-05/index.html. (2014), "International Update", febrero [en línea] https://www.ssa.gov/ policy/docs/progdesc/intl_update/2014-02/2014-02.pdf. (2013), "International Update", junio [en línea] https:/ / www.ssa.gov/policy/ docs/progdesc/intl_update/2013-06/index.html. (2011), "InternationalUpdate",marzo[enlínea]https: / /www.ssa.gov / policy / docs/progdesc/intl_update/2011-03/.

Social Watch (2010), European Social Watch Report 2010.Time for Action: Responding to Poverty, Social Exclusion and Inequality in Europe and Beyond [en línea] http:/ / www.socialwatch.eu/wcm/home.html.

Sojo, A. (2007), "La trayectoria del vínculo entre políticas selectivas contra la pobreza y políticas sectoriales", Revista de la CEPAL, N 91 (LC/G.2333-P), Santiago, Comisión Económica para América Latina y Caribe (CEPAL). (1990), "Naturaleza y selectividad de la política social", Revista de la CEPAL, $\mathrm{N}^{\circ}$ 41, Santiago, Comisión Económica para América Latina y Caribe (CEPAL) [en línea] http:// repositorio.cepal.org/handle/11362/11784.

Subsecretaria de Previsión Social (2016), "Comité de Ministros sobre el Sistema de Pensiones" [en línea] https://www.previsionsocial.gob.cl/sps/biblioteca/ comite-ministros-sistema-pensiones /.

(2013a), Propuestas para mejorar pensiones de vejez [en línea] http://www. previsionsocial.gob.cl/spsdownload/estudios-previsionales/comisionpensiones/ presentaciones_audiencias / PROPUESTA\%20PARA\%2MEJORAR\%20 PENSIONES\%20DE\%20VEJEZ\%20\%20BLANCO).PDF.

(2013b), Consejo Consultivo Previsional. Tercer Informe. Agosto de 2011 hasta diciembre de 2012, Chile, diciembre [en línea] http://www.previsionsocial. gob.cl/ccp/documentos/informes/informe-ccp-2012.pdf.

(2010), Informe anual 2009, Consejo Consultivo Previsional [en línea] http:/ / www.previsionsocial.gob.cl/ccp/documentos/informes/informeccp-2009.pdf.

SUPEN (Superintendencia de Pensiones) (s/f) [en línea] http:/ / www.supen.fi.cr/.

Uthoff, A. (2016), "Aspectos institucionales de los sistemas de pensiones en América Latina", serie Políticas Sociales, No 221 (LC/L.4282), Santiago, Comisión Económica para América Latina y el Caribe (CEPAL).

(2011), "Reforma al sistema de pensiones chileno", serie Financiamiento para el Desarrollo, N ${ }^{\circ} 240$ (/LC/L.3422), Santiago, Comisión Económica para América Latina y el Caribe (CEPAL) [en línea] http:/ / repositorio.cepal.org/ bitstream/handle/11362/5221/1/S1100849_es.pdf.

Von Gersdorff, H. (1997), "Pension reform in Bolivia: innovative solutions to common problems", Policy Research Working Paper, N $^{\circ} 1832$, Washington, D.C., Banco Mundial. 

Capítulo V

\section{El cuidado, pilar de la protección social: derechos, políticas e institucionalidad en América Latina}

María Nieves Rico ${ }^{1}$

Claudia Robles ${ }^{2}$

\section{Introducción ${ }^{3}$}

El cuidado es una función social, un bien público y un derecho básico sin el cual no es posible concebir la existencia y la reproducción de la sociedad. Interpela a un nivel medular el propio concepto de humanidad: todos y todas hemos requerido cuidados especiales durante nuestra infancia y probablemente los requeriremos al llegar a la vejez, según el nivel de dependencia que lleguemos a tener. Además, quienes viven con alguna discapacidad o enfrentan enfermedades crónicas o terminales, requieren de cuidados de forma permanente o con mayor intensidad en determinados períodos de su vida. La toma de conciencia sobre el hecho de que todas las

1 Directora de la División de Asuntos de Género de la Comisión Económica para América Latina y el Caribe (CEPAL).

2 Oficial de Asuntos Sociales de la División de Desarrollo Social de la Comisión Económica para América Latina y el Caribe (CEPAL).

3 En este capítulo se resumen los hallazgos principales del estudio Políticas de cuidado en América Latina: forjando la igualdad (Rico y Robles, 2016) y nuevas reflexiones de las autoras recogidas en CEPAL (2016a, 2016b y 2017a). Las autoras agradecen a Gwendoline Peltier por sus aportes a la sistematización de programas y leyes de cuidado en América Latina. 
personas requieren de cuidados produce un cambio en la perspectiva de análisis de las responsabilidades sociales y la interdependencia entre los individuos en términos de derechos y obligaciones (Tronto, 1993). Además, desde el punto de vista de las políticas, es fundamental considerar el cuidado como proceso en las intervenciones públicas de gran impacto en la esfera privada y las relaciones sociales.

El cuidado es materia fundamental de las políticas públicas y los Estados, al constituir una precondición para el desarrollo social y económico sostenible. Las condiciones en que se provee son gravitantes, por ejemplo, para garantizar el crecimiento integral de niños y niñas, así como para un envejecimiento digno. También es prioritario atender la situación de quienes se encargan del cuidado en los hogares, rol que por lo general ejercen las mujeres en sociedades aún marcadas por una cultura patriarcal, una desequilibrada división sexual del trabajo y estereotipos de género en torno a quién corresponde desempeñar esta función social. Culturalmente naturalizada como responsabilidad que recae sobre las madres, hijas, hermanas, abuelas, tías, nueras y vecinas, entre otros vínculos familiares y sociales. Como han puesto de relieve los movimientos de mujeres y los estudios feministas, muchas veces el cuidado se brinda a costa de los derechos de las mujeres y de su autonomía económica, política, e incluso física. La mayor o total carga de trabajo de cuidado no remunerado impacta en la posibilidad de integrarse, en igualdad de condiciones, al trabajo remunerado y acceder a puestos de poder. En su forma más extrema, impide que la mujer ejerza su derecho a una vida libre de violencia, en estrecho vínculo con su autonomía económica. Además, quienes se insertan en el trabajo de cuidado remunerado, por ejemplo, las trabajadoras domésticas remuneradas, las enfermeras, las educadoras y las cuidadoras enfrentan condiciones laborales más precarias, con acceso desigual o nulo a la seguridad y protección social, menores remuneraciones y mayor probabilidad de caer en la pobreza que quienes se insertan en otros sectores de la economía (CEPAL, 2013a y 2016b). Este panorama se agudiza al considerar el entrecruzamiento de las desigualdades étnicas y raciales, y de clase ${ }^{4}$.

El trabajo de cuidado no remunerado en el seno de los hogares, sumado a la menor, nula o desigual inserción en el trabajo remunerado, tiene consecuencias individuales a lo largo del ciclo de vida de las mujeres. Sin embargo, la mujer permanece sin reconocimiento ni reparación a un nivel económico, político y social más amplio, y esa situación también tiene consecuencias sobre el bienestar de los hogares y sobre la

La mayoría de las mujeres, en sus hogares, cuidan directa o indirectamente, y muchas veces lo hacen como actividad principal o exclusiva. Sin embargo, es importante indicar que el trabajo de cuidado también se encuentra potenciado por otras desigualdades, además de la de género. Así, las mujeres pobres, las indígenas y las afrodescendientes están sobrerrepresentadas en el trabajo doméstico remunerado en casi todos los países de la región (Rico y Vaca-Trigo, 2016). 
persistencia de la pobreza (CEPAL, 2013a). Las mujeres asumen el costo personal de una función social decisiva para garantizar la reproducción de las sociedades, e incluso, la sostenibilidad de las políticas públicas, en particular las políticas sociales. En términos económicos, esta contribución es significativa, pues refleja el aporte silencioso que hacen las mujeres a la economía y el desarrollo de los países ${ }^{5}$.

Reconocer, valorar, redistribuir e incidir en las dinámicas de cuidado en América Latina es urgente y prioritario en el marco de una agenda de derechos humanos, de género y de sostenibilidad política y social. Intervenir en la forma en que se accede a los cuidados y se proveen es precondición para detener la transmisión intergeneracional de la pobreza en los hogares, garantizar la protección social universal a todas y todos los ciudadanos, y avanzar hacia sociedades más igualitarias.

En este capítulo se intenta situar a las políticas de cuidado como pilar transversal de la protección social. Se proponen algunos elementos básicos a considerar en el diseño de sistemas integrados de cuidado y se indaga sobre el grado de avance en su formulación y los desafíos que su implementación presenta para la institucionalidad social en países de América Latina. El capítulo cierra con un análisis de las implicancias y oportunidades de la aplicación de un enfoque integrado en estas políticas y su plena incorporación a los sistemas de protección social en la región, transversalizando un enfoque de igualdad de género en su diseño desde su origen.

\section{A. El cuidado como bien público: elementos para el diseño de sus políticas}

El trabajo de cuidado es una función social que se expresa en la serie de actividades, bienes y relaciones destinados a preservar el bienestar cotidiano de las personas en los planos material, económico y emocional (CEPAL, 2013a; Marco y Rico, 2013). Incluye la provisión de bienes esenciales para la vida, como la alimentación, el abrigo, la higiene y el acompañamiento, así como el apoyo y la transmisión de conocimientos, valores sociales y prácticas mediante los procesos de crianza (Razavi, 2012). Se funda en relaciones "cara a cara" entre quienes lo reciben y quienes lo proveen de forma remunerada o no remunerada. Las políticas de cuidado deben cubrir, por tanto, a las cuidadoras y a quienes requieren

De acuerdo a la valorización y las cuentas satélite del trabajo no remunerado en los hogares efectuadas en ocho países de América Latina, el aporte económico por este concepto en equivalencia del PIB nacional alcanza entre el 11,5\% en Costa Rica (2011) y el 18\% en México (2014). El peso relativo del aporte realizado por las mujeres al valor económico total del trabajo no remunerado es considerablemente mayor que el de los hombres. Representa entre el $70 \%$ (en el Perú) y el 87\% (en Guatemala) del valor económico total del trabajo no remunerado como porcentaje del PIB (CEPAL, 2017a). 
esos servicios, incluidos niños y niñas, adultos mayores, y personas con discapacidad o con alguna enfermedad crónica o terminal en situación de dependencia 6 .

En América Latina, el trabajo de cuidado es mayoritariamente asumido por las mujeres de forma no remunerada en el hogar. Además, la expansión de los servicios públicos de cuidado es todavía limitada. Por ejemplo, la evidencia regional disponible muestra que el cuidado de niños y niñas de hasta tres años se provee mayoritariamente en los hogares por parte de las mujeres en el marco de regímenes de bienestar marcadamente familiaristas y del sistema patriarcal dominante ${ }^{7}$.

La irrupción de esta problemática como prioridad de la política pública ha ganado centralidad a partir de la llamada "crisis de los cuidados" (CEPAL, 2011). Esta se refiere a la creciente tendencia de una población dependiente de cuidados en aumento y transformación en términos de sus demandas y necesidades, y una base de cuidadoras no remuneradas que decrece, conforme se intensifica la inserción laboral de las mujeres (Rossel, 2016), sin que se produzca una redistribución de ese trabajo en el seno del hogar debido a la baja participación de los hombres ${ }^{8}$. Esta agenda se ha consolidado además como parte de las demandas reivindicativas y de derechos humanos de las poblaciones que requieren cuidados, incluidas las personas adultas mayores o con discapacidad en situación de dependencia.

Concebir el cuidado como un asunto público implica reorientar la forma en que se ha planteado esta función social como responsabilidad primaria de las familias, concretamente, de las mujeres. Con ello se cuestionan las bases institucionales que definen quién debe asumir los costos de la reproducción social y cómo se distribuye la carga de cuidado en las sociedades. El papel de las políticas públicas en esta transformación es innegable. Esto tiene al menos tres consecuencias.

En primer lugar, sitúa su responsabilidad en otros actores que trascienden a la familia e incluyen al mercado y la sociedad civil, y exige un nuevo pacto en que figure explícitamente el rol garante del Estado para resguardar el derecho al cuidado (Pautassi, 2007). En el seno de la familia, instala el imperativo de la corresponsabilidad en su ejercicio entre hombres y mujeres. En segundo lugar, pone de relieve la necesidad de adoptar medidas que favorezcan a quienes requieren y proveen cuidados desde

\footnotetext{
6 Se alude aquí al cuidado como apoyo o atención directa brindada a personas con algún nivel de dependencia, es decir, quienes precisan de algún tipo de apoyo o asistencia para realizar actividades esenciales de la vida cotidiana, por ejemplo, comer, bañarse, vestirse, movilizarse y trasladarse fuera del hogar (Salvador, 2015).

7 Véase Berlinski y Schady (2015), que consideran datos referentes al Brasil, Chile, el Ecuador, Guatemala, Nicaragua y el Uruguay, a partir de procesamientos de diversas encuestas nacionales.

8 De acuerdo a CEPAL (2011), las personas con dependencia moderada a severa se duplicarán entre 2000 y 2050.
} 
una perspectiva integral e integrada. En tercer lugar, implica reconocer su interconexión con otras políticas sociales, incluso las dirigidas a la infancia y a los adultos mayores, así como las de índole laboral, de salud, de educación, de seguridad social y de protección social, y relacionadas con la igualdad de género.

Así pues, las políticas públicas de cuidado son las que garantizan el bienestar físico y emocional cotidiano de las personas con algún nivel de dependencia e intervienen en la organización social del cuidado, de modo que contribuyen al logro de la igualdad sustantiva entre hombres y mujeres. Estas políticas inciden directamente sobre la distribución de responsabilidades en el cuidado entre Estado, mercado, familias y comunidades y, por tanto, sobre los regímenes de bienestar y el rol de la protección social en su configuración.

A continuación se enumeran algunas dimensiones que pueden considerarse en su diseño, transversalizando un enfoque de derechos y de género en la definición de su institucionalidad 9 . En primer lugar, se deben considerar los cuidados que se proveen en el hogar y fuera de él, de manera remunerada y no remunerada, y por diversos actores: las personas como miembros de una familia $u$ hogar, principalmente las mujeres, el sector privado, la comunidad y la oferta pública. También se debe contemplar la situación de quienes requieren y proveen cuidados, organizados conforme a los distintos niveles de dependencia de las personas cuidadas. Además, los instrumentos que se consideren deben estructurarse en función de los objetivos que se intenta resguardar ${ }^{10}$. A ese efecto, se deben definir al menos cuatro dimensiones estructurantes de políticas, subsistemas o sistemas integrales e integrados de cuidado: recursos económicos, tiempo, servicios (Ellingsaeter, 1999; Pautassi, 2007) y políticas regulatorias que definan estándares de calidad y normativa laboral asociada a su desarrollo (Gascón y Redondo, 2014; Marco, 2014). Finalmente, por su naturaleza multidimensional, estas medidas deben articularse de manera intersectorial e interinstitucional, a través de políticas de salud, educación, igualdad de género, familia, seguridad social y empleo, entre otras.

Los instrumentos resultantes son diversos. En primer lugar, los recursos económicos destinados a este fin pueden incluir transferencias monetarias

\footnotetext{
$9 \quad$ En esta sección se recogen propuestas desarrolladas por diferentes autoras (Batthyány, 2015; Blofield y Martínez, 2014; CEPAL, 2013a; Ellingsaeter, 1999; Huenchuan, 2014; Lamaute-Brisson, 2010; Marco, 2007; Marco y Rico, 2013; Salvador, 2011).

10 Por ejemplo, Blofield y Martínez (2014), al analizar las políticas de conciliación entre trabajo remunerado y familia, distinguen tres tipos de políticas: i) secuenciales, asociadas a la protección de ingresos y el empleo de las cuidadoras (licencias, flexibilidad laboral y trabajo a tiempo parcial); ii) que buscan explícitamente redirigir la responsabilidad en la provisión del cuidado desde las familias y las mujeres hacia el Estado impulsando el sector de servicios, y iii) políticas que buscan regular el empleo doméstico.
} 
directas para contratar servicios de cuidado o como contraprestación a las cuidadoras no remuneradas por su trabajo, con aportes estatales para sus cotizaciones en los sistemas de seguridad social. También se podrían instituir subsidios a la oferta de servicios públicos y privados de cuidado.

En segundo lugar, las políticas de tiempo se refieren al conjunto de mecanismos y regulaciones que permiten a personas cuidadoras acceder a licencias y tiempos de cuidado de niños y niñas y otros familiares en situación de dependencia, con protección de sus condiciones laborales. Pueden comprender políticas de conciliación entre el empleo y las responsabilidades familiares de cuidado, incluidas las que versan sobre las jornadas laborales y su flexibilidad respecto de los tiempos y lugares de trabajo, así como las licencias parentales. Estas corresponden, fundamentalmente, al ámbito de las políticas laborales y de regulación de los mercados laborales como parte de la protección social (véase el capítulo III) y, a la vez, pueden promoverse activamente desde el sector privado.

En tercer lugar, los servicios públicos ofrecen la respuesta más directa para garantizar el acceso a cuidados por parte de las personas que los requieren. También pueden incluir prestaciones dirigidas a las personas cuidadoras, en el caso de servicios de respiro que permiten a las familias con integrantes en situación de dependencia severa recibir cuidados domiciliarios, capacitación y acompañamiento psicológico, entre otras cosas. Por último, la existencia de estándares y regulaciones respecto de la forma en que se ejerce el cuidado, y la calidad del empleo en este sector, también dan cuenta del rol que asume el Estado en su regulación, organización y garantía de derechos, independientemente de que su provisión se efectúe desde el sector privado.

En el siguiente esquema se ofrece una propuesta sobre el menú de opciones disponible para el diseño de políticas y sistemas integrados de cuidado. Se combinan bidimensionalmente, por una parte, políticas en las dimensiones de tiempo, recursos monetarios, servicios y regulación del cuidado, y, por otra, la atención de estas políticas a las distintas poblaciones del cuidado, considerando en su diseño un enfoque de igualdad de género y de derechos (véase el diagrama V.1).

La forma en que se diseñan las políticas y se redistribuyen las responsabilidades en el cuidado no es neutral desde la perspectiva de la igualdad de género y la autonomía de las mujeres. Estas políticas pueden contribuir a esos objetivos a través de medidas que incentiven la corresponsabilidad del cuidado entre hombres y mujeres. Podrían incorporarse licencias paternales y parentales que no asignen exclusivamente la responsabilidad y costos de la reproducción y el cuidado a la mujer, o bien garantizarse un acceso universal a servicios de cuidado públicos. De lo contrario, estas políticas podrían también conllevar efectos adversos para 
la igualdad de género si en su diseño refuerzan orientaciones maternalistas que hacen recaer la responsabilidad primaria sobre las mujeres (Blofield y Martínez, 2014 y 2015). Por ejemplo, se ha argumentado que la entrega de transferencias monetarias directas a quienes proveen cuidados de manera no remunerada, por lo general mujeres, contribuye a reforzar los roles de género que perpetúan la desigual distribución del trabajo en la región (Matus y Vega, 2016). Esto sucedería porque las transferencias reafirman el concepto de que el trabajo de cuidado puede reconocerse mediante una reducida prestación monetaria, sin acceso garantizado a la seguridad social, lejos de los estándares del trabajo decente y el empleo de calidad, y sin incorporar incentivos para que los hombres participen en este trabajo. Además, los servicios de cuidado que no contemplen estándares de calidad del empleo en dicho sector, mayoritariamente atendido por mujeres en América Latina, consolidan la precariedad laboral y desprotección social que las afecta.

Diagrama V.1

Componentes de una política integrada de cuidado

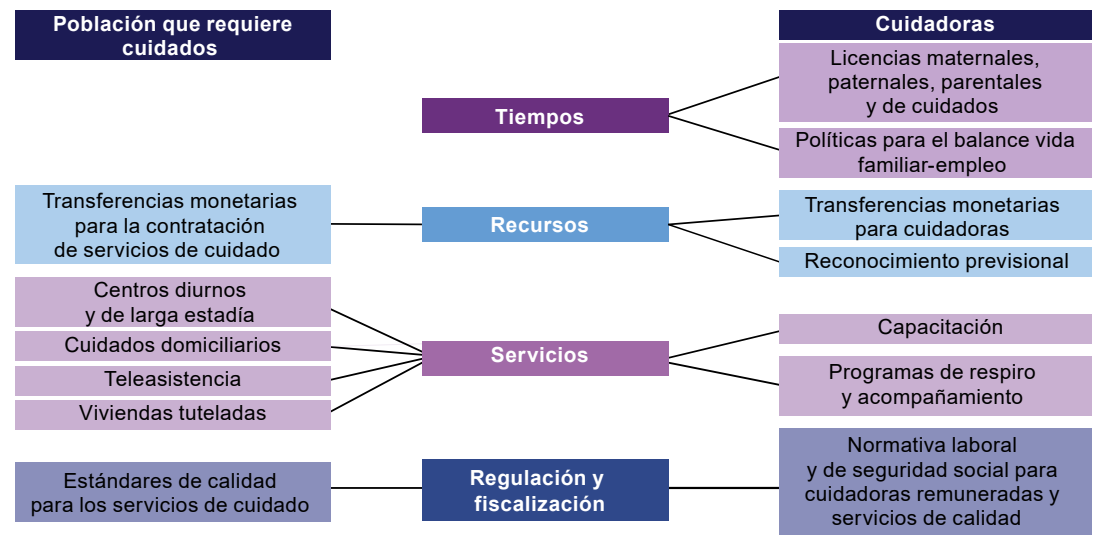

Fuente: M.N. Rico y C. Robles, "Políticas de cuidado en América Latina: forjando la igualdad", serie Asuntos de Género, № 140 (LC/L.4226), Santiago, Comisión Económica para América Latina y el Caribe (CEPAL), septiembre, 2016.

\section{B. Políticas integradas de cuidado como pilar de la protección social: desafíos para su institucionalidad}

Como consta en el diagrama V.1, hay múltiples interrelaciones entre los posibles instrumentos de una política integrada de cuidado y los que se han concebido tradicionalmente como parte de la protección social. Entre otros ejemplos cabe mencionar los instrumentos regulatorios del mercado laboral, que pueden cumplir simultáneamente funciones 
como políticas de empleo, de protección social y de cuidado, en el caso de los que establecen un salario mínimo o jornadas máximas de trabajo (CEPAL, 2016b). O bien, entre los instrumentos de reconocimiento previsional para las cuidadoras, puede considerarse el conjunto de pensiones sociales no contributivas que, en la región, benefician principalmente a las mujeres ${ }^{11}$. En otros casos, los programas que se encuentran en la frontera entre políticas de empleo y de protección social pueden considerar la vulnerabilidad específica que enfrentan las cuidadoras no remuneradas. Sucede así con los programas de capacitación y los servicios de intermediación laboral que comportan transferencias monetarias para la contratación de servicios de cuidado, que permitan a las mujeres insertarse en el trabajo remunerado (CEPAL, 2016a).

Una política integrada de cuidado debe considerarse como pilar transversal de la protección social (Rico, 2014), puesto que las necesidades y prácticas de cuidado encarnan riesgos sociales que pueden tornar muy vulnerable la situación de personas que lo requieren o lo proveen, al obstaculizar su ejercicio de derechos sociales y económicos y exponerlas a la inseguridad de ingresos y la pobreza. En un extremo, se encuentra la situación de adultos mayores, personas con discapacidad o enfermos terminales que, al carecer de recursos económicos o redes de cuidado familiar, y ante la fragmentación de los sistemas de protección social en la región, no cuentan con acceso a servicios sociales de cuidado. También entran en esta categoría las familias que comprometen una parte significativa de sus ingresos en el cuidado de personas en situación de dependencia. En el otro extremo está la situación de una proporción muy relevante de mujeres que en América Latina asumen el cuidado de diversas poblaciones sin remuneración, sin protección social, con severas restricciones para insertarse en el mercado laboral (Rico y Robles, 2016), dadas sus limitaciones de tiempo, y sin reconocimiento social por su trabajo. Según datos de la Comisión Económica para América Latina y el Caribe (CEPAL) provenientes de las encuestas de uso del tiempo, las mujeres realizan entre el $71 \%$ y el $86 \%$ del total de trabajo no remunerado que demandan los hogares (CEPAL, 2016b, pág. 62). Además, entre un 12\% y un $66 \%$ de las mujeres de entre 20 y 59 años en el Uruguay y El Salvador, respectivamente, se encuentran fuera del mercado laboral por razones familiares (CEPAL, 2016b, pág. 60).

Este contexto pone de relieve la necesidad de que, tanto el pilar que pueda constituir una política de cuidados como el sistema de protección social en su conjunto, transversalicen de manera explícita un enfoque de igualdad de género que permita lograr una integración equilibrada y coherente entre los objetivos de las políticas, sus impactos e instrumentos.

11 Una revisión de estas pensiones y sus coberturas puede encontrarse en Marco (2016). 
De esta forma, una política de cuidado como parte de sistemas de protección social debería consolidar determinadas condiciones. En primer lugar, quienes requieran cuidados deberían recibirlos a través de servicios de calidad, el acceso a cuidados en el mercado no debería profundizar la pobreza en los hogares, y el trabajo de cuidado no debería crear barreras en cuanto a educación y empleo en condiciones igualitarias entre hombres y mujeres. En segundo lugar, el cuidado no debería implicar la exclusión de la seguridad social, amenazar la autonomía económica ni cimentar la vulnerabilidad de las cuidadoras, sino que debería redistribuirse su carga.

Con esta función social en mente, las políticas de cuidado deben posicionarse desde una perspectiva integral, dado que precisan la articulación de distintos sectores y actores de la política social, así como de enfoques e instrumentos para la atención de las especificidades de quienes proveen y requieren cuidados. La perspectiva también debería ser integrada, al considerar el funcionamiento simultáneo de diversos instrumentos, y de derechos universales de ciudadanía, de forma que supere enfoques sectoriales y de atención a grupos poblacionales específicos. Esto, sin abandonar el principio de igualdad y no discriminación de un enfoque de derechos basado en el mandato de adoptar acciones prioritarias y positivas a favor de quienes se encuentran en situación de mayor vulnerabilidad o de clara desventaja, como sucede con las mujeres.

Estos postulados se empalman con los desafíos de la institucionalidad social en la región (véase el capítulo II), al mismo tiempo que interpelan la institucionalidad específica de la protección social en América Latina desde frentes diversos. En primer lugar, imponen un desafío organizacional de articulación de las entidades coordinadoras de las políticas de cuidado con los mecanismos de coordinación de los sistemas de protección social. Entre ellos cabe mencionar las secretarías ejecutivas, consejos, ministerios sociales y otras (CEPAL, 2016a), que forman parte de la construcción de una estrategia de largo plazo y representan un componente estable de la institucionalidad social de la región.

A nivel de los instrumentos, se requiere además la imbricación sustantiva y operativa entre los que forman parte de las políticas de cuidado y la protección social. Esto no solo implica una articulación formal, de modo que los programas de cuidado se incluyan oficialmente en los sistemas de protección social, sino también el posible rediseño de instrumentos para garantizar la transversalización de un enfoque de igualdad de género. Tal es el caso de programas de transferencias monetarias, cuyo diseño de condicionalidades puede reforzar la desigual división del trabajo productivo y reproductivo (CEPAL, 2013b), sobre todo si no se incorporan incentivos para que el cuidado sea asumido 
de forma corresponsable entre hombres y mujeres. Otro tanto sucede con la creación de mecanismos de acceso preferencial a los servicios de cuidado para familias priorizadas por los sistemas de protección social que enfrenten barreras para la plena incorporación de la mujer al empleo debido a su carga de trabajo no remunerado; o con los instrumentos de reconocimiento previsional para quienes han desempeñado trabajo de cuidado no remunerado durante su vida, o la flexibilización de las condiciones de acceso a la seguridad social para trabajadoras del sector informal y del cuidado. La coherencia entre los enfoques de igualdad de género y de derechos, con las especificidades del ciclo de vida, en el diseño y articulación entre las políticas de cuidado y los sistemas de protección social, exige solidez institucional en materia de gestión, con adecuadas capacidades técnicas y políticas en los equipos a cargo de las diversas fases de su implementación y evaluación. Además, plantea un requisito específico de consideración y puesta en marcha de espacios de participación y contraloría social, así como de rendición de cuentas, donde puedan encontrarse las diversas miradas de los actores involucrados en el cuidado y la protección social.

\section{La naciente institucionalidad de las políticas de cuidado en América Latina: oportunidades y desafíos de articulación con los sistemas de protección social}

Bajo un marco normativo compartido, pero también con especificidades a nivel de país, las políticas y programas de cuidado comienzan a expandirse progresivamente en la región. La situación de las políticas de cuidado en América Latina que se describe a continuación puede diferenciarse entre los países que cuentan con una oferta programática mínima o más amplia. Se considera que todos tienen al menos una política de cuidado, siendo más frecuentes las orientadas al cuidado infantil. En este tránsito, se encuentran experiencias pioneras de países que avanzan hacia la generación de una institucionalidad específica para su abordaje y la articulación de políticas integradas de cuidados en los sistemas de protección social, aunque de manera muy incipiente ${ }^{12}$.

12 El análisis que se presenta se construyó a partir de la revisión de la institucionalidad de las políticas de cuidado en 20 países de América Latina. Con ese fin, se levantó información primaria disponible hasta 2015 en cinco dimensiones de análisis: i) el marco jurídico-normativo de las políticas; ii) su oferta programática; iii) las entidades a cargo de su articulación; iv) los mecanismos de participación y construcción de acuerdos sociales y fiscales para su operación como parte de sus rasgos técnico-operativos y de planificación, v) y su financiamiento. Estas dimensiones se empalman con aquellas consideradas en este libro para el análisis de la institucionalidad social en América Latina (véase el capítulo I), así como en CEPAL (2016a). Pueden encontrarse mayores antecedentes en Rico y Robles (2016). 


\section{Un marco normativo común y diferenciado: ¿se instala el derecho al cuidado?}

La institucionalidad de las políticas de cuidado se desarrolla en un marco legal nacional e internacional que se encuentra en proceso de construcción. Por el lado de los instrumentos internacionales, que son indicativos de los compromisos asumidos por los países de la región en esta materia, cabe destacar la Estrategia de Montevideo para la Implementación de la Agenda Regional de Género en el Marco del Desarrollo Sostenible hacia 2030, recientemente aprobada por todos los gobiernos de la región en la XIII Conferencia Regional sobre la Mujer de América Latina y el Caribe (CEPAL, 2017b). En dicha Estrategia se establece que uno de los nudos estructurales imprescindibles de erosionar para avanzar hacia un desarrollo sostenible con igualdad es la división sexual del trabajo y la injusta organización social del cuidado. Pese a ello, la triple dimensión del derecho al cuidado, comprendido como el derecho a cuidar, a ser cuidado y a autocuidarse (Pautassi, 2007) aún no pasa de ser una realidad preliminar en los marcos normativos internacionales.

Si bien los Objetivos de Desarrollo Sostenible incluyen explícitamente en la meta 5.4 la necesidad de que los Estados reconozcan y valoren el trabajo de cuidado no remunerado y pongan en marcha servicios, infraestructuras y políticas de protección social, bajo una lógica de corresponsabilidad del cuidado (Naciones Unidas, 2015), en la práctica, solo dos instrumentos de derechos humanos aluden de manera integral a la conformación de sistemas integrados de cuidado como componente de los sistemas de protección social. Estos son: la Convención Interamericana sobre la Protección de los Derechos Humanos de las Personas Mayores, de naturaleza vinculante y aprobada en 2015 por la Asamblea General de la Organización de los Estados Americanos (OEA, 2015), y la Constitución Política de la Ciudad de México del 5 de febrero de 2017, que establece también, de manera explícita, el derecho al cuidado y la obligación de las autoridades respecto del establecimiento de un sistema de cuidados que considere a quienes los proveen y requieren, y que integre servicios y políticas públicas (artículo 9.B).

Las convenciones y tratados internacionales aluden principalmente a los servicios que se prestan a las personas en situación de dependencia. Sucede así con la Convención sobre los Derechos del Niño (CDN) (Naciones Unidas, 1989), la Convención sobre los Derechos de las Personas con Discapacidad (Naciones Unidas, 2006) y la Recomendación sobre los Pisos de Protección Social, 2012 (Núm. 202) de la Organización Internacional del Trabajo (OIT, 2012). En otros casos, se garantizan instrumentos específicos de atención a las cuidadoras, como las licencias de maternidad, sancionadas por el Convenio sobre la Protección de la Maternidad, 2000 (Núm. 183) (OIT, 2000) y el Convenio sobre los Trabajadores 
con Responsabilidades Familiares, 1981 (Núm. 156) (OIT, 1981), o los derechos de las cuidadoras remuneradas en el Convenio sobre las Trabajadoras y los Trabajadores Domésticos, 2011 (Núm. 189) (OIT, 2011a) y la Recomendación sobre el Trabajo Decente para las Trabajadoras y los Trabajadores Domésticos (OIT, 2011b).

Hay un antecedente importante en la Convención sobre la Eliminación de Todas las Formas de Discriminación contra la Mujer (Naciones Unidas, 1979), en que se destacó el concepto del cuidado como bien público y corresponsabilidad social y entre los sexos, incluido el incentivo a la provisión de servicios sociales de apoyo y la existencia de licencias de maternidad ${ }^{13}$. La preocupación por la responsabilidad en el cuidado y la valoración del trabajo no remunerado, compartida entre hombres y mujeres, y las familias, el Estado y el mercado, así como la valoración del trabajo no remunerado, figuran también como preocupación central en los acuerdos gubernamentales de las Conferencias Regionales sobre la Mujer de América Latina y el Caribe desde principios de este siglo (Lima, 2000; México, 2004; Quito, 2007; Brasilia, 2010; Santo Domingo, 2013, y Montevideo, 2016).

A nivel nacional, la legislación vigente refleja la tendencia observada en el ámbito internacional: existe una multiplicidad de regulaciones sobre prestaciones y servicios para grupos específicos, en especial, para la primera infancia y las cuidadoras remuneradas, y una escasa integralidad en la formulación de enfoques de cuidado, articulados explícitamente con la protección social. Esta situación dificulta que tal legislación sea conducente a reorganizaciones sustantivas en los arreglos de cuidado y su distribución entre hombres y mujeres.

Las licencias maternales han sido reguladas por todos los países de América Latina, aunque su duración es desigual. Entre 20 países considerados, solo 9 contemplan licencias iguales o superiores a las 14 semanas, duración mínima establecida por el Convenio núm. 183 de la $\mathrm{OIT}^{14}$. Por otra parte, 15 países ofrecen licencias de paternidad ${ }^{15}$.

13 El artículo 5 de la Convención sobre la Eliminación de Todas las Formas de Discriminación contra la Mujer indica que los Estados parte deben "garantizar que la educación familiar incluya una comprensión adecuada de la maternidad como función social y el reconocimiento de la responsabilidad común de hombres y mujeres en cuanto a la educación y al desarrollo de sus hijos, en la inteligencia de que el interés de los hijos constituirá la consideración primordial en todos los casos" (Naciones Unidas, 1979).

14 Cuando se terminó la revisión realizada para este estudio, estos países eran Bolivia (Estado Plurinacional de), el Brasil, Chile, Colombia, Costa Rica, Cuba, Panamá, Puerto Rico (solo para funcionarias públicas), el Uruguay y Venezuela (República Bolivariana de). Para obtener mayor información, véase Comisión Económica para América Latina y el Caribe (CEPAL), Observatorio de Igualdad de Género de América Latina y el Caribe, [en línea] http://oig.cepal.org/es.

15 Estos países son la Argentina, Bolivia (Estado Plurinacional de), el Brasil,Chile, Colombia, el Ecuador, El Salvador, Guatemala, México, el Paraguay, el Perú, Puerto Rico (para funcionarias públicas), la República Dominicana, el Uruguay y Venezuela (República Bolivariana de). Para obtener mayor información, véase Comisión Económica para América Latina y el Caribe (CEPAL), Observatorio de Igualdad de Género de América Latina y el Caribe [en línea] http:/ /oig.cepal.org/es. 
Sin embargo, su duración no se extiende a más de 15 días, tiempo muy reducido para incentivar la corresponsabilidad en el cuidado entre hombres y mujeres (Blofield y Martínez, 2015). Además, solo en tres países (Chile, Cuba y Uruguay) existe la licencia parental, es decir, una licencia orientada a brindar tiempo para el cuidado de niñas y niños pequeños una vez terminado el permiso maternal y que puede ser utilizada por padres $o$ madres en distintas modalidades, según defina cada legislación. Mientras tanto, las licencias legales para cuidar en ámbitos distintos a la maternidad, por ejemplo, ante la enfermedad de un hijo o hija o de un familiar, o en caso de adopción, son mucho menos frecuentes (Blofield y Martínez, 2015; Pautassi y Rico, 2011). Esto significa que no se tiene muy en cuenta el hecho de que el cuidado es un trabajo que va más allá del período del puerperio y las primeras semanas de vida de un hijo o hija, y que no solo los hijos biológicos tienen el derecho a ser cuidados.

Todos los países de América Latina cuentan con normativas que aluden a la operación de centros de cuidado para niños y niñas durante sus primeros años de vida. En ellas se regula su implementación o gestión para las hijas e hijos de las personas trabajadoras como una prestación laboral, se define el rol del Estado en su creación, o bien se establecen las llamadas "estrategias integrales de atención a la primera infancia". En estas últimas confluyen intervenciones en las dimensiones de salud, educación y estimulación temprana, nutrición y cuidado, en las que se reconoce la multiplicidad de ámbitos implicados en la protección integral de los niños y niñas (De Achaval y Aulicino, 2015). Varios de estos sistemas o políticas integrales están regulados por ley. Se identifica una entidad específica a cargo de su coordinación, ya sea a través de secretarías ejecutivas o comisiones presidenciales creadas de manera ad hoc para su funcionamiento, o bien de entidades sectoriales que regulan la política de infancia en los países, siendo más dispar su articulación explícita con los sistemas de protección social. Hay decretos o legislaciones de este tipo en Chile, donde la Ley núm. 20379 creó en 2009 el Subsistema de Protección Integral a la Infancia Chile Crece Contigo, como componente del Sistema Intersectorial de Protección Social; en Colombia, con la Ley núm. 1804 de 2016, por la que se creó la Política de Estado para el Desarrollo Integral de la Primera Infancia de Cero a Siempre; en Costa Rica y la Ley núm. 9220 de 2014, por la que se crea la Red Nacional de Cuido y Desarrollo Infantil (REDCUDI) como un sistema público universal de cuidado para el desarrollo integral de la primera infancia; en Cuba, con la ley pionera que creó en 1961 los círculos infantiles, y en México, con la Ley General de Prestación de Servicios para la Atención, Cuidado y Desarrollo Integral Infantil de 2011.

En el caso de otras poblaciones que requieren de cuidados, la normativa existente reproduce la tendencia descrita: tiende a centrarse 
en la regulación sobre la provisión de servicios, sobre todo de los que se brindan fuera del hogar en residencias de larga estadía ${ }^{16}$. La provisión de servicios en el hogar para quienes están en situación crónica de dependencia permanece casi invisibilizada en la normativa vigente. Las principales excepciones en esta materia son la Ley núm. 19.353, por la que se crea el Sistema Nacional Integrado de Cuidados en el Uruguay, y la Ley Orgánica del Sistema de Seguridad Social en la República Bolivariana de Venezuela que incluye, dentro del Régimen Prestacional de Servicios Sociales al Adulto Mayor y Otras Categorías de Personas, servicios de atención domiciliaria de apoyo para personas adultas mayores que los requieran.

En el caso de las personas cuidadoras, pese a los avances sustantivos a partir de la firma y ratificación del Convenio núm. 189 de la OIT, las trabajadoras domésticas enfrentan normativas específicas y más precarias que las del conjunto de trabajadores y trabajadoras de la región (CEPAL, 2013a) en cuanto a sus condiciones salariales, jornada, licencias y seguridad social. Por ejemplo, mientras que la mayoría de los países de América Latina ha regulado la afiliación obligatoria a la seguridad social por parte de las trabajadoras domésticas, cuatro países, El Salvador, Guatemala, Honduras y México, mantienen una política de afiliación voluntaria o de régimen especial con una cobertura inferior (CEPAL, 2016b). Además, la legislación sobre cuidadoras no remuneradas muestra un desarrollo limitado. Solo las constituciones de la República del Ecuador de 2008 y de la República Bolivariana de Venezuela de 1999 lo reconocen explícitamente y resguardan el derecho de estas cuidadoras a la seguridad social. Otras legislaciones definen mecanismos de valorización del trabajo no remunerado a través de cuentas satélite, o bien, versan específicamente sobre la extensión de los mecanismos previsionales para brindarles cobertura, como sucede en los casos de Bolivia (Estado Plurinacional de), Chile, el Perú y el Uruguay. En el caso del Ecuador, la Ley Orgánica para la Justicia Laboral y el Reconocimiento del Trabajo en el Hogar de 2015 sienta las bases para crear los mecanismos de reconocimiento del derecho a la seguridad social de quienes realicen este trabajo.

16 Estos son los casos, por ejemplo, del Decreto núm. 14 de Chile (2010) que define el reglamento de establecimientos de larga estadía para adultos mayores; el Decreto Ejecutivo núm. 3 de 1999 en Panamá, por el que se dictan normas para la apertura y funcionamiento de los centros de atención diurna, hogares o albergues para adultos mayores"; la Resolución núm. 322 de 2011 en el Paraguay que reglamenta la autorización, registro, acreditación e inspección de centros de atención de personas adultas mayores; el Decreto Supremo núm. 009-2010-PCM por el que se establecen requisitos mínimos para el funcionamiento de los centros de atención residencial para personas adultas mayores en el Perú y la Ley núm.17066 del Uruguay, por la que se establece el régimen de los establecimientos privados que alojan adultos mayores (1999). 
Debe destacarse que solo el Uruguay dispone hoy de un marco legal específicamente centrado en el cuidado con una perspectiva integral e integrada, es decir, que aluda a las poblaciones destinatarias y prestadoras de cuidados y a sus distintos instrumentos. La Ley núm. 19353, aprobada en 2015, creó en ese país el Sistema Nacional Integrado de Cuidados teniendo como principios la universalidad de los derechos a la atención, a los servicios y a las prestaciones para todas las personas en situación de dependencia, la inclusión de las perspectivas de género y generacional y la superación cultural de la división sexual del trabajo, y la articulación y coordinación de las políticas de cuidado. Con ello, consagra el derecho al cuidado en el país y sus garantías. Define como poblaciones titulares a las personas en situación de dependencia, incluidas las niñas y niños hasta los 12 años de edad y a las personas con discapacidad y mayores de 65 años que carecen de autonomía para realizar actividades básicas de la vida diaria, así como a las personas que cuidan de manera remunerada o no.

La creciente atención de los países a las políticas de cuidado se plasma en la ratificación reciente de una serie de marcos legales sobre los derechos de maternidad, licencias parentales, reconocimiento previsional del trabajo de cuidado, entre otros ámbitos. Una revisión de las legislaciones aprobadas en los países de América Latina y el Caribe entre los años 2015 y 2017, muestra que durante el período se han ratificado 12 legislaciones de este tipo en la región (véase el cuadro V.1).

En síntesis, el análisis de los marcos legales existentes sobre el cuidado pone de relieve una situación heterogénea respecto de legislaciones que dan origen a políticas integradas e integrales de cuidado, o bien, preservan la sectorialidad de su abordaje a través de servicios o licencias específicas. Cabe destacar que la existencia de una legislación que unifique en su ámbito de aplicación todas las posibles expresiones institucionales y prestaciones del cuidado no es de por sí una virtud y, de hecho, su creación no impide la coexistencia de múltiples marcos legales al respecto. El cambio de paradigma está asociado más bien a la consagración de un derecho universal que exige la creación y articulación de prestaciones para su garantía progresiva dentro de los países, con implicancias sustantivas en la institucionalidad de las políticas de cuidado, la definición del rol del Estado y la instalación de una lógica de corresponsabilidad social. Puede también impactar en los mandatos de las entidades a cargo de su gestión relacionados con la detección temprana de las brechas de cuidados en las distintas poblaciones y el avance, sinérgico y progresivo, hacia su resolución. 


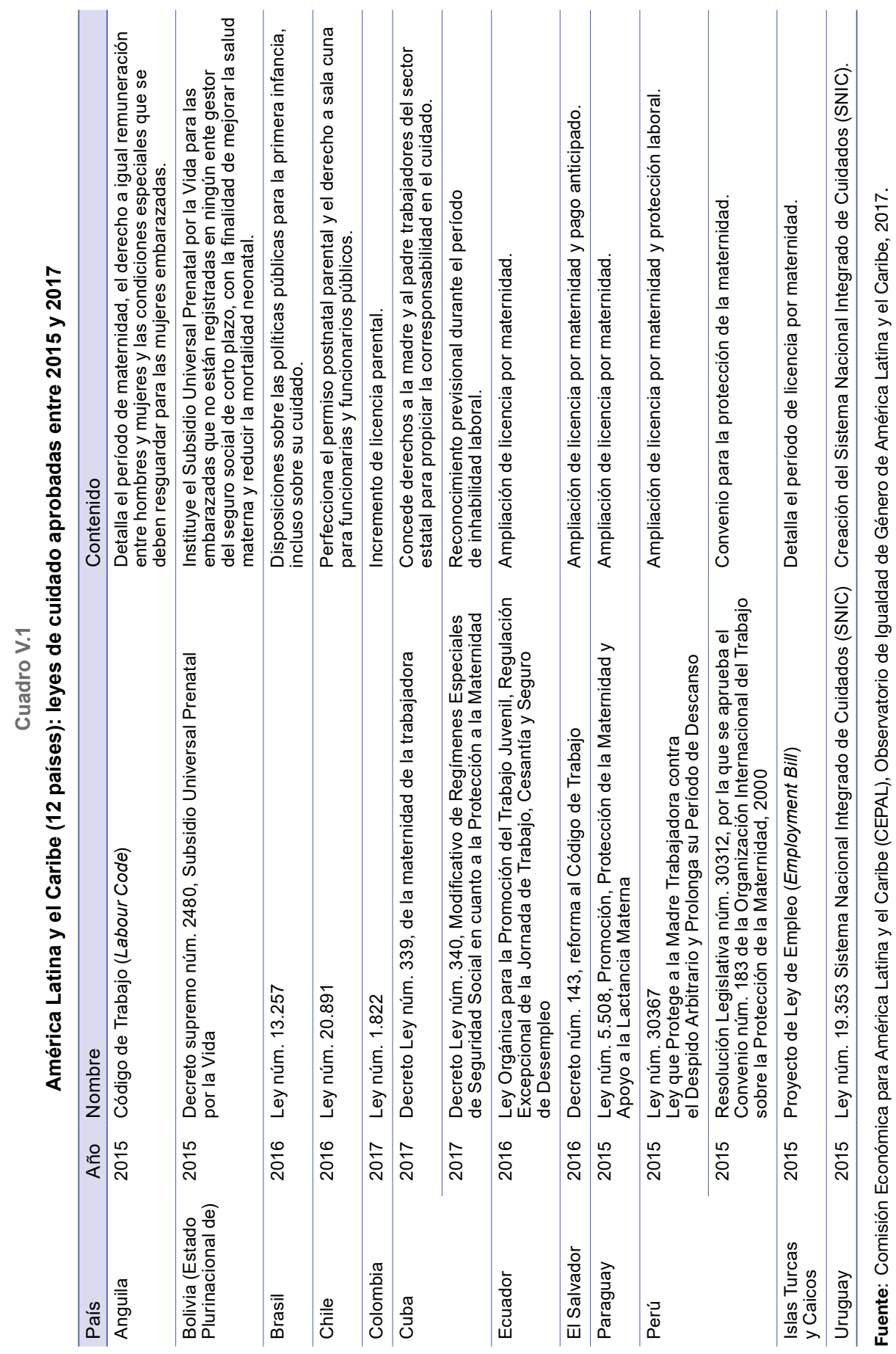




\section{Políticas y programas de cuidado: diversidad programática y baja carga fiscal}

Además de las licencias prescritas por legislación nacional, existe una serie de instrumentos, políticas y programas destinados a garantizar tiempos, servicios, recursos y regulaciones asociadas a los derechos a cuidar y a ser cuidado en América Latina. Nuevamente, su vínculo con los sistemas de protección social es escaso. Entre estos instrumentos se cuentan los servicios públicos dentro y fuera del hogar para el cuidado de las diversas poblaciones en situación de dependencia. También se incluye el conjunto de acciones dirigidas a las personas cuidadoras, tales como los programas de formación; los servicios de respiro o de acompañamiento psicológico; las transferencias monetarias para contratar servicios de cuidado o reconocer el trabajo de cuidado no remunerado ejercido por miembros de la familia, sobre todo las mujeres; y la regulación de los mercados laborales en cuanto a la forma en que se prestan los servicios de cuidado en el sector privado y público, así como los estándares aplicables a su funcionamiento y fiscalización. Cabe destacar que muchos de estos programas y políticas no traen asociada una normativa en su origen y desarrollo. Si bien la existencia de legislación contribuye a la estabilidad de las políticas, no la garantiza; al mismo tiempo, su ausencia no implica necesariamente su inestabilidad. Lo que parece ser primordial es la voluntad política respecto de su implementación, junto con la dotación de recursos y la definición de una institucionalidad clara para su gestión.

La mayoría de las políticas de cuidado existentes en América Latina están centradas en el cuidado infantil. Alrededor de 2015, diez países habían implementado políticas para la atención integral de la primera infancia, con un componente de cuidado ${ }^{17}$. En el caso de las personas adultas mayores, tres países han definido políticas que aluden a su cuidado integral: Brasil, Costa Rica y Cuba.

A nivel programático, todos los países tienen servicios públicos para el cuidado infantil y de personas adultas mayores en situación de dependencia. En relación con estas últimas, resaltan los centros diurnos y servicios institucionales de larga estadía. En Costa Rica, la Red de Atención Progresiva para el Cuido Integral de las Personas Adultas Mayores, gestionada por el Consejo Nacional de la Persona Adulta Mayor (CONAPAM), busca articular iniciativas lideradas desde la sociedad civil, las entidades públicas y las familias, con miras a formular e implementar políticas y estrategias de protección social que permitan resolver la necesidad de cuidado en la vejez con un enfoque de gestión territorial.

17 En una revisión realizada en 2015, fue posible identificar legislaciones plenamente vigentes que crean estos sistemas o políticas en Chile, Costa Rica, Colombia, Cuba, el Ecuador, El Salvador, México, Nicaragua, el Paraguay y la República Dominicana (CEPAL, 2016a; Rico y Robles, 2016). 
Entre las alternativas de atención contempladas se incluyen mecanismos como las familias solidarias o de acogida, asistentes domiciliarios, hogares comunitarios y centros institucionales externos ${ }^{18}$.

Una modalidad específica para la atención de personas en situación de dependencia y vulnerabilidad social, que no tienen condiciones familiares para ser atendidas en el hogar, es el de las familias de acogida. Este esquema, según el cual familias debidamente catastradas reciben una prestación para recibir, bajo estándares adecuados, a personas adultas mayores que requieren cuidados, se ha visto al menos en los casos del programa Família Acolhedora (Familia Acogedora) en el Brasil ${ }^{19}$ y de la Red de Atención Progresiva para el Cuido Integral de las Personas Adultas Mayores, componente de Familias Solidarias, en Costa Rica.

Otras modalidades que podrían contribuir de manera directa a atender y reconocer la situación de las personas cuidadoras no remuneradas son los servicios domiciliarios que se prestan a personas en situación de dependencia severa. En algunos casos, estos servicios se plantean como servicios de respiro para las cuidadoras e incluyen esquemas de capacitación para su formalización. Pueden contemplar subsidios para la contratación de asistentes personales, transferencias monetarias a las cuidadoras no remuneradas o acceso temporal a centros de cuidado fuera del hogar. Aunque la existencia de programas en esta línea es menos frecuente, algunos están en marcha, como el Programa Nacional de Cuidados Domiciliarios en la Argentina; el Programa de Atención Domiciliaria a Personas con Dependencia Severa en Chile; el Programa Integral de Atención al Adulto Mayor en Cuba y, en el Uruguay, el programa de cuidados domiciliarios para personas en situación de dependencia severa dentro del Sistema Nacional Integrado de Cuidados (SNIC). También existen programas de capacitación y formación de personas cuidadoras en la Argentina, el Brasil, Chile, Cuba, el Ecuador, México, el Paraguay y el Uruguay.

Hay, además, iniciativas pioneras de implementación de programas de transferencias monetarias para reconocer el trabajo de cuidado no remunerado o permitir la contratación de cuidadores remunerados o servicios de cuidado. El bono Joaquín Gallegos Lara en el Ecuador entrega 240 dólares por mes a la persona cuidadora y, en Chile, el bono y la prestación del Programa de Atención Domiciliaria a Personas con Dependencia Severa entregan 35 dólares por mes. En la perspectiva de la articulación entre las políticas de cuidado y las de

18 Véase Consejo Nacional de la Persona Adulta Mayor (CONAPAM), "Red de cuido" [en línea] http://www.conapam.go.cr/red-cuido.

19 Véase Ministerio de Seguridad Social, "Normas de funcionamento de serviços de atenção ao idoso no Brasil", 2014 [en línea] http://sbgg.org.br/wp-content/uploads/2014/10/servicos-de-atencao-ao-idoso.pdf. 
protección social, el programa de transferencias condicionadas Tekoporã en el Paraguay, implementado por la Secretaría de Acción Social (SAS) de la Presidencia de la República del Paraguay en coordinación con la Secretaría Nacional por los Derechos de las Personas con Discapacidad (SENADIS), incluye una transferencia monetaria otorgada a familias en que haya una persona con discapacidad severa, con el fin de ayudar en su cuidado ${ }^{20}$. También resulta interesante el caso del programa Asignación por Embarazo para Protección Social en la Argentina, que entrega una transferencia monetaria a las embarazadas que se encuentren fuera del mercado laboral o trabajen en el sector informal desde la semana 12 de gestación hasta el nacimiento del bebé, bajo la lógica de una licencia por maternidad para quienes no tienen acceso a esta prestación de la seguridad social ${ }^{21}$.

En menor número de casos, la transferencia monetaria se entrega directamente a la persona en situación de dependencia como un subsidio indirecto o directo. En la Argentina, las prestaciones del Programa de Asistencia Médica Integral (PAMI), gestionadas por el Instituto Nacional de Servicios Sociales para Jubilados y Pensionados, incluyen un subsidio para el pago de un cuidador domiciliario, en función del nivel de autonomía funcional de la persona destinataria. En Colombia, existe un subsidio económico indirecto para las personas adultas mayores con dependencia, que se entrega a través de los Centros de Bienestar del Adulto Mayor, esquema similar a la Red de Atención Progresiva para el Cuido Integral de las Personas Adultas Mayores ${ }^{22}$.

Además de los servicios, transferencias y licencias, los estándares y regulaciones sobre el cuidado son el cuarto componente de las políticas de cuidado. El desarrollo de este ámbito es heterogéneo en los países de América Latina. En el caso de adultos mayores en situación de dependencia, existen regulaciones sobre habilitación, evaluación y fiscalización de los centros de larga estadía en la Argentina (aunque solo a nivel descentralizado), y en el Brasil, Chile, Costa Rica, el Paraguay y el Perú. Solo dos países, Chile y el Ecuador, han regulado y normado la operación y el funcionamiento de los centros diurnos (Gascón y Redondo, 2014). En el caso de la primera infancia, los estándares varían de un país a otro. Hay indicadores de gestión y calidad en el Brasil, Colombia,

20 Véase Secretaría de Acción Social (SAS), "Tekoporã" [en línea] http://www.sas.gov.py/ pagina/54-tekopor.html.

21 Véase Administración Nacional de la Seguridad Social (ANSES), “Asignación por Embarazo para Protección Social" [en línea] http://www.anses.gob.ar/prestacion/asignacion-porembarazo-para-proteccion-social-93. Esta prestación se une a la Asignación Universal por Hijo, que, por medio del Decreto núm. 1602/2009, ha permitido extender el acceso a prestaciones familiares a trabajadoras y trabajadores informales por la vía del monotributo.

22 Véase Consorcio Colombia Mayor, “Programa Colombia Mayor" [en línea] http://colombiamayor. co/programa_colombia_mayor.html. 
el Ecuador, El Salvador y el Perú. Las entidades responsables de su cumplimiento son diversas, y entre ellas cabe mencionar los ministerios de salud, de educación y de desarrollo social (Marco, 2014).

En suma, la institucionalidad de las políticas de cuidado en los países de la región muestra intervenciones heterogéneas, múltiples y con un bajo nivel de articulación, lo que deriva en una multiplicidad de entidades responsables de su gestión, mayormente centradas en poblaciones específicas: los institutos o comisiones de la niñez, y para las personas adultas mayores o con discapacidad. Con menos frecuencia, intervienen los mecanismos de adelanto de la mujer, en su mayoría, insertos en la institucionalidad social de los países, ya sea en los ministerios de desarrollo social o en la Presidencia. En otros casos, las políticas se implementan desde los ministerios sectoriales de educación o salud.

Por último, conviene resaltar que el nivel de inversión en políticas de cuidado es todavía bastante bajo. Tras revisar las partidas presupuestas asignadas a programas específicos o políticas integradas de cuidado, se comprueba que no superan el 0,4\% del PIB y, en la mayoría de los casos, son inferiores al 0,03\%, con la excepción de la prestación asociada al Instituto Nacional de Servicios Sociales para Jubilados y Pensionados, cuya inversión representa poco menos del 1\% del PIB $^{23}$. Este presupuesto es extraordinariamente bajo si se le contrasta con el gasto social total como porcentaje del PIB que, de 2012 a 2013, oscilaba entre el $8 \%$ en los casos del Ecuador y Guatemala y el $23 \%$ en el de Costa $\mathrm{Rica}^{24}$. En cambio, la inversión pública en 33 países de la Organización de Cooperación y Desarrollo Económicos (OCDE) en 2011 solo en servicios de cuidado infantil llega en promedio al 1\% del PIB y supera el $2 \%$ en Dinamarca, Islandia y Suecia ${ }^{25}$.

23 Fue posible encontrar información sobre el presupuesto en torno a 2014 en los siguientes países: Argentina (Programa Nacional de Desarrollo Infantil “Primeros Años" y presupuesto del Instituto Nacional de Servicios Sociales para Jubilados y Pensionados, Programa de Asistencia Médica Integral), Chile (Chile Crece Contigo, Programa 4 a 7, Fondo de Subsidio para Establecimientos de Larga Estadía para Adultos Mayores, Programa de Cuidados en Domicilio, Programas Centros Diurnos del Adulto Mayor), Colombia (De Cero a Siempre), Costa Rica (Red de Atención Progresiva para el Cuido Integral de las Personas Adultas Mayores y Red Nacional de Cuido y Desarrollo Infantil), Perú (Programa Nacional Cuna Más), República Dominicana (Plan Nacional de Protección y Atención Integral a la Primera Infancia "Quisqueya Empieza Contigo") y el Sistema Nacional Integrado de Cuidados en el Uruguay. Las partidas informadas, en su mayoría, no cubren únicamente servicios de cuidado. Por ejemplo, los programas de atención integral para la infancia incluyen componentes de nutrición y salud, además de cuidado.

24 Sobre la base de Comisión Económica para América Latina y el Caribe (CEPAL), "Gasto público como porcentaje del Producto Interno Bruto (PIB) total y por sectores" [en línea] http://dds. cepal.org/gasto/indicadores/ficha/?indicador_id=28. Los países con información sobre el gasto público social total como porcentaje del PIB en 2012 o 2013 son Bolivia (Estado Plurinacional de), Chile, Colombia, Costa Rica, el Ecuador, El Salvador, Guatemala, México, Panamá, el Perú y Venezuela (República Bolivariana de).

25 Organización de Cooperación y Desarrollo Económicos (OCDE), "Families and Children", septiembre de 2014 [en línea] http:/ / www.oecd.org/els/family/. 
La información disponible muestra la escasa centralidad de las políticas de cuidado en función de su densidad presupuestaria. En particular, indica cómo los costos asociados al cuidado son delegados a las familias, y en particular, al trabajo no remunerado de las mujeres. De este modo se subvalora la necesaria inversión social requerida para asegurar empleos de calidad en el sector y garantizar el derecho a cuidar y a ser cuidado. Al mismo tiempo, se indican los desafíos institucionales que surgirán al pasar de una planificación de la inversión centrada en programas y servicios de cuidado individuales a un sistema o política integrada, en el contexto más amplio de los sistemas de protección social.

\section{D. ¿De programas a sistemas integrados de cuidado? Crear y fortalecer la institucionalidad}

En algunos países de América Latina se ha emprendido el esfuerzo de diseñar políticas o sistemas integrados e integrales de cuidado. Estos buscan explícitamente atender la situación de fragmentación de la oferta de servicios en ese ámbito y abordar las desigualdades de género producidas en torno a la economía del cuidado. La situación de estos países es muy dispar en cuanto a su grado de avance, disponibilidad de recursos, prioridad política asignada y la entidad coordinadora a cargo de su funcionamiento. En todos los casos, el debate y la construcción de las políticas reflejan que el cuidado es una problemática medular del desarrollo social y que requiere un mayor nivel de articulación del que se le ha asignado hasta ahora. Además, en todos ellos se crea una institucionalidad temporal o definitiva específica en relación con su diseño y gestión, basada en distintos formatos.

En esta línea, ya se ha adelantado el caso del Uruguay y el Sistema Nacional Integrado de Cuidados, que sin duda es el más avanzado a nivel regional. No obstante, también se constatan esfuerzos similares en Chile, Colombia, Costa Rica, el Ecuador, El Salvador y a nivel del gobierno de la Ciudad de $\mathrm{México}^{26}$. Es posible distinguir dos vías de desarrollo de estas políticas. Por una parte, algunos países las diseñan e implementan como componentes de los sistemas de protección social, de modo que constituyen subsistemas o políticas incluidos en su oferta. Por otra, hay países donde se

26 La información que se detalla a continuación recoge fuentes secundarias documentales, así como aquella sistematizada en el proceso de acompañamiento en la discusión e intercambio de experiencias sobre políticas de cuidado brindado por la División de Asuntos de Género y la División de Desarrollo Social de la CEPAL a cinco países de la región (Chile, Costa Rica, El Salvador, Paraguay y Uruguay), en el marco del Programa de Cooperación CEPAL-BMZ/GIZ 2014-2016, "Cambio estructural para un desarrollo sostenible e inclusivo en América Latina y el Caribe", y a seis ciudades de la región en el marco del Proyecto de la Cuenta de las Naciones Unidas para el Desarrollo “Desarrollo urbano, autonomía económica de las mujeres y políticas de cuidado": Bogotá, Cuenca, San Salvador, Ciudad de México, Montevideo y Santiago. 
inicia su discusión bajo el fuerte impulso de los mecanismos de adelanto de la mujer, sin explicitar necesariamente su conexión con los sistemas de protección social existentes.

En el primer grupo de países, en el que se destacan las experiencias de Chile, Costa Rica, El Salvador y el Uruguay, se aprecia un trabajo de coordinación de la entidad a cargo de la política social, las entidades encargadas de la atención y protección de los derechos de las distintas poblaciones que requieren cuidados (la infancia, las personas con discapacidad y adultos mayores) y los mecanismos de adelanto de la mujer. En estos países, se avanza en la implementación de las políticas, subsistemas o sistemas como componentes explícitos de los sistemas de protección social. En la mayoría de los casos donde se ha definido el rol de autoridad social, lo desempeña la entidad a cargo de la política social, unas veces mediante la creación de secretarías técnicas específicas para su gestión, y otras, mediante el establecimiento de una entidad colegiada para la coordinación de la política de cuidado.

En el Uruguay, el Sistema Nacional Integrado de Cuidados (SNIC) es coordinado por la Secretaría Nacional de Cuidados del Ministerio de Desarrollo Social y forma parte del sistema de protección social en el país. El Sistema opera a través de una Junta Nacional de Cuidados, que tiene una función de conducción estratégica, y es presidida por el Ministro de Desarrollo Social. En ella participan las y los Ministros de Economía y Finanzas, Educación y Cultura, Salud Pública y Trabajo y Seguridad Social, así como el Director de la Oficina de Planeamiento y Presupuesto, el Presidente del Consejo Directivo Central de la Administración Nacional de Educación Pública, el Presidente del Directorio del Banco de Previsión Social, el Presidente del Directorio del Instituto del Niño y Adolescente del Uruguay, y un representante del Congreso de Intendentes y del Instituto Nacional de las Mujeres. El Sistema cuenta también con un Comité Consultivo de Cuidados, integrado por representantes de las organizaciones de la sociedad civil, las instituciones académicas, los trabajadores y las trabajadoras y el sector privado.

El Sistema comprende prestaciones de cuidado dentro y fuera del hogar para las distintas poblaciones. En el caso de la primera infancia, incluye el conjunto de licencias de maternidad, paternidad y parentales; casas de cuidado comunitarias y la extensión de la cobertura de los diversos centros de cuidado infantil, así como becas de inclusión socioeducativa para la asistencia a centros privados de cuidado infantil, que se ofrecen a las familias en situación de vulnerabilidad cuando no exista oferta pública suficiente. Las personas en situación de dependencia pueden acceder a cuidados domiciliarios mediante un subsidio para la contratación de asistentes personales, teleasistencia, centros diurnos y residencias de 
larga estadía. También se contempla un subsidio cuando estos servicios se prestan en centros privados. Además, se ha implementado un programa de formación para las personas cuidadoras.

En Chile, está en proceso de construcción e implementación el Subsistema Nacional de Apoyos y Cuidados (SNAC), bajo la coordinación del Ministerio de Desarrollo Social. El Subsistema se ha planteado desde un inicio como parte del Sistema Intersectorial de Protección Social y busca abordar la situación de personas en situación de dependencia y apoyar a sus cuidadoras, a fin de contribuir al bienestar de sus hogares. Comprende acciones públicas y privadas con coordinación intersectorial y articulación con dos de los componentes del Sistema de Protección Social: el subsistema Seguridades y Oportunidades y al subsistema Chile Crece Contigo, que aborda el cuidado de niños y niñas en el país, con especial atención a quienes pertenecen al $60 \%$ de hogares más vulnerables. El sistema está en fase de diseño y su meta es coordinar acciones de acceso, derivación, seguimiento y acompañamiento a nivel local por conducto de la Red Local de Apoyos y Cuidados, un servicio de respiro domiciliario llamado Chile Cuida y otros servicios de cuidados domiciliarios e institucionalizados, la adaptación funcional de viviendas y un programa de educación pública (Rodríguez, 2016).

Costa Rica tiene redes de cuidado bien establecidas para dos poblaciones: niñas y niños durante su primera infancia y personas adultas mayores. Cada red se caracteriza por el alto grado de articulación interna entre los instrumentos y actores que participan en su gestión. Estas redes no conforman entre sí un sistema unificado de cuidados, sino que operan de manera autónoma.

La Red Nacional de Cuido y Desarrollo Infantil (REDCUDI) establece un sistema de cuidado y desarrollo infantil de acceso público, universal y financiamiento solidario, que articula las modalidades de prestación pública y privada de servicios. Es coordinada por el Instituto Mixto de Ayuda Social a través de la Secretaría Técnica de la REDCUDI, aunque opera bajo una lógica de gestión intersectorial con participación del Ministerio de Educación Pública, el Patronato Nacional de la Infancia, el Ministerio de Trabajo y Seguridad Social, el Ministerio de Salud, el Instituto Nacional de las Mujeres, la Caja Costarricense de Seguro Social, el Instituto Nacional de Aprendizaje, la Dirección Nacional de Centros de Educación y Nutrición y de Centros Infantiles de Atención Integral (CEN-Cinai), la Dirección Nacional de Desarrollo de la Comunidad y las municipalidades. Además, la Red de Atención Progresiva para el Cuidado Integral de las Personas Adultas Mayores es coordinada por el Consejo Nacional de la Persona Adulta Mayor, que pertenece a la Presidencia de la República. Busca articular iniciativas de la sociedad civil, las entidades 
públicas y las familias para resolver las necesidades de cuidado en la vejez, con un enfoque de gestión territorial. Incluye alternativas de atención como las familias solidarias o de acogida, asistentes domiciliarios, hogares comunitarios y centros institucionales externos.

Además, El Salvador ha iniciado la discusión de una política nacional de cuidados como componente del Sistema de Protección Social Universal (Meléndez, 2015). La naciente institucionalidad que discute su diseño, la Comisión de Seguimiento para la Construcción de una Política de Cuidados en El Salvador, está integrada por varias instituciones ${ }^{27}$. La Comisión considera de manera central la participación activa del mecanismo de adelanto para la mujer, el Instituto Salvadoreño para el Desarrollo de la Mujer (ISDEMU), en conjunto con la entidad a cargo de la implementación del sistema de protección social en el país, la Secretaría Técnica y de Planificación de la Presidencia (Salvador, 2015). Este proceso tiene por objeto definir acciones prioritarias, junto con la articulación de iniciativas y programas existentes, con un énfasis explícito en la igualdad de género en su diseño.

En un segundo conjunto, que incluye Colombia, el Ecuador y el gobierno de la Ciudad de México, la discusión y promoción de una política integrada de cuidados ha surgido con fuerte impulso desde los mecanismos de adelanto para la mujer y otras entidades técnicas, y se asienta en la implementación o la existencia previa de mecanismos de coordinación interinstitucional que facilitan su debate.

En el Ecuador, la mesa de coordinación interinstitucional técnicapolítica compuesta por la Asamblea Nacional, el Consejo Nacional para la Igualdad de Género, el Ministerio Coordinador de Desarrollo Social (MCDS), el Ministerio de Inclusión Económica y Social (MIES) y la Secretaría Nacional de Planificación y Desarrollo (SENPLADES), se encuentra discutiendo la implementación de un Sistema Nacional de Cuidados desde un enfoque de género y derechos (Consejo Nacional para la Igualdad de Género, s/f).

En Colombia, la Ley núm. 1413 sobre la economía del cuidado de 2010, además de institucionalizar la Encuesta de Uso del Tiempo y la Cuenta Satélite de economía del cuidado, creó una Comisión Multisectorial de economía del cuidado. Participan en ella la Consejería Presidencial

27 La Comisión de Seguimiento para la Construcción de una Política Nacional de Cuidados está conformada por el Consejo Nacional de Atención Integral para las Personas con Discapacidad (CONAIPD), el Instituto Salvadoreño para el Desarrollo de la Mujer (ISDEMU), el Instituto Salvadoreño para la Desarrollo Integral de la Niñez y la Adolescencia (ISNA), el Ministerio de Educación, la Unidad para la Equidad entre los Géneros del Ministerio de Trabajo y Previsión Social, el Ministerio de Salud, la Dirección de Adultos Mayores de la Secretaría de Inclusión Social (SIS), la Dirección de Programas Estratégicos, y la Unidad de Derechos Humanos y Género de la Secretaría Técnica de Planificación de la Presidencia (STPP). 
para la Equidad de la Mujer, el Ministerio de Salud y Protección Social, el Ministerio del Trabajo, el Departamento Nacional de Planeación (DNP), el Departamento para la Prosperidad Social y el Departamento Administrativo Nacional de Estadísticas (DANE), siendo este último el encargado de su coordinación. Desde 2016, la Comisión participa junto al DNP en la creación de las bases del Sistema Nacional de Cuidados de Colombia, según establece el Plan Nacional de Desarrollo 2014-2018 "Todos por un nuevo país". Este Sistema adopta un enfoque de corresponsabilidad social en el cuidado y busca articular la oferta de servicios, regulación, formación y gestión de la información vinculada a las políticas de cuidado en el país (DANE, 2017; Perfetti, 2016).

A nivel subnacional, la Comisión para el Impulso de la Economía del Cuidado y una Política de Igualdad Laboral al Interior del Gobierno de la Ciudad de México, conformada en marzo de 2014 por el Instituto de las Mujeres de la Ciudad de México y la Secretaría de Trabajo y Fomento al Empleo del gobierno de la Ciudad de México, ha buscado promover estrategias y mecanismos de evaluación y seguimiento de la política laboral y de la economía del cuidado dentro de la administración pública del gobierno de la Ciudad de México, desde una perspectiva de no discriminación e igualdad sustantiva entre mujeres y hombres. Está integrada por varias instituciones del gobierno de la Ciudad de México y evalúa posibles medidas, como un programa de salario ciudadano para cuidadoras y cooperativas de mujeres cuidadoras comunitarias (Gobierno de la Ciudad de México, 2014).

En definitiva, las experiencias reseñadas dan cuenta de una institucionalidad social aún en construcción. En la mayoría de los casos, su autoridad está en proceso de definición, aunque ha habido valiosos avances con respecto a la instauración de mecanismos colegiados capaces de hacer frente a los desafíos de la intersectorialidad requerida para coordinar acciones relacionadas con proveedores y receptores del cuidado, las que remiten a poblaciones con necesidades muy diversas. En cada uno de los procesos aludidos, cabe destacar el vínculo, en algunos casos de mayor densidad que en otros, que existe entre la entidad a cargo de las políticas sociales o de protección social y el respectivo mecanismo de adelanto para la mujer. Además, se aprecia el rol que cumple la voluntad política, en especial, del respaldo presidencial en la institucionalización de estas medidas, así como la planificación de etapas concretas en su diseño e implementación ${ }^{28}$. Donde se han implementado, es promisorio el papel de

28 En el Uruguay, la creación del SNIC fue definida como una de las prioridades del Gobierno del Presidente Tabaré Vázquez (Montevideo Portal, 2017). La creación del SNAC en Chile formó parte del programa presidencial de la Presidenta Michelle Bachelet (Rodríguez, 2016). En Costa Rica, la creación de la REDCUDI contó con el respaldo de la entonces Presidenta Laura Chinchilla (Guzmán, 2014). 
las secretarías técnicas o consejos a cargo de las políticas de cuidado que apoyan la identificación y cierre de las brechas de cobertura de los servicios de cuidado existentes y están encargadas de velar por la coherencia del sistema con un enfoque de igualdad de género, además de mantener las comisiones interinstitucionales que les dan origen ${ }^{29}$.

\section{E. ¿Se avanza en la transversalización?}

El panorama reseñado a nivel regional muestra la preponderancia de un enfoque familista en la provisión del cuidado en América Latina, aunque con señales incipientes de cambio. Se mantiene un rol subsidiario del Estado en la gestión de políticas de cuidado focalizadas para la población en situación de mayor vulnerabilidad. Salvo en los casos indicados en la sección anterior, las políticas y programas existentes no alcanzan aún a constituir un pilar de la protección social en la gran mayoría de los países de América Latina. Además, el efecto mancomunado de estas prestaciones no asegura la transversalización de un enfoque de igualdad de género para hacer frente a la actual división sexual del trabajo de cuidado (Blofield y Martínez, 2015).

Una excepción destacable entre las políticas actualmente en operación es la del SNIC en el Uruguay, que de manera decidida transversaliza una perspectiva de género en su diseño. Este Sistema alinea los diversos instrumentos que implementa el sistema en consonancia con el objetivo de propiciar la reorganización social del cuidado e integra su operación al sistema de protección social del país. Para ello, entre otros aspectos, se ha buscado fortalecer el acceso a servicios como prestación principal del sistema. No se ha considerado la entrega de transferencias monetarias directas a las personas cuidadoras, a fin de evitar que esta prestación termine manteniendo y fomentando la mayor feminización del trabajo de cuidado no remunerado.

En otros casos, la perspectiva de la igualdad de género tiene mayor presencia en programas específicos que buscan explícitamente intervenir en las barreras que se interponen a la inserción laboral que afecta a las cuidadoras no remuneradas. Por ejemplo, el Programa 4 a 7 en Chile, gestionado por el Ministerio de la Mujer y la Equidad de Género, ofrece servicios de cuidado infantil en un horario más amplio del que se ofrece habitualmente para facilitar la capacitación e inserción laboral de mujeres con responsabilidades de cuidado infantil ${ }^{30}$.

29 Así lo establecen, por ejemplo, la Ley núm. 9220, por la que se crea la Red Nacional de Cuido y Desarrollo Infantil en Costa Rica, y la Ley núm. 19353, por la que se crea el Sistema Nacional Integrado de Cuidados en el Uruguay.

30 Véase Servicio Nacional de la Mujer (SERNAM), “Programa 4 a 7" [en línea] https://portal. sernam.cl/?m=programa\&i $=5$. 
En la experiencia regional de las políticas de cuidado, se identifica un dispar involucramiento de los mecanismos de adelanto para la mujer, pese a que la problemática del cuidado esté asentada transversalmente en los planes de igualdad de género vigentes en los países de la región. Su rol se centra en incidir más en la transversalización de un enfoque de género en el diseño y operación de los programas, así como en los nacientes sistemas integrados de cuidado, y menos en la gestión directa de iniciativas. No obstante, en las políticas integradas en formación se aprecia un mayor protagonismo de estas entidades. La Comisión Técnica Interinstitucional de la REDCUDI incluye a una representante de la presidencia ejecutiva del Instituto Nacional de las Mujeres (INAMU). En el SNIC del Uruguay, el Instituto Nacional de las Mujeres participa de las reuniones de la Junta Nacional de Cuidados. En otras experiencias en construcción, como la de una política nacional de cuidados en El Salvador, la Comisión de Seguimiento para la Construcción de una Política de Cuidados en El Salvador considera la participación activa del Instituto Salvadoreño para el Desarrollo de la Mujer (ISDEMU) en las definiciones eje de la política (Salvador, 2015). Además, en el caso de Chile, el Ministerio de la Mujer y la Equidad de Género ha asesorado al Ministerio de Desarrollo Social en la transversalización de un enfoque de género en el diseño del SNAC (Rodríguez, 2016).

Sería conveniente que hubiera una mayor articulación entre las prestaciones y servicios que se ofrecen en los países, así como entre sus objetivos. Ello permitiría transversalizar una perspectiva de igualdad de género desde el diseño de las políticas y programas articulados, y garantizar así los derechos de las personas que requieren y proveen cuidados, la igualdad entre hombres y mujeres, la corresponsabilidad social del cuidado, y su redistribución entre las familias, el Estado, el mercado y la comunidad. Esto implica también plantearse el análisis y la intervención desde el vínculo entre las políticas y la práctica cotidiana de las personas, así como sobre el cuidado como un derecho de ciudadanía y un pilar de la protección social. Las políticas públicas, como conjunto de medidas o instrumentos de actuación, enfrentan en la actualidad el gran desafío de articular una institucionalidad que coordine, regule y garantice el derecho al cuidado, a través de servicios e infraestructura y una serie de programas sectoriales que afectan esta dimensión del bienestar. Las políticas sociales, en este contexto, tienen la oportunidad de incentivar modificaciones de la actual organización social y económica del cuidado hacia relaciones sociales más igualitarias y un andamiaje económico que reconozca el aporte del trabajo de cuidado al desarrollo y al crecimiento de los países, así como la estrecha interrelación entre producción y reproducción. 


\section{F. Reflexiones finales}

El cuidado debe comprenderse como pilar transversal de la protección social. El déficit para quienes lo requieren y las condiciones en que se provee son actualmente fuente y factores reproductores de pobreza y desigualdad, a la vez que un riesgo para la población y el bienestar. Este planteamiento, consecuente con la idea del cuidado como un bien público, obliga a reflexionar sobre la institucionalidad social requerida para abordar este desafío. Las políticas de cuidado y el sistema de protección social en su conjunto deben contemplar las necesidades de las personas cuidadas y cuidadoras en su complejidad, y transversalizar un enfoque de género y de derechos humanos en cuya formulación se tengan en cuenta las especificidades del ciclo de vida.

Una revisión de la institucionalidad social actual de las políticas de cuidado en América Latina sobre la base de sus dimensiones legal, programática, de financiamiento, fiscal y organizacional muestra un panorama marcado por el creciente interés de la política pública en esta función social. No obstante, ese interés coexiste con la fragmentación de las intervenciones existentes. En varios países, las políticas de cuidado solo cubren servicios específicos para poblaciones particulares, como la primera infancia, los adultos mayores o las personas con discapacidad. En otros casos, como el de Costa Rica, se aprecia la conformación de redes de atención a estas poblaciones, que no llegan a conjugar un sistema integral de cuidado. La situación de quienes proveen cuidados está considerada de forma desigual en estos instrumentos. Hay un amplio abanico de posibilidades, desde los que no la contemplan en lo absoluto, hasta el caso de sistemas como el uruguayo, que transversalizan una perspectiva de igualdad de género, tienen en cuenta a las mujeres cuidadoras remuneradas o no y se plantean como un objetivo la redistribución del cuidado desde la génesis de su diseño y de sus prestaciones.

En el caso de aquellos países donde el debate ha avanzado hacia la conformación de políticas, subsistemas o sistemas integrados de cuidado, salvo en el Uruguay, no está aún zanjado su abordaje como componente del sistema de protección social ni se han coordinado los rediseños programáticos que aseguren la coherencia y sinergia entre sus instrumentos. Tampoco están zanjados los debates sobre la legislación a impulsar, las entidades coordinadoras a consagrar, ni los mecanismos de gestión, participación social y rendición de cuentas a instalar, como parte de los desafíos institucionales en ciernes. Ello se explica por el punto germinal en que se encuentran estas experiencias y más bien marcan la pauta de los aspectos pendientes de afrontar y resolver. El avance evidenciado en la creación de entidades colegiadas para el diseño o rectoría de estas políticas es sin duda significativo, en cuanto las sitúa desde el enfoque de la intersectorialidad y la integralidad requerida para su funcionamiento. 
Las políticas de cuidado enfrentan diversos desafíos. Entre estos destacan: la adopción de decisiones sobre la ampliación de la cobertura de los servicios existentes frente a la creación de nuevos instrumentos, en un marco de creciente estrechez fiscal, y la ausencia de búsqueda de nuevas fuentes de financiamiento. Estas podrían encontrarse si se mejora la tributación y se controla la evasión; se promueve la planificación eficiente para evitar duplicaciones innecesarias de esfuerzos, allí donde la oferta programática o de proveedores de servicios públicos y privados sea mayor, y se crean instrumentos de gestión propios que se articulen de forma armónica con los ya existentes en los sistemas de protección social.

Desde la perspectiva de la institucionalidad social a sustentar, podrían tenerse en mente las siguientes consideraciones para impulsar el debate en los países que no contemplan aún la definición de políticas integradas e integrales de cuidado y en los que sí se han dado pasos a ese respecto. En primer lugar, en atención a su naturaleza multidimensional y sus necesidades para las distintas poblaciones, es un requisito ineludible la articulación intersectorial e interinstitucional. Diversas políticas y sectores intervienen en su abordaje, incluidas las de empleo, salud, educación, igualdad de género, además de las de protección social. En segundo lugar, el desafío de la intersectorialidad exige la definición de una entidad rectora y coordinadora eficaz, dotada de las atribuciones y el financiamiento requerido, no solo para poner en marcha programas nuevos o la ampliación de coberturas que puedan requerirse, sino para propiciar el diálogo y la coordinación entre los sectores. En tercer lugar, llevado al ámbito de la protección social, el cuidado como uno de sus pilares implica una definición por parte de estos sistemas respecto de si la coordinación de una política integrada o integral deberá gestionarse desde una entidad ya existente (por ejemplo, las secretarías técnicas de protección social o los ministerios sociales), o si conviene que estas funciones sean asumidas por una entidad externa o creada específicamente para su gestión (como la Secretaría Nacional de Cuidados en el Uruguay o la Secretaría Técnica de la REDCUDI en Costa Rica). En cualquier caso, la institucionalidad designada debe velar por la sinergia activa entre los instrumentos y enfoques rectores específicos del cuidado y de los otros componentes de los sistemas de protección social.

La integralidad ha de entenderse desde la necesaria articulación entre políticas sectoriales y de cuidado como componentes de la protección social, de actores que intervienen en cada uno de estos ámbitos a nivel nacional y local, y de instrumentos, que transversalicen un enfoque de igualdad de género y de derechos humanos desde su origen. Ello podría aportar una orientación fundamental para avanzar hacia la consagración del derecho al cuidado como un imperativo de justicia en la región. 


\section{Bibliografía}

Batthyány, K. (2015), “Las políticas y el cuidado en América Latina: una mirada a las experiencias regionales", serie Asuntos de Género, N 124 (LC/L.3958), Santiago, Comisión Económica para América Latina y el Caribe (CEPAL), febrero.

Batthyány, K., N. Genta y V. Perrotta (2015), “Avanzando hacia la corresponsabilidad en los cuidados: análisis de las licencias parentales en el Uruguay", serie Asuntos de Género, N ${ }^{\circ}$ 128, (LC/L.4085), Santiago, Comisión Económica para América Latina y el Caribe (CEPAL), octubre.

Berlinski, S. y N. Schady (eds.) (2015), Los primeros años: el bienestar infantil y el papel de las politicas públicas, Washington, D.C., Banco Interamericano de Desarrollo (BID).

Blofield, M. y J. Martínez (2015), "Are governments catching up? Work-family policy and inequality in Latin America", Discussion Paper, No 7, Nueva York, Entidad de las Naciones Unidas para la Igualdad de Género y el Empoderamiento de las Mujeres (ONU-Mujeres), septiembre.

(2014), "Trabajo, familia y cambios en la política pública en América Latina: equidad, materialismo y corresponsabilidad", Revista CEPAL, N¹14(LC/G.2629-P), Santiago, Comisión Económica para América Latina y el Caribe (CEPAL), diciembre.

CEPAL (Comisión Económica para América Latina y el Caribe) (2017a), Panorama Social de América Latina 2016. Documento informativo, Santiago, mayo. (2017b), Estrategia de Montevideo para la Implementación de la Agenda Regional de Género en el Marco del Desarrollo Sostenible hacia 2030 (LC/CRM.13/5), Santiago, marzo.

(2016a), Panorama Social de América Latina 2015 (LC/G.2691-P), Santiago, octubre, (2016b), Autonomía de las mujeres e igualdad en la agenda de desarrollo sostenible (LC/G.2686/Rev.1), Santiago, diciembre.

(2013a), Panorama Social de América Latina 2012 (LC/G.2557-P), Santiago, enero. (2013b), Observatorio de Igualdad de Género de América Latina y el Caribe. Informe anual 2012: los bonos en la mira, aporte y carga para las mujeres (LC/G.2561/ Rev.1), Santiago, marzo.

(2011), Panorama Social de América Latina 2010 (LC/G.2481-P), Santiago, enero.

Consejo Nacional para la Igualdad de Género (s/f), "Instalación de la mesa técnicopolítica para el diseño e implementación del Sistema Nacional de Cuidados", Quito, inédito.

DANE (Departamento Administrativo Nacional de Estadística) (2017), "Informe de gestión: Ley 1413 de 2010", Informe semestral, No 12, Bogotá, febrero.

De Achaval, O. y C. Aulicino (2015), "Estrategias de protección a la primera infancia en la experiencia internacional", Documento de Trabajo, No 145 , Buenos Aires, Centro de Implementación de Políticas Públicas para la Equidad y el Crecimiento (CIPPEC), noviembre.

Ellingsaeter, A. (1999), "Dual breadwinners between state and market”, Restructuring Gender Relations and Employment: The Decline of the Male Breadwinner, R. Crompton(ed.), Oxford, Oxford University Press.

Gascón, S. y N. Redondo (2014), "Calidad de los servicios de largo plazo para personas adultas mayores con dependencia", serie Políticas Sociales, No 207 (LC/L.3875), Santiago, Comisión Económica para América Latina y el Caribe (CEPAL), agosto. 
Gobierno de la Ciudad de México (2014), "Manual especifico de operación de la Comisión para el Impulso de la Economía del Cuidado y de una política de igualdad laboral al interior del gobierno de la Ciudad de México. Versión preliminar", Ciudad de México, agosto [en línea] http://data.om.cdmx. gob.mx/impulsoeconomia / ciecpilgcdmx/normatividad/MANUAL \%20 ESPECIFICO \%20DE\%20OPERACION\%20CIECPILIGCDMX\%20VERSION\%20 PRELIMINAR.pdf.

Guzmán, J. (coord.) (2014), “Red Nacional de Cuido y Desarrollo Infantil en Costa Rica. El proceso de construcción 2010-2014", serie Políticas Sociales, N 203 (LC/L.3858), Santiago, Comisión Económica para América Latina y el Caribe (CEPAL), junio.

Huenchuan, S. (2014), “'¿Qué más puedo esperar a mi edad?’ Cuidado, derechos de las personas mayores y obligaciones del Estado", Autonomía y dignidad en la vejez: teoría y práctica en políticas de derechos de las personas adultas mayores, S. Huenchuan y R. Rodríguez (eds.) (LC/L.3942), Ciudad de México, Comisión Económica para América Latina y el Caribe (CEPAL), diciembre.

Lamaute-Brisson, N. (2010), "Economía del cuidado de la niñez en Haití: proveedores, hogares y parentesco", serie Mujer y Desarrollo, No 95 (LC/L.3130-P), Santiago, Comisión Económica para América Latina y el Caribe (CEPAL), diciembre.

Marco, F. (2016), "La nueva ola de reformas previsionales y la igualdad de género en América Latina", serie Asuntos de Género, N 139 (LC/L.4225), Santiago, Comisión Económica para América Latina y el Caribe (CEPAL), octubre.

(2014), "Calidad del cuidado y la educación para la primera infancia en América Latina: igualdad para hoy y mañana", serie Políticas Sociales, N² 204 (LC/L.3859), Santiago, Comisión Económica para América Latina y el Caribe (CEPAL), julio.

(2007), "El cuidado de la niñez en Bolivia y Ecuador: derecho de algunos, obligación de todas", serie Mujer y Desarrollo No 89 (LC/L.2843-P), Santiago, Comisión Económica para América Latina y el Caribe (CEPAL), diciembre.

Marco, F. y M.N. Rico (2013), “Cuidado y políticas públicas: debates y estado de situación a nivel regional", Las fronteras del cuidado. Agenda, derechos e infraestructura, L. Pautassi y C. Zibecchi (coords.), Buenos Aires, Equipo Latinoamericano de Justicia y Género (ELA)/Editorial Biblos.

Matus, M. y M. Vega (2016), "Los cuidados para la atención a la dependencia", La economía de los cuidados, L. Gálvez (ed.), Sevilla, Deculturas Ediciones.

Meléndez, J. (2015), "Las necesidades de cuidado y los desafíos para la institucionalidad social a la luz del Plan Quinquenal de Desarrollo en El Salvador", documento presentado en el Seminario técnico "Los desafíos de la institucionalidad social en el desarrollo de una protección social universal bajo el enfoque de derechos", Santiago, Comisión Económica para América Latina y el Caribe (CEPAL) / Ministerio Federal de Cooperación y Desarrollo (BMZ) / Agencia Alemana de Cooperación Internacional (GIZ), 11 y 12 de agosto.

Montevideo Portal (2017), "Sistema de Cuidados "sigue siendo prioridad", afirmó Arismendi", Montevideo, 27 de marzo [en línea] http://www.montevideo. com.uy/contenido/Sistema-de-Cuidados-sigue-siendo-prioridad--afirmoArismendi-338586. 
Naciones Unidas (2015), "Proyecto de documento final de la cumbre de las Naciones Unidas para la aprobación de la agenda para el desarrollo después de 2015. Anexo Transformar nuestro mundo: la Agenda 2030 para el Desarrollo Sostenible"(A/69/L.85), agosto[enlínea]http:/ / www.un.org/ga/search/view_ doc.asp?symbol=A/69/L.85\&Lang=S.

(2006), "Convención sobre los Derechos de las Personas con Discapacidad" (A/RES/61/106), Nueva York, diciembre [en línea] https://documents-dds-ny. un.org/doc/UNDOC/GEN/N06/500/82/pdf/N0650082.pdf.

(1989), "Convención sobre los Derechos del Niño" (A/RES/44/25), Nueva York, noviembre [en línea] http:/ / undocs.org/es/A/RES/44/25.

(1979), "Convención sobre la Eliminación de Todas las Formas de Discriminación contra la Mujer" (A/RES/34/180), Nueva York, diciembre [en línea] http://undocs.org/es/A/RES/34/180.

OEA(Organización de los Estados Americanos) (2015), “Convención Interamericana sobre la Protección de los Derechos Humanos de las Personas Mayores", Washington, D.C., junio [en línea] http://www.oas.org/es/sla/ddi/docs/ tratados_multilaterales_interamericanos_A-70_derechos_humanos_personas_ mayores.pdf.

OIT (Organización Internacional del Trabajo) (2012), “Recomendación sobre los Pisos de Protección Social, 2012 (Núm. 202)", Ginebra, junio [en línea] http:/ / www.ilo.org/dyn/normlex/es/f?p=NORMLEXPUB:12100:0::NO::P12100_ ILO_CODE:R202.

(2011a), "Convenio sobre las Trabajadoras y los Trabajadores Domésticos, 2011 (Núm. 189)", Ginebra, junio [en línea] http://www.ilo.org/dyn/normlex/es/f? p=NORMLEXPUB:12100:0::NO::P12100_INSTRUMENT_ID,P12100_LANG_ CODE:2551460,es.

(2011b), "Recomendación sobre las Trabajadoras y los Trabajadores Domésticos, 2011 (Núm. 201)”, Ginebra, junio [en línea] http:/ / www.ilo.org/dyn/normlex/ es /f?p=NORMLEXPUB:12100:0::NO::P12100_INSTRUMENT_ID,P12100_ LANG_CODE:2551502,es.

(2000), “ConveniosobrelaProtección dela Maternidad,2000(Núm.183)"Ginebra, junio [en línea] http://www.ilo.org/dyn/normlex/es/f?p=NORMLEXPUB: 12100:0::NO::P12100_INSTRUMENT_ID,P12100_LANG_CODE:312328,es.

(1981), "Convenio sobre los Trabajadores con Responsabilidades Familiares, 1981(Núm.156)",Ginebra,junio[enlínea]http:/ / www.ilo.org/dyn/normlex/ es /f?p=NORMLEXPUB:12100:0::NO::P12100_INSTRUMENT_ID,P12100_ LANG_CODE:312301,es.

Pautassi, L. (2007), "El cuidado como cuestión social desde un enfoque de derechos", serie Mujer y Desarrollo, N ${ }^{\circ} 87$ (LC/L.2800-P), Santiago, Comisión Económica para América Latina y el Caribe (CEPAL), octubre.

Pautassi, L. y M.N. Rico (2011), “Licencias para el cuidado infantil. Derecho de hijos, padres y madres", Boletín Desafíos, N ${ }^{\circ} 12$, Santiago, Comisión Económica para América Latina y el Caribe (CEPAL)/Fondo de las Naciones Unidas para la Infancia (UNICEF), julio.

Perfetti, M. (2016), “Intervención: el aporte de las estadísticas a la economía del cuidado en Colombia", documento presentado en la XIII Conferencia Regional sobre la Mujer de América Latina y el Caribe, Montevideo, Comisión Económica para América Latina y el Caribe (CEPAL), 26 a 28 de octubre. 
Razavi, S. (2012), "Rethinking care in a development context: an introduction", Seen, Heard and Counted: Rethinking Care in a Development Context, Londres, Wiley-Blackwell.

Rico, M.N. (2014), “El desafío de cuidar y ser cuidado en igualdad. Hacia el surgimiento de sistemas nacionales de cuidado", "Pactos sociales para una protección social más inclusiva. Experiencias, obstáculos y posibilidades en América Latina y Europa", M. Hopenhayn y otros (eds.), serie Seminarios y Conferencias, $\mathrm{N}^{\circ} 76$ (LC/L.3820), Santiago, Comisión Económica para América Latina y el Caribe (CEPAL), mayo.

Rico, M.N. y C. Robles (2016), "Políticas de cuidado en América Latina: forjando la igualdad", serie Asuntos de Género, N 140 (LC/L.4226), Santiago, Comisión Económica para América Latina y el Caribe (CEPAL), septiembre.

Rico, M.N. e I. Vaca-Trigo (2016), “Trabajo doméstico remunerado en América Latina: el núcleo duro de la desigualdad de género en el mercado laboral", Santiago, Comisión Económica para América Latina y el Caribe (CEPAL), inédito.

Rodríguez, C. (2016), “El Sistema Nacional de Apoyos y Cuidados: lineamientos principales", documento presentado en el Seminario "La organización social del cuidado y los desafíos de la desigualdad: la construcción de políticas integradas de cuidado en Chile y Costa Rica", Santiago, Comisión Económica para América Latina y el Caribe (CEPAL)/Ministerio de Desarrollo Social/Agencia Chilena de Cooperación Internacional para el Desarrollo (AGCID), 25 de agosto.

Rossel, C. (2016), "Desafíos demográficos para la organización social del cuidado y las políticas públicas", serie Asuntos de Género, N 135 (LC/L.4186), Santiago, Comisión Económica para América Latina y el Caribe (CEPAL), junio.

Salvador, S. (2015), "Política de cuidados en El Salvador: opciones, metas y desafíos", serie Asuntos de Género, No 129, (LC/L.4086), Santiago, Comisión Económica para América Latina y el Caribe (CEPAL), octubre.

(2011), "Hacia un sistema nacional de cuidados en el Uruguay", , El desafío de un sistema nacional de cuidados para el Uruguay", M.N. Rico (coord.), serie Seminarios y Conferencias, No 66 (LC/L.3359), Santiago, Comisión Económica para América Latina y el Caribe (CEPAL), agosto.

Tronto, J. (1993), Moral Boundaries: A Political Argument for an Ethic of Care, Nueva York, Routledge. 

Parte 3

Políticas para poblaciones determinadas y su institucionalidad 



\section{Capítulo VI \\ Ciclo de vida y políticas sociales: las instituciones de juventud en la región}

Daniela Trucco ${ }^{1}$

\section{Introducción ${ }^{2}$}

La posición que ocupan los individuos en la sociedad no es resultado exclusivo de las circunstancias, esfuerzos, decisiones y trayectorias personales. Existe una estructura de oportunidades proporcionada por el conjunto de la sociedad, los Estados, los mercados, las familias y las comunidades, que escapan al control del individuo y condicionan sus perspectivas de movilidad social y acceso a bienestar. La edad de una persona es uno de los ejes que marcan fuertemente la distribución del bienestar y del poder en la estructura social. También es una de las bases de la organización social a partir de la que se asignan roles y responsabilidades (CEPAL, 2016). Cada etapa del ciclo de vida presenta oportunidades, desafíos y riesgos específicos (CEPAL, 2017). Ello pone de relieve la importancia de considerar, desde las políticas públicas, las especificidades de cada una de esas etapas. Al mismo tiempo, exige reflexionar y tomar en consideración cómo las brechas y desigualdades sociales se encadenan durante la vida, dada la acumulación progresiva de desventajas (o privilegios) sociales.

Oficial de Asuntos Sociales de la División de Desarrollo Social de la Comisión Económica para América Latina y el Caribe (CEPAL).

2 La autora agradece las contribuciones de Gabriel Kattan (Consultor) y Renato Briceño (pasante), de la División de Desarrollo Social de la Comisión Económica para América Latina y el Caribe (CEPAL). 
De ahí la importancia de que las políticas públicas acompañen a las personas en las diferentes etapas de su vida, atendiendo a las necesidades específicas de cada período, mientras se procura mantener una continuidad y articulación a lo largo del tiempo (CEPAL, 2016). En ese contexto, y dados los nudos críticos de la reproducción de la desigualdad social durante la juventud, una de las misiones centrales que debería considerar la institucionalidad dedicada a esta población es el diseño e implementación de políticas o programas específicos que garanticen las condiciones para que los jóvenes movilicen sus capacidades de modo que puedan llevar a cabo en forma autónoma sus proyectos de vida, y el fomento de una mayor articulación y visibilidad de sus necesidades particulares (CEPAL, 2017).

Tal como lo planteó la CEPAL, para lograr políticas que respondan a la multidimensionalidad y la integralidad del joven y promuevan su inclusión en la sociedad, se requiere un contexto institucional propicio (Trucco y Ullmann, 2015, pág. 263). Este reto, que es también válido para otras etapas de la vida (como la infancia), implica la coordinación y articulación de diversos sectores de la política pública que deben velar por los derechos y necesidades de la población al pasar por esta etapa de la vida y que, a diferencia de los demás segmentos o grupos poblacionales (definidos por género, territorio, etnia y raza, entre otros), es transitorio y abarca a todas las personas que dejan la niñez. Ello exige un diseño institucional complejo. El marco institucional define en gran medida el tipo de políticas que pueden implementarse para promover la inclusión social de los jóvenes, y también determina su alcance y su efectividad. Hay tres dimensiones de la institucionalidad que son factores decisivos en este proceso: i) el marco normativo; ii) los organismos ejecutivos y coordinadores de la temática, y iii) la existencia de políticas o planes nacionales de juventud.

Es importante reconocer que el concepto de juventud es una construcción social. En consecuencia, las definiciones etarias, características y roles que se le otorguen varían de acuerdo con los factores históricos y culturales de cada sociedad. Además, es relevante tener en consideración que las transiciones y trayectorias vitales de los jóvenes son heterogéneas, se desarrollan de distinta manera y en distintos tiempos, y no necesariamente siguen una trayectoria lineal (CEPAL/OIJ/IMJUVE, 2014). Por lo tanto, lo primero que se debe tener en cuenta al analizar el contexto institucional es la perspectiva sobre la juventud que se asume en las políticas y programas. Tal como se ha planteado en los informes iberoamericanos sobre el tema (CEPAL/OIJ, 2004 y 2008; CEPAL/OIJ/IMJUVE, 2014), la complejidad a que remite el término juventud y la manera de definirlo determinan la variabilidad de la concepción de las políticas con que se aborda este particular. Más allá del rango etario establecido, que en la mayoría de los países se sitúa entre los 15 y 24 años o entre los 15 y 29 años de edad, lo que determinará 
en gran medida la implementación de las políticas es la definición sustancial que se tenga de este segmento y dónde se sitúa. O sea, es preciso definir el lugar que ocupan los jóvenes dentro de la sociedad, así como los roles que se les asignan y los que les son vedados (CEPAL/OIJ/IMJUVE, 2014).

\section{A. Los marcos jurídicos nacionales (y supranacionales) en materia de políticas de juventud}

Tal como se plantea en CEPAL (2017), aunque no existe un instrumento internacional que promueva un sistema integral para la protección particular de los derechos de los jóvenes, ha habido impulsos en ese sentido desde 1985, cuando las Naciones Unidas celebraron el primer Año Internacional de la Juventud. En el Foro Mundial sobre Políticas para la Juventud, celebrado en Bakú en 2014, se consensuaron lineamientos básicos respecto de dichas políticas. Por ejemplo, se determinó que deberían basarse en derechos, ser inclusivas, integrales y participativas, tener perspectiva de género, guiarse por el conocimiento y la evidencia, ser responsables y contar con recursos (CEPAL, 2015). Muchos países de la región han venido elaborando estrategias que incorporan elementos del compromiso de Bakú, y han adoptado la perspectiva de la juventud como un espacio de ciudadanía, y al joven como un actor estratégico del desarrollo (CEPAL, 2017).

En América Latina existen dos instrumentos regionales relevantes en lo que respecta a la juventud. Uno de ellos es la Convención Iberoamericana de Derechos de los Jóvenes de 2005, firmada por 16 países, en que se consagran los derechos de la juventud en temas de salud, educación, trabajo, justicia, participación, igualdad de género y sexualidad, entre otros ${ }^{3}$. Los Estados firmantes adoptaron el compromiso de incorporar, de manera progresiva, decisiones y medidas concretas tendientes a considerar a los jóvenes como actores decisivos en el desarrollo de los países, habida cuenta de los desafíos actuales. Más recientemente, en el marco de la Cumbre Iberoamericana de Jefes de Estado y Gobierno, celebrada en octubre 2016 en Colombia, se consensuó el Pacto Iberoamericano de Juventud. Su objetivo es promover la participación de los jóvenes en la agenda global de desarrollo, ratificar el reconocimiento de los derechos de los jóvenes establecidos en la Convención Iberoamericana, elaborar iniciativas en materia de igualdad e inclusión y fortalecer la institucionalidad relacionada con la juventud, entre otros temas que inciden en el bienestar de las juventudes iberoamericanas ${ }^{4}$.

Véase [en línea] http://www.oij.org/file_upload/publicationsItems/document/20120607115106_ 98.pdf.

4 Véase [en línea] http://segib.org/documento/pacto-iberoamericano-de-juventud/. 
En el Caribe, también existe una agenda de desarrollo juvenil en la Comunidad del Caribe (CARICOM $)^{5}$. En dicha agenda se operacionaliza la Declaración de Paramaribo de 2010 sobre el futuro de la juventud (CEPAL, 2017). Se promueve la generación de un ambiente que contribuya al bienestar de la población adolescente y juvenil, su empoderamiento y su participación en el desarrollo nacional y regional.

A nivel nacional, la existencia de una normativa en materia de juventud es clave para el desarrollo de políticas al respecto. En estas normativas o regulaciones estatales, en forma de ley o decreto, se crean instituciones, se explicitan derechos, se definen los objetivos de la intervención, se establecen metas, se asignan recursos, y se distinguen niveles de responsabilidad y de articulación con los actores. El hecho de contar con un marco jurídico en este ámbito refleja un consenso de la sociedad respecto de la necesidad de atender a esta población con un abordaje particular. Por otra parte, obliga a los diferentes niveles del Poder Ejecutivo a definir e implementar las políticas necesarias para alcanzar los objetivos establecidos y a designar recursos del presupuesto público con ese fin. De esta manera, el marco jurídico proporciona estabilidad, permanencia de criterios, institucionalidad y recursos a las políticas públicas en la materia (CEPAL, 2015).

Los 18 países de América Latina cuentan con legislación general dedicada a la juventud. Con la excepción de Chile, Cuba y el Uruguay, que fueron pioneros en este ámbito, estas iniciativas de institucionalización se han establecido a partir de la década de 2000. Las normativas tienden a definir la población juvenil del país, así como sus derechos y, muchas veces, el tipo de organismo público que tendrá la responsabilidad de velar por las políticas en esa materia (véase el cuadro VI.1).

Cuadro VI.1

América Latina (18 países): marco jurídico nacional en el área de juventud

\begin{tabular}{|c|c|c|c|}
\hline País & Ley pertinente & $\begin{array}{c}\text { Año de } \\
\text { promulgación }\end{array}$ & Objetivo declarado \\
\hline Argentina & $\begin{array}{l}\text { Consejo } \\
\text { Federal de la } \\
\text { Juventud (Ley } \\
\text { núm. 26227) }\end{array}$ & 2007 & $\begin{array}{l}\text { Colaborar con el diseño y la coordinación } \\
\text { interjurisdiccional de las políticas de juventud, } \\
\text { construyendo mapas estratégicos de gestión que } \\
\text { permitan la construcción del concepto de ciudadanía } \\
\text { sobre la base de valores tales como solidaridad, } \\
\text { equidad, compromiso, justicia, responsabilidad, ética } \\
\text { e identidad nacional. }\end{array}$ \\
\hline $\begin{array}{l}\text { Bolivia } \\
\text { (Estado } \\
\text { Plurinacional } \\
\text { de) }\end{array}$ & $\begin{array}{l}\text { Ley de la } \\
\text { Juventud } \\
\text { (Ley núm. 342) }\end{array}$ & 2013 & $\begin{array}{l}\text { Garantizar a los jóvenes el ejercicio pleno de sus } \\
\text { derechos y deberes, el diseño del marco institucional, } \\
\text { las instancias de representación y deliberación de la } \\
\text { juventud, y el establecimiento de políticas públicas. }\end{array}$ \\
\hline
\end{tabular}

Véase [en línea] http://cms2.caricom.org/documents/13930-cydap_2012-2017_rev.pdf. 
Cuadro VI.1 (continuación)

\begin{tabular}{|c|c|c|c|}
\hline País & Ley pertinente & $\begin{array}{c}\text { Año de } \\
\text { promulgación }\end{array}$ & Objetivo declarado \\
\hline Brasil & $\begin{array}{l}\text { Estatuto de la } \\
\text { Juventud (Ley } \\
\text { núm. 12852) }\end{array}$ & 2013 & $\begin{array}{l}\text { Establecer los derechos de los jóvenes y las } \\
\text { directrices de las políticas públicas de juventud y } \\
\text { el Sistema Nacional de la Juventud (SINAJUVE). }\end{array}$ \\
\hline Chile & $\begin{array}{l}\text { Ley núm. } \\
19042\end{array}$ & 1991 & $\begin{array}{l}\text { Crear el Instituto Nacional de la Juventud, como } \\
\text { servicio público, funcionalmente descentralizado, } \\
\text { dotado de personalidad jurídica y patrimonio propio, } \\
\text { relacionado con el Presidente de la República } \\
\text { por intermedio del Ministerio de Planificación y } \\
\text { Cooperación (que luego pasó a ser Ministerio de } \\
\text { Desarrollo Social). }\end{array}$ \\
\hline Colombia & $\begin{array}{l}\text { Estatuto de } \\
\text { Ciudadanía } \\
\text { Juvenil (Ley } \\
\text { núm. 1622) }\end{array}$ & 2013 & $\begin{array}{l}\text { Establecer un marco institucional que garantice a } \\
\text { todos los jóvenes el ejercicio pleno de la ciudadanía } \\
\text { juvenil en los ámbitos civiles o personal, social y } \\
\text { público, el goce efectivo de los derechos reconocidos } \\
\text { en el ordenamiento jurídico interno y lo ratificado en } \\
\text { los tratados internacionales. }\end{array}$ \\
\hline Costa Rica & $\begin{array}{l}\text { Ley General } \\
\text { de la Persona } \\
\text { Joven (Ley } \\
\text { núm. 8261) }\end{array}$ & 2002 & $\begin{array}{l}\text { Elaborar, promover y coordinar la ejecución de } \\
\text { políticas públicas dirigidas a las personas jóvenes. } \\
\text { Coordinar el conjunto de las políticas nacionales de } \\
\text { desarrollo que impulsan las instancias públicas, de } \\
\text { modo que contemplen la creación de oportunidades, } \\
\text { el acceso a servicios y el incremento de las } \\
\text { potencialidades de las personas jóvenes. Propiciar la } \\
\text { participación política, social, cultural y económica de } \\
\text { las personas jóvenes, en condiciones de solidaridad, } \\
\text { equidad y bienestar. Promover y llevar a cabo } \\
\text { investigaciones que permitan conocer la condición de } \\
\text { las personas jóvenes y de sus familias. Proteger los } \\
\text { derechos, obligaciones y garantías fundamentales } \\
\text { de la persona joven. }\end{array}$ \\
\hline Cuba & $\begin{array}{l}\text { Código de } \\
\text { la Niñez y la } \\
\text { Juventud (Ley } \\
\text { núm. 16) }\end{array}$ & 1978 & $\begin{array}{l}\text { Regular la participación de los niños y jóvenes } \\
\text { menores de } 30 \text { años en la construcción de la nueva } \\
\text { sociedad y establecer las obligaciones de las } \\
\text { personas, organismos e instituciones que intervienen } \\
\text { en su educación, conforme al objetivo de promover } \\
\text { la formación de la personalidad comunista } \\
\text { en la joven generación. }\end{array}$ \\
\hline Ecuador & $\begin{array}{l}\text { Ley de la } \\
\text { Juventud }\end{array}$ & $2001 / 2011$ & $\begin{array}{l}\text { Reconoce las necesidades particulares de los jóvenes } \\
\text { y promueve el ejercicio pleno de sus derechos. En } \\
2011 \text { se actualiza la Ley con el fin de reflejar la nueva } \\
\text { Constitución (2008) y fortalecer la garantía real de } \\
\text { los derechos. }\end{array}$ \\
\hline El Salvador & $\begin{array}{l}\text { Ley General } \\
\text { de la Juventud } \\
\text { (Decreto } \\
\text { núm. 910) }\end{array}$ & 2012 & $\begin{array}{l}\text { Implementar políticas públicas, programas, } \\
\text { estrategias y planes para el desarrollo integral } \\
\text { de la población joven. }\end{array}$ \\
\hline Honduras & $\begin{array}{l}\text { Ley Marco } \\
\text { para el } \\
\text { Desarrollo } \\
\text { Integral de } \\
\text { la Juventud } \\
\text { (Decreto } \\
\text { núm. 260) }\end{array}$ & 2005 & $\begin{array}{l}\text { Establecer un marco jurídico, político e institucional } \\
\text { que promueva el pleno desarrollo de los jóvenes. }\end{array}$ \\
\hline México & $\begin{array}{l}\text { Ley del } \\
\text { Instituto } \\
\text { Mexicano } \\
\text { de la Juventud }\end{array}$ & 2012 & $\begin{array}{l}\text { Crear el Instituto Mexicano de la Juventud como } \\
\text { organismo público descentralizado, con personalidad } \\
\text { jurídica, patrimonio propio, autonomía técnica, } \\
\text { operativa y de gestión, y con domicilio } \\
\text { en el Distrito Federal. }\end{array}$ \\
\hline
\end{tabular}


Cuadro VI.1 (conclusión)

\begin{tabular}{|c|c|c|c|}
\hline País & Ley pertinente & $\begin{array}{c}\text { Año de } \\
\text { promulgación }\end{array}$ & Objetivo declarado \\
\hline Nicaragua & $\begin{array}{l}\text { Ley de } \\
\text { Promoción } \\
\text { del Desarrollo } \\
\text { Integral de la } \\
\text { Juventud (Ley } \\
\text { núm. 392) y su } \\
\text { Reglamento }\end{array}$ & 2001 & $\begin{array}{l}\text { Promover el desarrollo humano de hombres y mujeres } \\
\text { jóvenes, garantizar el ejercicio de sus derechos y } \\
\text { obligaciones, establecer políticas institucionales y } \\
\text { movilizar recursos del Estado y de la sociedad civil } \\
\text { en beneficio de la juventud. }\end{array}$ \\
\hline Panamá & $\begin{array}{l}\text { Ley de la } \\
\text { Secretaría } \\
\text { Nacional } \\
\text { de Niñez, } \\
\text { Adolescencia } \\
\text { y Familia (Ley } \\
\text { núm. 14) }\end{array}$ & 2009 & $\begin{array}{l}\text { Crear la Secretaría Nacional de Niñez, Adolescencia } \\
\text { y Familia. Fortalecer el marco institucional para la } \\
\text { protección y promoción de los derechos de la niñez } \\
\text { y adolescencia, a través de la consolidación de las } \\
\text { bases y los principios rectores del funcionamiento } \\
\text { del Sistema de Protección Integral de la Niñez y } \\
\text { la Adolescencia de la República de Panamá. }\end{array}$ \\
\hline Paraguay & $\begin{array}{l}\text { Decreto } \\
\text { núm. } 262\end{array}$ & 2013 & $\begin{array}{l}\text { Crear la Secretaría Nacional de la Juventud (SNJ) } \\
\text { como institución de derecho público, rectora y } \\
\text { responsable de orientar las acciones del Estado sobre } \\
\text { el conjunto de políticas públicas necesarias para lograr } \\
\text { la consecución de necesidades y expectativas de la } \\
\text { juventud, además de promover la participación juvenil } \\
\text { en los procesos de toma de decisiones. Reemplaza } \\
\text { la Ley Nacional de Juventud y Organismos Públicos } \\
\text { de Juventud (2005), que se circunscribía al área del } \\
\text { Ministerio de Educación y Cultura. }\end{array}$ \\
\hline Perú & $\begin{array}{l}\text { Decreto } \\
\text { Supremo } \\
\text { núm. 001- } \\
2008-E D\end{array}$ & 2008 & $\begin{array}{l}\text { Crear la Secretaría Nacional de la Juventud (SENAJU), } \\
\text { encargada de formular políticas de Estado en materia } \\
\text { de juventud, que contribuyan al desarrollo integral de } \\
\text { los jóvenes en temas de empleabilidad, mejoramiento } \\
\text { de calidad de vida, inclusión social, participación y } \\
\text { acceso a espacios en todos los ámbitos del desarrollo } \\
\text { humano, así como promover y supervisar programas } \\
\text { y proyectos en beneficio de los jóvenes. }\end{array}$ \\
\hline $\begin{array}{l}\text { República } \\
\text { Dominicana }\end{array}$ & $\begin{array}{l}\text { Ley General } \\
\text { de Juventud } \\
\text { (Ley núm. 49) }\end{array}$ & 2000 & $\begin{array}{l}\text { Instaurar un marco jurídico, político e institucional } \\
\text { que oriente las acciones del Estado, y la sociedad } \\
\text { en general, hacia la definición e implementación } \\
\text { del conjunto de políticas necesarias para lograr la } \\
\text { satisfacción de las necesidades y expectativas de } \\
\text { la población joven del país, así como una efectiva } \\
\text { participación de los jóvenes en los procesos de } \\
\text { toma de decisiones. }\end{array}$ \\
\hline \multirow[t]{2}{*}{ Uruguay } & $\begin{array}{l}\text { Ley núm. } \\
16170\end{array}$ & 1990 & \multirow{2}{*}{$\begin{array}{l}\text { Crear el Instituto Nacional de la Juventud (INJU), } \\
\text { que tendrá como cometido formular, ejecutar } \\
\text { y evaluar las políticas nacionales relativas a la } \\
\text { juventud, en coordinación con otros organismos } \\
\text { estatales. También deberá promover, planificar y } \\
\text { coordinar las actividades del Centro de Información } \\
\text { a la Juventud, que dependerá del referido Instituto, } \\
\text { mediante el asesoramiento y la capacitación del } \\
\text { personal de las unidades locales de información. }\end{array}$} \\
\hline & $\begin{array}{l}\text { Convención } \\
\text { lberoamericana } \\
\text { de Derechos } \\
\text { de los Jóvenes } \\
\text { (Ley núm. } \\
\text { 18270) }\end{array}$ & 2008 & \\
\hline $\begin{array}{l}\text { Venezuela } \\
\text { (República } \\
\text { Bolivariana } \\
\text { de) }\end{array}$ & $\begin{array}{l}\text { Ley Nacional } \\
\text { de Juventud } \\
\text { (Ley núm. } \\
37404 \text { ) }\end{array}$ & 2002 & $\begin{array}{l}\text { Regular y desarrollar los derechos y deberes de la } \\
\text { juventud, a fin de otorgar a los jóvenes las oportunidades } \\
\text { para su pleno desarrollo hacia la vida adulta productiva, } \\
\text { incluidas las garantías para su capacitación, primer } \\
\text { empleo y participación en el proceso de desarrollo } \\
\text { mediante políticas públicas del Estado, con la } \\
\text { participación solidaria de la familia y de la sociedad. }\end{array}$ \\
\hline
\end{tabular}

Fuente: D. Trucco y H. Ullmann (eds.), Juventud: realidades y retos para un desarrollo con igualdad, Libros de la CEPAL, N ${ }^{\circ} 137$ (LC/G.2647-P), Santiago, Comisión Económica para América Latina y el Caribe (CEPAL), 2015; y CEPAL, "Institucionalidad social. Base de datos para América Latina y el Caribe" [en línea] http://dds.cepal.org/bdips/. 


\section{B. Dimensión organizacional: la gobernanza de las políticas de juventud}

\section{Instituciones coordinadoras y autoridad}

En la mayoría de los textos legislativos enumerados en el cuadro VI.1 se define el tipo de organismo especializado que se encarga de velar por los derechos de las personas jóvenes. Una de las misiones centrales que debe considerar la institucionalidad dedicada a esta población es la provisión de recursos suficientes para la implementación de políticas y programas específicos que garanticen las condiciones para que los jóvenes de ambos sexos logren movilizar su capacidad de llevar a cabo en forma autónoma sus proyectos de vida. También se debe promover una mayor articulación $\mathrm{y}$ visibilidad de sus necesidades y aspiraciones particulares, sobre todo en temas relacionados con la permanencia escolar, la transición de la escuela al trabajo, la capacitación laboral, el acceso a la salud (en especial, aunque no únicamente, la sexual y reproductiva), la disponibilidad de servicios de cuidado, la protección frente a la violencia y su prevención, las posibilidades de participación y el acceso a la cultura. Se trata de temáticas cuyo nivel de prioridad cambia de un contexto a otro, pero en el que la institucionalidad posee una vocación de visibilización y articulación (CEPAL, 2017).

Existen diversas modalidades de instituciones gubernamentales rectoras de los temas relativos a la juventud. Se pueden identificar en la región ministerios o secretarías, viceministerios o subsecretarías, institutos, direcciones y consejos nacionales dedicados a estas cuestiones. En el cuadro VI.2 se detallan los organismos pertinentes en 26 países de América Latina y el Caribe, y su objetivo o misión oficial. También se presenta la institución que ejerce la rectoría del organismo de juventud, cuando este no tiene un rango ministerial. Aunque nueve países tienen una institución de rango ministerial, ello puede resultar engañoso, pues muchas veces se trata de instancias que agrupan varias temáticas (como deporte y cultura) o atienden a poblaciones priorizadas (como la mujer y la infancia) y no poseen recursos técnicos o financieros de envergadura (CEPAL, 2017). En siete países, la rectoría se ejerce desde la Presidencia o Vicepresidencia de la nación. Este enfoque puede ser ventajoso desde el punto de vista de la visibilidad y priorización de las políticas pero, al mismo tiempo, puede ser muy contingente en la voluntad y los intereses del gobierno de turno. Solo en cinco países la autoridad es el Ministerio de Desarrollo Social. 


\section{Cuadro VI.2}

\section{América Latina y el Caribe (26 países): articulación y rectoría de las instancias de gobierno dedicadas a las personas jóvenes}

\begin{tabular}{|c|c|c|c|}
\hline País & $\begin{array}{l}\text { Principal instancia } \\
\text { de protección } \\
\text { para la juventud }\end{array}$ & Objetivo declarado & $\begin{array}{l}\text { Autoridad que } \\
\text { coordina o ejerce } \\
\text { la rectoría }\end{array}$ \\
\hline $\begin{array}{l}\text { Antigua y } \\
\text { Barbuda }\end{array}$ & $\begin{array}{l}\text { Ministerio de } \\
\text { Educación, } \\
\text { Deporte, Juventud } \\
\text { y Asuntos } \\
\text { de Género }\end{array}$ & $\begin{array}{l}\text { Ofrecer educación de calidad a niños } \\
\text { y jóvenes (de preescolar a posgrado), } \\
\text { y trabajar con distintos actores } \\
\text { de la sociedad para fortalecer las } \\
\text { instituciones educativas, deportivas } \\
\text { y de empoderamiento de la juventud, } \\
\text { con miras a desarrollar ciudadanos } \\
\text { productivos, capaces de aprender } \\
\text { y trabajar de forma independiente y } \\
\text { colectiva y hacer un aporte a } \\
\text { sus comunidades. }\end{array}$ & $\begin{array}{l}\text { Ministerio de } \\
\text { Educación, Deporte, } \\
\text { Juventud y Asuntos } \\
\text { de Género }\end{array}$ \\
\hline Argentina & $\begin{array}{l}\text { Dirección Nacional } \\
\text { de Juventud } \\
\text { (DINAJU) }\end{array}$ & $\begin{array}{l}\text { Interpelar a los jóvenes como sujetos } \\
\text { protagonistas de la construcción de } \\
\text { la patria. Jerarquizar el tema de la } \\
\text { juventud por medio de la definición } \\
\text { de los lineamientos de las políticas } \\
\text { orientadas a la población juvenil, } \\
\text { desde una perspectiva federal e } \\
\text { intergubernamental. }\end{array}$ & $\begin{array}{l}\text { Ministerio de } \\
\text { Desarrollo Social }\end{array}$ \\
\hline Bahamas & $\begin{array}{l}\text { Ministerio de } \\
\text { Juventud, Cultura } \\
\text { y Deportes }\end{array}$ & $\begin{array}{l}\text { Promover el bienestar económico, físico, } \\
\text { cultural, espiritual y social de los jóvenes } \\
\text { de } 16 \text { a } 24 \text { años a nivel nacional en el } \\
\text { Commonwealth de las Bahamas. }\end{array}$ & $\begin{array}{l}\text { Ministerio de } \\
\text { Juventud, Cultura } \\
\text { y Deportes }\end{array}$ \\
\hline Barbados & $\begin{array}{l}\text { Ministerio de } \\
\text { Cultura, Deportes y } \\
\text { Juventud, División } \\
\text { de Asuntos } \\
\text { de Juventud }\end{array}$ & $\begin{array}{l}\text { Facilitar el desarrollo de individuos } \\
\text { seguros, orgullosos, autodependientes } \\
\text { y creativos, mediante la participación en } \\
\text { actividades que contribuyan al desarrollo } \\
\text { personal, comunitario y nacional. }\end{array}$ & $\begin{array}{l}\text { Ministerio de Cultura, } \\
\text { Deportes y Juventud }\end{array}$ \\
\hline Belice & $\begin{array}{l}\text { Ministerio de } \\
\text { Educación, } \\
\text { Juventud, Deporte } \\
\text { y Cultura }\end{array}$ & $\begin{array}{l}\text { Asegurar que todos los beliceños } \\
\text { tengan la oportunidad de adquirir los } \\
\text { conocimientos, habilidades y actitudes } \\
\text { necesarios para su desarrollo personal, } \\
\text { y para la participación plena y activa en } \\
\text { el desarrollo de la nación. }\end{array}$ & $\begin{array}{l}\text { Ministerio de } \\
\text { Educación, Juventud, } \\
\text { Deporte y Cultura }\end{array}$ \\
\hline $\begin{array}{l}\text { Bolivia } \\
\text { (Estado } \\
\text { Plurinacional } \\
\text { de) }\end{array}$ & $\begin{array}{l}\text { Consejo } \\
\text { Plurinacional de } \\
\text { la Juventud }\end{array}$ & $\begin{array}{l}\text { Trabajar con la juventud boliviana, } \\
\text { articular las organizaciones juveniles } \\
\text { del país. }\end{array}$ & Ministerio de Justicia \\
\hline Brasil & $\begin{array}{l}\text { Secretaria } \\
\text { Nacional de la } \\
\text { Juventud (SNJ) }\end{array}$ & $\begin{array}{l}\text { Formular, coordinar, integrar y articular } \\
\text { políticas públicas relacionadas con } \\
\text { la juventud, además de promover } \\
\text { programas de cooperación } \\
\text { con organismos nacionales e } \\
\text { internacionales, públicos y privados, } \\
\text { enfocados en políticas para los jóvenes. }\end{array}$ & $\begin{array}{l}\text { Presidencia, } \\
\text { Vicepresidencia o } \\
\text { delegado presidencial }\end{array}$ \\
\hline Chile & $\begin{array}{l}\text { Instituto Nacional } \\
\text { de la Juventud } \\
\text { (INJUV) }\end{array}$ & $\begin{array}{l}\text { Colaborar con el Poder Ejecutivo } \\
\text { en el diseño, la planificación y la } \\
\text { coordinación de las políticas relativas } \\
\text { a asuntos juveniles. }\end{array}$ & $\begin{array}{l}\text { Ministerio de } \\
\text { Desarrollo o } \\
\text { Inclusión Social }\end{array}$ \\
\hline
\end{tabular}


Cuadro VI.2 (continuación)

\begin{tabular}{|c|c|c|c|}
\hline País & $\begin{array}{l}\text { Principal instancia } \\
\text { de protección } \\
\text { para la juventud }\end{array}$ & Objetivo declarado & $\begin{array}{l}\text { Autoridad que } \\
\text { coordina o ejerce } \\
\text { la rectoría }\end{array}$ \\
\hline Colombia & $\begin{array}{l}\text { Dirección del } \\
\text { Sistema Nacional } \\
\text { de Juventud } \\
\text { "Colombia Joven" }\end{array}$ & $\begin{array}{l}\text { Promover políticas públicas para } \\
\text { jóvenes; fomentar la participación de } \\
\text { los jóvenes en los diferentes espacios } \\
\text { institucionales; consolidar el Sistema } \\
\text { Nacional de Información y Gestión } \\
\text { de Conocimiento en Adolescencia } \\
\text { y Juventud (SNIGCAJ); articular la } \\
\text { oferta pública institucional relativa a la } \\
\text { juventud, y promover oportunidades } \\
\text { socioeconómicas para este segmento. }\end{array}$ & $\begin{array}{l}\text { Presidencia, } \\
\text { Vicepresidencia o } \\
\text { delegado presidencial }\end{array}$ \\
\hline Costa Rica & $\begin{array}{l}\text { Viceministerio } \\
\text { de Juventud }\end{array}$ & $\begin{array}{l}\text { Dirigir y coordinar las actividades } \\
\text { internas y externas del Ministerio } \\
\text { de Cultura y Juventud, y velar por el } \\
\text { cumplimiento de la rectoría del Consejo } \\
\text { de la Persona Joven para la población } \\
\text { de } 12 \text { a } 35 \text { años. }\end{array}$ & $\begin{array}{l}\text { Ministerio de Cultura } \\
\text { y Juventud }\end{array}$ \\
\hline Dominica & $\begin{array}{l}\text { Ministerio de } \\
\text { Juventud, } \\
\text { Deportes, Cultura } \\
\text { y Empoderamiento } \\
\text { del Electorado, } \\
\text { División de } \\
\text { Desarrollo Juvenil }\end{array}$ & $\begin{array}{l}\text { Proveer servicios con el fin de } \\
\text { empoderar a los jóvenes para que } \\
\text { desarrollen su potencial, creatividad } \\
\text { y habilidades, como miembros } \\
\text { productivos y participativos de su } \\
\text { sociedad y comunidad. }\end{array}$ & $\begin{array}{l}\text { Ministerio de } \\
\text { Juventud, } \\
\text { Deporte, Cultura y } \\
\text { Empoderamiento } \\
\text { del Electorado }\end{array}$ \\
\hline Ecuador & $\begin{array}{l}\text { Ministerio } \\
\text { de Inclusión } \\
\text { Económica y } \\
\text { Social (MIES), } \\
\text { Dirección Nacional } \\
\text { de la Juventud } \\
\text { y Adolescencia }\end{array}$ & $\begin{array}{l}\text { Fomentar la participación juvenil y } \\
\text { promover la práctica democrática, } \\
\text { reconociendo a los jóvenes como } \\
\text { actores sociales que contribuyen a } \\
\text { la transformación social en el } \\
\text { siglo XXI, a través de un proceso } \\
\text { de acompañamiento, con el objetivo } \\
\text { de fortalecer a las organizaciones, } \\
\text { colectivos y grupos juveniles. }\end{array}$ & $\begin{array}{l}\text { Ministerio de } \\
\text { Inclusión Económica } \\
\text { y Social }\end{array}$ \\
\hline El Salvador & $\begin{array}{l}\text { Instituto Nacional } \\
\text { de la Juventud }\end{array}$ & $\begin{array}{l}\text { Ser responsable de la rectoría de } \\
\text { la Política Nacional de la Juventud, } \\
\text { especialmente en asuntos de prevención } \\
\text { social de la violencia juvenil. }\end{array}$ & $\begin{array}{l}\text { Presidencia, } \\
\text { Vicepresidencia o } \\
\text { delegado presidencial }\end{array}$ \\
\hline Guatemala & $\begin{array}{l}\text { Consejo Nacional } \\
\text { de la Juventud }\end{array}$ & $\begin{array}{l}\text { Establecer procesos sistemáticos que } \\
\text { faciliten el consenso entre sectores } \\
\text { organizados de jóvenes y permitan } \\
\text { la construcción de marcos jurídicos, } \\
\text { y políticas públicas que respondan a } \\
\text { las múltiples demandas de la juventud } \\
\text { guatemalteca. }\end{array}$ & $\begin{array}{l}\text { Presidencia, } \\
\text { Vicepresidencia o } \\
\text { delegado presidencial }\end{array}$ \\
\hline Guyana & $\begin{array}{l}\text { Ministerio de } \\
\text { Educación, } \\
\text { Departamento de } \\
\text { Cultura, Juventud } \\
\text { y Deporte }\end{array}$ & $\begin{array}{l}\text { Asegurar el empoderamiento de } \\
\text { la juventud de Guyana mediante } \\
\text { programas interactivos diseñados para } \\
\text { mejorar sus habilidades y actitudes, de } \\
\text { modo que puedan contribuir de manera } \\
\text { significativa al desarrollo nacional. }\end{array}$ & $\begin{array}{l}\text { Ministerio de } \\
\text { Educación }\end{array}$ \\
\hline Honduras & $\begin{array}{l}\text { Instituto Nacional } \\
\text { de la Juventud (INJ) }\end{array}$ & $\begin{array}{l}\text { Establecer el marco jurídico, político e } \\
\text { institucional para promover el desarrollo } \\
\text { de los jóvenes; definir políticas de } \\
\text { Estado sobre la juventud; orientar las } \\
\text { acciones del Estado, la sociedad y la } \\
\text { familia sobre estos asuntos, y fomentar } \\
\text { la participación activa, responsable y } \\
\text { permanente de los jóvenes en su propio } \\
\text { desarrollo y el del país. }\end{array}$ & $\begin{array}{l}\text { Presidencia, } \\
\text { Vicepresidencia o } \\
\text { delegado presidencial }\end{array}$ \\
\hline
\end{tabular}


Cuadro VI.2 (continuación)

\begin{tabular}{|c|c|c|c|}
\hline País & $\begin{array}{l}\text { Principal instancia } \\
\text { de protección } \\
\text { para la juventud }\end{array}$ & Objetivo declarado & $\begin{array}{l}\text { Autoridad que } \\
\text { coordina o ejerce } \\
\text { la rectoría }\end{array}$ \\
\hline Jamaica & $\begin{array}{l}\text { Ministerio de } \\
\text { Cultura, Género, } \\
\text { Entretenimiento } \\
\text { y Deporte }\end{array}$ & $\begin{array}{l}\text { Liderar la transformación social y } \\
\text { mejorar el bienestar de la sociedad } \\
\text { a través de programas, servicios y } \\
\text { actividades orientadas al avance de } \\
\text { la juventud, así como contribuir al } \\
\text { crecimiento económico y el progreso } \\
\text { mediante el desarrollo de la industria } \\
\text { cultural y la aplicación de políticas y } \\
\text { programas que ayuden a impulsar la } \\
\text { marca Jamaica. }\end{array}$ & $\begin{array}{l}\text { Ministerio de Cultura, } \\
\text { Género, Entretención } \\
\text { y Deporte }\end{array}$ \\
\hline México & $\begin{array}{l}\text { Instituto Mexicano } \\
\text { de la Juventud }\end{array}$ & $\begin{array}{l}\text { Formular políticas públicas a favor } \\
\text { de los jóvenes para entregarles las } \\
\text { herramientas necesarias en educación, } \\
\text { salud, empleo y participación social. }\end{array}$ & $\begin{array}{l}\text { Presidencia, } \\
\text { Vicepresidencia o } \\
\text { delegado presidencial }\end{array}$ \\
\hline Nicaragua & $\begin{array}{l}\text { Ministerio de } \\
\text { la Juventud }\end{array}$ & $\begin{array}{l}\text { Formular e implementar políticas, } \\
\text { programas y estrategias que promuevan } \\
\text { la participación consciente y protagónica } \\
\text { de la juventud nicaragüense en el } \\
\text { desarrollo económico, político, social } \\
\text { y cultural del país, desde un modelo } \\
\text { sustentado en valores cristianos, ideales } \\
\text { socialistas y prácticas solidarias. }\end{array}$ & $\begin{array}{l}\text { Ministerio de } \\
\text { otra cartera }\end{array}$ \\
\hline Panamá & $\begin{array}{l}\text { Ministerio de } \\
\text { Desarrollo Social }\end{array}$ & $\begin{array}{l}\text { Impulsar el desarrollo humano mediante } \\
\text { la participación, el fortalecimiento de la } \\
\text { familia y la comunidad, la integración } \\
\text { social y la reducción de la pobreza. }\end{array}$ & $\begin{array}{l}\text { Ministerio de } \\
\text { Desarrollo o } \\
\text { Inclusión Social }\end{array}$ \\
\hline Paraguay & $\begin{array}{l}\text { Secretaría } \\
\text { Nacional de } \\
\text { la Juventud }\end{array}$ & $\begin{array}{l}\text { Impulsar, generar, coordinar e } \\
\text { implementar políticas públicas inclusivas } \\
\text { dirigidas a satisfacer necesidades } \\
\text { prioritarias de la población joven del } \\
\text { país, con énfasis en aquella que se } \\
\text { encuentra en situación de pobreza y } \\
\text { vulnerabilidad, a fin de garantizar el } \\
\text { mejoramiento de sus condiciones de } \\
\text { vida y su participación activa en todas } \\
\text { las áreas de desarrollo nacional. }\end{array}$ & $\begin{array}{l}\text { Presidencia, } \\
\text { Vicepresidencia o } \\
\text { delegado presidencial }\end{array}$ \\
\hline Perú & $\begin{array}{l}\text { Secretaría } \\
\text { Nacional de } \\
\text { la Juventud }\end{array}$ & $\begin{array}{l}\text { Promover, articular, coordinar, monitorear } \\
\text { y evaluar políticas, planes, programas, } \\
\text { proyectos y acciones en beneficio de } \\
\text { los jóvenes de } 15 \text { a } 29 \text { años, } \\
\text { en el marco de un funcionamiento } \\
\text { participativo, inclusivo y democrático. }\end{array}$ & $\begin{array}{l}\text { Ministerio de } \\
\text { Educación }\end{array}$ \\
\hline $\begin{array}{l}\text { República } \\
\text { Dominicana }\end{array}$ & $\begin{array}{l}\text { Ministerio de } \\
\text { la Juventud }\end{array}$ & $\begin{array}{l}\text { Promover el desarrollo integral de } \\
\text { los jóvenes mediante la formulación, } \\
\text { coordinación, monitoreo y evaluación } \\
\text { de la Política Nacional de la Juventud. } \\
\text { En sintonía con las organizaciones } \\
\text { gubernamentales y no gubernamentales, } \\
\text { se procura garantizar la ejecución de } \\
\text { programas, planes y proyectos que } \\
\text { conduzcan a la implementación de } \\
\text { políticas sectoriales y la aplicación de } \\
\text { criterios de juventud. }\end{array}$ & $\begin{array}{l}\text { Ministerio de } \\
\text { la Juventud }\end{array}$ \\
\hline
\end{tabular}


Cuadro VI.2 (conclusión)

\begin{tabular}{|c|c|c|c|}
\hline País & $\begin{array}{l}\text { Principal instancia } \\
\text { de protección } \\
\text { para la juventud }\end{array}$ & Objetivo declarado & $\begin{array}{l}\text { Autoridad que } \\
\text { coordina o ejerce } \\
\text { la rectoría }\end{array}$ \\
\hline $\begin{array}{l}\text { Trinidad y } \\
\text { Tabago }\end{array}$ & $\begin{array}{l}\text { Ministerio de } \\
\text { Género, Juventud y } \\
\text { Desarrollo Infantil }\end{array}$ & $\begin{array}{l}\text { Proporcionar un liderazgo eficaz en } \\
\text { asuntos relacionados con el género } \\
\text { y el desarrollo, y una formulación de } \\
\text { políticas sobre niñez y juventud eficaz } \\
\text { y basada en la evidencia; implementar } \\
\text { servicios y programas de calidad, } \\
\text { garantizando la colaboración de las } \\
\text { partes interesadas en la planificación, el } \\
\text { monitoreo y la evaluación. }\end{array}$ & $\begin{array}{l}\text { Ministerio de Género, } \\
\text { Juventud y } \\
\text { Desarrollo Infantil }\end{array}$ \\
\hline Uruguay & $\begin{array}{l}\text { Instituto Nacional } \\
\text { de la Juventud }\end{array}$ & $\begin{array}{l}\text { Planificar, diseñar, asesorar, articular, } \\
\text { supervisar y ejecutar políticas públicas } \\
\text { de juventud y velar por su cumplimiento. }\end{array}$ & $\begin{array}{l}\text { Ministerio de } \\
\text { Desarrollo o Inclusión } \\
\text { Social }\end{array}$ \\
\hline $\begin{array}{l}\text { Venezuela } \\
\text { (República } \\
\text { Bolivariana } \\
\text { de) }\end{array}$ & $\begin{array}{l}\text { Instituto Nacional } \\
\text { del Poder Popular } \\
\text { de la Juventud }\end{array}$ & $\begin{array}{l}\text { Formular y ejecutar políticas dirigidas } \\
\text { al logro de la participación protagónica } \\
\text { de los jóvenes y su integración a los } \\
\text { procesos de transformación de una } \\
\text { patria socialista para la construcción del } \\
\text { poder popular juvenil. Ser la institución } \\
\text { rectora en la articulación de las políticas } \\
\text { juveniles con otros entes del Estado. }\end{array}$ & $\begin{array}{l}\text { Ministerio del Poder } \\
\text { Popular para la } \\
\text { Juventud y el Deporte }\end{array}$ \\
\hline
\end{tabular}

Fuente: D. Trucco y H. Ullmann (eds.), Juventud: realidades y retos para un desarrollo con igualdad, Libros de la CEPAL, N 137 (LC/G.2647-P), Santiago, Comisión Económica para América Latina y el Caribe (CEPAL), 2015; y Comisión Económica para América Latina y el Caribe (CEPAL), "Institucionalidad social. Base de datos para América Latina y el Caribe" [en línea] http://dds. cepal.org/bdips/.

En la gran mayoría de estas instancias se plantea como su misión principal ser la autoridad en la materia, el organismo que planifica, articula, coordina y regula, y que, en algunos casos, ejecuta las políticas y programas orientados a la población juvenil. Algunas también se consideran interlocutoras del Estado en el diálogo con las organizaciones juveniles de la sociedad civil. Como se ha discutido a lo largo de este documento, el rol de rectoría o coordinación que involucra a ministerios sectoriales de gran peso en el aparato público (como los de educación o salud), es muchas veces difícil de cumplir por estas entidades, ya sea por la debilidad del nivel institucional (en particular para los que no tienen rango ministerial), por la falta de capacidad instalada (autoridades que rotan con cierta frecuencia y que, por su juventud, tienen poca trayectoria en la gestión pública), o por la falta de recursos.

Otros objetivos institucionales comúnmente declarados son aquellos que realzan el rol de la población juvenil y su potencial contribución al desarrollo de cada país y sus entornos sociales. Por su parte, en un grupo importante de países se plantea el objetivo de promover el bienestar y desarrollo de los jóvenes de modo integral, considerando diversas dimensiones. Finalmente, algunos desempeñan un papel más centrado en la promoción de competencias y habilidades de la población juvenil (eje educación-empleo). 
Tal como se indica en Trucco y Ullmann (2015), la mayor parte de las instituciones de América Latina y el Caribe relacionadas con la juventud tienen su propio sitio web (en un $90 \%$ de los países). En general, publican noticias sobre esta temática e información sobre políticas y programas que están implementándose en cada país. Un poco más de la mitad de estos sitios $(60 \%)$ presentan información sobre las leyes y normativas conexas, alrededor de un $40 \%$ contiene publicaciones vinculadas a investigaciones sobre juventud realizadas por las propias instituciones y otros organismos, y menos del $30 \%$ cuenta con información estadística relativa a la juventud de su país.

\section{Canales de participación ciudadana}

Fortalecer la participación de los jóvenes es imprescindible para que todas las decisiones sean más relevantes, sostenibles y legítimas. Sin embargo, como ha planteado la CEPAL, los canales de participación para que los jóvenes puedan desempeñar un papel activo en la formulación, la implementación, el monitoreo y la evaluación de las políticas son insuficientes y no logran captar de una manera inclusiva y eficiente la voz de la juventud. Aunque existen algunas vías de participación a través de organizaciones de jóvenes, estas por lo general carecen de recursos y la coordinación entre ellas tiende a ser débil o nula. Frecuentemente, en la implementación de políticas públicas no se propicia la participación de los jóvenes de manera continua a lo largo del proceso, sino solo en las etapas finales y de manera ad hoc. Además, estas instancias de participación solo entran en juego cuando se trata de políticas que estén directamente vinculadas con la población juvenil y no en otros ámbitos (Trucco y Ullmann, 2015, pág. 270).

Una manera de integrar la participación de las organizaciones juveniles de la sociedad civil a los procesos de decisión sería incluirlas formalmente en la institucionalidad. La mayor parte de los países tienen alguna estructura formal con ese fin, ya sea consejo, red consultiva o asamblea. La mayoría de los países de América Latina (15 de 18) cuenta con una o más instancias o agrupaciones de la ciudadanía que tienen representación ante la entidad a cargo de la política en materia de juventud (véase el cuadro VI.3).

El grado de participación de estas entidades es heterogéneo. Puede ser puramente consultivo o implicar una mayor influencia en la toma de decisiones. En ese sentido, cabe destacar que la mayoría de los países tienen organismos de participación de nivel decisorio, o incluso de cogestión ${ }^{6}$. Así, hay un grupo de países que tienen consejos ciudadanos con niveles de cogestión de la participación en las políticas de juventud. En este nivel se busca que las personas y grupos no solo se involucren en la toma de

Términos utilizados en Sandoval, Sanhueza y Williner (2015). 
decisiones, sino en su implementación y seguimiento, de forma de asegurar que se lleve a cabo en forma adecuada (Sandoval, Sanhueza y Williner, 2015).

Por otro lado, hay otros tipos de organizaciones donde el nivel de participación del organismo ciudadano de juventud es de carácter decisorio. Es decir, las personas y grupos que participan tienen una influencia directa sobre la toma de decisiones (Sandoval, Sanhueza y Williner, 2015). El resultado del proceso es vinculante para el órgano público que implementa la política de juventud. Finalmente, están aquellas instituciones que solo tienen un carácter consultivo, donde el objetivo del proceso de consulta es recoger opiniones, propuestas e intereses de las personas y grupos que participan. La consulta en este caso no es vinculante para la autoridad.

En algunos casos, los miembros de estos consejos son designados, pero en varios son elegidos por votación. En la mayoría de los casos (véase el cuadro VI.3), el nivel de representación es nacional o intermedio (regional o estadual) y son menos los que llegan a representatividad local o comunal.

\section{Cuadro VI.3}

América Latina (18 países): canales de participación de las instituciones dedicadas a las personas jóvenes

\begin{tabular}{|c|c|c|c|c|}
\hline País & $\begin{array}{l}\text { Instancia de participación de } \\
\text { jóvenes en la elaboración } \\
\text { de políticas públicas }\end{array}$ & $\begin{array}{l}\text { Mecanismo } \\
\text { de elección de } \\
\text { representantes }\end{array}$ & $\begin{array}{l}\text { Nivel de } \\
\text { participación } \\
\text { ciudadana }\end{array}$ & $\begin{array}{l}\text { Nivel de } \\
\text { representación }\end{array}$ \\
\hline Argentina & $\begin{array}{l}\text { Consejo Federal } \\
\text { de la Juventud }\end{array}$ & No disponible & Nivel decisorio & $\begin{array}{l}\text { Nacional/ } \\
\text { Intermedio }\end{array}$ \\
\hline $\begin{array}{l}\text { Bolivia (Estado } \\
\text { Plurinacional de) }\end{array}$ & $\begin{array}{l}\text { Consejo Plurinacional } \\
\text { de la Juventud }\end{array}$ & Designacion & Nivel cogestión & $\begin{array}{l}\text { Nacional/ } \\
\text { Intermedio/Local }\end{array}$ \\
\hline Brasil & $\begin{array}{l}\text { Consejo Nacional de la } \\
\text { Juventud (CONJUVE) }\end{array}$ & Elección & Nivel decisorio & $\begin{array}{l}\text { Nacional/ } \\
\text { Intermedio/Local }\end{array}$ \\
\hline Chile & \multicolumn{4}{|c|}{ No cuenta con organización de participación directa de jóvenes } \\
\hline Colombia & $\begin{array}{l}\text { Consejos de la juventud } \\
\text { nacional, departamentales, } \\
\text { locales }\end{array}$ & $\begin{array}{l}\text { Elección/ } \\
\text { Designación }\end{array}$ & Nivel cogestión & $\begin{array}{l}\text { Nacional/ } \\
\text { Intermedio/Local }\end{array}$ \\
\hline \multirow[t]{3}{*}{ Costa Rica } & $\begin{array}{l}\text { Consejo Nacional de } \\
\text { la Política Pública de } \\
\text { la Persona Joven }\end{array}$ & Designación & Nivel cogestión & Nacional \\
\hline & $\begin{array}{l}\text { Red Nacional Consultiva } \\
\text { de Personas Jóvenes }\end{array}$ & Elección & Nivel decisorio & $\begin{array}{l}\text { Nacional/ } \\
\text { Intermedio/Local }\end{array}$ \\
\hline & $\begin{array}{l}\text { Asamblea Nacional de la Red } \\
\text { Nacional Consultiva de } \\
\text { la Persona Joven }\end{array}$ & $\begin{array}{l}\text { Elección/ } \\
\text { Designación }\end{array}$ & Nivel decisorio & Nacional \\
\hline \multirow[t]{2}{*}{ Ecuador } & $\begin{array}{l}\text { Consejo Nacional de } \\
\text { Políticas de la Juventud }\end{array}$ & $\begin{array}{l}\text { Elección/ } \\
\text { Designación }\end{array}$ & Nivel cogestión & Nacional \\
\hline & $\begin{array}{l}\text { Consejos Locales de } \\
\text { la Juventud }\end{array}$ & Elección & Nivel decisorio & Local \\
\hline El Salvador & $\begin{array}{l}\text { Consejo Nacional de } \\
\text { la Persona Joven }\end{array}$ & Elección & Nivel cogestión & Nacional \\
\hline Guatemala & Consejo Asesor de Juventud & Elección & Nivel decisorio & Intermedio/Local \\
\hline Honduras & \multicolumn{4}{|c|}{ No cuenta con organización de participación directa de jóvenes } \\
\hline
\end{tabular}


Cuadro VI.3 (conclusión)

\begin{tabular}{|c|c|c|c|c|}
\hline País & $\begin{array}{l}\text { Instancia de participación de } \\
\text { jóvenes en la elaboración } \\
\text { de políticas públicas }\end{array}$ & $\begin{array}{l}\text { Mecanismo } \\
\text { de elección de } \\
\text { representantes }\end{array}$ & $\begin{array}{l}\text { Nivel de } \\
\text { participación } \\
\text { ciudadana }\end{array}$ & $\begin{array}{l}\text { Nivel de } \\
\text { representación }\end{array}$ \\
\hline México & $\begin{array}{l}\text { Consejo Ciudadano de } \\
\text { Seguimiento de Políticas } \\
\text { Públicas en materia de } \\
\text { Juventud (CONSEPP) }\end{array}$ & Elección & $\begin{array}{l}\text { Nivel } \\
\text { consultivo }\end{array}$ & $\begin{array}{l}\text { Nacional/ } \\
\text { Intermedio }\end{array}$ \\
\hline Nicaragua & $\begin{array}{l}\text { Comisión Nacional de } \\
\text { la Juventud }\end{array}$ & Designación & Nivel decisorio & Nacional \\
\hline Panamá & $\begin{array}{l}\text { Consejo de Políticas Públicas } \\
\text { de la Juventud }\end{array}$ & Elección & Nivel decisorio & Nacional \\
\hline Paraguay & $\begin{array}{l}\text { Consejos nacional, } \\
\text { departamentales y } \\
\text { municipales de la niñez } \\
\text { y la adolescencia }\end{array}$ & Designación & Nivel decisorio & $\begin{array}{l}\text { Nacional/ } \\
\text { Intermedio/Local }\end{array}$ \\
\hline \multirow[t]{2}{*}{ Perú } & $\begin{array}{l}\text { Consejo Nacional de } \\
\text { la Juventud (CONAJU) }\end{array}$ & Designación & Nivel decisorio & Nacional \\
\hline & $\begin{array}{l}\text { Consejo de Participación } \\
\text { de la Juventud (CPJ) }\end{array}$ & Elección & Nivel decisorio & Intermedio/Local \\
\hline \multirow[t]{3}{*}{$\begin{array}{l}\text { República } \\
\text { Dominicana }\end{array}$} & $\begin{array}{l}\text { Consejos municipales } \\
\text { de la juventud }\end{array}$ & Elección & Nivel cogestión & Comunal \\
\hline & $\begin{array}{l}\text { Consejos provinciales } \\
\text { de la juventud }\end{array}$ & Designación & Nivel cogestión & Regional \\
\hline & $\begin{array}{l}\text { Consejo Nacional } \\
\text { de la Juventud }\end{array}$ & Elección & Nivel cogestión & Nacional \\
\hline Uruguay & \multicolumn{4}{|c|}{ No cuenta con organización de participación directa de jóvenes } \\
\hline $\begin{array}{l}\text { Venezuela } \\
\text { (República } \\
\text { Bolivariana de) }\end{array}$ & $\begin{array}{l}\text { Consejo Nacional } \\
\text { de la Juventud }\end{array}$ & Designación & Nivel cogestión & $\begin{array}{l}\text { Nacional/ } \\
\text { Intermedio }\end{array}$ \\
\hline
\end{tabular}

Fuente: Comisión Económica para América Latina y el Caribe (CEPAL), sobre la base de información oficial.

\section{Planes o políticas sectoriales y acceso a recursos}

La existencia de una normativa no garantiza su aplicación ni sus resultados. Su ejecución requiere una política o plan nacional de juventud. El papel de esa política o plan nacional también es crítico porque proporciona una visión respecto de todos los programas y actividades relacionadas con la juventud de un país, y permite construir e instalar a su vez una visión sobre lo que significa ser joven en el contexto histórico específico (Trucco y Ullmann, 2015, pág. 267). La mayor parte de los países de la región ha publicado una política o plan nacional en esta materia en los últimos años. De la revisión de documentos oficiales publicados en línea de los 18 países de América Latina se concluye que 7 tienen una política de juventud y 9 tienen planes sectoriales relativamente actuales (hay 2 que solo tienen programas).

Al examinar 14 de estas políticas y planes de juventud se pueden establecer algunos elementos comunes. Por ejemplo, en varios casos se declara que las acciones relacionadas con este grupo poblacional deben asumirse bajo la perspectiva de derechos. Además, en algunos documentos se menciona explícitamente la perspectiva de género y se declara la intención de realzar el rol de la juventud y su contribución al desarrollo. En términos de los ejes principales de acción existe bastante 
coincidencia. En los 14 documentos analizados se destaca el tema del trabajo decente, la inclusión laboral o el emprendimiento como una de las principales líneas de acción (véase el gráfico VI.1). En segundo lugar, y con similar número de casos (13 de 14), se destacan los ejes de educación o formación de capacidad (muchas veces muy ligados al eje de empleo) y el de participación ciudadana y democrática.

\section{Gráfico VI.1 \\ América Latina (14 países $^{\mathrm{a}}$ ): ejes principales de política o plan sectorial de juventud}

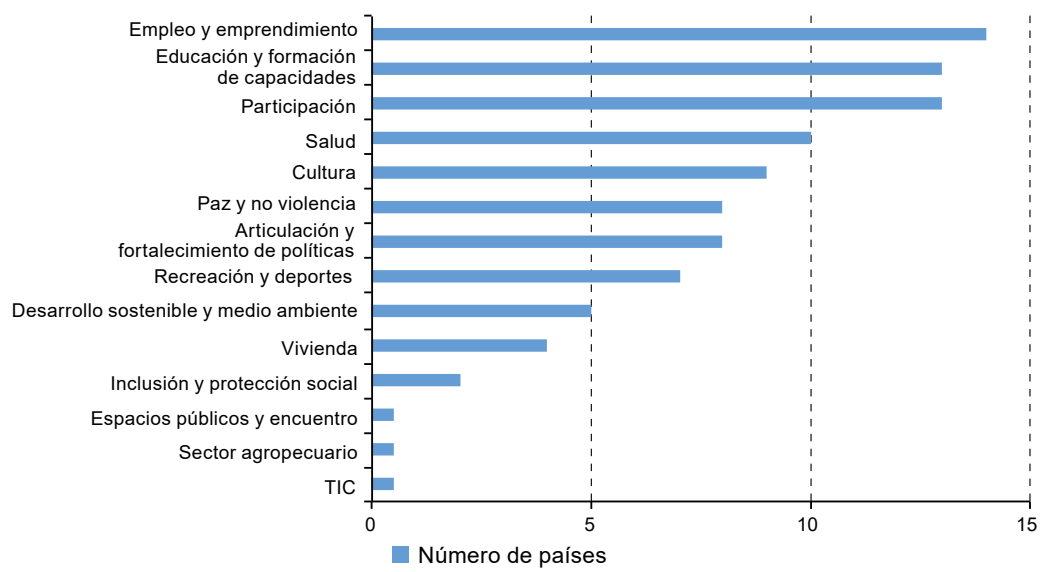

Fuente: Comisión Económica para América Latina y el Caribe (CEPAL), sobre la base de información oficial.

a Bolivia (Estado Plurinacional de), Brasil, Colombia, Costa Rica, Ecuador, El Salvador, Guatemala, Honduras, México, Panamá, Paraguay, Perú, República Dominicana y Uruguay.

Muchos de los organismos pertinentes asumen como rol central el ser el canal de voz y participación de las juventudes de su país. Una línea de acción en este sentido consiste en promover a través de medidas y programas la participación de organizaciones juveniles, o la formación de jóvenes en competencias de liderazgo y participación política. Además, varios organismos, al ser liderados por jóvenes, se constituyen en canales de participación formal en la gestión pública e instancia de formación política de las juventudes del partido político gobernante. Cabe destacar que esto podría entrañar el riesgo de que la institución correspondiente restrinja su rol de ente coordinador de las políticas de juventud en general y derive en un espacio de renovación y formación de las nuevas generaciones de los partidos políticos.

La salud es otro de los ejes de preocupación mencionados en los documentos de diez países. En la mayoría de los casos hay una referencia a la salud integral del joven, si bien en Honduras aún se privilegia la

En la sección anterior se describió el tipo de institucionalización que tienen los países en relación con la participación en la gestión pública. 
mirada exclusivamente sobre los aspectos de salud sexual y reproductiva. Como ha mencionado la CEPAL en publicaciones anteriores (Trucco y Ullmann, 2015), dada la baja morbilidad y mortalidad de este segmento poblacional, tiende a aplicarse una perspectiva restringida respecto de la salud y se invisibilizan muchas de las necesidades de este grupo. De ahí la importancia de plantear una mirada integral sobre las necesidades específicas de los jóvenes en materia de acceso a servicios de salud, siendo particularmente relevantes los temas de salud mental.

Otros asuntos destacables en los planes y políticas sectoriales de juventud se refieren a la cultura. En varios países se agrupan con temas de identidad, plurinacionalidad, y recreación y deportes (aunque, en algunos casos, las cuestiones culturales se enuncian de manera separada). La promoción de una cultura de paz y no violencia es también un eje en que se articulan varias de las estrategias de acción de juventud, sobre todo en los países centroamericanos y otros, como México y el Brasil, cuyos índices de violencia social son elevados.

En muchos de los planes o políticas se menciona de manera general la intención de fortalecer el rol de los organismos especializados, en tanto coordinadores y articuladores de las políticas de juventud. En 8 de los 14 documentos analizados se incluye este aspecto como uno de los ejes explícitos de acción. Entre los otros ejes destacados, aunque mencionados por menor cantidad de países, se encuentran los temas de desarrollo sostenible o medioambiente saludable, vivienda, inclusión social y protección frente a la pobreza y la vulnerabilidad, espacios públicos de encuentro, sector agropecuario, y tecnologías de la información y las comunicaciones (TIC).

\section{Dimensión fiscal y financiamiento de las políticas de juventud}

Muchos países de la región han elaborado estrategias de acción relevantes a partir de su política o plan nacional de juventud. No obstante, sigue siendo insuficiente la asignación de recursos a los jóvenes en los presupuestos públicos y se evidencian desfases entre los objetivos de dichos planes y el presupuesto público. Por ejemplo, como señala Rodríguez (2011), en los documentos de políticas públicas en materia de juventud se priorizan cuestiones como los jóvenes excluidos, la inserción laboral, la construcción de ciudadanía y la prevención de la violencia. Por su parte, en los presupuestos públicos se sigue priorizando a los jóvenes integrados a la educación formal y se destinan algunos recursos a la salud, pero relativamente pocos a la inserción laboral y la prevención de la violencia (CEPAL, 2015). 
El desafío del financiamiento es un tema que ha recibido atención a nivel mundial. La Agenda de Acción de Addis Abeba de la Tercera Conferencia Internacional sobre la Financiación para el Desarrollo representa el primer instrumento internacional en que se reconoce explícitamente que es esencial invertir en la juventud si se desea lograr un desarrollo inclusivo, equitativo y sostenible para las generaciones presentes y futuras ${ }^{8}$. Este mensaje encuentra eco en trabajos de la CEPAL y otras organizaciones que promueven el desarrollo juvenil en la región. En sus informes más recientes (CEPAL/UNFPA, 2012; CEPAL/OIJ/IMJUVE, 2014), la CEPAL ha avanzado en cuanto al análisis de la inversión social que se requiere a fin de implementar las políticas y estrategias relativas a la juventud, con el fin de brindar una garantía real de sus derechos. Por ejemplo, en CEPAL/UNFPA (2012) se plantea que la voluntad política expresada en los acuerdos y consensos internacionales no necesariamente se materializa en políticas o programas específicos que garanticen las condiciones para que los jóvenes incrementen su capacidad y lleven adelante de forma autónoma sus proyectos de vida.

De acuerdo con las estimaciones presentadas en el último informe iberoamericano de juventud (CEPAL/OIJ/IMJUVE, 2014), alrededor de 2012 se estimaba que la inversión social total en la región equivalía al 19,1\% del PIB (unos 660.000 millones de dólares). Del total de gasto público en inversión social, las estimaciones indican que la región destina alrededor de 102.000 millones de dólares a programas sociales cuyos destinatarios directos o indirectos son los jóvenes (183.000 millones de dólares a precios de 2005, expresados en paridad de poder adquisitivo). Tal como se plantea en la edición 2014 del Panorama Social de América Latina (CEPAL, 2014), dado que los márgenes actuales de expansión del gasto público son menores, es necesario mejorar la planificación de los gastos, junto con el desarrollo y fortalecimiento de los mecanismos de evaluación, con el propósito de aumentar la eficacia y eficiencia del uso de los recursos.

\section{E. Comentarios finales}

La elaboración e implementación de políticas públicas de juventud incluyentes y participativas, con una perspectiva del ciclo de vida, no es una tarea sencilla, sino que implica esfuerzos y compromisos concertados. Se requiere llevar a cabo consultas entre los jóvenes y sus organizaciones, así como una coordinación eficaz y sostenible entre los ministerios, además de la asignación de recursos suficientes y la integración de la

La Tercera Conferencia Internacional sobre la Financiación para el Desarrollo, organizada por las Naciones Unidas, se celebró entre el 13 y el 16 de julio de 2015 en Addis Abeba. El documento final, la Agenda de Acción de Addis Abeba, está disponible [en línea] en http://www.un.org/ ga/search/view_doc.asp?symbol=A/CONF.227/L.1. 
política nacional en la materia en los planes nacionales de desarrollo. Invertir en esta etapa del ciclo de vida y lograr la plena inclusión de los jóvenes es crucial para el proceso de desarrollo orientado a la construcción de capacidades y oportunidades que permitan alcanzar mayores niveles de igualdad en América Latina y el Caribe (Trucco y Ullmann, 2015).

La CEPAL ha planteado que, en general, no se aplica una perspectiva integral y multidimensional sobre la juventud en las políticas que abordan este ciclo de la vida. Por ejemplo, si se considera el eje principal de inclusión social de la población joven (es decir, la educación y el empleo), se observa que hay poca vinculación entre las políticas de estas dos áreas. También se concluye que en ninguno de los dos ámbitos se abarca de una manera central o amplia el tema de la familia y las tareas del cuidado. Justamente en esa etapa de la vida es más acuciante la necesidad de conciliar la educación con el empleo, y el peso de las responsabilidades familiares y de cuidado puede truncar las trayectorias educacionales y laborales de los jóvenes, sobre todo de las mujeres. De la misma manera, se releva la importancia de articular entre los sectores de salud, educación y seguridad el tema de la violencia que enfrenta la juventud en su proceso de desarrollo e inclusión, de modo que se puedan aplicar estrategias eficaces de prevención y acompañamiento de la población juvenil.

Independientemente de la variedad de modalidades que implementan y tareas que llevan a cabo para promover el desarrollo de la población juvenil en sus respectivos países, los organismos encargados de este tema (de manera similar a lo que ocurre con los ministerios o instituciones de desarrollo social) tienden a ser débiles, sobre todo cuando se comparan con la solidez de los ministerios sectoriales pertinentes, como los de educación, trabajo y salud. Estos son ministerios más antiguos en la historia de la gestión pública de la región y disponen de presupuestos muchísimo mayores. Las políticas nacionales de juventud son gestionadas por los entes coordinadores respectivos, que, como se ha mencionado, cuentan con recursos y poder político limitados. Al mismo tiempo, los ministerios sectoriales tienden a actuar de forma independiente en temas que afectan a los jóvenes. Esta fragmentación representa un importante obstáculo para la ejecución, el seguimiento y, en última instancia, la efectividad de la política (Trucco y Ullmann, 2015).

Este es uno de los grandes dilemas que afrontan los organismos llamados a articular iniciativas multisectoriales. El rol de coordinación de otras entidades que tienen mayor presupuesto, autonomía y prestigio en el aparato público se convierte en una tarea prácticamente imposible. El mecanismo que les permite disponer de cierta autonomía y presupuesto se basa en el compromiso de ejecutar ciertos programas específicos para llevar adelante algunos de los objetivos del plan sectorial, con escaso presupuesto y débil impacto. 
Se plantea claramente la prioridad de fortalecer la articulación entre los actores gubernamentales dedicados a promover el desarrollo juvenil. Los programas desarticulados no solo son más ineficientes en el uso de los escasos recursos disponibles, sino también, y particularmente, menos efectivos. Esta realidad justifica la implementación de políticas y programas integrales coordinados por las instancias de juventud, concertados entre los actores involucrados y diseñados de acuerdo con una lógica de atención a los grupos juveniles de sus entornos respectivos. También resulta necesario fortalecer las instancias locales (sobre todo municipales) para que lleven a cabo iniciativas de inclusión social juvenil que contemplen una mayor participación comunitaria, tanto en su diseño como en su ejecución (Trucco y Ullmann, 2015).

Ante este panorama, se impone la necesidad de reflexionar sobre las funciones esenciales que deberían desempeñar las entidades a cargo de los temas de las políticas de juventud. En este sentido, se propone que prioricen un rol de coordinación y articulación de iniciativas, a fin de dinamizar los procesos, lograr la visibilización de estas cuestiones en las políticas sectoriales e impulsar una mirada integral sobre la juventud en los diferentes sectores. Para ello, se requiere apoyo político de alto nivel con miras a enfatizar y visibilizar el tema de la juventud en los ministerios sectoriales y, paralelamente, reforzar y empoderar a los entes rectores correspondientes (Trucco y Ullmann, 2015). Además, es importante hacer que los equipos sean menos volátiles, de modo que alcancen a aprovechar capacidades formadas en estas instituciones, más allá de los gobiernos de turno.

Otro de los grandes dilemas que se plantean para este tipo de instituciones del sector social, que se enfocan en la atención de un segmento poblacional, es cómo compatibilizar las necesidades específicas de la etapa de vida en cuestión con el enfoque de ciclo de vida, integrando la mirada de las políticas con las de la etapa previa y posterior. La necesidad de llevar a la práctica el enfoque intergeneracional se suma a la de la articulación entre múltiples sectores, y resulta aún más difícil que esta.

Como se plantea en Trucco y Ullmann (2015), la mayor parte de estas iniciativas de institucionalización de las acciones relacionadas con la juventud se han establecido a partir de la década de 2000. O sea, es relativamente reciente la preocupación de los Gobiernos de la región por dar visibilidad y orientación a las acciones dirigidas a la juventud, y la toma de conciencia sobre la importancia de la legislación y las políticas adecuadas para responder a las necesidades, aspiraciones y demandas de los jóvenes. Sin embargo, la existencia de una normativa sobre temas de juventud, y un plan o política para ejecutarla, es una condición necesaria, aunque no suficiente, para promover la inclusión de los jóvenes. A pesar de los avances y compromisos, los desafíos descritos dificultan la efectiva implementación de estas medidas. 


\section{Bibliografía}

CEPAL (Comisión Económica para América Latina y el Caribe) (2017), Panorama Social de América Latina 2016. Documento informativo, Santiago, mayo. (2016), La matriz de la desigualdad social en América Latina (LC/G.2690(MDS.1/2)), Santiago.

(2015), "Hacia la inclusión social juvenil. Herramientas para el análisis y el diseño de políticas", Documentos de Proyectos, Estudios e Investigaciones (LC/M.28), Santiago.

(2014), Panorama Social de América Latina 2014 (LC/G.2635-P), Santiago.

CEPAL/OIJ (Comisión Económica para América Latina y el Caribe/Organización Iberoamericana de Juventud) (2008), Juventud y cohesión social en Iberoamérica: un modelo para armar (LC/G.2391), Santiago, octubre. (2004), La juventud en Iberoamérica. Tendencias y urgencias (LC/L.2180), Santiago de Chile, octubre.

CEPAL/OIJ/IMJUVE (Comisión Económica para América Latina y el Caribe/ Organización Iberoamericana de Juventud/Instituto Mexicano de la Juventud) (2014), Invertir para transformar: la juventud como protagonista del desarrollo, Madrid, septiembre.

CEPAL/UNFPA (Comisión Económica para América Latina y el Caribe/Fondo de Población de las Naciones Unidas) (2012), Informe Regional de Población en América Latina y el Caribe, 2011. Invertir en juventud en América Latina y el Caribe: un imperativo de derechos e inclusión, Santiago.

Rodríguez, E. (2011), "Políticas de juventud y desarrollo social en América Latina: bases para la construcción de respuestas integradas", documento presentado en el VIII Foro de Ministros de Desarrollo Social de América Latina, San Salvador, 11 y 12 de julio [en línea] http://www.unesco.org/new/fileadmin/ MULTIMEDIA/HQ/SHS / pdf / Youth \%20Policies $\% 20$ and $\% 20$ Social $\% 20$ Development $\% 20-\% 20 B u i l d i n g \% 20 I n t e g r a t e d \% 20 R e s p o n s e s \% 20 E S . P D F$.

Sandoval, C., A. Sanhueza y A. Williner (2015), “La planificación participativa para lograr un cambio estructural con igualdad", Manuales de la CEPAL, $\mathrm{N}^{\circ} 1$ (LC/L.4069/ Rev.1), Santiago, Comisión Económica para América Latina y el Caribe (CEPAL).

Trucco, D. y H. Ullmann (eds.) (2015), Juventud: realidades y retos para un desarrollo con igualdad, Libros de la CEPAL, N 137 (LC/G.2647-P), Santiago, Comisión Económica para América Latina y el Caribe (CEPAL). 
Capítulo VII

\section{Discapacidad y políticas públicas: avances y desafíos institucionales en América Latina}

Heidi Ullmann ${ }^{1}$

\section{Introducción ${ }^{2}$}

La discapacidad es mucho más que una condición de salud. Entendida desde su contexto social, es una experiencia de la diferencia (UNICEF, 2005). También puede ser una experiencia de exclusión y marginación. No obstante, en décadas recientes los países de América Latina y el Caribe han realizado importantes avances con miras a promover y proteger los derechos de personas con discapacidad y se ha construido una arquitectura institucional orientada a garantizar una vida más justa y equitativa para esta población. En este capítulo se hace una revisión de esa arquitectura institucional en los países de América Latina, partiendo del marco de análisis propuesto en el primer capítulo. En la primera sección se considera la dimensión jurídico-normativa, a nivel internacional, regional y nacional. En la segunda se presenta la dimensión organizacional y, finalmente, la técnico-operativa. El capítulo concluye con una reflexión sobre los avances y desafíos de la

Oficial de Asuntos Sociales de la División de Desarrollo Social de la Comisión Económica para América Latina y el Caribe (CEPAL).

2 La autora agradece la colaboración de Gabriel Kattan, Consultor de la División de Desarrollo Social de la CEPAL, en la recolección de información. 
institucionalidad en materia de discapacidad en los países de la región. También se ofrecen sugerencias para fortalecer esta institucionalidad, con miras a elaborar e implementar progresivamente mejores políticas sociales que permitan garantizar los derechos y la inclusión de la población con discapacidad.

\section{A. La dimensión jurídico-normativa}

Como se planteó en el primer capítulo, a medida que se ha consolidado la democracia y que el enfoque de derechos ha ganado terreno en el ámbito social, una dimensión de la institucionalidad social de gran relevancia es la jurídico-normativa. Permite conocer cuáles son los compromisos que cada país asume, tanto a nivel de la comunidad internacional como ante sus propios ciudadanos, así como el fundamento de las otras dimensiones de la institucionalidad. En el caso específico de la población con discapacidad, se observa que sus derechos están codificados en instrumentos internacionales, regionales y nacionales.

América Latina fue pionera en la defensa de los derechos de las personas con discapacidad, con la aprobación en 1999 de la Convención Interamericana para la Eliminación de todas las Formas de Discriminación contra las Personas con Discapacidad (CIADDIS) de la Organización de los Estados Americanos (OEA), que ha sido ratificada por los 19 Estados latinoamericanos miembros de esa organización (véase el cuadro VII.1). Los objetivos de esta Convención son prevenir y eliminar todas las formas de discriminación contra las personas con discapacidad, así como promover su plena integración en todos los ámbitos de la sociedad mediante leyes y programas sociales y educativos (OEA, 1999). En el momento de su adopción, la CIADDIS proporcionó la base conceptual sobre la discapacidad. También estableció, por parte de los Estados miembros, un compromiso más explícito respecto de la protección de los derechos de las personas con discapacidad que los que habían asumido en virtud de los instrumentos de derechos humanos en general, que solo se refieren al tema de forma parcial o indirecta.

En el marco de la OEA también se aprobó la Declaración del Decenio de las Américas por los Derechos y la Dignidad de las Personas con Discapacidad (2006-2016) y su Programa de Acción. En esos instrumentos los Estados miembros se comprometieron a adoptar gradualmente, y dentro de un plazo razonable, las medidas administrativas, legislativas y judiciales, así como las políticas públicas necesarias, para la efectiva aplicación del Programa de Acción, que abarca temas de sensibilización, salud, educación, empleo, accesibilidad, participación política, cultura, bienestar, asistencia social y cooperación internacional. 


\section{Cuadro VII.1}

América Latina (19 países): año de ratificación o adhesión a la Convención Interamericana para la Eliminación de Todas las Formas de Discriminación contra las Personas con Discapacidad (1999) y la Convención sobre los Derechos de las Personas con Discapacidad (2006), al 1 de abril de 2017

\begin{tabular}{|c|c|c|}
\hline País & $\begin{array}{l}\text { Convención Interamericana } \\
\text { para la Eliminación de } \\
\text { todas las Formas de } \\
\text { Discriminación contra las } \\
\text { Personas con Discapacidad } \\
\text { (CIADDIS) }\end{array}$ & $\begin{array}{l}\text { Convención sobre los } \\
\text { Derechos de las Personas } \\
\text { con Discapacidad (CDPD) }\end{array}$ \\
\hline Argentina & 2000 & 2008 \\
\hline Bolivia (Estado Plurinacional de) & 2003 & 2009 \\
\hline Brasil & 2001 & 2008 \\
\hline Chile & 2001 & 2008 \\
\hline Colombia & 2003 & 2011 \\
\hline Costa Rica & 1999 & 2008 \\
\hline Cuba & & 2007 \\
\hline Ecuador & 2004 & 2008 \\
\hline El Salvador & 2002 & 2007 \\
\hline Guatemala & 2002 & 2009 \\
\hline Honduras & 2011 & 2008 \\
\hline México & 2000 & 2007 \\
\hline Nicaragua & 2002 & 2007 \\
\hline Panamá & 2001 & 2007 \\
\hline Paraguay & 2002 & 2008 \\
\hline Perú & 2001 & 2008 \\
\hline República Dominicana & 2006 & 2009 \\
\hline Uruguay & 2001 & 2009 \\
\hline Venezuela (República Bolivariana de) & 2006 & 2013 \\
\hline
\end{tabular}

Fuente: Elaboración propia, sobre la base de Organización Iberoamericana de Seguridad Social (OISS), Medidas para la promoción del empleo de personas con discapacidad en Iberoamérica, Madrid, 2014.

Las primeras menciones sobre el tema de la discapacidad en el marco normativo internacional se pueden observar en los acuerdos y tratados de carácter universalista, en que se consagran derechos de todas las personas a partir de su condición de seres humanos. Entre ellos cabe mencionar la Declaración Universal de Derechos Humanos (1948) y el Pacto Internacional de Derechos Económicos Sociales y Culturales (PIDESC) (1976) ${ }^{3}$. La Convención de las Naciones Unidas sobre los Derechos de las Personas con Discapacidad (CDPD), el primer instrumento de derechos humanos del siglo XXI, es sin duda el mecanismo de derecho internacional más relevante en este sentido, ya que busca específicamente apoyar, proteger y promover los derechos y la dignidad de la población con discapacidad (Naciones Unidas, 2006). La Convención contiene

3 Por otra parte, se menciona la discapacidad en instrumentos que se refieren a poblaciones específicas, como la Convención sobre los Derechos del Niño (1989). 
50 artículos ${ }^{4}$. Se organiza en torno a un conjunto de principios: el respeto de la dignidad inherente y, la autonomía individual, la no discriminación, la participación e inclusión plenas y efectivas en la sociedad, el respeto por la diferencia y la aceptación de las personas con discapacidad como parte de la diversidad y la condición humana, la igualdad de oportunidades, la accesibilidad, la igualdad entre el hombre y la mujer, y el respeto a la evolución de las facultades de los niños y las niñas con discapacidad (Stang, 2011).

Más allá de la importancia de explicitar los derechos de la población con discapacidad de una manera holística e integral, este instrumento plantea un cambio de paradigma para entender la discapacidad: propone pasar de un enfoque biomédico centrado en las limitaciones individuales y orientado al asistencialismo, a un enfoque basado en los derechos humanos en que se reconozca que la discapacidad es el producto de una interacción entre deficiencias físicas, mentales, intelectuales o sensoriales de largo plazo que, al interactuar con diversas barreras en el entorno, pueden impedir a determinadas personas la participación plena y efectiva en la sociedad, en igualdad de condiciones con las demás (Naciones Unidas, 2006). Este cambio en el paradigma no es una consideración abstracta y académica, sino que tiene, o debería tener, un impacto directo en otras dimensiones de la institucionalidad que se ocupa de este tema.

A raíz de la ratificación de la CDPD y la CIADDIS han ocurrido muchos avances en las normativas nacionales respecto de los derechos de las personas con discapacidad. No obstante, es importante mencionar que, en muchos casos, los derechos de esta población están explicitados en las constituciones nacionales desde antes que se aprobaran los instrumentos mencionados. Muchas constituciones contienen artículos específicos sobre el tema, o hacen mención explícita de la población con discapacidad y de las poblaciones que recibirán protección especial en artículos referentes a la lucha contra la discriminación. Existen además leyes, decretos, disposiciones y regulaciones en otros instrumentos jurídicos, como los códigos de la niñez, del trabajo, de la familia, entre otros, que regulan el ejercicio de los derechos de las personas con discapacidad.

En todos los países de la región existen leyes específicas referidas a las personas con discapacidad (véase el cuadro VII.2). La más antigua es la Ley núm. 22431 de la Argentina, relativa al Sistema de Protección Integral

\footnotetext{
El Protocolo Facultativo de la Convención establece un mecanismo de denuncia y reconoce la competencia del Comité sobre los Derechos de las Personas con Discapacidad para recibir y considerar las comunicaciones presentadas por personas o grupos de personas sujetas a su jurisdicción que aleguen ser víctimas de una violación por un Estado Parte de cualquiera de las disposiciones de la Convención, o en nombre de esas personas o grupos de personas. La mayoría de los países de América Latina han ratificado el protocolo facultativo o se han adherido a él.
} 
de las Personas Discapacitadas, de 1981. En la década de 1990, seis países aprobaron legislación para regular el ámbito de la discapacidad, mientras que en la década de 2000 se vio un importante aumento en el número de leyes nacionales orientadas a promover y proteger los derechos de las personas con discapacidad. En muchos casos, estas fueron aprobadas a partir de, o de forma concurrente con, el año en que el país ratificó la CDPD. Al ratificar dicha Convención, los Estados Partes se comprometen a adoptar las medidas legislativas nacionales necesarias para aplicarla y a asegurar y promover el pleno ejercicio de todos los derechos humanos y las libertades fundamentales de las personas con discapacidad (Naciones Unidas, 2006). Así, en la mayoría de los casos (13 países), estas normativas tienen carácter de ley.

\section{Cuadro VII.2}

\section{América Latina (19 países): principal norma que explicita derechos de las personas con discapacidad}

\begin{tabular}{|c|c|c|}
\hline País y año & Tipo & Norma \\
\hline Argentina (1981) & Ley & $\begin{array}{l}\text { Ley núm. 22431, Sistema de Protección Integral } \\
\text { de las Personas Discapacitadas }\end{array}$ \\
\hline $\begin{array}{l}\text { Bolivia (Estado } \\
\text { Plurinacional de) (2012) }\end{array}$ & Decreto supremo & $\begin{array}{l}\text { Ley núm. 223, Ley General para Personas } \\
\text { con Discapacidad }\end{array}$ \\
\hline Brasil (1989) & Ley & $\begin{array}{l}\text { Ley núm. } 7.853 \text {, sobre el apoyo a las personas } \\
\text { con discapacidad y sobre su integración social }\end{array}$ \\
\hline Chile (2010) & Ley & $\begin{array}{l}\text { Ley núm. 20.422, que establece normas sobre } \\
\text { igualdad de oportunidades e inclusión social } \\
\text { de personas con discapacidad }\end{array}$ \\
\hline \multirow[t]{2}{*}{ Colombia $(1997 ; 2013)$} & Ley & $\begin{array}{l}\text { Ley núm. 361, por la cual se establecen } \\
\text { mecanismos de integración social de las personas } \\
\text { con limitación y se dictan otras disposiciones }\end{array}$ \\
\hline & Ley & $\begin{array}{l}\text { Ley núm. } 1618 \text {, por medio de la cual se establecen } \\
\text { las disposiciones para garantizar el pleno ejercicio } \\
\text { de los derechos de las personas con discapacidad }\end{array}$ \\
\hline Costa Rica (1996) & Ley & $\begin{array}{l}\text { Ley núm. } 7600, \text { Ley de Igualdad de Oportunidades } \\
\text { para las Personas con Discapacidad }\end{array}$ \\
\hline Cuba (1996) & Resolución & $\begin{array}{l}\text { Resolución núm. } 4 / 1996 \text { por la que se crea el } \\
\text { Consejo Nacional para la Atención a las Personas } \\
\text { con Discapacidad }\end{array}$ \\
\hline Ecuador (2012) & Ley & Ley Orgánica de Discapacidades \\
\hline El Salvador (2000) & $\begin{array}{l}\text { Declaración } \\
\text { legislativa }\end{array}$ & $\begin{array}{l}\text { Ley de Equiparación de Oportunidades para las } \\
\text { Personas con Discapacidad }\end{array}$ \\
\hline \multirow[t]{2}{*}{ Guatemala $(1996 ; 2008)$} & Decreto & $\begin{array}{l}\text { Ley núm. } 135 \text { de Atención a las Personas } \\
\text { con Discapacidad }\end{array}$ \\
\hline & Decreto & $\begin{array}{l}\text { Ley de Aprobación de la Política Nacional } \\
\text { en Discapacidad y Plan de Acción }\end{array}$ \\
\hline Honduras (2005) & Decreto & $\begin{array}{l}\text { Ley núm. } 160 \text { de Equidad y Desarrollo Integral } \\
\text { para las Personas con Discapacidad }\end{array}$ \\
\hline México (2011) & Ley & $\begin{array}{l}\text { Ley General para la Inclusión de las Personas } \\
\text { con Discapacidad }\end{array}$ \\
\hline Nicaragua (2011) & Ley & $\begin{array}{l}\text { Ley núm. } 763 \text { de los Derechos de las Personas } \\
\text { con Discapacidad }\end{array}$ \\
\hline
\end{tabular}


Cuadro VII.1 (conclusión)

\begin{tabular}{lll}
\hline País y año & Tipo & Norma \\
\hline Panamá (1999) & Ley & $\begin{array}{l}\text { Ley núm. 42, por la cual se establece la } \\
\text { equiparación de oportunidades para las personas } \\
\text { con discapacidad }\end{array}$ \\
\hline Paraguay (2012) & Ley & $\begin{array}{l}\text { Ley núm. 4720, por la que se crea la Secretaría } \\
\text { Nacional por los Derechos Humanos de las } \\
\text { Personas con Discapacidad (SENADIS) }\end{array}$ \\
\hline $\begin{array}{ll}\text { Perú (2012) } \\
\text { República Dominicana } \\
\text { (2013) }\end{array}$ & Lecreto supremo & $\begin{array}{l}\text { Ley núm. 29973, Ley General de la Persona } \\
\text { con Discapacidad }\end{array}$ \\
\hline $\begin{array}{l}\text { Uruguay 2010) } \\
\text { Venezuela (República }\end{array}$ & Ley & $\begin{array}{l}\text { Ley núm. 5 orgánica, sobre igualdad de derechos } \\
\text { de las personas con discapacidad }\end{array}$ \\
\hline $\begin{array}{l}\text { Bolivariana de) (2006) } \\
\text { Ley }\end{array}$ & $\begin{array}{l}\text { Ley núm. 18.651 de Protección Integral de } \\
\text { Personas con Discapacidad }\end{array}$ \\
\hline
\end{tabular}

Fuente: Elaboración propia, sobre la base de M.F. Stang, "Las personas con discapacidad en América Latina: del reconocimiento jurídico a la desigualdad real", serie Población y Desarrollo, N 103 (LC/L.3315-P), Santiago, Comisión Económica para América Latina y el Caribe (CEPAL), 2011; e información de los países.

En dos países (Cuba y Paraguay) la normativa nacional crea una instancia pública en materia de discapacidad. En los países restantes, además, se explicita una serie de derechos (véase el gráfico VII.1). Las leyes nacionales abarcan un amplio espectro de derechos económicos y sociales, como reflejo de la perspectiva de la CDPD que apunta a la construcción de una sociedad garantista de derechos, en que la participación de todas las personas con discapacidad dentro del desarrollo social sea plena, sin barreras ni exclusiones de ningún tipo (Vásconez y otros, 2013). Los derechos que más a menudo se contemplan en las principales leyes de discapacidad de los países de la región son los relacionados con la salud y la rehabilitación, la accesibilidad al entorno y a la comunicación, la educación, el trabajo o empleo y la protección contra la discriminación. Esto coincide con los derechos que son más ampliamente protegidos en las constituciones nacionales de los países (Stang, 2011). Otros ámbitos de derechos, como el acceso a la vivienda, a actividades culturales y a la participación política se mencionan con menor frecuencia.

En resumen, existe un extenso respaldo de los derechos de las personas con discapacidad en los marcos normativos en todos los niveles (internacional, regional y nacional) que instan a los gobiernos a aplicar una perspectiva holística e integral sobre los derechos de la población con discapacidad, así como adoptar medidas dirigidas hacia la creación de entornos favorables e inclusivos. Estas disposiciones legales confieren estabilidad y permanencia y expresan el compromiso del Estado de promover y proteger los derechos de las personas con discapacidad. Sin embargo, para traducir las aspiraciones contenidas en estas leyes en cambios concretos en las vidas de las personas con 
discapacidad, se requieren políticas e instituciones que puedan implementarlas. En vista de la mirada holística e integral de los derechos de esta población planteados en las normas vigentes, las instituciones de discapacidad deben ser capaces de coordinar y articularse con otras entidades del Estado para actuar de manera coherente en beneficio de esta población.

Gráfico VII.1

\section{América Latina (19 países): derechos consagrados en la ley principal de discapacidad}

(En número de países que hacen mención del ámbito de derecho)

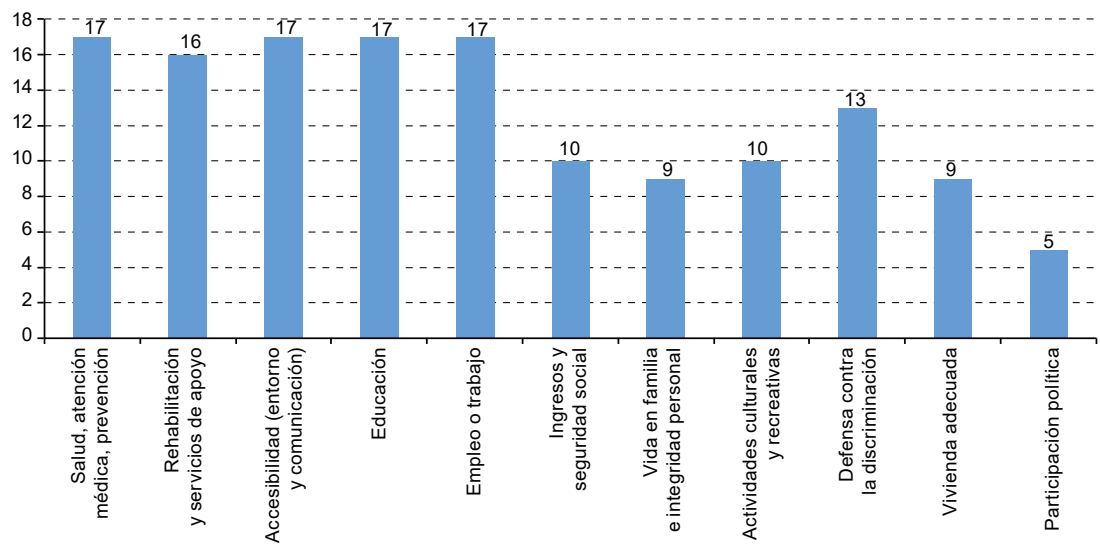

Fuente: Elaboración propia, sobre la base de M.F. Stang, "Las personas con discapacidad en América Latina: del reconocimiento jurídico a la desigualdad real”, serie Población y Desarrollo, № 103 (LC/L.3315-P), Santiago, Comisión Económica para América Latina y el Caribe (CEPAL), 2011; e información de los países.

\section{B. La dimensión organizacional}

A nivel internacional, el principal mecanismo de seguimiento de la Convención es el Comité sobre los Derechos de las Personas con Discapacidad. Este órgano de expertos independientes evalúa los informes enviados por los Estados Partes sobre las medidas que han adoptado para cumplir sus obligaciones surgidas de la Convención o los avances que han registrado desde la entrega del informe anterior, y emite recomendaciones ${ }^{5}$.

A la fecha, 18 países de América Latina han presentado informes al Comité, a saber: Argentina, Bolivia (Estado Plurinacional de), Brasil, Chile, Colombia, Costa Rica, Cuba, Ecuador, El Salvador, Guatemala, Honduras, México, Panamá, Paraguay, Perú, República Dominicana, Uruguay y Venezuela (República Bolivariana de). 
Los países de la región han dado pasos iniciales orientados a la creación de instancias regionales o subregionales con miras a proteger los derechos de las personas con discapacidad. Por ejemplo, el Mercado Común del Sur (MERCOSUR) tiene una Comisión Permanente de Promoción y Protección de los Derechos de las Personas con Discapacidad que se constituyó en 2008 con el objetivo de relevar información sobre la situación de los derechos humanos de las personas con discapacidad en la región, e impulsar el intercambio de experiencias y buenas prácticas entre los Estados Partes y asociados. También se ha presentado una propuesta en el parlamento del MERCOSUR de crear una subcomisión de la discapacidad en el marco de la Comisión de Ciudadanía y Derechos Humanos. Otro ejemplo es la Política Andina en Salud para la Prevención de la Discapacidad y para la Atención, Habilitación/Rehabilitación Integral de las Personas con Discapacidad del Organismo Andino de Salud-Convenio Hipólito Unanue, impulsado por los ministerios de salud de la subregión andina. Con esta política se busca fortalecer la gestión sanitaria de los países andinos con miras al mejoramiento de las medidas en materia de salud y protección, relacionadas con la prevención, atención, habilitación y rehabilitación de las personas con discapacidad, en el marco de la promoción, protección y garantía del derecho a la salud. Todo lo anterior debe realizarse en condiciones de equidad, promoviendo la participación de la población con discapacidad y propiciando el respeto a su dignidad y la posibilidad de su inserción o reinserción social (Organismo Andino de Salud-Convenio Hipólito Unanue, 2011). Este organismo se ha convertido en un referente para la elaboración de políticas públicas en materia de discapacidad en los países andinos.

\section{Las instituciones nacionales y sus características}

Todos los países de la región cuentan con una instancia gubernamental de promoción de los derechos de las personas con discapacidad (véase el cuadro VII.3). La figura más frecuente, observada en 12 países, es la de comisión intersectorial, seguida por secretarías. En primera instancia, son la autoridad en el tema de discapacidad, y hay bastante concordancia en cuanto a sus otras funciones, pues la mayoría de ellas formulan, ejecutan y gestionan políticas y programas. También son responsables, en muchos casos, de realizar labores de coordinación y articulación a nivel intersectorial. Como se ha mencionado, el desafío que enfrentan estas instancias es tener el liderazgo y la capacidad de cabildeo necesarios para coordinar y movilizar los recursos técnicos y financieros de las múltiples secciones que los componen de manera articulada. 


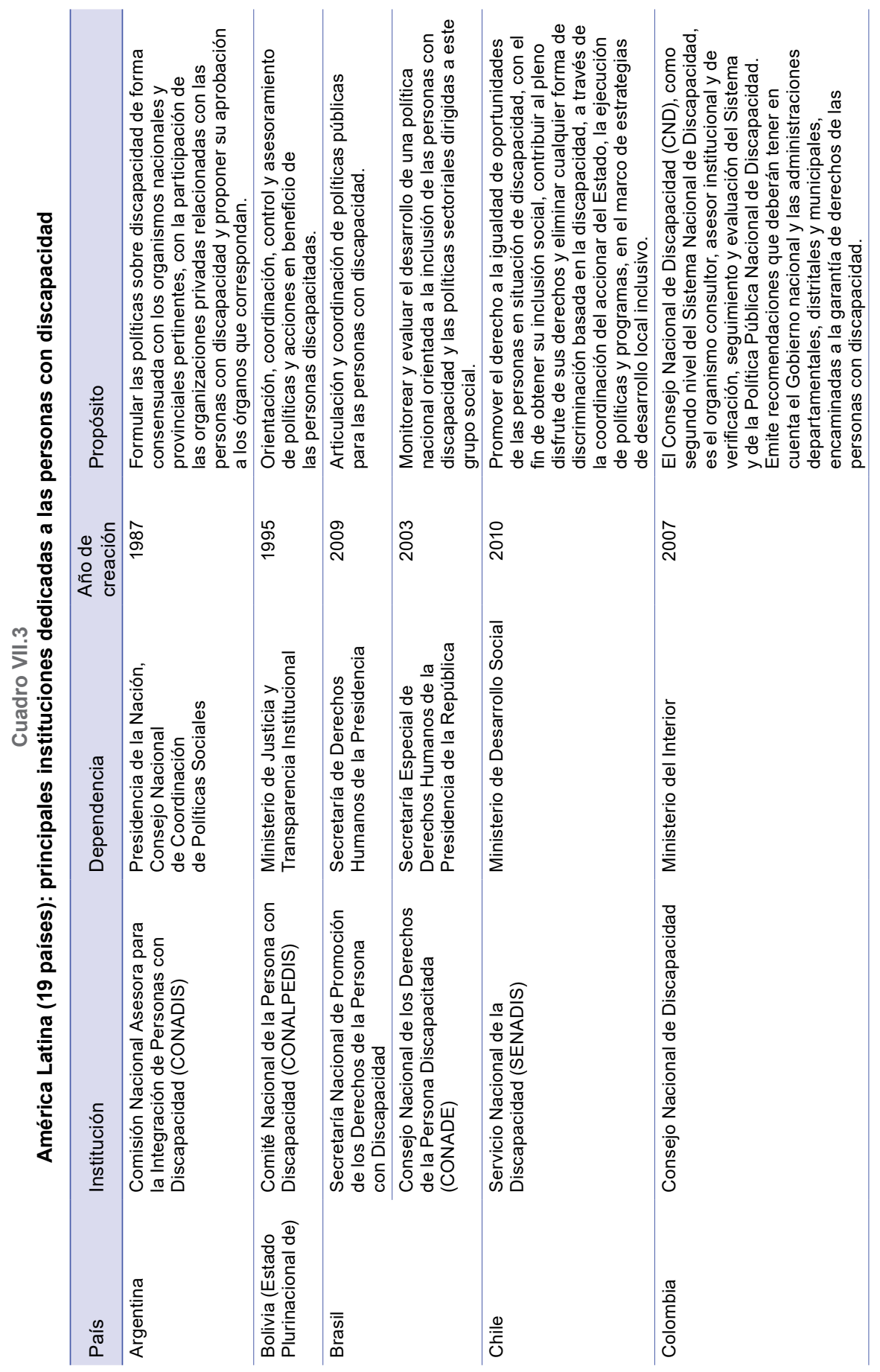




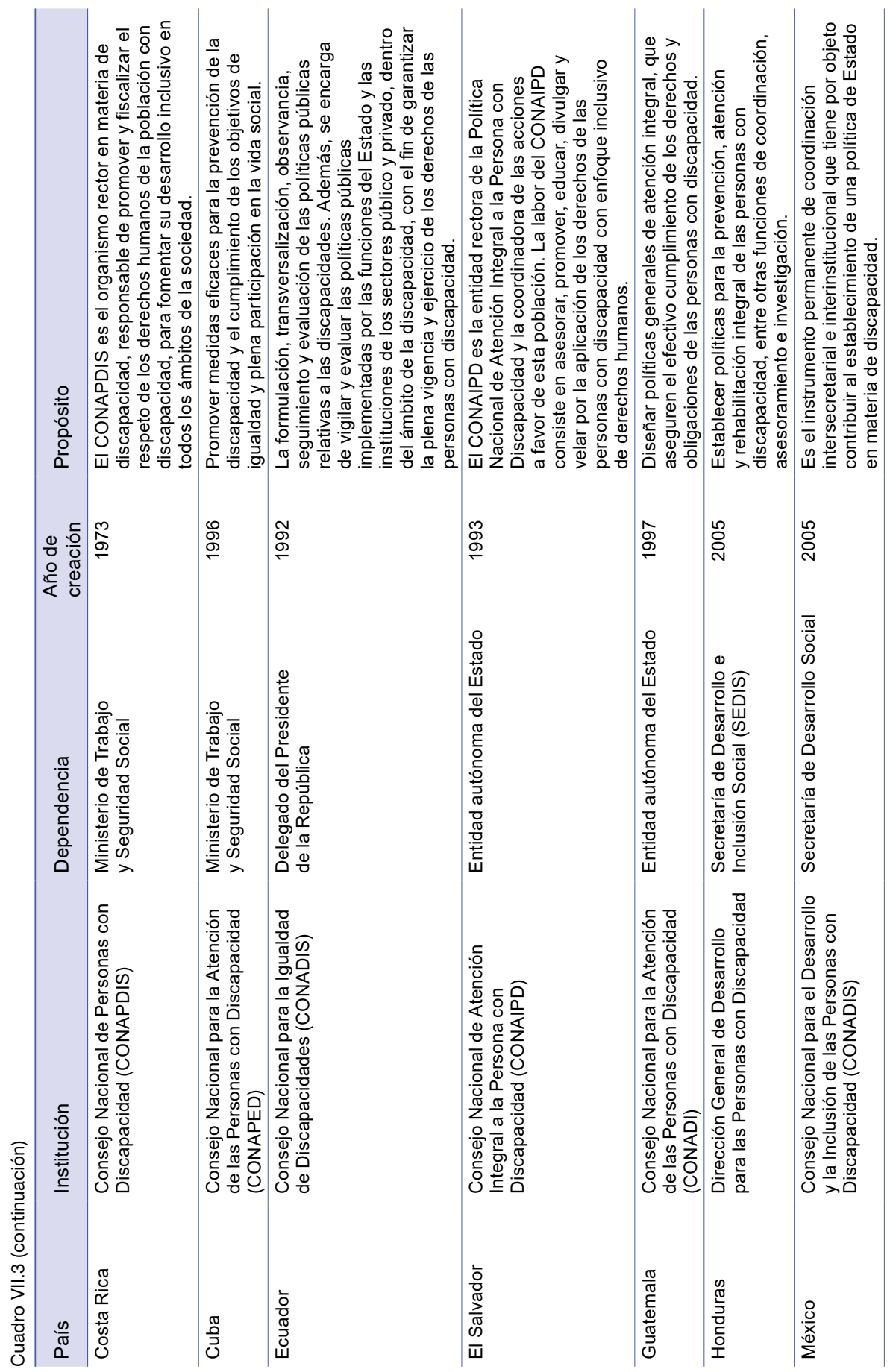




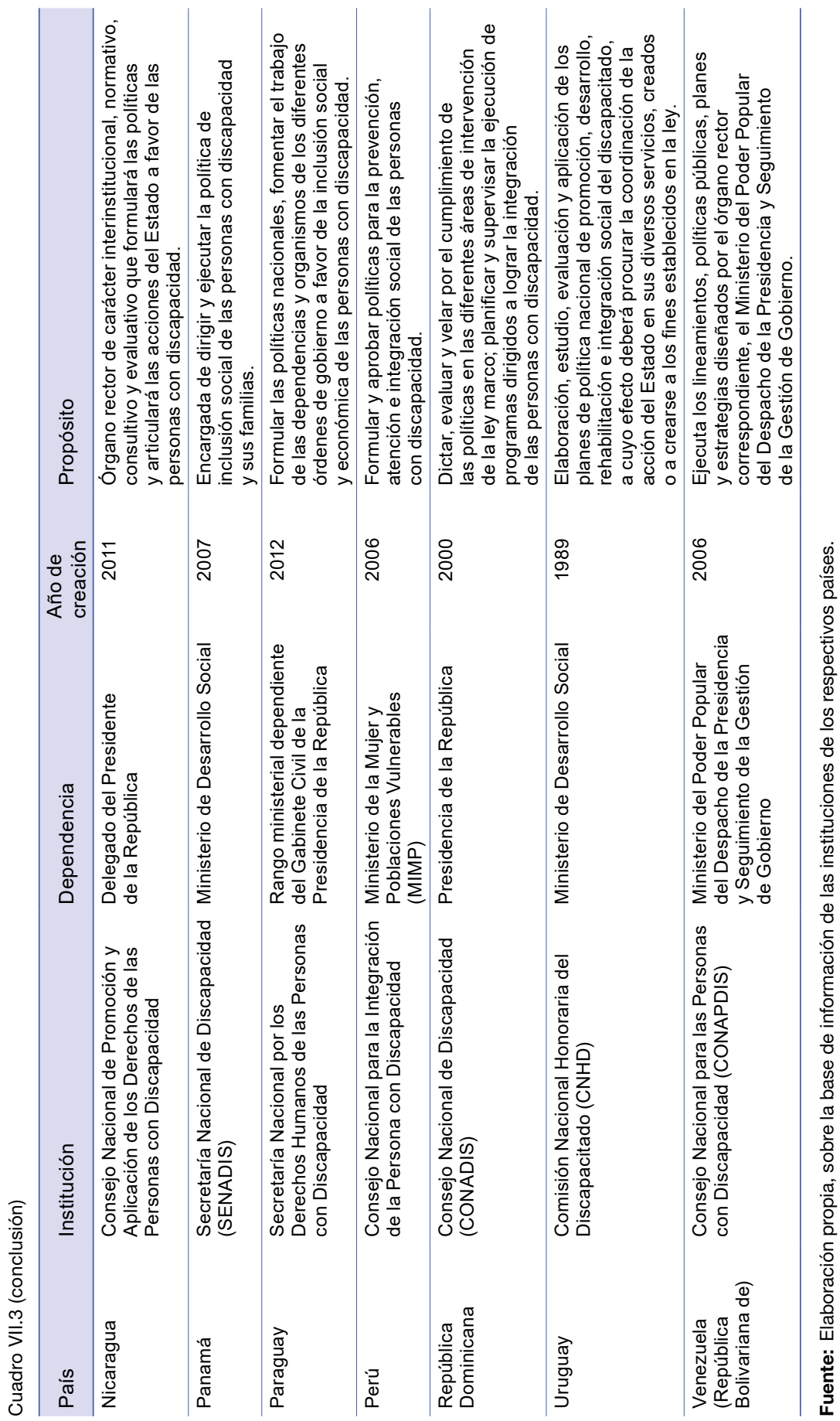


En cuanto a su dependencia, se observa algo de heterogeneidad. En 5 de los 19 países, las instancias dependen de la Presidencia y en otros 5 casos dependen del Ministerio de Desarrollo Social. El mandato de aplicar la CDPD recae sobre las instancias públicas de discapacidad y requiere articulación y coordinación con los ministerios sectoriales. En consecuencia, el hecho de estar situado al más alto nivel posible puede aportar un respaldo político importante para realizar esta difícil tarea (Naciones Unidas, 2006). En el resto de los casos, se trata de configuraciones subministeriales adscritas a los ministerios de trabajo, de desarrollo social, de justicia o del interior y, en el caso del Perú, al Ministerio de la Mujer y Poblaciones Vulnerables.

Estas instancias tienen una larga trayectoria en algunos países, siendo la más antigua el Consejo Nacional de Personas con Discapacidad (CONAPDIS) de Costa Rica, creado en $1973^{6}$. Sin embargo, en la mayoría de los países las entidades correspondientes emergen en el siglo XXI y, en muchos casos, a partir de 2005, para dar seguimiento y cumplimiento a los compromisos asumidos por los Estados al ratificar la CDPD, así como a lo establecido en la normativa nacional. A fin de evitar la duplicación y la dilución de responsabilidades entre los sectores gubernamentales, los Estados Partes en la Convención deben designar un organismo que sea responsable de coordinar su aplicación dentro del Gobierno (Naciones Unidas, 2006). Debido a su relativa juventud, un desafío para esas entidades es mantener su estabilidad a lo largo del tiempo y consolidar relaciones perdurables con otras instituciones.

Otro desafío importante que enfrentan estas instituciones es el de contar con los recursos humanos y financieros necesarios, de forma consistente, para poder lograr estos objetivos ambiciosos. La visibilidad y peso que tienen las instituciones y el tema de discapacidad en general son altamente variables y dependen en gran medida de la voluntad política e interés del gobierno de turno. Si bien la retórica en torno a los derechos de las personas con discapacidad está bastante incorporada al discurso político, no siempre sucede que esto vaya acompañado de la asignación de recursos para garantizar que las personas con discapacidad puedan ejercer esos derechos.

La Ley núm. 5347 del Consejo Nacional de Rehabilitación y Educación Especial (CNREE), de 3 de septiembre de 1973. El CONAPDIS asumió la rectoría en discapacidad. Más recientemente se aprobó la Ley núm. 18.547, por la que se reforma la institución y se le da el nombre de Consejo Nacional de las Personas con Discapacidad de 2012. 


\section{Participación ciudadana en las instancias de discapacidad}

Las organizaciones de la sociedad civil que abogan por el tema de la discapacidad tienen una larga trayectoria. Antes de que se consolidara una institucionalidad pública, eran ellas las que promovían la inclusión de las personas con discapacidad y daban visibilidad al tema (Giler, 2012). En tiempos recientes, la amplia ratificación de la CIADDIS y de la CDPC por los países de la región dio un mayor impulso a la movilización y generó nuevas demandas sociales por parte de estas organizaciones. Si bien existe cierta dispersión en sus objetivos, por las diversas necesidades que presentan los diferentes tipos de discapacidad, en su conjunto han logrado posicionar con firmeza el tema de los derechos de las personas con discapacidad en la agenda pública de la región. En el lema de estas organizaciones ("nada sobre nosotros sin nosotros"), se expresa la aspiración de estas personas y sus familiares de ser escuchados e incluidos en espacios de toma de decisiones como sujetos, y no vistos como objetos de caridad.

Las instituciones públicas a cargo de las políticas de discapacidad emplean diversas modalidades para articularse con las organizaciones por y para las personas con discapacidad (véase el cuadro VII.4). La configuración más recurrente es un consejo o comité asesor que incluye a representantes de esas organizaciones, entre otros actores. También se realizan diferentes actividades o ejercicios puntuales de participación dirigidos a un público más amplio. Por ejemplo, en 2014 se llevaron a cabo procesos participativos para la preparación de la Segunda Encuesta Nacional de Discapacidad (ENDISC II) de Chile, así como jornadas de participación en torno a temas específicos.

La participación en la toma de decisiones es clave para que las políticas implementadas sean más efectivas y legítimas. No obstante, es importante reflexionar sobre quiénes participan en estos espacios o, lo que es aún más importante: ¿quiénes no participan? ¿qué tan representativos son los espacios de participación? Esta última pregunta es especialmente relevante si se considera la gran heterogeneidad de experiencias de vida de las personas con discapacidad. Por ejemplo, las muy disímiles posibilidades de inclusión que tienen, según el tipo de discapacidad. En este sentido, es importante garantizar la accesibilidad para las personas con discapacidad en los espacios de participación, y considerar medidas tendientes a expandir el alcance de esos espacios para llegar a personas que quedan al margen de estos procesos, por ejemplo, las personas con discapacidad mental. 


\section{Cuadro VII.4 \\ América Latina (12 países): ejemplos de mecanismos de participación ciudadana en las instancias principales de discapacidad}

\begin{tabular}{|c|c|c|}
\hline País & Institución & Mecanismos de participación \\
\hline Argentina & $\begin{array}{l}\text { Comisión Nacional } \\
\text { Asesora para la } \\
\text { Integración de Personas } \\
\text { con Discapacidad } \\
\text { (CONADIS) }\end{array}$ & $\begin{array}{l}\text { El Comité Asesor tiene el propósito de potenciar el } \\
\text { diálogo civil y la participación efectiva en las políticas } \\
\text { públicas del movimiento asociativo, corresponsable } \\
\text { de la acción pública en la materia. Este Comité se } \\
\text { constituye en un factor esencial en la definición } \\
\text { de una acción pública integrada que considere las } \\
\text { necesidades y problemas reales de las personas } \\
\text { con discapacidad. Está integrado por organizaciones } \\
\text { no gubernamentales que se ocupan de temas } \\
\text { relacionados con estas personas. }\end{array}$ \\
\hline Chile & $\begin{array}{l}\text { Servicio Nacional de la } \\
\text { Discapacidad (SENADIS) }\end{array}$ & $\begin{array}{l}\text { El Consejo Consultivo de la Discapacidad tiene por } \\
\text { finalidad hacer efectiva la participación y el diálogo } \\
\text { social en el proceso de igualdad de oportunidades, } \\
\text { inclusión social, participación y accesibilidad de las } \\
\text { personas en situación de discapacidad. Sus miembros } \\
\text { incluyen representantes de organizaciones relacionadas } \\
\text { con las personas con discapacidad, así como del sector } \\
\text { empresarial y de organizaciones de trabajadores. }\end{array}$ \\
\hline Cuba & $\begin{array}{l}\text { Consejo Nacional para la } \\
\text { Atención de las Personas } \\
\text { con Discapacidad } \\
\text { (CONAPED) }\end{array}$ & $\begin{array}{l}\text { EI CONAPED está integrado por los organismos e } \\
\text { instituciones que tienen que ver con esta actividad y } \\
\text { las asociaciones de personas con discapacidad. Lo } \\
\text { preside el Ministro de Trabajo y Seguridad Social. }\end{array}$ \\
\hline Ecuador & $\begin{array}{l}\text { Consejo Nacional } \\
\text { para la Igualdad } \\
\text { de Discapacidades } \\
\text { (CONADIS) }\end{array}$ & $\begin{array}{l}\text { Consejo Consultivo conformado por federaciones } \\
\text { de y para personas con discapacidad. }\end{array}$ \\
\hline El Salvador & $\begin{array}{l}\text { Consejo Nacional de } \\
\text { Atención Integral a la } \\
\text { Persona con Discapacidad } \\
\text { (CONAIPD) }\end{array}$ & $\begin{array}{l}\text { El Comité Técnico, en su calidad de consejo pleno del } \\
\text { CONAIPD, tiene representación de las organizaciones } \\
\text { especializadas en temas relacionados con las } \\
\text { personas con discapacidad. }\end{array}$ \\
\hline Honduras & $\begin{array}{l}\text { Dirección General } \\
\text { de Desarrollo } \\
\text { para las Personas } \\
\text { con Discapacidad }\end{array}$ & $\begin{array}{l}\text { El Consejo Consultivo es un órgano auxiliar } \\
\text { de la Dirección General de Desarrollo para las } \\
\text { Personas con Discapacidad, que está compuesto } \\
\text { por representantes de secretarías de Estado, } \\
\text { representantes de organizaciones de personas con } \\
\text { discapacidad y asociaciones de familiares. }\end{array}$ \\
\hline México & $\begin{array}{l}\text { Consejo Nacional para el } \\
\text { Desarrollo y la Inclusión } \\
\text { de las Personas con } \\
\text { Discapacidad (CONADIS) }\end{array}$ & $\begin{array}{l}\text { La Asamblea Consultiva es un órgano de asesoría } \\
\text { y consulta del Consejo Nacional para el Desarrollo } \\
\text { y la Inclusión de las Personas con Discapacidad, } \\
\text { de participación ciudadana, conformación plural y } \\
\text { carácter honorífico, que tiene por objeto analizar } \\
\text { y proponer programas y acciones que incidan } \\
\text { en el cumplimiento del programa y ejercicios de } \\
\text { participación ciudadana. }\end{array}$ \\
\hline Nicaragua & $\begin{array}{l}\text { Consejo Nacional de } \\
\text { Promoción y Aplicación } \\
\text { de los Derechos } \\
\text { de las Personas } \\
\text { con Discapacidad }\end{array}$ & $\begin{array}{l}\text { El Gabinete del Poder Ciudadano de las Personas } \\
\text { con Discapacidad está compuesto por organizaciones } \\
\text { relacionadas con las personas con discapacidad } \\
\text { de todo el país, donde se debaten las decisiones y } \\
\text { cambios en legislación que les afectan y que sirve } \\
\text { como espacio de intercambio con los líderes políticos. }\end{array}$ \\
\hline Panamá & $\begin{array}{l}\text { Secretaría Nacional de } \\
\text { Discapacidad (SENADIS) }\end{array}$ & $\begin{array}{l}\text { El Consejo Nacional Consultivo de Discapacidad } \\
\text { (CONADIS) es un organismo de consulta y apoyo de } \\
\text { carácter interinstitucional e intersectorial, presidido por } \\
\text { el Órgano Ejecutivo, creado para promover los objetivos } \\
\text { y fines que debe cumplir la SENADIS en lo referente a la } \\
\text { ejecución de las políticas sociales sobre discapacidad. }\end{array}$ \\
\hline
\end{tabular}


Cuadro VII.4 (conclusión)

\begin{tabular}{|c|c|c|}
\hline País & Institución & Mecanismos de participación \\
\hline Paraguay & $\begin{array}{l}\text { Secretaría Nacional por } \\
\text { los Derechos Humanos } \\
\text { de las Personas con } \\
\text { Discapacidad }\end{array}$ & $\begin{array}{l}\text { La Comisión Nacional de la Discapacidad (CONADIS) } \\
\text { está conformada por las organizaciones de y para } \\
\text { personas con discapacidad y trabajará de cerca con } \\
\text { la SENADIS en la elaboración y aplicación de políticas } \\
\text { públicas orientadas a esas personas. }\end{array}$ \\
\hline Perú & $\begin{array}{l}\text { Consejo Nacional para la } \\
\text { Integración de la Persona } \\
\text { con Discapacidad }\end{array}$ & $\begin{array}{l}\text { La Comisión Consultiva es el órgano encargado } \\
\text { de asesorar al Consejo Directivo sobre las políticas } \\
\text { públicas en materia de discapacidad, desde } \\
\text { un enfoque ciudadano, y está conformada por } \\
\text { representantes de las organizaciones vinculadas a la } \\
\text { temática de discapacidad, de reconocida capacidad } \\
\text { o experiencia, elegidos por la sociedad civil y } \\
\text { acreditados mediante una resolución } \\
\text { de la Presidencia. }\end{array}$ \\
\hline $\begin{array}{l}\text { Venezuela } \\
\text { (República } \\
\text { Bolivariana de) }\end{array}$ & $\begin{array}{l}\text { Consejo Nacional } \\
\text { para las Personas } \\
\text { con Discapacidad } \\
\text { (CONAPDIS) }\end{array}$ & $\begin{array}{l}\text { El Consejo Presidencial de Gobierno Popular } \\
\text { de Personas con Discapacidad tiene el propósito } \\
\text { de coadyuvar en la generación y ejecución de políticas } \\
\text { públicas efectivas, así como el ejercicio del poder } \\
\text { popular, por medio de voceros a nivel de cada entidad } \\
\text { (estados y municipios). En asambleas populares se } \\
\text { recopila información relativa a necesidades globales } \\
\text { y planteamientos para su corrección y prevención, } \\
\text { que luego se somete a la consideración de los } \\
\text { ministros y el Presidente de la República. }\end{array}$ \\
\hline
\end{tabular}

Fuente: Elaboración propia, sobre la base de información de las instituciones de los respectivos países.

Es interesante observar en el cuadro VII.4 que los mecanismos que proporcionan un espacio de participación formal para las organizaciones por y para las personas con discapacidad en algunos casos también contemplan la participación de actores de los diferentes sectores que se vinculan a esa población. Por ejemplo, los consejos o comités de Cuba, Honduras y Panamá incluyen representantes de los diversos ministerios.

\section{Mecanismos de articulación}

Uno de los grandes retos institucionales es la articulación; existen mecanismos de articulación horizontal (véase el cuadro VII.5). Aquí se observa la existencia de comités o grupos de carácter intersectorial o interinstitucional dentro de las instancias de discapacidad (por ejemplo, en la Argentina, Colombia y Nicaragua) o comisiones sobre discapacidad en los ministerios e instituciones que se vinculan con la instancia de discapacidad (en Costa Rica). En Honduras existe la figura de Ministro Asesor en Asuntos de Discapacidad (secretaría sin cartera), que tiene como propósito crear un enlace entre las organizaciones y federaciones del sector de personas con discapacidad en el país. Algunos ejemplos de modalidades de trabajo articulado son los convenios de colaboración entre las instituciones o sectores y grupos o mesas de trabajo en torno a un tema específico. Por ejemplo, en Chile, el SENADIS conformó una Mesa Técnica Intersectorial de Derechos Sexuales y Reproductivos de las Personas con Discapacidad en colaboración con el Ministerio de la Mujer y la Equidad de Género. 


\section{América Latina (10 países): ejemplos de mecanismos y modalidades de articulación interinstitucional o intersectorial de las instancias principales de discapacidad}

\begin{tabular}{|c|c|c|}
\hline País & Institución & Mecanismo de articulación interinstitucional o intersectorial \\
\hline Argentina & $\begin{array}{l}\text { Comisión Nacional } \\
\text { Asesora para la } \\
\text { Integración de } \\
\text { Personas con } \\
\text { Discapacidad } \\
\text { (CONADIS) }\end{array}$ & $\begin{array}{l}\text { El Comité Técnico asiste a la CONADIS en la articulación } \\
\text { intersectorial e interministerial, y entre los diferentes poderes } \\
\text { del Estado en la coordinación de estrategias para la efectiva } \\
\text { aplicación de la Convención sobre los Derechos de las } \\
\text { Personas con Discapacidad y la normativa vigente, desde } \\
\text { un enfoque inclusivo. }\end{array}$ \\
\hline Chile & $\begin{array}{l}\text { Servicio Nacional } \\
\text { de la Discapacidad } \\
\text { (SENADIS) }\end{array}$ & Mesas de trabajo intersectoriales. \\
\hline Colombia & $\begin{array}{l}\text { Sistema Nacional } \\
\text { de Discapacidad }\end{array}$ & $\begin{array}{l}\text { Grupos de Enlace Sectorial (GES), la instancia técnica de } \\
\text { construcción, concertación y coordinación interinstitucional } \\
\text { de planes, proyectos y programas del Consejo Nacional de } \\
\text { Discapacidad (CND), bajo la coordinación de este, a través } \\
\text { de su Secretaría Técnica. Los GES se conforman con los } \\
\text { ministerios de salud y protección social; educación; transporte; } \\
\text { defensa; comercio, industria y turismo; tecnologías de la } \\
\text { información y las comunicaciones, y hacienda y crédito } \\
\text { público; además de instituciones adscritas como el Instituto } \\
\text { Colombiano de Bienestar Familiar, el Servicio Nacional de } \\
\text { Aprendizaje (SENA), el Instituto Nacional para Ciegos (INCI) } \\
\text { y el Instituto Nacional para Sordos (INSOR). }\end{array}$ \\
\hline Costa Rica & $\begin{array}{l}\text { Consejo Nacional } \\
\text { de Rehabilitación } \\
\text { y Educación } \\
\text { Especial(CNREE) }\end{array}$ & $\begin{array}{l}\text { Las comisiones que cada institución debe tener son } \\
\text { la contraparte con que cuenta el Consejo Nacional de } \\
\text { Personas con Discapacidad para mejorar la calidad de } \\
\text { atención que se da a la población con discapacidad cuando } \\
\text { acude a recibir los distintos tipos de servicios que ofrece la } \\
\text { institucionalidad costarricense. Algunas son conocidas como } \\
\text { Comisión Institucional en Materia de Discapacidad (CIMAD) } \\
\text { y otras como Comisión Institucional sobre Accesibilidad y } \\
\text { Discapacidad (CIAD). }\end{array}$ \\
\hline Ecuador & $\begin{array}{l}\text { Consejo Nacional } \\
\text { para la Igualdad } \\
\text { de Discapacidades } \\
\text { (CONADIS) }\end{array}$ & $\begin{array}{l}\text { Para formular la política pública en el ámbito de } \\
\text { discapacidades, el CONADIS orienta las acciones y convoca } \\
\text { a las instituciones de todos los poderes del Estado, a los } \\
\text { gobiernos autónomos descentralizados, así como a los actores } \\
\text { sociales, políticos y económicos con el fin de generar normas, } \\
\text { reglamentos, decretos, ordenanzas, convenios, acuerdos, } \\
\text { resoluciones, así como otros actos, acciones, proyectos y } \\
\text { decisiones. Su labor debe basarse en un enfoque de derechos } \\
\text { humanos, con énfasis en la igualdad y la no discriminación, } \\
\text { como garantía de los derechos individuales y colectivos de } \\
\text { las personas con discapacidad y sus familias. El CONADIS } \\
\text { conforma el primer nivel del Sistema Nacional de Protección } \\
\text { Integral de las Personas con Discapacidad (artículo 88 de la } \\
\text { Ley Orgánica de Discapacidades) y forma parte del Sistema } \\
\text { Nacional de Protección de Derechos (Ley Orgánica de los } \\
\text { Consejos Nacionales para la Igualdad), por tanto, articula } \\
\text { acciones con la Defensoría del Pueblo, la Defensoría Pública, } \\
\text { la Fiscalía General del Estado, entre otros. }\end{array}$ \\
\hline Guatemala & $\begin{array}{l}\text { Consejo Nacional } \\
\text { para la Atención } \\
\text { de las Personas } \\
\text { con Discapacidad } \\
\text { (CONADI) }\end{array}$ & Convenios de cooperación interinstitucional. \\
\hline Honduras & $\begin{array}{l}\text { Dirección General } \\
\text { de Desarrollo para } \\
\text { las Personas con } \\
\text { Discapacidad }\end{array}$ & $\begin{array}{l}\text { El Ministro Asesor en Asuntos de Discapacidad (secretaría } \\
\text { sin cartera) que tiene como propósito crear un enlace entre } \\
\text { las organizaciones y federaciones del sector de personas con } \\
\text { discapacidad en el país. }\end{array}$ \\
\hline
\end{tabular}


Cuadro VII.5 (conclusión)

\begin{tabular}{|c|c|c|}
\hline País & Institución & Mecanismo de articulación interinstitucional o intersectorial \\
\hline México & $\begin{array}{l}\text { Consejo Nacional } \\
\text { para el Desarrollo } \\
\text { y la Inclusión de } \\
\text { las Personas con } \\
\text { Discapacidad } \\
\text { (CONADIS) }\end{array}$ & Grupos de trabajo y comités intersectorial e interinstitucional. \\
\hline Nicaragua & $\begin{array}{l}\text { Consejo Nacional de } \\
\text { Promoción y Aplicación } \\
\text { de los Derechos de } \\
\text { las Personas con } \\
\text { Discapacidad }\end{array}$ & $\begin{array}{l}\text { Secretaría de Promoción y Articulación para la aplicación de } \\
\text { los derechos de las personas con discapacidad: órgano de } \\
\text { asesoría técnica y coordinación del Consejo. }\end{array}$ \\
\hline Perú & $\begin{array}{l}\text { Consejo Nacional } \\
\text { para la Integración } \\
\text { de la Persona } \\
\text { con Discapacidad }\end{array}$ & $\begin{array}{l}\text { EI Sistema Nacional para la Integración de la Persona con } \\
\text { Discapacidad (SINAPEDIS), que realiza un trabajo articulado y } \\
\text { compromete a los tres niveles de gobierno (el CONADIS y los } \\
\text { gobiernos regionales y municipalidades) en el cumplimiento de } \\
\text { las políticas en materia de discapacidad. }\end{array}$ \\
\hline
\end{tabular}

Fuente: Elaboración propia, sobre la base de información de las instituciones de los respectivos países.

En cuanto al alcance geográfico de la institucionalidad a nivel subnacional en materia de discapacidad se observan diversos ejemplos de mecanismos de articulación (véase el cuadro VII.6). En muchos países existe un mecanismo institucionalizado de vínculo con el ámbito local, y en otros, adquieren un carácter más ad hoc. Entre otros ejemplos de mecanismos institucionalizados cabe mencionar los consejos, comités y comisiones descentralizados que trabajan a nivel local. También es de destacar el trabajo directo en el marco de convenios y otros mecanismos con entidades locales, por ejemplo, los consejos de derechos humanos y, como acciones más ad hoc, los encuentros locales organizados por las instituciones de discapacidad.

\section{Cuadro VII.6}

América Latina (11 países): ejemplos de mecanismos de articulación territorial en las instancias principales de discapacidad

\begin{tabular}{lll}
\hline País & Institución & Mecanismo de articulación territorial \\
\hline Argentina & $\begin{array}{l}\text { Comisión Nacional } \\
\text { Asesora para la } \\
\text { Integración de Personas } \\
\text { con Discapacidad } \\
\text { (CONADIS) }\end{array}$ & $\begin{array}{l}\text { El Consejo Federal tiene por objeto la descentralización } \\
\text { y la capacidad resolutiva en el orden local y regional, y } \\
\text { el fomento de la interrelación permanente de los entes } \\
\text { gubernamentales y organizaciones de la sociedad civil que } \\
\text { actúan en el tema a nivel territorial. }\end{array}$ \\
\hline Brasil & $\begin{array}{l}\text { Consejo Nacional de } \\
\text { los Derechos de la } \\
\text { Persona Discapacitada } \\
\text { (CONADE) }\end{array}$ & Encuentros regionales; consejos estatales y municipales. \\
& Servicio Nacional de la & \\
Discapacidad (SENADIS) & $\begin{array}{l}\text { La Estrategia de Desarrollo Local Inclusivo (EDLI), es una } \\
\text { oferta multiprogramática que tiene como objetivo generar en }\end{array}$ \\
& $\begin{array}{l}\text { los territorios un proceso creciente de inclusión social } \\
\text { de las personas en situación de discapacidad, así como } \\
\text { de sus familias y organizaciones. Además, considera } \\
\text { un plan de apoyo a los municipios con la finalidad de }\end{array}$ \\
& $\begin{array}{l}\text { impulsar gestiones intersectoriales de envergadura para } \\
\text { estabilizar una política pública de largo plazo que fortalezca } \\
\text { planes de inclusión social de las personas en situación de } \\
\text { discapacidad, desde los gobiernos locales, en alianza con } \\
\text { las organizaciones comunitarias. }\end{array}$ \\
\hline
\end{tabular}


Cuadro VII.6 (conclusión)

\begin{tabular}{lll}
\hline País & Institución & Mecanismo de articulación territorial \\
\hline Colombia & Sistema Nacional de & El sistema opera en cuatro niveles: i) el Ministerio \\
& Discapacidad & de Salud y Protección Social o el organismo rector \\
& del Sistema; ii) el Consejo Nacional de Discapacidad \\
& (CND), como organismo consultor, asesor institucional \\
& y de verificación, seguimiento y evaluación del Sistema \\
& y de la Política Pública Nacional de Discapacidad; \\
& iii) los comités departamentales y distritales de \\
& discapacidad (CDD), como niveles intermedios de \\
& concertación, asesoría, consolidación y seguimiento \\
& de la Política Pública en Discapacidad; iv) los comités \\
& municipales y locales de discapacidad (CMD o CLD) como \\
& niveles de deliberación, construcción y seguimiento \\
& de la política pública de discapacidad.
\end{tabular}

\begin{tabular}{ll}
\hline Costa & Consejo Nacional \\
Rica & de Rehabilitación \\
& y Educación \\
& Especial(CNREE)
\end{tabular}

Rectorías regionales; las Comisiones Municipales sobre Accesibilidad y Discapacidad (COMAD), creadas mediante la Ley núm. 8822, son la instancia encargada en cada municipio de velar por que en el cantón se cumpla la Ley núm. 7600, de Igualdad de Oportunidades para las Personas con Discapacidad, de 2 de mayo de 1996.

Cuba Consejo Nacional para la Este Consejo funciona a nivel nacional, provincial y Atención de las Personas municipal. En esas dos últimas instancias es presidido con discapacidad (CONAPED), estructura intrasectorial por el Director de Trabajo del Órgano del Poder Popular y el Vicepresidente del Gobierno que atiende la esfera económica. Tiene la finalidad de formular y evaluar el cumplimiento del Plan de Acción Nacional para la Atención a las Personas con Discapacidad, que incluye un grupo de programas vinculados al proceso económico y de inserción laboral y social.

\begin{tabular}{|c|c|c|}
\hline Ecuador & $\begin{array}{l}\text { Consejo Nacional } \\
\text { para la Igualdad } \\
\text { de Discapacidades } \\
\text { (CONADIS) }\end{array}$ & $\begin{array}{l}\text { EI CONADIS trabaja directamente con los consejos } \\
\text { cantonales de protección de derechos, como instancias } \\
\text { de observancia ciudadana en los gobiernos autónomos } \\
\text { descentralizados cantonales. }\end{array}$ \\
\hline México & $\begin{array}{l}\text { Consejo Nacional } \\
\text { para el Desarrollo y la } \\
\text { Inclusión de las Personas } \\
\text { con Discapacidad } \\
\text { (CONADIS) }\end{array}$ & $\begin{array}{l}\text { Convenios de coordinación entre el CONADIS y los } \\
\text { gobiernos de las entidades federativas. }\end{array}$ \\
\hline Panamá & $\begin{array}{l}\text { Secretaría Nacional de } \\
\text { Discapacidad (SENADIS) }\end{array}$ & $\begin{array}{l}\text { Filiales regionales que se encargan de implementar todas } \\
\text { sus acciones, programas y proyectos en el interior del país. } \\
\text { Cada una de ellas cuenta con personal de administración, } \\
\text { asesores legales, trabajadoras sociales y unidades de enlace } \\
\text { en cada provincia. Por otra parte, las direcciones regionales } \\
\text { coordinan con las autoridades locales y con las direcciones } \\
\text { regionales de otras instituciones para transversalizar el tema } \\
\text { de la inclusión social de las personas con discapacidad } \\
\text { mediante los consejos provinciales de discapacidad } \\
\text { (CONADIS provinciales). }\end{array}$ \\
\hline Paraguay & $\begin{array}{l}\text { Secretaría Nacional por } \\
\text { los Derechos Humanos } \\
\text { de las Personas con } \\
\text { Discapacidad }\end{array}$ & Filiales regionales. \\
\hline Perú & $\begin{array}{l}\text { Consejo Nacional para la } \\
\text { Integración de la Persona } \\
\text { con Discapacidad }\end{array}$ & $\begin{array}{l}\text { Consejo de Coordinación Regional (CCR)/Consejo de } \\
\text { Coordinación Local (CCL). }\end{array}$ \\
\hline
\end{tabular}

Fuente: Elaboración propia, sobre la base de información disponible de las instituciones de los respectivos países. 


\section{La dimensión técnico-operativa}

Uno de los elementos clave al analizar la dimensión técnico-operativa de la institucionalidad es la existencia de instrumentos y herramientas para implementar acciones que permitan alcanzar los objetivos institucionales de manera efectiva y eficiente. En casi todos los países de la región existe una herramienta (plan, estrategia o política), que orienta las acciones de las instancias públicas en materia de discapacidad (véanse el cuadro VII.7 y el recuadro VII.1). Estos planes, estrategias y políticas parten de un enfoque de derechos e incluyen otros enfoques como el de género o de territorialidad, y se organizan en torno a ejes de acción temáticos como la educación, la salud y el empleo. En la mayoría de los países estas herramientas explicitan mecanismos para su implementación, ejecución y monitoreo y evaluación, al establecer líneas de acción, actividades, plazos de ejecución, asignación de roles a los diferentes actores, y temporalidad de las evaluaciones. Sin embargo, son pocos los países (por ejemplo, El Salvador, México y Perú) que incluyen indicadores para dar seguimiento a la implementación de estas herramientas. En muchos casos los planes explicitan cómo se insertan en el marco de la estrategia o plan nacional de desarrollo y cómo se vinculan con los mecanismos de seguimiento y planificación a nivel nacional.

Otro aspecto clave de la dimensión técnico-operativa es el de los sistemas de información. Los datos que permitan conocer la realidad sobre la situación de las personas con discapacidad son un componente imprescindible de la institucionalidad, ya que facilitan la toma de decisiones con base empírica en las distintas etapas de la gestión (diagnóstico, formulación, monitoreo y evaluación de procesos y de impactos). El artículo 31 de la CDPD señala que contar con herramientas capaces de recopilar datos estadísticos con fiabilidad, que permitan conocer la situación social de las personas con discapacidad, es una obligación y es indispensable para monitorear su cumplimiento y construir políticas públicas que conduzcan a reducir la discriminación y promover la integración y la igualdad de oportunidades (Naciones Unidas, 2006). Por otra parte, en la meta 17.18 de los Objetivos de Desarrollo Sostenible se hace un llamado a aumentar de forma significativa la disponibilidad de datos oportunos, fiables y de alta calidad, desglosados por discapacidad, entre otros factores.

La cuantificación de las personas con discapacidad presenta múltiples desafíos relacionados con la definición de discapacidad que se adopte, el instrumento de medición que se elija para la recolección de datos, los aspectos de la discapacidad que se quiera medir y las características de las fuentes de información disponibles (CEPAL, 2014). Si bien la inclusión de las personas con discapacidad en los sistemas de información de América Latina y el Caribe es un asunto de creciente importancia (sobre todo a partir de la ronda de censos de 2000), debido a las diferencias conceptuales, metodológicas y operativas que se observan en los 
procedimientos de recolección entre los países de la región, aún es difícil contar con una buena cuantificación de esta realidad y medir su evolución a lo largo del tiempo (CEPAL, 2014). El escenario también resulta complejo por la existencia de fuentes de información difusas y poco articuladas, en particular los registros administrativos. La invisibilidad estadística de la población con discapacidad es un reflejo de su marginación y exclusión y, a la vez, constituye una barrera para garantizar su ejercicio de derechos.

\section{Cuadro VII.7}

\section{América Latina (14 países): planes o estrategias nacionales para la promoción de los derechos de las personas con discapacidad}

\begin{tabular}{|c|c|c|c|}
\hline País & Plan & Propósito & Año \\
\hline $\begin{array}{l}\text { Bolivia } \\
\text { (Estado } \\
\text { Plurinacional } \\
\text { de) }\end{array}$ & $\begin{array}{l}\text { Plan Nacional } \\
\text { de Igualdad y } \\
\text { Equiparación de } \\
\text { Oportunidades }\end{array}$ & $\begin{array}{l}\text { Con el objetivo de lograr la igualdad y equiparación } \\
\text { de oportunidades de las personas con } \\
\text { discapacidades, el Plan articula diferentes } \\
\text { mecanismos para el establecimiento de políticas } \\
\text { sociales y públicas, destinadas al ejercicio pleno } \\
\text { de los derechos de esta población, en los ámbitos } \\
\text { nacional, departamental y municipal. }\end{array}$ & 2006 \\
\hline Brasil & $\begin{array}{l}\text { Plan Nacional de } \\
\text { los Derechos de } \\
\text { la Persona con } \\
\text { Discapacidad } \\
\text { (Vivir Sin Límite) }\end{array}$ & $\begin{array}{l}\text { Poner en práctica nuevas iniciativas e intensificar las } \\
\text { acciones que ya desarrolla el Gobierno en beneficio } \\
\text { de las personas con discapacidad. El Plan fue } \\
\text { elaborado por } 15 \text { ministerios con la participación } \\
\text { del CONADE. }\end{array}$ & 2011 \\
\hline Chile & $\begin{array}{l}\text { Política Nacional } \\
\text { para la Inclusión } \\
\text { Social de las } \\
\text { Personas } \\
\text { con Discapacidad } \\
2013-2020 \\
\end{array}$ & $\begin{array}{l}\text { El instrumento que permitirá guiar la gestión de } \\
\text { la institucionalidad estatal durante los próximos } \\
\text { siete años, y que rendirá cuenta ante la ciudadanía } \\
\text { y los organismos internacionales con que se ha } \\
\text { comprometido el Estado de Chile. }\end{array}$ & 2013 \\
\hline Colombia & $\begin{array}{l}\text { Política Pública } \\
\text { Nacional de } \\
\text { Discapacidad e } \\
\text { Inclusión Social } \\
\text { 2013-2022 }\end{array}$ & $\begin{array}{l}\text { Asegurar el goce pleno de los derechos y el } \\
\text { cumplimiento de los deberes de las personas con } \\
\text { discapacidad, sus familias y cuidadores para el } \\
\text { período } 2013-2022 \text {. Generar y promover procesos } \\
\text { de gestión pública que sean eficientes, efectivos, } \\
\text { articulados y transparentes, y que se traduzcan en } \\
\text { el diseño e implementación de planes y programas } \\
\text { orientados a las personas con discapacidad a nivel } \\
\text { nacional y territorial. }\end{array}$ & 2013 \\
\hline Costa Rica & $\begin{array}{l}\text { Política Nacional } \\
\text { en Discapacidad } \\
\text { (PONADIS) }\end{array}$ & $\begin{array}{l}\text { PONADIS constituye el marco político de largo } \\
\text { plazo de las instituciones públicas para promover, } \\
\text { respetar y garantizar los derechos de las personas } \\
\text { con discapacidad. Se basa en cuatro enfoques } \\
\text { fundamentales: derechos humanos, desarrollo } \\
\text { inclusivo, equidad de género y gerencia social por } \\
\text { resultados. La política se desarrolla según los cinco } \\
\text { ejes siguientes: institucionalidad democrática, salud, } \\
\text { educación, trabajo y empleo, personas, instituciones, } \\
\text { organizaciones y entorno inclusivo. }\end{array}$ & 2011 \\
\hline Cuba & $\begin{array}{l}\text { Plan de Acción } \\
\text { Nacional para la } \\
\text { Atención a las } \\
\text { Personas con } \\
\text { Discapacidad }\end{array}$ & $\begin{array}{l}\text { El Plan es un compendio de estrategias, acciones, } \\
\text { propuestas y programas dirigidos a la integración social } \\
\text { y la elevación de la calidad de vida de las personas con } \\
\text { discapacidad como objetivo esencial, que se aplica } \\
\text { en todas las provincias y municipios del país mediante } \\
\text { distintos programas territoriales de inclusión y desarrollo } \\
\text { comunitario, facilitando la creación de condiciones que } \\
\text { garanticen a las personas con discapacidad el pleno } \\
\text { acceso al empleo, la educación, la cultural, el deporte } \\
\text { y la recreación. }\end{array}$ & 2006 \\
\hline
\end{tabular}


Cuadro VII.7 (conclusión)

\begin{tabular}{|c|c|c|c|}
\hline País & Plan & Propósito & Año \\
\hline Ecuador & $\begin{array}{l}\text { Agenda } \\
\text { Nacional para } \\
\text { la Igualdad en } \\
\text { Discapacidades } \\
2013-2017\end{array}$ & $\begin{array}{l}\text { Impulsar y transversalizar en los sectores público y } \\
\text { privado, la equiparación de oportunidades para las } \\
\text { personas con discapacidad, así como la prevención } \\
\text { de discapacidades, a nivel nacional. Sus objetivos } \\
\text { específicos son: i) elaborar estrategias, programas } \\
\text { y proyectos encaminados a mejorar la calidad de } \\
\text { vida de las personas con discapacidad; ii) promover } \\
\text { la prevención de discapacidades tomando en } \\
\text { consideración los principales factores de riesgo en el } \\
\text { Ecuador, y iii) realizar el seguimiento del cumplimiento } \\
\text { de objetivos, políticas, estrategias, programas y } \\
\text { proyectos en los ámbitos de la discapacidad. }\end{array}$ & 2013 \\
\hline El Salvador & $\begin{array}{l}\text { Política Nacional } \\
\text { de Atención a las } \\
\text { Personas con } \\
\text { Discapacidad y } \\
\text { Plan de Acción }\end{array}$ & $\begin{array}{l}\text { Garantizar el cumplimiento y goce pleno de los } \\
\text { derechos de las personas con discapacidad en } \\
\text { sus diferentes dimensiones (individual, familiar y } \\
\text { comunitaria), así como en las diferentes etapas de su } \\
\text { ciclo de vida, de forma que promueva su desarrollo } \\
\text { integral, bienestar y mejora de la calidad de vida } \\
\text { mediante la articulación de acciones públicas y } \\
\text { privadas orientadas a la eliminación gradual y efectiva } \\
\text { de las barreras físicas y sociales. }\end{array}$ & 2014 \\
\hline Honduras & $\begin{array}{l}\text { Política Pública } \\
\text { para el Ejercicio } \\
\text { de los Derechos } \\
\text { de las Personas } \\
\text { con Discapacidad } \\
\text { y su Inclusión } \\
\text { Social }\end{array}$ & $\begin{array}{l}\text { Garantizar a todas las personas con discapacidad } \\
\text { el goce pleno de sus derechos humanos, facilitando } \\
\text { las condiciones para su ejercicio y exigibilidad, y } \\
\text { propiciando a la vez las transformaciones sociales } \\
\text { necesarias para lograr el respeto a su dignidad } \\
\text { inherente, y el acceso a las oportunidades sociales, } \\
\text { en condiciones de igualdad, respeto por la diferencia, } \\
\text { plena inclusión y ausencia de discriminación. }\end{array}$ & 2013 \\
\hline Guatemala & $\begin{array}{l}\text { Política Nacional } \\
\text { en Discapacidad }\end{array}$ & $\begin{array}{l}\text { Crear oportunidades de integración y participación } \\
\text { en la sociedad guatemalteca para las personas } \\
\text { con discapacidad. }\end{array}$ & 2007 \\
\hline México & $\begin{array}{l}\text { Programa } \\
\text { Nacional para el } \\
\text { Desarrollo y la } \\
\text { Inclusión de las } \\
\text { Personas con } \\
\text { Discapacidad } \\
2014-2018 \\
\text { (PNDIPD) }\end{array}$ & $\begin{array}{l}\text { Los objetivos del Programa son: i) impulsar la } \\
\text { aplicación de políticas públicas que garanticen el } \\
\text { pleno ejercicio de los derechos de la población } \\
\text { con discapacidad; ii) generar una cultura de la } \\
\text { discapacidad en todos los órdenes de la vida nacional; } \\
\text { iii) transformar el entorno público, social y privado, } \\
\text { y iv) promover el cambio cultural y de actitud en el } \\
\text { gobierno y la sociedad respecto de las personas } \\
\text { con discapacidad. }\end{array}$ & 2014 \\
\hline Panamá & $\begin{array}{l}\text { Política Nacional } \\
\text { de Discapacidad }\end{array}$ & $\begin{array}{l}\text { Promover y consolidar la inclusión social de la } \\
\text { población con discapacidad y su familia, a fin } \\
\text { de garantizar su desarrollo humano pleno. Con } \\
\text { ese objetivo, la familia, la comunidad y el Estado } \\
\text { asegurarán las condiciones para lograr su máxima } \\
\text { autonomía, independencia y participación en los } \\
\text { espacios cotidianos y de vida ciudadana. }\end{array}$ & 2009 \\
\hline Paraguay & $\begin{array}{l}\text { Plan de Acción } \\
\text { Nacional por los } \\
\text { Derechos de las } \\
\text { Personas con } \\
\text { Discapacidad } \\
\text { 2015-2030 }\end{array}$ & $\begin{array}{l}\text { Busca promover, coordinar y ejecutar las } \\
\text { políticas públicas y el accionar del sector privado, } \\
\text { transversalizando el enfoque de derechos de las } \\
\text { personas con discapacidad en los planes, programas } \\
\text { y proyectos, con miras a garantizar la igualdad, la no } \\
\text { discriminación, la inclusión y la accesibilidad. }\end{array}$ & 2015 \\
\hline Perú & $\begin{array}{l}\text { Plan de } \\
\text { Igualdad de } \\
\text { Oportunidades } \\
\text { para las } \\
\text { Personas con } \\
\text { Discapacidad } \\
2009-2018\end{array}$ & $\begin{array}{l}\text { Este plan es un instrumento técnico-político de } \\
\text { planificación para las acciones en beneficio de las } \\
\text { personas con discapacidad. Su elaboración ha sido } \\
\text { coordinada de manera intersectorial, en estrecha } \\
\text { relación con la sociedad civil mediante procesos de } \\
\text { consultas participativas. }\end{array}$ & 2009 \\
\hline
\end{tabular}

Fuente: Elaboración propia, sobre la base de información disponible de las instituciones de los respectivos países. 


\section{Recuadro VII.1 \\ La evolución de los enfoques de la discapacidad}

El concepto de discapacidad ha evolucionado mucho en las últimas décadas. En la actualidad coexisten tres enfoques principales. Por una parte, está el modelo biomédico, que considera la discapacidad como un problema personal de salud, causado directamente por una condición congénita, una enfermedad, un trastorno o un accidente. Por otra, el modelo biosicosocial, si bien se refiere a la salud, considera que la limitación de actividad y participación que experimentan las personas con discapacidad se debe a una interacción entre esas dificultades de salud y un entorno físico y actitudinal que impone barreras. Por último, el modelo social se refiere principalmente al ejercicio de los derechos humanos y la inclusión plena y efectiva en la sociedad, en igualdad de condiciones con los demás. La evolución de estos conceptos tiene su raíz en una serie de propuestas, comenzando por la primera Clasificación Internacional de Deficiencias, Discapacidades y Minusvalías (CIDDM) de la Organización Mundial de la Salud (OMS) de 1980, que reflejaba cabalmente el modelo biomédico y establecía una correlación entre deficiencias del cuerpo y de la mente, impedimento y anormalidad. Posteriormente, en 2001, se elaboró la Clasificación Internacional del Funcionamiento, de la Discapacidad y de la Salud (CIF) de la OMS, donde se ofrece una descripción clara y coherente de las dimensiones biológicas, individuales y sociales del funcionamiento humano. La Convención sobre los Derechos de las Personas con Discapacidad remite al modelo social, pero en su definición de la discapacidad se refiere a la interacción entre las deficiencias físicas, mentales, intelectuales o sensoriales con el entorno, como sugiere el modelo biosicosocial.

Desde estas perspectivas se desprenden respuestas radicalmente diferentes en materia de políticas. Partiendo del modelo biomédico, lo que se requiere es acción a nivel individual para la provisión de servicios médicos y de rehabilitación, y los encargados de implementar esa intervención serían los profesionales médicos y de rehabilitación. Según este punto de vista, la persona con discapacidad es un objeto de intervención, un paciente o un beneficiario. Al otro extremo del espectro, el modelo social plantea que una persona con discapacidad requiere ajustes en su entorno para alcanzar una participación plena. En este sentido, la acción pública debería ir orientada a eliminar barreras (tanto físicas como de actitud) para lograr la plena participación de personas con discapacidad en todos los ámbitos y, por lo tanto, es una responsabilidad que recae sobre la sociedad en su conjunto. Desde esta mirada, la persona con discapacidad es un agente empoderado que debe participar activamente en la toma de decisiones.

Se puede decir que estas lecturas sobre la discapacidad coexisten en las sociedades latinoamericanas. Por una parte, muchas de las agrupaciones que defienden derechos de las personas con discapacidad han acogido las perspectivas más integrales y holísticas (la biosicosocial y la social) y los Estados han incorporado paulatinamente estas visiones en la legislación. Por otra, en las políticas y programas y a nivel discursivo, aún prevalecen los estereotipos y prejuicios planteados por el enfoque biomédico a nivel de los funcionarios públicos, la sociedad en general, y aun entre personas con discapacidad y sus agrupaciones. Este escenario complejiza la labor de las instituciones encargadas de promover de una manera coherente el cumplimiento de los derechos de las personas con discapacidad.

Fuente: Comisión Económica para América Latina y el Caribe (CEPAL), Informe regional sobre la medición de la discapacidad: una mirada a los procedimientos de medición de la discapacidad en América Latina y el Caribe (LC/L.3860(CE.13/3)), Santiago, 2014. 
En respuesta a esta situación, la Conferencia Estadística de las Américas, un órgano subsidiario de la Comisión Económica para América Latina y el Caribe (CEPAL), acordó en su séptima reunión de 2013 la creación de un grupo de tareas que se encargaría de coordinar la preparación de un informe regional sobre la información estadística disponible en los países de América Latina y el Caribe y las dificultades encontradas para medir la situación de las personas con discapacidad. Desde 2016, el grupo de tareas pasa a ser un grupo de trabajo que tiene, entre otros objetivos, el de fomentar una conceptualización y un método unificados para medir la discapacidad en la región, mejorar la capacidad técnica de los países de la región para recopilar y difundir datos sobre discapacidad y formar una red de apoyo entre instituciones, organismos nacionales e internacionales.

\section{Reflexiones finales}

Lograr la plena inclusión de las personas con discapacidad en todas las esferas de nuestras sociedades es un compromiso impostergable. Para poder avanzar en este sentido se requiere una institucionalidad inclusiva y efectiva que dé una respuesta coherente e integral a las heterogéneas necesidades de las personas con discapacidad.

En la breve revisión presentada en este capítulo se constata la existencia de un sustrato legal-normativo sobre el que se construye una arquitectura institucional para el progresivo cumplimiento de los derechos de las personas con discapacidad. En este sentido, América Latina ha mostrado un firme compromiso con los derechos de las personas con discapacidad. En particular, la amplia ratificación de la CDPD en la región y la progresiva puesta en conformidad de la legislación nacional con ese instrumento son acciones alentadoras. No solo expresan un compromiso en cuanto a la garantía de derechos de la población con discapacidad, sino que proporcionan una perspectiva común basada en los derechos humanos. Esto es importante, ya que uno de los desafíos de la institucionalidad en materia de discapacidad es la necesidad de transversalizar el tema entre los diferentes ministerios sectoriales. Si bien cada sector debe abordar su propia agenda en el ámbito de sus responsabilidades y orientaciones (UNICEF, 2005), la existencia de una perspectiva unificada sobre el tema de discapacidad puede ayudar a orientar las acciones en una dirección común.

Sin embargo, tener un derecho no siempre significa poder ejercerlo. Persiste una brecha muy marcada entre el reconocimiento jurídico de esta población y la materialización de sus derechos (Stang, 2011), que se evidencia en grandes inequidades de inclusión desde el punto de vista educativo, laboral y de participación política, así como en la sobrerrepresentación de personas con discapacidad entre la población 
pobre. Esta situación de exclusión estructural se vuelve más aguda cuando se considera la intersección de la discapacidad con los otros ejes de la matriz de la desigualdad social, tales como la condición étnico-racial, el género y el territorio (CEPAL, 2016).

A nivel organizacional, existen instituciones que reúnen algunos de los elementos necesarios para mejorar la situación de la población con discapacidad. Cuentan con un marco legal que les asigna objetivos y responsabilidades claras, así como un plan o política que guía sus acciones en busca de esos objetivos. También tienen mecanismos de articulación y coordinación horizontal y vertical para evitar la dispersión, duplicación y fragmentación de la acción pública dirigida hacia esta población, y espacios de participación para incorporar las visiones y perspectivas de las personas con discapacidad en la toma de decisiones.

No obstante, el hecho de canalizar los pocos recursos humanos y financieros que tienen las instituciones de discapacidad hacia la ejecución de proyectos puede detraer de otras acciones, como la vigilancia y la presentación de propuestas en materia de políticas, además del logro de una mejor articulación entre actores del Estado (Mujica y Calle, 2006). Muchas de estas instituciones se enfocan en ejecutar pequeños programas que están limitados en el tiempo y tienen un alcance reducido, mediante los cuales no se logrará la verdadera inclusión de la población con discapacidad. Además, las instituciones existen en un contexto de incertidumbre debido a su alto nivel de sensibilidad ante las fluctuaciones políticas de los gobiernos y los ciclos económicos.

Por otra parte, la existencia de un mandato y de mecanismos de articulación y coordinación no basta para que en la práctica esto ocurra, sobre todo de una manera eficiente. Las organizaciones de personas con discapacidad a menudo consideran insuficiente la efectividad de los mecanismos de coordinación existentes. Entre los obstáculos para su éxito que más se mencionan, cabe resaltar la inexistencia de un mandato jurídico claro, la falta de recursos, la limitada participación de las personas con discapacidad o la exclusión de personas con determinados tipos de discapacidad (Naciones Unidas, 2014). También se señala que el éxito de estas iniciativas de coordinación y articulación puede depender de personas a título individual y de su capacidad de cabildeo, y no necesariamente de prácticas sistematizadas e institucionalizadas. Esto representa un desafío, dada la frecuente rotación de personal en las instituciones relacionadas con la discapacidad.

Más fundamentalmente, la dificultad principal que enfrentan las personas con discapacidad para el pleno ejercicio de sus derechos, que trasciende y a la vez permea, todas las dimensiones de la institucionalidad, es el anclaje en el concepto tradicional de la discapacidad a nivel de sociedad. 
Desde esa mirada desempoderante, la persona con discapacidad es vista como un individuo vulnerable, sin reconocer que las situaciones de su entorno, como la pobreza, la discriminación y la falta de accesibilidad son las que hacen que viva en una situación vulnerable. Este cambio de perspectiva requiere una transformación cultural profunda que se base en la valoración de la diversidad humana. Esto no es solo responsabilidad de las instituciones públicas, sino que es una tarea compartida por toda la sociedad.

\section{Bibliografía}

CEPAL (Comisión Económica para América Latina y el Caribe) (2016a), La matriz de la desigualdad social en América Latina (LC/G.2690(MDS.1/2)), Santiago.

(2014), Informe regional sobre la medición de la discapacidad: una mirada a los procedimientos demedicióndeladiscapacidaden AméricaLatinayelCaribe(LC/L.3860 (CE.13/3)), Santiago.

Giler, G. (2012), La gestión de la cooperación internacional y las relaciones internacionales de la Misión Solidaria Manuela Espejo, Quito, Vicepresidencia de la República del Ecuador.

Mujica, J. y L. E. Calle (2006), Los derechos de las personas con discapacidad en la legislación comparada, Lima, Fondo Editorial del Congreso del Perú.

Naciones Unidas (2014), "Aplicación y seguimiento nacionales. Nota de la Secretaría" (CRPD/CSP/2014/3), Convención sobre los Derechos de las Personas con Discapacidad.

(2006) "Convención sobre los derechos de las personas con discapacidad" (A/RES/61/106), Resolución 61/106 aprobada por la Asamblea General, Nueva York.

OEA(Organización de los Estados Americanos) (1999), “Convención Interamericana para la Eliminación de Todas las Formas de Discriminación contra las Personas con Discapacidad", Ciudad de Guatemala, 7 de junio [en línea] http:/ /www. oas.org/juridico/spanish/tratados/a-65.html.

OISS (Organización Iberoamericana de Seguridad Social) (2014), Medidas para la promoción del empleo de personas con discapacidad en Iberoamérica, Madrid.

Organismo Andino de Salud-Convenio Hipólito Unanue (2011), Política andina en salud para la prevención de la discapacidad y para la atención, habilitación/rehabilitación integral de las personas con discapacidad, Lima, Cellgraf SAC.

Stang, M.F. (2011), "Las personas con discapacidad en América Latina: del reconocimiento jurídico a la desigualdad real", serie Población y Desarrollo, N 103 (LC/L.3315-P), Santiago, Comisión Económica para América Latina y el Caribe (CEPAL).

UNICEF (Fondo de las Naciones Unidas para la Infancia) (2005), "Seminario internacional: inclusión social, discapacidad y políticas públicas" [en línea] http:/ / www.unicef.cl/archivos_documento/200/Libro\%20seminario\%20internacional $\% 20$ discapacidad.pdf.

Vásconez, A.C. y otros (2013), "Política de atención a personas con discapacidad en el Ecuador: hacia un modelo de exportación", Línea Sur, Nº 6. 

Capítulo VIII

\section{Afrodescendientes latinoamericanos: institucionalidad y políticas públicas}

Marta Rangel ${ }^{1}$

\section{Introducción ${ }^{2}$}

Se estima que en América Latina hay más de 125 millones personas que se autoidentifican como afrodescendientes (CEPAL, 2015). Se trata de una población afectada por la discriminación, la pobreza y la vulnerabilidad. Además, enfrenta mayores dificultades a lo largo del ciclo de vida, por ejemplo, para alcanzar niveles superiores de educación e insertarse laboralmente en condiciones de igualdad.

América Latina es una región marcada estructuralmente por una matriz de desigualdad social, siendo la pertenencia étnico-racial uno de sus determinantes. Junto con las desigualdades basadas en el género, la edad y el territorio, conforma ejes estructurantes que se entrecruzan y potencian entre sí (CEPAL, 2016a) ${ }^{3}$.

Consultora de la División de Desarrollo Social de la Comisión Económica para América Latina y el Caribe (CEPAL).

2 La autora agradece la colaboración en el análisis de la dimensión fiscal de Varinia Tromben, Oficial de Asuntos Económicos, y Carlos Kroll, Consultor de la División de Desarrollo Social de la Comisión Económica para América Latina y el Caribe (CEPAL). La elaboración de este capítulo contó con el apoyo del proyecto "Promoción de la igualdad: fortalecimiento de la capacidad de países en desarrollo seleccionados para diseñar e implementar políticas públicas y programas orientados a la igualdad", financiado por la Cuenta de las Naciones Unidas para el Desarrollo.

3 Para profundizar en la desigualdad étnico-racial y otros determinantes estructurales de la matriz de la desigualdad social, véase CEPAL (2016a). 
Dada la situación que viven las personas afrodescendientes, población que las políticas universales no logran alcanzar plenamente, se hace necesaria la formulación de políticas más inclusivas y focalizadas, que se pueden diseñar e implementar mejor si se cuenta con un marco institucional sensible a sus necesidades. La agenda de desarrollo de los pueblos afrodescendientes ha avanzado tanto en los ámbitos nacionales como en el regional, marcada por la institucionalización de mecanismos de promoción de la igualdad racial y por los avances de la sociedad civil en lo que respecta a la garantía de los derechos humanos, económicos, sociales, culturales y colectivos de esos pueblos. Así, en la actualidad, la mayoría de los países de América Latina cuenta con algún mecanismo de promoción de la igualdad racial y con diversas organizaciones civiles de afrodescendientes, y se ha incluido la temática étnico-racial en algunos foros y organismos intergubernamentales, tanto a nivel regional como subregional ${ }^{4}$.

El objetivo de este capítulo es contribuir al conocimiento de dicha realidad y su desarrollo institucional, en el marco del Decenio Internacional de los Afrodescendientes (2015-2024), período en que se espera que los países fortalezcan e implementen marcos institucionales y jurídicos que contribuyan al desarrollo de esta población y promuevan el conocimiento y el respeto de sus culturas (resolución 68/237 de 2014 de la Asamblea General de las Naciones Unidas). Con ese fin, se presenta un panorama de los mecanismos de promoción de la igualdad racial en América Latina, siguiendo el marco de análisis descrito en el capítulo I. Así, a continuación se discuten los principales elementos de sus marcos jurídico-normativos, sus modelos organizacionales, las herramientas de gestión utilizadas y la dimensión fiscal, y se destacan algunas políticas implementadas en los últimos años para la promoción de los derechos de las personas afrodescendientes. Finalmente, se describirán algunos desafíos para avanzar en cuanto a la garantía de sus derechos.

\footnotetext{
La Comisión de Derechos Humanos del Sistema Interamericano tiene una Relatoría sobre los Derechos de las Personas Afrodescendientes y Contra la Discriminación Racial; la Organización de los Estados Americanos (OEA) cuenta con la Secretaría de Acceso a Derechos y Equidad, que monitorea la implementación del plan de acción del Decenio Internacional de los Afrodescendientes. Desde 2005, la Secretaría General Iberoamericana (SEGIB) ha reconocido los derechos de las personas afrodescendientes e instado a los gobiernos a garantizarlos en varios ámbitos. En el referido año se constituyó el Parlamento Negro de las Américas. A nivel subregional, en 2011, en el marco del Sistema Andino de Integración, se creó la Mesa del Pueblo Afrodescendiente de la Comunidad Andina (CAN). El Sistema de la Integración Centroamericana (SICA) tiene la Comisión de Pueblos Indígenas y Afrodescendientes del Parlamento Centroamericano (PARLACEN), de carácter permanente. En 2015, el Mercado Común del Sur (MERCOSUR) aprobó la creación de la Reunión de Autoridades sobre los Derechos de los Afrodescendientes (RAFRO). Muchas de estas instancias cuentan con la participación de representantes de organizaciones afrodescendientes de diversos países.
} 


\section{A. El marco jurídico-normativo}

\section{El contexto internacional}

Junto con los avances en la institucionalidad de las políticas sociales observados en la región en las últimas décadas, los mecanismos gubernamentales encargados de los temas relacionados con las personas afrodescendientes han experimentado un crecimiento $y$ un cierto fortalecimiento institucional. Así, en América Latina más de una docena de países tienen hoy en día algún mecanismo gubernamental de promoción de la igualdad racial. Esta realidad es fruto de un largo trabajo de incidencia, que involucra de manera conjunta a los movimientos sociales afrodescendientes, otras organizaciones de la sociedad civil, los Gobiernos nacionales y los organismos internacionales (Rangel, 2016).

Se debe destacar también que estos mecanismos han ampliado su ámbito de actuación, de la atención inicial centrada en la superación del racismo, a objetivos más amplios e integrales, con vistas a construir una sociedad más igualitaria. Ya no cabe duda de que la tarea pendiente de acabar con el racismo, secularmente incorporado en las estructuras de las sociedades latinoamericanas, no podrá superarse solo con políticas de carácter universal, sino que además se requieren políticas de acción afirmativa, que han demostrado ser más efectivas para lograr una mayor igualdad racial ${ }^{5}$.

La gran mayoría de los mecanismos de promoción de la igualdad racial de la región se crearon a partir de 2000, con la intensificación del proceso de preparación de la Tercera Conferencia Mundial contra el Racismo, la Discriminación Racial, la Xenofobia y las Formas Conexas de Intolerancia, celebrada en Durban (Sudáfrica) en 2001. En los años subsiguientes, se crearon mecanismos de este tipo para dar cumplimiento a compromisos asumidos en el período posterior a la Conferencia. Sin embargo, cabe destacar que la existencia o no de una institucionalidad propia o la definición del momento de su creación también puede estar relacionada con la historia de los movimientos sociales afrodescendientes en cada país, tal como ocurrió en Colombia (1993), o con la existencia de una alta voluntad política, aun en países como la Argentina (1995), en que estos pueblos no son numerosos.

En el Brasil, por ejemplo, en 2004 solamente un 16,7\% de los jóvenes afrodescendientes de 18 a 24 años asistía a la educación superior. Este porcentaje ha aumentado a un $45,5 \%$ en 2014 . No obstante, entre las personas blancas dichos porcentajes eran, respectivamente, del $47,2 \%$ y el $71,4 \%$, lo que significa que la brecha sigue siendo muy grande y que el porcentaje de personas afrodescendientes que cursaban educación superior en 2014 aún era inferior al de blancos diez años antes (IBGE, 2015). El incremento refleja, entre otros factores, el peso de la implementación de acciones afirmativas para personas afrodescendientes en universidades, mediante la reserva de cupos en las públicas y la entrega de becas en las privadas, desde el comienzo de la década pasada (Feres Jr. y otros, 2013; Universidad de Brasilia, 2013). 
En línea con lo planteado en otros capítulos de este libro, entre los principales instrumentos legales internacionales que se refieren explícitamente al tema de la discriminación étnico-racial o a las personas afrodescendientes se destacan: el Convenio sobre la Discriminación (Empleo y Ocupación), 1958 (Núm. 111) de la Organización Internacional del Trabajo (OIT) ${ }^{6}$, la Convención Internacional sobre la Eliminación de Todas las Formas de Discriminación Racial (1965) 7 , el Pacto Internacional de Derechos Civiles y Políticos $(1966)^{8}$, el Pacto Internacional de Derechos económicos, Sociales y Culturales (1966)9 ${ }^{9}$ la Convención Internacional sobre la Represión y el Castigo del Crimen de Apartheid $(1973)^{10}$ y el Convenio sobre Pueblos Indígenas y Tribales, 1989 (Núm. 169) de la $\mathrm{OIT}^{11}$. A nivel regional, cabe mencionar la Convención Americana sobre Derechos Humanos o Pacto de San José (1969)12 y la Carta Andina para la Promoción y Protección de los Derechos Humanos (2002), que contiene

6 Artículo 1, párrafo 1: A los efectos de este Convenio, el término discriminación comprende: a) cualquier distinción, exclusión o preferencia basada en motivos de raza, color, sexo, religión, opinión política, ascendencia nacional u origen social que tenga por efecto anular o alterar la igualdad de oportunidades o de trato en el empleo y la ocupación (....). Artículo 2: Todo Miembro para el cual este Convenio se halle en vigor se obliga a formular y llevar a cabo una política nacional que promueva, por métodos adecuados a las condiciones y a la práctica nacionales, la igualdad de oportunidades y de trato en materia de empleo y ocupación, con objeto de eliminar cualquier discriminación a este respecto (OIT, 1958).

7 Parte I, artículo 2, párrafo 1: Los Estados partes condenan la discriminación racial y se comprometen a seguir, por todos los medios apropiados y sin dilaciones, una política encaminada a eliminar la discriminación racial en todas sus formas y a promover el entendimiento entre todas las razas (ACNUDH, 1965).

8 Parte II, artículo 2, párrafo 1: Cada uno de los Estados Partes en el presente Pacto se compromete a respetar y a garantizar a todos los individuos que se encuentren en su territorio y estén sujetos a su jurisdicción los derechos reconocidos en el presente Pacto, sin distinción alguna de raza, color, sexo, idioma, religión, opinión política o de otra índole, origen nacional o social, posición económica, nacimiento o cualquier otra condición social (véase [en línea] http://www.ohchr. org/SP/ProfessionalInterest/Pages/CCPR.aspx).

9 Parte II, artículo 2, párrafo 2: Los Estados Partes en el presente Pacto se comprometen a garantizar el ejercicio de los derechos que en él se enuncian, sin discriminación alguna por motivos de raza, color, sexo, idioma, religión, opinión política o de otra índole, origen nacional o social, posición económica, nacimiento o cualquier otra condición social (ACNUDH, 1966).

10 Articulo 1, párrafo 1: Los Estados Partes en la presente Convención declaran que el apartheid es un crimen de lesa humanidad y que los actos inhumanos que resultan de las políticas y prácticas de apartheid y las políticas y prácticas análogas de segregación y discriminación racial que se definen en el artículo II de la presente Convención son crímenes que violan los principios del derecho internacional, en particular los propósitos y principios de la Carta de las Naciones Unidas, y que constituyen una amenaza seria para la paz y la seguridad internacionales. Párrafo 2: Los Estados Partes en la presente Convención declaran criminales las organizaciones, las instituciones y los particulares que cometen el crimen de apartheid (ACNUDH, 1973).

11 Este convenio facilita la defensa de los derechos colectivos de las comunidades afrodescendientes, principalmente frente a la explotación de recursos de sus territorios sin utilización del mecanismo de consulta tal como define dicho Convenio (artículos 6 y 15) y consultas en otros ámbitos como la educación y la formación profesional (artículos 22, 27 y 28) (OIT, 1989).

12 Parte I, capítulo I, artículo 1, párrafo 1: Los Estados Partes en esta Convención se comprometen a respetar los derechos y libertades reconocidos en ella y a garantizar su libre y pleno ejercicio a toda persona que esté sujeta a su jurisdicción, sin discriminación alguna por motivos de raza, color, sexo, idioma, religión, opiniones políticas o de cualquier otra índole, origen nacional o social, posición económica, nacimiento o cualquier otra condición social (OEA, 1969). 
un apartado dedicado exclusivamente a los "pueblos indígenas y comunidades afrodescendientes", donde se les reconoce varios derechos individuales y colectivos ${ }^{13}$.

\section{La legislación en los países}

El marco legal sobre el que se desarrollan los mecanismos de promoción de la igualdad racial en los países de la región se basa en principios inspirados en instrumentos de carácter internacional y regional sobre derechos humanos que abarcan al conjunto de la población. También se tienen en cuenta algunos instrumentos específicos que se consideran fundamentales en la protección de los derechos de las personas afrodescendientes, dada su mención explícita de estos pueblos.

Los marcos normativos nacionales tienen distintos niveles de especificidad con que hacen referencia a la protección de los derechos y a la orientación de las políticas hacia la población afrodescendiente, ya sea por su mención explícita o como parte de las leyes antidiscriminación. En este sentido, los países de América Latina pueden ser clasificados según el acercamiento de su legislación a la defensa y promoción de los derechos de las personas afrodescendientes. En 2009, entre los países poseedores de extensa legislación orientada a las personas afrodescendientes, se incluían el Brasil, Colombia y el Ecuador. Por su parte, el Perú, Honduras y Costa Rica se identificaban con una escasa pero relevante legislación dirigida a las personas afrodescendientes, en tanto países como Guatemala y Nicaragua mostraban escasa legislación orientada a las personas afrodescendientes, pero una extensa legislación antidiscriminación. Finalmente, entre los países sin legislación dirigida a las personas afrodescendientes, pero que cuentan con legislación antidiscriminación, se encontraban, por ejemplo, Cuba y México (AfroAmérica XXI, 2009). En la presente década esta situación ha cambiado de manera positiva en varios países. Por ejemplo, en 2012 se promulgó en Chile la Ley 20.609, que establece medidas contra la discriminación, incluida aquella por motivo de "raza o etnia". Otro ejemplo es el Perú, que ha avanzado significativamente en lo relativo a la legislación de promoción de los derechos de las personas afrodescendientes.

Al analizar las constituciones nacionales, se puede decir que más de una docena de países de América Latina condenan la discriminación por motivos de raza, etnia o color, además de sexo y religión ${ }^{14}$. Algunos también condenan la discriminación por motivos de edad, origen (nacional, social o familiar), condición socioeconómica, opinión o ideas

13 Entre ellos, a la identidad, a una educación intercultural, a desarrollar sus prácticas tradicionales y a ser consultados sobre la explotación de los recursos naturales no renovables que se hallen en sus tierras o territorios.

${ }_{14}$ Bolivia (Estado Plurinacional de), Brasil, Colombia, Cuba, Ecuador, El Salvador, Honduras, México, Nicaragua, Panamá, Perú, República Dominicana y Venezuela (República Bolivariana de). 
(política, filosófica) y lengua. Además, en cuatro países (Bolivia (Estado Plurinacional de), Brasil, Colombia y Ecuador) se reconoce explícitamente a las personas afrodescendientes.

La Constitución del Ecuador de 2008 es la que más referencia hace a las personas afrodescendientes. En ella se les dedica un capítulo exclusivo donde se reconoce que los "pueblos negros o afroecuatorianos" forman parte del Estado y que este garantizará el respeto de sus derechos humanos y de sus derechos colectivos ${ }^{15}$. Entre estos últimos se incluyen el derecho a desarrollar su identidad, conservar la propiedad de las tierras comunitarias (inalienables, inembargables e indivisibles), hacer usufructo de los recursos naturales renovables, ser consultados sobre la explotación de recursos no renovables, incluso con la posibilidad de participar de los beneficios y recibir indemnizaciones.

En el Brasil, la Constitución vigente (de 1988) contempla el reconocimiento implícito de sujetos colectivos de derecho y establece el racismo como crimen imprescriptible y sin derecho a fianza, sujeto a pena de reclusión. También reconoce a las personas afrodescendientes pertenecientes a los quilombos ${ }^{16}$ la propiedad definitiva sobre sus tierras, por lo que el Estado debe emitirles los títulos respectivos (artículo 68 de las disposiciones transitorias $)^{17}$ y resguardar sus documentos y sitios históricos.

La Carta Magna de Colombia (1991) confiere fuerza jurídica a los instrumentos internacionales de derechos humanos, pues estos prevalecen en el orden interno. La Constitución se interpreta según los tratados internacionales ratificados por el país. Abrió el camino al reconocimiento de Colombia como nación pluriétnica y multicultural, lo que impulsó progresos legales en favor de las minorías indígenas, afrocolombianas, raizales y gitanas (Antón, 2010).

Desde 2009, la Constitución Política del Estado Plurinacional de Bolivia reconoce a la población afrodescendiente al señalar en su artículo 3 que "la nación boliviana está conformada por la totalidad de las bolivianas y los bolivianos, las naciones y pueblos indígena originarios campesinos, $\mathrm{y}$ las comunidades interculturales y afrobolivianas que en conjunto constituyen el pueblo boliviano"18.

Algunas constituciones, además de hacer referencia a la no discriminación por los motivos anteriormente mencionados, tales como

15 Capítulo 5: De los derechos colectivos. Sección primera. De los pueblos indígenas y negros o afroecuatorianos, conformados por tres artículos $(83,84$ y 85 ) (Asamblea Constituyente del Ecuador, 2008).

16 Se refiere a las comunidades formadas por personas esclavizadas que huían de la esclavitud. En español se llamarían palenques, es decir, rincones apartados de las ciudades o el campo donde vivían en libertad quienes escapaban de la esclavitud (cimarrones).

17 Esta última disposición fue regulada el 2013 mediante el Decreto núm. 4.887, que amparó el Programa Brasil Quilombola. Por quilombola se entiende a las personas residentes en comunidades descendientes de los quilombos originales.

18 Véase República de Bolivia (2008). 
raza, etnia, sexo y religión, hacen mención específica de la prohibición de actos discriminatorios contra los trabajadores o los estudiantes en los colegios. En la Argentina, Chile, Costa Rica, Guatemala, el Paraguay y el Uruguay, las constituciones no hacen referencia a pueblos afrodescendientes, población negra, raza o color de la piel. No obstante, muchas se refieren a la igualdad y la no discriminación por otros motivos.

Respecto a las leyes nacionales que pueden considerarse como marcos del reconocimiento y la defensa de los derechos de las personas afrodescendientes, se destacan el Estatuto de la Igualdad Racial (Ley núm. 12.288 de 2010) del Brasil. Esta legislación abarca prácticamente todas las dimensiones de la vida social, tales como salud, educación, cultura, libertad de culto religioso y acceso a la propiedad colectiva de la tierra, y sugiere medidas de promoción de la igualdad de las personas afrodescendientes ${ }^{19}$. Sin embargo, es relevante destacar que, aun cuando no se mencione específicamente a las personas afrodescendientes, algunas otras leyes tienen gran impacto sobre ellos. De hecho, se han aunado esfuerzos de organismos gubernamentales y organizaciones de la sociedad civil con miras a su aprobación. Ese es el caso, en el Brasil, de la legislación sobre derechos de los trabajadores domésticos (Enmienda Constitucional núm. 72/2013, Ley Complementaria núm. 150/2015), por su relevancia para las mujeres negras, que están sobrerrepresentadas en esta ocupación.

En Colombia, la ley de comunidades negras (Ley núm. 70 de 1993) se considera la principal y más importante herramienta para la protección de los derechos de las personas afrodescendientes en el país. A partir de ella han surgido varios instrumentos legales complementarios. En dicha Ley se reconoce oficialmente a las personas afrodescendientes, se otorgan derechos a la propiedad colectiva, se establecen mecanismos para la protección de su cultura y se ofrecen garantías para que puedan disfrutar de igualdad de oportunidades frente al resto de la sociedad. La legislación y las políticas aplicadas apuntan al establecimiento de los marcos legales necesarios para la concreción de un país pluriétnico y multicultural, tal como se define en la Constitución (Antón, 2010).

Respecto al Estado Plurinacional de Bolivia, se puede mencionar la Ley núm. 234 de 2008, en la que se le reconocen al pueblo afroboliviano derechos y garantías, incluido el reforzamiento de sus propias instituciones, costumbres, identidad y valores. En el Ecuador se destaca la Ley sobre los Derechos Colectivos de los Pueblos Negros o Afroecuatorianos (Ley núm. 46 de 2006). Con relación a Honduras, la Ley núm. 82 de 2004 regula

19 El Estatuto no impone ninguna obligación directa, sino que autoriza la adopción de medidas que quedan pendientes de otras disposiciones legales. Así, mediante el Decreto núm. 8.136 del 2013 se creó el Sistema Nacional de Promoción de la Igualdad Racial (SINAPIR), que organiza la adhesión voluntaria de los gobiernos provinciales y municipales al sistema. Un par de años después, 27 organismos estatales (provinciales) y 169 organismos municipales de promoción de la igualdad racial se habían adherido al sistema (SEPPIR, 2015). 
la propiedad colectiva de afrohondureños. En Nicaragua, la Ley núm. 445 de 2002 trata del régimen de propiedad de las comunidades étnicas.

En el Perú se promulgó en 2015 el Decreto Supremo núm. 004, por el que se declara de interés nacional y atención prioritaria el pleno disfrute de los derechos fundamentales por parte de las personas afroperuanas, con el objeto de fortalecer su desarrollo e inclusión durante el Decenio Internacional de los Afrodescendientes. De acuerdo a esto, todos los sectores y niveles gubernamentales deberán formular e implementar medidas, programas y proyectos encaminados al fortalecimiento de los derechos fundamentales de las personas afroperuanas, con una visión de inclusión social y con la participación plena de estas personas en todos los aspectos de la sociedad peruana.

Por último, cabe destacar la existencia de leyes que prohíben las manifestaciones y expresiones racistas y tipifican el racismo como delito. Actualmente hay 14 países $^{20}$ que han aprobado una legislación por la que se prohíbe y se tipifica la discriminación racial como delito que puede penalizarse con encarcelamiento, lo que es consecuente con el hecho de que 13 países $^{21}$ cuentan con dispositivos constitucionales contra la discriminación étnico-racial. Sin embargo, se debe señalar que estas dos condiciones solo se cumplen de manera simultánea en ocho países ${ }^{22}$.

\section{B. La dimensión organizacional: rasgos y características}

A nivel nacional, la mayor parte de los países de América Latina cuenta con estructuras organizacionales para diseñar e implementar políticas orientadas a las personas afrodescendientes, con base en instrumentos legales que le dan sustento.

Algunos de estos mecanismos fueron creados durante coyunturas muy específicas en que la condición de las personas afrodescendientes y la lucha contra el racismo adquirieron gran relevancia en la agenda pública. Sin embargo, posteriormente algunos mantuvieron una baja posición jerárquica dentro del Estado, lo que no solo pone en riesgo la estabilidad de la defensa de los derechos de los pueblos afrodescendientes, y de la lucha contra el racismo y la promoción de la igualdad racial, sino que también restringe su capacidad de influencia y margen de acción sobre las políticas públicas (véase el cuadro VIII.1).

\footnotetext{
20 Argentina, Brasil, Chile, Costa Rica, Cuba, Ecuador, El Salvador, Guatemala, México, Nicaragua, Panamá, Perú, República Dominicana y Uruguay.

21 Bolivia (Estado Plurinacional de), Brasil, Colombia, Cuba, Ecuador, El Salvador, Honduras, México, Nicaragua, Panamá, Perú, República Dominicana y Venezuela (República Bolivariana de).

22 Brasil, Cuba, Ecuador, El Salvador, México, Nicaragua, Panamá y Perú.
} 


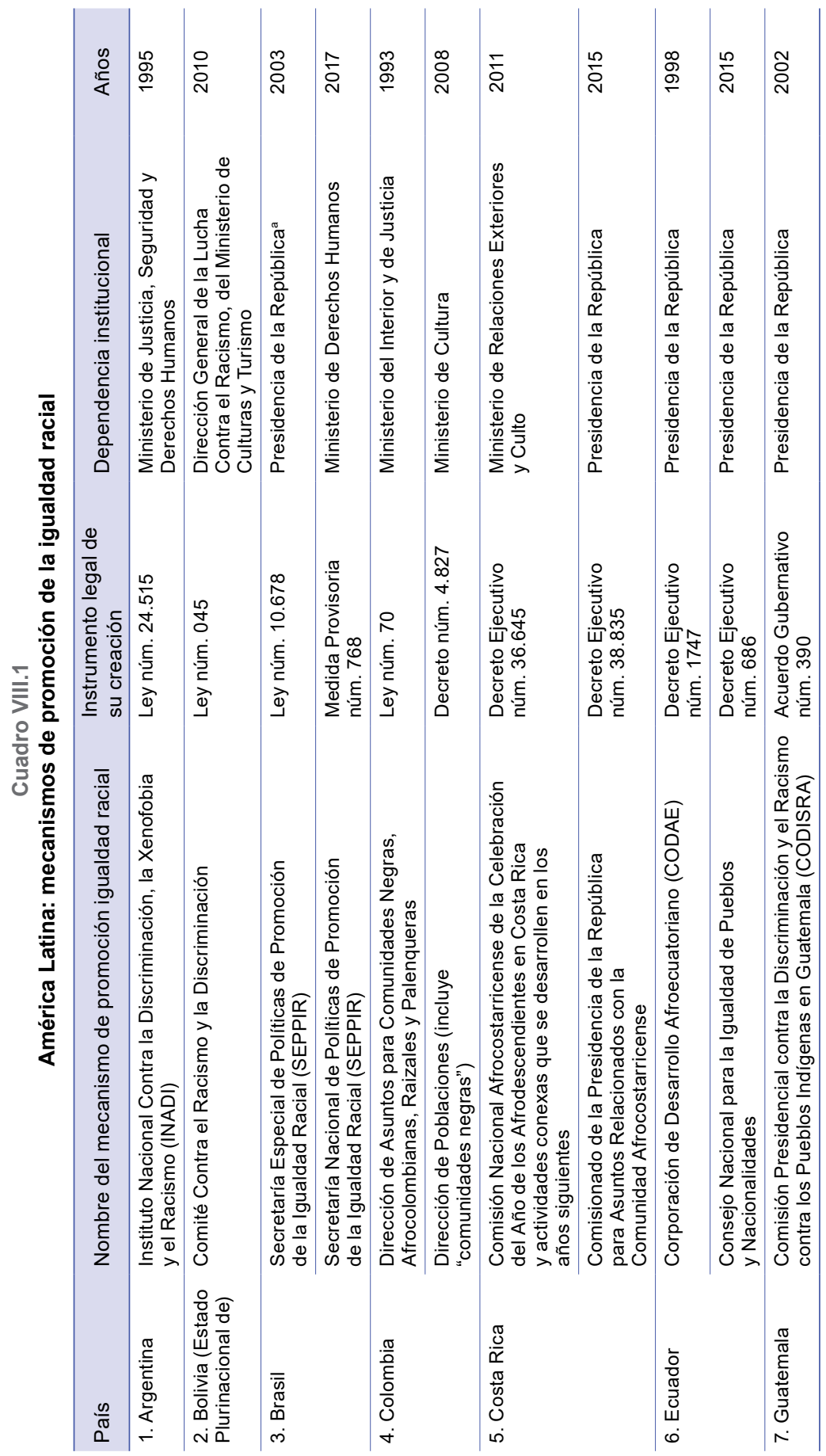




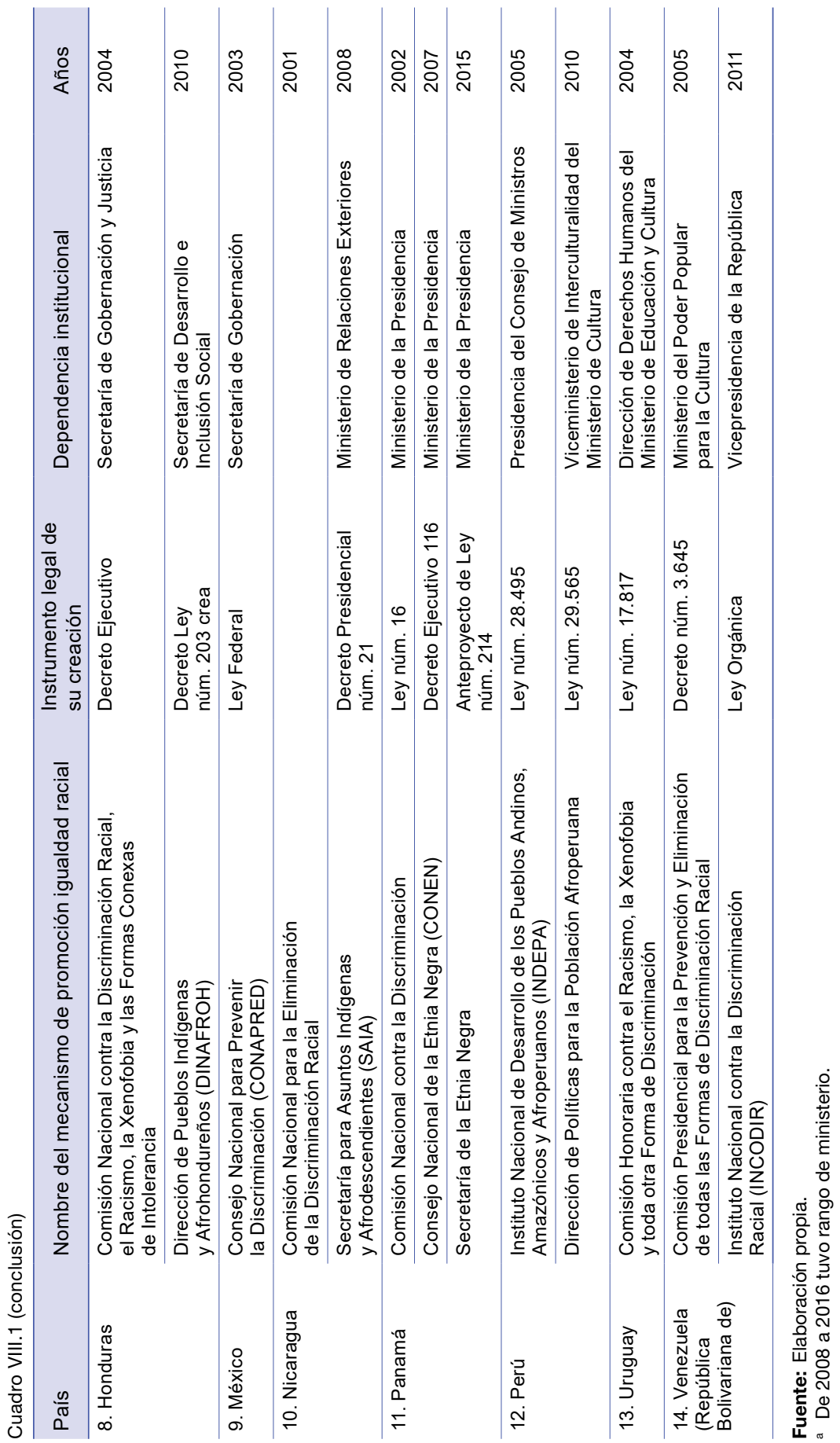


Los mecanismos de promoción de la igualdad racial presentan diversos tipos de arreglos o figuras institucionales que, a su vez, ocupan lugares diferentes en la jerarquía del Estado: direcciones, consejos, institutos, secretarías, comisiones, entre otros. La figura utilizada está muy relacionada con la forma en que los gobiernos enfrentan el tema de la transversalidad de las políticas con perspectiva étnico-racial y con la prioridad que otorgan al tema, si se considera que dichas políticas exigen un trabajo articulado entre distintas instancias del gobierno, tanto sectoriales como de niveles provinciales o locales. Así, junto con el modelo de autoridad, una parte central del diseño organizacional con que se llevan a cabo las políticas es la referida a los esquemas de comunicación, coordinación y articulación entre actores. En este sentido, en el desarrollo e implementación de los planes gubernamentales relacionados con las personas afrodescendientes, es de destacar la articulación existente entre los mecanismos de promoción de la igualdad racial con otras instituciones, lo que ocurre en varios niveles y con distintos tipos de organizaciones. Esto es fundamental, dadas las características de ese tipo de instancias, que se refieren a poblaciones determinadas con variados ámbitos de acción para atender sus necesidades y garantizar sus derechos en todos los ámbitos.

Pueden encontrarse ejemplos de articulación entre los mecanismos de promoción de la igualdad racial y otros organismos gubernamentales en varios niveles, tanto en el eje horizontal (articulación con otros ministerios e instituciones encargadas de las políticas sectoriales, como las referentes a salud, educación y lucha contra la pobreza), como en el vertical (articulación con otros niveles administrativos (provincias, ciudades)). Por ejemplo, el Sistema Nacional de Promoción de la Igualdad Racial (SINAPIR) del Brasil, además de articular el ámbito federal con los gobiernos estaduales y municipales en la implementación de políticas centradas en las personas afrodescendientes, también actúa como entidad coordinadora en el Gobierno federal.

Las instancias gubernamentales también se relacionan con otros ámbitos del Estado, tales como el Parlamento y el ministerio público. En el primer caso, pueden crearse comisiones y mesas de trabajo. En el Perú, se establecieron la Comisión de Pueblos Andinos, Amazónicos y Afroperuanos, Ambiente y Ecología ${ }^{23}$ y la Mesa de Trabajo Afroperuana del

23 Sin embargo, a pesar de lo que indica su nombre, el trabajo de la Comisión durante el período legislativo 2009-2010 se centró principalmente en la problemática de los pueblos indígenas. En el período siguiente (2011-2012), según un informe de la Defensoría del Pueblo del Perú, el Plan de Trabajo de la Comisión no contenía acciones efectivas que favorecieran a los afroperuanos (Defensoría del Pueblo, 2011) y la revisión de la memoria de dicha Comisión correspondiente al período 2013-2014 tampoco muestra avances sustantivos sobre el tema. 
Congreso de la República ${ }^{24}$. Respecto de la articulación con el Ministerio Público, en el Brasil, más precisamente en el estado de Pernambuco, desde 2002 se busca articular acciones con diversas instituciones, utilizando como concepto clave la idea de la lucha contra el racismo institucional (Ministerio Público de Pernambuco, 2013). De igual forma, el Ministerio Público del Trabajo creó, en 2002, la Coordinación Nacional de Promoción de Igualdad de Oportunidades y Eliminación de la Discriminación en el Trabajo (COORDIGUALDADE).

Por último, se debe mencionar la articulación con las organizaciones y los movimientos sociales. En el caso del Estado Plurinacional de Bolivia, el modelo organizacional vigente incluye organizaciones indígenas, campesinas e interculturales. En el Ecuador, comprende organizaciones de mujeres, comunidades afrodescendientes, organizaciones internacionales, universidades y otras entidades defensoras de derechos. En el caso del Brasil, desde 2005 se realizan las conferencias nacionales de promoción de la igualdad racial (CONAPIR) ${ }^{25}$. Esta es una importante instancia de consulta y toma de decisiones en temas relacionados con las personas afrodescendientes. También se estableció el Consejo Nacional de Promoción de la Igualdad Racial (CNPIR) ${ }^{26}$, cuya principal misión es proponer políticas de promoción de la igualdad racial, con énfasis en los pueblos afrodescendientes y otros segmentos raciales y étnicos de la población brasileña ${ }^{27}$. Dicho Consejo está presidido por la Secretaría de la SEPPIR y se compone de 22 organismos público federales, 19 entidades de la sociedad civil y personas de notable conocimiento sobre la materia y nombradas por la SEPPIR ${ }^{28}$.

24 Creada en 2008 y conformada por parlamentarios y ex parlamentarios afrodescendientes y por personas naturales y jurídicas comprometidas con la defensa de los derechos de los afroperuanos, buscaba visibilizar su aporte al desarrollo nacional, luchar contra el racismo, promover la inclusión de los afroperuanos y defender sus derechos fundamentales. Uno de sus logros más relevantes fue la creación del Museo Nacional Afroperuano (Defensoría del Pueblo, 2011). Sin embargo, es una instancia que no ha recibido los incentivos necesarios para continuar su labor y que necesita ser fortalecida.

25 La última conferencia se celebró en 2013 y movilizó a alrededor de 48.000 personas en 500 conferencias municipales y 26 estaduales, y 3 reuniones para comunidades tradicionales (SEPPIR (2014), en Rangel (2016)).

26 Creado en virtud de la Ley núm. 10.678 de 2003.

27 Otras atribuciones son: proponer estrategias de acompañamiento, evaluación y fiscalización, además de la participación en el proceso deliberativo sobre las directrices de políticas de promoción de la igualdad racial, con especial énfasis en la inclusión de la dimensión racial en las políticas públicas nacionales. El CNPIR también debe examinar la propuesta presupuestaria de la SEPPIR y sugerir prioridades en la asignación de recursos; presentar sugerencias a la planificación plurianual del Gobierno federal; acompañar, analizar y presentar sugerencias sobre las acciones gubernamentales, y llevar a la práctica los resultados de las deliberaciones de las conferencias nacionales de promoción da igualdad racial (véase [en línea] http://www.seppir.gov.br/articulacao/cnpir).

28 El Consejo incluye, además de las organizaciones de afrodescendientes (y las respectivas intersecciones de género, juventud y comunidad LGBT), las de comunidades indígenas, gitanas, árabes, palestinas y judaicas, y casi dos decenas de ministerios y secretarías (educación, salud, trabajo, justicia, ciudades, ciencia, desarrollo social, medioambiente, integración, relaciones exteriores, planificación, desarrollo agrario, deporte, cultura, comunicaciones, derechos humanos, políticas para mujeres, entre otras) (véase [en línea] http://www.seppir.gov.br/articulacao/cnpir). 
A menudo, los mecanismos están relacionados con la Presidencia de la República, o dependen institucionalmente de ella. Le siguen en importancia diversos ministerios sectoriales (de justicia, educación, cultura y relaciones exteriores), de gobernación y de desarrollo e inclusión social.

Los principales objetivos que orientan el accionar de los organismos a cargo de las políticas relacionadas con las personas afrodescendientes son coordinar los asuntos relacionados con los temas étnicos y raciales, y elaborar políticas de lucha contra el racismo, la discriminación y la promoción de la igualdad racial, promoviendo una ciudadanía intercultural. Esto se hace mediante la implementación de políticas que garanticen el ejercicio pleno de los derechos de las personas discriminadas por razones étnicas o raciales, y que incidan en las desigualdades o las profundas brechas que afectan a estos pueblos en materia económica, social, política y cultural.

Respecto a las funciones desempeñadas por estas instancias, es necesario destacar que son bastante heterogéneas en cuanto a su tamaño y ámbito de acción. Algunas tienen un carácter más modesto y cuentan con menos personal y presupuesto y, por consiguiente, abarcan un espectro de funciones más restringido. Sin embargo, aunque las funciones desempeñadas son variadas, la misión primordial es la formulación e implementación de políticas de promoción con miras a la transversalización del tema racial en las políticas públicas. Así, entre las funciones que cumplen gran parte de estas organizaciones se destacan:

- Realizar investigaciones sobre la realidad nacional.

- Elaborar estudios comparativos sobre los derechos internacionales de las personas afrodescendientes.

- Prestar asesoría jurídica gratuita a personas o grupos víctimas de actitudes discriminatorias.

- Promover la cultura afrodescendiente y estimular la participación de estos pueblos en la formulación y ejecución de políticas de inclusión.

- Divulgar los compromisos asumidos por el Estado con las normas internacionales de derechos, promover su cumplimiento y monitorear la implementación de medidas de lucha contra la discriminación y promoción de la igualdad racial.

- Diseñar e implementar planes de acción y campañas de sensibilización contra la discriminación.

- Registrar denuncias de discriminación racial y asesorar a los organismos judiciales en el proceso de los delitos de racismo.

- Promover la inclusión de la problemática y la historia de los pueblos afrodescendientes en los materiales educativos de los colegios. 
Sumado a lo anterior, las instancias a cargo de estas políticas en países como la Argentina, Bolivia (Estado Plurinacional de) y Colombia presentan algunas funciones particulares que merecen ser destacadas. En la Argentina, el Instituto Nacional Contra la Discriminación, la Xenofobia y el Racismo (INADI), contempla entre sus funciones las de constatar y denunciar la presencia en el país de personas que durante la Segunda Guerra Mundial hubieran participado en muertes y persecuciones por motivos de raza, religión, nacionalidad u opinión y, en este sentido, proponer la celebración de nuevos tratados de extradición ${ }^{29}$. En el Estado Plurinacional de Bolivia, el Comité Nacional contra el Racismo y la Discriminación promueve el reconocimiento público de personas naturales o jurídicas destacadas en la lucha contra el racismo y la discriminación, y de los héroes de los pueblos originarios, afrobolivianos y comunidades interculturales ${ }^{30}$. En Colombia, la Dirección de Asuntos para las Comunidades Negras, Afrocolombianas, Raizales y Palenqueras (DACN) tiene entre sus atribuciones el fortalecimiento de la gobernabilidad local a partir del asesoramiento de gobernaciones y alcaldías y la articulación con entidades territoriales, étnicas y de poblaciones vulnerables. Además, coordina la consulta previa en proyectos que puedan afectar a las comunidades, apoya la resolución de conflictos de manera coherente con las costumbres de las comunidades y coordina la definición de agendas ambientales ${ }^{31}$.

Es preciso reconocer la magnitud de las desigualdades de género, raza y etnia en áreas fundamentales del desarrollo social, así como el hecho de que el entrecruzamiento de tales desigualdades afecta en mayor grado a las mujeres indígenas y afrodescendientes. Teniendo esto en cuenta, además de demandas políticas específicas de este grupo (CEPAL, 2016a), cabe destacar que algunos países consideran a las mujeres afrodescendientes como una población específica. Por ejemplo, en el Brasil, la Secretaría Especial de Políticas de Promoción de la Igualdad Racial (SEPPIR), desde su creación, ha trabajado sobre el tema de género y de las mujeres negras conjuntamente con la Secretaría de Promoción de la Mujer (SPSM). Ambas entidades son un interesante ejemplo de articulación entre dos secretarías que tenían por misión promover la transversalización de la perspectiva de género y de la raza en las políticas públicas, y que colaboraron en temas

Véase [en línea] http://www.inadi.gob.ar/.

Véase [en línea] http://www.noracismo.gob.bo/.

Véase [en línea] http://dacn.mininterior.gov.co/. 
fundamentales como los derechos de las trabajadoras domésticas ${ }^{32}$. En Guatemala, la Secretaría Presidencial de la Mujer incluye a las mujeres garífunas como uno de los grupos objetivo de la Política Nacional para el Desarrollo Integral de las Mujeres ${ }^{33}$. En el caso de Honduras, el Instituto Nacional de la Mujer incluye en su Consejo Directivo una representante de organizaciones étnicas. Por último, el Instituto Nacional de las Mujeres del Uruguay incluye un área de trabajo dedicada específicamente a las mujeres afrodescendientes. También es de destacar una decisión del Mercado Común del Sur (MERCOSUR) de 2011, por la que se creó el "Plan Estratégico de Acción Social del MERCOSUR" con el objetivo de articular programas sociales con miras a erradicar el analfabetismo femenino, en especial entre las mujeres afrodescendientes.

Como se puede observar, el conjunto de mecanismos encargados de promover la igualdad racial en la región a nivel gubernamental es muy heterogéneo. Además, se desenvuelven en un mundo que vive un proceso constante de avances y retrocesos debido a su sensibilidad ante los ciclos económicos y de gobierno. Esto ha entrañado importantes cambios en dichos mecanismos, no solo en sus figuras jurídicas, sino en su adscripción institucional, sus modelos de organización y los alcances de su autoridad. A nivel general, se percibe que tales cambios tienden a mejorar su quehacer, pues aumentan su capacidad de incidencia en las políticas y les confieren mayor estabilidad y más recursos. Un ejemplo de esto es lo ocurrido en el Ecuador con la Ley Orgánica de las Instituciones Públicas de los Pueblos Indígenas del Ecuador y la Ley de los Derechos Colectivos de los Pueblos Negros o Afroecuatorianos, que fueron derogadas en favor de la Ley Orgánica de los Consejos Nacionales para la Igualdad, aprobada en 2014. Esta ha adquirido cada vez mayor importancia y representa un avance en las políticas para afroecuatorianos. En virtud de esta Ley se crean los Consejos Nacionales para la Igualdad, siendo uno de ellos el Consejo de Pueblos y Nacionalidades, al que corresponden los temas relacionados con los pueblos afrodescendientes. Dichos consejos tienen por objetivo implementar

32 También son ejemplos importantes la Política Nacional de Atención Integral a la Salud de la Mujer, que incorpora a la mujer negra; el Plan Nacional de Promoción de la Igualdad Racial (surgido a partir de las conferencias de igualdad racial, en las que participó la Secretaría de Políticas para las Mujeres (SPM)), que tiene entre sus objetivos combatir todas las formas de abuso de los derechos humanos de las mujeres negras; las políticas de salud para la población negra que buscan reducir las diferencias étnicas y raciales en las condiciones de salud, especialmente en cuanto a la morbilidad y la mortalidad materna e infantil http://bvsms.saude.gov.br/bvs/ publicacoes/politica_nacional_saude_integral_populacao.pd, y el Programa Proequidad de Género y Raza, coordinado por la SPM, dirigido a las grandes empresas (en su mayoría públicas) y otras instituciones gubernamentales, tales como las municipalidades y las secretarías de estados.

33 Sin embargo, se debe señalar que en Guatemala todavía se considera a la población afrodescendiente como parte de la población indígena (OEA, 2011a). 
políticas que garanticen la igualdad entre personas, comunidades, pueblos y nacionalidades, además de erradicar prácticas discriminatorias (Antón, 2010).

No obstante lo anterior, en algunos casos también pueden ocurrir retrocesos institucionales en función del contexto político de los países. Así, en el Brasil, entre 2003 y 2017, la Secretaría Especial de Políticas de Promoción de la Igualdad Racial (SEPPIR) pasó por varios cambios institucionales, desde la adquisición y posterior pérdida del estatus de ministerio, hasta cambios en el ministerio del cual dependía, todo acompañado de recortes presupuestarios ${ }^{34}$. Cabe destacar también que, en algunos casos, los mecanismos de promoción de la igualdad racial tienen un carácter casi simbólico. En ocasiones, no llegan a funcionar de forma oficial y, si logran hacerlo, a veces no se constituyen efectivamente como autoridades sociales ni reúnen las condiciones mínimas para desempeñar un rol coordinador e influyente sobre las políticas. Por ejemplo, en Nicaragua, según un informe publicado en 2008 por el Comité para la Eliminación de la Discriminación Racial (CERD), la Comisión Nacional para la Eliminación de la Discriminación Racial, creada en 2001 en el Ministerio de Relaciones Exteriores, no fue oficializada por instrumento legal y nunca funcionó de manera efectiva ${ }^{35}$. Otro ejemplo es el de Panamá, como se recoge en un informe preparado en 2010 por las Organizaciones Negras Panameñas con el fin de revisar los avances y debilidades en la aplicación de la CERD en el país ${ }^{36}$. Según este informe, la Secretaría Ejecutiva de la Comisión Nacional de la Etnia Negra (CONEN) nunca tuvo oficinas propias y funcionó con un presupuesto mínimo en comparación con otras instancias gubernamentales de similares funciones.

De esta manera, la figura organizacional asumida por las instancias gubernamentales de promoción de la igualdad racial es clave porque está directamente relacionada con su autoridad e influencia para proponer

34 En 2003 se creó en el Brasil la Secretaría Especial de Políticas de Promoción de la Igualdad Racial (SEPPIR), directamente vinculada a la Presidencia da República, cuyo titular participaba en las reuniones ministeriales e interministeriales, en igualdad de condiciones con los demás ministros. En 2008 la SEPPIR obtuvo legalmente el estatus de ministerio, vigente hasta octubre de 2015, cuando fue incorporada, como secretaría, al recién creado Ministerio de las Mujeres, de la Igualdad Racial y de los Derechos Humanos. Entre 2015 y 2017, la SEPPIR fue parte de dos ministerios recién creados y que luego fueron disueltos. Actualmente, es dependencia institucional del Ministerio de Derechos Humanos y ya es una secretaría nacional. Tantos cambios institucionales en tan corto período de tiempo, así como los recortes presupuestarios sufridos, son señales preocupantes, que pueden comprometer la consolidación y el avance del importante trabajo realizado por la SEPPIR entre 2003 y 2015, en términos de elaboración e implementación de políticas públicas de lucha contra el racismo y promoción de la igualdad racial en diversas áreas. Entre estas cabe mencionar las relacionadas con temas de salud, educación, empleo y trabajo, lucha contra la pobreza, promoción de la agricultura familiar y reforma agraria, reconocimiento y titulación de tierras de quilombolas, e investigación y definición de sistemas de indicadores.

35 Véase Naciones Unidas (2008).

36 Véase Coordinadora Nacional de Organizaciones Negras Panameñas (2010). 
e incidir en el diseño e implementación de políticas, así como en su ámbito de actuación, el volumen de recursos económicos y humanos a su disposición y, por lo tanto, en su capacidad de contribuir efectivamente a la disminución de la desigualdad y la discriminación racial existentes ${ }^{37}$. Se debe destacar que, al tratarse de un tema transversal, es fundamental el desarrollo de un trabajo bien coordinado entre varios sectores de política (educación, salud, trabajo, justicia, entre otros), niveles de gobierno (nacional, estadual o provincial, municipal) y con las organizaciones de la sociedad civil.

La heterogeneidad organizacional también está marcada por la población y los temas que atiende cada entidad. Esto es visible en los propios nombres de los mecanismos: algunos se dedican a la lucha contra la discriminación de carácter racial o étnico (Argentina, Bolivia (Estado Plurinacional de), México, Uruguay y Venezuela (República Bolivariana de)) y otros se centran solamente en los temas relacionados con la población afrodescendiente (Brasil, Colombia, Costa Rica, Ecuador, Panamá y Perú). También cabe destacar que hay mecanismos de promoción de la igualdad racial que se dedican, al mismo tiempo, a pueblos indígenas y afrodescendientes (Honduras ${ }^{38}$ y Nicaragua), o a otros grupos de población (Colombia) ${ }^{39}$ y a la lucha contra la xenofobia (Argentina y Uruguay).

Junto con las instancias de nivel nacional, en algunos países también existen algunas de alcance subnacional o local. Por ejemplo, en el Brasil, hasta mayo de 2015, el Sistema Nacional de Promoción de la Igualdad Racial (SINAPIR) contaba con 303 organismos y consejos de promoción de la igualdad racial (entre estaduales y municipales), distribuidos por todo el territorio nacional. En la Argentina, el Instituto Nacional contra la Discriminación, la Xenofobia y el Racismo (INADI) tiene 23 delegaciones provinciales a lo largo del territorio nacional.

${ }_{37}$ Por ejemplo, en el Brasil, la SEPPIR, antes de los cambios institucionales de este año, contaba con más de 100 funcionarios. Por su parte, el INADI de la Argentina contaba en 2016 con 429 cargos. La DACN de Colombia tenía 33 funcionarios y el Comisionado de la Presidencia de la República de Costa Rica para Asuntos Relacionados con la Comunidad Afrocostarricense, creado en 2015, está compuesto por apenas tres personas.

38 Hay rechazo de parte de los garífunas a ser llamados afrohondureños. Incluso, una organización presentó en 2013 denuncia ante el Ministerio Público por el presunto "despojo de identidad" que estaría realizando el Estado de Honduras en su contra. Además, pide que se elimine el mes de la herencia africana y se decrete un día nacional de la etnia garífuna de Honduras, que se cambie el nombre de la Secretaría de Pueblos Indígenas y Afrohondureños a Secretaría para el Desarrollo Étnico de Honduras y que se prohíba el funcionamiento de la Universidad Afrodescendientes de las Américas.

39 Además de las comunidades negras, afrocolombianas, raizales y palenqueras, la Dirección de Poblaciones de Colombia se ocupa de otros grupos, como los pueblos indígenas, pueblo Rom o gitanos, las personas con discapacidad, las víctimas de conflictos armados y los grupos de interés (tribus urbanas, barras bravas, comunidades árabes, campesinas, jóvenes en situación de riesgo, y primera infancia afrocolombiana o gitana) (véase [en línea] http://www.mincultura. gov.co/areas/poblaciones/Paginas/default.aspx). 
Cabe mencionar que algunos países tienen más de una instancia gubernamental de promoción de la igualdad racial. Tal es el caso de Colombia y el Ecuador. En Colombia hay dos mecanismos encargados de los pueblos afrodescendientes, a saber, la Dirección de Asuntos para Comunidades Negras, Afrocolombianas, Raizales y Palenqueras (DACN) (volcada específicamente hacia las comunidades mencionadas y vinculada institucionalmente al Ministerio del Interior) y la Dirección de Poblaciones (que atiende también a otros grupos de población y está vinculada al Ministerio de Cultura). En el Ecuador, los mecanismos de promoción de la igualdad existentes (Consejo de Desarrollo de las Nacionalidades y Pueblos Indígenas del Ecuador (CODENPE), Corporación de Desarrollo Afroecuatoriano (CODAE) y Consejo Nacional del Pueblo Montubio del Ecuador (CODEPMOC) están obligados constitucionalmente a constituirse en consejos nacionales para la igualdad, uno de los cuales es el Consejo Nacional para la Igualdad de Pueblos y Nacionalidades ${ }^{40}$. Estos se articulan con las entidades rectoras y ejecutoras y con los organismos especializados en la protección de los derechos humanos a todos los niveles de gobierno.

Como se indica en el capítulo I, la participación en las decisiones mediante la articulación con organizaciones y movimientos sociales constituye una herramienta fundamental para la gestión de las políticas, especialmente las de tipo transversal y de corte étnico-racial. La participación confiere mayor legitimidad a las decisiones y es clave para superar las desigualdades raciales. Cuando estos procesos se llevan a cabo de forma participativa en las diversas instancias de decisión, contribuyen a hacer que las políticas implementadas sean más eficaces. A este respecto, varios países incluyen en sus procesos de planificación a organizaciones y representantes de las personas afrodescendientes. En los procesos de planificación del Estado Plurinacional de Bolivia se considera la participación de organizaciones afrodescendientes; en el Brasil, las CONAPIR, antes mencionadas, constituyen una importante instancia de consulta desde el Gobierno hacia la sociedad civil. Por su parte, en Colombia se creó un Viceministerio para la Participación e Igualdad de Derechos, con competencia en temas étnicos; a nivel parlamentario está la Circunscripción Nacional Especial para las Comunidades Negras y también hay una circunscripción especial en la Cámara de Representantes; además de comisiones consultivas departamentales, distritales y sectoriales. En el Ecuador existe la Secretaría de Pueblos, Movimientos Sociales y Participación Ciudadana, y se han creado Consejos Nacionales para la Igualdad, integrados paritariamente por la sociedad civil y el Estado. En el Perú, se definió una

Los otros consejos de igualdad son el de género, el intergeneracional, el de discapacidad y el de movilidad humana. 
Política Nacional para la Transversalización del Enfoque Intercultural con participación de organizaciones afroperuanas. Por último, en la República Bolivariana de Venezuela se creó la Oficina de Enlace con las Comunidades Afrodescendientes. Es preciso destacar que, en países como Bolivia (Estado Plurinacional de), Colombia y el Ecuador, las comunidades afrodescendientes tienen derecho a ser consultadas sobre la posible explotación de los recursos naturales de sus territorios ${ }^{41}$.

\section{La dimensión técnico-operativa: herramientas de gestión}

Uno de los grandes desafíos en relación con el diseño de políticas orientadas a las personas afrodescendientes son las fuentes de datos desagregadas según el origen étnico o racial. Esto es básico no solo desde el punto de vista del diseño, sino del monitoreo y evaluación de las políticas. Sin embargo, hasta hace muy poco no se había avanzado en los procesos de identificación de las poblaciones afrodescendientes en los censos, encuestas y registros administrativos, por lo que apenas se ha comenzado a superar la invisibilidad estadística a que se encuentran sometidos estos ciudadanos. Ello se traduce en vulneración de uno de los principios básicos y fundamentales para el diseño de políticas públicas, a saber, la importancia de definir la población a la que hay que dirigir las acciones, determinar dónde se encuentra y clasificarla según sus necesidades específicas. La desagregación de los datos por raza o etnia constituye una herramienta imprescindible para poner de relieve los problemas de desigualdad. Actualmente solo quedan tres países latinoamericanos (Chile, Haití y República Dominicana) que no recogen información sobre la autoidentificación de las personas afrodescendientes en los censos de población. En cambio, en el caso de las encuestas de hogares, hasta ahora solo seis países recogen dicha información (Bolivia (Estado Plurinacional de), Brasil, Colombia, Ecuador, Perú y Uruguay) (CEPAL, 2016a).

Otro punto importante de la gestión de las políticas enfocadas en las personas afrodescendientes es su inclusión en los planes de desarrollo. En el Brasil, están consideradas en los planes plurianuales desde 2004. En Colombia, desde 1994 existe representación de las comunidades negras en los planes. En Costa Rica, el Plan Nacional Para Afrodescendientes (2015-2018) busca reducir las brechas en las condiciones de vida respecto al resto de la población. En Guatemala, el Plan de Equidad de Oportunidades (2008-2023) tiene entre sus

41 En cuanto a las herramientas de gestión relacionadas con sistemas de monitoreo y evaluación y de transparencia en las políticas públicas para la población afrodescendiente, figuran en el capítulo II del presente libro. Cuando se realizó este trabajo, no se disponía de información distinta a la referida a las políticas sociales en general. 
objetivos el desarrollo integral de mujeres garífunas. En el Perú, el Plan Nacional de Derechos Humanos Plan Nacional de Desarrollo para la Población Afroperuana (PLANDEPA) (2015-2024) es parte del compromiso asumido en el marco del Decenio Internacional de los Afrodescendientes. Por último, en el Uruguay, el Plan de Acción por los Derechos de los Afrodescendientes (2010-2015) apuntaba a romper la brecha racial en Montevideo ${ }^{42}$.

Se espera que el Decenio Internacional de los Afrodescendientes (2015-2024) contribuya a una mayor visibilidad de esta población y sus problemáticas. Dicha visibilidad puede promoverse a nivel estadístico, mediante el ejercicio del derecho a la autoidentificación en censos, encuestas, registros administrativos y otros instrumentos ${ }^{43}$. También debería aplicarse a nivel del fortalecimiento e implementación de marcos institucionales que favorezcan la coordinación de políticas de inclusión dirigidas a la superación del racismo y de las desigualdades raciales en la región.

\section{Dimensión de financiamiento}

Como se destaca en el capítulo I, los recursos públicos destinados a cada función de gobierno pueden considerarse un indicador de las prioridades y, de cierta manera, su monto, orientación y estabilidad reflejan el peso de las crisis económicas o políticas vividas por los países. En otras palabras, los ciclos económicos pueden tener efectos negativos sobre la asignación de recursos, la sostenibilidad y el fortalecimiento institucional de los organismos y de las políticas sociales (CEPAL, 2016b). Esto sucede también con las políticas de promoción de la igualdad racial, que se pueden ver afectadas por las coyunturas económicas. Sin embargo, pese a la importancia del financiamiento para la sostenibilidad de estas políticas, el estudio comparativo regional sigue siendo todavía una tarea pendiente.

Considerando lo anterior, en esta sección se presenta un ejercicio centrado en los recursos financieros destinados a los mecanismos gubernamentales de promoción de la igualdad racial en algunos países seleccionados, y no en el conjunto de políticas que pudieran incluir a la población afrodescendiente. Estos montos pueden ser mayores si se tienen

42 Para obtener mayor información sobre las orientaciones que tienen las políticas para población afrodescendiente, véase el apartado 5 de este capítulo.

43 A este respecto, a nivel regional, el Consenso de Montevideo sobre Población y Desarrollo dedica un capítulo exclusivamente a las personas afrodescendientes, que incluye la medida prioritaria núm. 98: “Generar conocimiento e información confiable y oportuna con perspectiva de género y desagregado por sexo, edad y condición socioeconómica, entre otras variables, sobre las poblaciones afrodescendientes, a través de procesos participativos, atendiendo los requerimientos y las recomendaciones internacionales relativas al asunto" (CEPAL, 2013). 
en cuenta los gastos efectuados por entidades ejecutoras de programas que incluyen proyectos o actividades relacionadas con servicios universales y los que están orientados a esta población pero dependen de otras reparticiones del Estado.

Otro elemento que hay que tener presente, y que refleja el grado de desarrollo institucional en esta área, es que los presupuestos de los mecanismos de promoción de la igualdad racial no siempre se encuentran publicados. Muchas veces, aunque el presupuesto de un país determinado esté disponible, no aparecen mencionados los correspondientes mecanismos porque los ítems de gastos no están suficientemente desagregados.

Considerando las limitaciones mencionadas, fue posible obtener información relevante de ocho países. Como se observa en el cuadro VIII.2, en 2016, los países contaban con presupuestos muy variados, desde alrededor de 500.000 dólares en Nicaragua hasta 14,5 millones de dólares en el Brasil. Sin embargo, las proporciones que representaban estos montos en los presupuestos de los respectivos países eran similarmente pequeñas.

En el Brasil, el presupuesto de la SEPPIR en 2016 fue bastante reducido con relación al año anterior (alrededor de 25 millones de dólares) aunque mayor que el de 2014 (cercano a 10 millones de dólares). Es decir, se registró un crecimiento en torno al 150\% entre 2014 y 2015, y una disminución del $40 \%$ en $2016^{44}$. Tales fluctuaciones evidencian la inestabilidad de los presupuestos de estas instituciones, relacionada con la coyuntura económica y política del país, que hizo que el Gobierno realizara un profundo ajuste fiscal que también repercutió en los recursos de la SEPPIR.

En el caso de Colombia, el Ministerio del Interior destinó a las personas afrodescendientes alrededor de 11.523 millones de pesos colombianos (casi 4 millones de dólares), lo que equivale a un 1,12\% del presupuesto de dicha entidad. Estos recursos se destinaron a los siguientes rubros: fortalecimiento de procesos organizativos y de concertación; mejoramiento de las comunidades y de sus gobiernos, y promoción de la igualdad económica, el reconocimiento, la diversidad y la inclusión. Además, otros ministerios contaban con presupuestos para acciones dirigidas a la población afrodescendiente en temas como la legalización de tierras, el desarrollo rural y el apoyo a la producción artesana $l^{45}$.

\footnotetext{
44 Véase [en línea] http://www.camara.leg.br/internet/comissao/index/mista/orca/orcamento/ OR2016/red_final/vol4/67_sec_politic_igualdade_racial.pdf.

45 Véase [en línea] http://www.minhacienda.gov.co/HomeMinhacienda/ShowProperty?nodeId =\%2FOCS\%2FMIG_50434604.PDF\%2F\%2FidcPrimaryFile\&revision=latestreleased.
} 


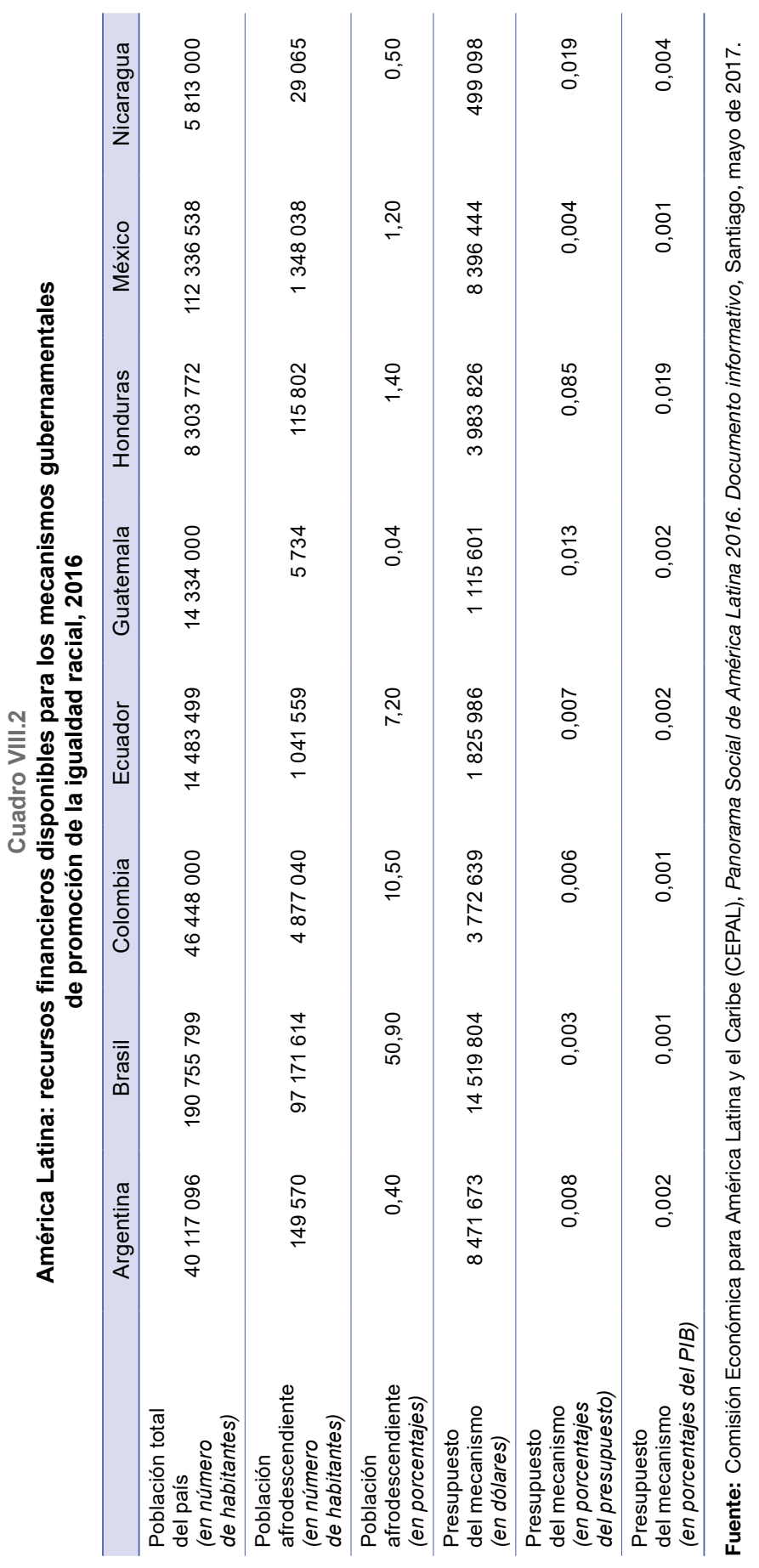




\section{E. Políticas destacadas para las personas afrodescendientes}

En respuesta al movimiento afrodescendiente, y también como consecuencia de los compromisos internacionales asumidos (sea en virtud de instrumentos de derecho internacional firmados anteriormente, del Programa de Acción de Durban o de las propias atribuciones de los mecanismos de promoción de la igualdad racial), en los últimos años se ha desplegado en diversos países de América Latina un conjunto de políticas de lucha contra el racismo y promoción de la igualdad racial. Esto refleja un avance en el desarrollo institucional hasta aquí reseñado.

Sin pretensiones de exhaustividad, el objetivo de este apartado es poner de relieve las principales políticas de lucha contra el racismo y promoción de la igualdad racial que se han elaborado en los últimos años. Estas políticas se suman al propio fortalecimiento institucional como objetivo y se desprenden de lo detallado más arriba. Se clasificaron en tres ejes, siguiendo la propuesta de Jaccoud (2009): i) políticas de prevención y enfrentamiento del racismo; ii) acciones afirmativas y valorativas (es decir, políticas de discriminación positiva y valorización de la cultura y de las tradiciones afrodescendientes), y iii) fortalecimiento de comunidades tradicionales (aquellas que se encuentran en territorios donde viven los descendientes de personas esclavizadas.

En el ámbito de la prevención y enfrentamiento del racismo, además de la legislación por la que se prohíben las manifestaciones racistas y se tipifica el delito de racismo, algunos países elaboran políticas más integrales para eliminar la discriminación racial. Entre ellos cabe mencionar el Ecuador (Plan Plurinacional para Eliminar la Discriminación Racial y la Exclusión Étnica y Cultural), Guatemala (Política Pública para la Convivencia y la Eliminación del Racismo y la Discriminación Racial) y el Brasil (Plan Nacional de Promoción de la Igualdad Racial). Otra forma de combatir el racismo es mediante intervenciones en los territorios donde hay una mayor presencia de personas afrodescendientes y más elevados índices de violencia y de jóvenes en riesgo social (Plan Juventud Viva (Brasil)), el desarrollo de cursos de formación en línea (Colombia), la recepción de denuncias por racismo y el acompañamiento legal de las víctimas (Argentina y Bolivia (Estado Plurinacional de)), la creación de observatorios y plataformas contra la discriminación (Argentina, Colombia y Perú) y la adopción de normativas de carácter local (Quito (Ecuador) y Callao (Perú)).

Las políticas de acción afirmativa consisten, principalmente, en la asignación a las personas afrodescendientes de una parte de los cupos (o cuotas) de matrícula en universidades públicas, además de la concesión 
de becas en universidades privadas. En esto, el Brasil es una referencia por haber sido uno de los países que más avances ha logrado, con la reserva de cupos para personas afrodescendientes e indígenas en universidades e institutos de educación técnica públicos ${ }^{46}$, junto con un programa de becas en universidades privadas ${ }^{47}$. Además, se han otorgado becas para que las personas afrodescendientes puedan prepararse para estudiar la carrera diplomática y se estableció una cuota del 10\% de los cupos para las personas afrodescendientes en la primera fase del proceso selectivo del servicio diplomático (OEA, 2001b). De modo similar, se instituyó la reserva de cupos en concursos para la administración pública y empresas proveedoras del Estado. Otros países, como Bolivia (Estado Plurinacional de), Colombia, el Perú, el Uruguay y Venezuela (República Bolivariana de), también han desarrollado acciones afirmativas.

Respecto a las políticas valorativas, destaca la institucionalización de días de celebración de la afrodescendencia en la mayoría de los países de la región ${ }^{48}$. Entre otras, se deben resaltar la enseñanza de la historia y la cultura africana en los colegios (por ejemplo, en el Brasil, Colombia y el Uruguay) y la implementación de políticas que incorporan visiones y prácticas ancestrales de salud enfocadas en enfermedades que afectan particularmente a personas afrodescendientes (por ejemplo, en el Brasil, el Ecuador, Nicaragua y el Perú). También cabe destacar el reconocimiento de figuras históricas afrodescendientes y de sus prácticas culturales como patrimonio histórico, el reconocimiento oficial del valor de las personas afrodescendientes en la formación nacional y en la cultura (por ejemplo, Bolivia (Estado Plurinacional de), Nicaragua, Panamá y Perú).

En el caso del fortalecimiento de las comunidades tradicionales, las políticas se orientan principalmente a las áreas de cimarrones, es decir, de ocupación histórica por personas esclavizadas que se fugaron. Las políticas de fortalecimiento de estas áreas no son generalizadas y, en ese sentido, se destacan los casos del Brasil, Colombia, Bolivia (Estado Plurinacional de) y el Ecuador. En esos países se les reconoce a las personas residentes en estos territorios la propiedad definitiva de las tierras ocupadas, por lo que el Estado no solo debe emitir sus títulos de propiedad, sino preocuparse de elaborar políticas integrales en dichas comunidades.

46 Desde 2001, varias universidades públicas habían adoptado diversas modalidades de reserva de cupos sobre la base de criterios étnicos, pero, a partir de la Ley núm. 12.711 (2012), tales criterios se homogeneizaron.

47 Ley núm. 11.096/2005, Programa Universidad para Todos (PROUNI).

48 Argentina, Bolivia (Estado Plurinacional de), Brasil, Colombia, Costa Rica, Ecuador, El Salvador, Guatemala, Honduras, Nicaragua, Panamá, Paraguay, Perú, Uruguay y Venezuela (República Bolivariana de). 


\section{F. Conclusiones y desafíos}

Con este capítulo se ha intentado contribuir a los análisis sobre la institucionalidad afrodescendiente en América Latina. Este es un pilar fundamental para avanzar en el desarrollo de políticas que garanticen los derechos de estos pueblos, sin discriminación y con inclusión en condiciones de igualdad, objetivos que adquieren cada vez mayor relevancia en la región.

Los países latinoamericanos han avanzado en las últimas décadas, aunque en grados distintos, en la creación de marcos normativos y de instituciones dedicadas específicamente a la promoción de la igualdad racial y a los pueblos afrodescendientes. El desarrollo de dicha institucionalidad, su fortalecimiento (o su desaparición), está estrechamente vinculado a los ciclos económicos y de gobierno. Esto significa que las crisis económicas y la voluntad política de los gobiernos de turno son fundamentales para el fortalecimiento de la institucionalidad que vela por los derechos de las personas afrodescendientes, aunque esta situación puede contrarrestarse, en parte, por la movilización de la sociedad civil. No obstante las dificultades, es razonable afirmar que las legislaciones de lucha contra el racismo y los mecanismos gubernamentales para la promoción de la igualdad racial se han seguido multiplicando y fortaleciendo. Por ejemplo, diez de los mecanismos aquí mencionados, o sea, la gran mayoría, fueron creados entre 2001 y 2005. Muchas veces se establecieron en forma de comisiones que luego evolucionaron hacia otras figuras organizacionales, como secretarías, direcciones o institutos, lo que a menudo representó un avance en términos institucionales. Es necesario destacar este aspecto porque una debilidad importante de los mecanismos de promoción de la igualdad racial en lo que se refiere a los aspectos organizacionales es la figura institucional asumida. A partir de esta última se define la posición que deberá ocupar dicho mecanismo en la estructura del Estado y los recursos disponibles para la realización de los objetivos propuestos.

Entre las principales fortalezas de los mecanismos de promoción de la igualdad racial se debe mencionar la coordinación de trabajos con otras instituciones, tanto públicas como de la sociedad civil. Este aspecto es fundamental, pues se trata de gestionar políticas de tipo transversal, de forma que incorporen los movimientos sociales vinculados a esta problemática.

Un elemento clave en la gestión de la institucionalidad afrodescendiente es el establecimiento definitivo de la visibilidad de estos pueblos en las estadísticas oficiales, pues de otro modo se ven limitadas las iniciativas de ampliar su participación en las políticas. En la actualidad solo quedan tres países latinoamericanos cuyos censos de población no recogen datos sobre la autoidentificación de las 
personas afrodescendientes. Sin embargo, en el caso de las encuestas de hogares, hasta el día de hoy, la situación es la opuesta, pues solo una minoría de esas encuestas recoge dicha información. Aunque se trate de una demanda antigua y creciente por parte de las organizaciones afrodescendientes, todavía hay un gran déficit de estadísticas y registros desagregados según autoidentificación étnico-racial, elementos fundamentales para el diseño de políticas focalizadas y transversales. Por lo tanto, es urgente incluir la autoidentificación étnico-racial en las diversas fuentes de datos para mejorar el diagnóstico de la situación de estos pueblos y aumentar la eficacia del diseño y el monitoreo de las políticas que se aplican a ellos.

En cuanto a la dimensión de financiamiento persiste en la región el desafío de analizar de manera comparativa no solo los recursos públicos financieros y humanos destinados a los mecanismos de promoción de la igualdad racial, sino también el gasto social destinado a las personas afrodescendientes. La transparencia en el uso y la divulgación de estos recursos propiciaría una discusión de más alto nivel respecto a la desigualdad étnico-racial en la distribución de los recursos públicos y permitiría hacer una repartición más igualitaria de dichos recursos.

Por último, se ha visto que en la región se han aplicado diversas prácticas y políticas de promoción de la igualdad en los últimos años, lo que representa una situación novedosa en comparación con el pasado reciente. Entre ellas destacan las políticas de prevención y enfrentamiento del racismo, así como las acciones afirmativas, de valoración de la cultura afrodescendientes, de fortalecimiento de comunidades de cimarrones, de regulación de la participación en decisiones y de inclusión en planes de desarrollo. De tales experiencias se han derivado enseñanzas importantes y modelos de buenas prácticas para el desarrollo de institucionalidades y de políticas que han contribuido al avance de la agenda de igualdad de la región, sobre todo en lo relativo a la igualdad racial. 


\section{Bibliografía}

ACNUDH (Oficina del Alto Comisionado de las Naciones Unidas para los Derechos Humanos) (1973), “Convención Internacional sobre la Represión y el Castigo del Crimen de Apartheid" [en línea] http://www.oas.org/DIL/ESP/1973_ Convencion_Internacional_sobre_la_Represion_y_el_Castigo_del_Crimen_de_ Apartheid.pdf.

(1966a), "Pacto Internacional de Derechos Civiles y Políticos" [en línea] http:/ / www.ohchr.org/SP/ProfessionalInterest/Pages/CCPR.aspx.

(1966b), "Pacto Internacional de Derechos Económicos, Sociales y Culturales" [en línea] http:/ / www.ohchr.org/SP/ProfessionalInterest/Pages/CESCR.aspx.

(1965), "Convención Internacional sobre la Eliminación de Todas las Formas de Discriminación Racial" [en línea] http://www.ohchr.org/SP/ ProfessionalInterest/Pages/CERD.aspx.

Afroamérica XXI (2009), "Compendio normativo: 'acciones afirmativas a favor del pueblo afrodescendiente de América Latina y legislación antidiscriminatoria'" [en línea] http://hutchinscenter.fas.harvard.edu/sites/all/files/COMPENDIO\%20 NORMATIVO\%20REGIONAL\%20AFRODESCENDIENTE\%20DE\%20 AMERICA\%20LATINA.pdf.

Antón Sánchez, J. (2010), "Implementación de los pactos y los convenios internacionales relacionados con los derechos civiles, culturales, económicos, políticos y sociales de la población afrodescendiente de Colombia, Ecuador, Perú y Venezuela", Proyecto Regional Población Afrodescendiente de América Latina del PNUD.

Asamblea Constituyente del Ecuador (2008), “Constitución de la República del Ecuador" [en línea] http:/ / www.asambleanacional.gob.ec/sites/default/files / documents/old/constitucion_de_bolsillo.pdf.

CEPAL (Comisión Económica para América Latina y el Caribe) (2017), Panorama Social de América Latina 2016. Documento informativo, Santiago, mayo.

(2016a), La matriz de la desigualdad social en América Latina (LC/G.2690 (MDS.1/2), Santiago.

(2016b), Panorama Social de América Latina, 2015 (LC/G.2691-P), Santiago.

(2015), Desarrollo social inclusivo: una nueva generación de politicas para superar la pobreza y reducir la desigualdad en América Latina y el Caribe (LC/L.4056/Rev.1), Santiago[enlínea]http:/ / repositorio.cepal.org/bitstream/handle/11362/39100/ S1600099_es.pdf?sequence=4.

(2013), Consenso de Montevideo sobre Población y Desarrollo (LC/L.3697) [en línea] http://repositorio.cepal.org/bitstream/handle/11362/21835/4/ S20131037_es.pdf.

Coordinadora Nacional de Organizaciones Negras Panameñas (2010), Informe sombra ante el CERD Panamá [en línea] http://tbinternet.ohchr.org/Treaties/ CERD/Shared\%20Documents/PAN/INT_CERD_NGO_PAN_76_9859_E.pdf.

Defensoría del Pueblo (2011), Los afrodescendientes en el Perú: una aproximación a su realidad y al ejercicio de sus derechos, Lima.

Feres Jr., J. y otros (2013), O impacto da Lei $n^{\circ} 12.711$ sobre as universidades federais. Levantamento das políticas de ação afirmativa, Río de Janeiro, Instituto de Estudios Sociales y Políticos de la Universidad del Estado de Río de Janeiro. 
IBGE (Instituto Brasileño de Geografía y Estadística) (2015), Síntese de Indicadores Sociais 2015 - uma análise das condições de vida da população brasileira, Brasilia.

Jaccoud, L. (org.) (2009), A construção de uma política de promoção da igualdade racial: uma análise dos últimos 20 anos, Brasilia, Instituto de Investigación Económica Aplicada (IPEA).

Ministerio Público de Pernambuco (2013), No país do racismo institucional: dez anos de ações do GT Racismo no MPPE, Recife.

Naciones Unidas (2008), "Examen de los informes presentados por los Estados partes de conformidad con el artículo 9 de la Convención" (CERD/C/NIC/ $\mathrm{CO} / 14)$, Convención Internacional sobre la Eliminación de Todas las Formas de Discriminación Racial [en línea] http://www.acnur.org/t3/fileadmin/ Documentos/BDL/2012/8795.pdf?view=1.

OEA (Organización de los Estados Americanos) (2011a), La situación de las personas afrodescendientes en las Américas (OEA/Ser.L/V/II) [en línea] http:/ /www.acnur. org/t3/fileadmin/Documentos/BDL/2012/8311.pdf. (2011b), II Taller de Expertos/as de la Temática Afrodescendiente en las Américas, Washington, D.C.

(1969), "Convención Americana sobre Derechos Humanos (Pacto de San José)" [en línea] https:/ / www.oas.org/dil/esp/tratados_b-32_convencion_americana_ sobre_derechos_humanos.htm.

OIT (Organización Internacional del Trabajo) (1989), "Convenio sobre Pueblos Indígenas y Tribales, 1989 (núm. 169)" [en línea] http:/ / www.ilo.org/dyn/normlex/es/f?p= NORMLEXPUB:12100:0::NO::P12100_INSTRUMENT_ID:312314. (1958), “Convenio sobre la Discriminación (Empleo y Ocupación), 1958 (núm. 111), Ginebra [en línea] http:/ / www.ilo.org/dyn/normlex/es/f?p=NORML EXPUB:12100:0::NO::P12100_ILO_CODE:C111.

Rangel, M. (2016), "Políticas públicas para afrodescendientes: marco institucional en el Brasil, Colombia, el Ecuador y el Perú", serie Políticas Sociales, N 220 (LC/L.4275), Santiago, Comisión Económica para América Latina y el Caribe (CEPAL).

República de Bolivia (2008), "Nueva Constitución Política del Estado" [en línea] http:/ / www.servindi.org/pdf/Bolivia_ConsPol_Oct2008.pdf.

SEPPIR (Secretaría Especial de Políticas de Promoción de la Igualdad Racial) (2015), Levantamento de órgãos e conselhos de igualdade racial para o SINAPIR, Brasilia. (2014), Balanço de gestão 2011-2014, Brasilia.

Universidad de Brasilia (2013), Análise do sistema de cotas para negros da Universidade de Brasília. Período: $2^{\circ}$ semestre de 2004 ao $1^{\circ}$ semestre de 2013, Brasilia. 


\section{Publicaciones recientes de la CEPAL ECLAC recent publications}

\section{www.cepal.org/publicaciones}

\section{Informes periódicos / Annual reports}

También disponibles para años anteriores / Issues for previous years also available

- Estudio Económico de América Latina y el Caribe 2016, 236 p. Economic Survey of Latin America and the Caribbean 2016, 232 p.

- La Inversión Extranjera Directa en América Latina y el Caribe 2016, 170 p. Foreign Direct Investment in Latin America and the Caribbean 2016, $164 \mathrm{p}$.

- Anuario Estadístico de América Latina y el Caribe 2016 / Statistical Yearbook for Latin America and the Caribbean 2016, $132 p$.

- Balance Preliminar de las Economías de América Latina y el Caribe 2016, 132 p. Preliminary Overview of the Economies of Latin America and the Caribbean 2016, $124 \mathrm{p}$.

- Panorama Social de América Latina 2015, 226 p. Social Panorama of Latin America 2015, 222 p.

- Panorama de la Inserción Internacional de América Latina y el Caribe 2016, 174 p. Latin America and the Caribbean in the World Economy 2015, $170 \mathrm{p}$.

\section{Libros y documentos institucionales / Institutional books and documents}

- Panorama fiscal de América Latina y el Caribe 2017: la movilización de recursos para el financiamiento del desarrollo sostenible, 2017, $115 \mathrm{p}$.

Fiscal Panorama of Latin America and the Caribbean 2017: Mobilizing resources to finance sustainable development, 2017, 108 p.

- ECLAC Thinking. Selected Texts (1948-1998), 2016, 520 p.

- La matriz de la desigualdad en América Latina, 2016, 96 p. The social inequality matrix in Latin America, 2016, 94 p.

- Autonomía de las mujeres e igualdad en la agenda de desarrollo sostenible, 2016, 184 p. Equality and women's autonomy in the sustainable development agenda, 2016, 168 p. Autonomia das mulheres e igualdade na agenda de desenvolvimento sustentável. Sintese, 2016, $106 \mathrm{p}$.

- La Unión Europea y América Latina y el Caribe ante la Agenda 2030 para el Desarrollo Sostenible: el gran impulso ambiental, 2016, $112 p$.

The European Union and Latin America and the Caribbean vis-à-vis the 2030 Agenda for Sustainable Development: The environmental big push, 2016, 112 p.

- Horizontes 2030: la igualdad en el centro del desarrollo sostenible, 2016, $176 \mathrm{p}$. Horizons 2030: Equality at the centre of sustainable development, 2016, 174 p. Horizontes 2030: a igualdade no centro do desenvolvimento sustentável, 2016, 176 p.

- 40 años de agenda regional de género, 2016, 130 p. 40 years of the regional gender agenda, 2016,128 p.

- La nueva revolución digital: de la Internet del consumo a la Internet de la producción, 2016, 100 p. The new digital revolution: From the consumer Internet to the industrial Internet, 2016, 100 p. 


\section{Libros de la CEPAL / ECLAC books}

144 Desde el gobierno abierto al Estado abierto en América Latina y el Caribe, Alejandra Naser, Álvaro Ramírez-Alujas, Daniela Rosales (eds.), 2017, 466 p.

143 Protección social en América Latina: la desigualdad en el banquillo, Ana Sojo, 2017, 246 p.

142 Consensos y conflictos en la política tributaria de América Latina, Juan Carlos Gómez Sabaini, Juan Pablo Jiménez y Ricardo Martner (eds.), 2017, 446 p.

141 Brechas y transformaciones: la evolución del empleo agropecuario en América Latina, Jürgen Weller (ed.), 2016, $274 \mathrm{p}$.

140 Protección y formación: instituciones para mejorar la inserción laboral en América Latina y Asia, Alberto Isgut, Jürgen Weller (eds.), 2016, 428 p.

Protection and training: Institutions for improving workforce integration in Latin America and Asia, Alberto Isgut, Jürgen Weller (eds.), 2016, 428 p.

139 Hacia una nueva gobernanza de los recursos naturales en América Latina y el Caribe, Hugo Altomonte, Ricardo J. Sánchez, 2016, 256 p.

138 Estructura productiva y política macroeconómica: enfoques heterodoxos desde América Latina, Alicia Bárcena, Antonio Prado, Martín Abeles (eds.), 2015, 282 p.

\section{Páginas Selectas de la CEPAL / ECLAC Select Pages}

- Planificación y prospectiva para la construcción de futuro en América Latina y el Caribe. Textos seleccionados 2013-2016, Jorge Máttar y Mauricio Cuervo (comps.), 2016, 222 p.

- Desarrollo inclusivo en América Latina. Textos seleccionados 2009-2016, Ricardo Infante (comp.), 2016, $294 \mathrm{p}$.

- Globalización, integración y comercio inclusivo en América Latina. Textos seleccionados 2010-2014, Osvaldo Rosales (comp.), 2015, 326 p.

- El desafío de la sostenibilidad ambiental en América Latina y el Caribe. Textos seleccionados 2012-2014, Carlos de Miguel, Marcia Tavares (comps.), 2015, 148 p.

\section{Copublicaciones / Co-publications}

- El imperativo de la igualdad, Alicia Bárcena, Antonio Prado, CEPAL/Siglo Veintiuno, Argentina, 2016, $244 \mathrm{p}$.

- Gobernanza global y desarrollo: nuevos desafíos y prioridades de la cooperación internacional, José Antonio Ocampo (ed.), CEPAL/Siglo Veintiuno, Argentina, 2015, 286 p.

- Decentralization and Reform in Latin America: Improving Intergovernmental Relations, Giorgio Brosio and Juan Pablo Jiménez (eds.), ECLAC/Edward Elgar Publishing, United Kingdom, 2012, 450 p.

- Sentido de pertenencia en sociedades fragmentadas: América Latina desde una perspectiva global, Martín Hopenhayn y Ana Sojo (comps.), CEPAL/Siglo Veintiuno, Argentina, 2011, 350 p.

\section{Coediciones / Co-editions}

- Perspectivas económicas de América Latina 2017: Juventud, Competencias y Emprendimiento, 2016, 338 p. Latin American Economic Outlook 2017: Youth, Skills and Entrepreneurship, 2016, 314 p.

- Desarrollo e integración en América Latina, 2016, 314 p.

- Hacia un desarrollo inclusivo: el caso del Uruguay, 2016, 174 p.

- Perspectivas de la agricultura y del desarrollo rural en las Américas: una mirada hacia América Latina y el Caribe 2015-2016, CEPAL/FAO/IICA, 2015, 212 p. 


\section{Documentos de Proyectos / Project Documents}

- La transversalización del enfoque de género en las políticas públicas frente al cambio climático en América Latina, Marina Casas Varez, 2017, 101 p.

- Financiamiento para el cambio climático en América Latina y el Caribe en 2015, Joseluis Samaniego y Heloísa Schneider, 2017, 76 p.

- El cambio tecnológico y el nuevo contexto del empleo: tendencias generales y en América Latina, Sebastian Krull, 2016, 48 p.

- Cambio climático, políticas públicas y demanda de energía y gasolinas en América Latina: un meta-análisis, Luis Miguel Galindo, Joseluis Samaniego, Jimy Ferrer, José Eduardo Alatorre, Orlando Reyes, 2016, 68 p.

- Estado de la banda ancha en América Latina y el Caribe 2016, 2016, 46 p.

\section{Cuadernos Estadísticos de la CEPAL}

44 Las cuentas de los hogares y el bienestar en América Latina. Más allá del PIB, 2016.

43 Estadísticas económicas de América Latina y el Caribe: Aspectos metodológicos y resultados del cambio de año base de 2005 a 2010

\section{Series de la CEPAL / ECLAC Series}

Asuntos de Género / Comercio Internacional / Desarrollo Productivo / Desarrollo Territorial / Estudios Estadísticos / Estudios y Perspectivas (Bogotá, Brasilia, Buenos Aires, México, Montevideo) / Studies and Perspectives (The Caribbean, Washington, D.C.) / Financiamiento del Desarrollo / Gestión Pública / Informes y Estudios Especiales / Macroeconomía del Desarrollo / Medio Ambiente y Desarrollo / Población y Desarrollo / Política Fiscal / Políticas Sociales / Recursos Naturales e Infraestructura / Seminarios y Conferencias.

\section{Manuales de la CEPAL}

5 Estimación de las erogaciones sociales a partir del sistema de cuentas nacionales: una propuesta para las funciones de educación, salud y protección social, María Paz Colinao, Federico Dorin, Rodrigo Martínez y Varinia Tromben, 2016, 63 p.

4 Territorio e igualdad: planificación del desarrollo con perspectiva de género, 2016, 84 p.

3 Manual de formación regional para la implementación de la resolución 1325 (2000) del Consejo de Seguridad de las Naciones Unidas relativa a las mujeres, la paz y la seguridad, María Cristina Benavente R., Marcela Donadio, Pamela Villalobos, 2016, 126 p.

2 Guía general para la gestión de residuos sólidos domiciliarios, Estefani Rondón Toro, Marcel Szantó Narea, Juan Francisco Pacheco, Eduardo Contreras, Alejandro Gálvez, 2016, 212 p.

\section{Revista CEPAL / CEPAL Review}

La Revista se inició en 1976, con el propósito de contribuir al examen de los problemas del desarrollo socioeconómico de la región. La Revista CEPAL se publica en español e inglés tres veces por año.

CEPAL Review first appeared in 1976, its aim being to make a contribution to the study of the economic and social development problems of the region. CEPAL Review is published in Spanish and English versions three times a year. 


\title{
Observatorio demográfico / Demographic Observatory
}

Edición bilingüe (español e inglés) que proporciona información estadística actualizada, referente a estimaciones y proyecciones de población de los países de América Latina y el Caribe. Desde 2013 el Observatorio aparece una vez al año.

Bilingual publication (Spanish and English) proving up-to-date estimates and projections of the populations of the Latin American and Caribbean countries. Since 2013, the Observatory appears once a year.

\section{Notas de población}

Revista especializada que publica artículos e informes acerca de las investigaciones más recientes sobre la dinámica demográfica en la región. También incluye información sobre actividades científicas y profesionales en el campo de población. La revista se publica desde 1973 y aparece dos veces al año, en junio y diciembre.

Specialized journal which publishes articles and reports on recent studies of demographic dynamics in the region. Also includes information on scientific and professional activities in the field of population. Published since 1973, the journal appears twice a year in June and December.

\section{Las publicaciones de la CEPAL están disponibles en: ECLAC publications are available at: www.cepal.org/publicaciones}

También se pueden adquirir a través de: They can also be ordered through: www.un.org/publications

\author{
United Nations Publications \\ PO Box 960 \\ Herndon, VA 20172 \\ USA
}

\section{Tel. (1-888)254-4286}

Fax (1-800)338-4550

Contacto / Contact. publications@un.org

Pedidos / Orders: order@un.org 


\section{Institucionalidad social en América Latina y el Caribe}

\section{RODRIGO MARTÍNEZ} Editor
El mundo atraviesa un período de cambios. La volatilidad del crecimiento económico, el cambio climático, la revolución tecnológica, la migración

y la transición demográfica son reflejo de ello. También lo son los impactos que estos cambios generan en la realidad social y los desafíos que imponen a las políticas públicas.

Continuar con los avances logrados en materia social en América Latina y el Caribe, evitar retrocesos y alcanzar los Objetivos de la Agenda 2030 para el Desarrollo Sostenible, sin que nadie se quede atrás, supone que las políticas públicas asuman nuevos y mayores esfuerzos en materia de cobertura y calidad. Para ello, es fundamental contar con una institucionalidad a la altura de los desafíos presentes y futuros, que haga viables y sostenibles los logros y que garantice el ejercicio de los derechos de manera universal.

En este libro se analizan elementos de la institucionalidad de las políticas sociales en la región, en particular las centradas en la protección social. Así, se discuten los principales conceptos y avances registrados a nivel regional y nacional, a partir de cuatro dimensiones analíticas complementarias: jurídico-normativa, organizacional, técnico-operativa y fiscal. 